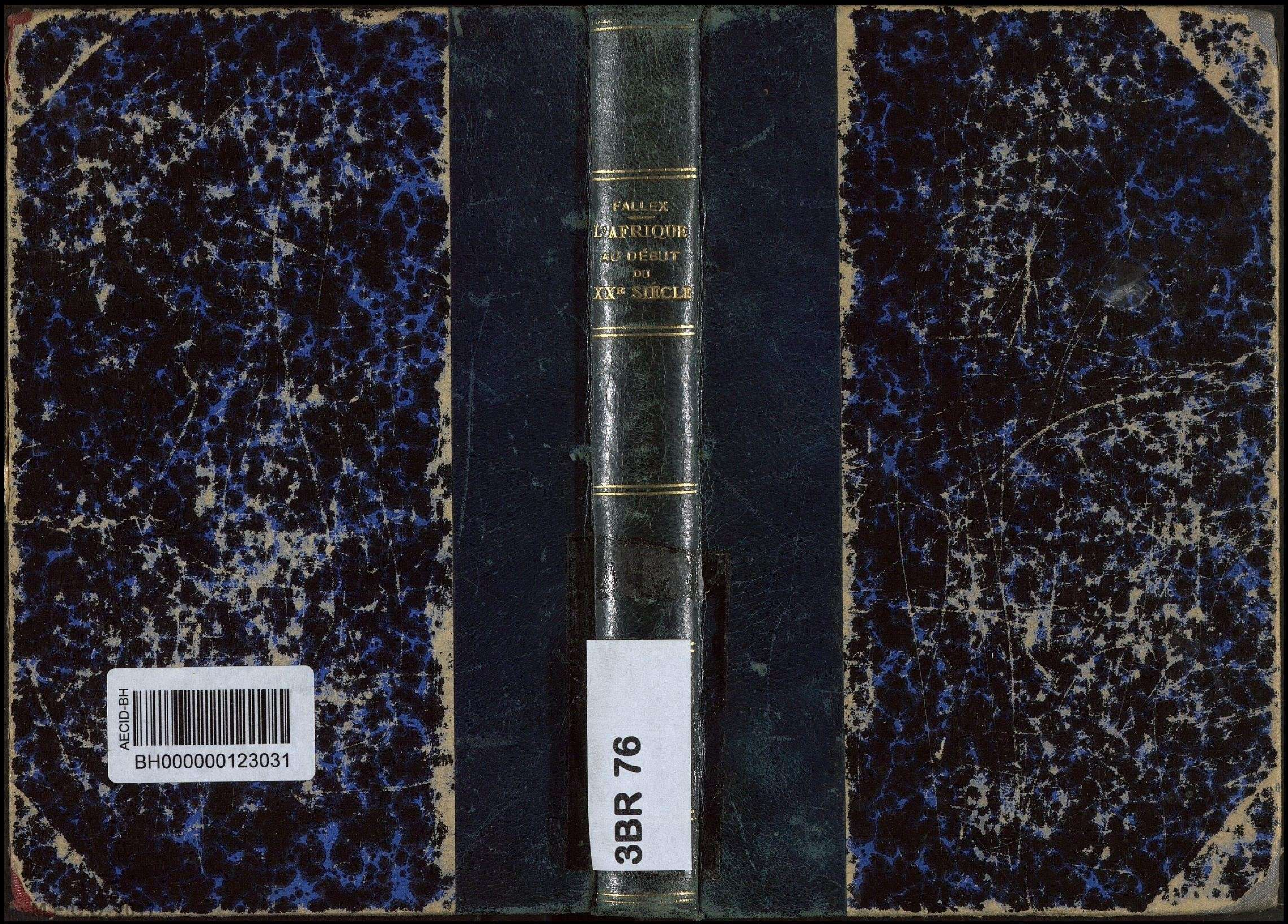




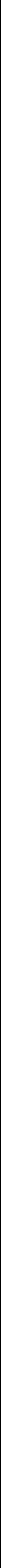


41355994 


\section{M.E.C.D. 2017}




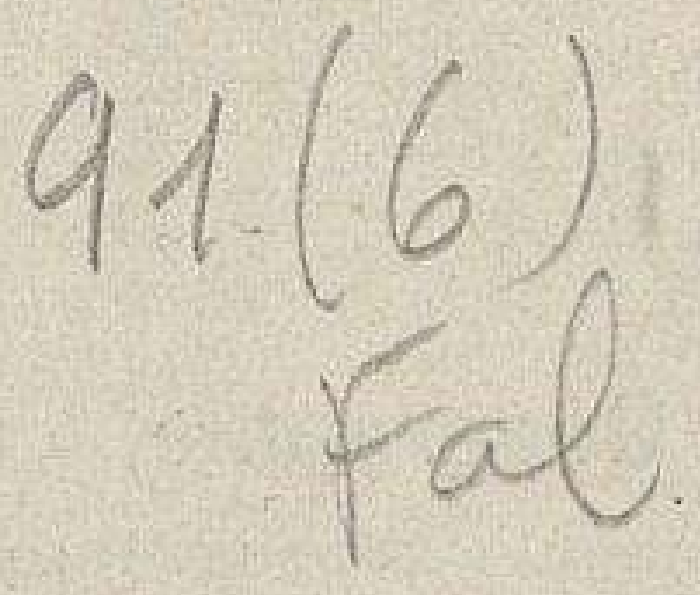

L'Afrique

AU DÉBUT DU XX SIĖCLE 


\section{A LA MÊME LIBRAIRIE}

Nouveau Cours de Géographie, à l'usage de l'Enseignement secondaire, rédigé conformément aux programmes officiels du 31 mai 1902 et du 28 juillet 1905 .

\section{PREMIER GYGLE}

Géographie générale, Amérique, Australasie. Grasse de Sixí̀me, par M. Fallex et A. Mairey.

Asie, Insulinde, Afrique. Glasse de Ginquième, par M. Fallex et A. Hentgen. $3^{\circ}$ édition.

Europe. Glasse de Quatrième, par M. Fallex et A. Mairey. $2^{\text {e }}$ édition. La France et ses colonies. Chasse de Troisrikme (Sous presse).

\section{SEGOND CYGLE}

Géographie générale. Classe de Seconde, par G. Lespagnol. $3^{\circ}$ édition. Ja France et ses colonies. Classe de Premì̀re (En préparation). Les principales Puissances du Monde. Classes de Philosophie Et de Matnématroues, par M. Fallex et A. Mairey. $2^{\circ}$ édition. 


\section{COLLECTION PUBLIÉE SOUS LA DIRECTION DE M. LESPAGNOL}

\section{L'Afrique}

\section{AU DÉBUT DU XX $X^{E}$ SIËGLE}

P A R

M. FALLEX

Professcur agrégé d'histoire et de géographie au lycée Carnot

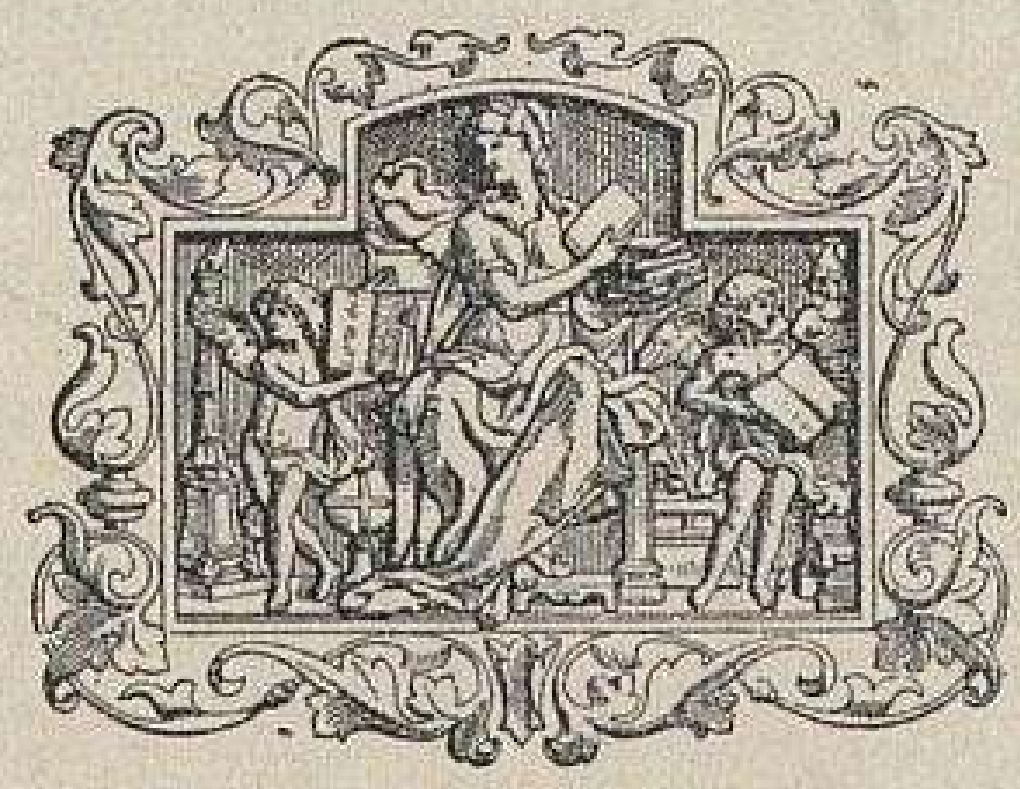

PARIS

15, I UE SOUFFLOT, 15 



\section{INTRODUGTION}

La géographie a franchi l'étape décisive : elle y a été conduite par le progrès continu des connaissances qui facilitent ses recherches, par l'essor admirable des sciences de la nature et de l'homme dont le concours lui est indispensable. Elle a pris enfin conscience d'elle-même, de son objet, de ses moyens d'enquète, de sa méthode, : désormais elle a droit de cité parmi les sciences. Il est temps pour elle, grand temps, d'entrer délibérément dans la voie scientifique et de répudier les compromissions de la géographie d'autrefois, qui, établie sur des bases incertaines, ne pouvait accomplir, malgré la haute valeur de certains géographes, qu'une œuvre incohérente et stérile.

La physionomie de la terre est faite de traits d'âges différents : il serait puéril de prétendre l'étudier autrement qu'à la lueur projetée sur elle par l'histoire du passé, quand ce passé retentit encore sur le présent; il serait puéril de vouloir comprendre autrement la diversité des formes de la surface, certains faits de la distribution des êtres vivants et de l'activité humaine.

La terre est une sorte d'organisme dont toutes les parties sont dans une dépendance réciproque; les traits de 
la surface du globe sont, on peut le dire, solidaires et présentent un enchainement d'actions et d'influences, de causes et d'effets, avec répercussion des effets sur les causes, comme il doit arriver en un corps bien organisé.

C'est le rôle original de la géographie, devenue une description et une explication, dans le sens scientifique des mots, de remettre en contact les faits que d'autres sciences ont étudiés isolément et de replacer dans la complexité des conditions naturelles, dans le mouvement de la vie, les phénomènes du monde physique et organique. La synthèse géographique, par ses études de rapports et d'enchaînements, expression profonde de la réalité des choses, découvre des horizons nouveaux et donne aux faits toute leur signification et toute leur portée; elle apparaît comme l'image fidèle d'une évolution qui continue. Elle montre comment la vie des plantes et des animaux s'harmonise avec les formes terrestres, et comment cet ensemble se reflète et s'imprime dans les phénomines vitaux de l'humanité. "L'accord magnifique de la terre et de tout ce qui germe et se déreloppe à la surface », l'harmonieux déterminisme de la vie naturelle, donnent à la géographie toute sa beauté et fixent son idéal.

G. Lespagnol, M. Fallex. 


\title{
AFRIQUE
}

\author{
CHAPITRE I
}

\author{
ÉTUDE GÉNÉRALE DE L'AFRIQUE \\ GÉOGRAPHIE PHYSIQUE
}

\section{SOMMAIRE}

I. Situation et limites. - Situee au Sud-Ouest de l'ancien continent, l'Afrique est entourée de tous côtés par les mers : la Méditerranèe au Nord, l'Atlantique à l'Ouest, l'ocean Indien et la mer Rouge à l'Est. Le canal, percé à travers l'isthme de Suez, la sèpare de l'Asie.

II. Dimensions. -30 millions de $\mathrm{kmq}$.

III. Configuration. - L s contours de l'Afrique sont massifs et mal articulés : pas de mers intérieures, pas de presqu'îles allongeees.

IV. Position astronomique. - L'Afrique est le continent tropical par excellence : coupée par l'équateur et par les deux tropiques, elle n'a qu'un cinquième de ses terres dans la zone tempérée.

v. Relief. - Si l'on fait exception de l'Atlas, qui n'est pas une terre proprement africaine, le continent a la forme d'un plateau, tres ancien, au relief tout a fait indécis; releve sur les bords, il se creuse en bassins (lac Tchad, Congo, Zambeze, etc). L'Afrique orientale, est ine région de grande dislocation : elle aligne, dans le sens du méridien, une sèrie de lacs, longs et profonds; elle supporte d'enormes cratères: la surgit la plus haute montagne de tout le continent, le Kilimandjaro $(5.893 \mathrm{~m}$.).

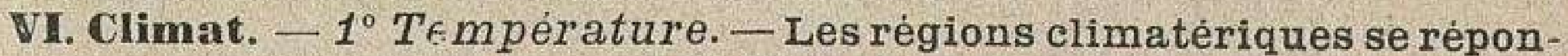
dent exactement, en fartant de l'équateur, d'un hèmisphère à l'autre. La region équatoriale est chaude, humide, à temperature peu variable; vers $10^{\circ}$ Lat. la temperature varie suivant la position du soleil

G. Lesp.anoL ET M. FALLEX. - Afrique. 
pendant l'annèe; au delá du tropique, la région désertique, de chaleur sèche, est sujette à des écarts sensibles; enfin vient une région tem. pérée chaude.

$2^{\circ}$ Vents. - A la région des calmes équatoriaux succèdent la région des alizés, puis la région des vents variables.

Dans l'ocean Indien alternent les moussons, ou vents saisonniers, très caractérisés.

Parmi les vents locaux, le siroco, le r'amsin et le harmattan soufflent, embrasés et secs, de l'intérieur du désert.

$3^{\circ}$ Pluies. - Sous l'équateur, les pluies tombent toute l'année, par averses orageuses; - sous les tropiques, l'annèe se partage en deux saisons, l'une de pluie, l'autre de sécheresse;-dans les déserts, les pluies sont très rares; - enfin dans les régions tempérées chaudes (Atlas et Cap) la saison pluvieuse est l'hiver.

VII. Formes hydrographiques. - Le réseau hydrographique est aussi indécis que le relief : les cours d'eau cherchent leur pente, tombent par des chutes et des rapides du haut des plateaux étagés, et généralement étalent leurs alluvions en forme de deltas.

Le Congo, le second fleuve de la terre pour le volume, est fleuve équatorial.

Le INil, beaucoup plus long, est successivement fleuve équatorial, fleuve tropical, fleuve désertique.

Le Zambèze a plus d'une analogie avec le Congo, et le $N$ iger avec le Nil.

L'Orange finit misérablement dans une contrée fort sèche.

Le Chari se perd dans le bassin ferme du lac Tchad.

Quant aux oueds du Sahara, ils n'ont plus d'eau; ce sont des fleuves fossiles.

En résumé, les rivières de l'Afrique ne sont jamais navigables que sur des portions de leur cours ou bien à la saison des hautes eaux: ce ne sont pas des rivières civilisatrices.

VIII. Côtes. - Tantôt rocheuses, escarpèes, et tantôt basses, sans profondeur, tantôt torrides, désertiques et tantôt trop humides, malsaines, ailleurs encore empâtées par les coraux, presque partout battues par le ressac, les côtes sont peu hospitalières à l'étranger; elles ne sollicitent pas davantage l'indigène : il n'y a de populations maritimes que sur la côte de Guinée, au cap des Palmes, et que sur l'océan Indien, vers Zanzibar.

\section{DÉ VELOPPEMENT}

I. Situation et limites. - Une des cinq parties du monde, l'Afrique est située au Sud-Ouest de l'ancien continent. Au Nord la Méditerranée unit l'Afrique et l'Europe plus qu'elle ne les sépare; elle établit entre elles des rapports naturels : un isthme sous-marin joint les caps tunisiens à la Sicile et par suite à l'Italie; le détroit de Gibraltar (16 à $30 \mathrm{~km}$. de large) est une fracture continentale entre l'Espagne et le 
Maroc, par lui l'océan Atlantique alimente la Méditerranée. L'Espagne est déjà africaine, ou, si l'on veut, l'Algérie est encore européenne, de structure, de climat et de productions.

Avant d'être coupé par le canal (1869), l'isthme de Suez, bas et sablonneux, unissait l'Afrique à l'Asie. Et nous avons vu déjà que l'Arabie et l'Inde ont des rapports étroits, de plus d'une sorte, avec l'Afrique orientale. La mer Rouge est un couloir d'effordrement que les eaux de l'océan Indien ont rempli par la rupture du détroit de Bab-el-Mandeb; l'océan Indien luimême, où se manifeste avec une intensité extraordinaire le phénomène des moussons, est asiatique aussi bien qu'africain. La carte des profondeurs marines révèle le lien qui unit Madagascar au cap Comorin, malgré une distance de 4.000 kilomètres. Ces relations d'ordre physique ont eu pour conséquence des relations économiques, biologiques et humaines.

A l'Ouest, l'océan Atlantique met une distance énorme entre '’Afrique et les Amériques; pourtant, par sa saillie occidentale, par les iles du cap Vert, l'Afrique s'avance au-devant du Brésil, et Dakar est l'escale naturelle des grands paquebots sur la route de l'Europe vers l'Amérique du Sud.

C'est seulement au Sud que l'Afrique est complètement isolée : elle regarde vers les grandes étendues inhospitalières de l'océan Antarctique.

II. Dimensions. - L'Afrique est le second des continents, après l'Asie ( 43 ou 44 millions de kmq.) ou le troisième, si l'on considère que les deux Amériques n'en forment qu'un seul : elle mesure près de 30 millions de kilomètres carrés; c'est trois fois l'Europe. La distance entre ses points extrêmes est sensiblement égale : 8.000 kilomètres du cap Blanc au cap des Aiguilles, 7.500 kilomètres du cap Vert au cap Guardafui : on a calculé qu'un train express la franchirait dans un sens en 130 heures et en 120 dans l'autre.

III. Configuration. - Ses contours sont lourds et épais. Plus large au Nord, elle s'amincit vers le Sud de façon à rappeler, mais avec des formes émoussées, l'Amérique du Sud, l'Australie et l'Inde. Sa masse contraste avec les fines 'articu- 
lations de l'Europe : bien que trois fois plus petite, celle-ci présente un développement de côtes sensiblement plus long (Afrique $26.200 \mathrm{~km}$., Europe $32.000 \mathrm{~km}$.).

C'est que l'Afrique ne compte pas de mers intérieures. En Europe les points les plus éloignés des côtes sont à 400 ou 500 kilomètres, en Afrique à 1.600 kilomètres et plus. Dans la Méditerranée, le golfe de la grande Syrte, celui de Gabès ou de la petite Syrte sont largement ouverts, et dans l'océan Atlantique l'on ne saurait dire exactement où commence, où finit le golfe de Guinée.

Point de péninsules : la " corne orientale " habitée par les Somali mérite à peine le nom de presqu'île, tant elle est compacte et largement soudée à la masse africaine.

De ces formes massives résultent des conséquences de toute sorte que révéleront successivement la géographie physique et la géographie humaine : l'Afrique est le plus fermé de tous les continents.

IV. Position astronomique. - L'Afrique est le continent tropical par excellence : la masse de ses terres, traversée par l'équateur, s'étend entre les tropiques. Le cinquième seulement de sa superficie totale est compris dans les deux zones tempérées, la portion de l'hémisphère Nord étant trois fois plus grande que celle de l'hémisphère austral.

Le cap des Aiguilles $\left(34^{\circ} 51^{\prime}\right.$ Lat. S.) est plus éloigné du pôle antarctique que l'Amérique du Sud et même que l'Australie. Le cap Blanc en Tunisie ( $37^{\circ} 20^{\prime}$ Lat. N.) n'est pas sensiblement plus loin de l'équateur. "Repliée sur l'équateur comme charnière, la partie septentrionale de l'Afrique tomberait à peu près sur la partie méridionale : c'est ce qui explique comment les deux extrémités de l'Afrique, bien que très éloignées, offrent entre elles tant d'analogies de climat et d'aspect. ”

Au contraire, le méridien de Paris, tracé à l'Ouest d'Alger, à l'Est des oasis sahariennesd'Ain-Salah, au-dessus enfin du Dahomey, coupe le continent en deux parties très inégales; l'Afrique s'avance plus loin que le l'Europe vers le couchant; le cap Vert atteint $19^{\circ} 53^{\prime}$ Long. O., le cap Guardafui $48^{\circ} 54^{\prime}$ Long. E., et l'heure de Madagascar est à peu près celle d'Astrakhan. 
E

$\vdots$

¿

용

0

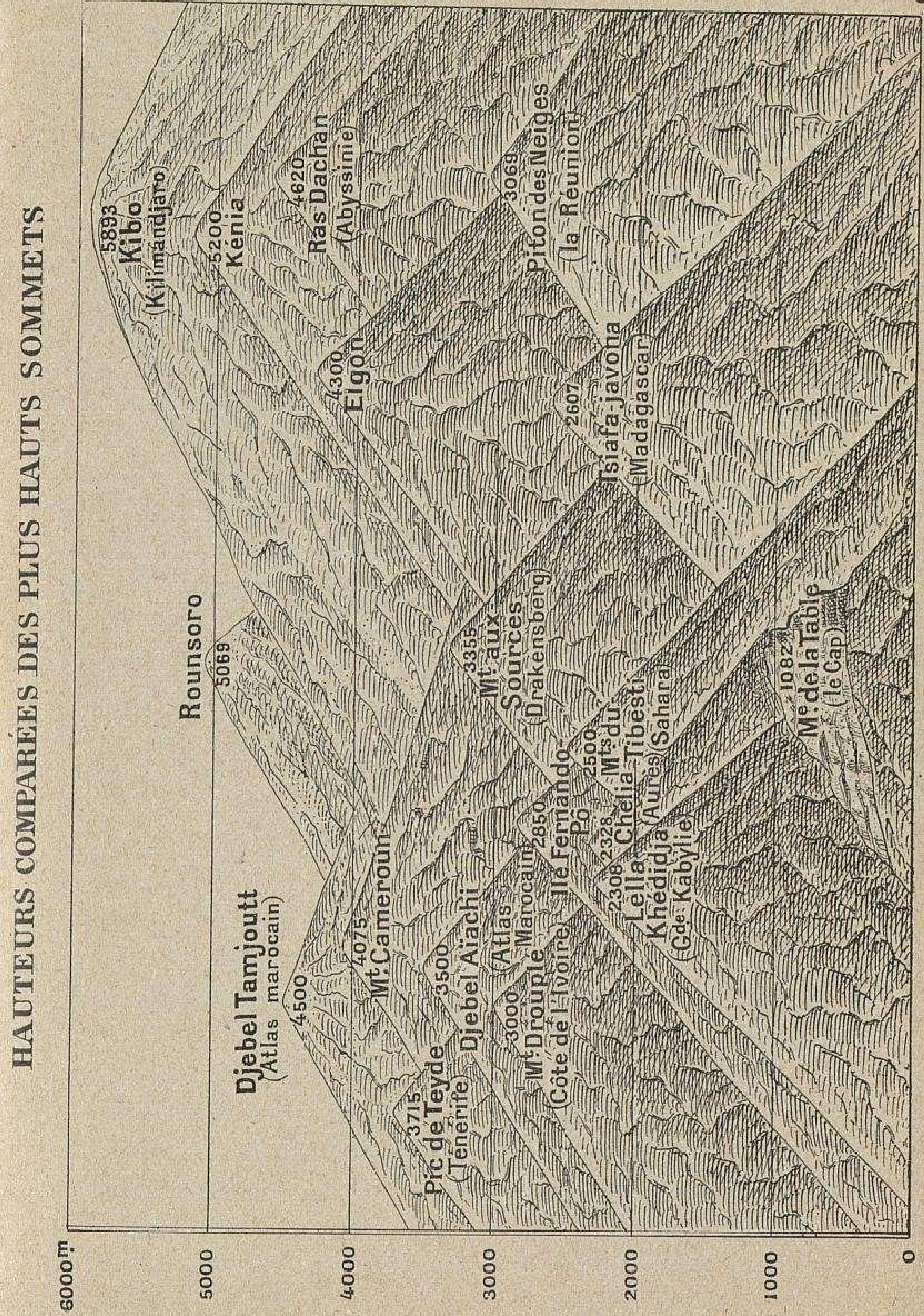


V. Relief. - Très élevée, la hauteur moyenne de l'Afrique atteint 660 mètres, alors que celle de l'Europe est seulement de 330 mètres. Pourtant l'Afrique n'a pas de chaîne de montagnes comparable aux Alpes, encore moins à l'Himalaya, ou à la Cordillère des Andes : c'est un plateau.

Si l'on met à part la région de l'Atlas, qui n'est pas à proprement parler une terre africaine, mais bien une dépendance de l'Europe méditerranéenne, aussi jeune qu'elle, l'Afrique est un continent extrêmement ancien, que les eaux marines n'auraient plus recouvert depuis les temps primaires. Les effondrements qui ont donné naissance à l'océan Atlantique et à l'océan Indien ont tranché si net ses contours que la ligne des profondeurs océaniques de 1.000 mètres accompagne partout à faible distance les bords de la plate-forme.

L'Afrique orientale est une région de grande dislocation; les cavités d'effondrement ont été remplies par les eaux : là s'aligne une série de lacs, tous de forme allongée, tous encaissés entre de hautes falaises, tous très profonds (Nyassa, Tanganyika, Albert-Édouard, Albert, Rodolphe, etc.). La mer Rouge elle-même n'est pas autre chose qu'une tranchée que les eaux de l'océan Indien ont envahie par la cassure du détroit de Babel-Mandeb. En même temps le plateau était soulevé à de fortes altitudes (le Rounsoro, 5.069 mètres), et des crevasses s'entr'ouvraient par où jaillissaient les laves : le Kilimandjaro $(5.893 \mathrm{~m}$.$) , la plus haute cime du continent, le Kenia$ (5.200 m.), etc., sont d'anciens cratères, et l'Abyssinie ou Ethiopie n'est tout entière qu'un énorme massif volcanique. L'alignement ininterrompu de ces lacs d'effondrement et de ces cônes d'éruption commence au Nyassa et se termine seulement en Asie dans la dépression de la mer Morte.

Le reste du continent, c'est-à-dire la plus grande masse, a un relief indécis, tout à fait vague : pas d'arêtes montagneuses pour dessiner les versants; seulement des bassins, en forme de cuvettes : ceux-ci tantôt descendent à la mer par des étages de terrasses (bassins du Zambèze, du Congo, du Niger et du Nil) et tantôt ne trouvent pas leur écoulement (bassins fermés du lac Tchad, du lac Ngami).

Ainsi le plateau est la forme dominante du relief. Les plaines, 
c'est-à-dire les niveaux inférieurs à 200 mètres, font exception : elles ne se laissent guère apercevoir que sur le pourtour du continent, en contre-bas des plateaux; encore ne forment-elles qu'une lisière étroite.

Dans l'océan Indien, Madagascar est également un plateau; ses bords effondrés tombent raide vers l'Est, et dans maint endroit des roches volcaniques le surmontent. Au point de vue du relief, c'est une Afrique en miniature.

VI. Climat. - $1^{\circ}$ Température - Partagée presque également par l'équateur, l'Afrique est de tous les continents le plus chaud.

Ce n'est pas cependant à l'équateur que l'on note les températures les plus élevées, pas plus qu'on ne relève les plus basses au pôle : comme il y a un "pôle du froid ", il existe un " équateur thermique ». L'un et l'autre apparaissent dans des régions que l'éloignement de la mer et la direction des vents soustraient aux influences adoucissantes des brises océaniques. C'est dans la plus forte épaisseur de l'Afrique qu'est tracée la ligne de la plus grosse chaleur : elle se maintient longtemps entre $10^{\circ}$ et $20^{\circ}$ Lat. N., puis contourne le massif éthiopien pour s'échapper par le cap Guardafui. Dans les parties les moins hautes du Sahara, le thermomètre atteint normalement en été $50^{\circ}$; ce chiffre est dépassé dans les vallées encaissées, à l'abri du vent, c'est-à-dire exceptionnellement. Si forte qu'elle nous paraisse, la plus grande chaleur reste bien inférieure, comme nombre de degrés centigrades, au plus grand froid $\left(-69^{\circ}, 8\right)$.

Dans chaque hémisphère, les régions climatériques se répondent exactement; vu la monotonie du relief, c'est le soleil principalement qui règle la température.

$1^{0}$ Sous l'équateur, et de chaque côté, est une contrée chaude, à température peu variable : l'atmosphère est en effet toujours très humide, et si les pluies sont plus abondantes lors du passage du soleil au zénith, aucun mois n'en est dépourvu. 


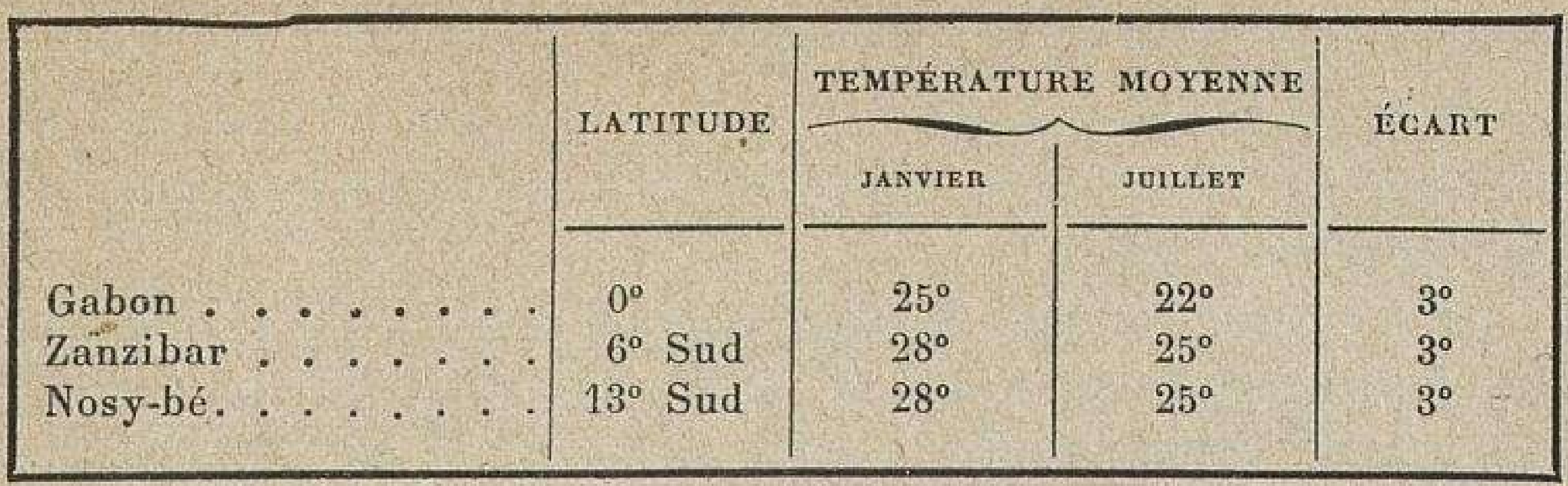

Là, l'Européen ne peut s'acclimater : sans parler des insolations, il est guetté par les fièvres et par la dysenterie.

$2^{\circ} \mathrm{Au}$ Nord et au Sud des contrées équatoriales, est une région chaude encore, mais à température très variable : l'air y est très sec. Tels sont dans le Nord le Sahara et dans le Sud le désert de Kalahari.

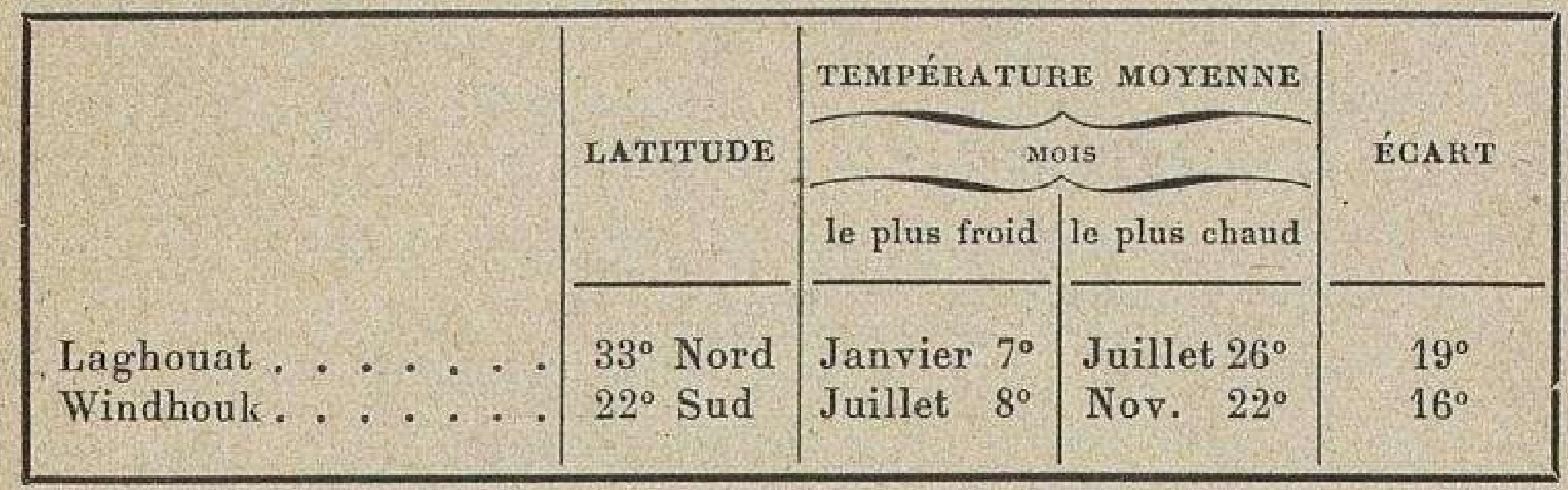

$3^{\circ}$ Les pays méditerranéens et le Cap appartiennent à la région tempérée chaude.

\begin{tabular}{|c|c|c|c|c|c|c|c|c|}
\hline \multirow{4}{*}{ Alexandrie. } & & & & & \multirow{3}{*}{ LATITUDE } & \multicolumn{2}{|c|}{ TEMPÉRATURE MOYENNE } & \multirow{3}{*}{ ÉCART } \\
\hline & & & & & & \multicolumn{2}{|c|}{ Mois } & \\
\hline & & & & & & le plus froid & le plus chaud & \\
\hline & - & & & & $31^{\circ}$ Nord & Janvier $14^{\circ}$ & Juillet $26^{\circ}$ & $12^{\circ}$ \\
\hline Alger. . & - & & & & $36^{\circ}$ Nord & Janvier $12^{\circ}$ & Juillet $25^{\circ}$ & $13^{\circ}$ \\
\hline Le Cap. & & & & & $33^{\circ} \mathrm{Sud}$ & Juillet $12^{\circ}$ & Janvier $25^{\circ}$ & $13^{\circ}$ \\
\hline
\end{tabular}

Les chiffres d'Alger et du Cap sont les mêmes exactement, mais intervertis : l'été d'Alger correspond à l'hiver du Cap.

$2^{\circ}$ Vents. - Le régime des vents qui soufflent sur l'Afrique est, dans l'ensemble, assez simple, toujours parce que le continent est partagé par l'équateur. On peut distinguer : 
$1^{\circ}$ La région des calmes équatoriaux : l'air chaud est aspiré vers les hautes régions de l'atmosphère.

$2^{\circ}$ La région des alizés, du Sud-Est dans l'hémisphère Sud. Dans l'hémisphère Nord, l'alizé du Nord-Est est transformé en moussons, pendant l'été.

$3^{\circ}$ Les contrées africaines de l'océan Indien sont, comme les contrées asiatiques, et pour les mêmes raisons, influencées par les moussons, de même que le littoral de la Guinée et du Sierra Leone. Le renversement de ces vents saisonniers donne lieu, dans la mer des Indes, à de terribles cyclones.

$4^{\circ}$ L'Algérie et le Cap sont dans la région des vents variables.

En outre l'Afrique a ses vents locaux : le siroco souffle du Sahara sur l'Algérie et la Tunisie, vent sec, énervant, qui soulève d'impalpables poussières. Le r'amsin de l'Égypte, lo harmattan du Sénégal ont même caractère et même origine.

Pendant les mois d'été soufflent du Nord et de la Méditerranée des vents périodiques, attirés par les dépressions qui occupent le Sahara surchauffé; ils portent les voiliers de la Grèce vers la presqu'île de Barka : ce sont les vents étésiens des anciens, à ranger dans la catégorie des moussons.

$3^{\circ}$ Pluies. - La carte des pluies concorde avec la température et avec les vents.

$1^{\circ}$ Les pluies équatoriales sont de très grosses averses, des orages diluviens. Alors qu'en France sous nos climats tempérés la hauteur moyenne des pluies est de 80 centimètres par an, elle est de 3 et de 4 mètres autour du lac Nyassa, et sur la côte orientale de Madagascar. Le fond du golfe de Guinée, qui comme le Bengale et l'Assam est ouvert en forme d'entonnoir, a jusqu'à 9 mètres, chiffre exceptionnel.

$2^{\circ}$ Les pluies tropicales sont périodiques : elles coincident avec le passage du soleil au zénith d'avril à octobre dans l'hémisphère Nord, de septembre à mai dans l'hémisphère Sud, et la quantité tombée diminue graduellement de la côte vers l'intérieur. Au tropique l'année se partage en deux saisons, l'une sèche, l'autre mouillée; puis en quatre, lorsqu'on se rapproche de l'équateur, deux saisons de pluie, deux saisons de sécheresse, les unes et les autres d'inégale durée.

Les marins, en quittant les côtes arides du Sahara et du 
Sénégal, entrent dans le pot au noir à partir du Sierra Leone. Là s'abattent les fortes pluies de la mousson.

$3^{\circ}$ A mesure que l'on s'écarte des tropiques, la pluie se fait très rare; l'étendue des déserts est plus grande dans l'hémisphère Nord, où le continent est plus épais.

$4^{\circ}$ Enfin sur l'Atlas méditerranéen et sur la région du Cap,

HAU TEUR. MOYENNE DE LA PLUIE

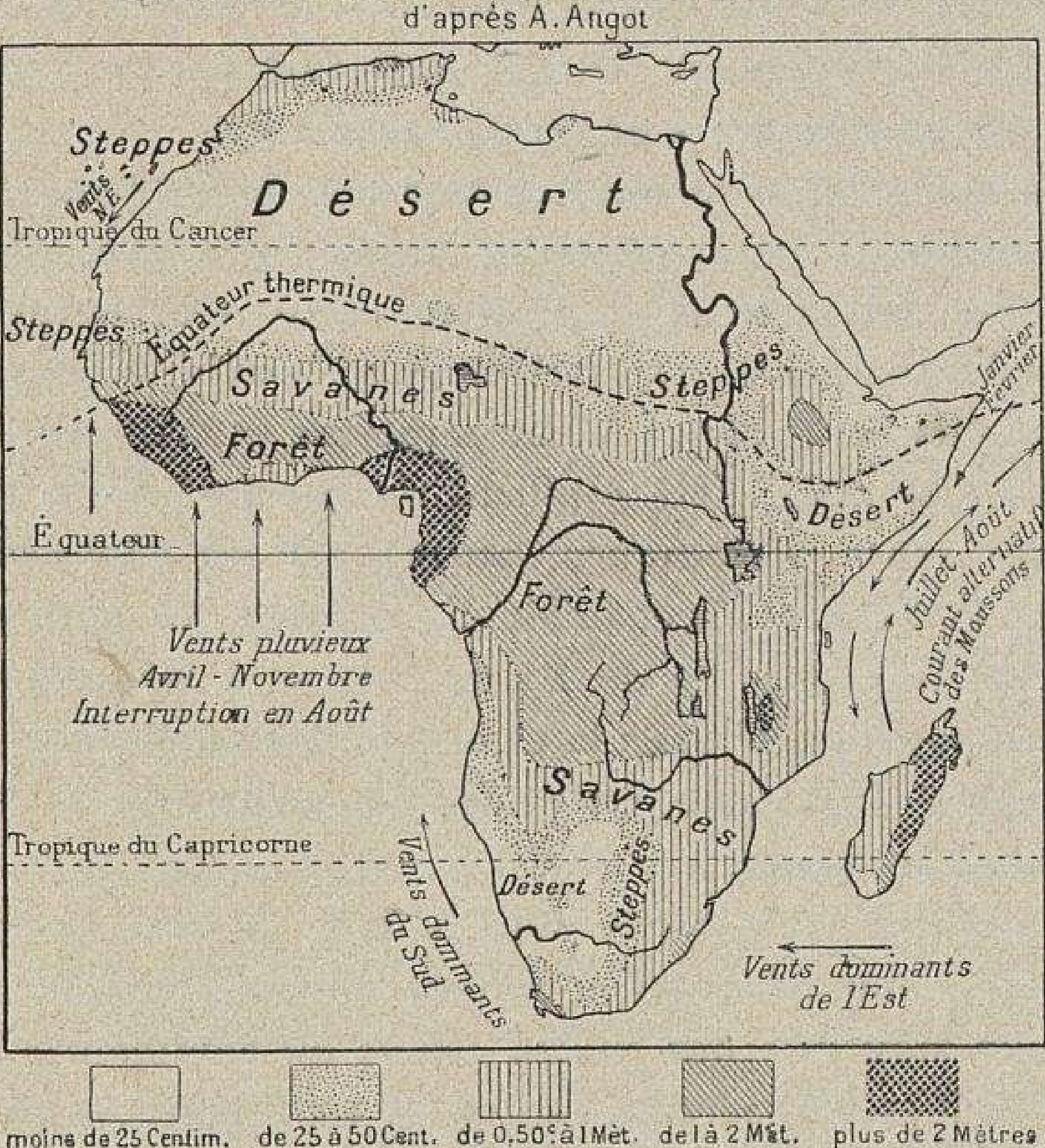

la pluie tombe surtout dans les mois d'hiver : c'est qu'alors la terre s'est refroidie plus vite que la mer.

VII. Formes hydrographiques. - De contours massifs, tropicale par sa situation, l'Afrique compte quelques-uns des plus longs et des plus gros fleuves de la terre.

$1^{\circ}$ Pente. - Le réseau hydrographique est, comme le relief, d'un dessin si informe qu'on le dirait inachevé. Dans des bassins mal clos, sans ligne de partage nettement caractérisée, les cours d'eau ont des allures indécises : ils cherchent leur pente. Les uns, comme le Niger, commencent par tourner le dos à la 
mer, et ne l'atteignent qu'après un long circuit; les autres,

Wil $\quad 6.497 \mathrm{~km}$

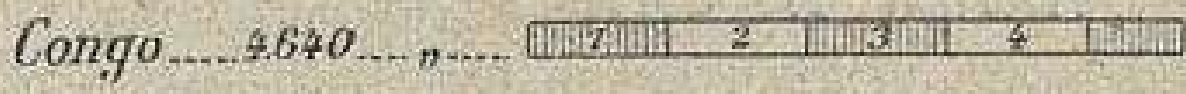

Niger..... $3.962 \ldots . ., \ldots$.

Zambèze.2.660...n.

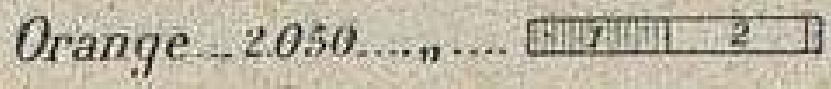

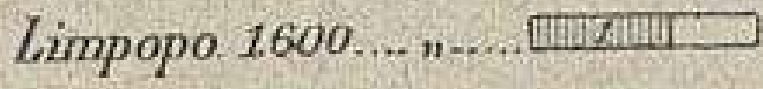

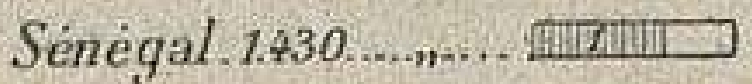

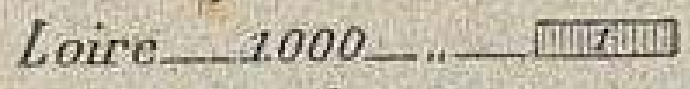

GRANDS FLEUVES DE LAFRIQUE Longueur comparée comme le Chari, meurent dans des dépressions lacustres, sans issue. Tous dévalent les terrasses des plateaux par des cataractes et par des rapides : il n'est pas de spectacle plus grandiose sur le globe que les chutes du Zambèze, dites chutes Victoria. Et presque tous, avant de forcer les

défilés qui les étranglent, avant de sauter les paliers qui les coupent ou les roches qui les barrent, amassent leurs eaux dans des bassins de retenue naturels: tel le Gongo dans le Stanley Pool. Enfin, le plus souvent alimentés par des pluies abondantes, sujets à de fortes crues, ils charrient des alluvions dont la masse s'étale en d'immenses deltas : celui du Nil est le plus célèbre, et le nom même de delta que les Grecs empruntèrent à la quatrième lettre majuscule de leur alphabet, pour l'appliquer à ses bouches triangulaires, est passé depuis dans la langue géographique. Rares sont par contre les fleuves à estuaire : cependant la masse des eaux douces du Congo refoule loin vers le large les eaux salées de l'océan Atlantique.

$2^{\circ}$ Volume et régime. - Pour le vo. lume, le Congo est le premier des fleuves africains et le
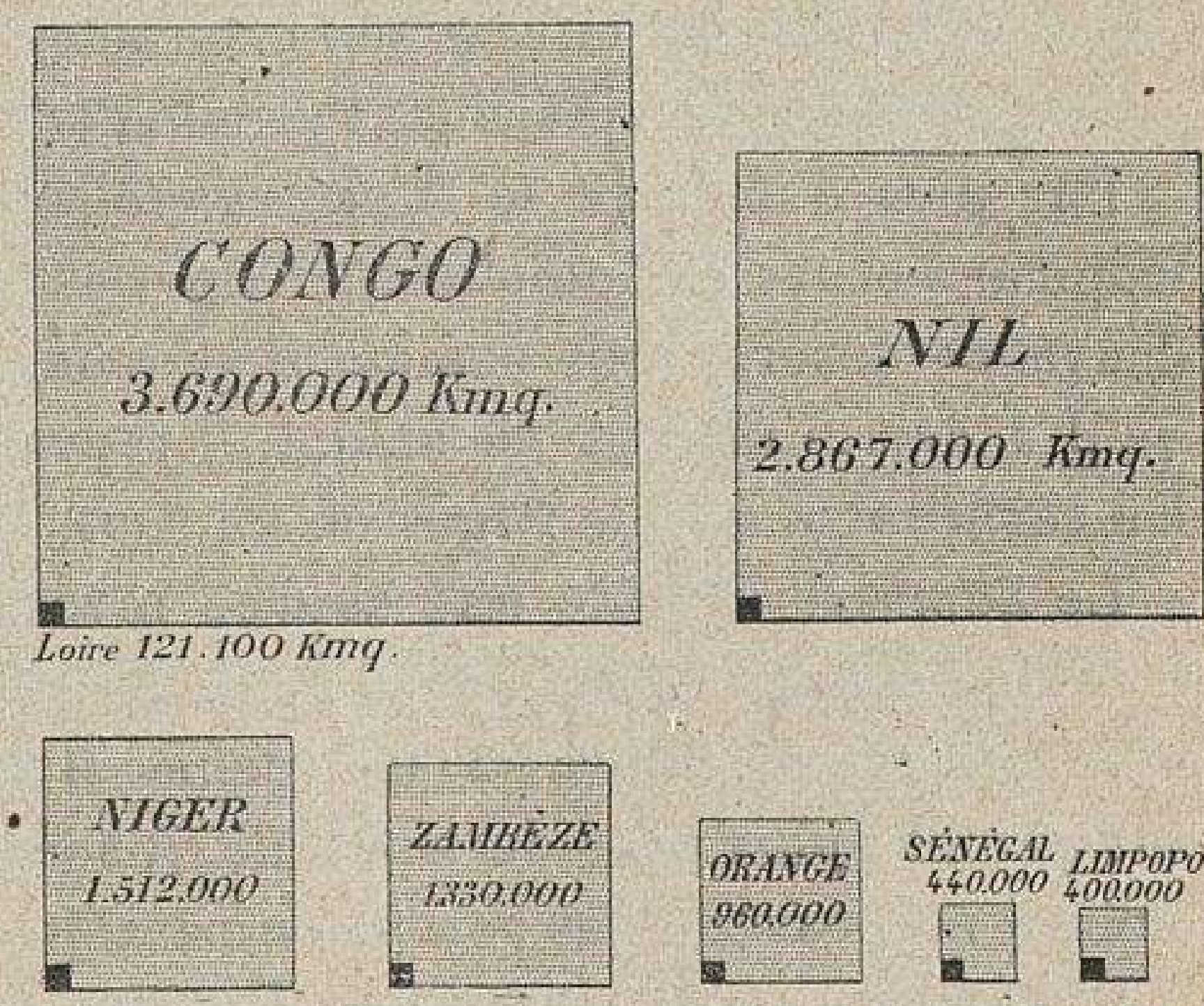

GRANDS BASSINS FLUVIAUX DE LAARIQUE Superficie comparé second de toute la terre : il vient après l'Amazone, et tous deux sont fleuves 
équatoriaux. Mais tandis que l'Amazone est dirigé dans le sens de l'équateur, le Congo s'en approche, puis s'en écarte de manière à le couper deux fois. Quand le soleil gagne l'hémisphère Nord, ses affluents de gauche décroissent, mais ceux de droite entrent en crue; puis, à la saison suivante, le phénomène se renverse, de telle sorte que le niveau des eaux garde un équilibre presque complet.

Le $N i l$, le plus long fleuve du globe $(6.497 \mathrm{~km}$.), si l'on ne tient pas compte du groupe Mississipi-Missouri, coule du Sud au Nord sur une distance de plus de 30 degrés de latitude (on en compte 9 de Perpignan à Dunkerque). Il commence par être un fleuve équatorial qu'alimentent d'immenses réservoirs lacustres: le lac Victoria couvre une superficie supérieure au bassin de la Seine. Puis il devient fleuve tropical, c'est-à-dire qu'il est influencé par l'alternance des saisons sèche et humide, par des périodes de crues et de décrues : à cette seconde section de son cours appartiennent le Bahr-el-Ghazal, qui lui arrive à gauche, et le Nil bleu descendu de l'Abyssinie. Pour finir c'est un fleuve de désert, sans un seul affluent; s'il ne disparaît pas complètement par infiltration et par évaporation, si sa vallée met aujourd'hui, comme au temps des pharaons, un long ruban d'oasis sur la ligne des déserts, il le doit aux lacs et aux marais équatoriaux; il le doit en outre à ses cataractes qui, comme autant de barrages naturels, retardent l'écoulement des eaux.

Par plus d'un trait le Niger rappelle le Nil. D'abord fleuve tropical à crues périodiques, le Niger est dans son cours moyen fleuve de dúsert, mais comme il se recourbe vers les latitudes qu'il a déjà franchies en amont, il reprend le régime tropical. En réalité il y a trois Niger en un seul.

Le Zambèze dessine une courbe inverse de celle du Congo; il draine comme lui d'anciens fonds lacustres, superposés. Mais plus souvent encombré par les roches, il présente moins de biefs navigables; plus près du tropique, il soutient moins son débit; enfin il ne possède pas son incomparable ramure d'affluents.

L'Orange suit une direction Est-Ouest : il s'annonce comme un puissant cours d'eau, lorsque les pluies de l'océan Indien le gonflent; mais plus il avance et plus il s'appauvrit, car il gagne des contrées sèches. 
Sur le Sahara les cartes figurent de longues et larges rivières; elles sont presque toujours vides : ce sont des fleuves fossiles. Du moins leur lit dessine les grandes routes du désert et les points d'eau qui les jalonnent abreuvent les caravanes.

Enfin dans la région de l'Atlas au Nord, dans la colonie du Cap au Sud, les cours d'eau appelés oueds, des plus irréguliers, sont sujets à de très forts écarts : très pauvres une grande partie de l'année, ou même comp̄lètement à sec, ils roulent brusquement, et pour peu de temps, des eaux furieuses.

Conclusion. - Les fleuves de l'Afrique ne fournissent pas de voies de pénétration intérieure; l'embouchure est gênée presque toujours par une barre ou bien la navigation se heurte assez vite à des chutes infranchissables. En amont, ils portent bateau seulement sur des parcours limités, sur des biefs, ou seulement à la saison des crues. Dans les régions tempérées chaudes, l'industrie de l'homme ne peut les utiliser que pour l'irrigation.

Bref, la nature du réseau hydrographique prive l'Afrique d'un élément essentiel de vie.

VIII. Côtes. - Les côtes ne compensent pas l'insuffisance et l'imperfection des cours d'eau, tant elles sont monotones et mal articulées; elles ne dessinent que de grandes courbes concaves ou d'énormes protubérances.

$1^{\circ}$ Méditerranée. - Bas et alluvionnaire à l'arrivée du Nil, le littoral ne compte en Égypte que des ports artificiels, préservés contre les atterrissements à grands renforts de digues. Port-Saïd n'existerait pas sans le canal de Suez, Alexandrie est de même entourée de marais salés et de sables désertiques.

La Tripolitaine n'est que la bordure maritime du Sahara : dans les golfes des deux Syrtes, peu profonds et secoués par des vagues dangereuses, les navires mouillent à distance des plages.

Depuis le cap Bon, qui n'a de bon que le nom, jusqu'au détroit de Gibraltar, l'Atlas redresse la côte; celle-ci avait déjà chez les Romains mauvaise réputation, car elle manque d'abris. Tunis s'est ouvert un chenal et creusé des bassins dans une lagune; Bizerte, dont la France fait un puissant port de guerre,

G. Lespagnol ez M. Fachex. - Afrique. 
communique avec un grand lac intérieur, profond et poissonneux. Quant à l'Algérie et au Maroc, ils ne présentent le plus souvent qu'un front de falaises; de distance en distance s'ouvrent des baies en forme de croissant; là se sont blottis les ports, encore sont-ils exposés aux vents du Nord et de l'Est, Alger notamment.

$2^{\circ}$ Atlantique. - Au delà du détroit de Gibraltar la côte n'est pas plus favorisée. Après les sables fauves, aveuglants et stériles du Sahara, c'est avec joie que les marins saluent la végétation du cap Vert; derrière lui et face à l'îlot de Gorée, Dakar est un très bon port que sa position à l'extrême Ouest du continent désigne pour être l'escale des paquebots, de ceux qui s'enfoncent vers le Sud Africain, de ceux aussi qui mettent le cap sur l'Amérique du Sud.

Plus loin, les rivières, toutes garnies de palétuviers, creusent leurs estuaires au pied des terrasses du Fouta-Djalon, et le contre-courant équatorial de Guinée contribue à déblayer les chenaux.

Au cap des Palmes l'orientation change, et le long du golfe de Guinée les boues et les sables forment des cordons littoraux très longs et très plats; en avant déferle incessamment le " ressac »; en arrière s'étalent tranquilles les eaux des lagunes, dans le décor d'une végétation exubérante.

De nouveau, après le delta vaseux et malsain du Niger, la côte tourne au Sud, hérissée de monts volcaniques, échancrée par les estuaires de grosses rivières. C'est par excellence la contrée du palmier à huile.

Jusqu'au Cap, le littoral est une bande étroite de terres basses en arrière desquelles s'étagent les gradins des plateaux. Peu d'accidents à noter : parmi les principaux, le large estuaire du Gabon, le delta de l'Ogooué, la bouche énorme du Congo. Et peu à peu la végétation s'appauvrit, les pluies se font de plus en plus rares, c'est le désert. Des mers antarctiques arrive un courant froid, celui de Benguella; la baie des Baleines signale par son nom même une faune marine nouvelle, les otaries ont remplacé les requins, et des bandes d'oiseaux de mer transforment les îles en guano.

A l'extrême Sud enfin l'aspect change : derrière la montagne 
de la Table s'ouvre une baie très sûre, sur laquelle fut bâtie de bonne heure par les Hollandais la ville du Cap. Le cap de BonneEspérance est un des plus connus du globe : le nom est de meilleur augure que celui de cap des Tempêtes qui lui fut donné tout d'abord.

$3^{\circ}$ Océan Indien et mer Rouge. - Le cap des Aiguilles est à une latitude plus méridionale et là vraiment se heurtent les flots des deux océans, Atlantique et Indien. Escarpé, dur et mauvais, le littoral ne s'abaisse que lorsque s'écartent les terrasses des plateaux intérieurs; chaud et très mouillé, il est bordé de lagunes, toujours malsaines. La baie Delagoa porte la ville de Lourenço Marquès, débouché naturel du Transvaal.

Après le delta du Limpopo, après celui du Zambèze, commencent les formations de coraux; ils frangent de leurs récifs le continent aussi bien que les îles. Zanzibar, dans la zone des moussons, est depuis une très haute antiquité le grand centre commercial de l'océan Indien.

Mais bientôt, avec la péninsule des Somali, le désert reprend et les paquebots européens passent au large, sans faire escale. Au delà du cap Guardafui, en face d'Aden, des ports se sont installés, Djibouti par exemple, à la fois relâche importante de nos vaisseaux, guerre ou commerce, et débouché de l'Éthiopie méridionale.

Au delà du détroit de Bab-el-Mandeb, que garde l'îlot de Périm, la côte de la mer Rouge est torride et désertique. Port Soudan a remplacé Souakin comme débouché du Soudan anglo-égyptien. Suez, qui a donné son nom au canal, n'a pas pris l'essor qu'on croyait pouvoir lui prédire.

Madagascar est comme un petit continent dans l'océan Indien. La côte orientale, rectiligne, garnie de lagunes, très insalubre et sans ports véritables, est battue par le courant équatorial qui s'y brise en deux branches. Au Nord, des deux côtés du cap d'Ambre, les rades sont au contraire fort belles, Diego Suarez entre beaucoup d'autres. Les récifs de coraux accompagnent le littoral désertique du Sud-Ouest.

Conclusion. - Au total les côtes africaines sont inhospitalières : désertiques, ou bien trop mouillées et alors fiévreuses, 
presque partout battues par le ressac, bordées de coraux dans la partie orientale, elles ne possèdent que par exception de bons ports naturels. Peu accueillante aux étrangers, la mer ne vient pas davantage solliciter l'indigène, et l'Afrique n'a jamais eu de populations maritimes qu'au cap des Palmes, les Krou, et i utour de Zanzibar, les Souaheli. 


\title{
CHAPITRE II
}

\author{
ÉTUDE GÉNÉRALE DE L'AFRIQUE (suite) \\ VIE VÉGÉTALE. - VIE ANIMALE. - VIE HUMAINE
}

\section{SOMMAIRE}

I. Vie végétale. - En Afrique, ce sont les pluies surtout qui règlent la vie végétale.

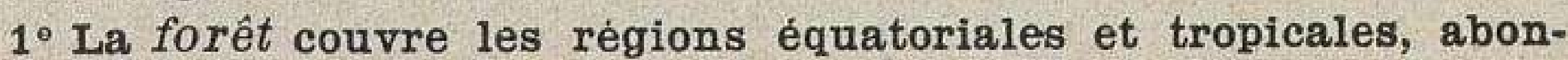
damment mouillèes : forêt immense, feuillue, impénétrable, sombre. sous laquelle flottent de chaudes vapeurs. Les lianes comme le caoutchouc, les bananiers, le palmier à huile sont les essences les plus caractéristiques.

2. A mesure que l'humidité diminue, la forêt fait seulement galerie le long des cours d'eau; ailleurs règne la savane ou pays des grandes herbes, elle prend la forme tantôt de parc et tantôt de steppe. Les espèces arborescentes, à feuilles caduques, sont des mimocèes, des acacias, l'euphorbe à candélabre et le baobab.

3. Au désert, la végètation, fort pauvre, est ligneuse ou charnue ou toute en épines; le palmier dattier crée l'oasis.

4. Dans les régions tempérées chaudes, la végétation forestière est à feuilles persistantes : chêne liège et olivier.

II. Vie animale. - Les rapports sont étroits entre la végétation et l'animal.

1. Dans la forêt, le monde animal perche et grimpe dans les arbres : oiseaux et singes.

Les fleuves sont infestès de crocodiles; l'hippopotame est exclusiment africain.

$2^{\circ}$ Sur les Savanes paissent les herbivores : l'éléphant, la girafe qu'on ne trouve qu'en. Afrique, le zèbre, l'antilope, le buffle et le bœuf domestique. La mouche tsétsé est le fléau du bétail.

Les carnassiers guettent les herbivores : le lion, la panthère, le léopard, le renard, l'hyène, le chacal.

3. Au désert, l'animal type est le chameau, marcheur, coureur, très sobre.

4. Dans les régions tempérées charcios, les animaux sauvages 
sont rares; pas de bêtes á cornes, mais la chèvre, le mouton, et surtout le cheval, l'âne, le mulet.

5. Madagascar est la terre des lémuriens.

III. Vie humaine. - $1^{\circ}$ La population, évaluée à 130 millions (densité : 5 habitants par $\mathrm{kmq}$.), est répartie très inégalement.

$2^{\circ}$ Races. - Il s'en faut que le "continent noir " soit uniquement habité par des Nègres.

1. Au Nord, les Berbères et les Arabes sont de race blanche.

$2^{\circ}$ A l'Est, parmi les Hamites, les plus purs sont les Galla.

$3^{\circ} \mathrm{Du}$ Sénégal au pays des Galla habitent des peuples mélangés.

4. De chaque côté de l'équateur, les Nègres comprennent entre autres les Négrilles et les Bantous.

$5^{\circ}$ Les Hottentots et les Bochimans ne sont pas des nègres.

6. Des peuples ètrangers sont venus d'Asie (Persans, Hindous et Malais); puis d'Europe arrivèrent colons, missionnaires et conquèrants.

$3^{\circ}$ Langues. - Quatre groupes principaux : sémitique, nègre, hottentot, européen.

$4^{\circ}$ Religions. - A. L'Islam a èté importé par les Arabes.

B. Les Nègres sont fètichistes.

C. Parmi les chrétiens, les Coptes d'Égypte et les Ethiopiens forment une secte à part, l'Église copte.

D. Les Juifs sont dispersés dans le Nord.

IV. Vie civilisée et vie sauvage. - Le plus grand nombre des habitants de l'Afrique se range parmi les peuples incultes, qui ne connaissent pas l'écriture.

Au plus bas degré de la civilisation, les Bochimans sont des chasseurs,

Les Nègres sont chasseurs sur la lisière de la forêt, pêcheurs sur le bord des fleuves; mais le plus grand nombre vit d'agriculture et d'élevage sur la savane.

Les peuples pasteurs, nomades (Arabes, Berbères, Somali) acquièrent par leur genre de vie un tempérament énergique et fler; ils forment des sociètés de guerriers pillards.

La civilisation européenne entame à peine l'Afrique, qui demeure encore le plus barbare de tous les continents.

\section{DÉVEL OPPEMENT}

I. Vie végétale. - Dans l'Afrique, continent tropical par excellence, c'est principalement l'humidité qui règle la vie végétale.

$1^{\circ}$ Les contrées équatoriales, abondamment mouillées, revêtent une végétation très feuillue, qui ne subit jamais un seul temps d'arrêt : là règne la Fonk̂́, mais une forêt à double et triple étage dont nos régions tempérées de France ne sauraient donner une idée. 
Le feuillage y est tellement serré que les rayons du soleil n'arrivent pas à le percer; deux voyageurs ne s'aperçoivent pas à une distance de deux ou trois pas, et le son de la voix arrive aussi amorti qu' un lointain appel. En dehors des cours d'eau, souvent coupés de rapides, il n'est pas d'autres chemins, lorsqu'il en existe, que des sentiers qui serpentent capricieusement, semblables à des passées d'animaux sauvages. C'est à coups de hache et par une gymnastique incessante qu'il faut s'ouvrir une piste, et celle-ci a tôt fait de disparaître, sous la poussée vigoureuse des plantes.

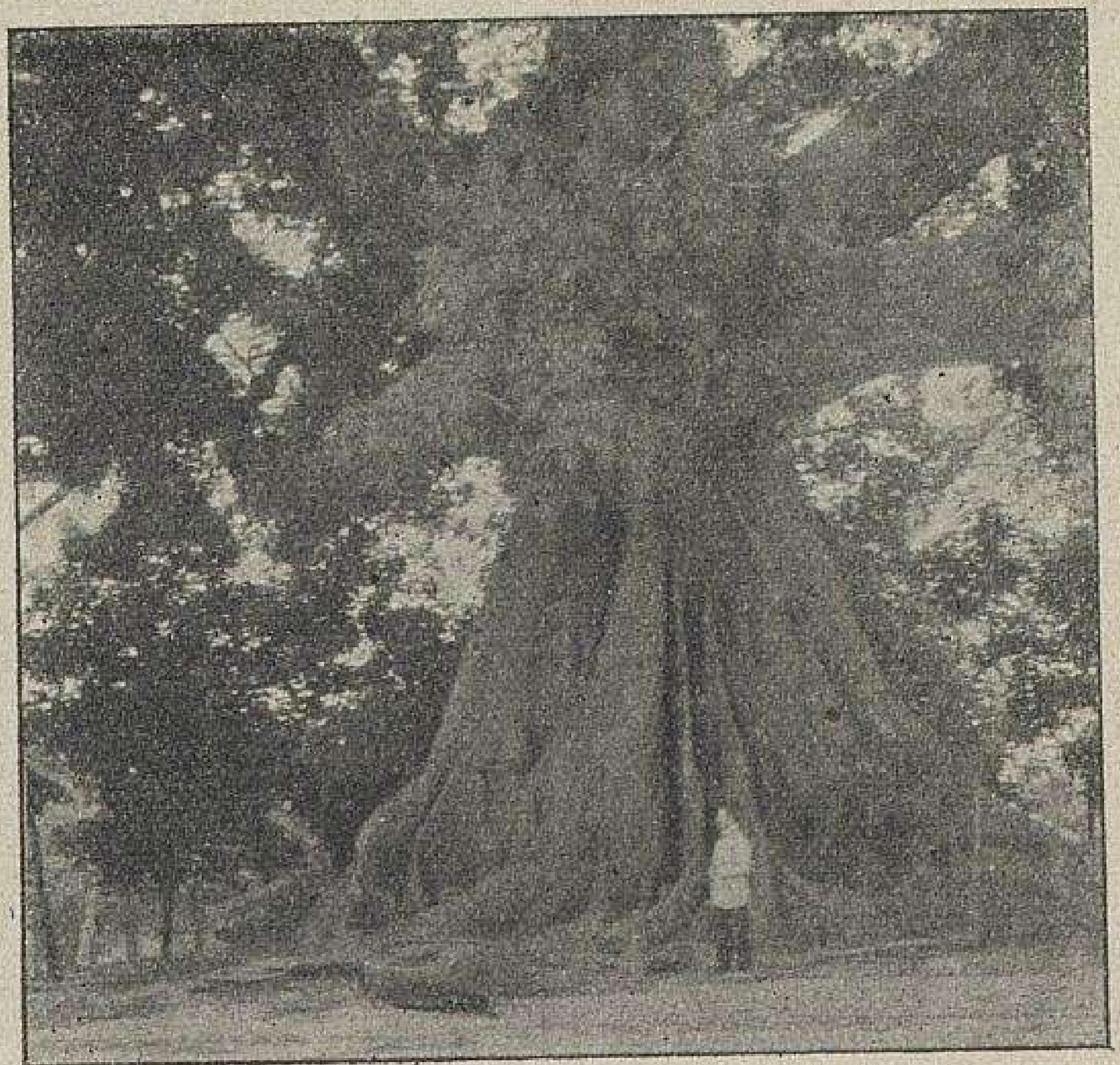

TRONC D'UN FROMAGER, A. KONAKRX.

(Photographie de M. Dybowski.)

Ainsi appelé parce que ses graines aplaties ressemblent à un fromage, le fromager ou bombax est un très grand arbre de 50 à $60 \mathrm{~m}$. de haut, sur 8 à 10 de diamètre. Le tronc forme des contreforts qui lui ont valu, dans la dénomination scientifique, l'épithète de anfractuosum. Le bois est très tendre: les indigènes y creusent des pirogues qui peuvent tenir plus de 100 hommes. Le fruit est reeouvert d'une laine épaisse, l'ouate végétale; employée surtout comme rembourrage, celle-ci peut se filer, lorsqu'on la mélange au coton.

Les espèces géantes, fromagers, acajous, ébènes, etc., pointent vers le eiel, cherchant l'air et le soleil, et sous leur voûte s'étagent les arbres moindres, tandis qu'aux ramures adhèrent les plantes parasites et s'enlacent des lianes inextricables; le sol enfin, mou, spongieux, fait de débris en décomposition, baigne dans les buées lourdes d'une chaude vapeur et se voile d'une obscurité presque complète. Stanley shemina pendant trois mois dans la grande forêt congolaise, sans en trouver la fir, à travers les ténèbres de l'Afrique, et les voyageurs venus de la côte de Guinée éprouvent un sentiment de délivrance et de joie à retrouver l'air libre et le soleil sur la brousse du Soudan. 
Parmi les essences les plus caractéristiques de la forêt vierge, il faut citer le palmier à huile, le caoutchouc, le bananier.

$2^{\circ} \mathrm{Peu}$ à peu, à mesure que l'humidité diminue, de chaque côté de l'équateur, la forêt s'éclaircit, les racines des arbres ne trouvant plus assez d'eau pour compenser l'évaporation des feuilles. Elle apparaît encore dans les vallées profondes et

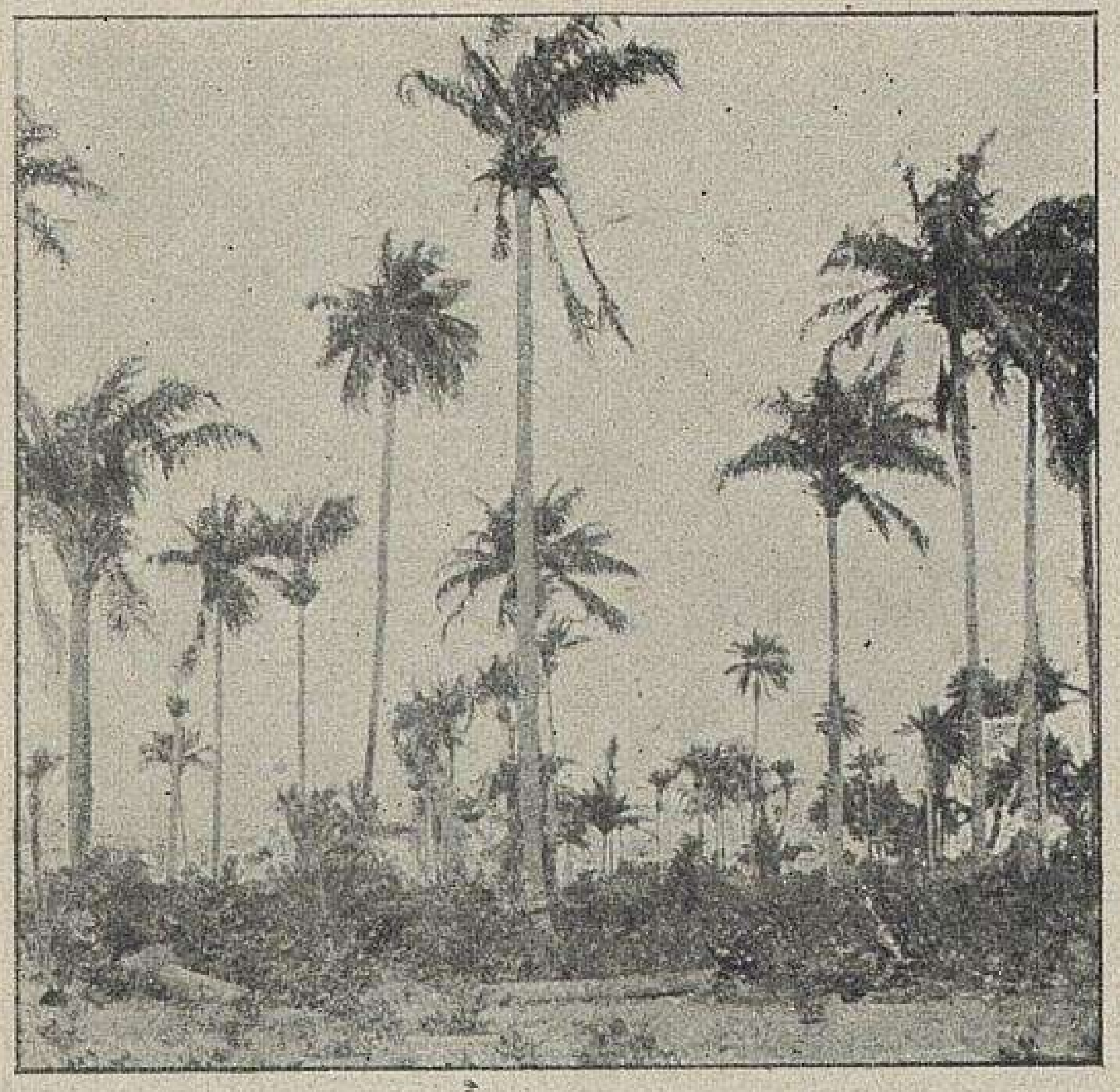

PALMIERS A HUILE, A KONAKRT.

(Photographis de M. Dybowski.)

Très abondant s. I: la côte occidentale d'Afrique entre $15^{\circ} \mathrm{Lat}$. N. et $15^{\circ} \mathrm{Lat}$. S., et sous l'équateur jusqu'à la région des Grands lacs, le palmier a huile ou élaïs porte, en hrv: d'un tronc rugueux, qui lentement atteint $15 \mathrm{~m}$., un bouquet de grandes feuilles pendantes, d'un beau vert. Le fruit, aggloméré en régime, a la grosseur d'une prune; il recouvre un noyau et une amande blanche. Pour la cueillette, les noirs grimpent jusqu'au sommet, les reins appuyés sur une large ceinture dont ils entourent le trone de l'arbre et qu'ils font glisser par saccades répétées, tout en maintenant leurs pieds sur les rugosités. - Avec l'huile de palme, on fabrique du savon, des bougies, des huiles industrielles et des articles de parfumerie. Les indigènes en tirent bien d'autres profits; la sève par exemple fournit un vin de palme, qui les plonge dans l'ivresse.

(D'après A. Breschin.)

humides, le long des cours d'eau; on l'appelle alors d'un mot qui fait image, la ForÊt GALERIE. Quant aux bas-fonds et aux marécages, ils se couvrent de grands roseaux de plusieurs mètres de haut, de joncs, de papyrus, d'ambatch, le tout tellement dru, tellement enchevêtré, que la navigation y devient impossible. 
Sur le plateau se développe une nouvelle formation végétale : la savane. Elle caractérise l'Afrique au même degré que les jungles l'Asie méridionale, que la forêt vierge l'Amérique du Sud, que les scrubs épineux l'Australie. C'est le domaine des graminées : flétries à la saison sèche, et alors incendiées par les indigènes, les grandes herbes reprennent vie aux

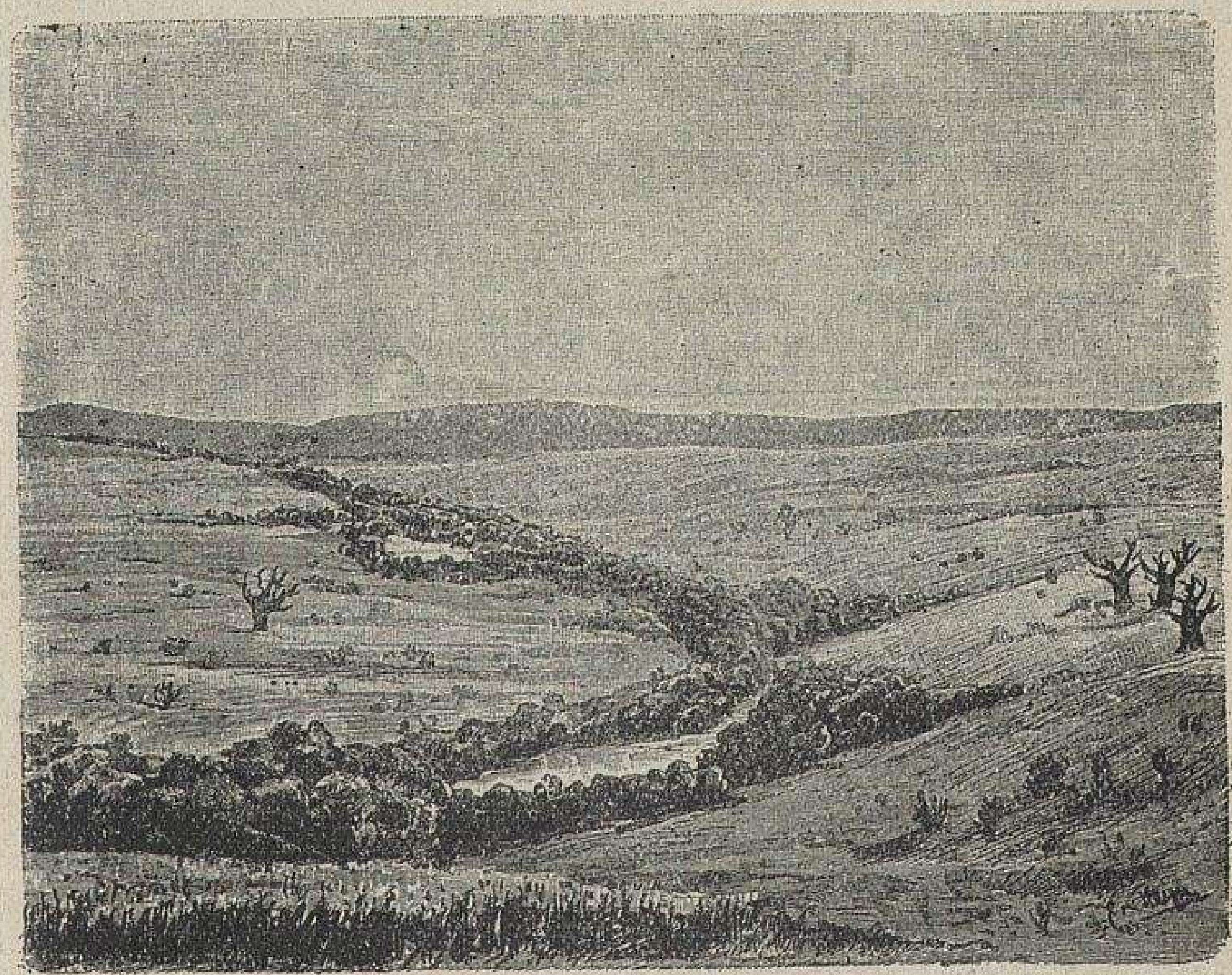

FORÊT GALERIE, DANS L'AFRIQUE CLGIDENTALE, AVEG VÉGÉTATION DE BAOBAB.

(D'après Pechuel-Loesche.)

premières pluies, avec une vigueur telle qu'un cavalier y disparaît avec sa monture.

La savane présente plusieurs types : le parc et la steppe. Dans le parc les bouquets d'arbres alternent avec les espaces herbacées; l'homme s'empare des clairières, élève des bestiaux et cultive des céréales, non pas nos céréales d'Europe, mais celles à croissance rapide, le sorgho ou millet, le maîs, puis encore l'igname, le manioc dont les racines sont riches en fécule. Sur les steppes l'arbre n'a pas la force de se développer : rien que des arbrisseaux, des buissons, la brousse; une herbe 
rare, imprégnée de sel, que les troupeaux des nomades broutent après les pluies.

Sous quelque aspect que se présente la savane, la végétation doit se défendre contre la sécheresse; plus ou moins longue, suivant la latitude et l'orientation, celle-ci joue le même rôle que le froid de l'hiver. L'arbre alors possède des réserves aqueuses ou sécrète la gomme; la plante est grasse, les fruits pulpeux. De toutes les espèces la plus caractéristique peut-être, une des plus répandues tout au moins, est l'euphorbe à candé-

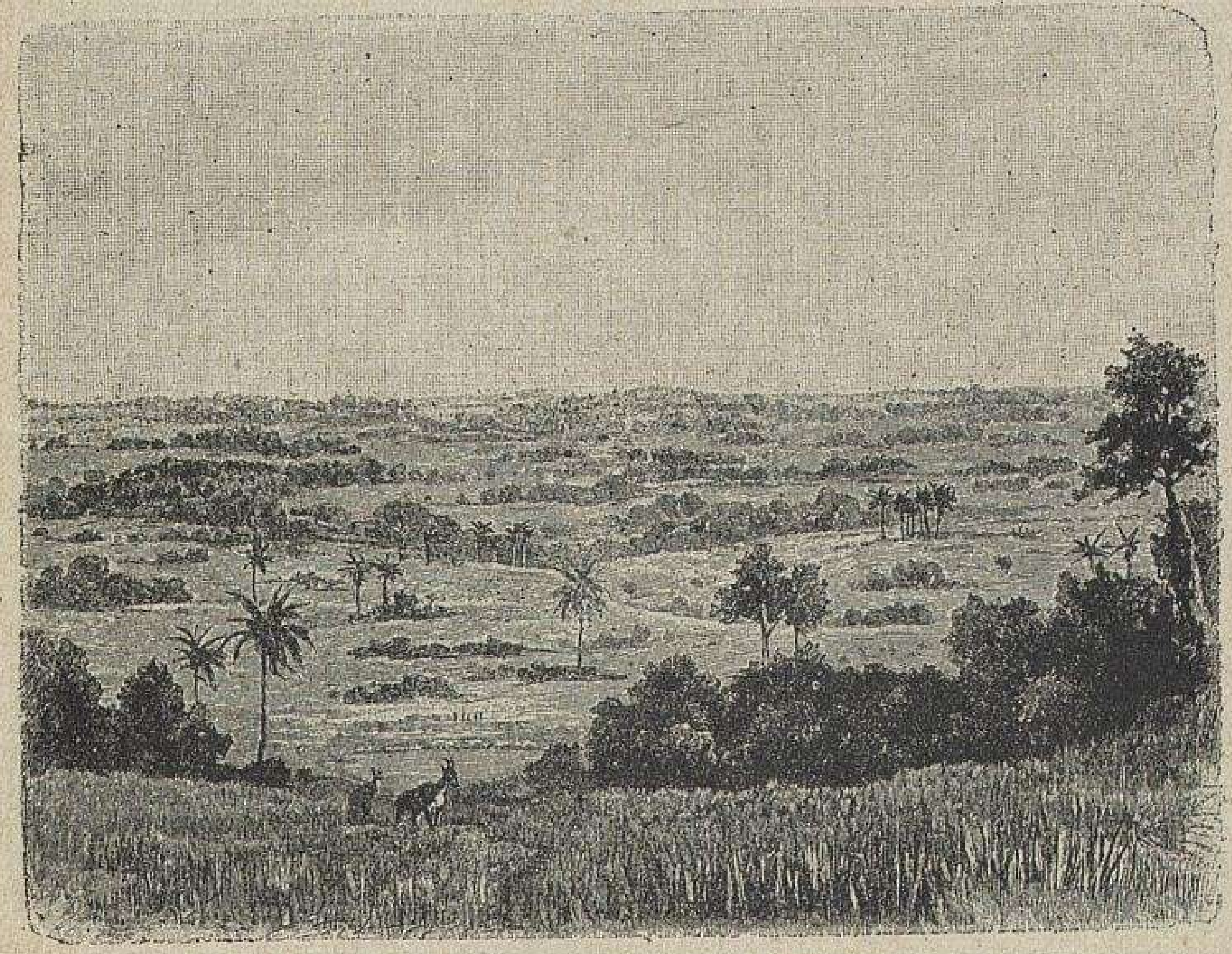

SAVANE DE L'AFRIQUE ÉQUATORIALE.

(D'après Pechuel-Loesche.)

labre: le nom seul indique la forme des tiges. Afin de réduire la surface d'évaporation, l'arbre encore atrophie ses organes de transpiration; le tronc prend des dimensions inusitées, les parties ligneuses se développent, et les épines remplacent les feuilles, les feuilles elles-mêmes tombent à la saison sèche, autrement dit pendant l'hiver. Tels les mimosas et les acacias; " parasol d'épines, penché à droite et à gauche sur un tronc grêle, l'éternel mimosa des solitudes africaines ne produit rien, ne sert à rien, ne donne même pas d'ombre $)$; tels encore les tamariniers, les sycomores. De la brousse surgit un " monstre végétal », le baobab ou arbre à pain de singe : rien de plus disgracieux que son tronc colossalement gros, sa ramure courte et ramassée, la petitesse ou l'absence totale des feuilles.

$3^{\circ}$ Les steppes annoncent et précèdent le désert. Ici la sécheresse est telle ( 25 à $30 \mathrm{~cm}$. de pluie par an au maximum) 
que la végétation ou bien manque complètement, ou bien est des plus pauvres, des moins variées, des plus clairsemées. Plus que jamais arbustes et plantes cherchent à limiter la transpiration, à conserver le peu d'humidité péniblement recueillie dans le sol : aussi revêtent-ils des organes coriaces, des épines, une tige ligneuse, des feuilles poilues ou encore des feuilles dures,

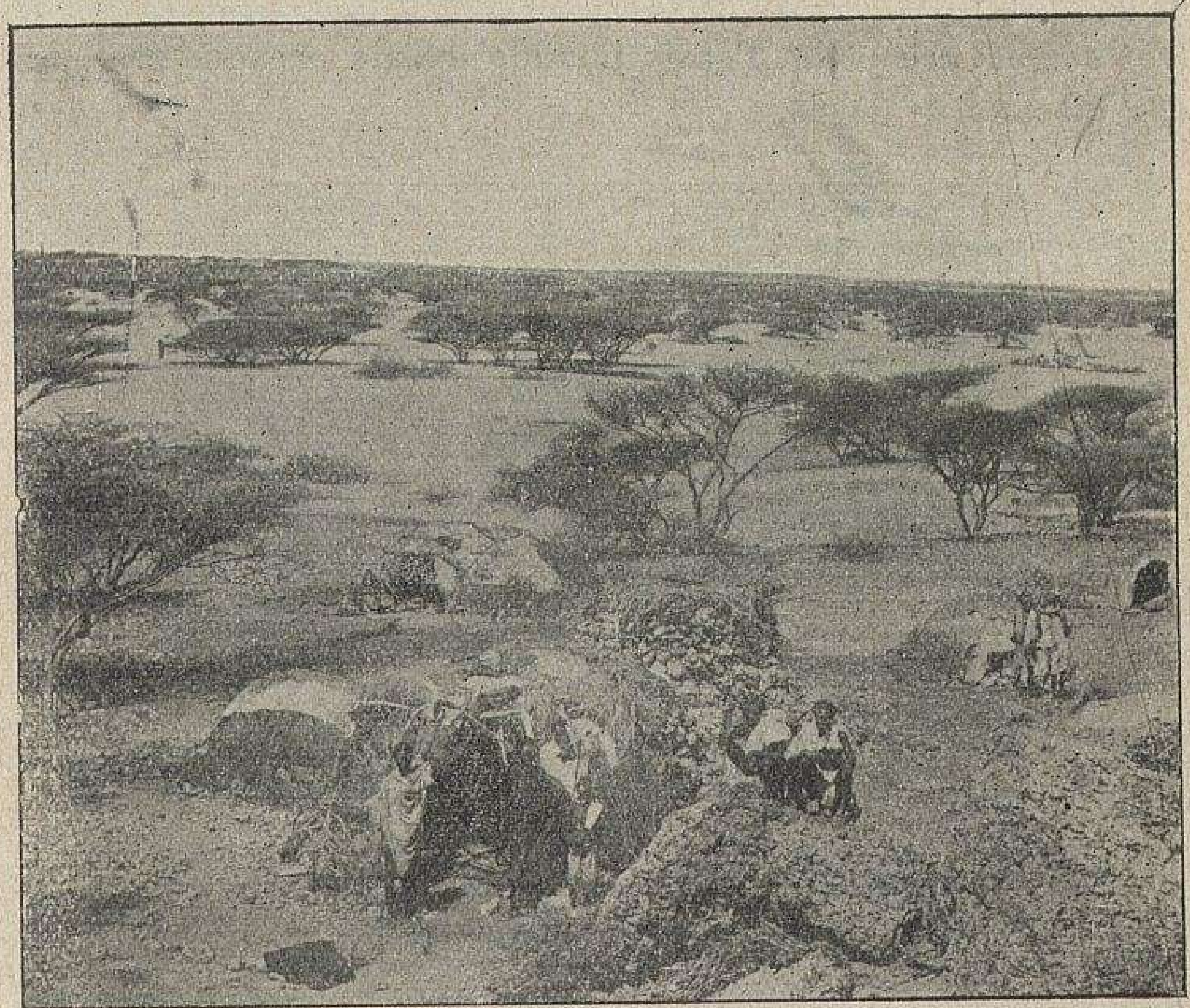

TYPE DE FORÊT DANS LES PAYS DE CLIMAT SEC. - AU PAYS DES SOMALI.

Forêt clairsemée, d'arbres à épines, d'acacias, sans feuillage et sans ombre.

roides, luisantes comme le métal; il en est qui sécrètent une huile éthérée dont ils s'enveloppent et se protègent contre l'ardeur du soleil; d'autres encore, les plantes grasses, les cactées, sont toutes charnues.

Au désert le sol n'est stérile que parce qu'il n'est pas arrosé; fait-on jaillir l'eau à la surface par des puits artésiens, la distribue-t-on dans des rigoles, que l'homme a soin parfois do creuser sous terre pour moins en perdre par évaporation, ou simplement l'eau chemine-t-elle à une profondeur assez faible 
pour que les racines y atteignent, alors naît l'oasis. Les anciens remarquèrent déjà que sur le sol fauve du désert les oasis dessinent les « mouchetures d'une peau de tigre ». C'est le palmier dattier qui les crée : il est l'arbre providentiel. La tête au plein soleil, et les racines dans l'eau, il abrite de son ombre protectrice plusieurs étages de végétation, arbres fruitiers et légumes. Mais cette richesse se paie : alors que le désert très sec est très sain, l'oasis humide exhale presque toujours des miasmes de fièvre.

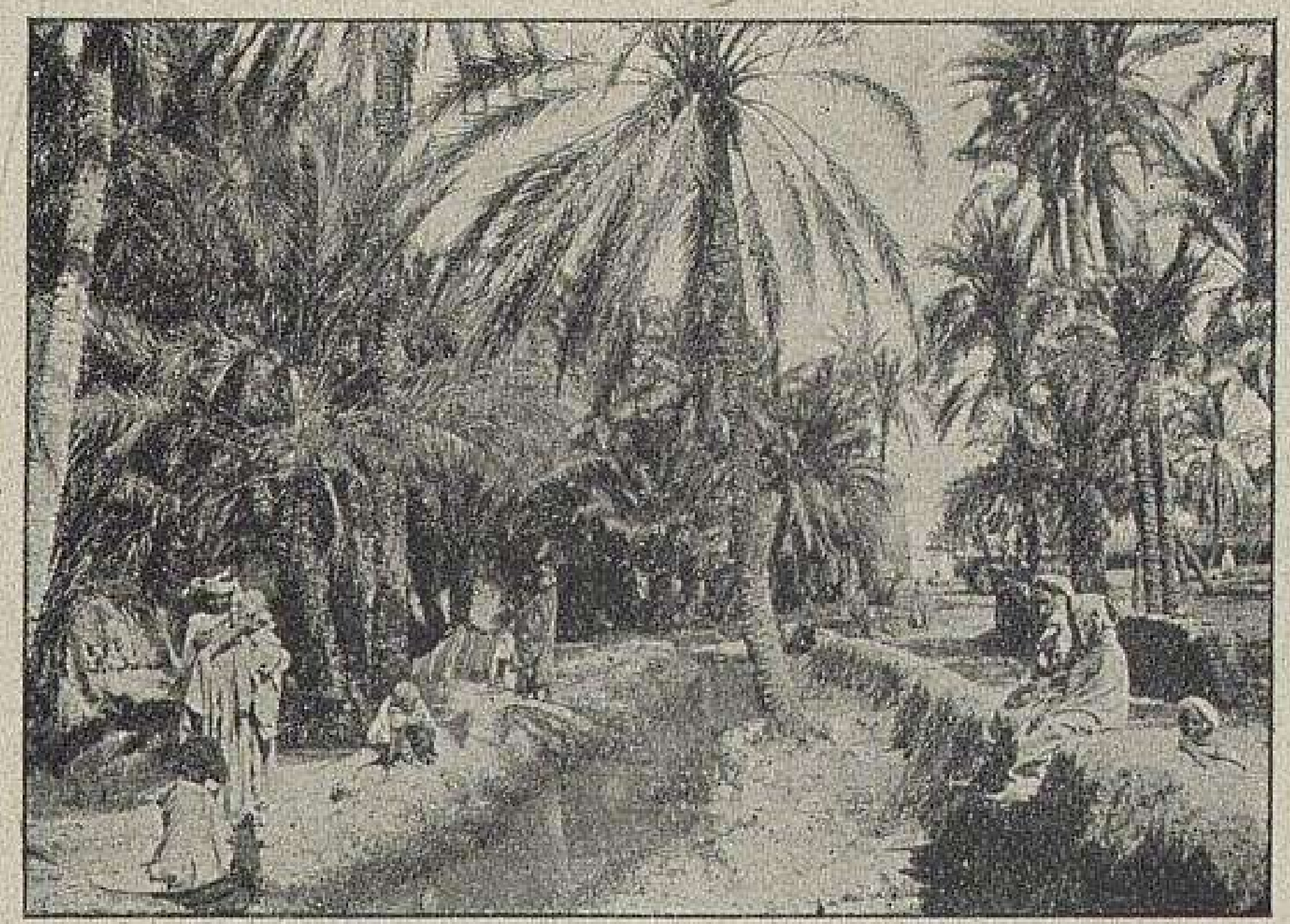

AU SAHARA : UNE OASIS.

Rigole d'arrosage ou seguia et palmiers dattiers, à Biskra.

(Photographie de M. Dybowshi.)

$4^{\circ} \mathrm{Au}$ delà de $30^{\circ}$ latitude, c'est-à-dire dans les régions tempérées à étés secs, à hivers pluvieux, la végétation subit une transformation nouvelle. Les arbres, rarement d'une haute taille, sont à feuilles persistantes; les buissons du maquis sont toujours verts, mais d'une verdure robuste, aux tons grisâtres. C'est le domaine du chéne liège et de l'olivier. Sur les hauts sommets de l'Atlas souvent le cèdre forme de magnifiques forêts. Les parties basses, si elles sont bien irriguées, conviennent aux cultures maraîchèrez, aux primeurs, et les jardins se décorent d'orangers, de citronniers, de grenadiers, etc. Bref, la flore est déjà çu est encore celle de l'Europe méditerranéenne, car les parties des deux continents, placées vis-à-vis, se renvoient l'une à l'autre leur image. 
II. Vie animale. - Entre la vie végétale et la vie animale il existe des rapports étroits.

1. Dans la grande forêt l'arbre absorbe toute la place; c'est dans les arbres que vivent les animaux : les oiseaux aux plumes multicolores, les perroquets gris à queue rouge entre autres,

\section{RÉPARTITION DES ESPE்CES ANIMALES}

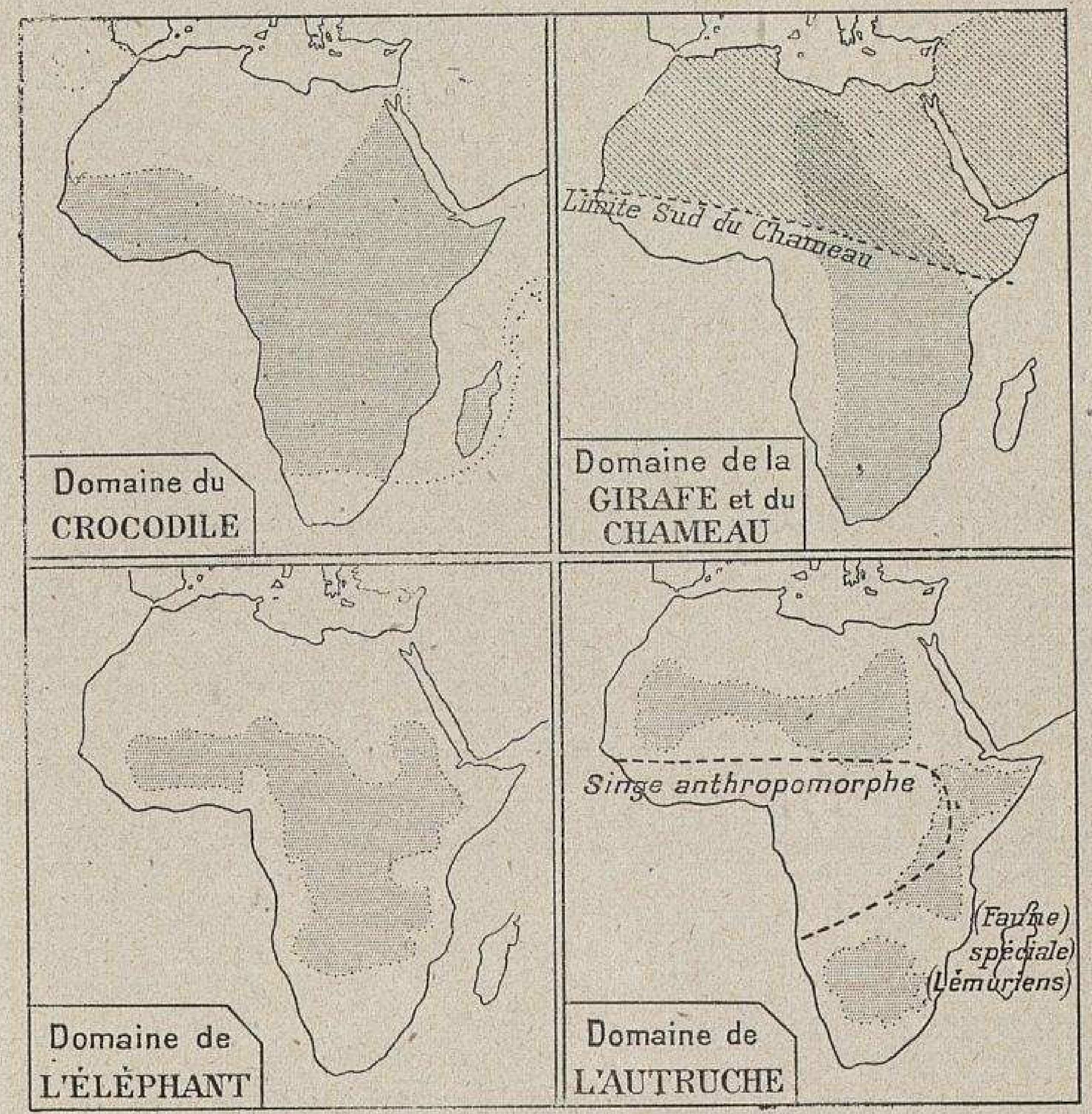

les singes qui grimpent, gambadent et font un tapage assourdissant, et parmi eux le chimpanzé qui rappelle étrangement la figure humaine. La panthère se tapit sur les branches les plus basses. Sur le sol puilule tout un monde d'insectes, et des crapauds énormes et des fourmis en longues colonnes. Des sangliers au redoutable boutoir. L'éléphant, par son poids même, s'ouvre passage; l'hippopotame, en compagnie du crocodile, infeste les fleuves et les marais : l'hippopotame est un herbivore 
amphibie exclusivement africain, et parmi les oiseaux aquatiques figure un des plus beaux, la grue couronnée.

$2^{\circ}$ Sur la savane l'animal reprend tous ses droits. L'éléphant peuple de ses bandes nombreuses toute l'Afrique tropicale depuis le fleuve Orange jusqu'aux confins du Sahara. L'espèce, distincte de celle d'Asie, ne se domestique pas : on la chasse pour ses défenses d'ivoire, tant et si bien qu'elle a disparu de certaines contrées et finira par disparaître complètement, si les Européens ne prennent des mesures de protection. Il y a plus de vingt ans, on remarquait déjà que le commerce annuel de l'ivoire supposait la destruction de 65.000 individus.

A côté des gros pachydermes, d'autres herbivores rapides : la girafe, douce et timide, qu'on ne trouve pas ailleurs qu'en Afrique; le zèbre, qui va par grandes troupes; l'antilope aux variétés innombrables et de toute taille, depuis l'antilope naine jusqu'à l'élan; les ruminants d'espèce bovine, sauvages, comme le bouf à longues cornes ou à bosse. Mais tous ont un terrible ennemi, une mouche de la grosseur d'une abeille, la mouche tsé-tsé dont la piqûre leur est infailliblement mortelle.

Enfin les carnassiers suivent et guettent les herbivores : au nombre des félins, le lion, la panthère et le léopard. Nulle part le renard n'est aussi commun qu'en Afrique, ainsi que l'hyène et le chacal.

$3^{\circ}$ Dans les déserts, où l'animal doit se déplacer sur des espaces immenses à la recherche d'une nourriture maigre et rare, où l'eau manque autant que les remises, l'animal est organisé pour la marche et la course; il est sobre au point de se priver de boire plusieurs semaines de suite; il revêt enfin une robe fauve ou grise, dont la couleur se confond avec le sable ou les roches.

Le désert est le domaine du chameau, chameau de bât, à la forte encolure, ou chameau de course, aux jambes minces et hautes : ni l'un ni l'autre ne s'acclimatent dans les contrées humides. Là encore la gazelle des dunes, le mouflon, l'autruche; parmi les animaux domestiques la chèrre et le mouton. Les reptiles sont nombreux et très redoutés, vipère cornue, scorpion, etc., enfin, dans le monde des rongeurs, il en est qui se classent parmi les sauteurs. 
$4^{\circ}$ Dans les régions tempérées chaudes, la présence de l'homme a refoulé les animaux sauvages. Le climat est trop sec pour l'élevage des bêtes à cornes, mais convient à la chèvre, au mouton, et encore aux volailles, aux abeilles. Un fléau pour l'agriculture est la sauterelle ou criquet voyageur : quand un vol s'abat, il ne reste plus traces de récoltes; tout est tondu, rasé jusqu'au sol.

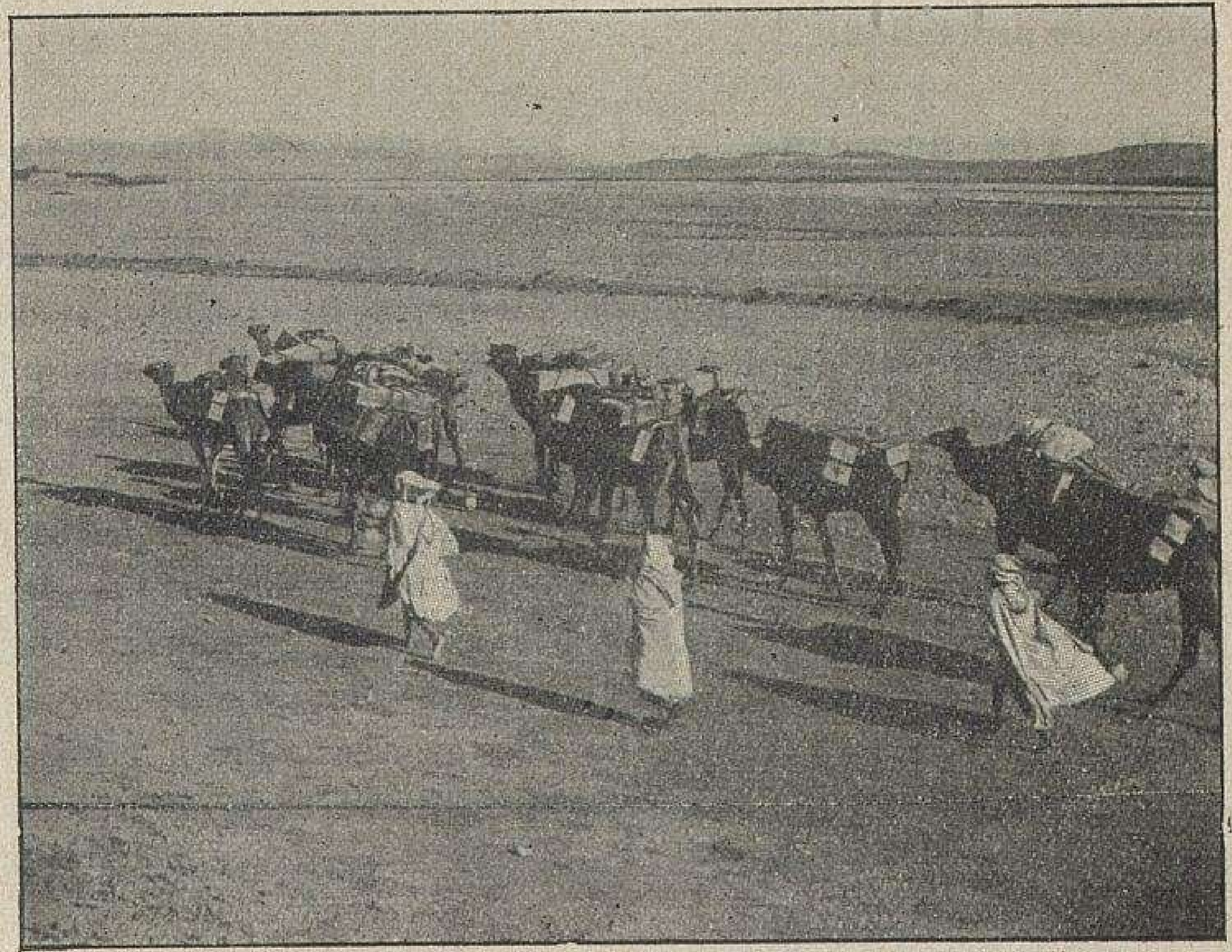

AU SAHARA : UNE CARAVANE EF MARGHE

(Phot. ND.)

Le cheval manque dans tout le centre du continent. Au Sud, i] a été importé tardivement, et la race, si robuste qu'elle soit, n'y est pas belle. Son domaine, ce sont les contrées du Nord, et là sont passés, là demeurent les peuples de cavaliers conquérants. Le cheval arabe a des qualités bien connues de finesse et d'endurance. L'âne, le bourricot ou bien l'âne de haute taille, joue, ainsi que le mulet, un rôle important dans la vie des sociétés du Nord.

$5^{\circ}$ Madagascar forme une région zoologique à part; c'est qu'elle fut isolée du continent à une époque géologique très 
ancienne, et des analogies se remarquent avec les espèces de l'Inde et de la Malaisie. On dit volontiers que Madagascar est la terre des lémuriens, parce que le lémurien la caractérise : c'est une espèce de singe, doux et inoffensif. Dans les îles environnantes, on chasse encore les tortues vertes, bien qu'elles disparaissent de plus en plus; quant à la tortue géante, elle a été anéantie dans les Mascareignes au cours des trois derniers siècles; on ne la rencontre plus qu'aux Séchelles, dans des zones de protection.

III. Vie humaine. - $1^{\circ}$ Population. - Il n'est pas possible de dire le chiffre exact de la population de l'Afrique : on l'évalue à 130 millions. C'est moins que l'Asie, et l'on ne s'en étonne guère, car certaines contrées de la Chine et de l'Inde contiennent les plus grosses fourmilières d'hommes qui existent; mais c'est moins que l'Europe, pourtant trois fois plus petite (densité moyenne : 5 par kmq.).

Ces 130 millions d'individus sont très inégalement répartis : par exemple, dans les déserts qui sont vides d'habitants, les oasis regorgent, ilots humains perdus dans l'immensité des sables et des roches ( $330 \mathrm{~h}$. par kmq. dans les oasis de Libye). En général l'homme s'est porté dans les grandes vallées fluviales ou bien sur le littoral : la comparaison d'une carte des pluies et du relief expliquerait plus d'une fois la carte de densité de la population.

$2^{\circ}$ Races. - On dit volontiers que l'Europe est le continent blanc, l'Asie le continent jaune, l'Afrique le continent noir; il s'en faut cependant que les Nègres peuplent toute l'Afrique.

A. - Le Nord est occupé par les Berbères et les Arabes; ils appartiennent à la race blanche, mais le grand soleil brûle et basane leur peau. Parmi les Berbères, il faut ranger, entre autres, les Kabyles des montagnes de l'Algérie, ot les Touareg du Sahara.

Quant aux Arabes, ce sont des Sémites venus d'Asie depuis Mahomet (vir ${ }^{\mathrm{e}}$ siècle), et surtout lors de la grande invasion du $\mathrm{xv}^{\mathrm{e}}$ siècle; ils se sont mélangés aux Berbères. Aussi le groupe du Nord est-il appelé arabo-berbère.

B. - Les Hamites, venus aussi de l'Asie méridionale, sont les Éthiopiens, les Nubiens et les Galla; ceux-ci ont le mieux 
conservé la pureté du type primitif. La peau est foncée, d'un brun rougeâtre.

G. - Entre le Nord de l'Afrique (race blanche) et le centre (race noire) vivent des peuples mixtes, mélange de Hamites et de Nègres. Ils occupent une longue bande de pays depuis le lac Rodolphe à l'Est jusqu'au Sénégal à l'Ouest. Parmi eux les Peul

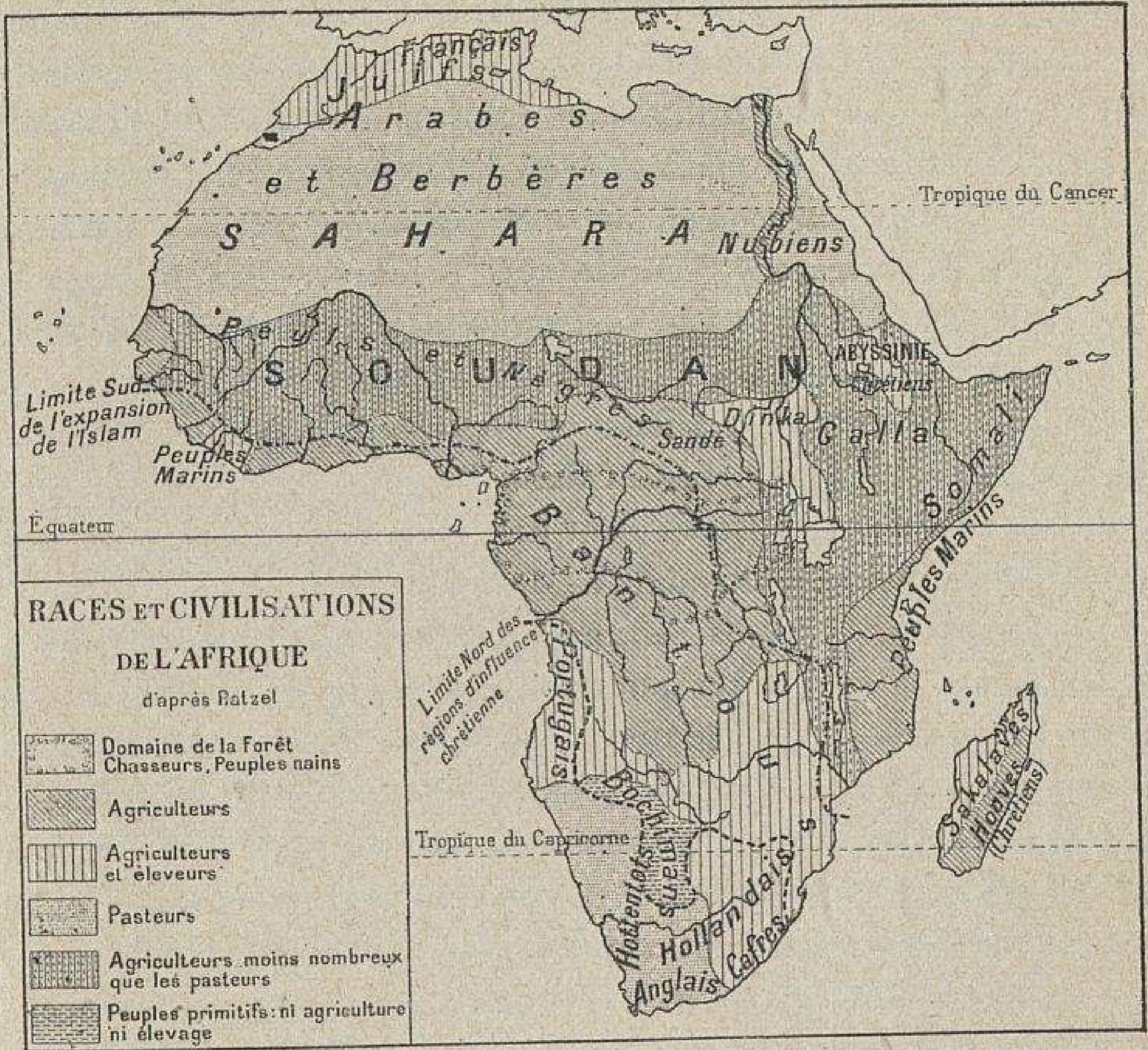

comptent au nombre des peuples de couleur les mieux doués.

D. - Le territoire nègre, la Nigritie, s'étend de chaque côté de l'équateur, depuis l'Atlantique et le bassin du haut Nil. Trùs variés sont les divers types nègres; les signes distinctifs sont : cheveux crépus, nez large et aplati, lèvres épaisses et proéminentes, taille élevée.

Mais il est des Nègres de petite taille (env. $1 \mathrm{~m} .40$ ); ces nains ou Négrilles vivent dispersés, en îlots, dans la forêt, où ils semblent les restes de populations primitives, chassées par de nouveaux arrivants. Les plus purs sont les Akkas.

Les Bantous figurent la plus belle des races noires; ils cou-

c. Lgapagaiol et M. Fallex。 - Afrique. 
vrent toute l'Afrique du Sud-Est et s'avancent même jusqu'à l'Atlantique à l'Ouest et jusqu'au Congo français. Les Musulmans les ont appelés Kafir (infidèles), dont nous avons fait Cafres. Les Zoulous sont des Nègres Bantous; leur taille élevée mesure $1 \mathrm{~m}$. 70 en moyenne.

E. - Les Hottentots, les Bochimans ne sont pas des Nègres; refoulés par les Bantous sur les plateaux incultes de l'Afrique australe, ils sont peu nombreux, quelques milliers de familles. Hottentot est un mot hollandais déformé qui signifie « borné, bête "; Bochiman, de même, désigne l' " homme de la brousse ".

F. - L'Afrique a reçu encore par migration, par colonisation, des peuples étrangers : sur la côte orientale, des Persans et des Hindous; à Madagascar, des populations venues de Malaisie. Puis, par endroits, les Européens entament le pourtour de l'Afrique : Français, Italiens et Espagnols dans les régions méditerranéennes; Portugais dans l'Angola et le Benguella; Anglais au Cap. Les Boers sont une race de paysans, d'où leur nom, mélangée de Hollandais et de Français.

$3^{\circ}$ Langues. - Les langues parlées sont innombrables. Elles peuvent se ranger en quelques groupes, répondant en partie aux races précédentes : Berbères, Arabes, Hamites de langues sémitiques; - nègres : plusieurs centaines de dialectes; la langue des Souaheli, langue commerciale de tout l'océan Indien, moitié arabe et moitié bantoue; - le groupe hottentot; - enfin les idiomes européens, français, anglais, portugais, hollandais.

Les langues indigènes ont ce trait commun de ne-pas accumuler les consonnes; presque toutes les syllabes se terminent par des voyelles. Cela ne veut pas dire qu'elles sont plus douces; car les sons gutturaux et les aspirations ont beaucoup de rudesse.

$4^{\circ}$ Religions. - A. Musulmans. - Les Arabes ont introduit et colporté la religion de l'Islam au Nord, à l'Est et au Sud-Est, jusqu'à la limite des moussons. Aujourd'hui ils atteignent, au cour du continent, le bassin du Congo.

Le dogme, la morale, les pratiques, très simples, s'adaptent à l'hygiène, au genre de vie, à la mentalité des indigènes. Mais la religion de Mahomet est un obstacle à la prédication chrétienne et même à la civilisation européenne; du moins elle a 
marqué un progrès chez les peuples barbares qu'elle a conquis.

B. Fétichistes. - La grande majorité des peuples africains est paienne et livrée à des superstitions grossières. Les Nègres attribuent des vertus spéciales à toutes sortes d'objets, même les plus vils, un bâton, une pierre, un bout de corde, une mèche de cheveux, etc. : ce sont les fétiches, pour lesquels ils con-

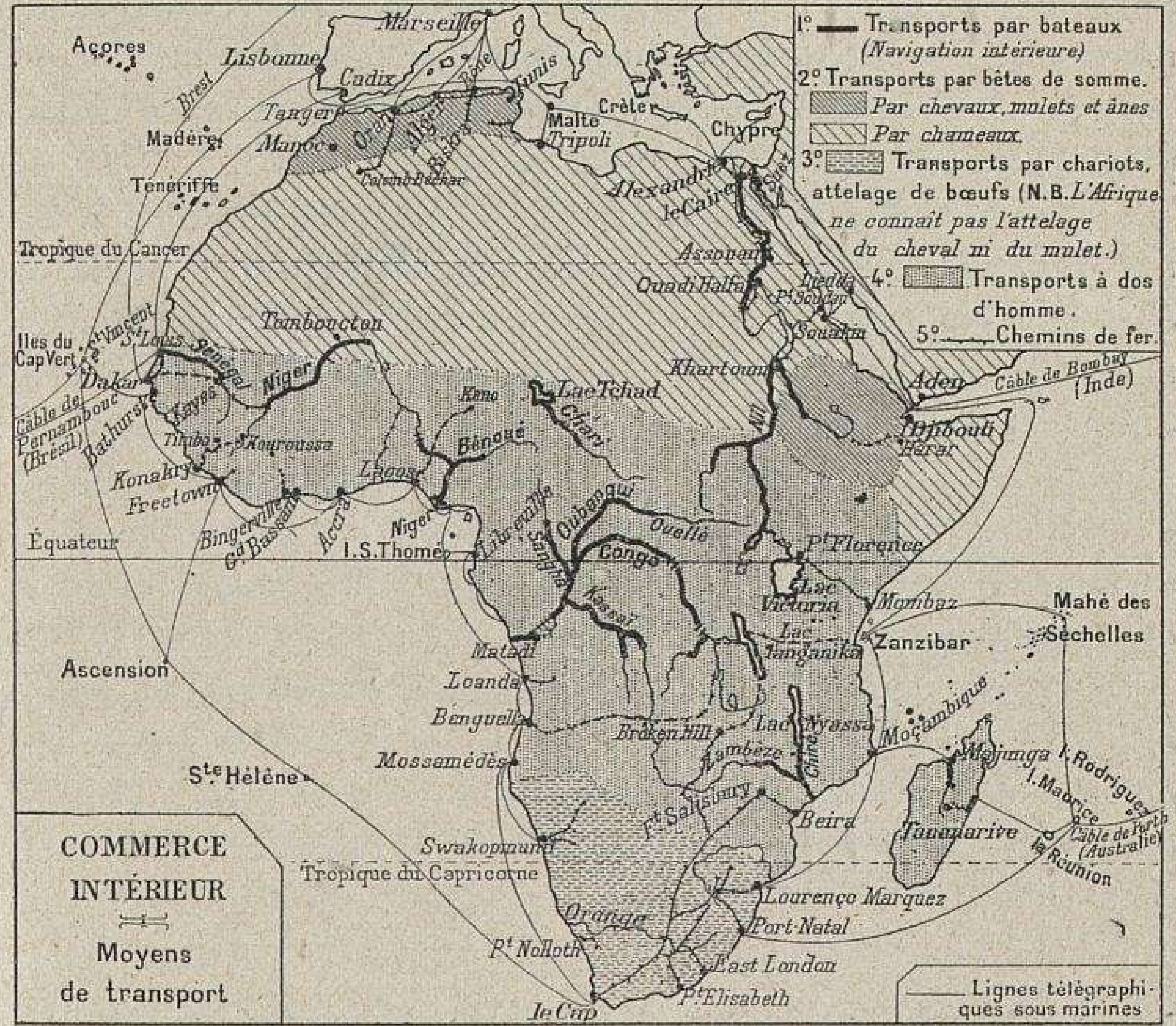

struisent une petite case particulière; ils en absorbent même comme médecine. Pour eux, le monde, air, forêt, fleuves, etc., est peuplé d'esprits malfaisants, afin de les écarter, les féticheurs leur adressent des prières, des incantations, des sacrifices; on ne peut les qualifier de prêtres, mais bien plutôt de sorciers, de magiciens et de médecins. Leur intervention est réclamée pour tous les actes de la vie, individu, famille et tribu : d'où leur rôle important. Le fétichisme est la forme la plus primitive de l'adoration d'un pouvoir supérieur. L'idolâtrie constitue déjà un progrès, si grossière, si immonde qu'elle soit. 
C.-Les chrétiens sont relativement peu nombreux. Les Coptes en Égypte et les Éthiopiens sont chrétiens de longue date; mais leur catholicisme n'est ni romain ni grec : ils sont de rite copte, monophysites, ne reconnaissant à Jésus-Christ qu'une seule nature.

Le catholicisme romain a été introduit par les Français dans le Nord, par les Portugais dans l'Afrique australe.

Le protestantisme est la religion des Boers.

Enfin catholiques et protestants entretiennent nombre de missions aussi bien à Madagascar que sur le continent.

D. - Les Juifs ne se rencontrent que par groupes isolés, principalement dans l'Afrique du Nord.

$5^{\circ}$ Vie civilisée et vie sauvage. - La civilisation n'a pas rencontré en Afrique de conditions favorables : point de chaînes de montagnes qui bordent les vallées fluviales, pour en faire le berceau naturel des peuples; point de mers intérieures qui pénètrent les terres et ménagent des domaines distincts aux agglomérations humaines. Souvent, en l'absence de limites naturelles, les tribus laissent entre elles des zones vides et incultes. L'uniformité du relief a eu pour conséquence l'uniformité de la vie humaine.

Les Bochimans ou San sont des peuples chasseurs. Au degré le plus bas de la civilisation, ils ne se construisent même pas de cabanes; ils s'abritent derrière des buissons épais, à grosses épines, et dans des trous, comme des bêtes; sans loi, sans chef, sans Dieu, ils errent par petits groupes, cueillant les fruits sauvages, poursuivant le gibier de la brousse, et avalant, lorsque la faim les talonne, tout ce qu'ils trouvent, racines, reptiles, larves de fourmis. Ils ne connaissent pas l'écriture.

Les Nègres sont agriculteurs et éleveurs sur la savane, pêcheurs sur les bords des fleuves et sur les marécages, chasseurs enfin sur la lisière de la forêt. Bien différentes sont leurs sociétés suivant les conditions physiques du sol; mais en général c'est le règne végétal (bois, feuillages, roseaux) qui fournit les matériaux et de l'habitation (case ronde ou à toit conique, ou rectangulaire avec un toit à double pente), et du peu de vêtement qu'ils portent (le pagne, attaché à la ceinture), des armes qu'ils se fabriquent et encore des engins de pêche.Dans les régions du bananier, le Nègre n'a qu'à se laisser vivre, 
sans se donner d'autre peine que de cueillir les fruits des arbres; comme il n'est pas poussé par la nécessité, il est mou, indolent, corrompu et lâche, et si le besoin de viande se fait trop impérieusement sentir, il se nourrit de chair humaine, il est anthropophage. Le moyen de combattre cette coutume monstrueuse serait de développer l'élevage du bétail. - Ailleurs il lui faudra demander à la terre la nourriture de chaque jour, cultiver les céréales, millet et doura, travailler en un mot. Les procédés sont fort primitifs; encore est-il besoin de herser, de semer, de moissonner, de serrer les récoltes; la hutte alors est moins primitive, plus solide; en avant est ménagée une aire pour battre le grain; à côté, des cabanes servent de greniers. - La boisson natırelle du Nègre est l'eau, mais il sait fort bien se fabriquer des liqueurs, le vin de palme par exemple, qu'il apprécie plus que de raison; et les alcools d'importation exercent sur lui de tels ravages

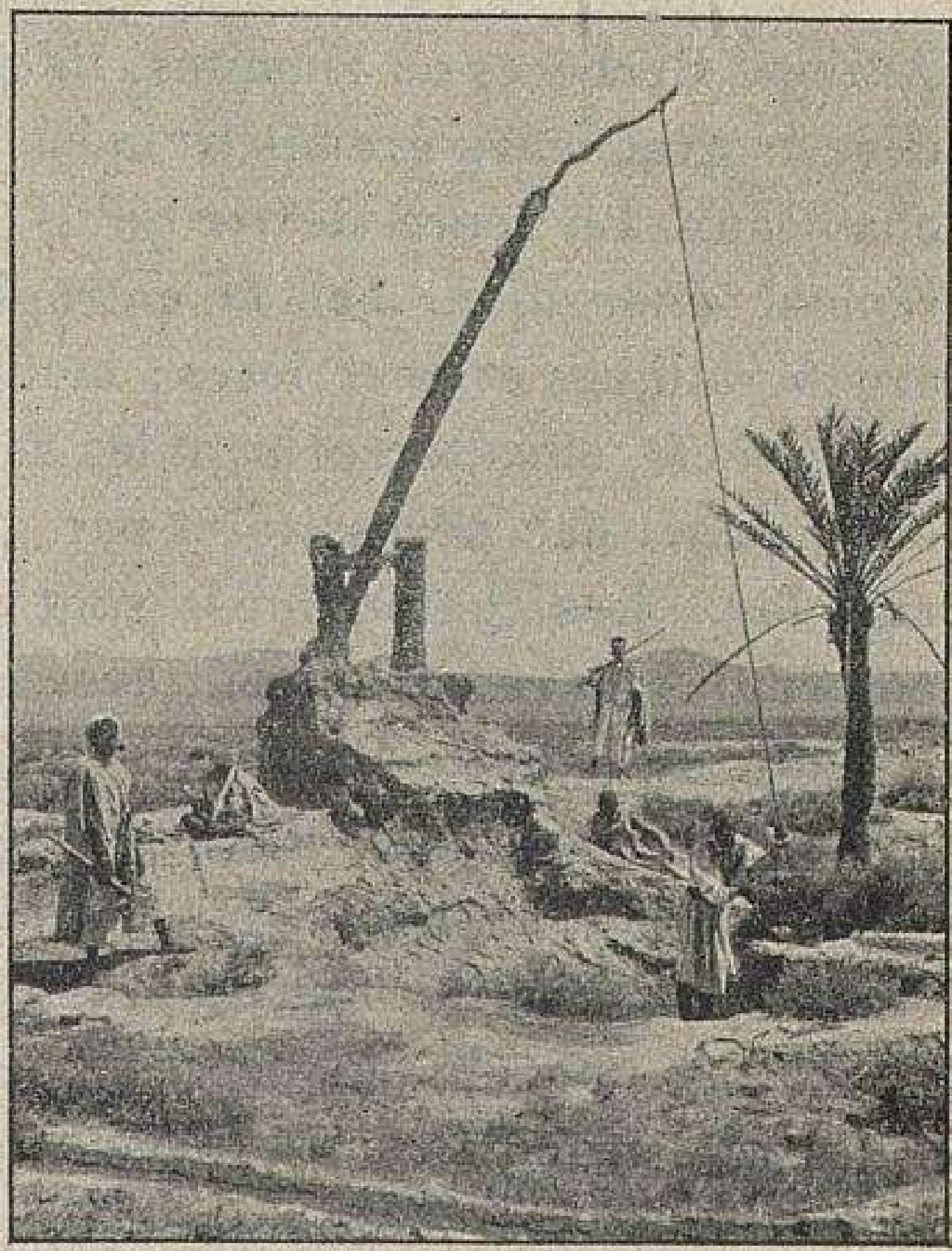

AU SAHARA： SYSTĖME D'ARROSAGE (Phot. ND.)

Kattara ou puits d'irrigation, à comparer avec le chadouf égyptien, au chapitre xvir.

qu'en plus d'une colonie les Européens les ont, par mesure humanitaire, frappés de droits très élevés qui équivalent à une prohibition. Il arrive parfois, lorsque le sol est riche en minerai, que les peuples travailleurs forgent eux-mêmes leurs instruments de travail, le hoyau, la bêche, et ainsi se créent des industries locales. - Mais qu'ils vivent de bananes ou de céréales bouillies, exception faite des Zoulous et des Cafres, les Nègres ne connaissent d'autre groupement que la famille et le village; et ces sociétés menues, morcelées, vivent à l'écart les unes des autres, indépendantes. Aussi sont-elles la proie 
des nomades des steppes, et c'est parmi eux qu'a sévi durant trois siècles l'épouvantable traite. Des marchands d'esclaves organisaient des battues humaines et ramenaient de longues files de captifs, destinés soit aux monarchies despotiques de l'Islam, soit aux plantations des colons américains. Ce sera l'honneur de l'Europe d'avoir entravé et arrêté ce commerce odieux, répugnant, de l'homme par l'homme.

Tout autre est la vie des peuples pasteurs. Qu'ils soient Arabes, Berbères ou Hamites, ils parcourent les steppes et les déserts avec leurs grands troupeaux de boufs, de moutons, de chameaux. Le genre de vie qu'ils mènent leur vaut un tempérament énergique, fier et entreprenant. Leurs sociétés sont aristocratiques et guerrières; bien disciplinées, elles obéissent à des chefs, elles terrorisent les sédentaires, les razzient et les oppriment; par nécessité et par goût, tous sont voleurs incorrigibles. Les habitations sont faites avec des matériaux empruntés au règne animal, avec des peaux de bêtes; à côté de la tente, de la hutte réservée à la famille, est celle des serviteurs et des esclaves; un enclos palissadé abrite parfois le troupeau, la seule richesse, contre les voleurs et contre les fauves. C'est le bétail encore qui fournit la laine à tisser et le vêtement. Au Sahara, le nomade troque ses troupeaux contre le grain et les dattes du sédentaire, et l'oasis, aux maisons de boue, devient un centre naturel d'échanges, un centre religieux et politique. Une solidarité se crée de la sorte entre les seigneurs du désert et le cultivateur ou l'artisan de l'oasis. Mais de part et d'autre la vie est bien précaire. Dans l'oasis, sous un soleil de feu, le premier besoin de l'homme, c'est l'eau; à l'eau plus encore qu'à la terre est attachée l'idée de propriété. La possession, la distribution, la réglementation des sources fécondantes est une question vitale, c'est la cause de fréquentes querelles, de conflits armés et sanglants : l'état de guerre est permanent, l'anarchie est la forme la plus ordinaire des sociétés.

Aujourd'hui la civilisation européenne s'efforce de pénétrer le continent. Elle s'était portée d'abord sur les régions de climat tempéré, au Cap avec les Boers et les Anglais, en Algérie et en Tunisie où les Français sont en contact avec une société d'influence turque et arabe, en Égypte avec les Français encore 
et les Anglais. Actuellement elle s'attaque aux pays tropicaux, moins pour les peupler que pour les mettre en valeur; car les conditions du climat ne permettent de long séjour que dans les parties les plus hautes, à l'abri de la dysenterie et des fièvres.

Dans l'ensemble, l'Afrique demeure encore le plus barbare de tous les continents. 


\section{CHAPITRE III}

\section{EXPLORATIONS ET PARTAGE POLITIQUE}

\section{SOMMAIRE}

I. Explorations et déconvertes. - L'Afrique a èté jusqu au XIX ${ }^{\circ}$ siècle le plus mal connu des continents. C'est le $\mathrm{XIX}^{\circ}$ siècle qui l'a explorée et vraiment découverte.

$1^{\circ}$ Au XVIII' siècle, la carte du géographe français d'Anville porte beaucoup de noms sur les côtes et laisse en blanc l'intérieur du continent.

$2^{\circ}$ En 1788 l'Association africaine de Londres se propose la découverte du Niger: voyages de l'Écossais Mungo Park, des Anglais Denham et Clapperton, de Richard Lander.

Un Français, René Cailliè, traverse le Sahara occidental et visite Tombouctou, 1827-1828.

Un Allemand, Barth, 1850-1859, explore scientifiquement les pays du Soudan et du Niger.

$3^{\circ}$ Déjà s'était posé le problème des sources du Nil.

Les tentatives faites, en remontant la vallee du fleuve, par l'expédition de Bonaparte et par Mèhèmet Ali, sont rendues impossibles par les cataractes et par les grandes herbes des marais.

On atteignit les sources en partant de la côte de Zanzibar: les voyages de Burton et Speke (1857-1859), de Speke et Grant, de Baker découvrent les grands lacs Tanganika, Victoria, Albert et Albert-Édouard.

Stanley achève les découvertes : il est prouvè que le Nil est un fleuve alimenté par des lacs.

$4^{\circ}$ La découverte du Zambèze et du Congo fut l'œuvre d'un missionnaire, Livingstone : sèrie de voyages de 1849 a 1873 , date de sa mort; première traversèe du continent d'Ouest en Est.

Stanley en 1874 descend le Congo sur toute sa longueur; Savorgnan de Brazza le devance en 1881 sur le bas fleuve, pour le compte de la France.

$5^{\circ}$ La fin du XIX sieccle devient une course a l'exploration pour tous les grands Etats européens : l'acte de Berlin de 1885, celui de Bruxelles de 1890 fixent les zones d'influence respectives. 
Pour s'assurer sa part, la France lance au cour du continent Binger, Monteil, Mizon, Marchand; enfin les missions FoureauLamy, Meynier-Joalland et Gentil operent leur jonction autour du lac Tchad.

II. Partage politique. - L'Afrique n'a d'Etats indigènes indèpendants que la Tripolitaine qui est turque, l'empire du Maroc, la république nègre de Liberia et l'Abyssinie; l'Égypte continue à être occupéé par l'Angleterre.

Tout le reste est possessions européennes.

A la France, l'Algérie; la Tunisie (pays de protectorat); l'Afrique occidentale qui comprend le Sènégal, le Haut Sènégal-Niger, la Guinée, la Côte de l'Ivoire, le Dahomey, et en arrière deux territoires, l'un civil et l'autre militaire; l'Afrique équatoriale; Madagascar et les iles voisines, dont l'ile de la Réunion; la côte des Somali à l'entrée de la mer Rouge.

A l'Angleterre, la Gambie, le Sierra Leone, la Côte de l'Or, les deux Nigeria jusqu'au lac Tehad, l'Afrique australe, du Cap au lac Nyassa, l'Afrique orientale, l'Ėgypte occupée depuis 1882 , le Soudan anglo-égyptien, une portion de la côte des Somali; enfin de nombreuses escales dans l'Atlantique et dans l'ocean Indien.

A l'Allemagne, le Togo, le Cameroun, le sud ouest africain et l'Afrique orientale.

A l'Italie, le protectorat d'ane partie de la côte des Somali et, sur la mer Rouge, l'Erythrèe.

A l'Espagne, seulement quelques points de la côte marocaine, les Canaries, le rio de Oro; enfin, au fond du golfe de Guinèe, le rio Mouni, les iles Fernando Po et Annobon.

Au Portugal, les îles du cap Vert, la Guinée dite portugaise, les iles du Prince et Saint-Thomas, l'Angola et le Benguella sur l'Atlantique, l'Afrique orientale dite portugaise.

A la Belgique, la colonie du Congo.

Le $\mathbf{X X}^{\cdot}$ siecle se réserve de transformer l'état matériel et l'état moral de l'Afrique, que le $\mathrm{xIX}^{\circ}$ siècle a découverte.

\section{DÉ VELOPPEMENT}

\section{Explorations et découvertes. - Longtemps l'Afrique} est demeurée le plus mal connu des continents; on connut mieux et plus vite l'Amérique, qui pourtant ne fut découverte qu'au xv siècle, mieux même les régions glacées des pôles.

La découverte de l'Afrique est l'œuvre du xıx siècle : explorateurs, missionnaires et soldats de toutes nationalités ont arraché au continent mystérieux le secret que gardaient ses plateaux, ses fleuves coupés de rapides, ses déserts ou ses forêts vierges. Beaucoup sont morts à la tâche, et si l'on marquait les lieux où sont tombés tant de héros. victimes les uns du climat, 
les autres de la sauvagerie et du fanatisme des habitants, la carte de l'Afrique apparaîtrait couverte d'autant de croix mortuaires qu'un cimetière immense.

$1^{\circ}$ Les anciens ne connaissaient de l'Afrique que les parties voisines de la Méditerranée : l'Égypte, qui, grâce aux inondations périodiques du Nil, fut le siège d'une des premières civilisations humaines; la Cyrénaïque où les vents étésiens portèrent les marins grees; la Tunisie et l'Algérie colonisées par les Phéniciens qui fondèrent Carthage, puis conquises et cultivées par les Romains depuis les guerres puniques.

Le détroit de Gibraltar, appelé alors détroit de Gadès ou solonnes d'Hercule, avait été franchi vers l'an 600 avant J.-C. par le Carthaginois Hannon qui atteignit la côte actuelle de Sierra Leone, à l'entrée du grolfe de Guinée.

$A u v{ }^{e}$ siècle avant J.-C., un événement intéressant, mais sans résultat pour la connaissance de l'Afrique, avait été le voyage fait par les Phéniciens pour le compte du pharaon d'Egypte, Néchao. L'expédition partie de la mer Rouge revint par le détroit de Gibraltar; quand elle eut doublé le cap que nous appelons aujourd'hui cap de Bonne-Essérance, lorsqu'elle remonta vers le Nord, elle fut frappée d'étonnement : le soleil se levait maintenant à sa droite.

L'invasion des Arabes et la conquête musulmane au vir ${ }^{\bullet}$ siècle après J.-C. fermèrent l'Afrique aux chrétiens et la couvrirent d'un voile impénétrable.

Au xIv ${ }^{e}$ siècle, des marins de Dieppe installèrent des comptoirs sur les côtes de Guinée; leurs traces ne furent reprises qu'au xv'e siècle par les Portugais, à la recherche de la route des Indes. Barthélemy Diaz découvre, en 1487, le cap des Tempêtes, appelé par la suite d'un nom de meilleur augure cap de Bonne-Espérance. Vasco de Gama le double en 1497 et atteint le but cherché, c'est-à-dire l'Inde. Ce sont les Portugais qui établirent les premières cartes marines du littoral.

Jusqu'à la fin du xvmie siècle, l'Europe ne connut guère que le dessin des côtes. C'est à peine si l'on commençait à avoir quelques notions précises sur l'arrière-pays du Sénégal, où déjà les Français se lançaient; sur le Cap grâce aux Hollandais et aux Calvinistes français; sur l'Abyssinie, l'unique terre qui 
fût demeurée chrétienne, et sur le Zambèze enfin où s'aventuraient les missionnaires portugais.

La belle carte du géographe français $d$ 'Anville publiée en 1749 est la première carte scientifique du continent; elle ne porte que des indications certaines, c'est-à-dire fort peu de chose. Les côtes sont chargées de noms; l'intérieur reste en blanc.

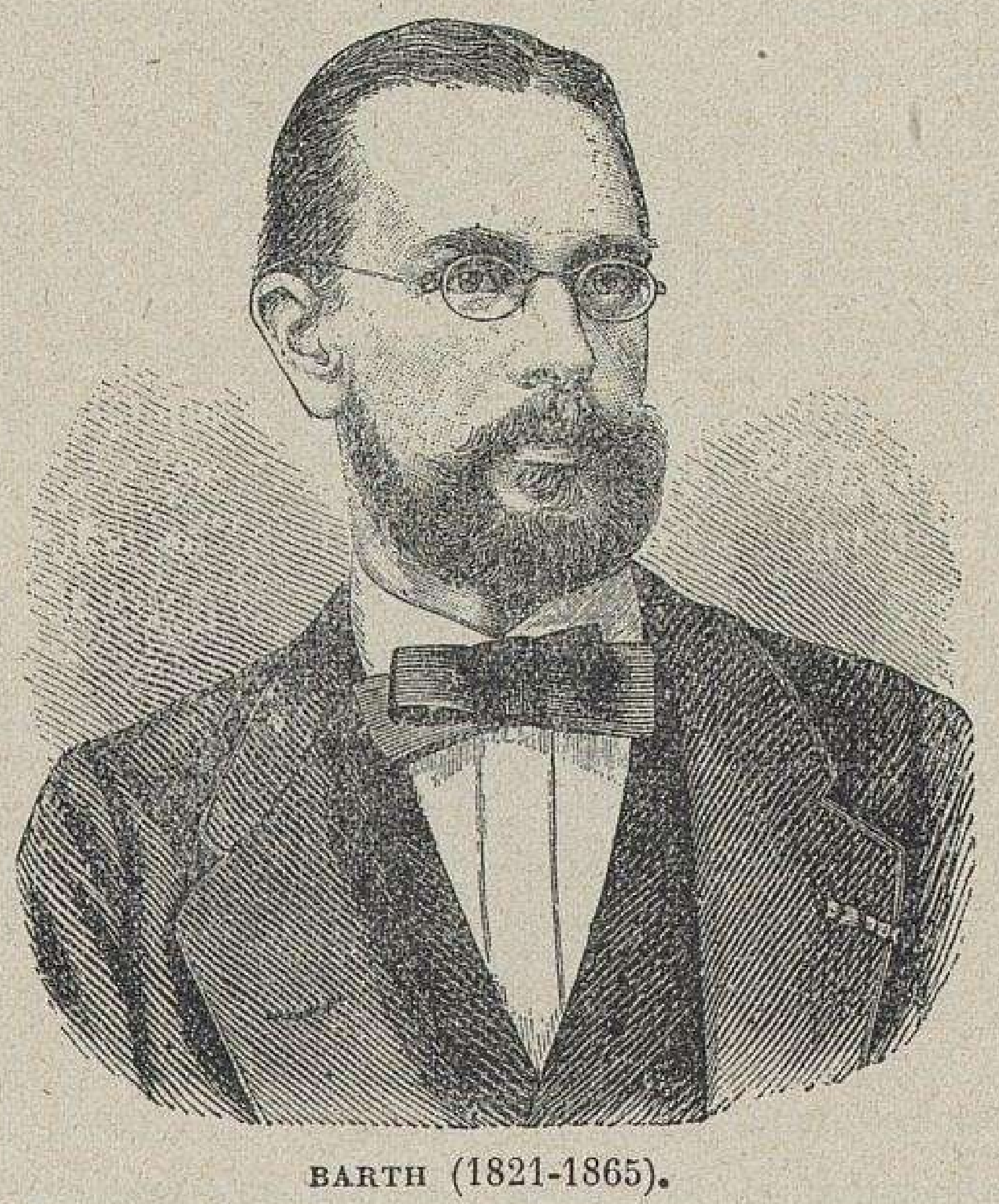

$2^{\circ}$ En 1788, une Association africaine se fonda à Londres : l'ère des explorations méthodiques et des grandes découvertes allait s'ouvrir.

Le problème que l'Association africaine chercha à résoudre fut celui du Niger. Ćn Écossais, Mungo Park, parti de la Gambie, reconnut qu'il se dirigeait vers l'Est, mais il mourut en 1805 , dans les rapides de Boussa. De 1822 à 1825, Denham et Clapperton partent de Tripoli, traversent pour la première fois le Grand désert, découvrent le lac Tchad et les royaumes musulmans du Soudan central. Enfin en 1825, Richard Lander, venu du golfe de Bénin, atteint le Tchad par le Sud; et en 1830 il est démontré que le Niger, après un long circuit au Nord, rejoint 
le golfe de Guinée. Auparavant déjà, avec de faibles ressources, un Français, René Caillié, avait traversé du. Sud au Nord l'Afrique occidentale; en se faisant passer pour musulman, il connut la région du Niger supérieur, visita Tombouctou et à travers le Sahara revint en Europe par le Maroc (1827-1828).

L'exploration scientifique du Sahara fit un grand pas au milieu du xıxe siècle : un des voyages les plus fructueux, autant pour la longueur dés itinéraires parcourus que pour la valeur des documents recueillis, fut celui de l'Allemand Barth (18501855) de Tripoli au Soudan central et au Niger moyen. Son ouvre fut complétée par l'Allemand Gerhard Rohlfs (1865-67, 1874 et 1879), par un autre Allemand Nachtigal (1869-74) et en 1859 un Français Henri Duveyrier commençait une série d'explorations au Sahara algérien.

$3^{\circ}$ Mais déjà un autre problème s'était posé : celui des sources du Nil. D'où venait le grand fleuve? L'antiquité, le moyen âge, les temps modernes ne le surent jamais.

L'impulsion fut ici donnée par l'expédition de Bonaparte en Égypte en 1798, c'est-à-dire par les Français ; puis par les conquêtes de Méhémet Ali : en 1823 les deux branches du Nil, le Nil bleu et le Nil blanc, sont trouvées par Caillaud et Khartoum est fondée au confluent.

Mais il était impossible d'atteindre la région des sources par ce procédé, très simple sur un autre continent, qui consiste à remonter le fleuve; car le lit du Nil est coupé de cataractes, encombré de grandes herbes inextricables. Alors les explorateurs firent de la côte de Zanzibar leur base d'opérations : de là ils se lancèrent à l'Ouest, au coeur de l'Afrique. En 1849 on découvre sous l'équateur des montagnes géantes, couvertes de neige. Puis de 1857 à 1859 Burton et Speke atteignent le lac Tanganyika;ils constatent que ce grand réservoir ne s'écoule pas vers le Nord, du Nord au contraire un cours d'eau lui arrive : ce n'était donc pas la source cherchée du Nil. Au retour Speke se détacha de Grant et aperçut le lac Victoria : le Nil était trouvé! Mais Speke ne rencontra guère que des contradicteurs et des incrédules, parmi lesquels Burton lui-même. Alors il organise une seconde expédition, cette fois avec Grant; tous deux atteignent de nouveau le lac Victoria, suivent quelque 
temps le fleuve qui s'en échappe, puis renoncent à le suivre plus longtemps vers l'Ouest et piquent droit au Nord. Ils rencontrent Baker qui le remontait, et Baker complète leur exploration par la découverte du lac Albert.

Ce ne fut que beaucoup plus tard, par une série de voyages

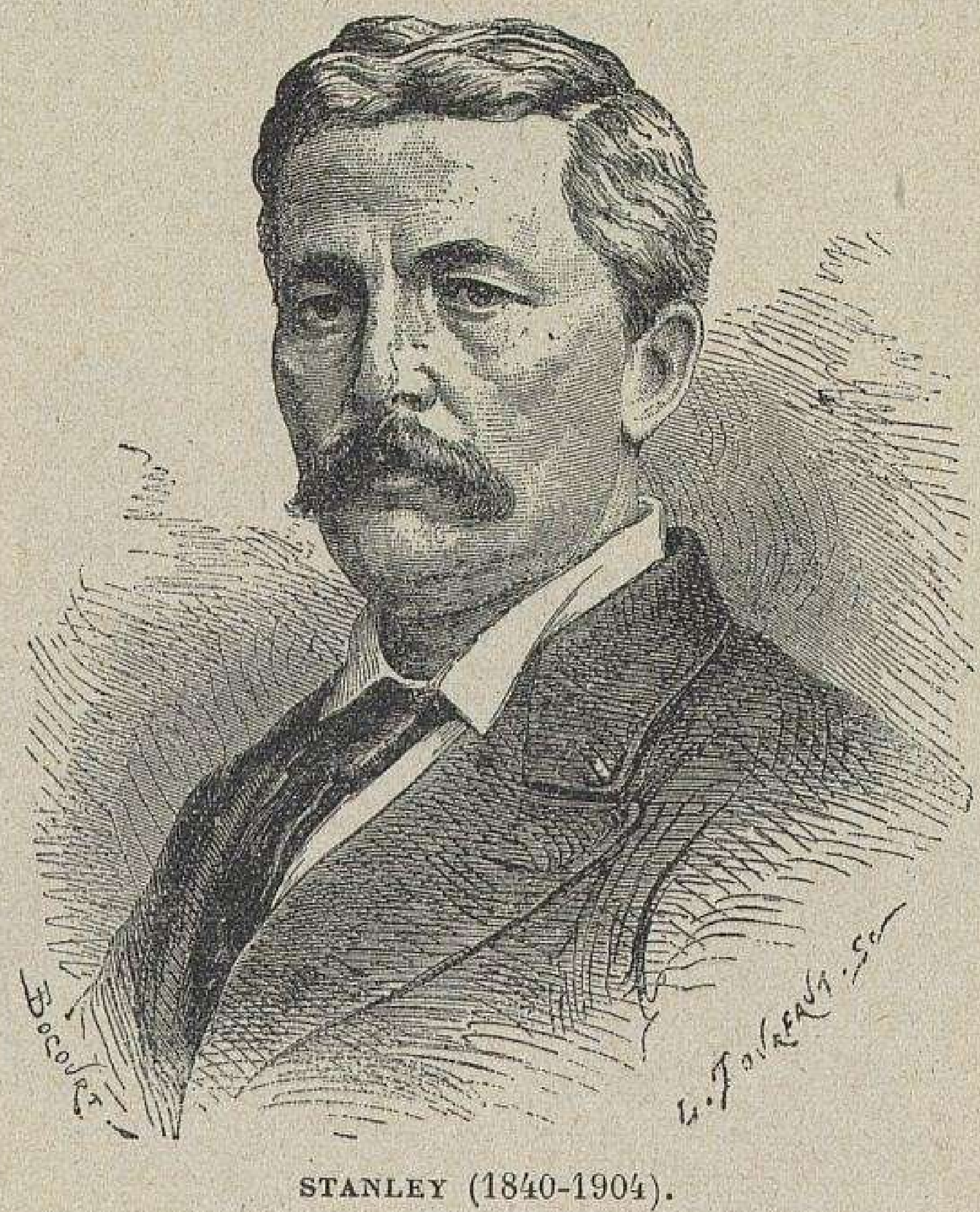

en 1875 et 1887, que les résultats se précisèrent et se complétèrent.

Stanley, un Anglais du pays de Galles, au service d'un grand journal américain qui fournissait les fonds, explora la rive Sud du lac Victoria, reconnut l'embouchure d'un gros fleuve, le Kagera, qui peut être regardé comme la source la plus lointaine du Nil, découvrit encore le lac Albert-Édouard et fixa la ligne de partage des eaux entre le Congo et le Nil. On savait maintenant que le lac Albert réunissait les eaux du lac Victoria, celles aussi du lac Albert-Édouard, et que le Nil était un fleuve alimenté par de grands réservoirs lacustres.

La région du Bahr-el-Ghazal et le pays des Rivières avaient 
été auparavant reconnus et scientifiquement étudiés par Schweinfurth de 1868 à 1871 .

$4^{\circ} \mathrm{La}$ découverte du Zambèze et du Congo fuit l'œuvre d'un Écossais, Livingstone; missionnaire et savant, en servant la science, il servit l'humanité; car il évangélisa les Nègres à l'état de nature. Parti de l'Afrique australe, de 1849 à 1852 il découvre

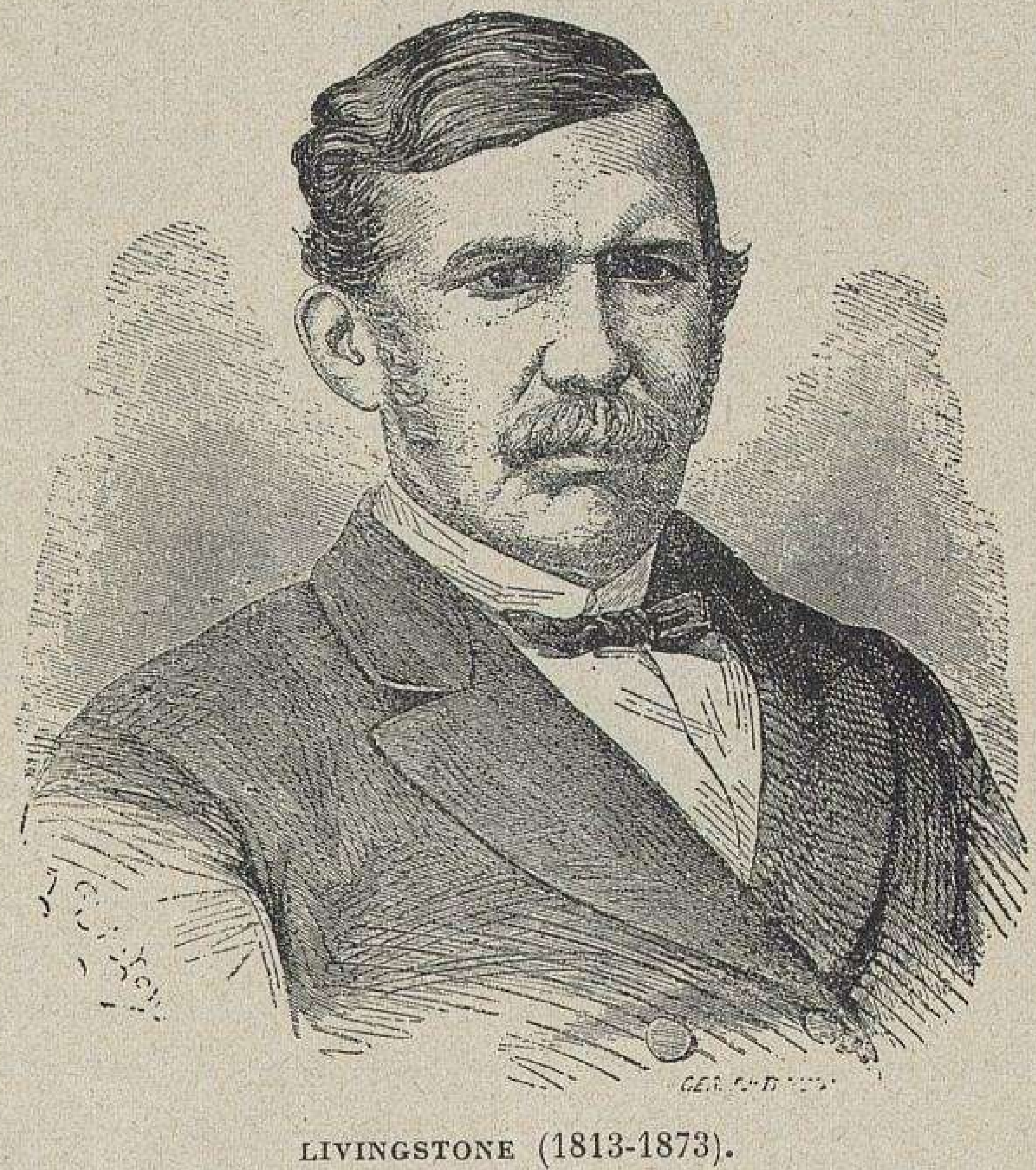

Né à Blantyre, près Glasgow - mort à Tchitambo, Afrique australe.

la dépression du lac Ngami, puis le Zambèze, puis un grand affluent du Congo, le Kassaï, et rejoint la côte Atlantique à SaintPaul de Loanda. Il a ainsi ouvert une route vers l'Ouest. Il repart pour frayer celle de l'Est, descend le Zambèze, aperçoit les chutes grandioses qu'il baptise du nom de la reine Victoria et atteint l'océan Indien. Le premier il a traversé de part en part l'Afrique australe. - Dans une série d'explorations nouvelles, il remonte le Chiré, affluent rive gauche du Zambèze inférieur, et découvre le lac Nyassa, au moment où Speke découvrait plus au Nord les lacs Tanganyika et Victoria (1859). - Enfin de 1866 à 
1873, en cherchant le Nil, il trouve le bassin supérieur du Congo; il meurt alors à Tchitambo, 1873, en pleine Afrique, et les Nègres qui l'accompagnaient rapportent pieusement sa dépouille. Cameron, qui arrive trop tard pour lui porter secours, continue ses explorations par la première traversée effectuée d'Est en Ouest, mais il ne les achève pas.

L'honneur en revint à Stanley en 1874 : homme d'une énergie.

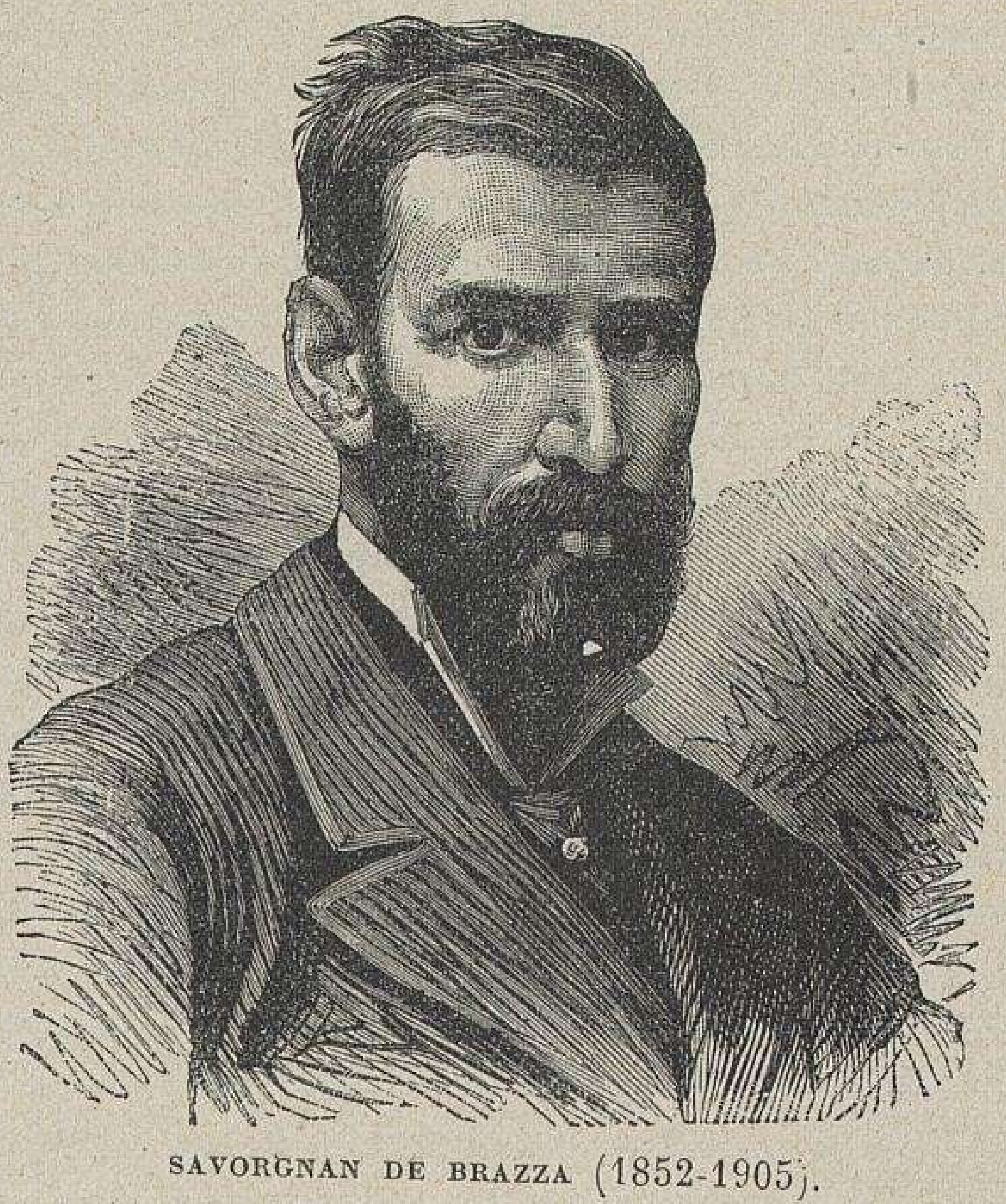

incroyable, mais sans scrupules humanitaires et prompt à faire parler la carabine, Stanley descend le Congo jusqu'à son embouchure. Son nom est resté aux chutes du fleuve sous l'équateur, Stanley falls, et à la grande nappe lacustre où ses eaux s'amoncellent avant de s'étrangler pour descendre les gradins qui le séparent de la mer, le Stanley pool.

De retour au Congo en 1881, pour le compte du roi des Belges, Stanley fut surpris et dépité d'apercevoir notre drapeau tricolore sur les rives du fleuve : Savorgnan de Brazza l'avait devancé sur le Pool en remontant l'Ogooué; il avait ainsi fondé la colonie 
française du Congo. En face de Brazzaville s'éleva Léopoldville.

$5^{\circ}$ Alors ce fut, dans la fin du $\mathrm{xIx}^{\mathrm{e}}$ siècle, une vraie course aux explorations. Maintenant les grands États européens luttaient de vitesse, afin de pénétrẹr les premiers le cour du continent africain; ils signaient des traités avec les petits souverains indigènes et se réservaient ainsi pour l'avenir le droit exclusif de l'occupation et de l'exploitation; chaque nation localisait ses efforts dans une région.

L'acte général de Berlin de 1885, l'acte général de Bruxelles en 1890 déterminèrent de grandes zones d'influence française, anglaise, allemande, etc. C'est pour s'attribuer des droits sur l'arrière-pays, l' " hinterland " de ses possessions côtières que la France combina une série d'explorations à qui nous devons un vaste domaine africain.

Le désir de relier le Sénégal et la Guinée, l'Afrique française du Nord et le Soudan provoque les voyages du capitaine Binger qui, parti de Saint-Louis, visite le pays de Kong et sort par la Côte de l'Ivoire (1887-89), du commandant Monteil, qui de Saint-Louis encore atteint le Tchad et revient par Tripoli (1890-92) et de la mission d'Ollone sur le Cavally (1898-1900). - La reconnaissance du Niger est faite par le général Gallieni (1879-81), Caron et Lefort (1887), le commandant Toutée (1895), le lieutenant de vaisseau Hourst (1896) et le capitaine Lenfant (1901). A la conquête du Tchad s'élancent Mizon qui remonte la Bénoué, mais est contraint de revenir au Congo par la Sangha (1890-92); Crampel, assassiné en 1891; Maistre qui le remplace atteint le Chari et rejoint la Bénoué (1893); Gentil lance le premier vapeur sur le lac (1895-98); la mission de Foureau, lequel de 1884 à 1896 n'a pas fait moins de neuf voyages dans le Sahara septentrional, et du commandant Lamy, part de l'Algérie, celle de Meynier-Joalland du Niger, celle de Gentil du Congo et toutes opèrent leur jonction autour du Tchad en 1900; enfin le colonel Destenave fixe l'hydrographie et lève la carte du lac (1902). - Dans l'intervalle le commandant Marchand s'efforce d'unir nos possessions du Congo et du Chari à l'Abyssinie et par celle-ci à notre colonie de la Côte des Somali; un instant il coupe la grande ligne de communication que les Anglais prétendent faire courir du Cap au Caire, mais il faut 
évacuer Fachoda(1896-98).-L'étude de Madagascar, commencée par les grands travaux scientifiques d'Alfred Grandidier à partir de 1865, est continuée par Catat et Maistre (1889-91) entre la côte Est, Tananarive et le Sud-Est, par E. Gautier (1892-99) au Centre et à l'Ouest, et la reconnaissance de l'île se poursuit méthodiquement sous la haute direction du général Gallieni.

Nos concurrents avaient déployé une activité égale à la nôtre. Parmi tant de voyages intéressants, nous relèverons seulement les expéditions qui établissent l'hydrographie du Congo. Wissmann explore (1881-87) les affluents de gauche; Van Gèle identifie l'Ouellé et l'Oubangui en 1887; Stanley, envoyé à la délivrance d'Emin pacha que bloque la conquête mahdiste, remonte l'Arouhouimi (1887-90), enfin Lemaire détermine les sources du Kassai, du Congo et du Zambèze (1900).

II. Partage politique de l'Afrique. - Aujourd'hui, bien peu nombreux sont en Afrique les États indigènes indépendants : il n'y a d'autonomes que le Maroc, l'Abyssinie et la République nègre de Libéria. La Tripolitaine est province turque. De la T'urquie relève l'Égypte, occupée par l'Angleterre. Tout le reste du continent appartient à des États de l'Europe.

1. La France possède les territoires les plus étendus, mais non toujours les plus riches et les plus peuplés :

L'Algérie, dont la conquête a commencé en 1830, et la Tunisie placée sous notre protectorat depuis 1881 : l'une et l'autre prolongent la France au delà de la Méditerranée et servent de base à notre pénétration saharienne; l'Afrique occidentale (Sénégal, Haut-Sénégal et Niger, Guinée, Côte de l'I I৩oire, Dahomey, territoire civil de Mauritanie, territoire militaire du Niger s'étendant jusqu'au lac Tchad); l'Afrique équatorialo (Gabon, Moyen Congo, Oubangui-Chari-Tchad); Madagascar avec ses dépendances (les Comores) et la Réunion; enfin, à la sortie de la mer Rouge, la Côte des Somali d'où partent les voies de pénétration vers l'Abyssinie rnéridionale.

$2^{\circ}$ L'Angleterre possède en Guinée des territoires enclavés dans nos possessions : la Gambie, le Sierra Leone, la Côte de l'Or et le pays des Achanti, puis la Nigeria qui a absorbé le Lagos et qui s'étend jusqu'au lac Tchad.

G. Lespagiol Et FALLEx, - Afrique. 
Mais son empirc véritable est ailleurs. C'est l'A frique australe, depuis le Capjusqu'aux lacs Nyassa et Tanganyika. C'est l'A/rique orientale, d'où elle atteint par le lac Victoria la région du haut Nil. C'est l'Égypte, qu'elle occupe depuis 1882, et le Soudun angloégyptien. C'est encore, en face d'Aden, des ports sur la côte des Somali. Cies trois dernières possessions cherchent à se joindre et dessinent un mouvement enveloppant autour de l'Abyssinie.

Parmi les îles, Ascension et Sainte-Hélène, dans l'Atlantique, l'ile de France et Rodriguez, les îles Séchelles dans l'océan Indien fournissent des relâches précieuses à ses flottes, des points d'atterrissement à ses câbles sous-marins.

$3^{\circ}$ L'Allémagne, la dernière venue, s'est taillé par lambeaux, en Afrique, un domaine colonial; elle possède le Togoland, voisin du Dahomey; le Cameroun, qui étire bizarrement ses frontières jusqu'au lac Tchad; le Sud-Ouest africain allemand; l'Afrique orientale allemande.

$4^{\circ}$ L'Italie, moins heureuse, exerce un protectorat sur la partie orientale de la côte des Somali, et possède sur la mer Rouge l'Erythrée, qui lui donne accès dans l'Abyssinie du Nord

$5^{\circ}$ L'Espagne n'a pas su se faire la part que sa situation semblait lui ménager. Elle occupe, sur la côte méditerranéenne du Maroc, Ceuta et les Présides; dans l'Atlantique, l'archipel des Canaries; sur le littoral saharien, le Rio de Oro; au fond du golfe de Guinée, les illes Fernando Po et Annobon, enfin vis-àvis, sur le continent, le Rio Mouni.

$6^{\circ}$ Le Portugal n'a pas davantage su conserver dans leur intégrité ses établissements d'Angola et de Benguella sur l'Atlantique, de Moçambique sur l'océan Indien; il les a laissé couper en deux tronçons par les Anglais. A ces possessions encore immenses s'ajoutent les îles du Cap-Vert et la Guinée dite portugaise, enfin l'ille du Prince et Saint-Thomas.

$7^{\circ}$ L'État indépendant du Congo, institué par le Congrès de Berlin et mis d'abord sous la souveraineté du roi des Belges, est devenu en 1908 une colonie de la Belgique.

- Le $\mathrm{xix}^{\mathrm{e}}$ siècle a découvert l'Afrique; a $\mathrm{xx}^{\mathrm{e}}$ siècle revient la mission de la mettre en valeur et de la civiliser. 


\title{
CHAPITRE IV
}

\section{RÉGION DE L'ATLAS OU MAGHREB}

\author{
I. - MAROC
}

\section{SOM M A IRE}

Au Nord-Ouest de l'Afrique, l'Atlas forme une grande région naturelle que la politique a partagée entre le Maroc, l'Algérie et la Tunisie.

I. Limites. - Bien définies par la mer sur deux côtés (Méditerranée, détroit de Gibraltar et océan Atlantique), les limites du Maroc demeurent le plus souvent vagues dans l'intérieur des terres; il confine à l'Algérie sur une longue étendue.

II. Superficie. - Approximativement $440.000 \mathrm{kmq}$.

III. Relief. - Au Nord, la chaine du Rif (3.000 m.) borde la Mèditerranée. Au Sud s'allonge la crête rectiligne du Haut Atlas $(4.500 \mathrm{~m}$. à la plus haute cime), doublée du Petit Atlas. Entre le Rif et l'Atlas s'ouvre une dépression.

IV. Climat. - L'Atlas dètermine trois régions climatériques : $1^{\circ}$ Le versant Nord-Ouest ou Atlantique est celui de la pluie; la température, moins élevèe que ne le ferait croire la latitude, est d'abord constante sur la côte, plus inègale à l'intérieur, rude enfin sur les montagnes neigeuses. $2^{\circ}$ Le Nord-Nord-Est ou versant méditerranéen est encore humide, mais moins. $3^{\circ}$ Le Sud ou versant Saharien est sec.

V. Hydrographie. - Le grand centre de dispersion des eaux est le Djebel Alachi.

A la Méditerranèe descend la Moulouïa; - á l'Atlantique, l'oued Sebou et l'oued Oum er Rebia; ces cours d'eau ne tarissent jamais. Au Sahara se perdent les torrents descendus de l'Atlas méridional: l'Oued Draa qui n'atteint presque jamais l'Atlantique et l'Oued Guir.

VI. Côtes. - Les côtes de la Mèditerranée sont rocheuses, celles de I'Atlantique sablonneuses; ni les unes ni les autres ne possédent de bons ports. 
VII. La vie végétale est en harmonie avec l'humidité du versant atlantique, avec la secheresse du versant saharien.

VIII. Vie animale. - Les animaux sont de même ceux des régions tempérèes chaudes et des règions désertiques.

IX. Géographie humaine. - De 5 à 7 millions d'habitants, comprenant les Berbères qui habitent la montagne, les Arabes la plaine, les Maures et les Juifs les villes.

Les Européens forment de très petites colonies dans les villes maritimes.

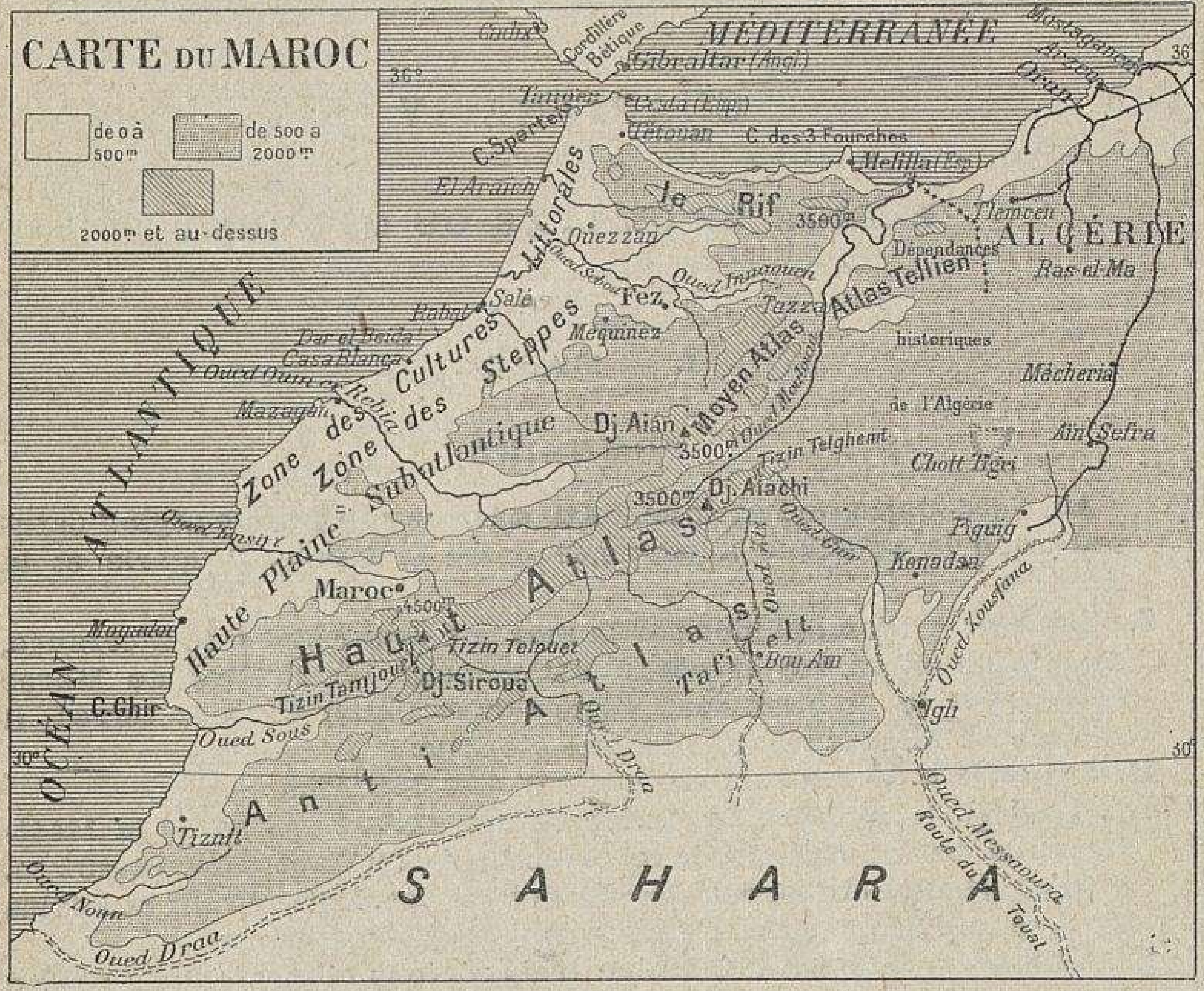

La religion est le Mahométisme; elle unit dans un fanatisme farouche tous les indigènes contre l'étranger.

X. Gouvemement. - Le Sultan du Maroc est un souverain absolu, à la fois religieux et temporel. Son administration est despotique, oppressive, systématiquement hostile à tout progrès. L'insurreotion est l'état normal des tribus.

XII. Villes. - Toutes les villes en contiennent trois : la kasba ou citadelle, la ville proprement dite et le quartier juif. $F e z$, Mequinez et Maroc ont toutes trois rang de capitale. Tanger est la résidence des diplomates européens. Le Tafilelt et Figuig sont des oasis sahariennes.

XII. Hise en valeur. - Le Maroc demeure figé dans une immobilité séculaire.

Pays d'agriculture et d'élevage, il ne pratique l'une et l'autre que suivant des procédès primitifs. 
Il en est de même de l'industrie. Les richesses minières ne sont pas exploitèes.

Le commerce est entravé par l'absence de voies de communication et par des prohibitions excessives.

XIII. Question du Maroc. - Les ressources inexploitées du Maroc, son ètat anarchique, sa magnifique position sur le détroit de Gibraltar excitent les convoitises des puissances européennes; leur jalousie est la meilleure garantie de son indépendance. Voisine du Maroc par l'Algérie, la France ne peut laisser aucune puissance européenne s'implanter aux flancs de sa colonie d'Afrique.

\section{DÉVELOPPEMENT}

Au Nord-Ouest de l'Afrique, l'Atlas dessine une grande région naturelle, que limitent, à l'Est et au Nord la Méditerranée; à l'Ouest, l'Atlantique; au Sud, le Sahara. Les partages politiques ont pu la découper arbitrairement entre le Maroc, l'Algérie et la Tunisie; elle n'en forme pas moins un ensemble géographique homogène, d'une réelle unité, unité de terrains, de relief, de climat, unité de ressources naturelles, unité enfin de races, de langues et de religions.

Pour les Arabes, c'est le “ pays du Couchant», Maghreb; pour les géographes d'Europe, la Berbérie ou mieux encore l'Afrique mineure, un' petit continent dans le grand.

Comme précédemment, nous noterors ici le sens des mots indigènes, arabes ou berbères, qui se rencontrent souvent dans la nomenclature géographique.

Aïn, source.

Erg, pluriel Areg, dunes.

$B a b$, pluriel Biban, porte.

Bir, pluriel Biar, puits maçonné.

Bled, pays, région.

Bordj, maison fortifiée.

Chäbet, ravin.

Chebka, filet, réseau de vallées enchevêtrées.

Chott, nappe salée.

Dä̈a, mare, cuvette, bas-fond.

Djebel, montagne.

Djerid, palme.

Gara, pluriel Gour, témoin rocheux d'érosion.

Gassi, long couloir de sol ferme, entre les dunes.
Hamada, plateau rocheux.

Hammam, source chaude.

Kef, rocher, pic.

Kheneg, gorge.

Ksar, pluriel Ksour, village fortifié. Ogla, pluriel Oglat, réunion de puits.

Oued, cours d'eau temporaire.

Ouadi, vallée sèche.

Ras, tête, sommet, cap.

Redir ou Ghedir, réservoir naturel d'eau de pluie.

Sahel, pays plat; par extension côte.

Souk, marché.

Sebkha, bas-fond salin.

Teniet, Tizi, col. 


\section{I. - MAROG}

I. Limites. - Le Maroc - de l'arabe Marrakech, une des capitales, - occupe l'extrême Ouest de la Berbérie (Maghreb-el$A k s a)$. Ce n'est pas un empire au sens européen du mot; l'État n'est pas organisé, le territoire même n'est pas délimité par des bornages. Le Maroc comprend deux parties très distinctes : $1^{\circ}$ les pays qui obéissent au Sultan; $2^{\circ}$ les pays - et ce sont de beaucoup les plus étendus - qui ne lui obéissent pas, ne paient pas d'impôt et n'acquittent aucun service militaire. Au Nord et à l'Ouest, la Méditerranée, le détroit de Gibraltar, l'Atlantique font au Maroc une limite naturelle. Mais du côté des terres il n'est pas facile de dire où il finit.

Vers l'Algérie et la province d'Oran, la frontière n'a été tracée depuis la mer que sur une longueur de $350 \mathrm{~km}$. environ. Au delà, le traité de 1845 a réparti les tribus nomades et les Ksour (villages indigènes) entre le Maroc et la France : il n'y a pas eu et il ne pouvait pas y avoir de délimitation, vu les déplacements réguliers des pasteurs en quête des pâturages intermittents. Si notre diplomatie eût été alors plus hardie et mieux informée, elle eût réclamé pour frontière l'Oued Moulouïa, qui de toute antiquité, au temps des Romains comme au temps des Turcs, constitua la limite naturelle et historique. Figuig, aux confins du désert, a été laissé au Sultan, mais nos postes militaires et notre chemin de fer sont installés à moins d'une lieue. On ne songea mème pas en 1845 à un partage des tribus sahariennes, parce que le Sahara passait pour inhabitable; actuellement nous occupons la ligne qui conduit au Touat, c'est-à-dire l'Oued Zousfana et l'Oued Saoura qui sont des dépendances géographiques de l'Algérie. - Sur le versant méridional de l'Atlas enfin, le Maroc se perd dans le Grand désert, sans limites précises, en un point quelconque.

II. Superficie. - Il est impossible de l'évaluer même approximativement : 440.000 kilomètres carrés sont peut-être le chiffre qui approche le plus de la vérité. Ce serait moins que la France.

III. Relief. - Le Maroc appartient au système de l'Atlas. Ses chaines puissantes, plissées en bordure de la cuvette méditerranéenne, sont faites des mêmes roches, ont même allure et même âge que les montagnes du Sud de l'Espagne, la Cordillère hétique. Le détroit de Gibraltar doit être envisagé comme une cassure entre les deux continents d'Europe et d'Afrique : sa 
partie la plus étroite mesure seulement 13 kilomètres de large.

Les traits généraux du relief apparaissent très simples :

$1^{\circ} \mathrm{Au}$ Nord, une chaîne longe la Méditerranée : c'est le Rif;

$2^{\circ} \mathrm{Au}$ Sud, s'aligne le grand massif de l'Atlas;

$3^{\circ}$ Entre les deux, parallèlement, s'ouvre d'Ouest en Est une dépression, une “ trouée " : c'est la grande voie historique, de Fez par Taza vers Tlemcen et l'Algérie.

$1^{\circ}$ Le Rıf recourbe ses plis parallèlement au rivage méditerranéen, depuis le cap des Trois Fourches jusqu'à la pointe de Ceuta; il surgit brusquement de la mer; ses pentes, vite inaccessibles, montent à des sommets de plus de 3.000 mètres. Vers l'intérieur, elles s'abaissent plus doucement et sont sillonnées par les rivières qui gagnent l'Oued Sebou.

$2^{\circ}$ L'Atras, Adrar en langue indigène, commence sur l'Atlantique entre le cap R'ir et l'Oued Sous, et se poursuit en Algérie, toujours orienté Sud-Ouest-Nord-Est; au Maroc, c'est une crête très longue, toute droite, à peine dentelée, toujours très haute $(3.900, \mathrm{~m}$. en moyenne) : aussi les neiges la couvrent-elles pendant de longs mois. La cime culminante ne doit pas être de beaucoup inférieure à notre mont Blanc (le Tamjoutı, 4.500 mètres), et les cols qu'empruntent les caravanes pour aller de Maroc et de Fez vers le Sahara se maintiennent à 2 et 3.000 mètres. Le Djebel Aiachi aurait seulement 3.500 mètres; au delà le Haut Atlas s'abaisse assez rapidement et se prolonge sous forme de cheblia ou hautes plaines découpées par un réseau de rivières. - Le Moyen Atras dessine le noud du Djebel Ä̈an (env. 3.500 m.); de là partent en éventail plusieurs contreforts qui s'inclinent progressivement, l'un au dessus de Mequinez et de Fez, un autre au-dessus du seuil de Taza, un troisième enfin est continué par l'Atlas tellien au delà de la Moulouia. - Les vallées supérieures de l'oued Sous, de l'oued Draa et de l'oued Ziz séparent le Haut Atlas d'une chaîne parallèle, dont l'élévation un peu moindre se maintient uniformément à 2.000 mètres : c'est le Petit Atras ou Anti-Atras. Vers l'Est, il ne forme plus une muraille, mais un plateau dont les bords Nord et Sud, redressés en bourrelets, annoncent déjà la structure de l'Atlas algérien. - Plus au Sud encore, s'étend ie SaIrara, dunes de sables ou plateaux de roches. 
IV. Climat. - Situé entre $28^{\circ}$ et $36^{\circ}$ environ Lat. N., le Maroc est visité, à l'Ouest et au Nord-Ouest, par les vents marins, en hiver et au printemps. Le climat est très sain : ni épidémies ni malaria.

L'Atlas détermine trois versants, et par suite trois régions climatériques.

$1^{\circ}$ La région du Nord-Ouest, ouverte entre le Rif et le HautAtlas, est le versant de la pluie; elle jouit par conséquent d'une température moins élevée que ne le ferait supposer la latitude.

$1^{\circ}$ De l'Atlantique à l'Atlas, les zones de température s'harmonisent avec le relief : $1^{\circ}$ la zone littorale ne connait ni les fortes chaleurs de l'été, ni les froids rigoureux : la brise océanique, un courant marin froid, l'humidité (40 à $60 \mathrm{~cm}$. de pluies) rendent la température presque uniforme, et la terre possède une fécondité merveilleuse. Mogador est une des rares régions du globe réputées pour la salubrité et la constance de leur climat.

\begin{tabular}{|c|c|c|c|c|c|c|}
\hline \multirow{4}{*}{$\begin{array}{l}\text { Mogador. } \\
\text { Tanger . }\end{array}$} & \multirow{2}{*}{$\begin{array}{l}\text { LATI- } \\
\text { TUDE }\end{array}$} & \multirow{2}{*}{$\begin{array}{l}\text { ALTI- } \\
\text { TUDE }\end{array}$} & \multicolumn{4}{|c|}{ TEMPÉRATURE MOYENNE } \\
\hline & & & ANNÉE & JANVIER & AOUT & İCART \\
\hline & $31^{\circ}$ & $15^{\mathrm{m}}$ & $19^{\circ}$ & $16^{\circ}$ & $21^{\circ}$ & $5^{\circ}$ \\
\hline & $35^{\circ}$ & $60^{\mathrm{m}}$ & $18^{\circ}$ & $13^{\circ}$ & $20^{\circ}$ & $7^{\circ}$ \\
\hline
\end{tabular}

$2^{\circ}$ En arrière, la région subatlantique est plus sèche et de température déjà moins égale. Les vallées sont eultivées et fertiles, mais les terrasses qui les séparent sont occupées par les steppes.

\begin{tabular}{|c|c|c|c|c|c|c|}
\hline \multirow[b]{3}{*}{ Maroc. . . } & \multirow{2}{*}{$\begin{array}{l}\text { LATI- } \\
\text { TUDE }\end{array}$} & \multirow{2}{*}{$\begin{array}{l}\text { ALTI- } \\
\text { TUDE }\end{array}$} & \multicolumn{4}{|c|}{ TEMPÉRATURE MOYENNE } \\
\hline & & & ANNÉE & JANVIER & JUTLLET & ÉCART \\
\hline & $31^{\circ}$ & $530^{\mathrm{m}}$ & $22^{\circ}$ & $11^{\circ}$ & $32^{\circ}$ & $11^{\circ}$ \\
\hline
\end{tabular}

$3^{\circ}$ Sur les pentes de l'Atlas, à partir de $1.000 \mathrm{~m}$., la température devient de plus en plus rude, et les prácipitations de plus en plus fortes. Depuis les pâturages et les forêts compactes, on s'élève jusqu'aux neiges des bauts sommets; celles-ci persistent jusqu'en août et septembre.

$2^{\circ}$ La région saharienne, abritée des vents pluvieux par l'écran de l'Atlas, exposée de plus aux vents chauds et desséchants du Sud, a le climat sec et à fortes variations des déserts. 
$3^{\circ}$ La région du Nord-Est est celle du Rif et de la Moulouia. Le Rif exposé aux vents du Nord-Ouest, froids et humides, a un climat rude qu'explique encore l'altitude; le bassin de la Moulouia appelle les vents d'Est, qui par exception apportent ici une assez forte quantité de pluies.

V. Hydrographie. - Le Djebel Ä̈achi est le grand centre hydrographique du Maroc; on le compare volontiers au SaintGothard. Les oueds ou rivières s'écoulent de là vers trois directions : à la Méditerranée, à l'océan Atlantique, au Sahara.

Les rivières méditerranéennes et atlantiques, alimentées par des pluies abondantes, par les neiges, ont de l'eau toute l'année, et quelques-unes possèdent un domaine très ample. Toutes ou à peu près sont sujettes à des crues d'hiver, très fortes, mais de peu de durée. Aucun pont ne les franchit: l'indigène les passe tantôt sur des radeaux faits avec des outres gonflées d'air, avec des bâtons et des cordages en feuilles de palmier nain; tantót à gué : il dresse son campement sur la rive et attend patiemment la baisse. Rien n'a été tenté pour régulariser le régime; aucun barrage ne maintient le plan d'eau; arrivée à la mer, la rivière est gênée par une barre de sable qui parfois la ferme complètement. Les plus fortes pourraient être navigables une bonne partie de l'année. Mais elles ne sont utilisées que pour l'irrigation des champs et des jardins, et à ce genre de travaux hydrauliques le Marocain excelle; ces saignées les appauvrissent bien plus que l'évaporation.

1. A la Méditerranée arrive l'Oued Mouloüa (env. $450 \mathrm{~km}$.), dont les eaux, toujours abondantes dans la montagne, très grosses d'avril à juin lors de la fonte des neiges, deviennent plus indigentes dans la plaine, sans jamais tarir complètement.

$2^{\circ}$ A l'Atlantique s'écoulent plusieurs grands fleuves aux affluents nombreux, aussi importants parfois que le fleuve même, l'Oued Sebou, alimenté à la fois par l'Atlas et par le Rif, le cours d'eau le plus important de l'Afrique du Nord, l'Oued Oum er Rebia, tous constants et grossis par les crues d'hiver. L'Oued Tensift longe le Haut Atlas qui lui envoie de nombreux tributaires sur la rive gauche. L'Oued Sous, encadré par le Grand et le Petit Atlas, est déjà un fleuve temporaire, desséché presque totalement dans son cours inférieur pendant l'été.

$3^{\circ}$ Sur le versant saharien, les'eaux, d'abord abondantes et robustes, diminuent de volume, à mesure qu'elles descendent; 
elles s'infiltrent, elles s'évaporent; le reste est détourné par l'irrigation des oasis. Pendant quelque temps humide d'une circulation souterraine, le lit, aux berges écartées, tranchées net, se dessèche et ressemble alors à un défilé entre deux falaises.

L'Oued Draa est incontestablement le plus long cours d'eau du Maroc (1.200 km.); mais si, dans son cours moyen, il fertilise des oasis populeuses, après le coude brusque qui le jette à l'Ouest, il ne présente qu'un lit asséché, utilisé comme piste, comme terrain de parcours par les nomades; il faut des pluies exceptionnellement fortes sur les grandes cimes de l'Atlas pour qu'il apporte un tribut même insignifiant à la mer. L'Oued Ziz court du Nord au Sud et se perd, après les oasis du Tafilelt, dans une lagune salée et sous les dunes de sables. L'Oued Guir court au Sud-Est; rejoint par l'Oued Zousfana, il prend le nom de Oued Messaoura et trace la route des oasis françaises du Touat.

VI. Côtes. - $1^{\circ}$ Méditerranée. - Après les plaines basses où se déverse la Moulouĩa, la côte se redresse et les montagnes du Rif découpent des falaises verticales, projettent des caps rocheux entre des plages de sable et parsèment au large des écueils et des îlots : rade de Mélilla (Esp.), cap des Trois pointes, baie d'Alhucemas, rade de Tétouan. Inhospitalier, sans un seul bon port, le littoral est encore rendu mauvais par les courants qui arrivent de l'Océan, dangereux par l'absence de phares, et par l'hostilité des Rifains; il est prudent pour les navires à voiles de se tenir hors de portée.

$2^{\circ}$ Détroit de Gibraltar. - De la pointe de Ceuta, sur la Méditerranée, à Tanger sur l'Atlantique et au cap Spartel, les escarpements font face au rocher de Gibraltar et à la pointe de Tarifa.

$3^{\circ}$ Atlantique. - La direction change, puis la montagne s'écarte. Presque droite, la côte est en général basse, sablonneuse, bordée de dunes; çà et là des falaises, mais jamais de bons ports, seulement des mouillages médiocres, que les vents d'Ouest rendent dangereux. Les plus fréquentés sont Casablanca (le Ras el Beida des Marocains) et Mogador. Au Sud des caps $R^{\prime} i r$ et Noun où surgit l'Atlas, commence le désert, aussi bien sur l'Océan qu'à l'intérieur du continent. 
VII. Vie végétale. - Les formes de la végétation s'harmonisent avec l'humidité du versant maritime, avec la sécheresse du versant désertique.

Les plaines conviennent aux céréales (blé dur et orge), à l'olivier, aux jardins (arbres fruitiers et cultures maraîchères) entretenus par les rigoles d'arrosage et abrités par des haies épineuses de cactus et d'aloès : le Maroc est aujourd'hui ce qu'il était dans l'antiquité, le jardin des Hespérides aux pommes d'or (orangers). L'arar ou arbre à sandaraque donne un bois odoriférant, incorruptible; l'arganier qui pousse sur les roches est spécial au Maroc. Les steppes et les plateaux portent ies pâturages intermittents et des touffes d'alfa dans les parties plus sèches; les pentes de l'Atlas, des pâturages permanents. La montagne (Rif et Atlas) est revêtue de belles forêts.

$\mathrm{Au}$ Sud, la végétation prend un caractère désertique; les oasis du Tafilelt, plantées de palmiers, fournissent des dattes succulentes, célèbres dans le monde musulman.

VIII. Vie animale. - Les formes animales sont celles des régions tempérées chaudes, au Nord, et du désert, au Sud : nous les avons définies dans l'étude générale de l'Afrique.

Parmi les animaux utiles, les bêtes à cornes, les chèvres et moutons, le cheval, l'âne, le mulet et le chameau.

Les sauterelles sont un fléau plus terrible encore qu'en Algérie.

IX. Géographie humaine. $-1^{\circ}$ Population. - L'absence de recensement et d'état civil, l'absence de frontières rendent impossible une évaluation exacte de la population : de 5 à 7 millions, suivant les calculs les plus vraisemblables.

$2^{\circ}$ Races. - Les Berbères sont en majorité; ils peuplent les hautes régions du Rif et de l'Atlas, ainsi que les oasis sahariennes. Les Arabes, moins anciens, sont venus en conquérants; ils cultivent les plaines ou parcourent les steppes avec leurs troupeaux. Les Maures et les Juifs résident dans les villes : les Maures, mélange de Berbères et d'Arabes, se livrent au commerce et à l'industrie; c'est la classe riche où se recrute le personnel des fonctionnaires. Quant aux Juifs, traités 
très durement, astreints à porter un costume spécial qui les distingue, à habiter un quartier réservé, ils font le commerce de l'argent; beaucoup descendent des Juifs chassés d'Espagne. Les Nègres, amenés par les caravanes du Soudan, sont libres ou esclaves; mais leur sort n'est pas dans ce dernier cas aussi triste qu'on serait tenté de le croire, car ils font partie de la famille. En infime minorité enfin, les Européens forment de petites colonies dans les villes maritimes et surtout à Tanger.

$3^{\circ}$ Religion. - La religion dominante est le mahométisme. Fez est la capitale religieuse non pas seulement du Maroc, mais de tout l'Islam occidental; elle renferme les plus puissantes des confréries religieuses et, comme ville sainte, vient après la Mecque.

L'Islam, voilà le lien solide qui unit Berbères, Arabes et Maures. Le Maroc ne forme pas une nation : il n'y a pas de patrie marocaine, l'indigène ne connaît que sa tribu; tribus berbères, tribus arabes sont toujours en guerre les unes contre les autres, pour des questions de sources, de pâturages, de bestiaux volés et de palmiers coupés, en guerre aussi contre le Sultan auquel elles ne paient l'impôt qu'une fois vaincues; la guerre est l'état normal. Mais tous les Musulmans oublieraient leurs querelles pour s'unir contre l'étranger, contre " l'Infidèle » et se lèveraient comme un seul homme à l'appel de la « Guerre Sainte ».

X. Gouvernement. - C'est par une fiction que le Maroc est qualifié Empire : il n'y a pas même de gouvernement.

Le sultan n'est pas héréditaire; aucune loi ne règle la succession, car Mahomet n'a pas désigné celui qui lui succéderait. De là des révolutions constantes, des intrigues perpétuelles; le sultan ne se maintient qu'à la condition d'être le plus fort; obéi de çrtaines tribus, il est méconnu par le plus grand nombre.

Son autorité est double : religieuse et temporelle. - $1^{\circ}$ Recigreuse, elle dépasse de beaucoup les régions soumises à sa domination politique. Il a le titre de chérif, c'est-à-dire qu'il descend du Prophète; mais il est d'autres chérifs, et celui d'Ouezzan a une puissance égale, sinon supérieure, à la sienne. Il s'intitule Prince ou Commandeur des croyants, vicaire d'Allah sur la terre; mais un grand nombre de musulmans sont affiliés à des con. 
grégations dont parfois les ehefs résident hors du Maroc. - $2^{\circ}$ Souverain TEMPOREL, le sultan est maitre absolu du territoire, des biens et même de la vie de ses sujets. C'est un despote. La loi fondamentale est le Coran : il l'interprète à son gré. Pas de ministres au sens où nous l'entendons en Europe. Le sultan s'entoure bien de hauts dignitaires, mais c'est lui qui prend toutes les décisions. Le vizir à qui il délègue son autorité et tous ceux qui participent aux actes du gouvernement constituent le makhzen. Du haut en bas, l'arbitraire est la règle; à tous les degrés les fonctionnaires - qui ne sont pas rétribués ou le sont très peu - volent et pillent leurs administrés, et contre leurs exactions les tribus n'ont d'autre ressource que la révolte; or la révolte est partout. L'armée du makbzen n'a aucune valeur militaire, malgré ses instructeurs européens. Ge qui préserve le Maroc d'une conquête, e'est le nombre et la valeur guerrière des tribus berbères, c'est leur fanatisme féroce. Elles sont armées de fusils à tir rapide, car le seul progrès qu'elles aient jamais compris, qu'elles aient tout de suite accepté de la civilisation européenne, c'est celui des armes à feu. - Maintenir ce qui est, refuser systématiquement la moindre amélioration, tel est le premier, l'unique soin du gouvernement : il n'y a ni travaux publics, ni agriculture, ni commerce, ni instruction. Un pareil état de choses ne saurait durer plus longtemps, aux portes mêmes de l'Europe.

XI. Villes. - Au Maroc toutes les villes, ou à peu près, se ressemblent. Vues de loin, leur aspect est pittoresque, ravissant ou grandiose. $\mathrm{Au}$ milieu de jardins verts et touffus court une enceinte, presque toujours délabrée, de hautes murailles et de tours qui s'écroulent; puis, c'est un fouillis de maisons à terrasses, au-dessus desquelles s'élancent les minarets des mosquées, élégants, avec leur triple boule dorée. Franchissez la porte et l'enchantement cesse : rues sans trottoirs, étroites, tortueuses, sombres, mal aérées, encombrées d'immondices, où l'on ne circule qu'à pied, à cheval ou àne - la voiture est inconnue - ; maisons basses, sans fenêtres sur la rue, ouvertes seulement sur une cour intérieure, sans numéros, les rues elles-mêmes ne portant pas de noms. Les rares monuments dont le style et l'architecture attirent les regards, tombent en ruines. D'ordinaire chaque ville en contient trois, toutes munies de leur enceinte particulière : $1^{\circ}$ la citadelle ou kasba renferme le palais du gouverneur, le magasin à poudre, l'arsenal, la prison, etc.; $2^{\circ}$ la ville proprement dite: là sont les bazars ou souks, où grouille la foule. Chaque rue, recouverte d'une méchante toiture, a sa spécialité : étoffes et tapis de laine, cuirs et maroquins; poteries et faïences vernies; joaillerie et métal repoussé, etc.; $3^{\circ}$ le quartier juif ou mellah.

Fez, Mequinez et Maroc ont rang de capitales, Fez avec 102.000 habitants, chiffre qui la classerait au $5^{\mathrm{e}}$ rang des villes de l'Afrique. Taza garde la route de Fez à Tlemcen. A Ouezzan réside un chérif très respecté. Tétouan, de l'intérieur des terres, regarde la Méditerranée. Sur le détroit de Gibraltar, Ceuta, tout à fait déchue, est espagnole; Tanger (46.000 h.), le principal en’repôt des marchandises européennes, est la résidence du 
corps diplomatique; sur la côte atlantique, Rabat, Casablanca et Mogador. - Au Sud de l'Atlas, le Tafilelt est un groupe très étendu d'oasis, un centre économique, politique et religieux tout à la fois, qui compte $300 \mathrm{ksour}$ ou villages fortifiés, autant que de jours dans l'année, disent les indigènes dans leur orgueilleuse naïveté. Le concours de la France a permis au sultan d'installer un représentant à Figuig.

XII. Mise en valeur. - Le Maroc demeure ce qu'il était il y a des milliers d'années.

C'est un pays d'agriculture et d'élevage. Mais l'agriculteur limite son travail à ses besoins; il gratte la terre, plus qu'il ne laboure, avec un morceau de bois recourbé, en guise de charrue; il ne la retourne pas, ne la fume pas; mais cette terre est si bonne, le climat si favorable que la moisson rapporte encore cent fois la semence. L'horticulture seule possède un système fort bien compris de canaux et de rigoles. L'élevage se pratique comme aux temps bibliques, et les résultats sont malgré tout excellents.

Restreinte, elle aussi, aux besoins du peuple, l'industrie est stationnaire. Avec des outils d'une incroyable simplicité, l'ouvrier continue à fabriquer des produits que depuis des siècles le monde musulman apprécie et dont l'originalité, le cachet et le goût sont reconnus des Européens eux-mêmes : tissus de laine ou soie, tapis moelleux et épais, broderies sur velours, cuirs, peaux de chèvres ouvragées, les « maroquins », orfèvrerie, poteries vernissées, long's fusils décorés d'arabesques, etc.

Les ressources minières sans doute sont abondantes, mais on les connaît à peine (fer, plomb, cuivre, sel gemme, eaux minérales et pétrole).

Le Maroc échange les produits de l'agriculture et de l'élevage (œufs, amandes, poils de chèvres et laines, fèves, pois chiches, graines de lin, bois d'adrar et de cèdre, alpiste, cire et bétail) contre des tissus, coton et soie, du sucre, du thé, des allumettes, des bougies, de la quincaillerie, etc. Le Commerce s'est élevé en 1906, d'après les rapports consulaires anglais, à 118 millions qui se répartissaient ainsi : France 47,3 millions (40 p. 100); Angleterre 37,9 millions (32 p. 100); Allemagne 
13,4 millions ( 11 p. 100); Espagne 5,6 millions, Belgique, Italie, etc. Les 8 ports ouverts au trafic international sont, par ordre d'importance : Tanger, Casablanca, Mogador, Mazagan, Larache, Safi, Rabat et Tetouan.

XIII. La question du Maroc. - Le Maroc est sans force, à l'état d'anarchie et de ruine, et pourtant seul des États du Maghreb, il a gardé son autonomie; sa meilleure garantie contre toute conquête, ce sont les jalousies mêmes des puissances européennes, dont il excite les convoitises par son climat favorable, par ses richesses naturelles de toutes sortes, encore inexploitées, par sa situation stratégique de premier ordre enfin sur l'Océan, la Méditerranée et le détroit de Gibraltar.

Voisine du Maroc sur des centaines de kilomètres, la France ne peut laisser aucune puissance européenne s'implanter aux flancs de sa grande colonie africaine, sans en compromettre gravement la sécurité; elle ne peut davantage admettre la rupture, à son détriment, de l'équilibre méditerranéen. Aussi a-t-elle adopté comme principes politiques l'intégrité territoriale du Maroc, la souveraineté du sultan et l'introduction dans l'Empire de réformes nécessaires pour tous, pour l'Empereur, pour elle-même, pour les puissances commerciales, pour la cause en un mot de la civilisation générale. - En échange de l'abandon de ses droits sur l'Égypte, elle s'était fait reconnaitre par la convention franco-anglaise d'avril 1904 le droit de procéder à des réformes administratives, économiques, financières et militaires au Maroc, dont elle recueillerait, comme de juste, les bénéfices, sans porter atteinte aux droits reconnus par les traités. L'Espagne adhéra à cet accord en octobre 1904. Mais au début de 1905 , l'Allemagne, qui pourtant avait reçu notification de ces accords, sans formuler de réserves, prétendit les ignorer et déclara qu'elle ne s'estimait nullement liẻe par eux. Aprè's le voyage de l'Empereur Guillaume II à Tanger (31 mars 1905), elle nous imposa la conférence d'Algésiras et fit ainsi doublement échec à notre politique : elle annula en fait nos engagements antérieurs et rendit stériles les sacrifices que nous avions consentis à l'Angleterre, à l'Espagne et même à l'Italie; “au système des protocoles de désintéressement " en notre faveur, elle substitua le principe de la participation de toutes les puissances au règlement des affaires marocaines. L'acte final de la conférence d'Algésiras (16 janvier-7 a vril 1906) reconnut les principes, que nous avions solennellement proclamés, de la souveraineté du sultan, de l'intégrité de son empire et de la liberté com. merciale; elle laissa hors de toute discussion et de tout examen les droits qui nous appartiennent dans la région frontière de l'Algérie; enfin, parmi beaucoup d'autres questions, elle résolut les deux plus graves, l'organit santion de la police des ports et d'une banque d'État. Mais depuis lons la question marocaine n'a pas cessé un seul jour d'ètre une des gyajes préoccupations du temps présent (expédition française de Casablañea, proclamation en 1908 d'un nouveau sultan, expédition de Fez, etc.). 


\title{
CHAPITRE V
}

\section{RÉGION DE L'ATLAS OU MAGHREB (suite)}

\author{
II. - ALGÉRIE
}

\section{SOM M A IRE}

I. Limites. - L'Algérie est une colonie française, limitèe au Nord par la mer Méditerranée, à l'Ouest par le Maroc, à l'Est par la Tunisie, au Sud enfin par le Sahara.

II. Superficie. $-199.971 \mathrm{kmq}$. pour l'Algérie proprement dite et $2.700 .000 \mathrm{kmq}$. pour le Sahara algérien.

III. Relief. - C'est l'Atlas qui donne á l'Algèrie sa structure en bandes longitudinales : $1^{\circ}$ Au Nord 1'Atlas tellien; $2^{\circ}$ Au Sud l'Atlas saharien; $3^{\circ}$ Entre les deux, les Hauts plateaux.

1. L'Atlas tellien forme la grande Kabylie (Djurdjura $2.300 \mathrm{~m}$ ), la petite Kabylie, en bordure de la mer; puis, dans l'intérieur, le massif du Ouarsenis et celui des Biban ou des Portes de fer.

Il encadre des plaines basses, plaine d'Oran, plaine d'Alger ou Mitidja, plaine de Bône, et des plaines élevées, plaine de Tlemcen, plaine de Sidi-bel-Abbès, plaine de Sétif.

$2^{\circ} L^{\prime}$ Atlas saharien porte, au massif de l'Aurès (2.328 m.), la plus haute cime de toute l'Algérie.

$3^{\circ}$ Les Hauts plateaux sont la région des steppes (altitude mpyenne $800 \mathrm{~m}$ ); ils sont déprimes et forment des bassins sans écoulement, les chotts.

IV. Climat. - L'Algèrie a un climat méditerranèen; l'hiver est la saison des pluies, l'ète la saison sèche.

1. Dans le Tell, à proximité de la mer, les écarts de température sont faibles; les pluies tombent plus abondantes vers l'Est.

$2^{\circ}$ Sur les Hauts plateaux, plus sees, les ècarts deviennent trés sensibles.

3० Le Sahara, très sec, est le " pays de la soif ".

V. Hydrographie. - Les oueds sont des cours d'eau inconstants : sujets a des erues soudaines, mais courtes, ils tarissent pendant l'eté; aucun n'est navigable.

1. Les cours d'eau du Tell vont à la Méditerranée : la Tafna, la 
Macta; le Chèlif le plus long est le seul qui soit né dans l'Atlas saharien; l'Oued Sahel, l'oued el Kebir, la Seybouse.

2. Sur les Hauts plateaux, les chotts sont des nappes d'eau saumâtre, qui se dessechent et se couvrent d'une croûte de sel.

$3^{\circ}$ Les Oueds de l'Atlas saharien s'échappent par des gorges vers le désert, où ils disparaissent totalement.

VI. Côtes. - Rocheuses, sans être découpées, les côtes n'ont pas de ports naturels, seulement des rades ouvertes au Nord : rades d'Oran, d'Alger, de Bougie, de Philippeville et de Bône.

VII. Vie végétale. - La végétation, mèditerranéenne, comme le climat, se dèveloppe en hiver et s'arrête en étè.

1. Le Tell est la région des arbres a feuilles persistantes (olivier, chêne liège) et des cultures (céréales, arbres fruitiers, cultures maraîchères).

$2^{\circ}$ Les Hauts plateaux sont la région des steppes ou de l'alfa.

3. Le Sahara n'a d'eau, d'arbres et de cultures que dans les oasis.

VIII. Vie animale. - Les animaux sauvages disparaissent à mesure que la colonisation s'ètend.

Le pays, trop sec pour les bêtes à cornes, convient très bien au mouton, à la chèvre. Le cheval est réputé. Le mulet et l'âne sont la providence des indigènes.

Le chameau est l'animal caractéristique du désert.

IX. Géographie humaine. - L'Algèrie proprement dite a une population de 4.786 .000 habitants.

Sur ce chiffre, 4 millions sont des indigènes : les Berbères et les Arabes qui diffèrent par leur genre de vie; les Maures mèlangès de Berbères et d'Arabes; les Israèlites.

Les Europèens ne sont que 719.000 , dont 449.000 Français et 166.000 étrangers, surtout des Espagnols.

X. Gouvernement et administration. - L'Algérie forme une colonie; à sa tête est un Gouverneur général.

Comme la France, elle est divisèe en départements, au nombre de trois.

X1. Villes. - $1^{\circ}$ Province d'Alger. - Alger, capitale de la colonie $(138.000$ h.), est un grand centre commercial, un port animé et une ville d'hiver.

Blida, entourée d'une forêt d'orangers.

$2^{\circ}$ Province d'Oran. - Oran (100.500 h.), chef-lieu du département, est le second port algérien; Tlemcen, Sidi-bel-Abbès au centre de plaines trés fertiles.

$3^{\circ}$ Province de Constantine. - Constantine, chef-lieu du département, sur un roc escarpé, a pour port Philippeville; Bône et Bougie sont aussi des ports. - Setif et Guelma, centres agricoles. - Batna et Tébessa gardent les pentes Nord de l'Aurès. - Biskra est une oasis saharienne.

XII. Hise en valeur. - L'Algérie est essentiellement un pays d'agriculture et d'élevage. Elle récolte des céréales, du vin, des olives, des primeurs et des fruits; elle èlève surtout le mouton.

Le sol abonde en minerai de fer et en phosphates. Mais l'industrie manufacturière est peu dèveloppée faute de houille; elle traite uniquement les produits agricoles.

$$
\text { G. Lispagnol ex M. Fallex. - Afrique. }
$$


Les voies commerciales suivent deux directions :

1. De l'Ouest a l'Est, la voie ferrée Tlemcen-Oran vers Alger et dAlger sur la Tunisie.

$2^{\circ}$ Sur cette grande artère se greffent, d'une part, les lignes qui aboutissent aux ports, Bougie, Philippeville et Bône, et de l'autre les lignes dites de pénètration, Colomb-Béchar, Biskra, Tébessa.

Le commerce de l'Algèrie dépasse 1 milliard et se fait pour les trois quarts avec la France.

L'Algèrie est une seconde France, la France africaine.

\section{DÉ VEL OPPEMEN T}

L'Algérie est la plus belle des colonies françaises de climat tempéré; à 24 heures de Marseille, elle complète et prolonge la France par delà la Méditerranée.

I. Limites. - L'Algérie occupe la portion centrale de l'Atlas, entre le Maroc à l'Ouest et la Tunisie à l'Est. Nous savons déjà ce qu'il faut entendre par frontière marocaine; quant à la frontière tunisienne, elle n'a plus qu'une valeur administrative et douanière, depuis que la Tunisie est sous le protectorat de la France. Vers le Sud l'Algérie finit avec les dernières chaînes de l'Atlas; il est bien vrai que notre occupation s'étend fort au delà, mais le Sahara, qualifié d'algérien, n'est plus l'Algérie.

II. Superficie. - L'Algérie proprement dite couvre $199.971 \mathrm{ki}$ lomètres carrés (France, 536.464) et le Sahara algérien 2.700.000.

III. Relief. - Le relief de l'Algérie, très tourmenté, est, comme celui du Maroc, tout entier constitué par le système de I'Atlas.

Les plissements affectent surtout des terrains jurassiques et crétacés; ils datent de l'époque tertiaire. Il n'y a de terrains anciens que le long de la mer, à l'état de débris : le reste s'est abîmé dans la Méditerranée sous l'effort des plissements; l'effondrement fut accompagné de phénomènes volcaniques. L'analogie est grande avec l'Apennin, les roches anciennes et les appareils éruptifs qui jalonnent en Italie la mer Tyrrhénienne.

Les chaines de l'Atlas s'alignent en échelons du Nord au Sud : au Nord, l'Atlas méditerranéen et tellien; au Sud, l'Atlas saharien; entre les deux une région de hautes terres. L'Algérie est dépourvue par suite de centre naturel. On la découpe habi- 
tuellement en bandes horizontales : le Tell et les Hauts plateaux, puis au delà le Sahara; division très simple, exacte en général, qui permet de s'orienter au milieu de la complexité du relief, mais qui n'a rien d'absolu. L'Atlas tellien et l'Atlas saharien, par

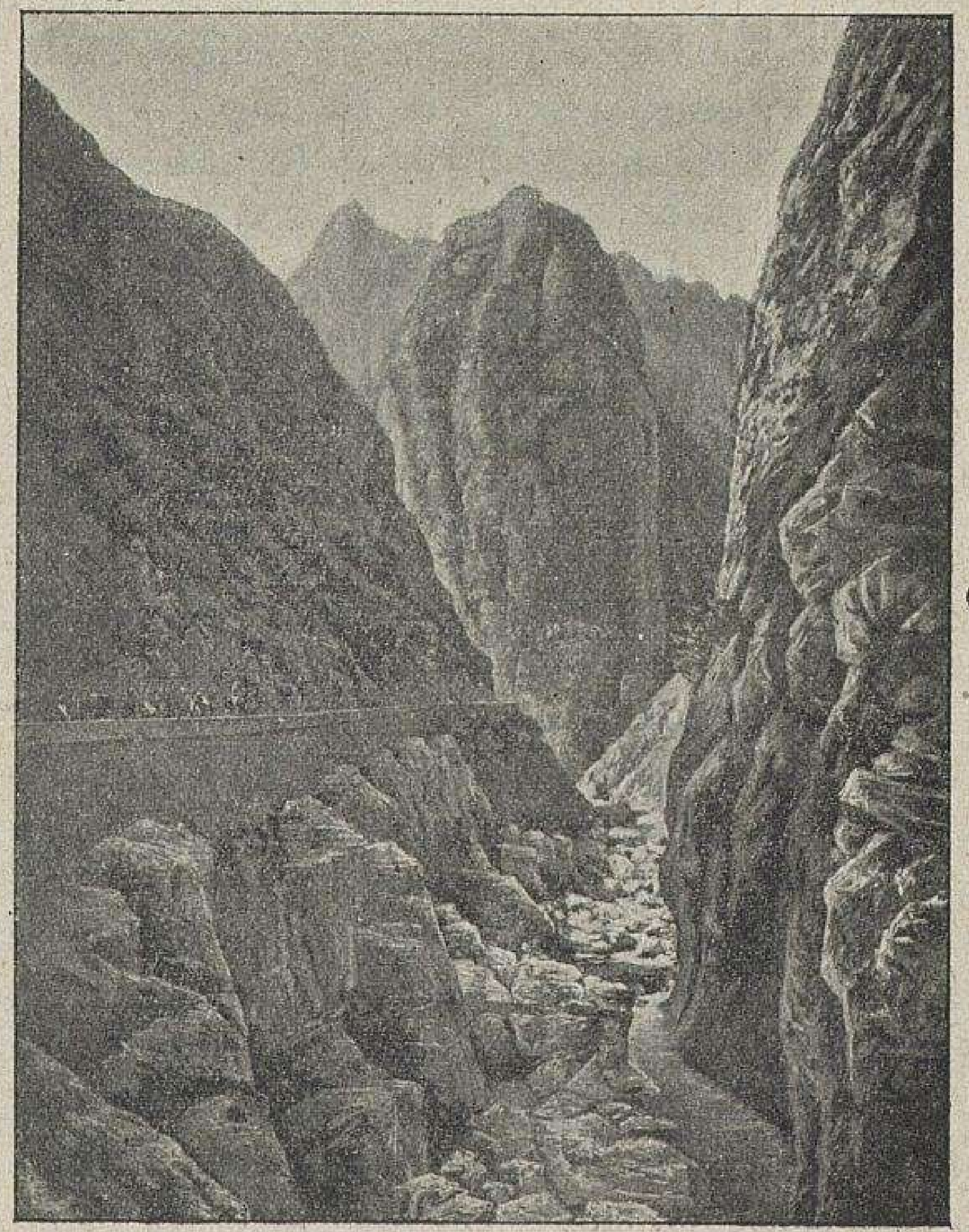

GORGES DU CHABET-EL-AKRA.

(Phot. ND.) .

Route de Bougie à Sétif, par la petite Kabylie.

exemple, ne sont pas parallèles : très écartés à l'Ouest, ils se rapprochent peu à peu vers l'Est; l'Atlas saharien, orienté Sud-Ouest-Nord-Est, finit par relayer dans la province de Constantine les plissements telliens qui ne dépassent pas la ligne Bône-Guelma.

I. L'Atlas tellien aligne une série de chaînes ou de massifs depuis la mer jusqu'aux Hauts plateaux. $1^{\circ}$ Les chaînes Lixto- 
RALES continuent d'abord le Rif marocain : c'est le Dahra, dos de montagne entre le Chélif et la mer; puis la grande Kabylie, massif puissant, bien individualisé, aux cimes aiguës, enveloppé par le demi-cercle du Djurdjura, qui porte à 2.308 mètres le Lalla Khedidja, couvert de neiges de novembre à mai; puis la petite Kabylie des Babor, entaillée par un défilé de 7 kilomètres, le Chabet-el-Akra; enfin le massif de l'Edough. $-2^{\circ}$ Mais ces massifs n'ont pas la continuité rigide du Rif marocain; ils s'interrompent pour faire place à des plaines LitTorales ou sublittorales : plaines au Sud d'Oran, vallée du Chélif, Mitidja au Sud d'Alger, vallée du Sahel qui finit à Bougie, plaine de Bône. $-3^{\circ}$ Dans l'arrière-pays, les plissements recommencent à s'étager : massif du Ouarsenis, nœud orographique des plus remarquables ( $1.995 \mathrm{~m}$. au Kef Sidi Amar), chaîne des Biban ou Portes de fer, monts de Constantine. - $4^{\circ}$ Ces massifs encadrent, comme les précédents, des plaines, mais des plaines qui cette fois sont élevées : plaines de Tlemcen, de Sidi-bel-Abbès et de Mascara, de Sétif, bassins de Constantine et de Guelma.

II. L'Atlas saharien continue le massif de Figuig; ses chaînons longs et minces, décharnés et calcinés, sont la barrière septentrionale du désert. Ils portent différents noms : monts des Ksour, Djebel Amour, monts des Oulad Naïl et du Zab, massif de l'Aurès, très puissant, qui porte le plus haut sommet de l'Algérie (le Chelia, $2.328 \mathrm{~m}$.), enfin monts de Tébessa.

III. - L'Atlas tellien au Nord, l'Atlas saharien au Sud enserrent les Hauts plateaux. On appelle ainsi des plaines élevées, où l'eau courante, faiblement alimentée, n'a pu accomplir son ouvre d'érosion et de déblaiement; elles se creusent en divers points dans le sens de la longueur et donnent naissance à des bassins intérieurs, à des cuvettes sans écoulement, à des chotts. Plus larges et plus hauts dans la province d'Oran que dans celle d'Alger, difficiles à distinguer du Tell dans la province de Constantine, les Hauts plateaux constituent par leur sécheresse et leur aridité une région de steppes; ils participent déjà du régime désertique, si bien qu'on les appelle le « Petit désert $\gg$.

IV. Climat. - Par sa latitude, l'Algérie appartient à la 
zone tempérée chaude : méditerranéen dans son ensemble, c'està-dire caractérisé par des pluies d'hiver, par un été sec, le climat diffère dans le Tell, sur les Hauts plateaux et vers le Sahara, et dans chacune de ces régions l'altitude, l'orientation, la distance de la mer déterminent des contrastes.

$1^{\circ}$ Tell. - L'influence de la mer est prépondérante; sur le littoral la température est égale et l'hiver très doux; de même sur les plaines basses, le thermomètre ne s'élève pas beaucoup, mais la chaleur humide de l'été est déprimante. Sur les montagnes, l'hiver est rude, neigeux, et l'été très chaud. Les pluies véhiculées par les vents d'Ouest et de Nord-Ouest croissent de juillet à décembre et décroissent de janvier à juillet; elles deviennent plus abondantes vers l'Est, où les vents se chargent de plus de vapeur d'eau sur la Méditerranée élargie. La saison sèche coïncide avec les vents d'Est et de Nord-Est.

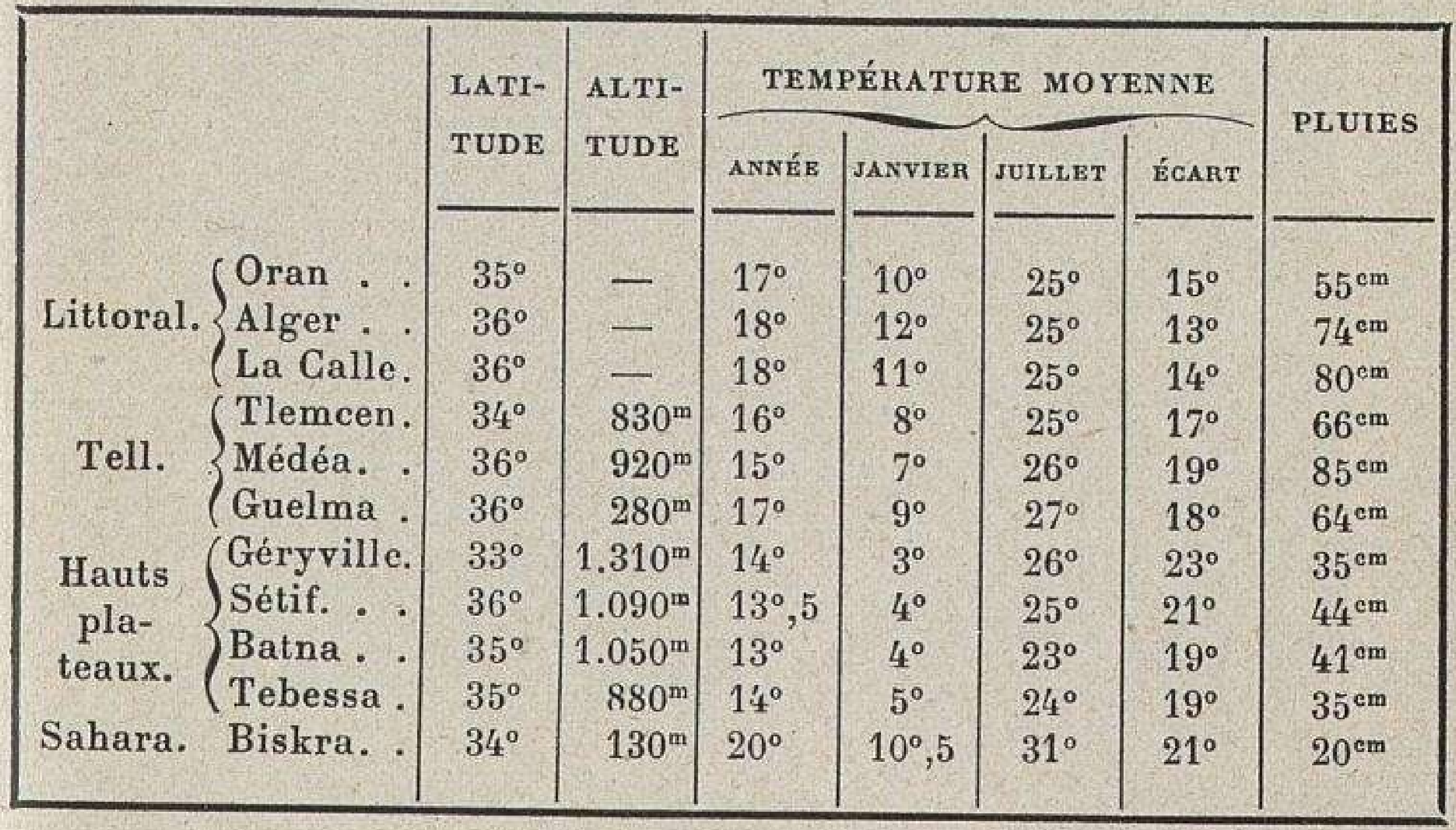

$2^{\circ}$ Hauts plateaux. - L'influence du continent l'emporte sur l'influence de la mer et la sécheresse prédomine; les écarts sont sensibles d'une saison à l'autre et du jour à la nuit, et ce climat inégal est sain, vivifiant. En hiver la neige tombe fréquemment et le thermomètre descend jusqu'à $-10^{\circ}$; en été il monte à l'ombre à $+40^{\circ}$, et le rayonnement nocturne est intense.

$3^{\circ}$ Nous verrons qu'au Sahara la sécheresse s'exagère, les pluies deviennent l'exception : c'est le "pays de la soif ». Le ciel est pur de nuages, mais souvent voilé de poussières; les 
écarts sont tels que Biskra a des froids nocturnes de $-5^{\circ}$ et des chaleurs diurnes de $+45^{\circ}$.

V. Hydrographie. - Les cours d'eau dépendent du relief et du climat. Or l'Algérie ne possède pas de grandes vallées; les rivières ou oueds ont un cours saccadé, elles suivent les dépressions, se coudent brusquement et font brèche à travers les chaînons montagneux qui leur barrent la route. Il n'est pas rare alors que le même cours d'eau porte successivement autant de noms qu'il traverse de compartiments distincts. - Et ces oueds sont des torrents : après les grandes chutes de pluies, ils gonflent instantanément, ravinent leurs berges et roulent des eaux sauvages, jaunâtres et terreuses; mais ces crues soudaines ne durent pas. Pendant l'été, à moins de tarir complètement, l'eau traîne un mince filet dans un lit, trop large, de sables et de cailloux, ou bien s'amasse et séjourne dans des trous ou dans des flaques. Jamais navigable, l'oued ne suffit pas même à l'irrigation, si l'on ne prend soin de capter les crues dans des réservoirs; on barre pour cela les vallées et l'eau est parcimonieusement distribuée, lors de la saison sèche, aux plaines situées en aval.

$1^{0}$ Versant méditerranéen. - En général les cours d'eau descendent des chaînes du Tell et du bourrelet des Hauts plateaux; seul le Chélif fait exception.

La Tafna a pour bassin d'alimentation la haute plaine de Tlemcen; la Macta, celle de Sidi-bel-Abbès. Le Chélif traverse toute la largeur des Hauts plateaux et descend par les défilés de Boghar dans le Tell; il se recourbe alors autour du massif du Ouarsenis qui lui envoie des torrents nombreux, et sa vallée s'allonge d'Est en Ouest au pied du Dahra, en un couloir étroit qui ne s'élargit, pour former plaine, qu'au voisinage de la mer. L'Oued Isser est la rivière centrale de la grande Kabylie; l'Oued Sahel en forme le fossé méridional et fertilise la vallée qui s'ouvre sur la rade de Bougie. L'Oued Agrioun n'est ni long ni abondant; mais il force un défilé célèbre, le Chabet-el-Akra, long de plus de deux lieues, entre des montagnes à pic de 1.500 et 1.600 mètres. Le Roummel coule au fond de gorges qui découpent le rocher de Constantine et prend le 
nom d'oued el Kebir, à travers la petite Kabylie, jusqu'à la mer. De tous les oueds algériens, la Seybouse est le moins inégal; après avoir parcouru le bassin de Guelma, elle finit dans la plaine de Bône, et est capable, fait extraordinaire, de

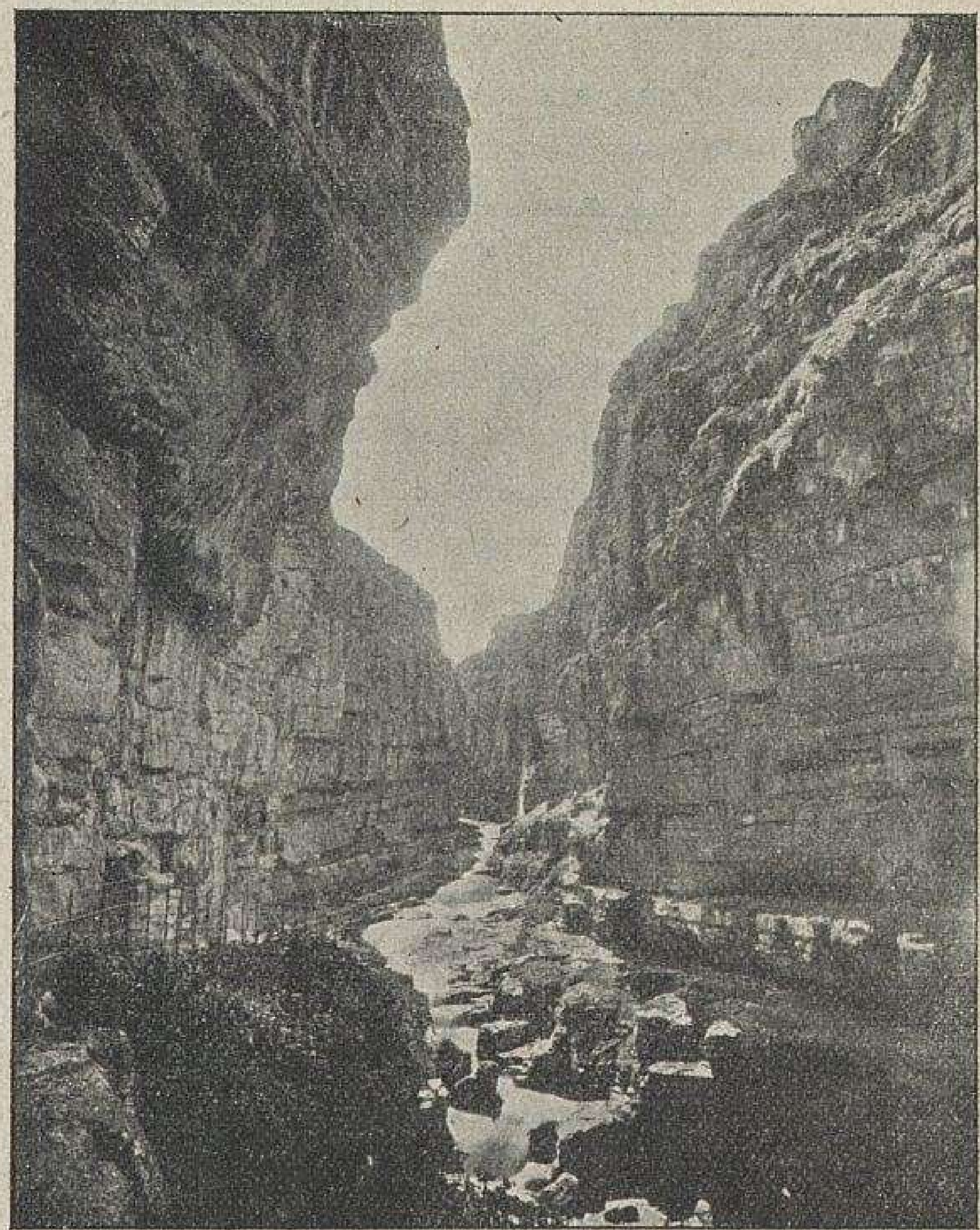

GORGES DU ROUMMEL.

(Phot. ND.)

Constantine sur le roc, à droite.

porter des barques à son embouchure. La Medjerda, née en Algérie, gagne vite la Tunisie.

$2^{\circ}$ Hauts plateaux. - Le caractère temporaire des oueds s'accentue encore et les eaux, lorsqu'elles coulent, ne trouvant pas d'issue, s'amassent dans les dépressions des Chotts. Les chotts, les sebakh (pluriel de sebkha) ne sont pas des lacs, mais des nappes peu profondes d'eau vaseuse, saumâtre, jamais potable. En été, l'oued tarit, le chott se dessèche, et à sa place 
subsistent seulement des couches de sel, des cristaux de gypse, que le soleil fait briller d'éclats éblouissants.

Dans la province d'Oran, les deux Chotts, Gharbi(occidental) et Chergui (oriental); - dans la province d'Alger, les deux Zahrez; - dans la province de Constantine, le Hodna.

$3^{\circ}$ Versant saharien. - Entre les chaịnons de l'Atlas saharien, les cours d'eau arrosent de petits bassins alluvionnaires où se fixent des populations sédentaires, puis s'échappent par des défilés tellement étroits, souvent, qu'il n'y a de place que pour leur lit.

VI. Côtes. - Longues d'environ 1.100 kilomètres, les côtes sont orientées d'Ouest en Est. De la mer, on n'aperçoit que des roches, des montagnes et des falaises abruptes; ni découpures ni articulations; point d'abris naturels, pas d'habitants. De distance en distance seulement s'ouvrent des golfes larges, en forme de croissant; c'est derrière leur pointe rocheuse Nord-Ouest que se blottissent les villes et les ports : mais il leur a fallu se défendre contre les vents et la mer par la construction de môles et de digues. Ces rades sont au nombre de six : Oran, Arzeu, Alger, Bougie (fort belle, à l'abri du cap Carbon), Stora et Philippeville, enfin Bône.

VII. Vie végêtale. - Les formes végétales font transition entre la flore méditerranéenne, près de la mer, et la flore désertique. La plante et l'arbre actifs en hiver se reposent en été; c'est le contraire sur les montagnes.

10 Tell. - Les arbres sont à feuilles persistantes; le plus caractéristique est l'olivier : il en existe des forêts. Lentisques, palmiers nains, arbousiers, genévriers, etc., forment des broussailles, un vrai maquis, le pin parasol de petits bouquets de bois; sur les parties découvertes se développent les herbes odorantes, menthe, lavande, thym, serpolet, romarin. Les sommets portent des forcts, chênes verts et surtout chênes lièges, pins d'Alep, parfois de beaux cèdres (à 1.200 et $1.400 \mathrm{~m}$.). Le long des cours d'eau s'alignent des saules, des tamaris, des lauriers roses, des eucalyptus importés d'Australie. 


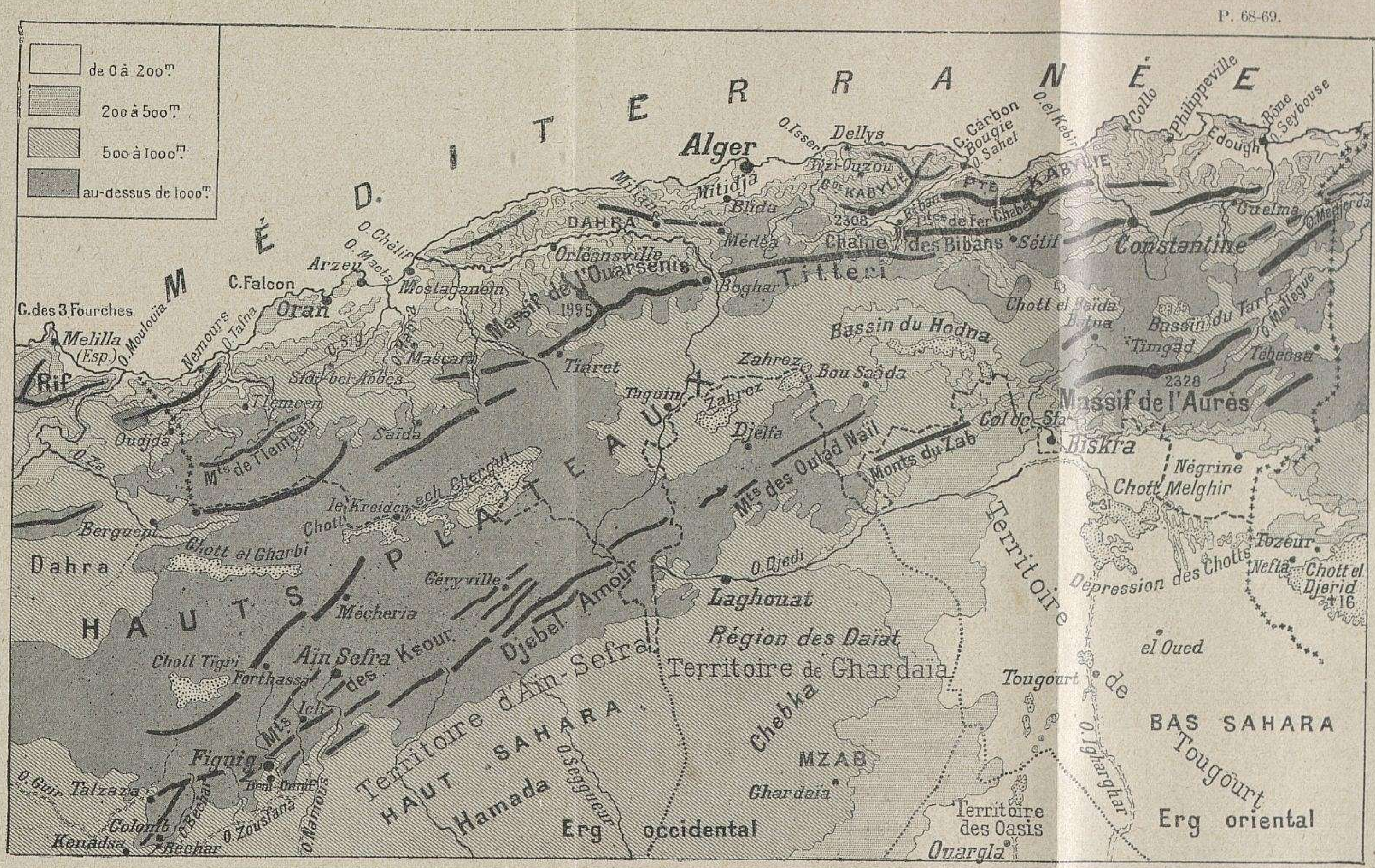

LxSPaginol Ex FaLLeX. 
Les cultures consistent en céréales (l'orge qui reàoute moins la sécheresse, le blé dur dont les indigènes fabriquent le couscous, le blé tendre semé par les Européens) et en vignobles. Beaucoup d'arbres fruitiers, orangers de Blida, figuiers de Kabylie, etc. Les plaines bien irriguées sont réservées aux cultures maraíchères (fèves, pois, asperges, primeurs

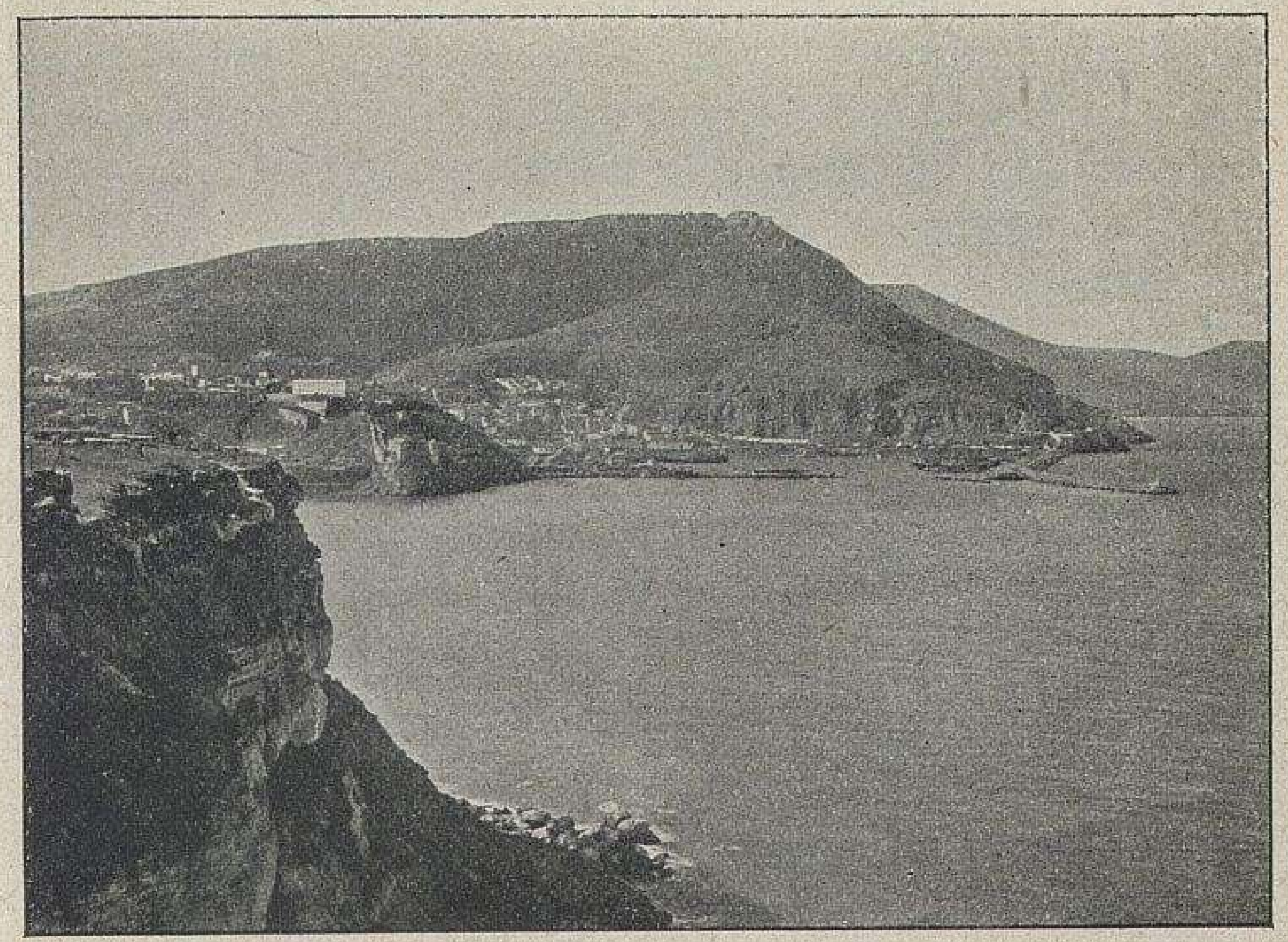

TYPE DE CÔTE ALGÉRIENNE : ORAN.

(Phot. ND.)

Le port s'abrite au pied des falaises; en mer, de longues jetées.

de tout genre); toujours l'aloès et le figuier de Berbérie servent de clôtures aux vergers.

$2^{\circ}$ Hauts plateaux. - Trop secs pour porter forêts et cultures, les Hauts plateaux sont la région des steppes herbeuses. Après les pluies, les steppes verdissent, les nomades y conduisent leurs troupeaux, très friands de pâturages salins. La graminée caractéristique est l'alfa; elle se plait dans les terrains secs et s'étend, comme une mer uniformément grise, sur de vastes espaces; sa pulpe nourrit les chevaux et les chameaux, et sa tige bottelée sur place est expédiée dans les ports, surtout à Oran. 
$3^{\circ}$ Sahara. - Nous dirons, au chapitre VII, quelles sont ses formations végétales; seules les oasis sont cultivées.

VIII. Vie animale. - Les animaux sauvages, l'éléphant, l'ours, le lion ont disparu à mesure que les colons défrichaient le sol et la brousse, cherchant asile dans les forêts ou au désert. La panthère se rencontre encore; bien plus communs sont le chat sauvage, l'hyène, le chacal et le renard, et parmi les herbivores, la gazelle, le mouflon. Les gorges de la Chiffa au Sud d'Alger et la Kabylie abritent encore des singes, des magots. Le criquet pèlerin, les sauterelles qui voyagent par nuée, sont une plaie pour l'agriculture.

Dans ces pays de sécheresse, le manque de prairies rend impossible l'élevage du gros bétail; les vaches sont mauvaises laitières et les boufs de petite taille. C'est le mouton, c'est la chèvre qui se plaisent partout, mais surtout sur les steppes. Le cheval arabe, fin et résistant, jouit d'une réputation méritée; le mulet, l'âne de petite taille ou bourricot, tous deux durs à la fatigue et aux coups, sont la providence de l'Arabe; enfin on élève le chameau sur " le petit désert » des Hauts plateaux.

\section{Géographie humaine. - La population de l'Algérie} se compose d'indigènes (4.067.000) et d'Européens (719.000).

$1^{\circ}$ Les indigènes sont les Berbères et les Arabes.

Berbères et Arabes portent le même costume : un vêtement de dessous qui laisse à nu les jambes et les bras, et le burnous de laine, vêtement de dessus, dans lequel ils se drapent. Tous sont très sobres, se nourrissent de laitage, de fruits, de dattes, de café et d'une farine granulée, fort épicée, appelée couscous. - Les Berbères descendent des habitants primitifs (les Numides des Romains); la conquête arabe les a refoulés dans les montagnes, par exemple dans la Kabylie (Kabyles) et dans l'Aurès (Chaouia). Sédentaires, ils habitent des villages, comme nos paysans, mais des villages perchés au sommet de la montagne, véritables postes-vigies, fort pittoresques de loin avec leurs toits en tuile rouge. Rues et intérieurs sont des plus malpropres. Tout à l'entour, la moindre parcelle de terre est cultivée, au moyen d'une charrue très primitive, la même dont on se servait au temps des Romains. Mais le Berbère n'a pas seulement l'amour de la terre; c'est encore un artisan, habile à beaucoup de métiers, potier, forgeron, tourneur de bois, ete, bien que son outillage soit des plus simples. A des jours fixes se tiennent des marchés où les transactions sont des plus animées, où grouillent bêtes et gens. La plaine enfin attire aussi le Berbère : il émigre passagèrement, se fait colporteur, ouvrier 
agricole au temps de la moisson, terrassier, eic., puis il regagne sa montagne quand il a amassé un petit pécule. Les communautés kabyles sont des démocraties, régies par l'assemblée des citoyens égaux entre eux (djemâa) et par la coutume.

Tout autre est l'Arabe; en général il est nomade, mais beaucoup ont adopté la vie sédentaire. C'est la race conquérante. L'Arabe de grande tente, appelé aussi Bédouin, mène la vie pastorale et guerrière des anciens patriarches. Il habite sous la tente en poils de chameau et se déplace

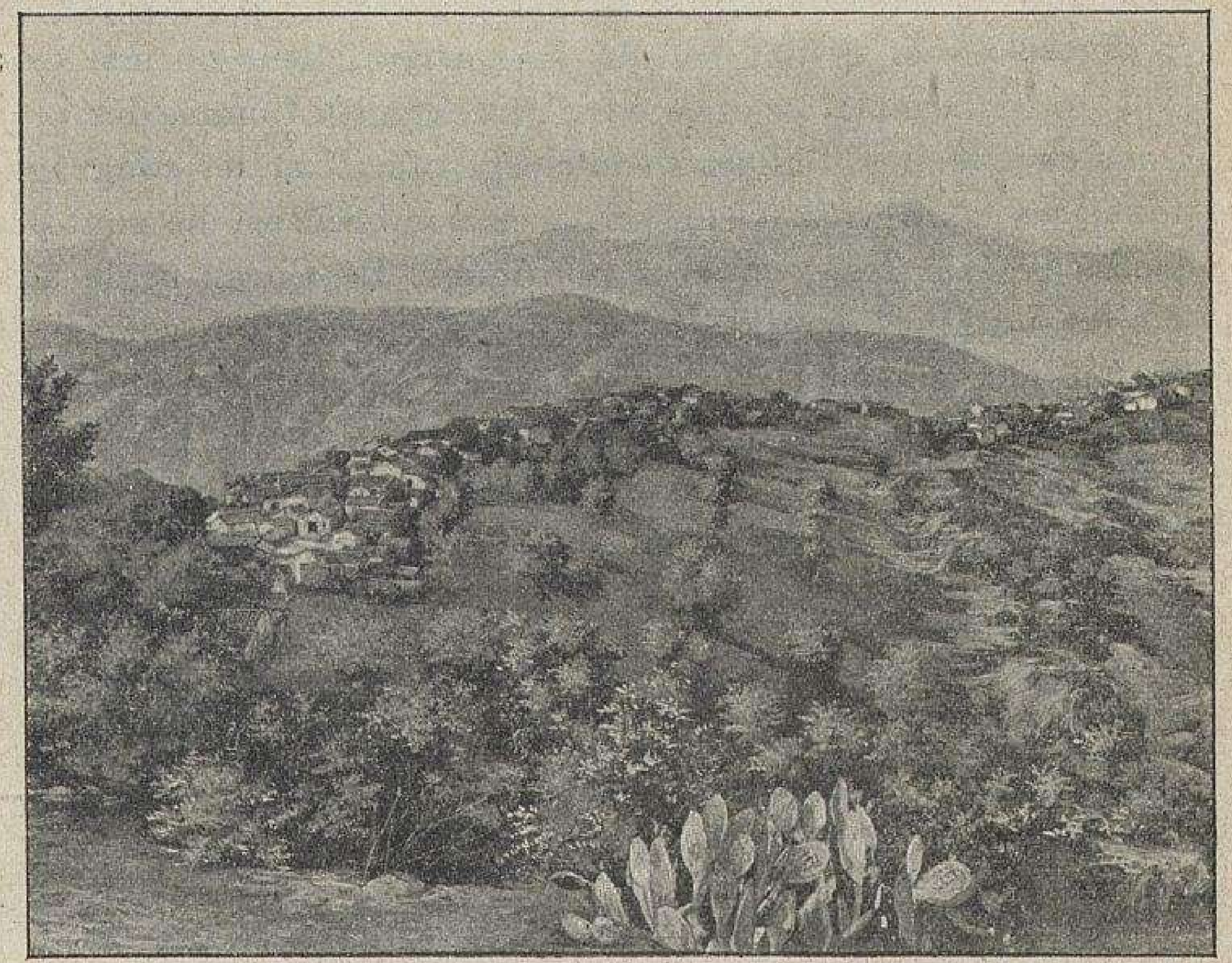

DANS LA GRANDE KABYLIE.

(Photographie J. Geiser.)

Type de village kabyle (Taourirt Amokran) : il aligne ses maisons aux toits rouges sur la crête de la montagne. Tout à fait en avant un figuier de Berbérie, cactée aux raquettes charnues, aplaties, garnies de poils et d'aiguillons.

avec les saisons suivant un parcours toujours le même. Son luxe, ce sont les troupeaux, les chevaux, etc. Il méprise la culture de la terre et aime l'odeur de İa poudre. A la femme, que l'on traite comme un être inférieur, à l'égal d'une bête de somme, on laisse les travaux pénibles. L'homme est brave, hospitalier, mais très fourbe. Un ensemble de tentes forme un douar; plusieurs douars obéissent à un cheikh; au-dessus enfin, la tribu est commandée par le caïd. C'est une société tout aristocratique. Les Arabes sédentaires se construisent des habitations en pisé, au toit plat, qui réunies forment des ksour ou villages. Les plus misérables habitent des huttes en branchages recouvertes de roseaux, des gourbis. Médiocre agriculteur, l'Arabe pratique tous les métiers, toujours avec des instruments rudimentaires; mais le temps ne compte pas pour lui et, à force de 
patience, il produit des ocuvres élégantes et solides, tissus, broderies, tapis, poteries, meubles incrustés, cuirs, cuivres ciselés, etc.

Les Maures sont mélangés de Berbères, d'Arabes et d'Européens; ils habitent les villes et excellent au négoce, mais n'ont pas les belles qualités de l'Arabe.

Tous, Berbères, Arabes et Maures sont unis par la communauté de la langue et de la religion. En bons musulmans, ils sont résignés et à tout ce qui leur arrive, heur ou malheur, répètent la formule : c'était écrit! (Mektoub). Comme les religions chrétiennes, l'Islam a son clergé officiel et ses congrégations, ses confréries. Celles-ci, très nombreuses, ne sont pas confinées dans les frontières politiques. Le Coran règle à la fois les pratiques religieuses et toute l'organisation sociale, la vie publique comme la vie privée : il est une Bible et un Code.

Les Israélites sont un élément important de la population indigène (env. 65.000); un décret du 24 octobre 1870 les a naturalisés en bloc : tous sont donc citoyens français.

Des persécutions auxquelles ils étaient en butte depuis des siècles, les Israélites ont gardé des habitudes de dissimulation et d'humilité obséquieuse. Et comme ils avaient à craindre toujours d'être dépouillés, ils n'amassaient de richesses que celles qu'ils pouvaient facilement cacher: l'argent. Avec l'argent qu'ils ont amassé, ils sont banquiers, hommes d'affaires et font l'usure.

Les Nègres, qu'on rencontre en petit nombre, ont été importés du Soudan, au temps où se faisait le commerce des esclaves. Fort misérables, ils exercent tous les métiers.

$2^{\circ}$ Les Européens constituent une minorité en Algérie : en face des 4 millions d'indigènes, ils ne sont pas plus de 719.000. Les Français d'origine ou les Français naturalisés forment à peu près les $2 / 3$ (449.000). Les étrangers (166.000) sont surtout des Espagnols (117.000) et des Italiens (33.000), uassés respectivement dans les provinces voisines de leur pays d'origine, celle d'Oran et celle de Constantine.

X. Gouvernement et administration. - L'Algéric est une colonie de la France; à sa tête, le Gouverneur général (assisté d'un conseil de gouvernement, d'un conseil supérieur et de trois délégations financières) est investi d'attributions 
étendues. L'Algérie n'est plus assimilée à la France : elle a son budget spécial, autonome.

Mais l'administration reproduit en partie celle de la France : trois provinces ou départements (Oran, Alger, Constantine), divisés en arrondissements et communes, avec préfets, souspréfets et maires, et représentés au Parlement par 3 sénateurs et 6 députés; les citoyens français sont seuls électeurs.

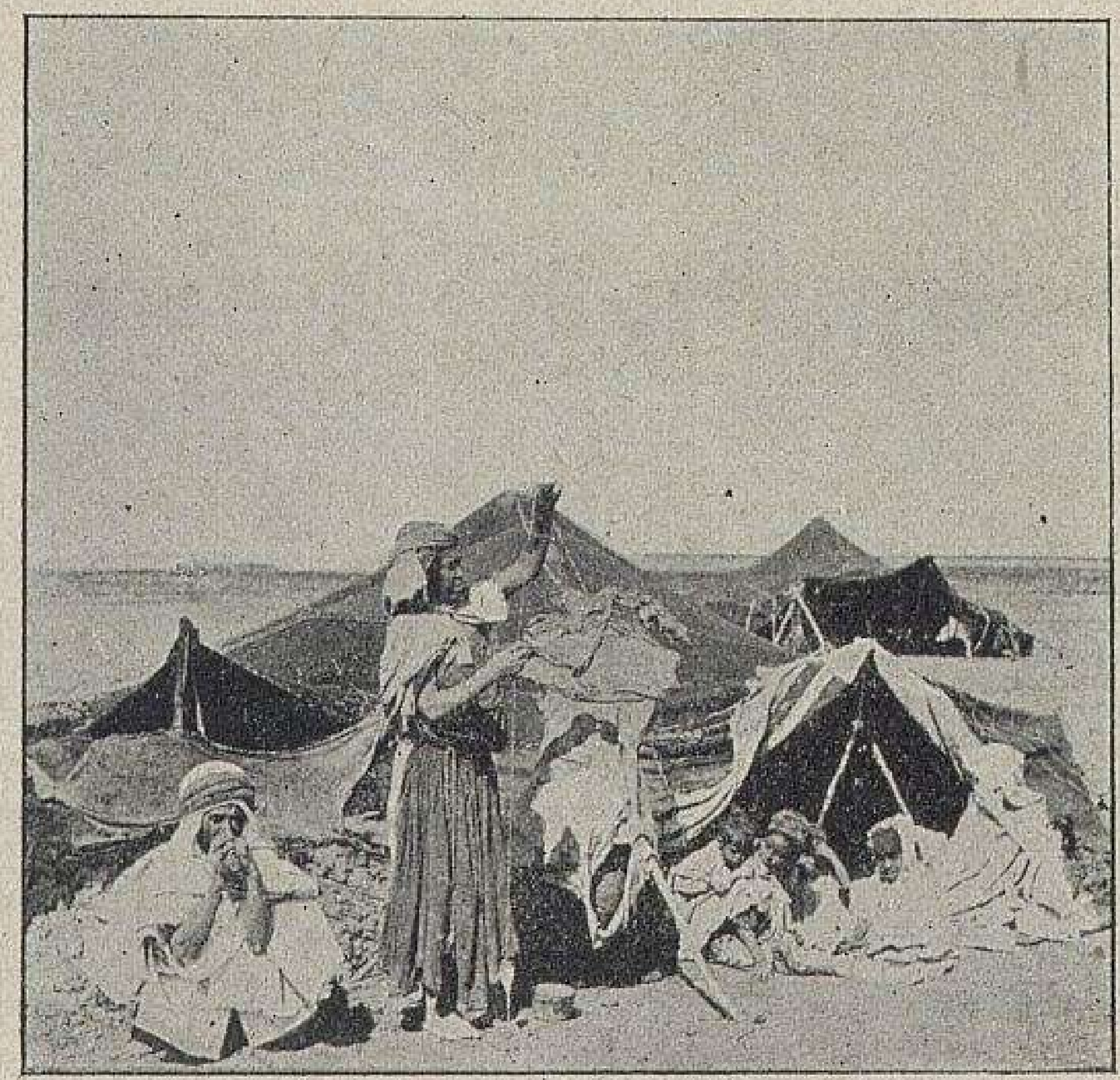

CAMPEMENT DE NOMADES SAHARIENS.

Debout devant la tente, en poils de chameaux, la femme file; l'homme est assis, inoccupé. (Photographie de M. Dybowski.)

XI. Villes. $-1^{\circ}$ Province d'Alger. - Alger, capitale de la colonie (138.000 h.), sur la Méditerranée, est à une distance. sensiblement égale d'Oran et de Constantine et à 750 kilomètres de Marseille.

Vu du large, le panorama de la ville est merveilleux : sous un ciel très pur, elle émerge des flots bleus de la mer, toute blanche au milieu de la verdure sombre des environs. Son port, abrité par deux puissantes digues, est dominé par les arcades qui portent en terrasse le boulevard de la République et de hautes maisons européennes. Par derrière, en amphithéâtre sur la colline, monte la ville arabe, avec ses maisons blanchies à la chaux, ses ruelles étroites, tortueuses et grimpantes. Tout en haut la Kasba, l'ancienne forteresse turque, sert aujourd'hui de caserne. Et 
ce sont des mosquées, des palais, des bouquets de palmiers. La banlieue s'étire de chaque côté du rivage en belles promenades et en jolies villas.

La douceur du climat attire ehaque hiver les étrangers. Centre commercial où affluent tous les produits algériens, Alger, le second des ports français pour le mouvement des navires et le tonnage de jauge, est le premier port charbonnier de la Méditerranée.

Au Sud de la Mitidja et au pied de l'Atlas, Blida (17.000 h.) est une ville délicieuse, bien arrosée, qui s'enveloppe d'une forêt d'orangers, de mandariniers, de citronniers et d'oliviers. Les chefs-lieux d'arrondissement sont : Tizi-Ouzou, le centre de la grande Kabylie, que domine Fort-National, Médéa, Miliana, et dans la vallée du Chélif, Orléansville.

$2^{\circ}$ Province d'Oran. - Le chef-lieu du département, Oran (100.500 h.) est, après Alger, le plus grand port; construite sur une large baie que domine le roc fortifié de Mers-el-Kébir, elle étage ses maisons sur les deux flancs d'un ravin, et, trop à l'étroit dans son mur d'enceinte, déborde à l'Est et au Sud.

Les chefs-lieux d'arrondissement sont ensuite : Mostaganem, ãu débouché de la vallée du Chélif; Tlemcen (24.000 h.), dans un site pittoresque, à 800 mètres d'altitude, ville très ancienne, autrefois capitale de royaumes arabes et maures, entourée d'une longue muraille garnie de tours carrées; de son passé splendide, elle a conservé quelques édifices, des mosquées d'une grande richesse; Sidi-bel-Abbès (24.500 h.), de fondation récente (1843), jolie ville, dans une plaine merveilleusement fertile; enfin Máscara (19.000 h.), perché sur deux mamelons qui dominent une haute plaine.

$3^{\circ}$ Province de Constantine. - Constantine (47.000 h.), chef-lieu du département, occupe un promontoire escarpé, un vrai nid d'aigle, au-dessus des gorges profondes du Roummel, qui descend en cascades et creuse des voûtes en tunnel. Elle n'était abordable, avant la construction d'un pont sur le ravin, que par un isthme étroit. Le quartier européen aligne ses rues droites; le quartier indigène a des ruelles en zigzag et en escalier, souvent voûtées et toujours sales. Ce fut de tout temps une forteresse, tour à tour numide, romaine, byzantine, arabe et turque.

Philippeville $(17.000$ h.), le port de Constantine, a été créé par 
la France : aussi la ville est-elle tracée au cordeau. Les autres ports sont : Büne, la quatrième ville de l'Algérie $(36.000$ h.) (anc. Hippone), bâtie au pied des forêts de l'Edough, a, derrière elle, une campagne superbe que fertilise l'oued Seybouse. Bougie $(10.400$ h.), le meilleur port de toute l'Algérie, s'abrite derrière les contreforts de la Kabylie et le cap Carbon; le site est des plus pittoresques. C'est le débouché de l'oued Sahel.

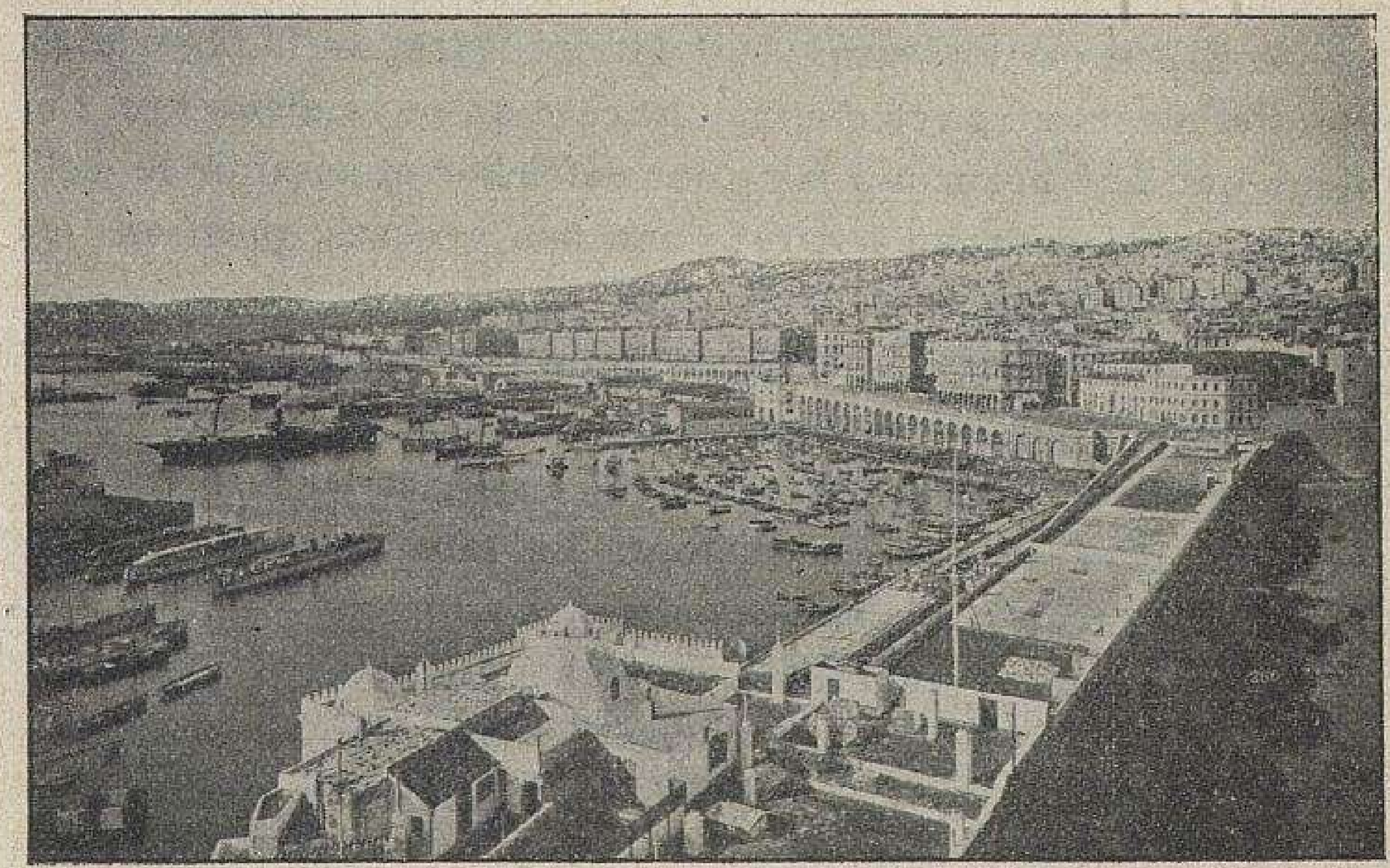

VUE D ALGER, PRISE DU PHARE.

(Cliché ND.).

Le port et la station des torpilleurs; le boulevard de la République supporté par des arcades; au-dessus, la Kasba; à l'horizon, Moustapha.

Sétif ( 12.000 h.) est une ville moderne, qui commande la route d'Alger à Constantine; ses environs sont suivant la saison couverts d'une mer de moissons ou bien complètement nus et d'une désespérante monotonie. Guelma $(6.600 \mathrm{~h}$.), dans un bassin fertile, est sur la route de Constantine à Tunis. Batna $(5.200$ h.) et Tébessa $(5.700$ h.) gardent les pentes Nord de l'Aurès. Batna est un centre militaire créé en 1848; Tébessa, au contraire, est une ancienne ville romaine qui renaît de ses ruines et est appelée à un nouvel avenir : ses environs sont fertiles, riches surtout en phosphates; enfin, elle est à proximité 
de la frontière tunisienne. Biskra $(4.200$ h.) est au Sud de l'Aurès, à l'entrée du Sahara. La ville indigène allonge ses jardins et ses maisons dans une forêt de 150.000 palmiers et de 6.000 oliviers. La ville neuve, aux hôtels luxueux, attire par milliers les touristes et les malades que séduisent la douceur de son hiver et la facilité des communications. Constantine, Philippeville, Bône, Bougie, Sétif, Guelma et Batna sont les sept chefs-lieux d'arrondissement de la province.

XII. Mise en valeur. - $1^{\circ}$ Agriculture. - L'Algérie est essentiellement un pays d'agriculture et un pays d'élevage. Les colons ont déjà beaucoup fait pour défricher et assainir le Tell, mais il reste beaucoup à faire; l'une des grosses questions est celle de l'irrigation.

L'Algérie produit en première ligne les céréales (blé dur et blé tendre, orge), en seconde ligne la vigne et enfin l'olivier. Ensuite viennent les cultures maraîchères, et les arbres fruitiers, orangers et figuiers surtout. Le tabac est une culture industrielle récente. L'absence de routes empêche l'exploitation méthodique des forêts, riches en chênes lièges.

La sécheresse du climat, l'absence de prairies naturelles sont des conditions peu favorables à l'élevage des bêtes à cornes. Aussi l'Algérie est-elle par excellence le pays du mouton, puis de la chèore dont la présence est désastreuse pour la végétation forestière. L'élevage du cheval est encouragé, car la race est excellente, fine et robuste. Le mulet, l'âne fournissent les bêtes de transport.

$2^{\circ}$ Industrie. - Les ressources industrielles sont abondantes. Les phosphates, surtout dans le Sud de la province de Constantine, paraissent inépuisables; le fer se rencontre, d'excellente qualité, dans l'Oranie (Beni-Saf), dans la province de Constantine (Ouenza); le zinc, le plomb, le cuivre en différents endroits. On n'a pas découvert de gisements houillers; du moins le pétrole existe des deux côtés de la vallée du Chélif. Le sel des mines ou des chotts, les eaux minérales (celles de Hammam Meshoutine près de Guelma ont une température de $96^{\circ}$ ) fournissent encore d'abondantes ressources.

Mais ces produits naturels ne sont pas travaillés sur place; 
ils sont exportés bruts. L'industrie européenne ne traite que les produits agricoles : elle extrait l'huile des olives, travaille le liège, a des minoteries et des distilleries. Faute de combustible, elle utilise, quand elle le peut, la force motrice des cours d'eau. - Quant à l'industrie indigène, elle est, avec son outillage primitif, incapable de résister à la concurrence européenne; aussi est-elle en décadence.

$3^{\circ}$ Commerce. - L'Algérie n'a pas de voies navigables; les voies commerciales, routes et chemins de fer $(3.000 \mathrm{~km}$. env.), suivent en Algérie deux grandes directions :

$1^{\circ}$ D'Ouest en Est, parallèlement à la côte, elles desservent la région la plus peuplée et la mieux cultivée, le Tell. D'Alger partent deux grandes lignes ferrées, l'une vers Constantine et la Tunisie, l'autre vers Oran et Tlemcen, aux portes du Maroc.

$2^{\circ} \mathrm{Du}$ Nord au Sud, les chemins de fer unissent des contrées dont les produits diffèrent. Sur la grande voie ferrée transversale s'amorcent, d'une part, les lignes qui conduisent aux ports, Arzeu, Mostaganem, Bougie, Philippeville et Bône; et d'autre part des lignes dites de pénétration : ce sont $1^{\circ}$ le chemin de fer du Sud-Oranais qui par delà les Hauts plateaux atteint Colomb-Béchar (juillet 1905), en plein Sahara, visant à la fois le Touat et le Tafilelt; $2^{\circ}$ dans la province d'Alger, le chemin de fer n'est prolongé qu'au Sud de Médéa, bien loin encore du point visé, Laghouat; enfin $3^{\circ}$ dans la province de Constantine, le chemin de fer de Biskra (à continuer sur Tougourt et Ouargla), et celui de Tébessa (à raccorder avec les lignes tunisiennes).

De grands travaux ont été faits pour aménager les ports. L'Algérie est unie par des lignes régulières de paquebots avec la Corse, avec Marseille (d'Alger à Marseille, traversée en vingt-quatre heures), avec Cette, avec Port-Vendres, et même avec les ports français de l'Atlantique et de la mer du Nord, Bordeaux, le Havre et Dunkerque. Enfin des lignes côtières réunissent entre eux les ports algériens. - Des câbles sousmarins sont immergés, de Marseille à Alger, de Marseille et d'Ajaccio à Bône, de Marseille à Oran, de Bône à Bizerte en Tunisie, d'Oran à Tanger.

Le commerce de l'Algérie, en plein essor, dépasse 1 milliard;

G. Lespagnol et Fallex. - Afrique. 
il se fait pour les trois quarts avec la France, par bateaux français : c'est que " la loi d'assimilation douanière de 1884, qui lie la métropole et la colonie, a rendu plus difficile le commerce avec l'étranger, en faisant de l'Algérie un des meilleurs clients de la France et du marché français le plus gros acheteur des produits algériens. " De la sorte la France et l'Algérie se complètent, très heureusement, elles ont besoin l'une de l'autre : aux liens d'affection qui les unissent s'ajoutent des liens plus puissants encore, ceux que crée la communauté d'intérêts.

L'œuvre réalisée déjà prouve irréfutablement les aptitudes colonisatrices des Français; les étrangers qui visitent l'Algérie, plus prompts que nous-mêmes à nous rendre justice, sont les premiers à manifester leur admiration sincère.

Commerce de l'Algérie (commerce spécial).

\begin{tabular}{|c|c|c|c|c|}
\hline ANNÉE: & & $\begin{array}{l}\text { IMPORTATIONS } \\
\text { Tissus. Taine, coton } \\
\text { ct sol e. Habillement. } \\
\text { Charbons. } \\
\text { Bois. } \\
\text { Machines et outils. } \\
\text { Denrées coloniales: } \\
\text { café, sucre. }\end{array}$ & $\begin{array}{l}\text { EXPORTATIONS } \\
\text { Produits de l'agri- } \\
\text { culture: vin, céréales, } \\
\text { blé, primeurs, tabac, } \\
\text { alfa, liège. } \\
\text { Produits de léle- } \\
\text { vage : moutons, lai- } \\
\text { nes, peaux et cuirs. } \\
\text { l'roduitsdesmines. } \\
\text { phosphates, minerais } \\
\text { de fer, zinc. }\end{array}$ & TOTAL \\
\hline \multirow[t]{2}{*}{1910} & \multirow[t]{2}{*}{$\begin{array}{l}\text { Avec la France. } \\
\text { Avec l'étranger } \\
\text { et les colonies } \\
\text { françaises. }\end{array}$} & $\begin{array}{l}433.544 .000 \mathrm{fr} \\
74.278 .000 \mathrm{fr}\end{array}$ & $\begin{array}{l}391.790 .000 \mathrm{fr} . \\
101.477 .000 \mathrm{fr} .\end{array}$ & \\
\hline & & $507.822 .000 \mathrm{fr}$. & $493.267 .000 \mathrm{fr}$ & 1.001 .089 .000 \\
\hline
\end{tabular}




\section{CHAPITRE VI}

\section{RÉGION DE L'ATLAS OU MAGHREB (fin)}

\section{III. - TUNISIE}

\section{SOM M A IRE}

La Tunisie complète l'Algèrie à l'Est; elle est placée sous le protectorat de la France qui l'occupe militairement.

I. Limites. - De deux côtès, elle est baignée par la Méditerranèe; au Sud-Est elle confine à la Tripolitainè, au Sud elle se perd dans le Sahara.

II. Superficie. - Environ $125.000 \mathrm{kmq}$.

III. Relief. - La Tunisie est traversée du Sud-Ouest au Nord-Est par l'Atlas saharien; sous le nom de monts de Zeugitane, il la divise en deux régions : au Nord, le Tell; au Sud, les steppes.

IV. Climat. - Les pluies décroissent du Nord au Sud et tombent en hiver. La température est très inègale, mais le climat très sain.

V. Hydrographie. - Les monts de Zeugitane distribuent les eaux entre les deux versants, le Nord et l'Est.

$1^{\circ} \mathrm{Au}$ Nord l'Oued Medjerda finit dans le golfe de Tunis.

$2^{\circ}$ A l'Est les cours d'eau ne coulent qu'après les pluies et n'arrivent pas jusqu'à la mer.

VI. Côtes. - Au cap Bon se rencontrent deux directions :

$1^{\circ}$ au Nord. La côte, rocheuse, est dite "Côte de fer ". Bizerte occupe une position admirable, à l'entrée d'un lac profond; Tunis est au fond d'un golfe que les alluvions des rivieres ont bien réduit.

2' à l'Est, le littoral est plat, sablonneux, et la mer peu profonde; les ports de Sousse et de Sfax ont ètè crèes au prix de grands travaux.

Au Sud-Est, Gabès est une oasis sur un golfe en entonnoir, où les marées sont appréciables.

L'île de Djerba est très populeuse et bien cultivée.

VII. Vie végétale. - Quatre zones de végétation s'harmonisent avec le climat. 
1. Au Nord, des mohtagnes forestières et des plaines à céréales.

$2^{\circ}$ Au Centre, une zoze de broussailles et de maigres forêts.

$3^{\circ}$ L'Est est la région de l'olivier

$4^{\circ}$ Le Sud, région des steppes et de l'alfa, annonce et précéde le dèsert.

VIII. Vie animale. - La faune est celle de l'Algérie. Les côtes abondent en poissons, en corail, en éponges.

1X. Vie Inmmaine. - La population indigène est évaluée à 1.900.000 h.; ce sont des Berbères, des Arabes, des peuples mélangés, des Israélites.

Les Européens sont 129.000 (Italiens 81.500, Français 34.600).

X. Gouvernement et administration. - La Tunisie est une Régence que gouverne un bey, sous le protectorat de la France.

La France est représentée par un résident général, et, à côté des Caïds, par des contrôleurs civils.

XI. Villes. - Les villes se composent invariablement d'une ville arabe, ancienne, et d'une ville europeenne, toute neuve.

Sur la côte : Tunis, la capitale, est une très belle ville, la troisième de toute l'Afrique (204.000 h.).

Bizerte, port de commerce et port de guerre.

Sousse, débouché de Kairouane, la ville sainte, et $S f a x$ sont les deux ports du Sahel.

Gabès est une oasis saharienne, au bord de la Méditerranée.

Dans l'intèrieur, au Nord, Bèja, grand marchè agricole; au Sud, Gafsa, entrepôt des phosphates.

L'ille de Djerba a une population de pêcheurs et d'horticulteurs.

XII. Mise en valeur. - $1^{\circ}$ Agriculture. La Tunisie est en premier lieu un pays agricole : céréales, vigne, arbres fruitiers, olivier. Les forêts de Khroumirie abondent en chênes lièges. - Les steppes du Sud produisent l'alfa; les oasis des dattes.

L'élevage ne donne pas d'aussi bons résultats qu'en Algérie.

Les pêcheries sont fructueuses.

$2^{\circ}$ Industrie. - La Tunisie devient par surcroit un pays de grande production minière : phosphates, fer et zinc.

L'industrie indigène est en dècadence: l'industrie europèenne ne traite encore que les produits agricoles.

$3^{\circ}$ Gommerce. - Le commerce dispose déjà de voies ferrées et de ports bien aménagès: Tunis est relièe à Bizerte, à l'Algérie, à Zaghouane; - Sfax à Gafsa, à Sousse, et Sousse à Kairouane.

Le commerce, supérieur dèjà à 200 millions de francs, s'accroit d'annèe en année; la part de notre pavillon est prépondèrante.

La France a complètement transformé l'ancienne Régence et imprimé à la Tunisie un prodigieux essor.

\section{DÉVEL O P P EMEN T}

La Tunisie forme la partie orientale du Maghreb et continue l'Algérie; elle est « protégée » par la France qui l'occupe militairement. 
I. Limites. - Enveloppée de deux côtés, au Nord et à l'Est, par la mer, la Tunisie occupe une position merveilleuse : elle dessine un angle saillant, en face de la Sicile, et commande par suite le passage (de $140 \mathrm{~km}$.) du bassin occidental au bassin

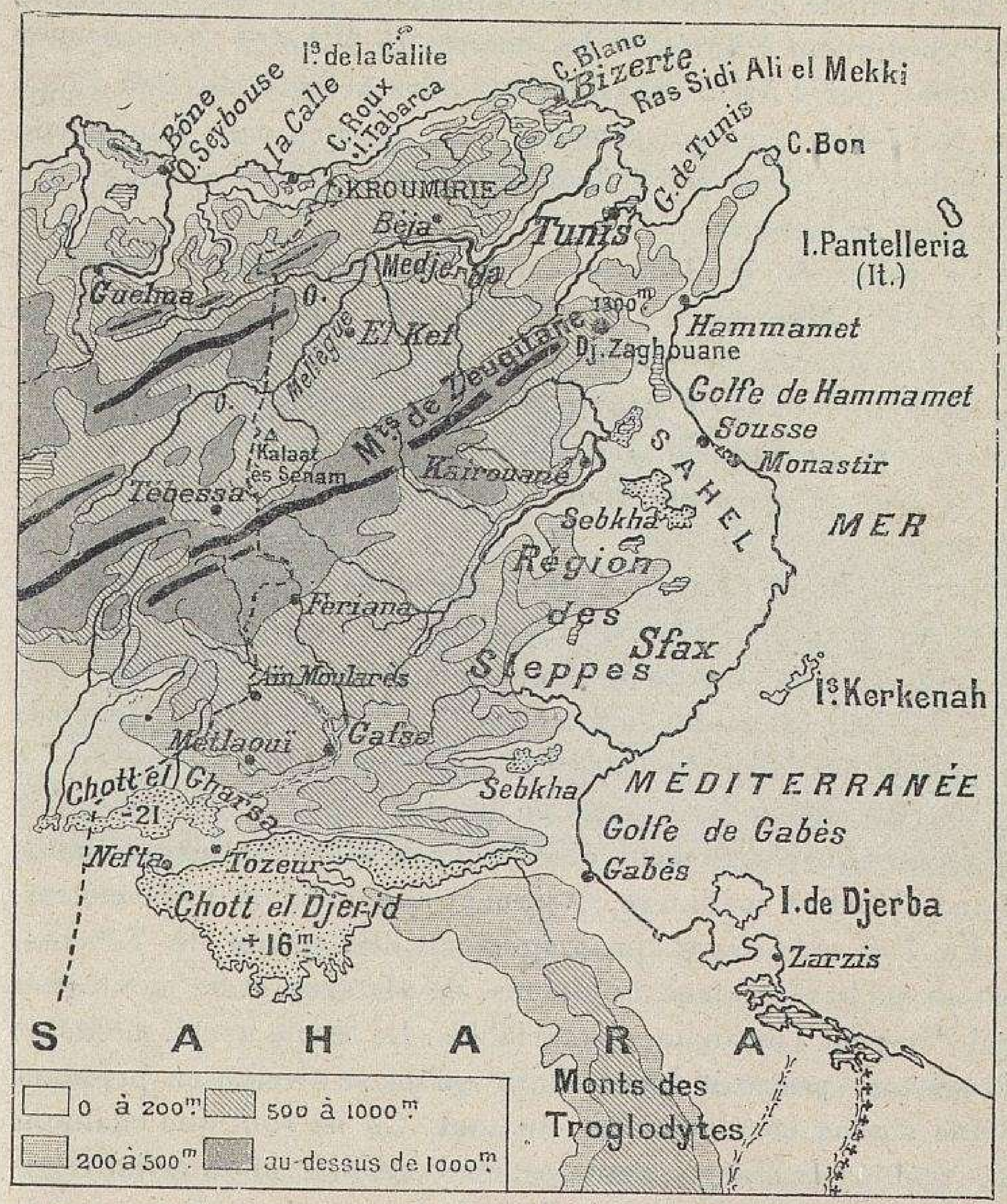

oriental de la Méditerranée. Au Sud-Est elle confine à la Tripolitaine qui est une province turque : la frontière, fixée sur la côte, est incertaine dans l'intérieur et se perd au désert du Sahara.

II. Superficie. - Elle est évaluée à 125.000 kilomètres carrés, chiffre tout à fait approximatif. L'Algérie proprement dite compte environ 75.000 kilomètres carrés de plus. 
III. Relief. - On ne trouve pas en Tunisie de roches anciennes; les terrains sont constitués par des roches secondaires, jurassiques et crétacées, par des dépôts tertiaires et par des alluvions quaternaires.

La Tunisie est traversée obliquement par les plissements qui continuent l'Aurès et les monts de Tébessa et, par conséquent, par l'Atlas saharien, toujours orienté du Sud-Ouest au Nord-Est. Ces plissements sont appelés dans leur partie méridionale monts de Zeugitane. C'est la masse montagneuse centrale de la contrée.

Le relief de la Tunisie est de la sorte très différent de celui de l'Algérie; les Hauts plateaux qui caractérisent la province d'Oran, celle d'Alger encore, perdent peu à peu leur individualité dans la province de Constantine : ils manquent totalement en Tunisie. L'Atlas saharien relaie l'Atlas tellien : à lui seul il constitue tout le système orographique de la Tunisie.

La Tunisie ne comprend donc que deux régions distinctes : $1^{\circ}$ Au Nord des monts de Zcugitane, le Tell;

$2^{\circ} \mathrm{Au}$ Sud des monts de Zeugitane, la steppe.

$1^{\circ}$ Le Tell est coupé en deux par le sillon de l'Oued Medjerda depuis la frontière algérienne jusqu'au golfe de Tunis.

Le Tell septentrional porte en bordure de la mer le massif de Khiroumirie,prolongement des monts de l'Aurès; les sommets, d'une élévation médiocre, atteignent au maximum 1.450 mètres.

Le Tell méridional, prolongement des monts de Tébessa, est un enchevêtrement de plaines, de plateaux et de montagnes qui s'étagent à des hauteurs variables. Le terme usuel, monts de Zeugitane, pourrait faire croire qu'on se trouve en présence d'une chaîne continue. Pas du tout. Ce ne sont que chaînons très nombreux, courts, dentelés, ou d'ordinaire d'un relief régulier; ils forment des dômes dont la base est circulaire ou de forme ovale, et limitent des compartiments qui sont autant de cuvettes.

L'altitude est plus faible qu'en Algérie (max. 1.600 m.). Le sommet le plus connu, mais non le plus élevé, est le Djebel Zaghouane: il n'a pas 1.300 mètres, mais il domine une plaine basse; ses formes sont hardies, ses crêtes déchiquetées. 
Une érosion énergique a donné aux différents massifs des formes particulières que les indigènes désignent par des noms spéciaux : ils appellent Kef un crêt rocheux, et Kalaat un sommet en plate-forme, un palier, une table calcaire dont le pourtour est taillé à pic. La plus célèbre est la Kalaat-ès-Senam; sur tous ses côtés elle dresse une falaise abrupte, une muraille droite de 40 ou 50 mètres de haut, qu'on ne peut escalader

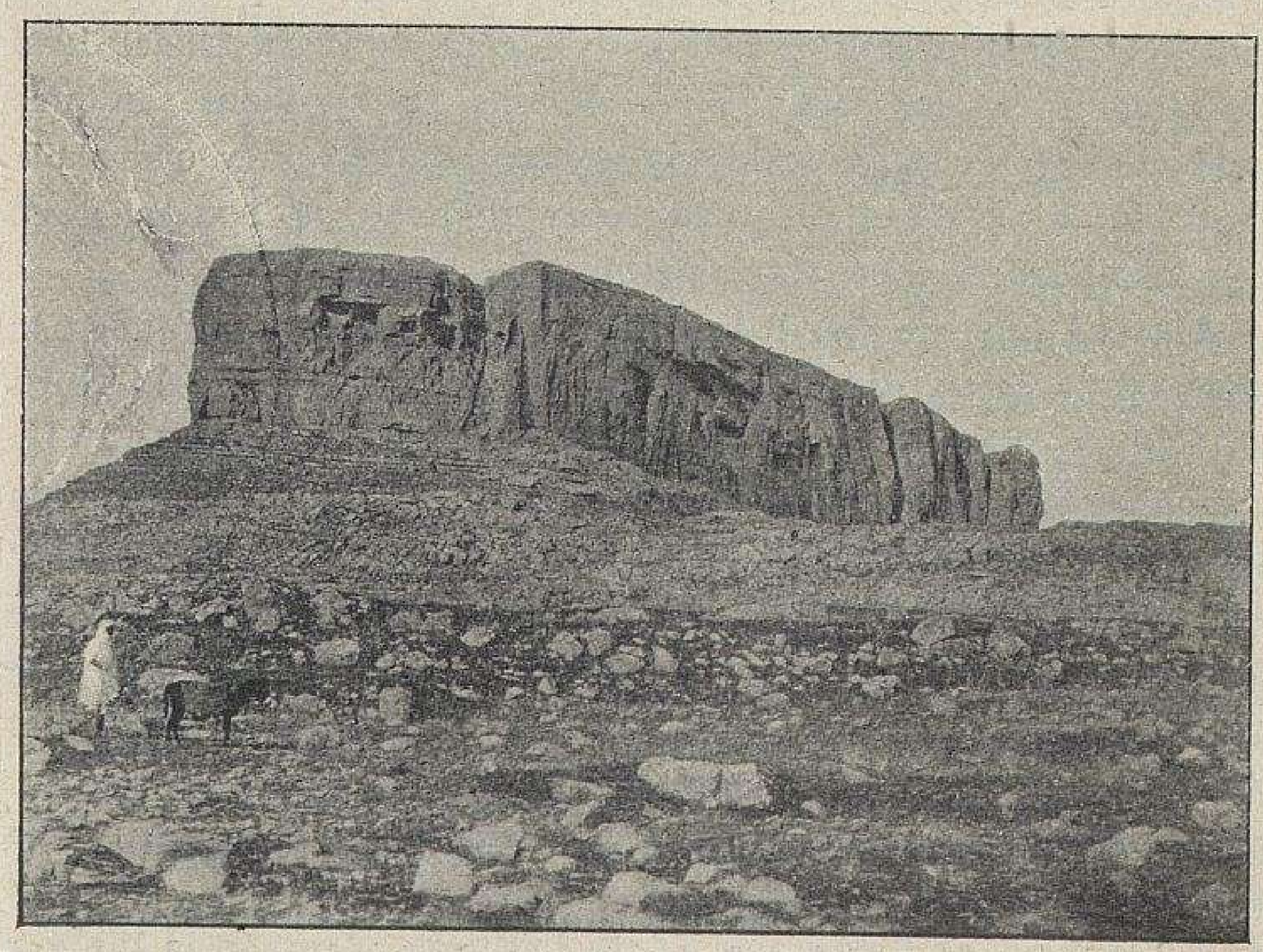

LA KALAAT-ËS-SENAM.

(Photographie communiquée par M. Pervinquiere.)

(Étude geologique de la Tunisie centrale.)

autrement que par un escalier taillé de main d'homme dans le roc.

$2^{\circ} \mathrm{Au}$ Sud des monts de Zeugitane l'altitude faiblit, la sécheresse s'accuse et les chaînons, changeant de direction, finissent par s'aligner suivant une orientation franche d'Ouest en Esst. La pente descend jusqu'à la dépression des chotls où finit la Tunisie proprement dite; ils font une véritable barrière de la mer à l'Algérie.

La dépression s'enfonce de plus en plus vers l'intérieur : le chott Djerid n'est qu'à 16 mètres au-dessus du niveau de la 
Méditerranée, et le chott el Gharsa est à 21 mètres al-dessous.

1V. Climat. - Placée entre deux mers, la Tunisie est plus favorisée par les pluies que l'Algérie; celles-ci tombent toujours en hiver, par averses fortes, mais irrégulières et courtes, comme dans les pays méditerranéens. - Dans le Tell, les vents Nord et Nord-Ouest prédominent; les vents Nord-Est et Est, au Sud des monts de Zeugitane : les uns et les autres se sont chargés d'humidité sur la mer - ceux de Nord-Ouest dans de plus fortes proportions; - comme ils soufflent toujours avec violence et qu'ils trouvent passage entre les courts chaînons des montagnes jusqu'au cœur du pays, la Tunisie n'est pas insalubre, malgré les variations du climat.

A part l'extrême Nord, la température se fait remarquer par son peu de fixité, par ses brusques écarts : c'est que du Nord au Sud la quantité de pluie diminue progressivement. $1^{\circ} \mathrm{La}$ région septentrionale du Tell, qui correspond aux montagnes de la Khroumirie, est très pluvieuse, et c'est dans la saison d'hiver que tombe la moitié des pluies (Ain Draham, 1 m. 95). L'humidité empêche les écarts de température : le mois d'août, le plus chaud, a une moyenne de $25^{\circ}$ à $27^{\circ} .2^{\circ}$ La région méridionale du Tell (versant Nord des monts de Zeugitane) est pluvieuse, simpleinent (Le Kef, 61 cent.). Chaque année la neige tombe sur les hauteurs. La température est plus variable, à cause de l'éloignement de la mer et de l'altitude, (extrêmes d'hiver $-5^{\circ}$, d'été $\left.+44^{\circ}\right) \cdot 3^{\circ}$ Au Sud des monts de Zeugitane, la région dite des steppes est peu pluvieuse. $4^{\circ}$ Enfin la région des chotts est très peu pluvieuse et la sécheresse est cause de forts écarts. A Gafsa, le thermomètre marque $-4^{\circ}$ en hiver et $+48^{\circ}$ en été.

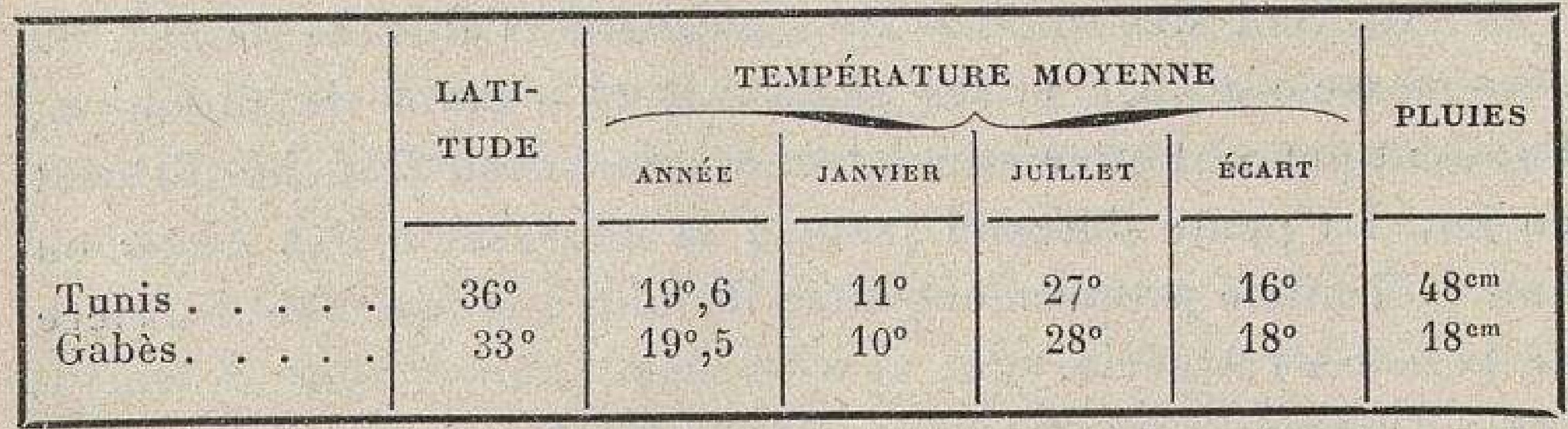

V. Hydrographie. - Le massif des monts de Zeugi- 
tane joue un rôle prépondérant dans l'hydrographie tunisienne : il répartit les eaux entre le Nord et le Sud, et les rivières s'orientent finalement, comme les plissements, Nord-Est.

$1^{\circ}$ Le versant Nord, bien arrosé, a des rivières permanentes. L'oued Medjerda est celle qui roule le plus fort volume d'eau; né en Algérie, il recueille de longs affluents (l'oued Mellègue, par exemple, qui le rejoint dans un bassin de riches alluvions, bassin du Dakhla), s'étrangle une dernière fois dans des gorges et finit à travers une large plaine qu'il a faite lui-même en comblant de ses apports un ancien golfe marin. L'oued Miliane déverse au fond du golfe de Tunis les eaux du mont et de la ville de Zaghouane.

$2^{\circ} \mathrm{Au}$ Sud, les cours d'eau ont rarement la force d'atteindre la mer - une fois tous les huit ans -; ils se perdent dans les sebakh - étangs saumâtres en hiver, dépôts salins en été qui bordent toute la côte orientale (le Sahel). Très encaissé dans la montagne, leur lit s'élargit plus bas démesurément; aux sécheresses, le voyageur qui n'est pas prévenu le traverse sans s'en douter; mais viennent les gros orages, et la plaine se change en un lac de plusieurs kilomètres, pas pour longtemps d'ailleurs : car le sol absorbe vite l'eau. Tel est l'oued Zeroud et telle la plaine de Kairouane.

Vers l'extrémité Sud, le caractère temporaire des oueds s'exagère encore : le chott Djerid n'a guère d'eau permanente que dans son centre; les caravanes, au risque d'être englouties, le traversent sur les couches épaisses de sel qui le recouvrent.

VI. Côtes. - Les côtes se développent suivant deux directions que sépare le cap Bon.

$1^{\circ}$ Côte Nord. - La côte de Khroumirie ou " côte de fer ", toujours escarpée, s'entr'ouvre seulement à la baie de l'îlot de Tabarka. Plus loin, la France a fait de Bizerte un puissant port de guerre, au débouché d'un lac profond et large, oú toute une flotte peut trouver un abri sûr. Le golfe de Tunis est l'ancien golfe de Carthage. Mais les atterrissements des oueds l'ont en partie comblé et déformé, et si Tunis est devenu un port européen, c'est au prix de grands travaux; un chenal rec- 
tiligne a été ménagé par des dragages à travers la lagune qui reléguait la ville au loin dans les terres.

Le cap Bon est ainsi nommé, par antiphrase, depuis l'antiquité; en réalité les courants de la mer et de l'atmosphère le rendent fort mauvais, en s'y heurtant.

$2^{\circ}$ Côte Est. - Plate, sablonneuse, avec un chapelet de lagunes, accompagnée d'îles basses sur une mer sans profondeur, la côte orientale n'est pas faite pour la vie maritime. Les navires devaient mouiller au large de Sousse et de Sfax, avant qu'on eût pratiqué un chenal et construit des quais.

Le golfe de Gabès est la petite Syrte des anciens. Là le littoral se creuse et se courbe. Toujours aussi peu hospitalier, il est la fin du désert dont Gabès est une oasis. Par une singularité qu'explique la forme du rivage, les marées ont ici une assez forte amplitude.

Au Sud de l'île de Djerba, plate aussi et sablonneuse, mais dotée d'un climat très doux et de très belles cultures, la côto se découpe en promontoires, en baies, et finalement est bordée de lagunes saumâtres pour disparaître vers la Tripolitaine.

VII. Vie végétale. - Aux quatre zones de climat et de pluies correspondent quatre zones de végétation; les caractères sont les mêmes qu'en Algérie.

$1^{\circ}$ Les montagnes du Nord, très arrosées, portent de belles foréts; celle de Khroumirie couvre d'un seul tenant 120.000 hectares; le chêne liège y domine. Les vallées où s'accumule la terre végétale sont fertiles.

$2^{\circ}$ Le Centre, c'est-à-dire le versant des monts de Zeugitane, plus sec, est en grande partie déboisé; les forêts s'y rencontrent par exception; elles sont maigres et contiennent des pins d'Alep, des thuyas, des oliviers sauvages. En général, ce ne sont que de maigres broussailles, une végétation rabougrie.

Les plaines alluvionnaires et basses sont plus étendues qu'en Algérie; elles suivent le cours de la Medjerda et entourent Tunis : là se cultivent les céréales et la vigne.

$3^{\circ} \mathrm{Au}$ Sud des monts de Zeugitane s'étend l'immensité monotone des steppes; depuis Kairouane jusqu'aux chotts l'alfa couvre environ 1.500 .000 hectares. 
Le Sahel forme le long de la côte une bande qui s'amincit progressivement vers le Sud; le sol et l'insuffisance des pluies en font la terre par excellence de l'olivier.

$4^{\circ}$ Enfin tout à fait au Sud, vers Gafsa, commence la nature saharienne; les oasis du moins y sont en plus grand nombre qu'en Algérie.

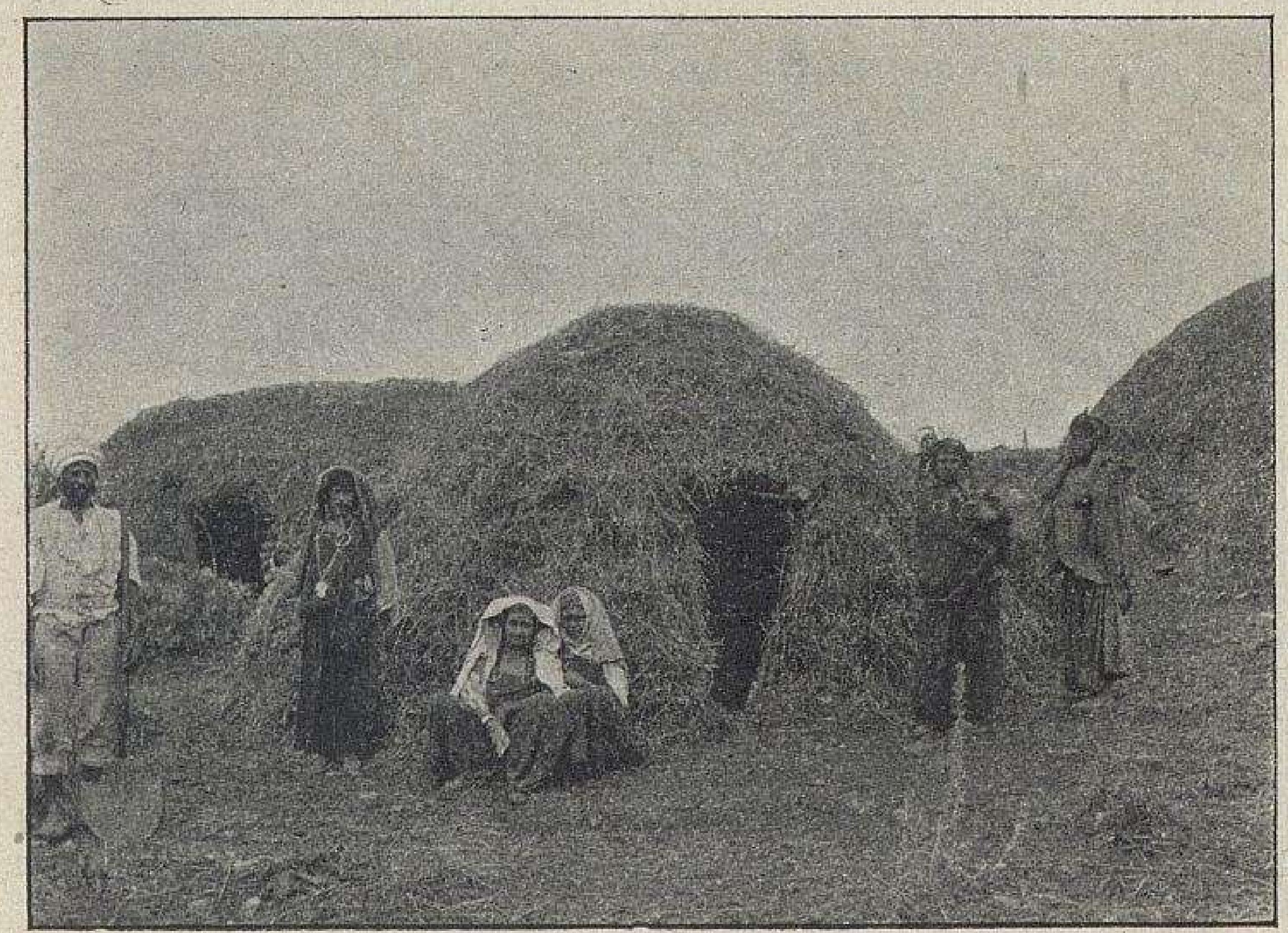

UN GOURBI TUNISIEN, HUTTE EN BRANCHAGES

(Phot. ND.)

VIII. Vie animale. - La faune est, comme la flore, identique à celle de l'Algérie. A noter cependant que les côtes sont très poissonneuses : la pêche de l'anchois, du thon, de la sardine occupe des milliers de pêcheurs. On récolte le corail vers l'île de Tabarka, vers l'ìle de la Galite et l'éponge sur le golfe de Gabès, depuis Sfax jusqu'à la Tripolitaine.

IX. Vie humaine. - La population indigène de la Tunisie est évaluée à 1.900 .000 , la population européenne à 129.000 habitants (1906).

Les indigènes sont, comme en Algérie, des Berbères ou des Arabes ou des races mélangées, enfin des Israélites; leurs mœurs 
ont été décrites au chapitre précédent. Sur 129.000 Européens qui forment dans Tunis une cité à part compacte, les Italiens sont de beaucoup les plus nombreux (81.500). Le chiffre des Français n'est que de 34.600 , mais l'immigration française s'accroît et la natalité française est très forte. Ensuite viennent les Maltais (10.000 h.). Les Français sont grands propriétaires; les Italiens sont ouvriers agricoles ou industriels.

Chaque année la Tunisie reçoit environ 12.000 immigrants.

\section{Gouvernement et administration. - La Tunisie} est une Régence gouvernée par un bey; depuis le traité du Bardo du 12 mai 1881 et depuis la convention additionnelle du 8 juin 1883, elle est placée sous le protectorat de la France.

La France est représentée par un Résident général qui relève du ministre des affaires étrangères. Il approuve et contresigne les lois qu'édicte le bey; il a des pouvoirs militaires et diplomatiques, il contrôle tous les services publics de l'administration tunisienne. La Régence est divisée en caïdats : les caïds ont à leurs côtés, pour les surveiller et les conseiller, des contróleurs civils. Dans les villes principales siègent, à côté des autorités indigènes, des conseillers municipaux; ils ne sont pas élus comme en France, mais nommés par décret.

XI. Villes. - En Tunisie chaque ville est double et se compose de deux villes juxtaposées, l'une arabe et l'autre européenne. La ville arabe a été respectée : elle est ancienne, fort pittoresque à distance, toute blanche derrière son eneeinte de murs, avec ses maisons plates, les tours et les dómes de ses mosquées, avee sa kasba ou citadelle; mais à l'intérieur ce ne sont que ruelles étroites, tortueuses, infectes. Chaque rue a son genre de commerce et de métier; ce sont les souks; dans la boutique, tout étroite, petite comme une boite, le marchand se tient accroupi. Aux portes, un marché périodique réunit, dans un indescriptible fonillis, choses, hommes et bêtes.

A côté, la ville européenne, de création récente, a été faite de toutes pièces : les rues sont larges, droites, plantées d'une ou de plusieurs rangées d'arbres; elle a ses promenades et ses squares, ses statues, ses édifices publics, sa gare ou son port.

Deux civilisations sont ainsi côte à côte, et chacune jouit des avantages de l'autre.

Tunis, capitale de la Régence, à 870 kilomètres de Marseille, est la troisième ville de l'Afrique, après le Caire et Alexandrie (204.500 en 1906).

La ville européenne, entre l'enceinte et le lac, possède de larges avenues, de hautes maisons, des édifices publics (bôtel des postes, résidence, cathé- 
drale, etc.), de grands magasins, des cafés... La ville indigène construite au hasard, sans aucun plan, a ses soukhs voûtés, où se vendent parfums, bijoux, harnachements, étoffes, etc.; des mosquées et le palais du bey; enfin son quartier juif. A $3 \mathrm{~km}$. est le Bardo, amas de palais beylicaux qui, faute d'entretien, tombent en ruines. Un chemin de fer unit Tunis à la Goulette, ville de plaisance, station de pêche et port d'expédition des minerais de fer; à Carthage, dont l'emplacement porte la cathédrale Saint-Louis et un musée d'antiquités phéniciennes; à la Marsa, où

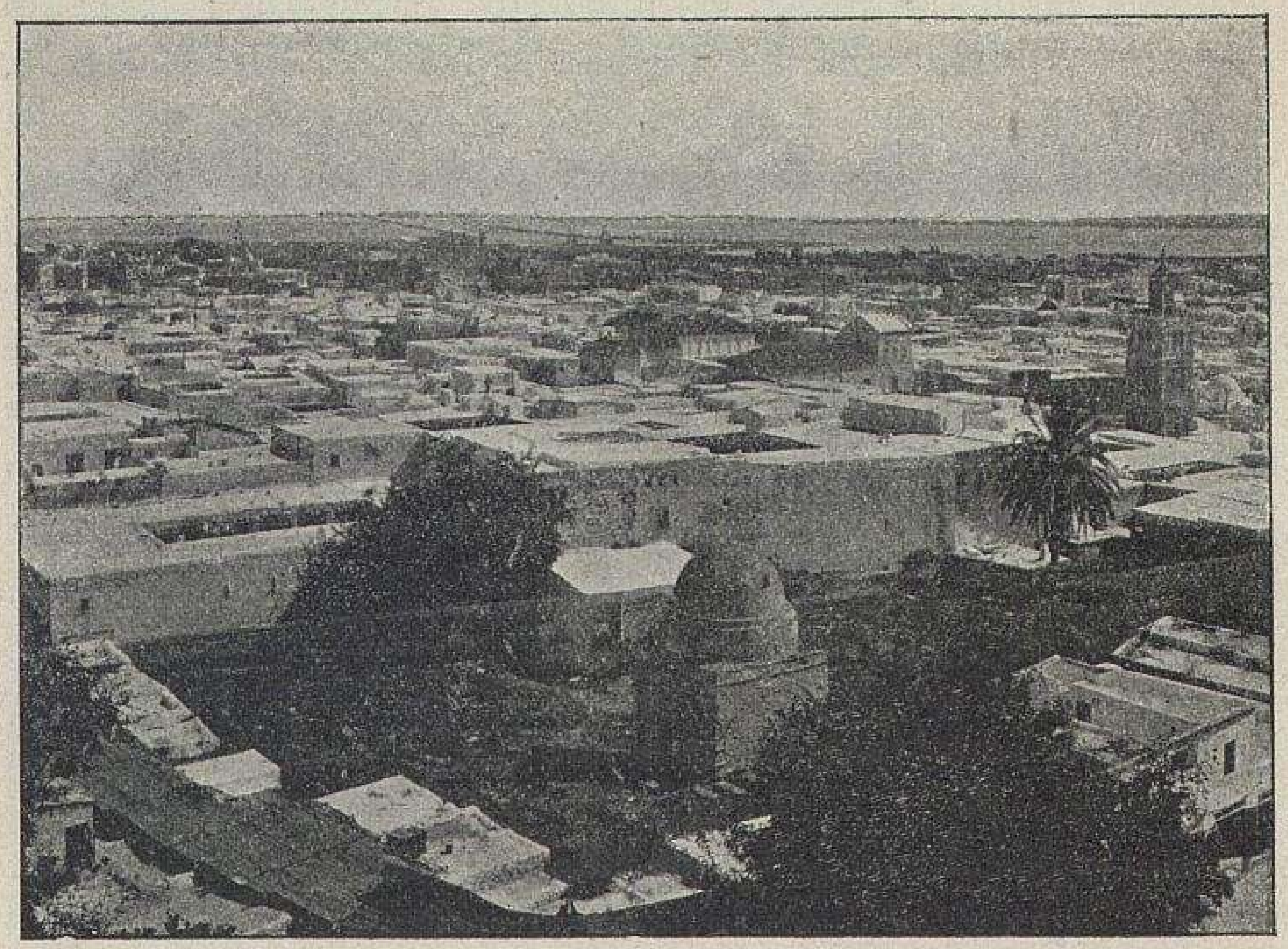

VUE GÉNÉRALE DE TUNIS. PRISE DE LA KASBA.

(Phot. ND.)

Aux premiers plans la ville indigène, avec maisons blanches, à terrasses el à cours intérieures. La ville européenne est au fond avec son port, sur la lagune : on aperçoit le chenal rectiligne, qui sort sur la pleine mer vers la Goulette.

habite ordinairement le bey et où le ministre de France fixe en été sa résidence.

Bizerte et Ferryville, en l'honneur de Jules Ferry, à qui la France doit la Tunisie, sont l'un un arsenal de guerre et l'autre un port de commerce, appelé à servir de débouché aux gisements miniers de l'arrière-pays.

Souss et Sfax sont les deux ports de la côte orientale, du Saliel: Sousse, débouché de la Tunisie du centré, est le port de Kairouane, la ville sainte des Musulmans, aux mosquées aussi 
belles que nombreuses; sfax, débouché de la Tunisie du Sud, se voit à peine du large, tant elle est blottie dans la plaine (69.000 hab.); les îles Kerkenah lui font un brise-lames naturel et protègent sa rade contre les vents dominants du NordEst; l'exploitation des oliviers, l'exportation des phosphates de l'intérieur, la pêche, lui promettent un brillant avenir.

Gabès, moins heureuse, est une oasis, au bord de la mer, qui exporte les produits de ses vergers. Dans l'intérieur des terres, dans le Tell, Béja est le premier marché de grains de toute la Tunisie; Zaghouane alimente par ses sources l'aqueduc de Tunis, comme autrefois les citernes de Carthage. Le Kef est perché sur une hauteur. Tournée vers le Sahara, Gafsa, jadis simple oasis, est en train de devenir une grande place de commerce depuis qu'elle est dotée d'un chemin de fer. Tozeur est le marché des dattes très estimées que produit le Djerid; enfin lîle de Djerba a une population compacte d'horticulteurs et de pêcheurs.

XII. Mise en valeur. - $1^{\circ}$ Agriculture. - Comme l'Algérie, et pour les mêmes raisons, la Tunisie est tout d'abord un pays agricole.

L'œuvre de colonisation, beaucoup plus récente qu'en Algérie, a donné déjà des résultats brillants. Son caractère est très particulier; jusqu'à présent, les colons français sont de grands propriétaires qui font valoir en moyenne 200 hectares et utilisent la main-d'œuvre étrangère, italienne surtout. Aussi deux questions capitales se posent à l'heure présente : la formation de petits domaines, et l'émigration de petits colons français, en face de l'invasion, alarmante par le nombre, des Italiens.

Le Tell est la terre des céréales, de la vigne et des arbres fruitiers. Les forêts de Khroumirie abondent en chêne liège. Les cultures maraîchères donnent lieu à une exportation de jour en jour plus appréciable. Le Sahel est la terre de l'olivier : c'est la région de Sfax et de Sousse. Les steppes du Sud, la terre de l'alfa. L'extrême Sud saharien, la terre du palmier dattier : les dattes du Djerid, très appréciées, sont l'objet d'une exportation considérable.

Les conditions du climat se prêtent aussi peu qu'en Algérie 
à l'élevage du gros bétail; en outre, l'élevage du cheval est moins développé et la race moins belle. L'indigène utilise surtout l'âne et le mulet. Quant aux moutons, ils sont d'une espèce médiocre; leur laine est grosse, leur viande peu appréciée. A côté du mouton, toujours on élève la chèore; dans le Sud enfin

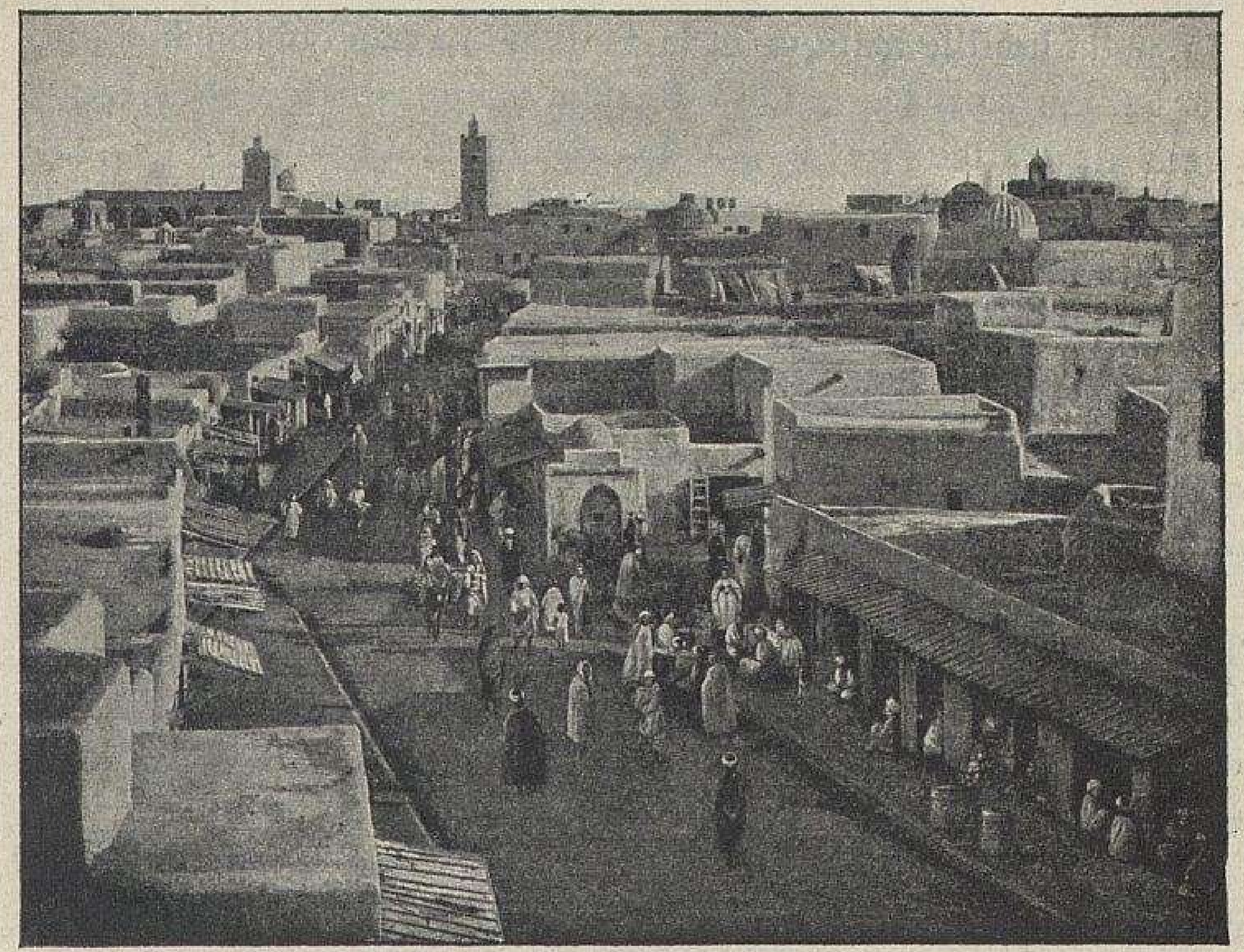

LA RUE SAUSSIER A KAIROUANE.

(Phot. ND.)

Vêtue du burnous et coiffée du turban, la foule circule, à pied ou à âne, devant les boutiques dont on apercoit à gauche les auvents levés. Toujours maisons cubiques, blan ches, à terrasses, que dominent les dômes et les minarets des mosquées.

le chameau. Nous avons eu l'occasion déjà de signaler l'importance des pécheries.

$2^{\circ}$ Industrie. - Une série de découvertes récentes a fait en peu d'années de la Tunisie un des grands pays miniers du monde. En première ligne viennent les phosphates (1.293.000 tonnes en 1910), dont les gisements occupent une superficie et une épaisseur considérables aux environs de Gafsa (Metlaoui et Ain-Moularès) et dans la région du Kef (Kalaat-es-Senam et Kalaat-ed-Djerda). C'est ensuite le fer dont 5 grands gisements ont été reconnus, notamment dans les Nefza et à Nebeur; le 
zinc; le plomb; le manganèse entre Gafsa et Gabès, sans compter les beaux marbres de Chemtou et de Djebel-Oust (oued Miliane). Partout les prospections continuent et l'essor des industries extractives tient du prodige. Il convient de ne pas oublier les salines, non plus que les eaux minérales (Hammam-Lif).

Mais la houille manque et la Tunisie n'a pas été touchée plus que l'Algérie par la grande industrie manufacturière. Les Européens ne traitent guère que les produits agricoles : vinification, minoterie, huilerie, savonnerie, distilleries de fleurs pour la production des essences de rose, de géranium et de jasmin. Quant à l'industrie indig̀̀ne, elle décline et l'imperfection de son outillage la met dans l'impossibilité de concurrencer les produits similaires manufacturés en Europe : cependant les tapis de Kairouane, les burnous et les haïks de Djerba, les poteries de Nabeul maintiennent leur vieille réputation.

$3^{\circ}$ Commerce. - Un grand effort a été fait déjà pour doter la Tunisie de routes et de voies ferrées, pour aménager les ports; mais la prospérité a été si rapide et les besoins nouveaux sont devenus brusquement si nombreux que tout un programme de travaux étendus est actuellement en cours d'exécution.

Les chemins de fer ont été tracés d'après la configuration même du relief : ils empruntent les vallées $N$. E. et $S$. W. On s'emploie maintenant à relier ces réseaux les uns aux autres, suivant une direction générale Nord-Sud.

$1^{0}$ Ligne de la Medjerda vers l'Algérie : de Tunis à Ghardimaou (195 km.), avec deux embranchements sur Ferryville-Bizerte et sur Béja. De Mateur une double ligne est projetée vers les gisements de fer des Nefza par la vallée de l'oued Sedjenane et vers ceux de Nebeur par Béja.

$2^{\circ}$ Ligne de Tunis à Kalaat-ed-Djerda (235 km.), avec 4 embranchements : sur Zaghouane, sur le Kef, sur Slata et sur Kalaat-es-Senam.

$3^{\circ}$ Ligne de Sousse à Kairouane et à Sbeitla, avec prolongement prévu sur Henchir-Souatir.

$4^{\circ}$ Ligne de Sfax à Gafsa et à Metlaoui $(243 \mathrm{~km}$.). Les trois premières ont été d'abord reliées entre elles par la ligne de Tunis-HammametSousse-Moknine et Mahdia. Puis la voie de Ouardine à Sfax a relié la $3^{\circ}$ et la $4^{\mathrm{e}}$ par la région littorale, enfin la liaison s'est faite aussi par l'intérieur de Sbeitla à Gafsa.

Ces voies ferrées ont transformé en grands centres maritimes les ports de Sfax, qui, grâce aux phosphates, a conquis le pre- 
mier rang pour le chiffre tout au moins de tonnes de marchandises, de Tunis, de Sousse et de Bizerte.

Le commerce extérieur, qui ne dépassait pas 23 millions en 1881, dépasse 225 millions en 1910. La part de la France est prépondérante grâce à la loi du 19 juillet 1890 : 49 p. 100 à l'entrée et 33 p. 100 à la sortie.

Marseille n'absorbe pas tout le commerce; Lyon, Rouen, Roubaix et Tourcoing y participent davantage chaque jour. Les relations sont naturellement très suivies avec l'Algérie. Bien loin derrière la France viennent, par rang d'importance, l'Angleterre, Malte et l'Italie.

En résumé, l'établissement du protectorat français (1881) a complètement transformé la Tunisie. Partout les terres sont défrichées, assainies, irriguées et mises en valeur; partout s'ouvrent les galeries de mines et partout de grands travaux s'exécutent; les savants fouillent le sol et exhument les antiquités phéniciennes, romaines, byzantines; par les écoles, l'instruction et la langue française se répandent; les finances, obérées jadis, se soldent régulièrement par un excédent de recettes. Ces résultats magnifiques sont l'œuvre de la France, qui a le droit d'en être fière.

Commerce extèrieur de la Tunisie.

(En millions de francs.)

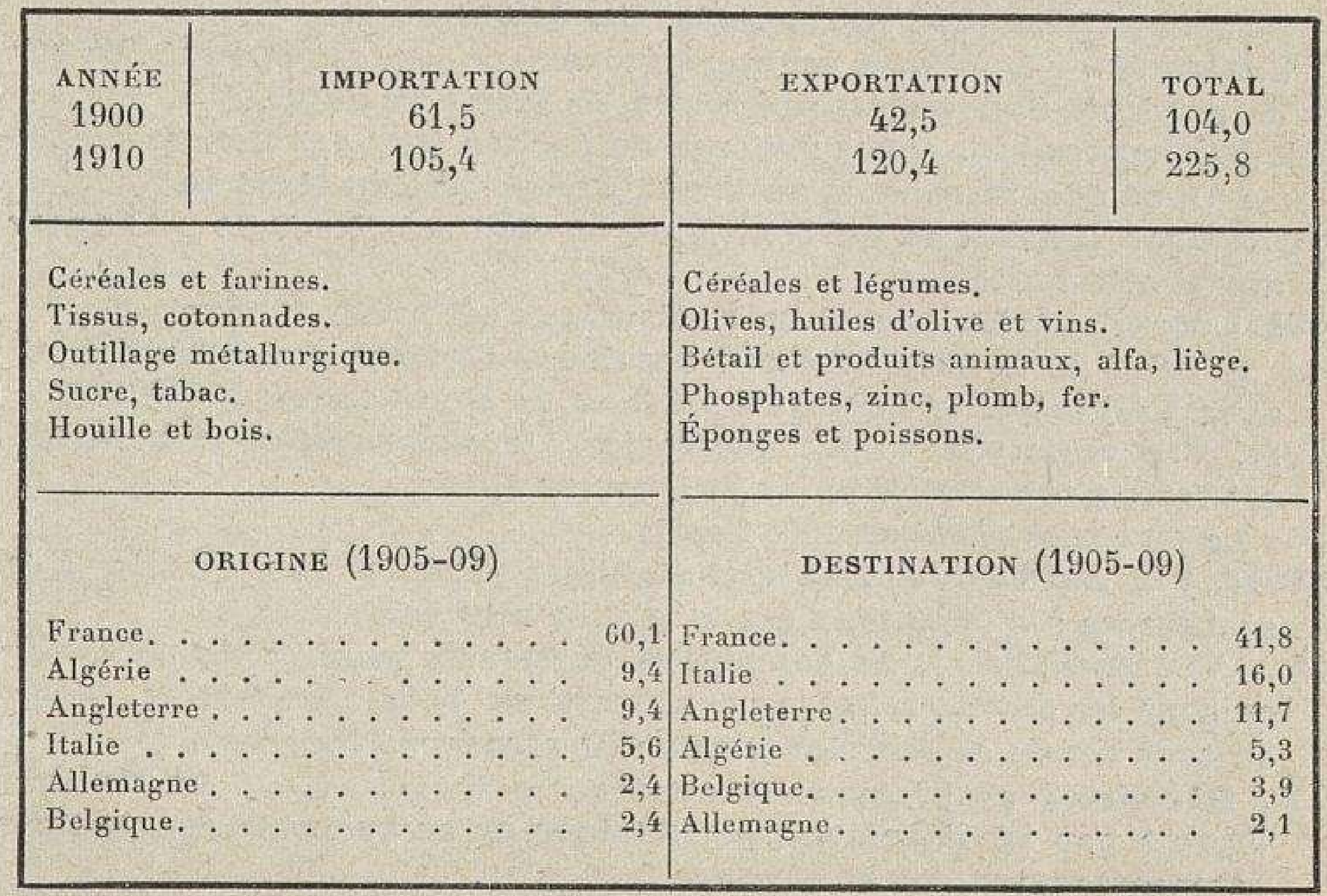

G. Lespagnol et Fallex, - Afrique. 


\title{
CHAPITRE VII
}

\author{
SAHARA. - TRIPOLITAINE
}

\section{SOMMAIRE}

I. Limites. - Le Sahara, ou Grand désert couvre toute la région du Nord de l'Afrique qui s'étend au Sud de l'Atlas et de la Mèditerranée, et où la chute annuelle des pluies est inférieure à 200 millimètres. Dans la partie orientale, il prend le nom de désert de Libye.

II. Sa superficie équivaut à peu près au tiers de l'Afrique.

III. Relief. - Le Sahara n'est pas uni et plat comme le fond d'une mer desséchée ; toutes les natures de roches s'y rencontrent, le relief y est très varié, plaine, plateau, montagne.

Sa partie centrale est un ensemble de hautes terres (Tibesti, $2.700 \mathrm{~m}$., Ahaggar, $2.200 \mathrm{~m}$.), entourées de dépressions (Chotts, Touat, Niger moyen, Tchad, Libye).

l'effroyable usure du sol : les Hamada sont des plateaux horribles de gros galets, l'Erg est la région des dunes.

IV. Climat. - Le climat, extraordinairement sec, est caractèrisé par de brusques écarts de température, du jour à la nuit.

V Hydrographie. - Les rivières du Sahara sont des fleuves morts. L'Oued Saoura conduit au Touat, c'est-à-dire du Nord au Sud.

L'Oued Igharghar, au contraire, du Sud au Nord, de l'Ahaggar aux chotts tunisiens.

VI. Cótes. - 1. Le littoral de l'Atlantique est brûlé, inhospitalier.

2. Celui de la Méditerranée dessine les golfes des deux Syrtes, avec Tripoli, et la saillie du plateau de Barka avec Benghazi.

VIII. Vie végétale. - La végétation, très pauvre et peu variée est faite d'arbustes epineuz et d'herbes dures.

Le palmier dattier crée l'oasis.

VIII. Vie animale. - L'animal aussi est organisé pour résister à la sécheresse : le chameau est le type le plus parfait.

IX. Vie humaine. - La population, ou bien se masse dans les oasis: ce sont les sédentaires, agriculteurs; ou bien parcourt le désert en tous sens : ce sont les nomädes, pasteurs (Touareg).

X. Divisions politiques et centres principanx. - Le Sahara, autant par sa situation géographique qu'en vertu de conventions internationales, est d'influence française. 


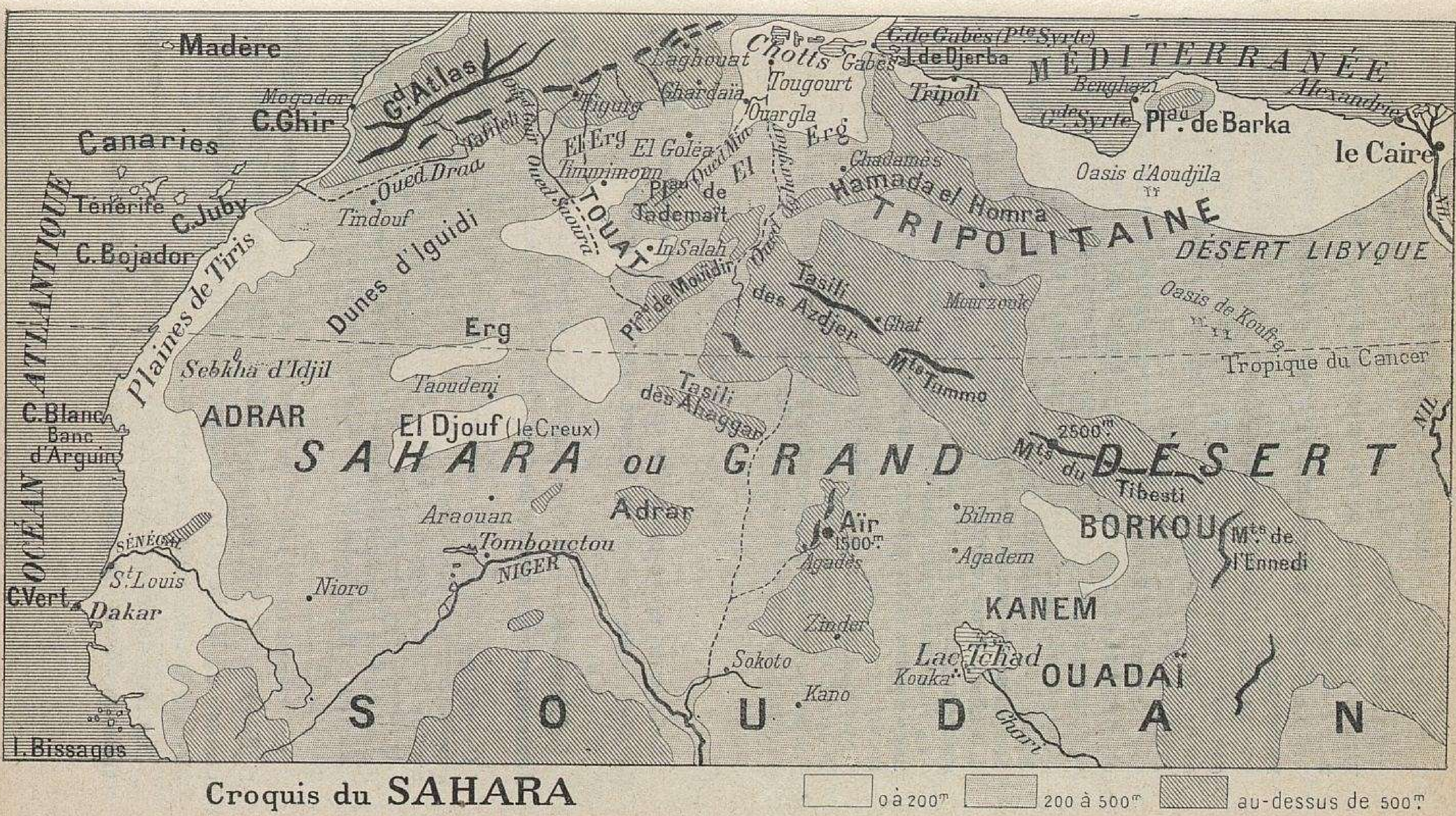


1. Le Maroc n'a aucune autoritè sur le Tafilelt et c'est avec l'appui de la France qu'un représentant du Makhzen a èté installé à Figuig.

$2^{\circ}$ La France a reconnu à l'Espagne le rio de Oro, le long de l'Atlantique.

$3^{\circ}$ La Tripolitaine, qui n'est que la partie maritime du désert, sur la Mèditerranée, est une province turque. Les ports de Tripoli et de Benghazi communiquent par caravanes avec R'adamès, $R$ 'at, Mourzouk et avec les oasis libyques.

$4^{\circ}$ Le reste du Sahara appartient á la France et dépend, au Nord, de l'Algérie (Territoires du Sud: Ain Sefra, les oasis, Ghardaia et Touggourt), au Sud, de l'Afrique occidentale (Mauritanie, HautSénégal et Niger avec Tombouctou, et Territoire du Niger avec Zinder). - Lioccupation française s'étend de jour en jour et devient plus effective, grâce aux Compagnies sahariennes.

xi. Valeur économique. - La culture et l'industrie des oasis ne suffisent pas aux besoins même les plus élèmentaires des indigènes.

Le commerce leur apporte du dehors, par caravanes, les denrèes alimentaires et les produits manufactures et remporte des dattes ou du sel.

On songe en France a construire une voie ferrèe qui traverserait le désert du Nord au Sud, c'est le Transsaharien.

A moins de découvertes minières, le Sahara n'aura jamais qu'une valeur économique des plus mèdiocres.

\section{DÉVELOPPEMENT}

Sahara est un terme arabe qui signifie Grand désert. De tous les déserts du monde, le Sahara est le plus grand.

I. Limites. - Il n'est pas facile, il est même impossible de déterminer rigoureusement ses limites et sa superficie.

On sait que les déserts occupent les régions du globe où la chute annuelle de pluie est inférieure à 200 millimètres. Or, la courbe de 200 millimètres borde la région de l'Atlas, depuis la côte de l'océan Atlantique, à la hauteur des îles Canaries, jusqu'aux chotts tunisiens et au golfe de Gabès. Au Sud elle commence vers le cap Vert, coupe la boucle du Niger, contourne le Nord du lac Tchad et atteint le Nil vers Khartoum. (Voir la carte, p. 10.)

Le Sahara couvre tout le Nord de l'Afrique, depuis l'Atlantique jusqu'au Nil, exception faite de la région de l'Atlas et du plateau de Barka ou Cyrénaïque. La Tripolitaine en fait partie; c'en est le seuil méditerranéen.

Le nom de Sahara est réservé aux parties occidentale et centrale du désert; le nom de Libye à la partie orientale. 
II. Superficie. - La superficie n'est pas sensiblement inférieure à celle de l'Europe; elle équivaut au tiers de l'Afrique : 8 à 10 millions de kilomètres carrés; 1.500 kilomètres du Nord au Sud et 5.000 de l'Océan au Nil.

III. Relief. - Longtemps on s'est représenté le Sahara uni et plat; on disait qu'il était le fond sablonneux d'une mer desséchée. C'est là une erreur que les explorations ont complètement dissipée. De quelque côté qu'on l'aborde, il faut monter; son relief consiste en massifs confus, en plateaux, en dépressions, et sa hauteur moyenne (450 m.) est supérieure à celle de l'Europe $(330 \mathrm{~m}$.); enfin ses roches sont des plus variées. " Le Sahara a ses granites comme la Bretagne, ses grès dévoniens comme l'Angleterre, ses calcaires crétacés comme la Champagne, ses calcaires éocènes comme le bassin de Londres, ses terrains volcaniques comme l'Auvergne »(Schirmer).

Toute sa partie centrale est un ensemble de hautes terres, surmonté de massifs qui tantôt surgissent isolément et tantôt se groupent par files : au Nord-Est le Tassili des Azdjer et le Tibesti $(2.700 \mathrm{~m}$.$) , orientés du Nord-Ouest au Sud-Est; à$ l'Ouest, l'Ahaggar $(2.200 \mathrm{~m}$.); au Sud, l'Ä̈r (1.700 m.) qui est de nature volcanique.

Une série de dépressions entourent cette masse rugueuse: au Nord, la dépression des chotts algériens et tunisiens; au Nord-Ouest, la dépression du Touat; au Sud-Ouest, la dépression du Niger moyen; au Sud-Est, la dépression du Tchad; à l'Est enfin, la dépression du désert de Libye.

La sécheresse de l'air et l'absence de végétation qui en résulte donnent au Sahara le modelé habituel aux déserts. Le sol, sans cohésion, n'est ni protégé, ni fixé par les racines et par l'humidité; il se fissure, il éclate, il se dégrade sous l'action alternée de la chaleur du jour et du froid de la nuit. Au lieu de s'allonger en pente doucement inclinée, comme dans les pays humides, la montagne finit en parois verticales, ses bords sont échancrés; les versants roides, chauves et décharnés tombent brusquement sur de grandes plaines horizontales, sables ou cailloux. Dans nos pays les éboulis sont emportés par les eaux courantes; là-bas ils restent sur le sol, ils se désagrègent sur place. Le vent en fait sa proie: il les triture, il les ronge, il les débite en partieules menues, en grains de sable, en poussières, il les pousse, les roule et " les grains de quartz, déplacés par le vent, agissent sur les surfaces qu'ils balayent à la façon des poudres dures qu'on emploie pour le polissage. Les roches homogènes finis- 
sent par prendre le poli des marbres. " (Lapporent). Au moindre obstacle, broussailles, rochers, ces sables s'accumulent pour former des dunes. Sur des espaces immenses, le Sahara ne présente qu'une surface de dénudation.

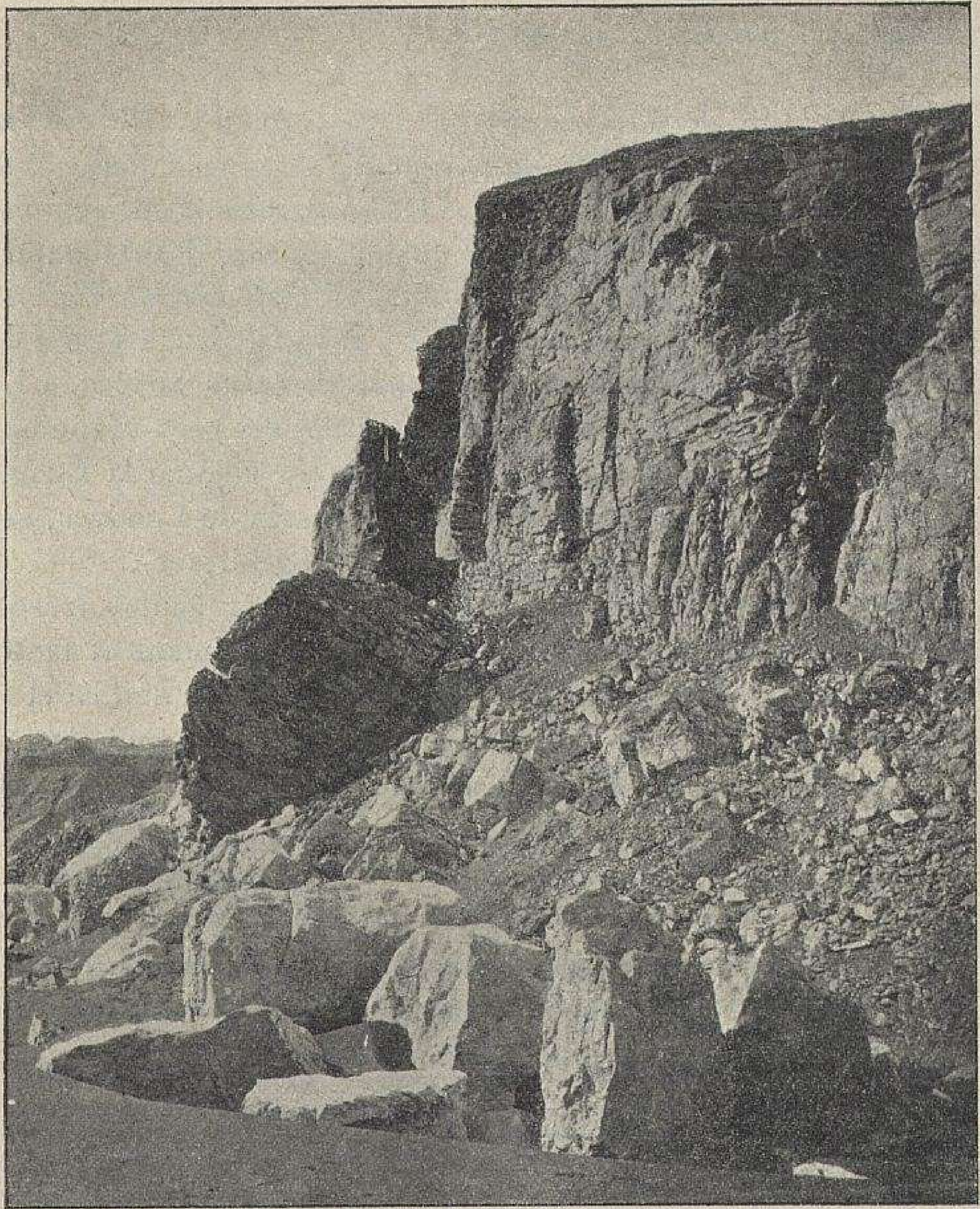

PHENOMENE D'ÉROSION : FALAISE AU DESSERT DE LIBYE.

(Photographie G. Rohlfs communiquée par la Société de Géographie de Paris.)

Les deux formes les plus ordinaires sont : $1^{\circ}$ le plateau, appelé Hamada par les Arabes, et Tassili par les Berbères; $2^{\circ}$ les dunes de sable, appelées Erg ou Iguidi.

1. La Hamada est une surface plate et dure, nue, rugueuse ou polie 
par le frottement des sables que roule le vent; à perte de vue, ce ne sont que gros cailloux, galets et rocailles; pas d'eau, pas de végétation, pas d'ombre : un paysage de désolation. La Hamada tombe en falaises sur des vallées sèches, appelées Ouadi; dans leur fond s'alignent et s'espacent les puits; souvent elles aboutissent à une Sebkha, ciest-à-dire à un hassin sans écoulement, couvert, quand il est à sec, d'efflorescences.

L'érosion a été si énergique parfois, elle s'est exercée pendant un si long temps, que le plateau tout entier a disparu; mais de place en place, des buttes rocheuses, plus dures, ont résisté : elles sont des témoins géologiques, qui dressent très haut au-dessus de la plaine leurs arêtes

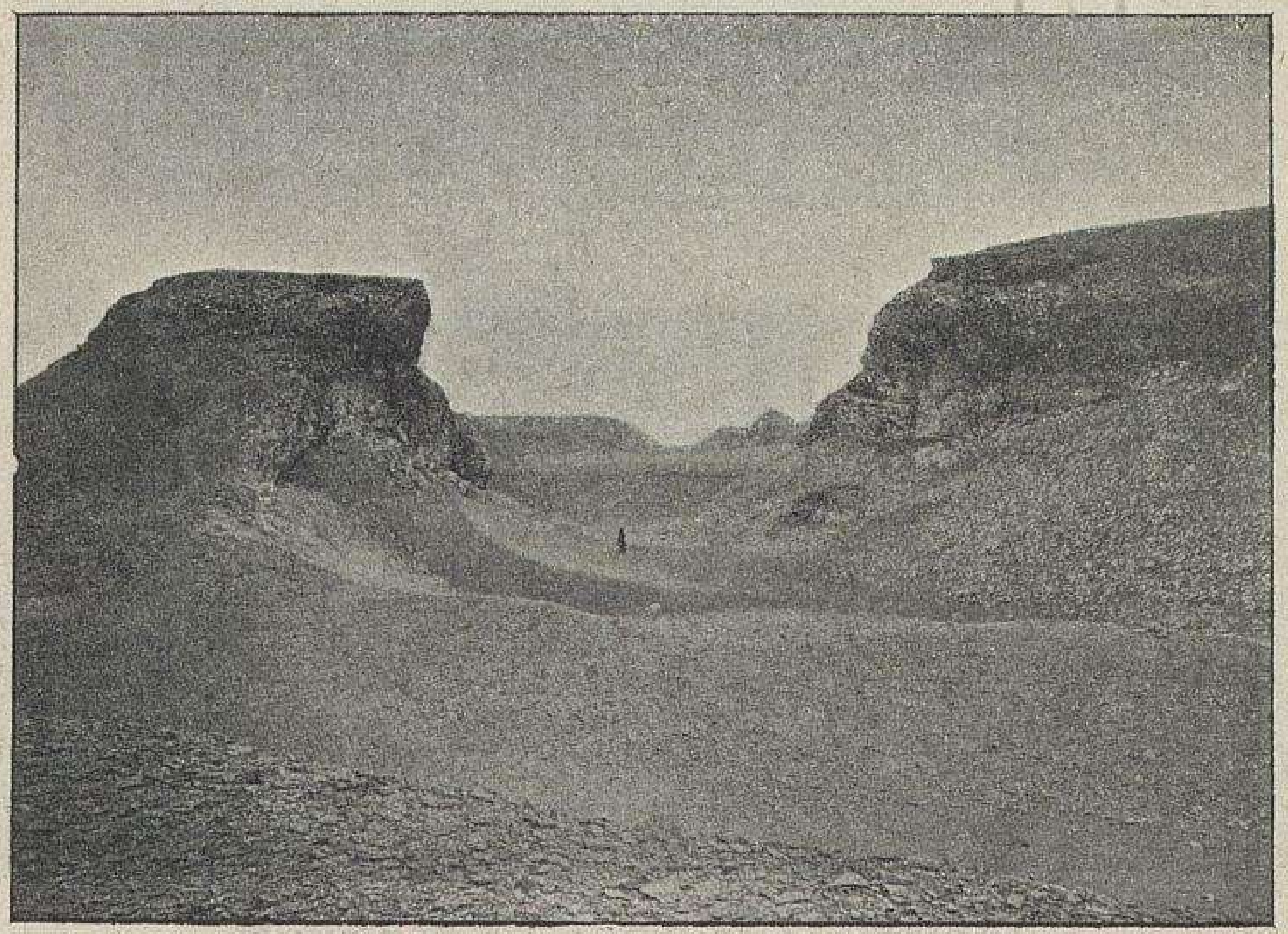

PHÉNOMENE D'ÉROSION ÉOLIENNE : GOUR DU DÉSERT LIBYQUE, PRES DAKHEL.

(Photographie G. Rohls, communiquée par la Societé de Géographie de Parts.)

Au milieu, l'homme fait échelle, en même temps qu'il marque l'emplacement de la montagne disparue : la roche de gauche demeure comme un témoin.

vives et leurs sommets tabulaires. Ces buttes isolées s'appellent gour (pluriel de gara).

$2^{\circ}$ L'Erg est aussi mourementé qu'un système de montagnes. Les dunes les plus élevées ne semblent pas atteindre $400 \mathrm{~m}$.; en général la hauteur est de 100 à $200 \mathrm{~m}$.

Erg, « cela veut dire les veines, et c'est fort bien nommé : car celui qui pourrait contempler ce paysage en le dominant, comme par exemple du haut de la nacelle d'un ballon, constaterait qu'en effet toutes les dunes se rattachent les unes aux autres en procédant comme les veines, c'est-à-dire en se ramifiant à l'infini autour d'un piton central plus élevé que les autres ». (Foureau.)

Pour traduire l'impression de ruine que produisent les grandes dunes, 
les Sahariens les comparent à une mer sans eau (bahar bla el ma) : et l'Erg est bien en effet une mer furieuse, mais une mer figée, immobile, silencieuse; les vagues, aux crêtes en lame de sabre, sont des masses toutes lisses et de couleur fauve; suivant l'heure du jour, le soleil les allume de reflets d'or ruisselant, ou bien les enveloppe de tons très doux, bleu violacé, orange ou rose.

La région des dunes, aux replis inextricables, au sol fuyant et instable, est des plus pénibles à franchir, lorsqu'elle ne se coupe pas de trouées, de couloirs, au sol plat, dur, appelés les gassi. Dans les gassi plus que dans toute autre partie du désert, le voyageur peut observer dans toute son intensité le phénomène du mirage. Sous les vibrations de l'air calme ct

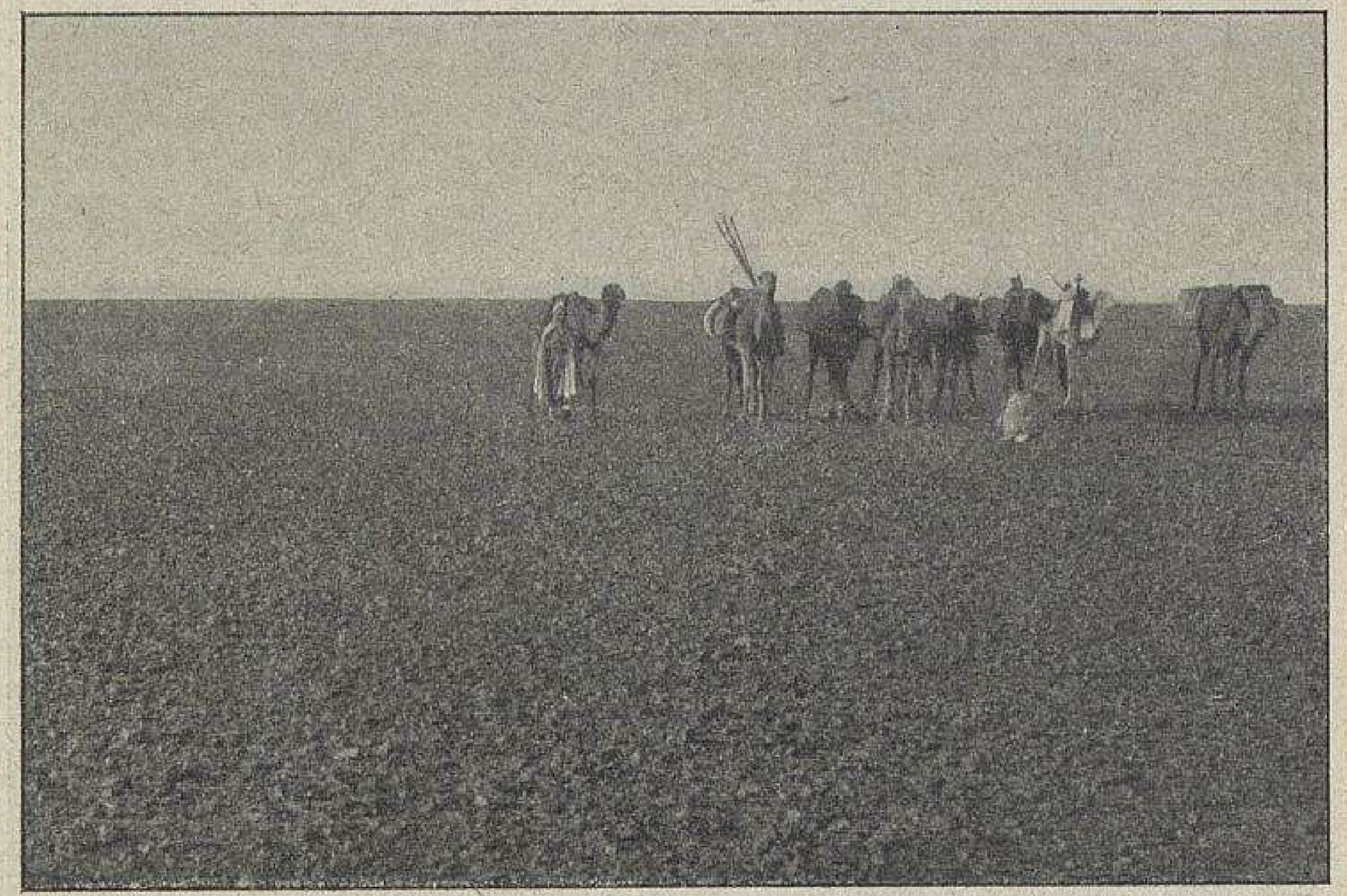

AU SAHARA : LA HAMADA NOIRE DU TADEMAÏT.

(Photographie de M. Foureau, communiquée par la Société de Geographie de Paris.)

surchauffé, et suivant la hauteur du soleil sur l'horizon, le même objet prend à distance les formes les plus variées et les plus trompeuses.

Moins désolé que la Hamada, l'Erg porte une maigre végétation d'arbustes épineux et des pâturages éphémères.

Mais ces sables fins sont mobiles, le vent les chasse : la dune " fume ", dit-on, lorsque sa crète s'enveloppe d'un léger nuage de poussière. Cependant même après les plus grandes tempètes de vent, les dunes ne se sont pas sensiblement modifiées; leur relief n'est pas altéré : sources et puits se retrouvent aux mêmes endroits.

Les principales régions de dunes sont à l'Ouest, l'Iguidi; au Sud de l'Algérie et de la Tunisie, l'Erg occidental et l'Erg oriental; enfin dans l'Est, les amoncellements prodigieux du désert libyque.

IV. Climat. - La stérilité du Sahara n'est pas due à la nature des roches, non plus qu'à la forme du relief : elle a pour 
cause le climat et l'absence de pluies. La sécheresse est extraordinaire. En hiver, le Sahara est un centre d'émission de vents, vents continentaux et secs; en été, il est un foyer d'appel, mais sans résultat : car l'Atlas d'un côté, le massif éthiopien de l'autre font aux pluies un écran, et les vents marins, débarrassés déjà d'une partie de leur humidité, s'éloignent en outre du point de saturation, quand ils arrivent sur ces terres

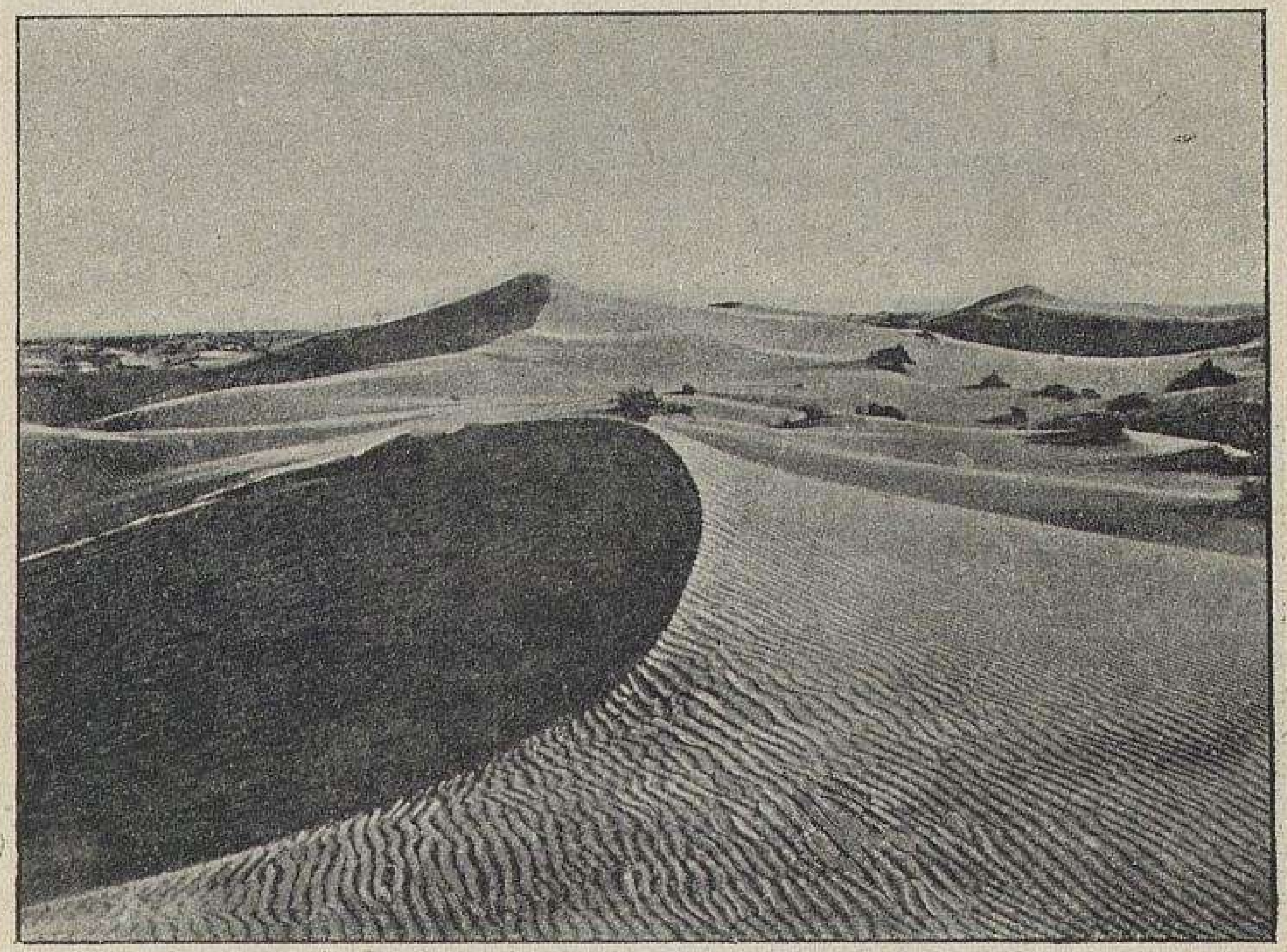

AU SAHARA : DUNES DE L ERG.

(Photographie Vuillot.)

surchauffées. Aussi le ciel est-il toujours sans nuage, limpide, profond, d'un bleu intense, bleu indigo, et cette transparence de l'atmosphère, qui tranche les contours des objets, trompe étrangement sur leur distance réelle. La nuit étincelle des feux ardents de milliers d'étoiles; dans l'air très calme la fumée des bivouacs monte tout droit, très haut.

Sans doute, les pluies ne font pas absolument défaut, mais elles tombent très irrégulièrement, de préférence sur les montagnes, qui connaissent aussi la neige chaque hiver. Les averses sont très fortes, mais si courtes qu'aussitôt le ciel reprend sa pureté. Les indigènes se souviennent d'une période de neuf 
années pendant laquelle ils n'ont pas vu tomber une goutte d'eau.

Le Sahara mérite le nom que lui donnent les indigènes : le pays de la soif, " bled el ateuch ».

Par suite de la sécheresse, la température est très variable. Comme il n'y a ni nuages, ni vapeur d'eau pour interposer un

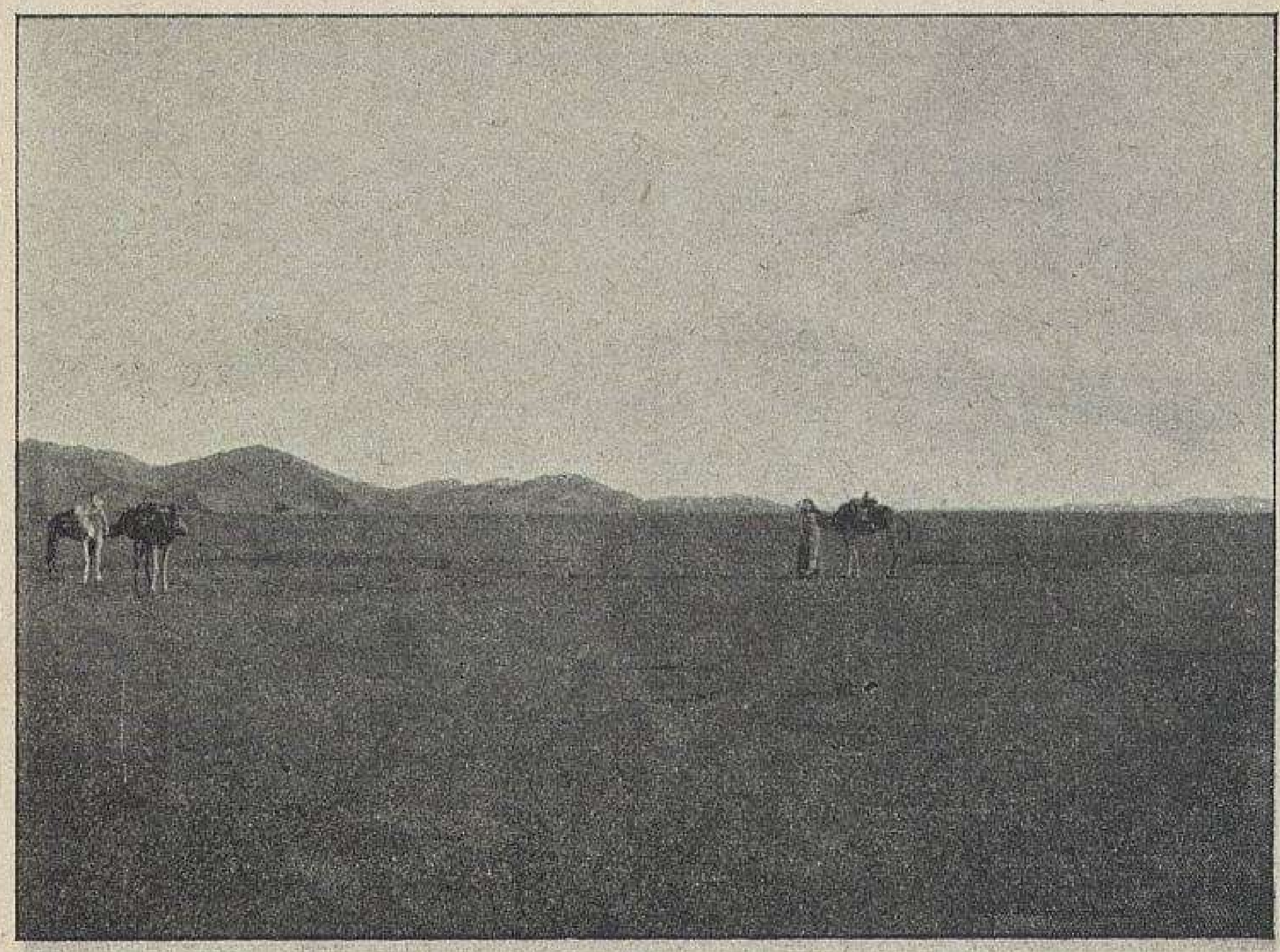

AU SAHARA : UN GASSI DE L'ERG.

(Photographie de $M$. Foureau, communiquée par la Société de Geographie de Paris.)

écran protecteur entre ciel et terre, l'insolation, puis le rayonnement sont intenses. La chaleur est brûlante pendant le jour; à peine le soleil est-il levé, sans crépuscule, sans aurore, que ses rayons sont brûlants; puis, le soir, la terre rayonne, une température de glace succède à une chaleur de fer, et l'on grelotte.

Dans tout le Sahara, le thermomètre peut monter jusqu'à $50^{\circ}$ centigrades à l'ombre, à $70^{\circ}$ au soleil; des explorateurs, Rohlfs, Nachtigal, ont dû chausser leurs chiens de sortes de sandales, pour les garantir du sable brûlant, ou les faire voyager à dos de chameau. Pendant la nuit, il s'abaisse au point de glace, ou même à plusieurs degrés, $8^{\circ}$ et $10^{\circ}$, au-dessous de zéro. 
On comprend que des variations aussi fortes et aussi brusques fassent éclater les roches.

V. Hydrographie. - Il n'existe au Sahara que des fleuves morts, des fleuves fossiles, vestiges de cours d'eau puissants.

Des rivières descendent, il est vrai, de l'Atlas, peut-être en descend-il de l'Ahaggar; mais elles ne tardent pas, au sortir de la montagne, à s'épandre sur une zone immense; elles s'infiltrent, elles disparaissent dans

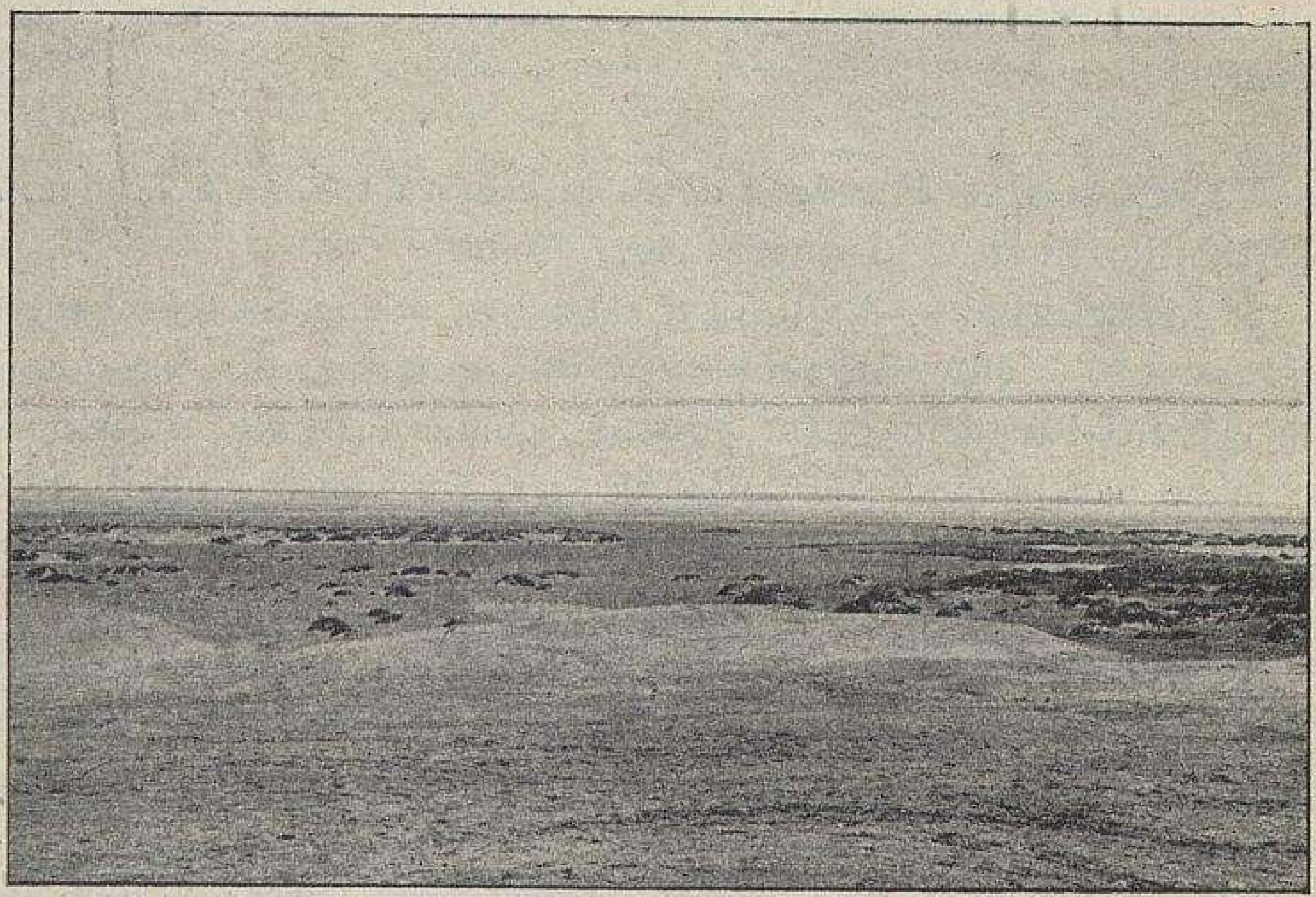

AU SAHARA : LE CHOTT MELGHIR.

(Photographie J. Geiser.)

le sol avide : il y a bien un lit, mais les eaux n'y roulent, sauvages, torrentueuses, que pendant quelques heures, à la suite d'un orage; des mares de limon et de sable, appelées daïa, subsistent après leur disparition. Elles circulent le plus souvent sous terre, et, pour créer les oasis, les indigènes les font jaillir en forant des puits artésiens.

Il n'existe pas plus de lacs qu'il n'existe de fleuves : un chott, une sebkha sont des dépressions, des cuvettes plates qui peuvent s'emplir momentanément, mais qui se dessèchent, parfois totalement; les fonds ne portent alors qu'une couche de limon, des mottes de terre salée, ou bien des croûtes de sel, durcies et boursouflées.

Jadis les conditions de climat ont dû être très différentes : car des lits de rivière, très longs, très larges descendent des montagnes; seules des masses d'eau puissantes ont pu les creuser.

Ces oueds descendent suivant plusieurs pentes : $1^{\circ}$ de l'Atlas marocain et de l'Atlas oranais les lits sont orientés vers le 
Sud : l'oued Saoura, qui conduit au Touat, est fait de la réunion de l'oued Guir et de l'oued Zousfana; $2^{\circ}$ de l'Atlas de la province d'Alger, ils se dirigent d'Ouest en Est, vers les grands chotts, vers le chott Melr'ir par exemple; $3^{\circ}$ c'est vers ces mêmes chotts qu'arrivent du Sud et l'oued Mia et l'oued Igharghar; $4^{\circ}$ enfin des lits de rivières rayent les cartes, au Sud de l'alignement des monts Ahaggar et du Tibesti; les uns tendent vers le Niger, les autres vers le lac Tchad. Le désert de Libye ne laisse pas apercevoir un seul de ces ravins desséchés.

VI. Côtes. - Par deux côtés le Sahara touche à la mer, à l'Atlantique et à la Méditerranée.

$1^{\circ}$ Atlantique. - Le littoral est aride, bordé de très hautes dunes (120 à $180 \mathrm{~m}$.$) , tout à fait inhospitalier; des bas-fonds$ dangereux l'accompagnent, comme le banc d'Arguin, tristement célèbre par le naufrage de la Méduse. Du moins sont-ils très poissonneux et fréquentés par les pêcheurs des îles Canaries, à la hauteur du cap Blanc par exemple.

$2^{\circ}$ Méditerranée. - Depuis la frontière tunisienne et le golfe de Gabès, le littoral s'enfonce de plus en plus vers le Sud; il abrège ainsi la distance à franchir jusqu'au Soudan central.

Le golfe des deux Syrtes, grande et petite, était très redouté des anciens; les marées, variables et peu puissantes en général dans la Méditerranée, atteignent ici par exception $1 \mathrm{~m}$. 50 et 2 mètres. En arrière de la côte plate et sablonneuse, frangée parfois d'écueils, s'allongent des lagunes, puis c'est la steppe, avant-garde du désert. Pas de ports naturels : celui de Tripoli n'est commode que pour les petits navires, les plus gros mouillent au large, sur une rade ouverte et sans profondeur.

Le plateau de Barka, véritable massif montagneux, dont l'altitude est supérieure à 1.000 mètres, dessine des caps rocheux, des baies, des îles et des îlots; de toutes les rades, la plus fréquentée, celle de Benghazi, n'est pas la mieux abritée. C'est l'ancienne Cyrénaique qui attira les colons grecs par sa verdure, ses eaux courantes, son climat doux et égal, par la fertilité de son sol. 
Au delà, jusqu'à Alexandrie, en Égypte, la côte est à peine touchée par le commerce européen.

VII. Vie végétale. - La végétation n'est pas totalement absente du Sahara, mais elle est très pauvre et peu variée. Surtout elle a un aspect étrange et des mœurs particulières. L'arbre utile par excellence est le palmier dattier.

La végélation a dû s'adapter aux conditions désertiques. La plante déjoue la sécheresse par sa rapidité à croître, fleurir et fructifier (telles sont les éphémères); ou bien elle se cuirasse d'une tige ligneuse, d'épines dures et coriaces. Afin d'offrir moins de prise à l'évaporation, elle s'enveloppe d'un vernis mauvais conducteur de la chaleur, ou encore sécrète une huile éthérée, volatile. Enfin pour puiser la rare humidité du sol, les racines sont énormes ou bien s'étalent largement. Le retem, l'acacia gommier forment des buissons sans feuilles; le drinn est une herbe dure qui vient par touffes; des graminées rampent sur les dunes; dans le lit des oueds, faiblement humide, on rencontre le tamarix, le pistachier et encore des acacias.

Le palmier dattier ne donne de fruits qu'au désert, "les racines dans l'eau et la tête au soleil ". C'est lui qui fait l'oasis. Son tronc élancé et dur porte à 20 et $30 \mathrm{~m}$. un bouquet de palmes en parasol d'où pendent les régimes de dattes. Fraîche ou sèche et pilée, la datte est un aliment pour l'homme et pour les bestiaux; distillée, elle donne un sirop apprécié, une boisson fermentée et capiteuse. Les meilleures, sucrées et charnues, sont un objet d'échange et même d'exportation. - Au-dessous du dattier, dans une atmosphère de serre chaude, poussent les arbres fruitiers, qu'il abrite de son ombre même contre l'ardeur du soleil : orangers, citronniers, figuiers, grenadiers, abricotiers, ete., auxquels la vigne suspend et enlace ses pampres. Enfin, au ras du sol, quelques cultures de céréales, orge et mil, des légunies, comme melons, concombres, pastèques.

En dehors de l'oasis, tout est brûlé, vide; mais après une pluie d'orage, des pâturages verdissent comme par enchantement, et disparaissent aussi vite.

VIII. Vie animale. - L'animal s'est, comme la plante, adapté au milieu. Il est organisé pour supporter la soif pendant plusieurs jours; les membres moteurs sont très développés : c'est qu'il lui faut se déplacer dans ces solitudes, sur d'immenses espaces, pour trouver la nourriture rare.

Tels sont, parmi les animaux domestiques, le mouton, la chèvre, le cheval, l'âne, le chien, mais surtout le chameau, à une seule bosse.

Le chameau est le type le plus parfait de l'animal du désert. Il ne peut vivre sous un climat humide. Sa sobriété est devenue proverbiale, et même on l'exagère; il reste facilement trois jours sans boire, et par 
exception jusqu'à huit et dix jours. C'est un marcheur sans pareil. - Il en est de deux espèces : l'une, forte, d'épaisse encolure, est la bête de somme; l'autre, fine, élégante, effilée, rapide, haute sur jambes, est la bête de course ou mehari; on cite l'exemple de mehara qui ont couvert $300 \mathrm{~km}$. en quarante-huit heures ou franchi $100 \mathrm{~km}$. par jour, pendant une semaine.

Les animaux sauvages ont de même une grande force musculaire, une incomparable agilité : le lion, sans crinière, le chacal, la gazelle, l'antilope, etc. Et tous ont revêtu sur ces espaces dénudés une robe de même couleur que le sol, avec lequel ils se confondent à distance.

Les oiseaux sont des plus rares. Très nombreux au contraire les reptiles, vipères, couleuvres, lézards, scorpions, tous doués d'une grande force de résistance.

\section{Vie humaine. - Même harmonie entre l'homme et} le désert.

Le Sahara est très peu peuplé; il n'est cependant pas, comme on se l'est figuré longtemps, inhabité ni inhabitable. Les nomades parcourent en tous sens l'Erg et les Hamada. Quant aux oasis, elles sont habitées par des sédentaires.

$1^{\circ}$ Nomades. - Les Arabes l'emportent en nombre dans le Sahara du Nord; mais les maîtres incontestés du Grand désert sont des Berbères, les Touareg.

Les Touareg appartiennent à la race blanche, mais le soleil bronze et cuit leur peau. De haute taille, d'une force rare, ils sont secs et maigres : c'est l'effet du climat, de la transpiration, d'une sobriété involontaire et d'une mobilité excessive. Ils portent un costume chaud destiné à les préserver des variations brusques de la température, et ramènent sur la bouche et le nez un voile noir - appelé litham par les Arabes - qu'ils ne quittent jamais, pas même pour manger. A l'inverse de ce qui se passe chez les Arabes, ici l'homme est vuilé : c'est la femme qui ne l'est pas.

Les Touareg sont musulmans, mais comme ils ne pratiquent guère, ils ne sont pas fanatiques. Depuis un temps immémorial ils mènent le genre de vie que leur impose le désert, vie toute de misère et de brigandage. Le temps, les distances ne sont rien pour eux : tandis que leurs serfs gardent les troupeaux, ils parcourent l'espace sans fin, montés sur leurs chameaux rapides qui filent jambes et cou allongés, et ces " buveurs d'air " battent toujours l'estrade, en quête de caravanes à piller, d'animaux à voler au pàturage, en quête de razzia.

Dans le Sahara oriental, dans le Tibesti, les Tibbou appartiennent à une race nègre métissée de Berbères et d'Arabes. Loueurs de chameaux, convoyeurs et conducteurs de caravanes, ils sont d'une agilité incroyable que les Arabes comparent à celle de l'oiseau. Leur extrême pauvreté fait d'eux des pillards et des voleurs aussi terribles que les Touareg. 
$2^{\circ}$ Sédentaires. - Les sédentaires habitent les oasis; cultivateurs avant tout, ils fabriquent encore des tissus avec la laine des nomades. Ils sont de races fort mêlées. Car les oasis sont des centres naturels d'attraction, des marchés, des carrefours de routes.

Nomades et sédentaires ont besoin les uns des autres : il s'établit entre eux une étroite solidarité. Mais toujours le sédentaire est exploité et terrorisé par le nomade, qui vit à ses dépens.

\section{Divisions politi-} ques et centres principaux. - Le Sahara est enveloppé au Nord par nos possessions méditerranéennes de l'Algérie et de la Tunisie, au Sud par notre empire de " l'Afrique occidentale ». Sa situation géographique et plusieurs traités internationaux le réservent à l'influence française.

$1^{\circ}$ Les oasis du Tafilelt, complètement indépendantes du Maroc, entrent peu à peu dans la sphère économique de l'Algérie.

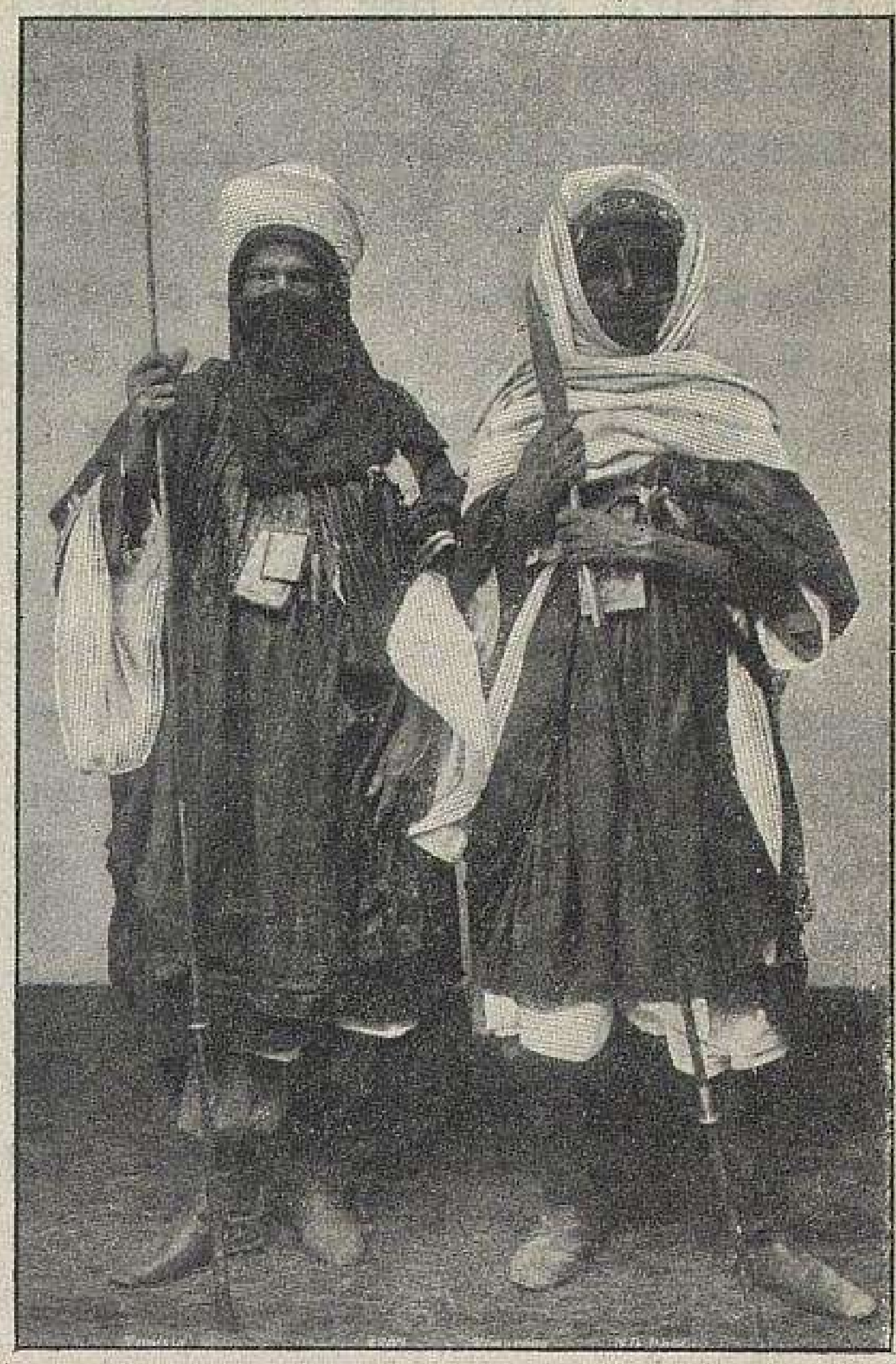

TYPES TOUAREG.

(Phot. ND.)

Costume : longue chemise à manches, en toile de coton blanc; large pantalon bleu, tombant jusqu'à la cheville, à la manière du pantalon des anciens Gaulois; blouse bleue et ceinture à la taille; sur la bouche, le voile ou litham. Sur la poitrine des amulettes. En main, la lance sur laquelle l'homme s'appuie en marchant à grandes enjambées, par saccades, tout comme l'autruche et le chameau.

Un représentant du Makhzen réside dans les Ksour de Figuig; mais c'est la France qui a prêté son concours à son installation, manifestant ainsi son respect scrupuleux du traité de 1845 .

$2^{\circ}$ Sur la côte de l'Atlantique, la France a reconnu à l'Espagne le territoire de Rio de Oro qui complète l'archipel des Canaries et qui s'étend du cap Bojador au cap Blanc. 
$3^{\circ}$ Sur les golfes méditerranéens des Syrtes, la Tripolitaine est une province (vilayet) de la Turquie. Le désert commence immédiatement en arrière de la ville de Tripoli ( 35.000 h.); le port est médiocre et les Turcs se refusent à l'aménager, autant par incurie que par crainte de l'étranger. C'est de là que rayonnent et c'est là que convergent les caravanes du Sahara et du Soudan. Les importations (11 millions en 1905) consistent en cotonnades, en tabac de la régie ottomane, en sucre et en farines; les exportations ( 9,5 millions en 1905) en sparte principalement, puis en éponges, en peaux, plumes d'autruches, œufs, etc. Le pavillon italien est prépondérant; mais l'Angleterre et la France font un chiffre d'affaires bien supérieur. Benghazi (20.000 h.), capitale du pays de Barka, est le port des caravanes qui parcourent le désert de Libye et le Soudan oriental. Celles-ci font étape aux oasis d'Aoudjila, d'où elles bifurquent à l'Est vers les oasis égyptiennes de Faredgha (Djaraboub) et de Siouah, au Sud vers les oasis de Koufra et de Kebabo perdues dans l'immensité des sables libyques. Dans l'intérieur, les Turcs tiennent garnison à $R$ 'adamès et à $R^{\prime}$ 'at, qui demeurent en réalité dans la dépendance des Touareg Azdjer. Les oasis du Fezzan ont pour centre principal Mourzouk.

$4^{\circ}$ Tout le reste du Sahara appartient à la France : le Nord est dans la zone d'influence de l'Algérie, le Sud dans la zone d'influence de l'A frique occidentale française.

La limite des zones d'influence respective part du cap Noun, coupe la piste descaravanes de Tombouctou au Maroc à mi-chemin entre Marabouti et Taodeni, suit la ceinture du bassin de l'oued Telemsi (Tin Zaouten) et rejoint la frontière tripolitaine à mi-chemin entre Ghat et la piste du Tchad à Mourzouk.

La loi du 24 décembre 1902 et une série de décrets, dont le dernier est du 10 avril 1907, ont détaché de l'Algérie et organisé les 4 Territoires du Sud : Ain Sefra, les Oasis, Ghardaïa et Touggourt. A la tète de chacun d'eux est placé un commandant militaire qui relève directement du gouverneur général de l'Algérie; les troupes dont celui-ci dispose (compagnies sahariennes, montées à mẻhara, et détachements du $19^{\circ}$ corps d'armée) ont adopté, pour mieux faire la police du désert, le genre de vie et la mobilité d'action des nomades eux-mêmes, c'est-à-dire des mours militaires en parfaite harmonie avec le climat, la nature du sol et l'immensité de l'espace.

A) Le Territoire d'Aïn Sefra, chef-lieu Ain Sefra, surveille 
tout le Sud-Ouest Algérien, depuis Mecheria et Géryville, sur les Hauts Plateaux, jusqu'au Haut-Touat (Tamentit et Adrar) et au Gourara (Timmimoun). Des postes de $1^{\text {re }}$ et de $2^{\mathrm{e}}$ ligne Berguent, Forthassa, Beni-Ounif, Talzaza, Colomb-Béchar, Bou Denib, Tar'it, Beni-Abbès et Gourara) assurent la sécurité du territoire : ils exercent une action mobile à grand rayon et sont reliées entre eux par d'incessantes patrouilles.

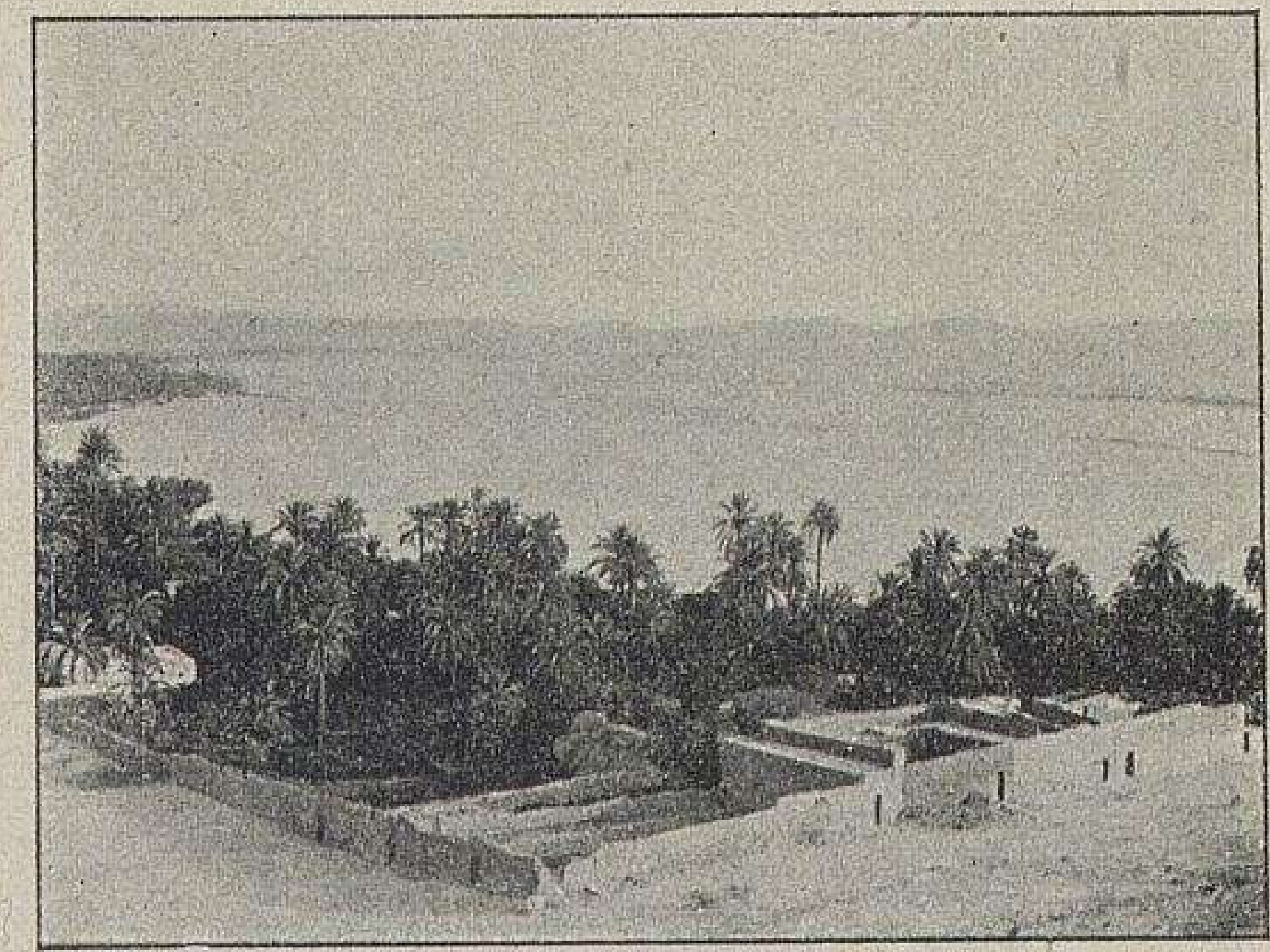

AU SAHARA : LAGHOUAT.

(Photographie de M. Dylowski.)

Maisons à terrasses, palmiers dattiers et vallée de l'Oued Mzi.

B). Le Territoire des Oasis, chef-lieu Ain Salah, dans le Tidikelt, s'ouvre largement, en éventail, vers le Sud : il étend son action à de grandes distances, chez tous les Touareg (Hoggar et Azdjer), en même temps qu'il opère la liaison avec l'Afrique occidentale française par Tombouctou. Les deux positions d'avant-garde sont Aïn Salah, à un important carrefour de pistes sahariennes, et Fort Flatters (Temassinine) : la première est dans le prolongement d'el Goléa, que flanquent, en équerre, aux abords du plateau de Tademait, les forts Mac Mahon, Miribel et Hassi Inifel; la seconde dans celui de Ouargla, située dans un bas-fond malsain, et de Fort Lallemand. A l'Ouest de R'at, Djanet, est dans notre sphère d'action.

C). Le Territoire de Touggourt, avec l'annexe d'el Oued, chef-lieu provisoire Biskna, a un rôle beaucoup plus restreint:

G. Lespagnol ex M. Fallex. - Afrique. 
il observe les confins de la Tripolitaine et surtout $R$ 'adamès. Le forage de puits artésiens a transformé la vallée de l'oued $\mathrm{P}^{\prime}$ ir en une immense palmeraie, dont les dattes savoureuses sont expédiées en France.

D) Le Territoire de Ghardaïa, chef-lieu Laghouat $(5.000$ h.) s'étend au Sud de la province d'Alger, et, de même que celle-ci est flanquée par les provinces d'Oran et de Constantine, il est

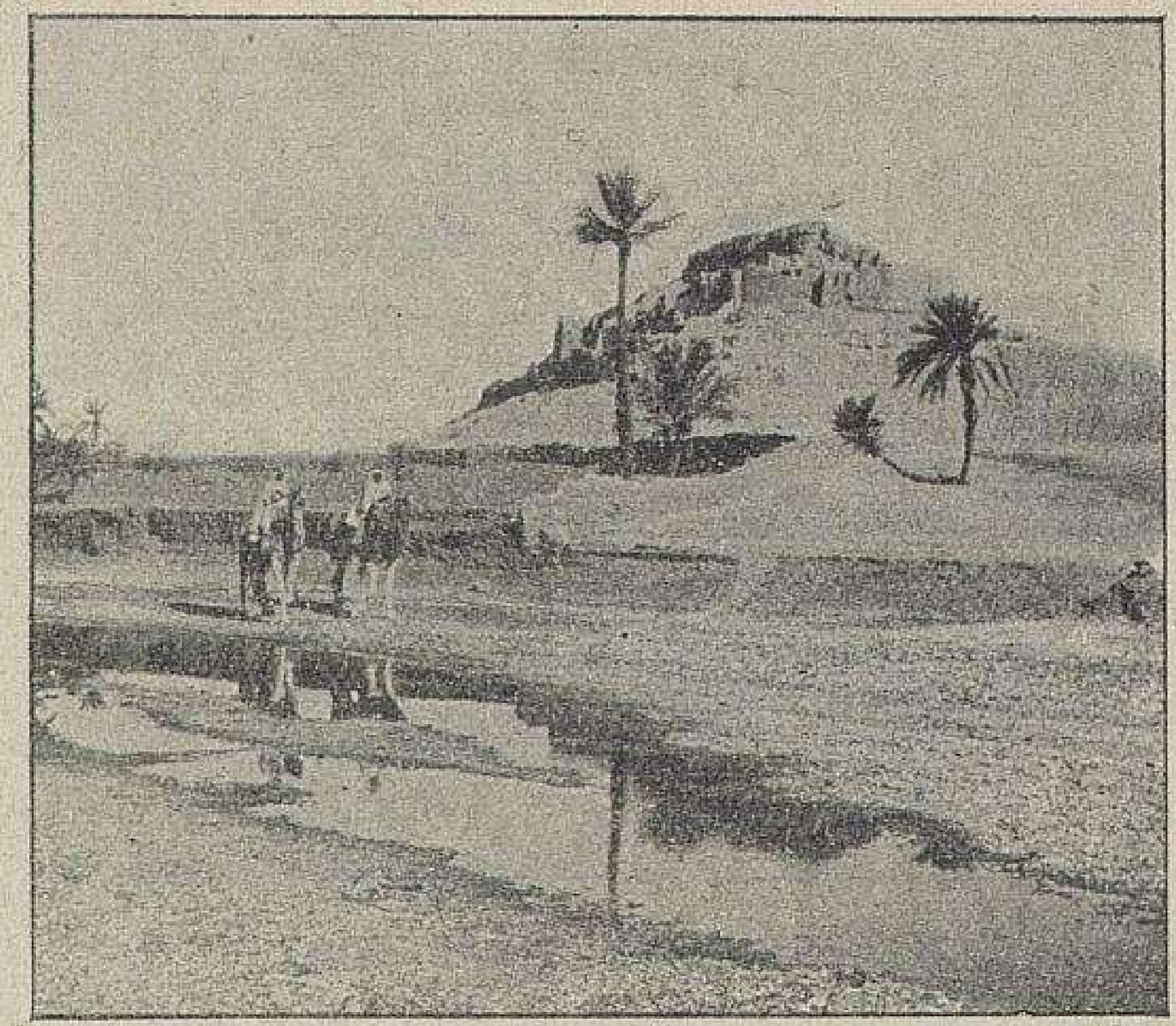

AU SAHARA : UN KSAR. EL GOLÉA.

(Photographie de M. Dybowshi,)

complètement enveloppé par les autres territoires et apparaît ainsi comme la clef de voûte de tout le système de défense. Djelfa, sur les Hauts Plateaux, est le centre des Oulad Naïl; Ghardaĩa (8.000 h.), à l'extrême Sud, le centre de la confédération des Beni Mzab.

XI. Valeur économique. - Les cultures ne sont possibles que dans les oasis : nous avons dit ci-dessus ce qu'elles étaient. Elles ne suffisent pas à nourrir les habitants.

L'industrie, toute locale, est limitée aux besoins les plus élémentaires, aux vêtements, burnous et haiks, aux objets en cuir, aux cordes en poil de chameau, etc.

Aussi nomades et sédentaires attendent-ils du commerce les 
denrées et les produits manufacturés de première nécessité dont la privation leur rend la vie des plus précaires.

Le commerce se fait au Sahara par caravanes; elles sont de plusieurs centaines, parfois de plusieurs milliers de chameaux.

La caravane a son chef, ses règles et sa police. Le guide est un personnage : car de lui dépend la vie de toute cette société qui marche sous un ciel de feu, à travers des régions désolées, pendant des semaines, sur des centaines et des centaines de kilomètres. Il sait la route, les points d'eau, les pâturages; il décide le départ, le moment et le lieu de l'arrêt. Le convoi, divisé par petits groupes, se met chaque matin en marche, longtemps après le lever du soleil : ear les hommes et les bêtes ont besoin de secouer l'engourdissement eausé par le froid de la nuit. Une fois parti, on ne s'arrête plus qu'au coucher du soleil, mais comme l'allure est lente, l'étape n'est que de 35 à $40^{\prime} \mathrm{km}$. Les chameaux vont par files de quinze ou vingt, attachés à un chameau de tête, un vieux routier bien dressé; ils broutent de-ci de-là, tout en marchant, les herbes dures et les branches épineuses. Arrivé au puits, chaque groupe fait à son tour sa provision d'eau, et quand les outres sont pleines, on abreuve les bêtes, chameaux, chevaux et bourricots. Sur les pâturages de l'Erg on fait séjour. Une attaque est toujours à craindre de la part des tribus sahariennes dont la caravane excite les convoitises; le moment que celles-ci choisissent de préférence, est celui des préparatifs de départ, parce que c'est le moment du plus grand désordre.

Longtemps, jusqu'à ces dernières années, le commerce des caravanes fut de deux sortes : commerce de ravitaillement purement saharien, et commerce de transit ou transsaharien.

Ravitaillement : des régions méditerranéennes ou bien du Soudan partent périodiquement des caravanes qui apportent aux sédentaires des oasis les denrées dont ils n'ont pas assez ou qu'ils n'ont pas du tout (grains, viande sèche, viande sur pied, sucre), puis des marchandises européennes (tissus, mercerie, quincaillerie, etc.); au retour elles ramènent au Nord les dattes, et au Sud, c'est-à-dire au Soudan, le sel.

Transit : Le Sahara était un pays de passage entre la Méditerranée et le Soudan. Mais aujourd'hui le Soudan est abordé par l'Ouest et par le Sud, bientôt il le sera par l'Est; de nouvelles voies s'ouvrent, moins coûteuses, moins périlleuses; aussi le commerce transsaharien est-il en déclin. C'est ainsi que l'occupation de Tombouctou par la France a supprimé à peu près complètement le transit dans le Sahara occidental entre le Maroc ou la Tripolitaine et le Niger; et depuis longtemps déjä, 
les caravanes évitaient nos territoires algériens, d'autant plus que l'esclave nègre constituait le principal objet du trafic.

Au Maroc les caravanes se formaient à Mogador, à destination du Kaarta et du Niger. La Tripolitaine comptait deux ports de départ: Tripoli d'où l'on gagnait le Soudan central, et Benghazi d'où, par Koufra, on atteignait le Soudan oriental et l'Ouadaï.

Le Touat était le point de jonction des itinéraires marocains et tripolitains.

A l'aller on transportait des grains (orge, blé), du sucre, du café, des étoffes, des tapis, des ouvrages de cuir, de la verroterie, de la quincaillerie, des armes, de la poudre et du sel. - Et au retour, après une absence qui pouvait durer deux ans, le mil du Soudan, les étoffes de Guinée, les peaux, le tabac, les plumes d'autruche et surtout les esclaves

\section{Le Transsaharien. - Aux caravanes on a songé en} France à substituer une forme de commerce moins primitive : le chemin de fer. L'idée a réuni des partisans convaincus, optimistes; elle est traitée de rêve et de chimère par « l'unanimité des rares Européens, qui vivent au Sahara en face de l'horrible réalité. » (E.-F. Gautier.)

Les difficultés matérielles de la construction, si grandes soient-elles, ne sont pas pour effrayer nos ingénieurs modernes, et personne ne semble contester les avantages politiques et stratégiques que nous pourrions en recueillir. Mais les partisans eux-mêmes d'un Transsaharien ne s'entendent pas plus sur le choix de la gare de départ - aujourd'hui le tracé Philippeville, Constantine, Biskra, Ouargla semble de plus en plus en faveur - que sur le choix de la gare d'arrivée : après bien des fluctuations, il semble que l'on doive actuellement préférer le lac Tchad. Les adversaires nient que la voie donne un rendement fructueux ou même équilibre les dépenses et les recettes; le Sahara ne fournira aucune marchandise, tant qu'on n'y aura pas découvert - ce qui après tout est possible - des gisements miniers, par exemple le nitrate, et le trafic ne se fera qu'aux deux bouts de la ligne, Méditerranée et Soudan. N'est-il pas plus simple alors et plus naturel que le Soudan communique avec les ports de l'Ouest (Sénégal), et avec ceux du Sud (Guinée)? - A défaut du Transsaharien, l'accord parait s'être établi sur la construction de voies sahariennes; il s'agirait d'achever les lignes algériennes de pénétration, déjà amorcées : $1^{\circ}$ celle d'Oran, construite actuellement jusqu'à ColombBéchar, non loin de Kenadsa, serait poussée vers le Touat; $2^{\circ}$ celle d'Alger-Berrouaghia, jusqu'à Laghouat; $3^{\text {s }}$ celle de Philippeville-Biskra sur Ouargla : et chaque province de l'Algérie aurait ainsi la satisfaction de posséder son chemin de fer saharien.

De toute façon, il ne faut pas le dissimuler, le Sahara francais $n$ \& qu'une valeur économique des plus médiocres. 


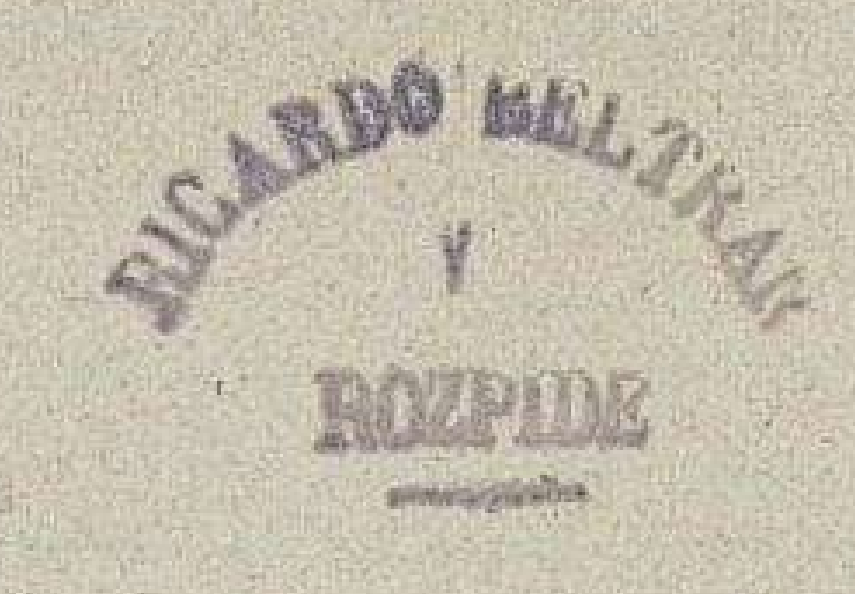

\title{
CHAPITRE VIII
}

\section{SOUDAN OCCIDENTAL SÉNÉGAL, GUINÉE}

\author{
I. - GÉOGRAPHIE PHYSIQUE
}

\section{SOMM A IR E}

Le Soudan ou pays des Noirs est la règion tropicale qui s'étend, au. Sud du Sahara, dans toute la largeur de l'Afrique depuis le FoutaDjalon jusqu'au massif éthiopien.

Sa superficie dépasse 5 millions de $\mathbf{k m q}$.

On le divise en Soudan occidental, Soudan central et Soudan oriental.

\section{1. - SOUDAN OCCIDENTAL, SENEGAL ET GUINÉE}

I. Relief. - Le Soudan occidental est un plateau à terrasses; le noud orographique est constitué par les massifs du Fouta-Djalon (1.350 m.) du Kouranko et du Konian (1.644 m.).

II. Climat. - Le Soudan est un pays de moussons. Les régions climatériques se succèdent du Nord au Sud.

$1^{\circ}$ Au Nord est une région subdésertique, sèche, à fortes variations.

$2^{\circ}$ Au centre, une région tropicale; l'annèe s'y partage en deux saisons, l'une de pluies, l'autre de sècheresse, en harmonie avec la marche du soleil.

$3^{\circ}$ Au Sud, une région équatoriale, chaude et humide, à température égale, pas excessive, mais des plus malsaines.

III. Hydrographie. - Tous les cours d'eau sont grossis périodiquement par les pluies tropicales, et tous sont coupés de barrages et de rapides. Le Fouta-Djalon, le Kouranko et le Konian constituent un centre de dispersion remarquable.

$1^{\circ}$ Le $N$ iger $(4.000 \mathrm{~km}$.) est fait de trois fleuves en un seul. Le haut Tiger est un fleuve tropical, le moyen INiger un fleuve désertique; les hautes eaux retenues par les barrages naturels d'aval couvrent une immense zone d'inondation (lac Debo). En se recourbant vers le Sud, le Niger, dans son cours inférieur, redevient tropical : il flnit dans le golfe de Guinèe après les rapides de Boussa. 
2。 Le Sénégal est barré de rapides jusqu'à Kayes; au delà il est navigable lors des crues d'été et finit après Saint-Louis dans l'Atlantique.

$3^{\circ}$ Fleuves côtiers. Les rivières dites du sud qui succèdent à la Gambie ont leur cours rèduit par le voisinage du Fouta-Djalon; mais dans le golfe de Guinée de grands fleuves, comme la Volta, ont leurs sources très loin dans l'arrière-pays.

IV. Côtes. - Les côtes sont désertiques, monotones et sablonneuses jusqu'au cap vert.

Au delà elles se creusent en estuaires et sont accompagnées de récifs et d'iles.

Le littoral de Libéria, plus rectiligne, se redresse en falaises.

Enfin, depuis le cap des Palmes, il est en génèral bas, précédé d'un ressac, et derrière un mince cordon de sables s'étalent et s'allongent des lagunes.

V. Vie végétale. - Les régions végétales sont les mêmes que les régions climatériques.

$1^{\circ}$ La région subdésertique porte des steppes et des arbustes épineux (acacias gommiers). La vallè du Niger est seule aussi riche que celle du Nil en Egypte.

$2^{\circ}$ Le Soudan proprement dit est caractérisé par la brousse herbacée et par des bouquets d'arbres.

$3^{\circ}$ Au Sud l'humidité constante et chaude entretient la grande forêt, avec le kolatier, le palmier à huile, le bananier et le caoutchouc.

VI. Vie animale. - $1^{\circ}$ Dans la région subdésertique vivent les animaux sauvages, qui s'accommodent d'une sécheresse prolongèe, et des troupeaux nomades; c'est le domaine du chameau.

$2^{\circ}$ Le Soudan est le pays du bceuf, de l'âne et du cheval.

$3^{\circ}$ La forêt équatoriale n'a guère que des animaux arboricoles.

\section{DÉVELOPPEMENT}

Le Soudan. - (pluriel d'un mot arabe qui signifie noir) ou pays des Nègres - n'est point une région géographique bien définie. 11 barre toute la largeur du continent depuis le massif du Fouta-Djalon à l'Ouest jusqu'au massif éthiopien à l'Est. Vers le Nord, des steppes d'étendue variable ménagent la transition avec le Grand désert. Au Sud, il finit à la forêt tropicale, parallèle au golfe de Guinée, monte jusqu'au seuil de partage Chari-Congo et reçoit le Nil tombé du lac Albert.

Sa superficie, supérieure à la moitié de l'Europe, dépasse 5 millions de kilomètres carrẻs.

Nous diviserons son étude en trois parties, en réservant la troisième pour un chapitre ultérieur : 


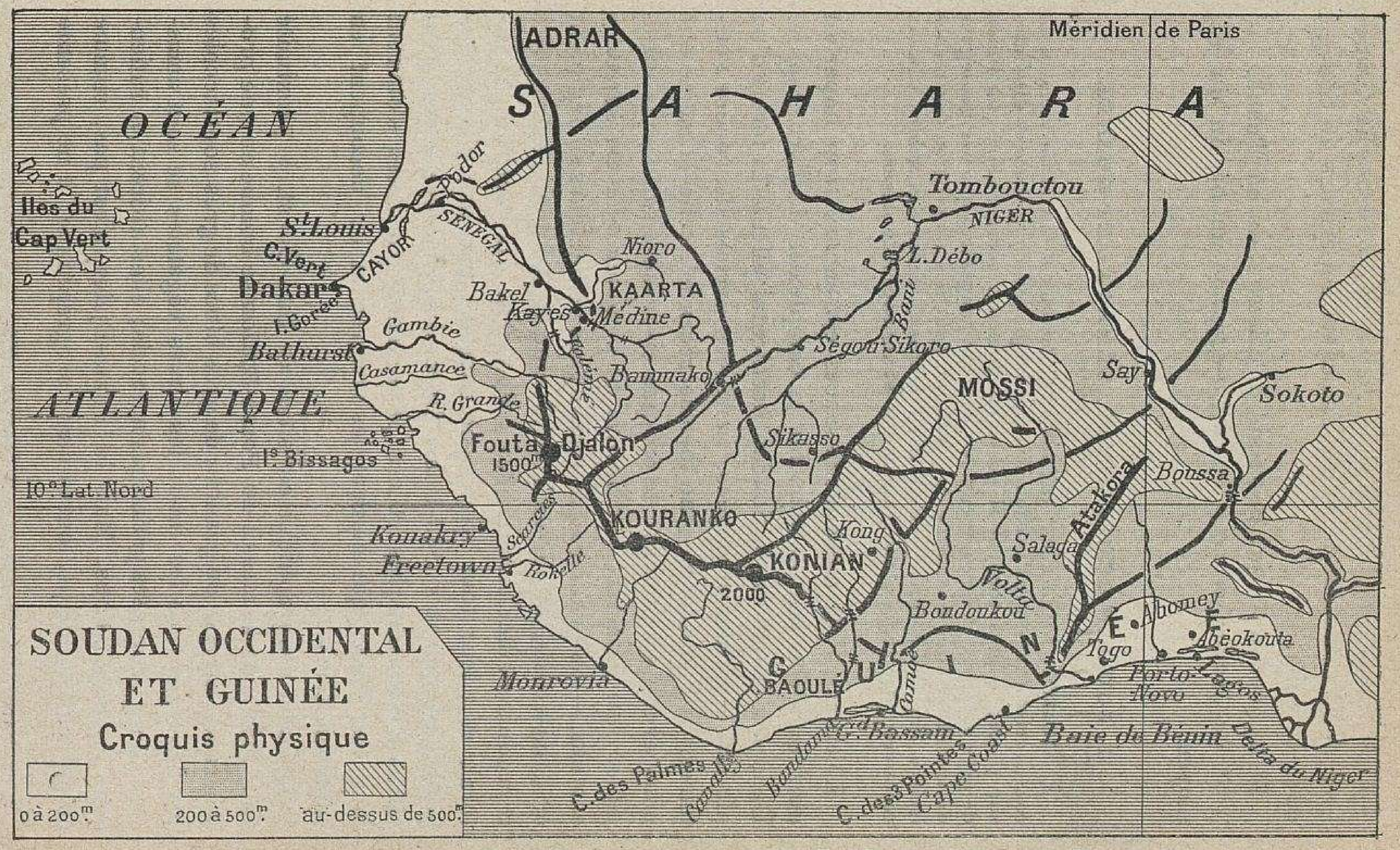


$1^{\circ}$ Le Soudan occidental - auquel nous joindrons la Guinée - répond au bassin du Niger, aux cours supérieurs du Sénégal et de la Volta.

$2^{\circ}$ Le Soudan central au bassin du Chari et du lac Tchad.

$3^{\circ}$ Le Soudan oriental ou anglo-égyptien au bassin du Nil moyen.

\section{SOUDAN OGGIDENTAL, SENEGAL ET GUINEEE}

I. Relief. - Le socle qui porte le Soudan est fait uniformément de roches cristallines que l'érosion atmosphérique a décomposées et dissoutes sur place; le plus souvent il porte un manteau sédimentaire, un limon de grès argileux et ferrugineux, de couleur rougeàtre, que les géologues désignent du nom de laterite. Cà et là pointent des massifs ou des roches isolées, qui, moins friables, n'ont pas été arasés. Enfin des sables siliceux recouvrent les régions septentrionales et annoncent le désert.

L'état actuel de nos connaissances est encore trop imparfait pour qu'il soit aisé de démêler la complexité de l'orographie. Dans son ensemble, le Soudan occidental affecte la forme d'un plateau à terrasses étagées, hérissées parfois de roches solitaires. Si l'on accepte une théorie récente ${ }^{1}$, celle-là même que nous avons adoptée sur le croquis ci-dessus, sans nous dissimuler son caractère provisoire, et combien elle est sujette à caution, - on peut dire que trois lignes de hauteurs se déploient en demi-cercle, autour de Tombouctou choisi pour centre; elles reproduisent fidèlement, elles " épousent » la courbure du littoral, et à leur tour elles sont coupées par des plissements parallèles orientés Sud-Ouest Nord-Est. A travers ces trois chaînes concentriques et ces plissements parallèles s'ouvrent tous les seuils qui barrent les rivières et les découpent en autant de biefs.

Le nœud orographique est situé au Sud-Ouest, à proximité de l'Océan. Là le massif du Fouta-Djalon se bombe en une protubérance énorme de granite; de gros blocs de grès sont accolés aux flancs, et dans les fonds les terres végétales se sont amassées; il s'y forme des pâturages naturels; elles attirent et retiennent les populations. Mais le Fouta-Djalon n'est pas, comme on l'a cru longtemps, tout le noud orographique; il ne présente

1. Dr Barot, La Géographie, 15 janvier 1903. 
pas davantage les plus fortes altitudes: en effet il ne couvre que le tiers d'un massif bien plus étendu et ses pics arrondis n'atteignent pas la hauteur des Vosges (mont Tembiko, mont Daro 1.350 m.). Les deux autres tiers sont formés par le Kouranko et le Konian; là se dresse une pyramide superbe (mont Nimba, $1.644 \mathrm{~m}$.); quant aux monts Drouplé, ils atteignent seulement 1.339 mètres. Tout ce bloc de montagnes, voisin de la mer, est

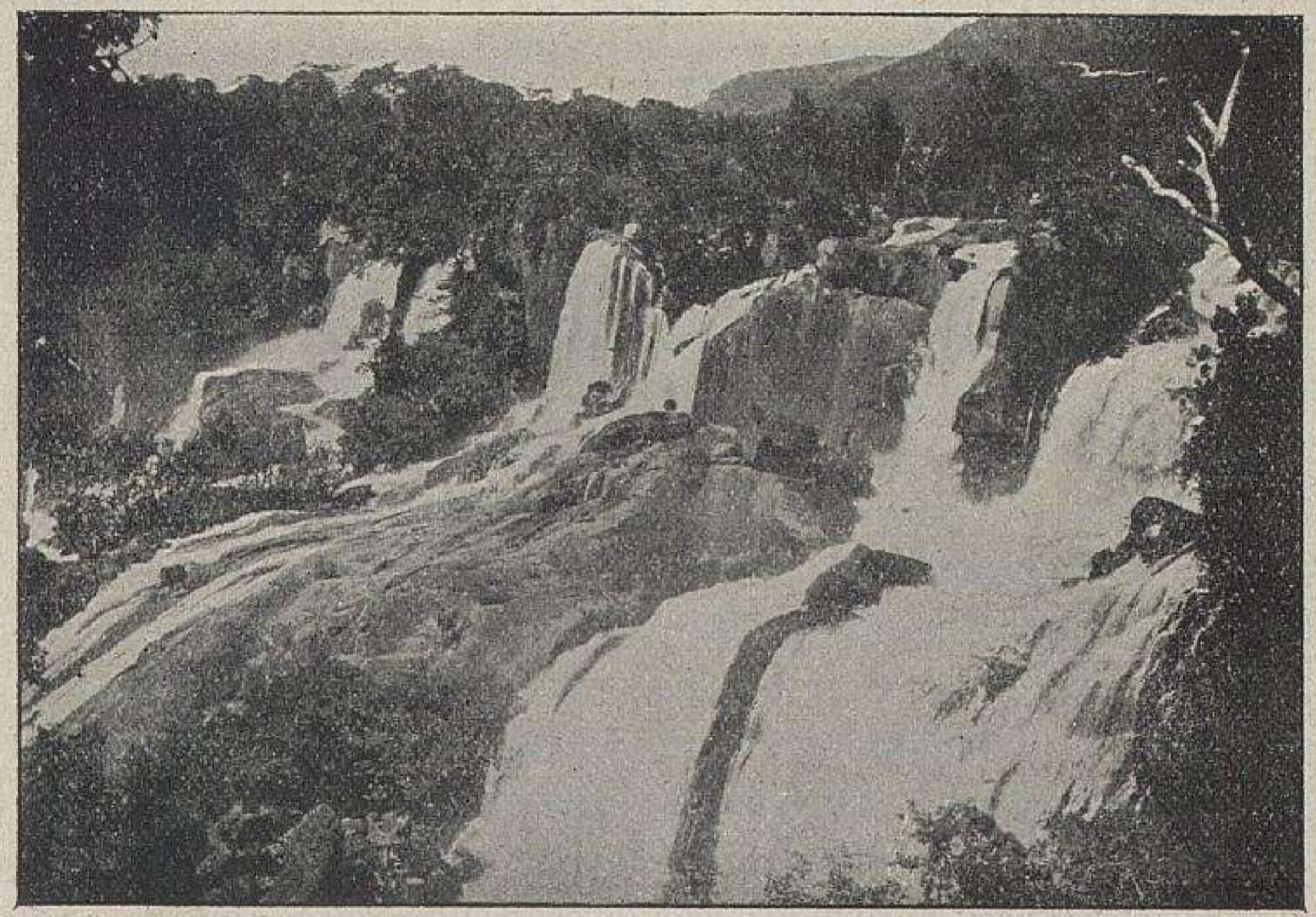

GIIUTES DU TINKISSO A KAMBAYA (FOUTA-DJALON).

(Photographie communiquée par M. le Dr Maclaud.)

abondamment arrosé par les pluies; de toutes parts ruissellent les filets d'eau, les rivières courent, et de là descendent les plus grands fleuves, le Sénégal et le Niger. - Les deux versants diffèrent. Vers l'océan Atlantique, le massif se brise et s'abaisse en deux ou trois terrasses successives, dont chacune est découpée de vallées profondes et surmontée, de place en place, par des pitons. Vers le Nord au contraire, la pente s'allonge et conduit doucement à un plateau de 500 kilomètres d'étendue.

II. Climat. - Le Soudan est un pays de moussons. Deux influences contraires exercent successivement leur action : d'une part l'Océan, de l'autre la masse continentale. Périodi- 
quement, lorsque le soleil passe au zénith, les nuées, appelées du Sud par l'échauffement excessif des terres, déversent la pluie par trombes, par bourrasques, en orages désastreux; du Sud au Nord la saison pluvieuse est de plus en plus tardive, et aussi de plus en plus courte. Puis, lorsque le soleil est sur l'hémisphère austral, le vent s'établit de la terre vers la mer, il est sec et s'appelle harmattan (d'un mot arabe = terre brûlée).

Dans l'ensemble, le relief est trop faible pour exercer une influence prépondérante; c'est suivant la courbe du rivage et suivant la courbe des lignes du relief, que se succèdent du Nord au Sud les régions climatériques.

Comme l'humidité diminue graduellement vers l'intérieur, les écarts croissent et le thermomètre s'élève d'autant plus que l'on s'écarte de la ligne équinoxiale : l'équateur thermique se tient aux environs de $10^{\circ}$ Lat. $\mathrm{N}$.

$1^{\circ} \mathrm{Au}$ Nord d'une ligne tracée de l'Atlantique entre le cap Vert et la Gambie vers Kayes sur le Sénégal, vers Ségou sur le Niger, vers Dori dans la boucle du Niger, enfin vers Say, s'étend une région subdésertique ou présaharienne. La sécheresse est excessive, et très forts sont les écarts de température: en janvier, à Tombouctou, le thermomètre monte le jour à $43^{\circ}$ et descend la nuit à $1^{\circ}$. Quand arrivent les pluies (en août et septembre surtout), elles tombent par rafales et les tornades emplissent de leurs déluges des flaques énormes, aussitôt bues et évaporées; cette saison est la plus pénible, elle provoque de terribles maladies épidémiques. Podor est réputé pour sa chaleur; elle est passée en proverbe: “ chaleur sénégalienne ». C'est un enfer.

$2^{\circ} \mathrm{Au} \mathrm{Sud}$, le sol se relève, la mer est plus proche : aussi les ondées temporaires de l'hivernage ${ }^{1}$ sont-elles et plus abondantes et plus précoces (en moyenne $60 \mathrm{~cm}$.); les écarts de température sont moindres. C'est la région soudanienne proprement dite, la région tropicale par excellence.

En raison de son altitude, la haute vallée du Niger est celle où les Européens rencontrent les conditions d'habitabilité les

1. Hivernage, terme de marine, pour désigner le temps de la mauvaise saison que les navires passent en relâche, est synonyme de saison pluvieuse dans les régions équinoxiales. 
plus favorables, celle où les populations sont le plus denses: là est le " centre vital de l'Afrique occidentale ». "S'il se fonde jamais un empire dans le Soudan français, disait Faidherbe, c'est dans cette région, sur le haut Niger, que sera la capitale ».

$3^{\circ}$ Plus bas encore, vers le Sud, à la région tropicale succède la région équatoriale. C'est vers le large de Sierra Leone que les marins s'apprêtent à quitter le ciel clair de Dakar pour s'enfoncer dans les brumes du " pot au noir ». Sous le ciel gris et nuageux, l'air est saturé d'humidité; la température toujours égale, sans être pourtant excessive, épuise et anémie les blancs : elle les expose aux diarrhées infectieuses, à la fièvre jaune, à la fièvre bilieuse hématurique, au tétanos, aux plaies ulcéreuses, etc. Bathurst passe pour être affligé du climat le plus meurtrier du monde : c'est le tombeau des Européens. Les villes doivent se résigner à n'être le plus souvent que des centres d'exploitation et non de peuplement.

La côte méridionale de Guinée connaît deux saisons pluvieuses (6 $6^{\circ}$ Lat. N.). La raison en est que le soleil passe deux fois au zénith à des intervalles assez éloignés; la grande saison des pluies dure d'avril à juillet, et la seconde, plus courte, de septembre à octobre.

\begin{tabular}{|c|c|c|c|c|c|c|c|c|c|}
\hline \multirow{3}{*}{ RÉGIONS } & \multirow{3}{*}{ LOCALITÉS } & \multirow{3}{*}{ 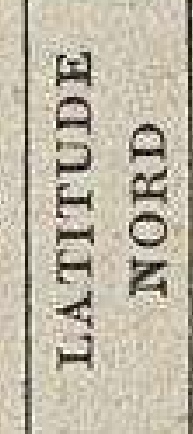 } & \multicolumn{4}{|c|}{ TEMPÉRATURE MOYENNE } & \multicolumn{3}{|c|}{ PLUIES } \\
\hline & & & & & & & 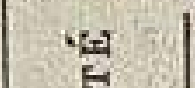 & & \\
\hline & & & $\frac{\pi}{4}$ & $\begin{array}{l}\text { le plus } \\
\text { frais }\end{array}$ & $\begin{array}{l}\text { le plus } \\
\text { chaud }\end{array}$ & 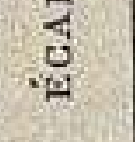 & $\begin{array}{l}5 \\
\vdots \\
\vdots \\
a\end{array}$ & $\stackrel{?}{\circ}$ & DATE \\
\hline \multirow{3}{*}{$\begin{array}{c}\text { I. Subdésertiqu } \\
\text { Littoral }\end{array}$} & & & & & & & & & \\
\hline & $\left\{\begin{array}{l}\text { St-Louis } \\
\text { Gorée. }\end{array}\right.$ & $\begin{array}{l}16^{\circ} \\
14^{\circ}\end{array}$ & $\begin{array}{l}23^{\circ} \\
23^{\circ}\end{array}$ & $\begin{array}{l}\text { Mars } 19^{\circ} \\
\text { Fév. } 18^{\circ}\end{array}$ & $\begin{array}{l}\text { Sept. 27० } \\
\text { Sept. 27० }\end{array}$ & $\begin{array}{l}8^{\circ} \\
9^{\circ}\end{array}$ & $\left|\begin{array}{l}0^{\mathrm{m}}, 40 \\
0^{\mathrm{m}}, 52\end{array}\right|$ & $\begin{array}{l}35 \\
35\end{array}$ & $\begin{array}{l}\text { Juin à oct. } \\
\text { Juin à oct. }\end{array}$ \\
\hline & Podor . . & $16^{\circ}$ & $28^{\circ}$ & Janv, 220 & Mai $31^{\circ}$ & $9^{\circ}$ & $0^{\mathrm{m}}, 32$ & - & Juillet à oct. \\
\hline \multirow[t]{2}{*}{ Intérieur. } & $\left\{\begin{array}{c}\text { Tombouctou } \\
250^{\mathrm{m}} .\end{array}\right.$ & $16^{\circ}$ & & Janv. $20^{\circ}$ & Juin $35^{\circ}$ & $15^{\circ}$ & $0^{\mathrm{m}}, 22$ & 30 & Juin à oct. \\
\hline & Kayes $60^{\mathrm{m}}$. & $14^{\circ}$ & $29^{\circ}$ & Janv. $23^{\circ}$ & Mai $37^{\circ}$ & $14^{\circ}$ & $0^{\mathrm{m}}, 36$ & 30 & Juill. à sept. \\
\hline \multirow[t]{2}{*}{ II. Tropicale } & Bathurst & $13^{\circ}$ & $24^{\circ}$ & Fév, $21^{\circ}$ & Oct. $26^{\circ} \mid$ & $5^{\circ}$ & $1 \mathrm{~m}, 33$ & 48 & Mai à oct. \\
\hline & Sierra Leone. & $8^{\circ}$ & $25^{\circ}$ & Août 240 & Avril 27० & 30 & $4^{\mathrm{m}}, 30$ & 137 & Avril à nov. \\
\hline \multirow{3}{*}{$\begin{array}{c}\text { Intérieur. } \\
\text { II. Equatoriale. } \\
\text { Littoral . }\end{array}$} & (Timbo $600^{\mathrm{m}}$. & $10^{\circ}$ & $24^{\circ}$ & Janv. $22^{\circ}$ & Avril 270 & $5^{\circ}$ & $1^{\mathrm{m}}, 49$ & 125 & Avril à oct. \\
\hline & Kita $358^{m}$. & $12^{\circ}$ & $27^{\circ}$ & Déc. $25^{\circ}$ & Mai $32^{\circ}$ & $7^{\circ}$ & $1^{\mathrm{m}}, 25$ & 98 & Juin à oct. \\
\hline & Porto-Novo & $6^{\circ}$ & $27^{\circ}$ & Août $24^{\circ}$ & Mars 290 & $5^{\circ}$ & $1^{\mathrm{m}}, 69$ & 125 & $\begin{array}{l}\text { Avril à Juil. } \\
\text { Sept. à oct. }\end{array}$ \\
\hline Intérieur. & Salaga $165^{\mathrm{m}}$. & $8^{\circ}$ & $26^{\circ}$ & Août $24^{\circ}$ & Mars 28 & $4^{\circ}$ & $1^{\mathrm{m}}, 65$ & & $\begin{array}{l}\text { Avril à mai } \\
\text { Sept. à oct. }\end{array}$ \\
\hline
\end{tabular}


III. Hydrographie. - Tous les cours d'eau ont des traits communs qui résultent du relief et du climat : ils sont sujets à des crues périodiques; ils tombent en cataractes, ou bien en cascades, ou encore par de simples rapides semés de roches; et tous ces barrages retiennent les eaux qui refluent en amont et inondent de grands espaces après la saison des pluies.

Les massifs du Fouta-Djalon, du Kouranko et du Konian sont un centre de condensation des pluies, un centre par conséquent de dispersion remarquable.

$1^{0}$ Niger. Son nom le dit assez : le Niger est le fleuve des Noirs. Le troisième des cours d'eau africains par la longueur $(4.000 \mathrm{~km}$.), il décrit une grande courbe vers le Nord et se décompose en trois fleuves distincts.

A. Haut Niger. - Né sur les pentes orientales du FoutaDjalon par 850 mètres d'altitude seulement, il est, jusque vers Ségou, fleuve tropical de plateau. Son lit, bordé à gauche d'une falaise élevée, est gêné par de hauts fonds, barré par des rapides dont les derniers fort dangereux (roches de Sotouba) le coupent en aval de Bamako. Touś les cours d'eau qui le forment se sont joints avant Siguiri : le Tinkisso à gauche, navigable en toute saison jusqu'à Dinguiray, et la rivière de Kankan à droite.

B. Moyen Niger. - A partir de Ségou, les arbres cessent sur les rives : de tropical qu'il élait le Niger devient fleuve de désert. Comme la pente est très faible et qu'il existe moins une vallée qu'une plaine immense, à peine ondulée, en forme de cuvette, les eaux calmes s'étalent sur une largeur de 2 kilomètres à l'étiage, et c'est un lacis de bras, de marigots, un delta véritable que complique l'arrivée d'un gros affluent de droite, le Bani ou Mayel Balevel. A l'époque des crues, tout est submergé, si bien que la même terre se prête alternativement à l'élevage et aux cultures, ensuite aux pêcheries. Des lacs nombreux constituent des bassins naturels de retenue : l'un, le lac Débo, est traversé par le fleuve, qui s'y étale sur de belles plages de sables; d'autres se répartissent sur les deux rives : le Faguibine, le plus long $(110 \mathrm{~km}$.), troue un plateau ferrugineux, stérile; et tous servent à régulariser les eaux du fleuve, en aspirant le trop-plein des eaux qu'ils renvoient ensuite lors 
de la saison sèche. De la sorte la crue ne s'écoule pas, inutile, en une seule masse; elle débute en mai, monte progressivement, sans violence, se maintient constante durant douze ou quinze jours, puis faiblit jusqu'en octobre; pendant sept mois, toute une flottille anime le fleuve de longues et grandes pirogues indigènes, capables de contenir trente tonnes, ou de barques légères, qui filent gracieuses et rapides. Aux basses eaux, on avance à la perche, en froissant les grandes herbes. Telle se présente la zone d'inondation du $M a-$ cina.

Arrivé à la hauteur de Tombouctou, le Niger se recourbe devant la falaise saharienne, vers l'Est d'abord, puis vers le SudEst. Son lit, large de 2 à 3 kilomètres et peu profond, est obstrué de rapides (rapides d'Ansongo) qui, sans être abso-

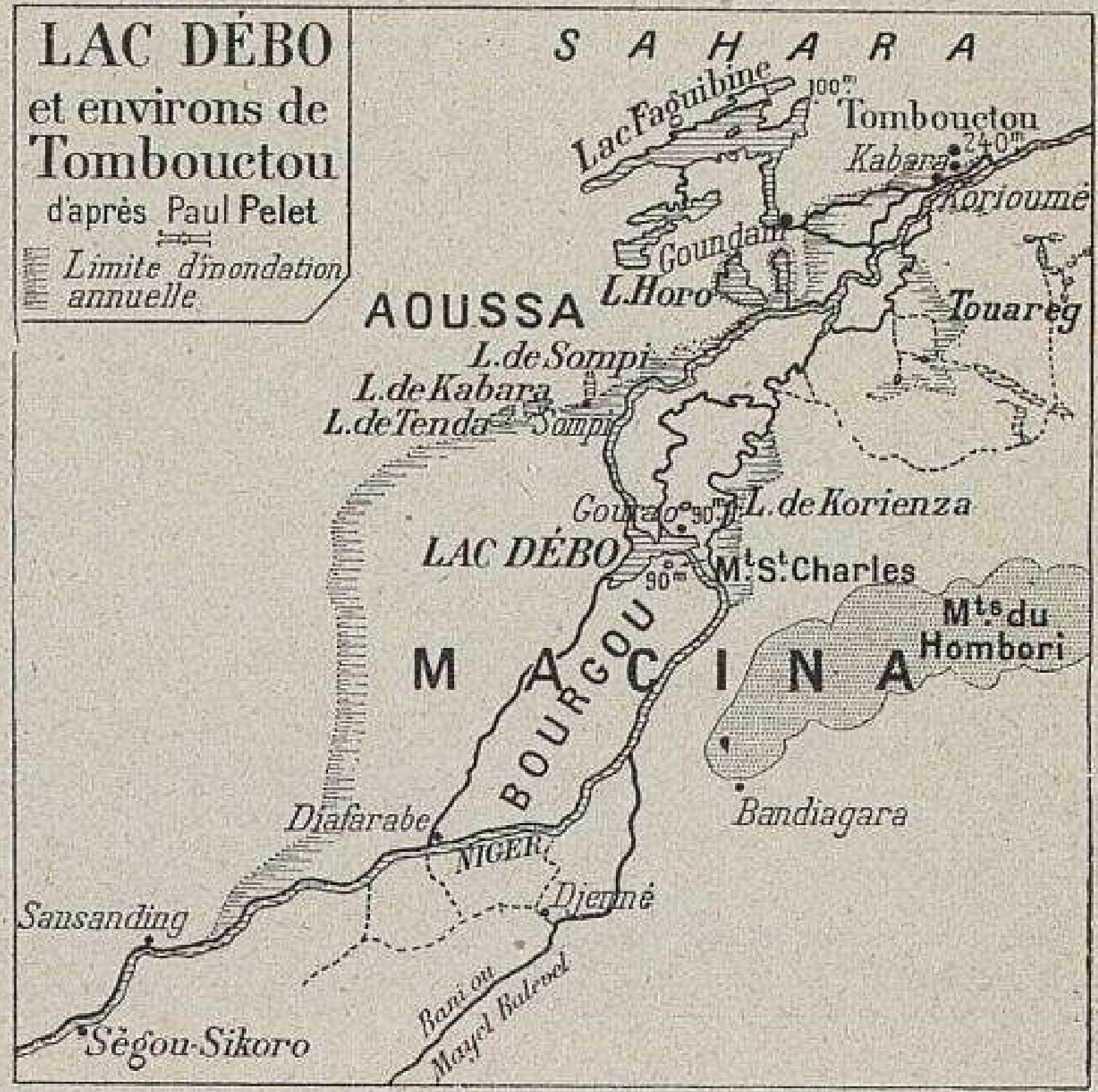
lument infranchissables, suffisent à retenir les eaux d'amont, si bien que la crue arrive ici en pleine saison sèche (août à février); seules les îles, seules les rives immédiates, qui sont inondables, portent quelque végétation. Au delà, tout de suite, c'est le désert.

C. Bas Niger. - A force de redescendre vers le Sud, le Niger rentre dans, la région tropicale qu'il avait déjà traversée dans son cours supérieur : un troisième Niger commence alors vers la frontière franco-anglaise. Ce qui le caractérise, c'est que la période des crues est double : la première en date est produite par les pluies des moussons qui pénètrent la basse vallée de juin en octobre; la seconde plus tardive - car il lui a fallu décrire un long parcours - par l'arrivée des eaux supérieures. Alors, c'est deux fois par an, au lieu d'une, que le $\mathrm{N}$ ger 
déborde, lorsqu'il n'est pas contenu par des rives verticales : de bienfaisant qu'il était, le voilà devenu nuisible, et des boues toujours liquides rendent les plaines inhabitables et malsaines.

Avant d'arriver à la mer, il franchit les derniers gradins du plateau par des rapides : ce sont ceux de Boussa, les plus longs de tous $(200 \mathrm{~km}$.). Les eaux se précipitent à une allure vertigineuse (40 ou $50 \mathrm{~km}$. à l'heure), roulent dans des couloirs de granite, bondissent entre les aiguilles de porphyre qui hérissent

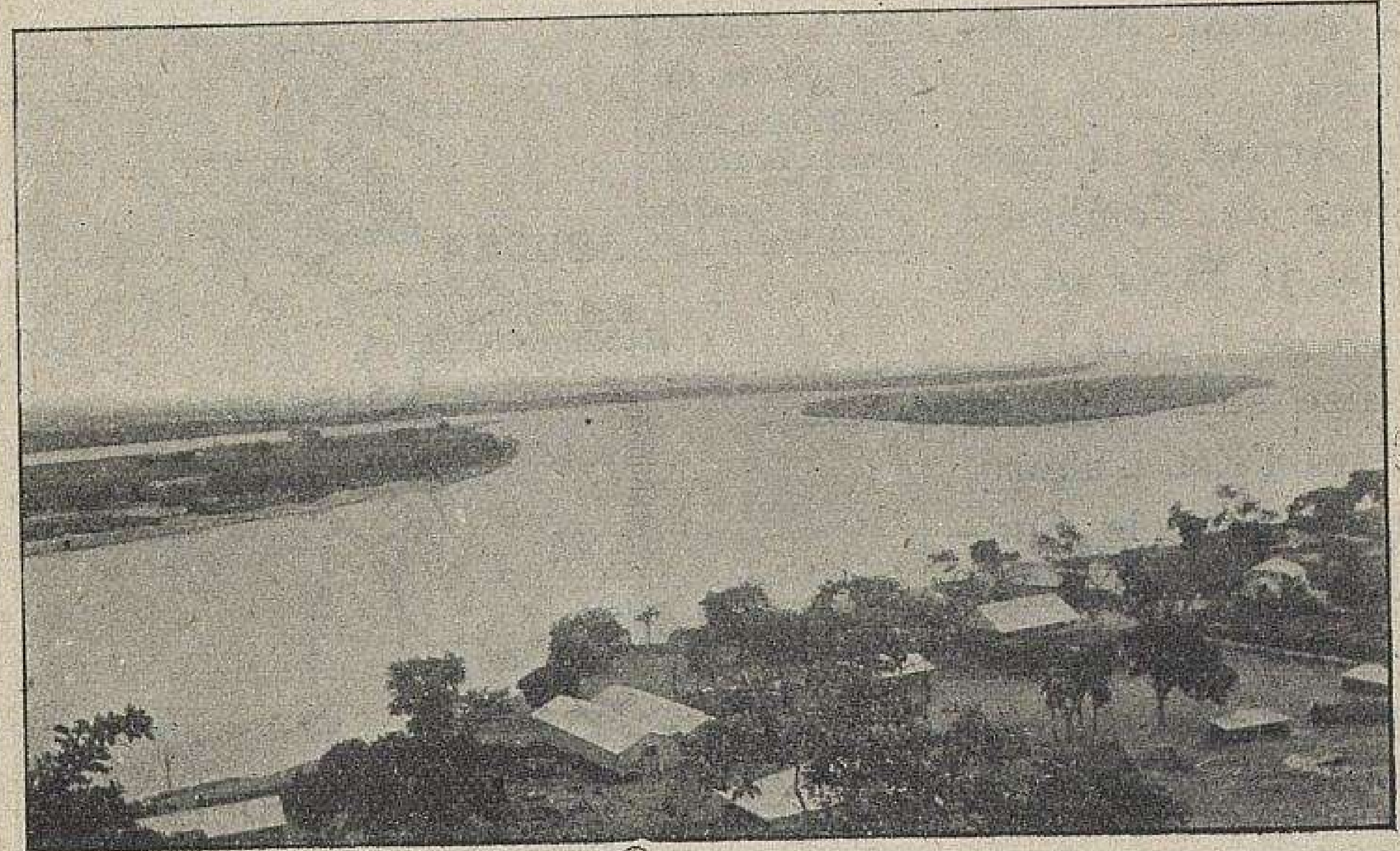

VUE DU NIGER, EN AVAL DES RAPIDES DE BOUSSA

(Photographie du capitaine Lenfant.)

Le village de Djebba ou Jebba, partie rive droite et partie dans une île, n'est plus qu'un poste secondaire; la nouvelle capitale britannique a été transportée à 20 kilomètres au Nord.

le lit et tourbillonnent secouées par de puissants remous. Et cependant, pour qui connaît les courants et les roches, les passes peuvent être franchies sur des embarcations légères avec l'aide de piroguiers rompus à la manœuvre.

Depuis longtemps le Niger a quitté ses allures sauvages, il a pris une ampleur majestueuse, lorsqu'il absorbe à Lokodja une rivière large de 1.500 mètres : la Bénoué; nous la retrouverons en étudiant le Soudan central, vers lequel elle ouvre une voie de pénétration. Bientôt se dessine la tête du delta, et c'est par seize branches, sur un front de 350 kilomètres, que le Niger 
disparaît dans le golfe de Guinée; la rivière Noun et la rivière Forcados sont les deux bouches adoptées par la navigation.

$2^{\circ}$ Le Sénégal $(1.430 \mathrm{~km}$.) présente plus d'une ressemblance avec le Niger; mais son cours ne comprend que deux sections, l'une tropicale et l'autre désertique.

Comme le Niger, il s'alimente au Fouta-Djalon. Les cours

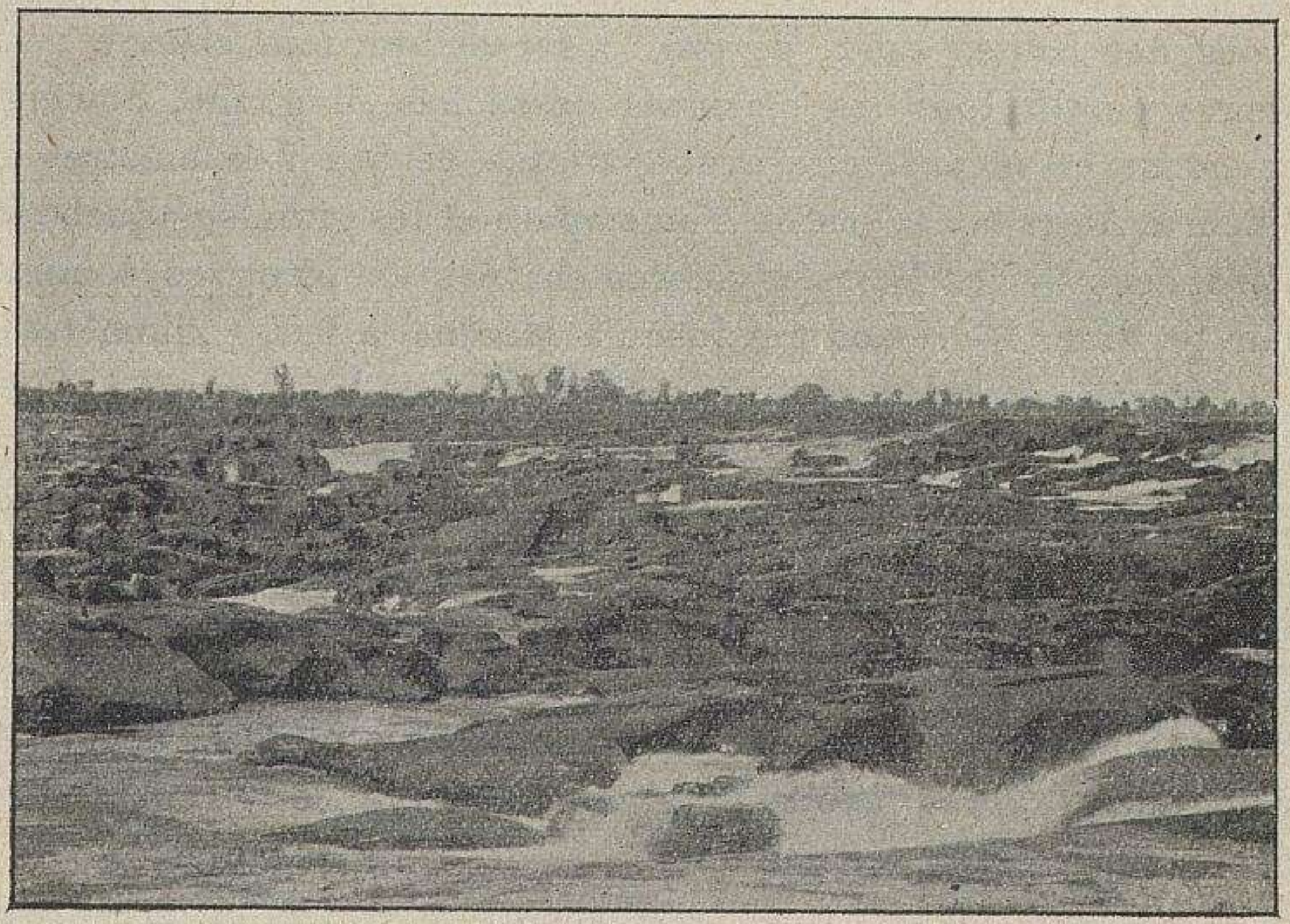

CHUTES DU FELOU, SUR LE SENÉGAT, PAR BASSES EAUX, AVEC MARMITES DE ROCHES.

(Photographie communiquée par M. Binger.)

d'eau qui le forment, très encaissés, tombent de chute en chute; ce sont le Bakhoy et le Bafing qui se joignent à Bafoulabé, puis la Falémé qui, très forte à l'hivernage, fort maigre le reste de l'année, conflue beaucoup plus bas, avant Bakel. Quant au Baoulé, à droite, c'est un cours d'eau temporaire, de steppes semi-désertiques.

Après les Chutes du Felou, et plus exactement à Kayes, où les bateaux ne risquent plus de s'empaler sur les pointes de rochers qui le hérissaient encore, le Sénégal entre dans la seconde partie de son cours. Sans doute il n'y a plus de barrage pour couper la navigation; mais du même coup plus rien ne soutient le plan d'eau, par surcroît les pluies dimi- 
nuent de durée et de force : à droite, à gauche s'étendent des déserts, le Kaarta et le Ferlo. De là un régime des plus inconstants : entre les berges argileuses, coupées à pic (10 à $12 \mathrm{~m}$. de haut; 250 à $450 \mathrm{~m}$. d'écartement), le Sénégal est à la saison sèche si pauvre qu'on peut le passer à gué, et dans les trous s'ébattent les caimans et les hippopotames. Tel il se montre jusqu'à Mafou où la marée vient soutenir son volume. Lors des hautes eaux, de juin à septembre, tout change : le fleuve emplit tous les marigots desséchés, il gonfle, devient immense et se précipite à une vitesse de 5 à 7 kilomètres à l'heure. Alors la navigation s'en empare et les grands paquebots européens - les Noirs n'y circulent pas en pirogues comme sur le Niger - remontent jusqu'à Médine, à 1.000 kilomètres de l'Océan. Alors aussi l'inondation prépare la campagne pour les semailles indigènes.

Arrivé à la fin de sa course, le Sénégal, influencé par les marées, s'étale sur de grands espaces $(30 \mathrm{~km}$. aux hautes eaux); sa pente devient presque nulle; il forme des lacs latéraux, mais peut encore porter aux plus basses eaux des navires calant 3 mètres. G'est au delà de Saint-Louis qu'il se décide à disparaître, après avoir longtemps côtoyé le rivage; son embouchure est gênée par une barre des plus instables.

$3^{\circ}$ Fleuves côtiers. - Nombreuses sont les rivières qui tombent directement du Fouta-Djalon dans l'océan Atlantique : la Gambie, la Casamance, le rio Grande, etc., descendent par des chutes les terrasses montagneuses et finissent par de larges estuaires que garnit une épaisse végétation.

Au delà du cap des Palmes, les cours d'eau du golfe de Guinée n'ont plus leur cours réduit par le voisinage des hauts massifs : leurs sources plongent très loin au cœur du pays, jusqu'à $14^{\circ}$ Lat. N., et les pays que le Niger enveloppe de sa boucle ne font pas partie de son domaine. Ce sont toujours des rivières à cascades, et toujours elles sont sujettes aux crues des pluies tropicales; des savanes découvertes elles passent sous la grande forêt, les racines et les feuilles y retiennent les terres et empêchent l'érosion des rives; de la sorte les atterrissements ne comblent pas les lagunes où, pour la plupart, elles achèvent leur course. Quelques-unes ont seules assez de 
puissance pour rompre le cordon littoral et maintenir toujours libre la sortie vers la haute mer. Tels sont, de l'Ouest à l'Ést, le Cavally, le Sassandra, le Bandama qui traverse le Baoulé et

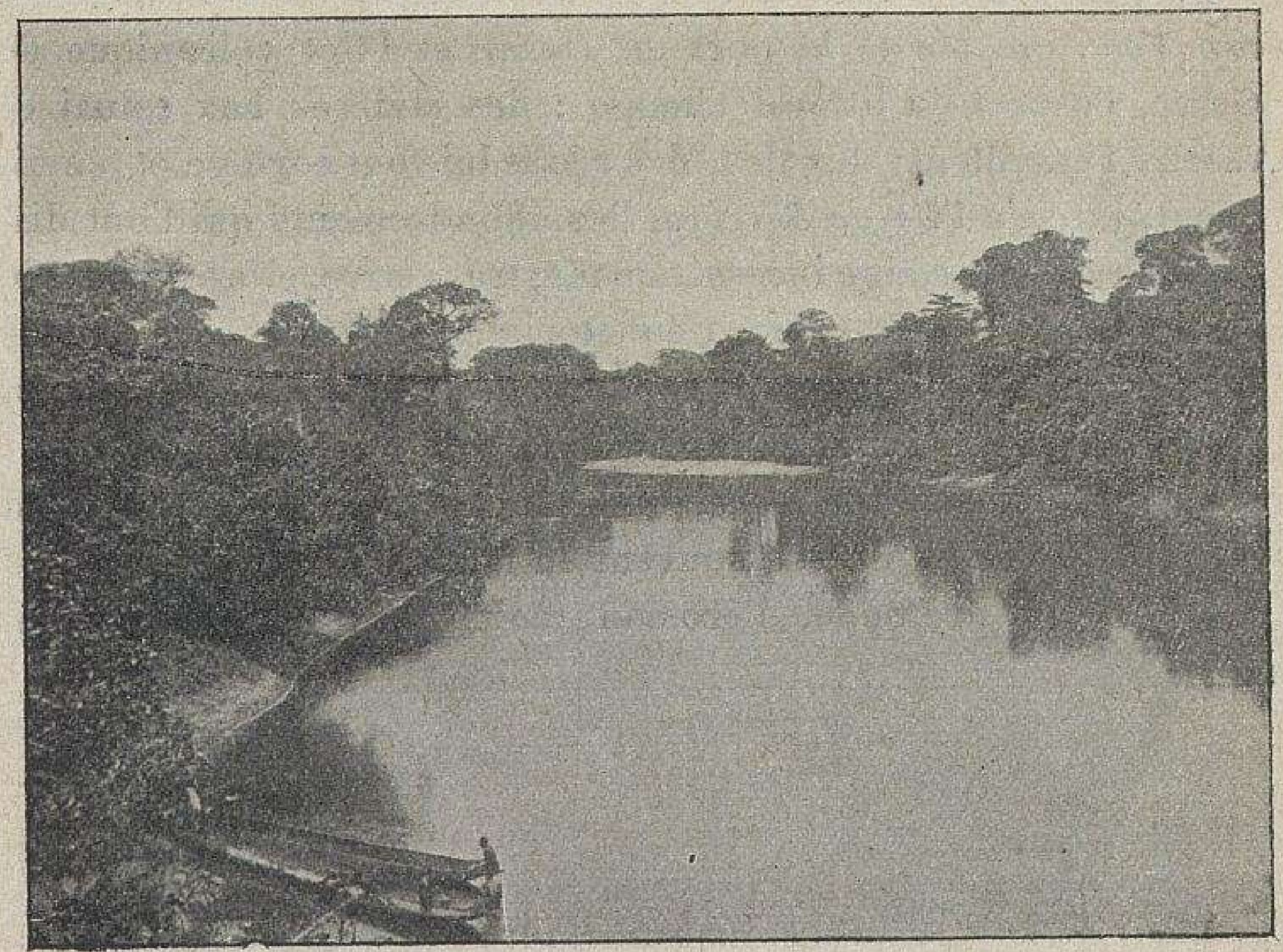

TYPE DE RIVIĖRE A LA CÓTE DE L IVOIRE.

LE TANOÉ, A TRAVERS LA FORÊT.

(Photographie de la mission Binger, communiquée par l'Office Colonial.)

finit en face de Grand Lahou, le Comoé, rivière du pays de Kong, qui emporte par le chenal de Grand Bassam les eaux de la lagune Ebrié, la Volta, l'Ouémé enfin qui se perd dans la lagune dahoméenne de Porto-Novo.

La Volta est le plus long de tous les cours d'eau rencontrés depuis l'embouchure du Sénégal jusqu'au delta du Niger. Son nom portugais est très expressif : il est peu de rivières qui voltent comme elle. La Volta noire coule d'abord parallèlement au Niger supérieur, puis un affluent la heurte de front? elle se jette au Sud; mais un massif de grès et de granite la renvoie au-devant de la Volta blanche, qui descend du Mossi, orientée comme le Niger inférieur. A l'inverse de ce qui se passe normalement, c est le bassin supérieur qui est large, et le bassin inférieur resserré.

IV. Côtes. - A. Côtes désertiques. - Lies côtes sahariennes, monotones et rectilignes, accompagnées de dunes sablonneuses et aussi d'étangs salins, sont d'autant plus inhospitalières que l'alizé refoule le flot vers le large. La mer est

G. Lisspagiol Et M. Falhex. - Afrique. 
peu profonde, par suite très poissonneuse; c'est sur le banc d'Arguin que périt la Méduse en 1817. Seule l'arrivée du Sénégal coupe la plage.

B. Côtes tropicales à estuaires. - Après les falaises du cap Vert, qui abrite le port de Dakar et l'îlot volcanique de Gorée, l'aspect du littoral change : des rivières aux estuaires vaseux l'entaillent; des îles, des récifs lui font cortège et témoignent, jusqu'à l'île de Sherbro, des effondrements qui l'ont disloqué. La mer le ronge incessamment; très active, elle est poussée par le flot du contre-courant équatorial, poussée encore par les courants atmosphèriques qui soufflent de l'Ouest : au Rio Nunez, les marées s'élèvent au chiffre très fort de 6 mètres.

C. Côte libérienne. - Moins échancrée, plus droite, la côte libérienne se dresse souvent en falaises; la mer est moins dure, moins profonde, l'érosion moins forte, et les sables

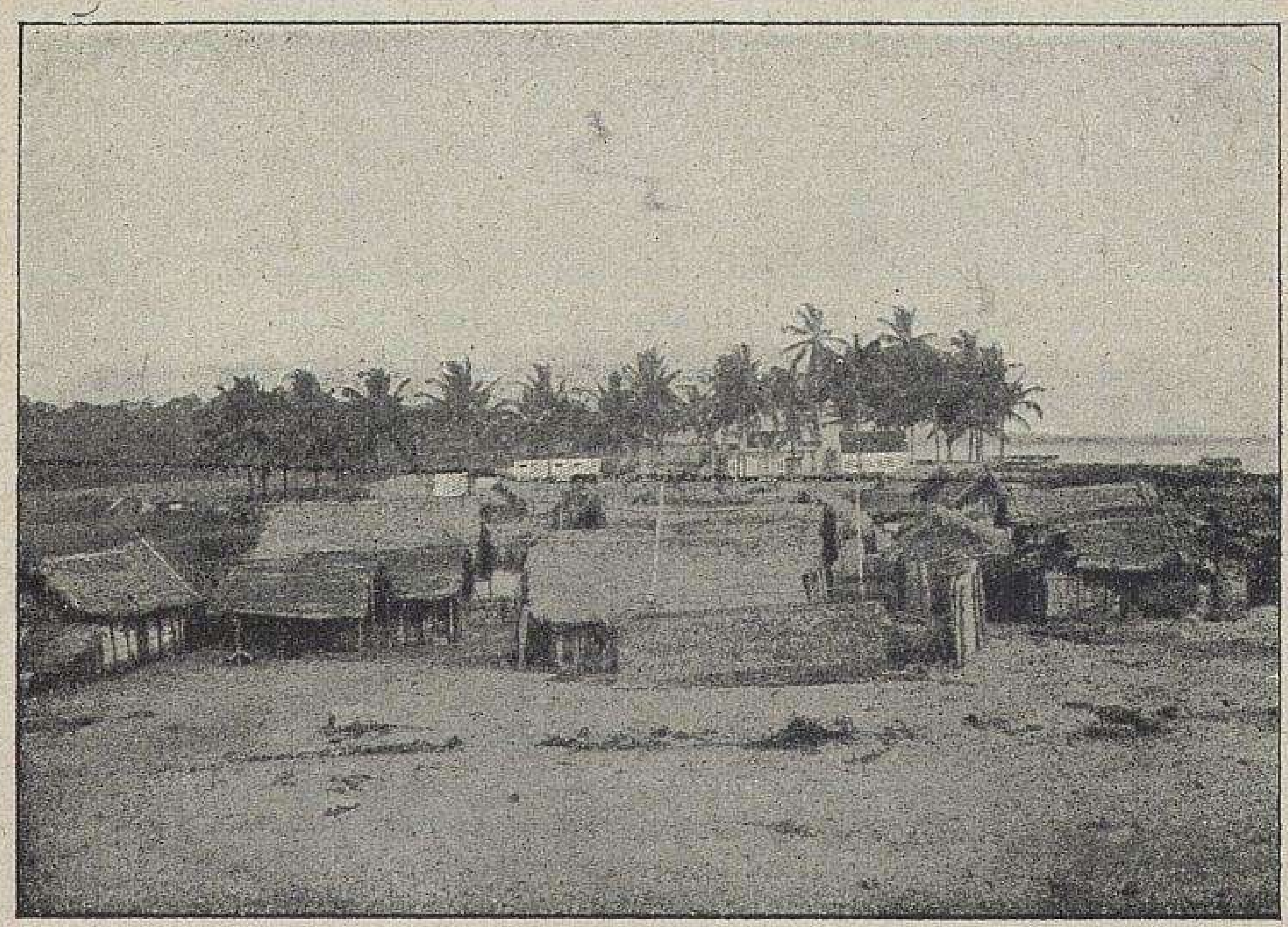

VILLAGE D'ASSINIE, PLAGE DE LA CÓTE DE L'IVOIRE.

(Photographie de la mission Binger, communiquée par l'Office Colonial.)

obstruent les embouchures des rivières toujours nombreuses. Déjà le ressac déferle continuellement, lorsque au cap des Palmes l'orientation change.

D. La Côte de Guinée s'étend jusqu'au golfe de Bénin, jus- 
qu'aux bouches du Niger. A part quelques exceptions (cap des Trois Pointes, rochers de la Côte de l'Or) elle est d'ordinaire basse, plate, d'une régularité parfaite; ni inflexion, ni brisure; à

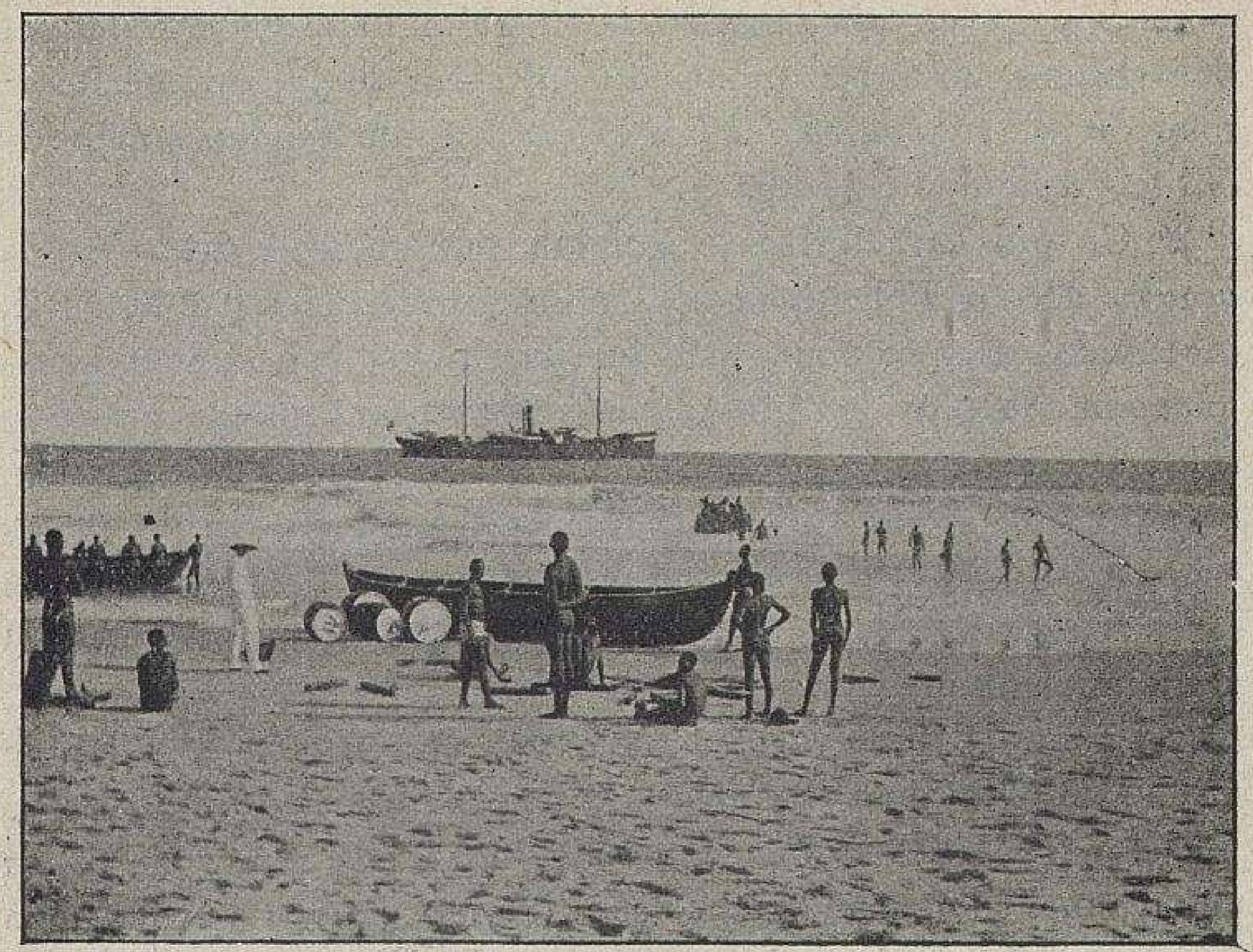

PASSAGE DE LA BARRE SUR LA GÔTE DE GUINÉE. AU DAHOMEY.

(Photographie communiquée par M. Binger.)

perte de vue, des plages de sable et de coquillages. En avant la mer brise avec fracas et la barre rend l'accès encore plus difficile.

Derrière le cordon littoral s'allonge un chapelet de lagunes (Grand Lahou, Ebrié et Grand Bassam, Assinie, Kotonou, Lagos, etc.). Ce ne sont pas des nappes marécageuses et croupissantes, comme le mot le ferait croire, mais de petites mers intérieures, aux eaux calmes et bleues, aux rives très peuplées et toutes parsemées d'îles; elles se prêtent à la navigation, à celle des pirogues indigènes, comme à celle des petits bâtiments européens. La communication avec l'Océan s'établit par des graus, en général à l'arrivée des plus grands fleuves.

V. Vie végétale. - $1^{\circ}$ La région subdésertique n'a d'autre végétation que des herbes dures et des arbres épineux ou à gomme, de maigre apparence dans le nombre, l'acacia gom- 
mier, en forêts naines, sans broussailles, dans le Kaarta et le Ferlo. L'arachide est une graine oléagineuse dont le Cayor est tout entier planté.

Le Sénégal et, plus encore, le Niger mettent sur ces steppes désertiques un long ruban de cultures; le Niger mérite le nom de Nil soudanien : il fait la fertilité du Soudan comme le Nil fait celle de l'Égypte.

$2^{\circ} \mathrm{Ge}$ qui caractérise le Soudan proprement dit, c'est la brousse : les grandes herbes ( 2 à $3 \mathrm{~m}$.) desséchées par le soleil, incendiées chaque année par les indigènes, reprennent brusquement vie lors des pluies tropicales et font un tapis vert au sol ferrugineux et rougeâtre. Les arbres forment des bouquets, de moins en moins rares vers le Sud. A signaler le karité ou arbre à beurre, le fromager très haut ( 50 à $60 \mathrm{~m}$.), d'un bois assez tendre pour que les noirs y creusent leurs pirogues, et le disgracieux baobab.

Le Fouta-Djalon, bien arrosé, est une région à part, de forêts, de pâturages et d'arbres fruitiers (oranger), etc.

$3^{\circ}$ La forêt dense forme depuis le Libéria jusqu'au .Niger une bande compacte, parallèle au rivage : nous l'avons déjà décrite. Aussi nous contenterons-nous de signaler les essences les plus utiles : le kolatier dont les graines sont pour le Nègre une panacée universelle, le palmier à huile, le caoutchouc, les gommiers (vernis copal), les bois d'ébénisterie et naturellement le bananier.

VI. Vie animale. - Elle varie suivant les régions climatériques et avec la végétation : steppe désertique, brousse et forêt. Nous l'avons, comme la vie végétale, définie au chapitre II. Notons seulement que de la steppe à la brousse le chameau fait place à l'âne, au cheval et au bœuf. L'éléphant a presque complètement disparu de certaines régions; il est rare dans l'Est de la côte d'Ivoire, mais la mission Hostains et d'Ollone en a rencontré en nombre considérable dans le Haut Cavally, voire même dans les régions riveraines du Soudan. En tout cas le commerce de l'ivoire n'est pas important. 


\title{
CHAPITRE IX
}

\section{SOUDAN OCCIDENTAL, SENEEGAL, GUINÉE (fin)}

\author{
11. - GEOGRAPHIE HUMAINE
}

\section{SOMMAIRE}

I. Vie humaine. - 10 La région subdésertique est parcourue par des peuples pasteurs, musulmans, Ies Maures et les Touareg, qui opprimaient les sédentaires de la vallèe du Niger.

$2^{\circ}$ Sur le Soudan proprement dit, les migrations ont produit un métissage gènéral des peuples noirs. Les aborigènes sont les Sonrhaï, qui cultivent les alluvions du Niger comme les fellahs égyptiens les alluvions du Nil.

Très anciens sont les Mandé : parmi eux les Bambara sont agriculteurs, les Dioula colporteurs.

Les Peul ou Foulbé, peuples de pasteurs et de conquérants venus de l'Est, forment au Fouta-Djalon un groupe compact.

$3^{\circ}$ Les populations de la forét ont gardé des mœurs très primitives et farouches, prèservées qu'elles étaient de tout contact extérieur.

Vers le cap des Palmes, les Krou sont les meilleurs marins de tout le littoral de Guinèe.

11. Grouvermement et villes. - $1^{\circ}$ France. Les possessions françaises, sous le nom d'Afrique occidentale, forment un immense empire dont la capitale est Dakar; le Gouverneur génèral a sous ses ordres les lieutenants gouverneurs de cinq colonies, le commissaire du territoire eivil de la Mauritanie et le commandant du territoire militaire du Niger.

A. - La colonie du Sénégal, capitale Saint-Louis $(50.000 \mathrm{~h}$. avec la banlieue); Rufisque est le grand marché d'exportation; Dakar le port d'importation et un appui pour notre flotte de guerre.

B. - Le territoire civil de Mauritanie a son centre principal dans l'Adrar.

G. - La colonie de Haut-Sénégal et Niger a son chef-lieu à Bamako; Tombouctou lui a èté incorporé en 1910.

D. - Le territoire militaire du Niger, bien réduit maintenant, a son centre principal à Zinder.

$E$. - La colonie de Guinée, capitale Konakry, est le point de depart des routes vers le Fouta-Djalon (Timbo) et vers le Haut Niger (Siguiri).

F. - La colonie de la Gôte de l'Ivoire a transférè sa capitale de 
Grand Bassam, sur la côte, a Bingerville, sur la lagune. Dans l'interieur, Kong est la capitale d'un royaume protégé.

G. - La colonie du Dahomey, chef-lieu Porto-IVovo, s'allonge jusqu'au Niger.

$2^{\circ} L^{\prime}$ Angleterre est la seconde puissance coloniale de l'Afrique occidentale.

A. - La Gambie, enclavè dans nos possessions, a pour capitale Sainte-Marie de Bathurst.

B. - Le Sierra Leone, capitale Freetown, port de guerre.

C. - La Gôte de l'Or, capitale $A k k r$, fait son plus gros commerce par Cape Coast Castle. En arrière le pays des Achantia pour centre Koumassi.

D. - La Nigeria du Sud, à laquelle le Lagos a èté réuni, et la Nigeria du Nord s'étendent du Dahomey et des bouches du Niger au Soudan central.

$3^{\circ}$ Le Portugal possède les Iles du Cap-Vert et la Guinee dite Portugaise.

$4^{\circ} L^{\prime}$ Allemagne, la dernière venue, a le Togo, capitale Lomé.

$5^{\circ}$ Le Libéria est une république nègre, cap. Monrovia.

III. Mise en valenr. - $A$. - L'Afrique occidentale, comme tous les pays neufs, fournit des produits exclusivement agricoles.

Dans les régions sèches, la gomme et les arachides; dans les régions plus arrosees ou très humides, l'huile et les amandes de palme, le caoutchouc, l'acajou et l'ébène.

Des essais de plantations coloniales (café de Libéria, indigo, coton, cacao, vanille) sont faits par les Européens.

La noix de Kola est pour les indigènes le principal objet d'échange. $L$ 'élevage est pratiqué par les Peul du Fouta-Djalon.

$B$. - Les industries indigènes (travail du fer et mètiers à tisser) ne suffisent pas aux besoins pourtant restreints des populations.

$L$ 'or, que depuis longtemps les Nègres apportaient en poudre á la côte, est actuellement l'objet de prospections et de concessions nombreuses dans le Baoulé français et dans la Cóte de l'Or anglaise.

G. - Marseille et Bordeaux, Liverpool, Anvers et Hambourg ont des relations régulières avec l'Afrique occidentale.

Toutes les colonies européennes construisent des chemins de fer de pénetration : la voie de Saint-Louis à Rufisque et Dakar a transformé le Cayor; de Kayes une autre voie relie le Sénègal au Niger vers Bamako; de Konakry une autre encore atteint le Niger vers Kouroussa. Partout de grands travaux s'ezécutent. L'essor de nos colonies de Guinée et de la Côte de l'Ivoit'e autorise de grands espoirs.

\section{DÉ VELOPPEMENT}

I. Vie humaine. - Rien de plus confus et de plus mal établi que l'ethnographie des peuples du Soudan. Mais les différences de climat ont imposé à l'homme des manières de vivre différentes. 


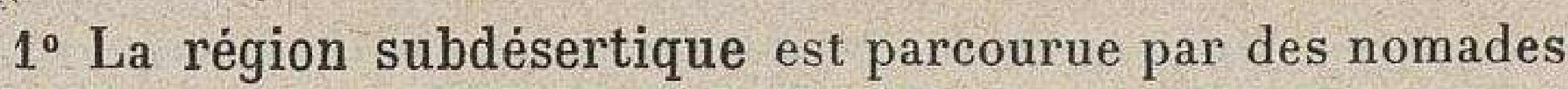
musulmans, les Maures entre le Sénégal et le Niger, de Bakel à Tombouctou, et les Touareg, aux environs de Tombouctou.

Comme les Touareg, que nous connaissons déjà, les Maures sont de race berbère, mais croisés plus ou moins de sang nègre; on le comprend de reste, puisque le pays qu'ils occupent sert de transition entre le Sahara et le Soudan. De peau jaune, la barbe peu fournie, mais soyeuse, les

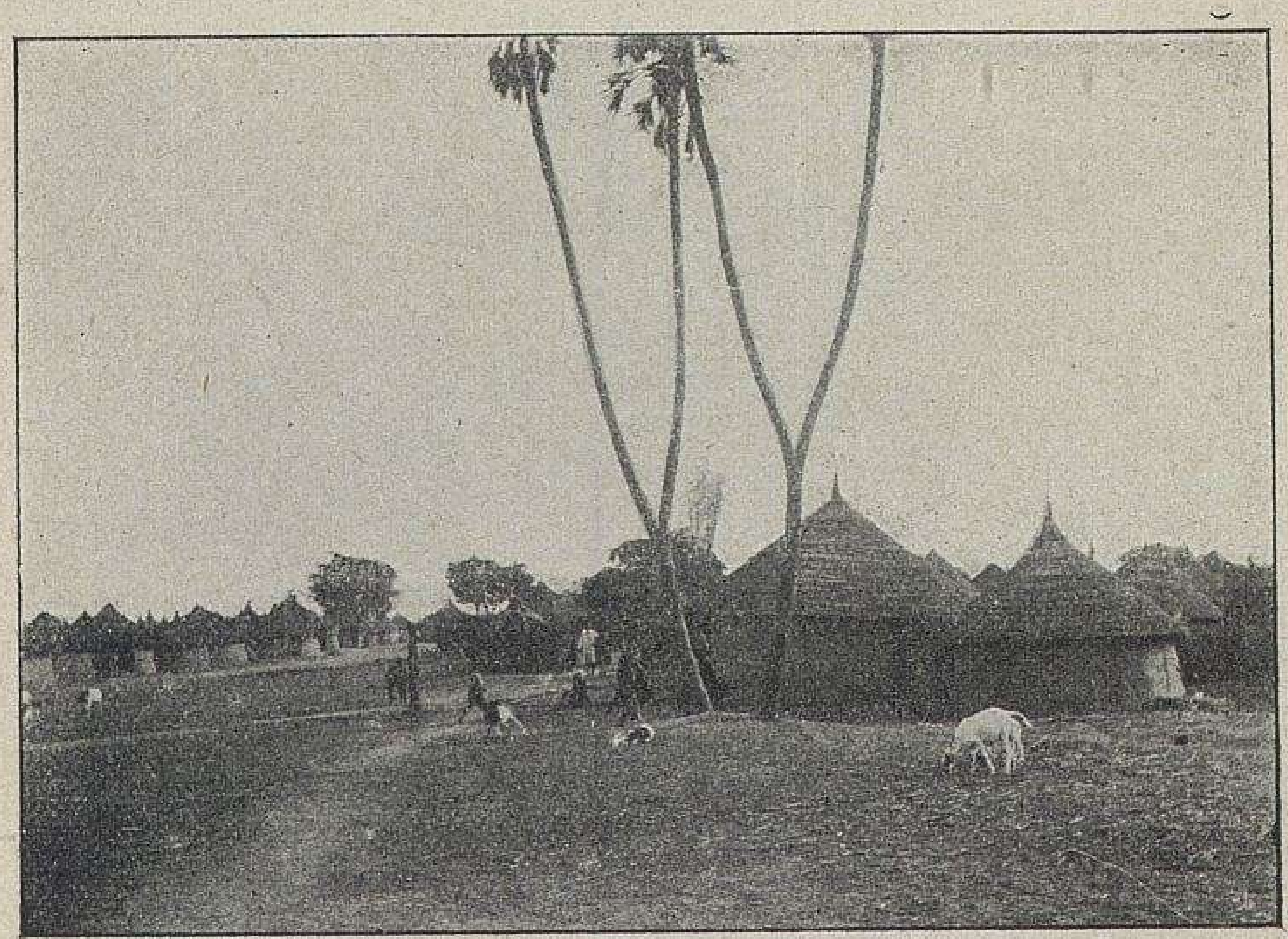

VILLAGE DE SAY, SUR LE NIGER.

(Photographie du capitaine Lenfant.)

Cases rondes à toits coniques, en paillottes. Palmier doum, au trone bifurqué. . Chèvres, poulets, etc.

cheveux noirs, flottants, en broussaille, ils forment une société aristocratique, divisée en tribus, à forme esclavagiste. Volontiers pillards et cruels, ils sont nomades, éleveurs de chameaux, ou sédentaires, agriculteurs et même commerçants; ce sont eux qui apportent à Médine les gommes et les plumes d'autruche en échange des cotonnades, et dans les centres nigériens, Tombouctou et autres, le sel gemme du Sahara en échange de la noix de kola.

$2^{\circ}$ Soudan proprement dit. - Les peuples noirs du Soudan vivent disséminés sur d'immenses territoires, sans aucune cohésion; les migrations, les invasions ont passé sans obstacle, puis reflué, produisant un métissage général. 
Les aborigènes sont les Sonrhaï; semblables aux fellahs d'Égypte, ils cultivent les alluvions du Niger, ce Nil du

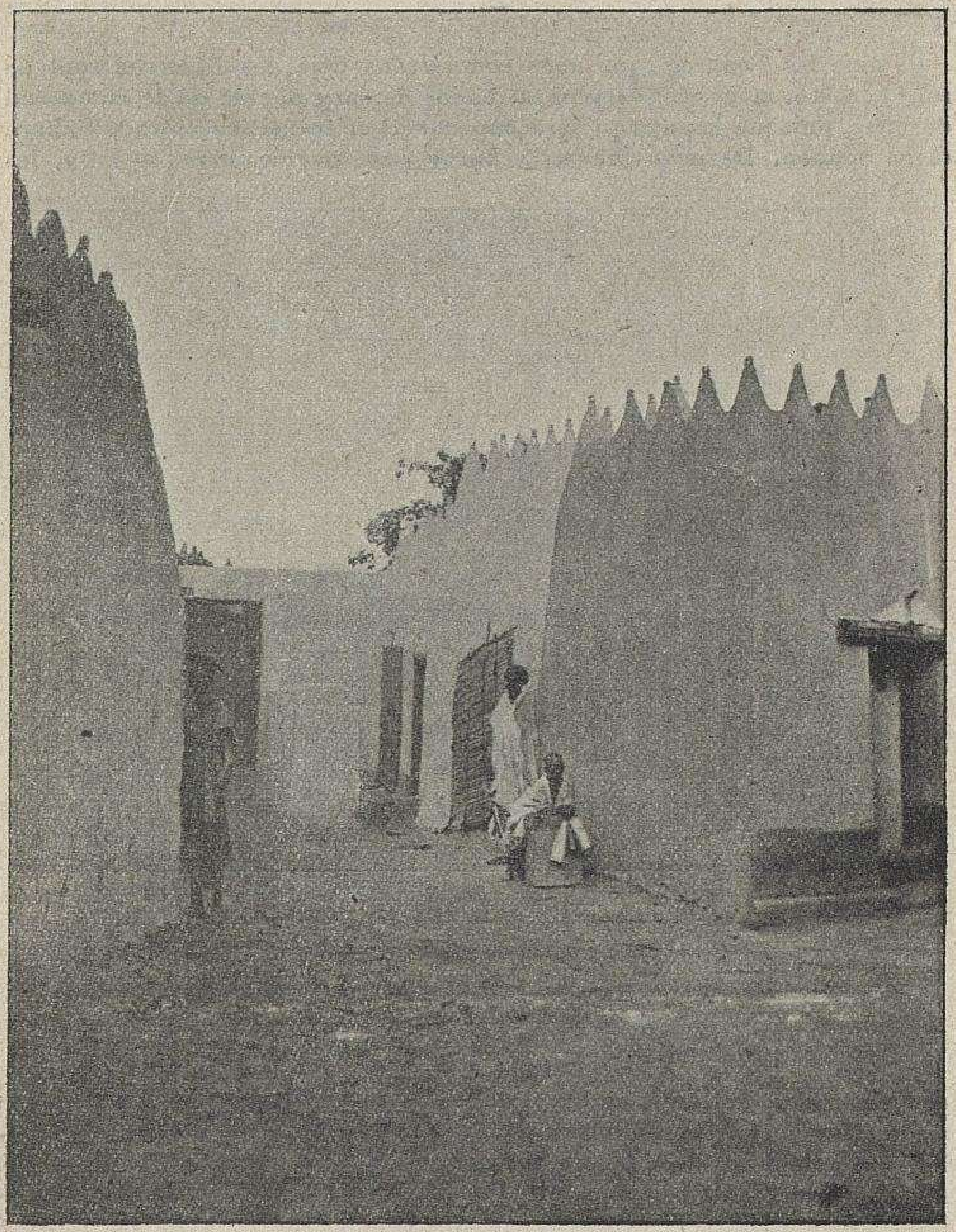

UNE RUE DE BONDOUKOU (CÔTE DE L'IVOIRE).

(Photographie de la mission Binger, communiquée par l'Office colonial.)

Soudan, et comme eux ils ont été asservis et abêtis par des peuples conquérants, les Touareg.

Les Mandé, établis au Soudan depuis des temps fort reculés, habitent, par groupes particulièrement compacts, le Haut Niger, 
le Haut Sénégal et les pentes occidentales du Fouta-Djalon. lls nous semblent fort laids, avec leur nez écrasé et leurs

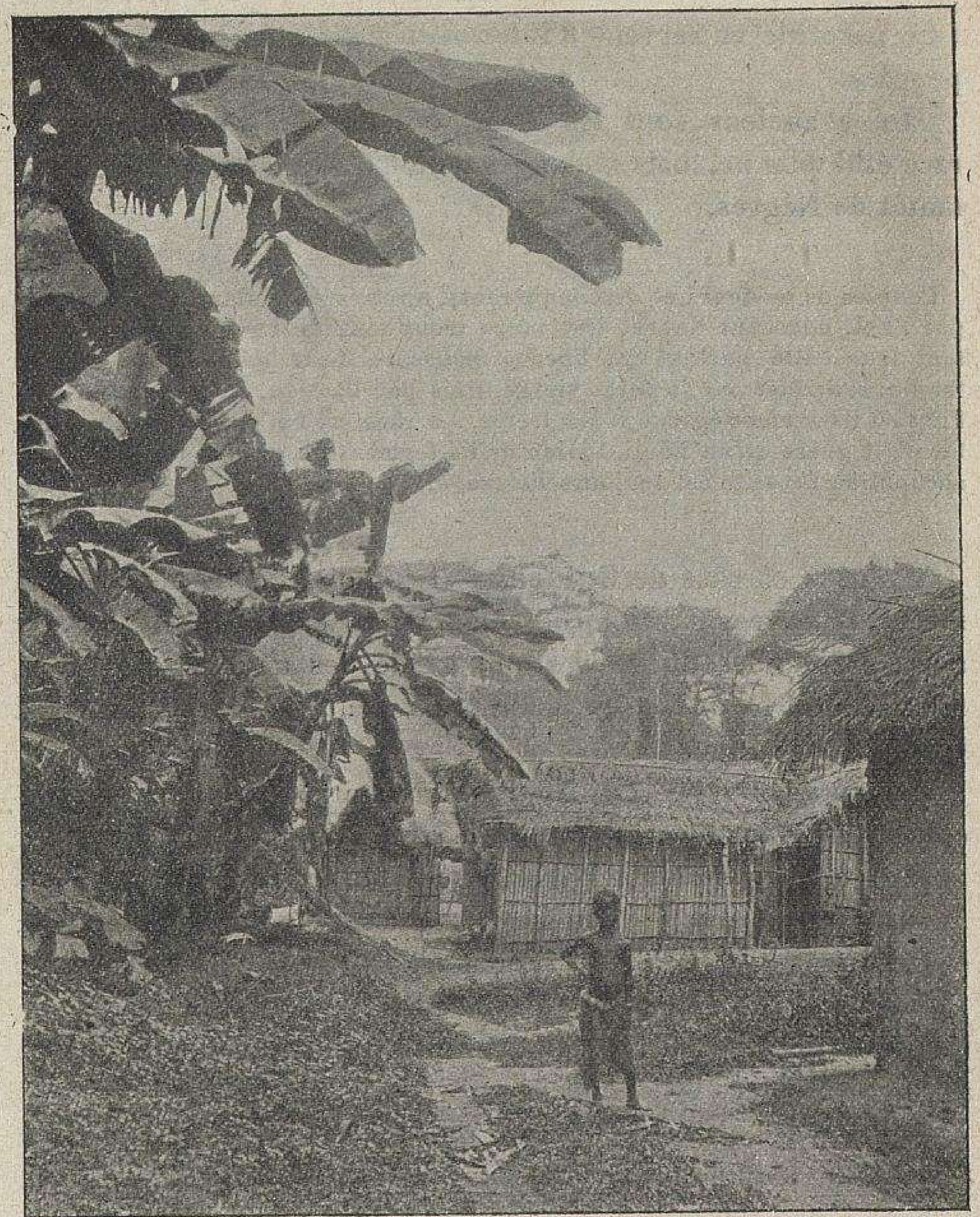

VILLAGE DE LA BROUSSE, AVEC BANANIERS (CÓTE DE L'IVOIRE).

(Pholographie de la mission Binger, communiquée par l'Office colonial.)

mâchoires proéminentes. Parmi eux les Bambara font de bons agriculteurs; quand ils ont incendié les grandes herbes, procédé primitif pour nettoyer le sol et l'engraisser en même temps, ils le binent à la main et le sarclent avec une pioche à 
fer plat : pas d'autre instrument. Parmi eux encore, les Dioula; leur instinct de l'économie, de l'ordre et du commerce en a fait les colporteurs du Soudan; ils le parcourent avec leur pacotille et servent d'intermédiaires entre les pays et les peuples.

Moins anciens sont les Peul ou Foulbé. On les croit de race éthiopienne, mais mélangés tantôt d'Arabes et de Berbères, tantôt de Nègres.

Peuples de pasteurs et de conquérants, apôtres de l'Islam, ils arrivèrent par l'Est, poussant devant eux leurs troupeaux de boufs à bosse, plantant leur tente partout où l'herbe poussait. Leur colonne s'allongeait toujours; arrêtés par la forêt vierge, puis par l'Océan, ils refluèrent vers l'Est oủ ils avaient égrené leurs frères. La race est belle, fine, intelligente. Ce n'est guère qu'au Fouta-Djalon qu'ils forment un groupe compact; leur occupation favorite est toujours l'élevage.

$3^{\circ}$ Forêt et côte de Guinée. - Les populations noires de la forêt, préservées par la forêt même, inextricable, de tout contact avec les peuples du dehors, ont gardé des mœurs primitives, farouches et belliqueuses; elles pratiquent l'anthropophagie, si la faim les talonne.

Au cap des Palmes, les Nègres Krou ont la réputation d'agriculteurs, de commerçants et de marins; ils excellent à manier la pirogue, à franchir la barre, et composent les équipages des navires européens. - Les Achanti passent pour aptes à tout; car ils sont intelligents et laborieux. - Bien doués aussi, les Dahoméens appartiennent à une des plus belles races de l'Afrique occidentale; de conquérants qu'ils étaient, ils ont dû se faire courtiers de commerce.

- Tous les peuples nègres, qui n'ont pas été convertis à l'Islam - lequel a marqué pour eux un progrès - n'ont d'autre forme de religion qu'un fétichisme grossier. L'esclavage est la base de la société, les esclaves sont des captifs. Divisés en petits groupes indépendants, les noirs obéissent à des chefs de village, à des roitelets ou bien à des almamy (chefs de la religion); la moindre décision à prendre est l'occasion de palabres ou conférences, que le chef préside, bien plus qu'il ne les commande. 
II. Gouvernement et villes. - A part la République de Libéria, toute l'Afrique occidentale est partagée entre les

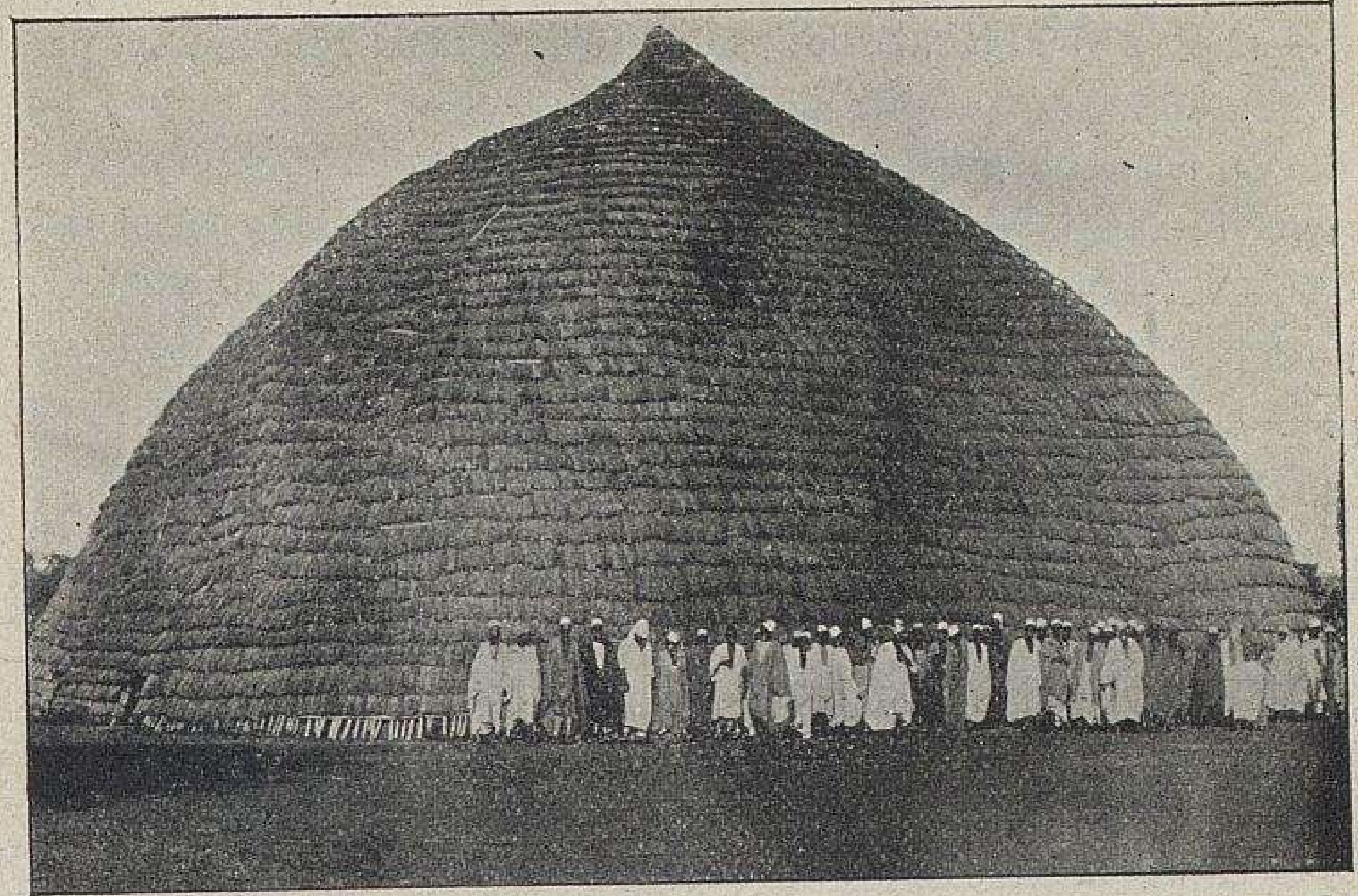

MOSQUEE DE DINGUIRA.

(Photographie communiquée par M. le Dr Maclaud.)

puissances européennes, France, Angleterre, Allemagne et Portugal.

\section{A. - POSSESSIONS FRANGAISES}

Les Possessions françaises forment, sous le $\cdot$ nom d'Afrique occidentale, un empire immense $(3.913 .000 \mathrm{kmq}$. et environ 10 millions d'h.), que nos explorateurs, nos soldats et le gouvernement ont créé, dans ces dernières années, avec un esprit de suite bien digne d'être remarqué : tous, qu'ils en aient eu conscience ou non, ont obéi à des fatalités géographiques.

L'Afrique occidentale constitue un gouvernement général, avec Dakar pour capitale. Sous la haute autorité du Gouverneur général, cinq lieutenants gouverneurs administrent cinq colonies : Sénégal, Haut-Sénégal et Niger, Guinée, Côte de l'Ivoire, et Dahomey; un Commissaire, le territoire civil de Mauritanie, et un officier supérieur, le territoire militaire du Niger, dont l'étendue diminue suivant les progrès de la pacification. 
$1^{\circ}$ Colonie du Sénégal. - Son territoire est bien réduit depuis le décret qui a groupé en une eolonie distincte les territoires du Haut-Sénégal et Niger.

Dakar (25.000 h.), résidence du Gouverneur général, est par sa situation au Sud du cap Vert, en face de l'îlot fortifié de Gorée, au point le plus occidental du continent, l'escale naturelle des navires qui desservent l'Afrique, de ceux aussi qui mettent le cap sur l'Amérique du Sud. C'est maintenant un port de commerce, parfaitement outillé, le plus beau de toute

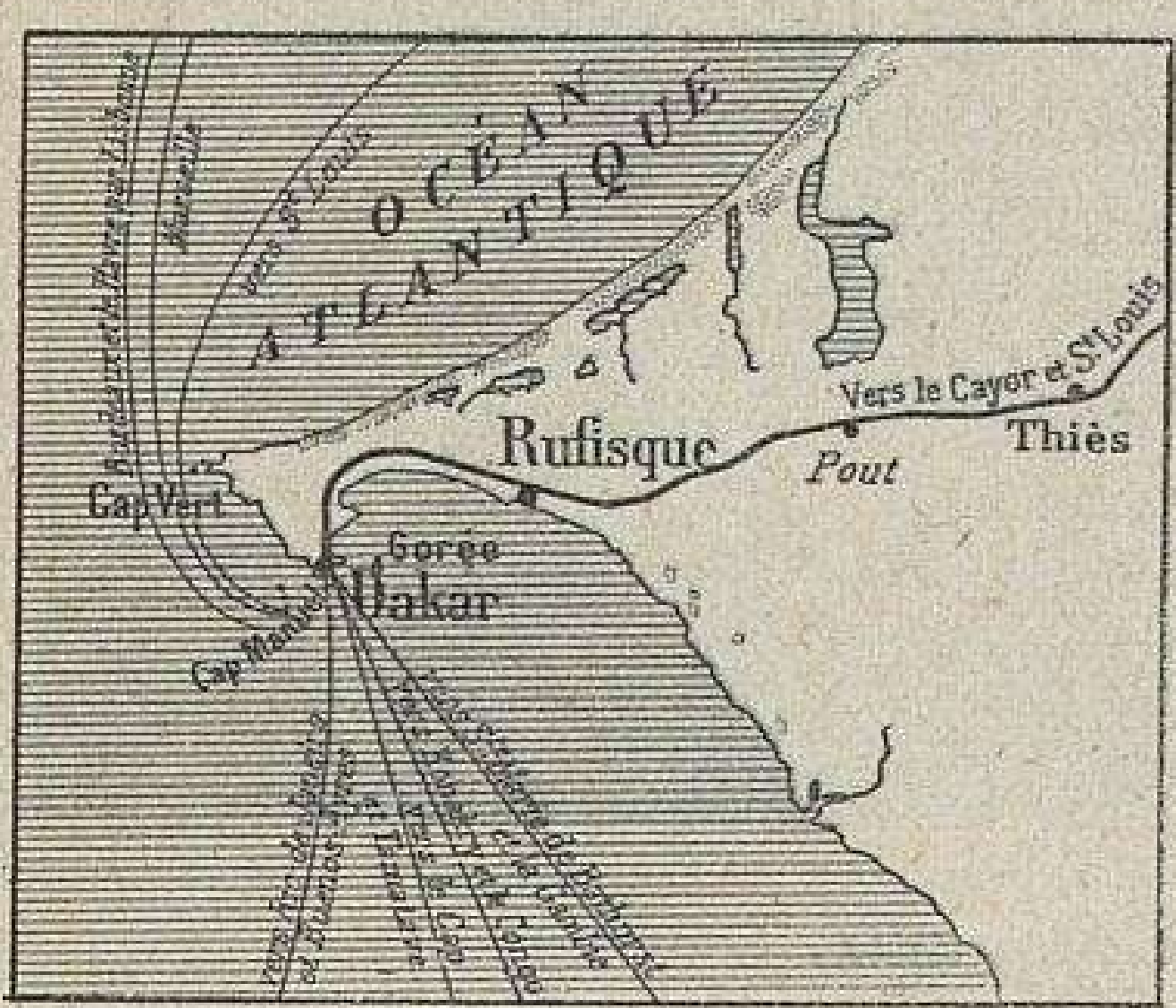
l'Afrique de l'Ouest, jusqu'au Cap, et un point d'appui pour notre flotte de guerre. Rufisque $(12.000$ h.) est le marché des arachides du Cayor : 100.000 tonnes sont par an expédiées sur Marseille.SaintLouis, la vieille capitale de la colonie, est la plus grande ville de l'Afrique occidentale $(25.000$ h. et 50.000 avec la banlieue). Elle est bâtie dans une île du Sénégal, à 16 kilornètres de la mer. Les maisons européennes, à terrasses, peintes en blanc comme celles d'Algérie ou en jaune pâle, lủi donnent un aspect séduisant. Elle exporte les gommes à destination de Bordeaux et fait le transit avec le haut Sénégal et le Soudan, avec Podor, accessible en toute saison, avec Bakel et Kayes, accessibles lors des hautes eaux:

Par la convention d'avril 1904, l'Angleterre a cédé à la France un point d'atterrissage pour les vaisseaux de haute mer, sur la Gambie (Yarboutenda). La Casamance, isolée entre la Gambie anglaise au Nord et la Guinée portugaise au Sud, a plusieurs entrepôts de commerce fort actifs (Zighinchor et Sedhiou).

$2^{\circ}$ Les territoires situés sur la rive droite du Sénégal, en aval de Kayes (Trarza, Brakna, Tagant, Adrar), dépendent directement du Gouverneur général et forment le Territoire civil de la Mauritanie, administré par un commissaire (Tidjikdja). $3^{\circ}$ Colonie du Haut-Sénégal et Niger. - Elle commence à 
Kayes, le point terminus de la navigation du Sénégal (en août et septembre les navires se hâtent de débarquer et d'embarquer leurs marchandises avant la baisse des eaux), et en même temps la gare de départ d'une voie ferrée qui, par Bafoulabé et Kita, atteint le Niger au-dessous de Bamako, le chef-lieu de la colonie. Ségou $(6.000$ h.), sur le Niger, se compose de cases indigènes et de quelques maisons européennes. Djenné, qui fut longtemps la métropole commerciale, est maintenant en déclin; le commerce européen lui préfère Mopti, mieux située, au confluent du Bani et du Niger : là arrivent les denrées d'Europe; de là s'exportent les laines et les peaux; il se fait enfin un grand trafic de riz et de mil.

La colonie du Haut-Sénégal et Niger comprend encore : $1^{\circ}$ au Nord-Ouest, une région subdésertique, le Kaarta, dont Nioro, le grand marché de la gomme, est le centre principal; $2^{\circ}$ au Sud-Est, le domaine de la haute Volta, où des résidents sont installés à Ouaghadougou (Mossi) et à Bobo Dioulaso; $3^{\circ}$ enfin au Nord-Est toute la boucle du Niger et la région de Tombouctou, qui ont été détachés du territoire militaire grâce au progrès de la pacification.

Ville du Sahara méridional, à l'extrême limite Nord du Soudan, Tombouctou est née de ce contact même. A $1.550 \mathrm{~km}$. de Saint-Louis et $2.400 \mathrm{~km}$. d'Alger, elle pose sur une plaine de sable ondulée, sans autre végétation que des arbustes épineux, des acacias et de rares palmiers. Elle n'a pas d'enceinte. Comme dans les villes arabes, les maisons sont basses et à terrasses, mais elles sont en terre : car la pierre manque dans le Soudan; et ce sont des sables, des graviers qui remplissent ses rues tortueuses et étroites. Au-dessus monterst les tours massives et carrées, les trois minarets de grandes mosquées, dont l'une ne contient pas moins de douze nefs. Aujourd'hui une église, une école, des forts témoignent que Tombouctou se transforme, qu'elle se relève des ruines que pendant des siècles des conquérants toujours nouveaux y ont accumulées, des pillages aussi qu'en dernier lieu y commettaient les Touareg.

Jamais Tombouctou ne fut la eapitale d'un empire. Placée au contact de deux mondes, peuples blancs et peuples noirs, elle était un centre religieux, une ville lettrée, un entrepôt commercial: Berbères (Touareg et Maures), Sémites (Arabes), Nègres (Sonrhaï, Mandé, etc.), Peul s'y rencontrent, s'y frôlent et s'y mêlent. Aujourd'hui que les marchandises européennes n'arrivent plus par la voie du désert, elle a perdu le privilège, d'oủ elle tira sa grandeur passée, d'unir les régions méditerranéennes au Soudan oceidental. Mais les grandes pirogues du Niger llui apportent encore du Sud, peut-être pas pour longtemps, les grains, la kola, le beurre de karité, les pagnes, les tissus, l'or, et les caravanes du Sahara le sel en barre que les chameaux chargent à Idjil et à Taodeni. 
$4^{\circ}$ Le territoire militaire du Niger est maintenant réduit à la région qui s'étend du moyen Niger au lac Tchad; il a pour chef-lieu Zinder. Au Nord, Agadès tient la route de l'Aïr et Bilma celle de Tripoli.

$5^{\circ}$ Colonie de Guinée. - Konakry, la capitale, ne date que d'une quinzaine d'années, et c'est déjà une ville de 6.000 habitants, fort attrayante : avenues longues et larges, maisons blanches à vérandas, le tout disparaissant sous la verdure des palmiers à huile, des tamariniers et des manguiers. Or en 1890 on ne voyait, à la place qu'elle oceupe, que quelques cases indigènes et l'on chassait la panthère dans les fourrés. Son fondateur est le $\mathrm{D}^{\mathrm{r}}$ Ballay. Un pont métallique unit l'íle où elle est bâtie à la terre ferme ; le mouvement du port s'accroît rapidement et s'accroîtra de plus en plus, grâce au chemin de fer qui aboutit depuis 1910 à Kouroussa, sur le Niger supérieur et qui, draine les produits du Fouta-Djalon (Timbo, Dinguiray, etc.).

6o Colonie de la Côte de l'Ivoire. - Aussi grande que la moitié de la France (300.000 kmq.), elle s'étend sur le golfe de Guinée entre la République de Libéria et la colonie anglaise de la Côte de l'Or et s'avance dans l'intérieur jusqu'à $10^{\circ}$ Lat. N., débordant, bien au delà de la grande forêt, sur les plateaux dénudés du Soudan. Son rapide développement, commercial, agricole et minier, la rend aussi intéressante, plus encore peutêtre, que la Guinée. La capitale a été transférée de Grand Bassam, trop insalubre, à Bingerville. Sur la rive Nord de la lagune Ebrié, Bingerville, ainsi nommée de M. Binger, comprend deux villes, l'une administrative et sanitaire, en train de naître, au milieu de beaux ombrages touffus, et l'autre commerciale (Abidjan), future gare d'un chemin de fer de pénétration, dont le port a des fonds de 10 et 15 mètres. Dans l'arrière-pays, Kong, capitale d'un royaume protégé, est une ville de commerce et d'industrie (10.000 h.) fort propre, ce qui est rare au Soudan; les minarets pyramidaux de ses mosquées s'élèvent au-dessus des maisons en terre.

$7^{\circ}$ Colonie du Dahomey. - Le Dahomey s'allonge en couloir entre le Togo allemand et le Lagos britannique, pour s'élargir dans le haut pays jusqu'au Niger.

Le chef-lieu est sur la lagune, Porto-Novo, moitié indigène, 
moitié européenne; d'aspect agréable, avec de nombreuses factoreries, c'est par son chiffre de population (19.000 h.), une des plus fortes villes de l'Afrique française. - Sur le littoral, s'alignent le poste fortifié, assez triste, de Kotonou, et les comptoirs de Ouida, de Grand Popo. Dans l'intérieur, Abomey $(11.000$ h.) fut la capitale du dernier roi Behanzin; plus au Nord, Carnotville unit le Bas et le Haut Dahomey.

$8^{\circ}$ Enfin le gouvernement britannique a cédé à bail à la

LAGUNE DE GRAND-BASSAM (Côte de l'lvoire)

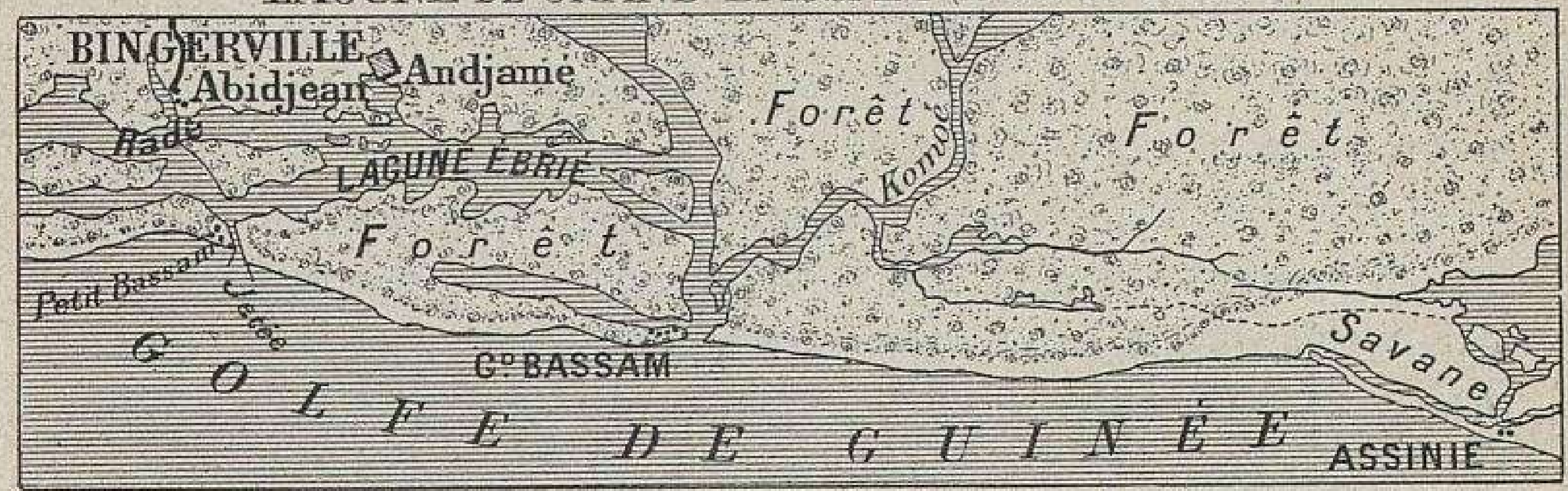

France deux terrains enclavés dans la Nigérie : l'un fluvial à Badjibo, sur la rive droite du Niger, et l'autre maritime sur la rade superbe que forme la rivière Forcados. Là sont installés des appontements, des magasins et des cases.

\section{B. - POSSESSTONS ANGLAISES}

Bien loin derrière la France, l'Angleterre est la seconde puissance coloniale de l'Afrique occidentale.

$1^{\circ}$ Gambie. - La colonie de la Gambie découpe sur les deux. rives de la Gambie inférieure une bande étroite de terres que cernent partout les possessions françaises. Ses factoreries sont françaises pour la plupart, et c'est par navires français que se fait presque tout le commerce. - La capitale, Sainte-Marie de Bathurst $(8.800$ h.), fort malsaine, est reliée par câble sousmarin avec Saint-Vincent (îles du Cap-Vert) et le Sierra Leone.

$2^{\circ}$ Sierra Leone. - La colonie de Sierra Leone doit son nom à une croupe de montagne à laquelle les prémiers navigateurs, des Portugais, trouvèrent la forme d'un lion couché; elle s'encadre entre la Guinée française et la République de Libéria. La capitale, Freetown (34.500 h.), dont le climat meurtrier jouit 
d'une réputation détestable, est un port de guerre et un dépôt de charbon, mais elle lutte difficilement contre la concurrence commerciale de Konakry, en plein essor. Un chemin de fer a été amorcé de la côte vers le Fouta-Djalon. Les Nègres Sierra Leonais sont très recherchés par les commerçants européens : sur toutes les côtes de Guinée, ils servent de courtiers entre les noirs et les blancs.

$3^{\circ}$ Côte de l'Or. - La colonie de la Côte de l'Or (Gold Coast) est comprise entre la Côte française de l'Ivoire et le Togo allemand; la découverte de gisements aurifères, exploités de longue date par les indigènes, légitime plus que jamais son nom, alors que les termes de Côte de l'Ivoire à l'Ouest et de côte des Esclaves à l'Est n'ont plus de raison d'être. - Le chef-lieu est $A$ kkra (14.800 h.), mais la ville la plus commerçante est sur la côte, Cape Coast Castle (28.900 h.); plus à l'Ouest, Elmina (3.900 h.). - Le gouverneur de la Côte de l'Or est en outre gouverneur du pays des Achanti, définitivement annexé en 1901 (centre principal, Koumassi). Quant aux régions septentrionales qu'arrose la Volta, on les connaît à peine; les frontières même ne soni tracées que dans leurs grandes lignes.

$4^{\circ}$ Nigérie du Sud. - Depuis le $1^{\text {er }}$ mai 1906 , la colonie de Lagos a été incorporée à la Nigérie du Sud (Colonie et Protectorat), dont le centre administratif est devenu la ville même de Lagos (53.000 h. avec la banlieue). Située sur la mer, celle-ci est le point de départ d'un chemin de fer de pénétration, qui dessert Abéokouta, le pays de Yorouba, Ibadan, confédération de plus de 160 villages enclos dans une enceinte de 30 kilomètres, Ilorin, dans la Nigérie du Nord, enfin Djebba sur le Niger, d'où il doit être prolongé sur Zounguerou.

\section{G. - POSSESSIONS PORTUGAISES}

1. Les îles du Cap-Vert, à 600 kilomètres au large du cap du même nom, forment un archipel voleanique (parfois $2.000 \mathrm{~m}$.), très sain de climat. Sa situation sur la route directe de l'Europe au Brésil est incomparable, et Saint-Vincent est le port de ravitaillement et de relâche tout indiqué entre Lisbonne et Pernambouc : là est un dépôt de eharbon, là encore atterrissent les 
cábles sous-marins de Bathurst, de Pernambouc et de Lisbonne. Mais la mauvaise administration des Portugais l'a laissé tomber dans un tel délabrement qu'il ne peut lutter contre la concurrence victorieuse de Dakar et le déclin s'accuse d'année en année.

Madère et les Açores, qualifiées officiellement " iles adjacentes ", forment une province du Portugal; et en effet, par leur situation dans la zone tempérée, par leur climat, leurs cultures, leurs populations enfin, elles n'ont rien d'africain.

$2^{\circ}$ La Guinèe portugaise n'est pas mieux administrée. Encastrée dans les possessions françaises de la Casamance et de la Guinée, elle comprend, en outre du cours inférieur du rio Grande et du rio Geba, l'archipel des Bissagos. Colonie très vieille, très arriérée, la Guinée entretient des fonctionnaires à la charge du budget de la métropole, et ce sont des maisons françaises qui absorbent presque tout le trafic. Bissao est le centre du commerce, mais la capitale est Boulam, un village misérable qui connut la prospérité à l'époque de la traite des noirs. L'arrière-pays, inexploré, peu sûr, est habité par des tribus belliqueuses, que l'on suppose de population dense.

\section{D. - POSSESSION ALLEMANDE}

Togoland. - Le Togoland, situé sur la côte des Esclaves, entre la Côte de l'Or et le Dahomey, a pris rang de pays de protectorat allemand en 1884; il est administré par un gouverneur impérial qui réside à Lomé, le port principal. Sur la côte encore, Petit Popo et Porto Seguro; un peu en arrière, sur la lagune, Togo $(8.000 \mathrm{~h}$.) a donné son nom à tout le territoire. Parmi les stations de l'intérieur on peut citer Bismarckbourg et Sansanné Mango.

Une convention anglo-allemande de 1899 a déclaré Salaga zone neutre.

\section{E. 一 IIBÉRIA}

Le Libéria est une république nègre. Elle fut fondée au début du $x x^{e}$ siècle par une association philanthropique américaine au moyen des Nègres affranchis d'Amérique, qu'on rendit à

G. Lespagnol et M. Fallex. - Afrique. 
leur continent d'origine. Mais cette création humanitaire n'a pas donné les résultats espérés, et nulle a été l'influence exercée par les Nègres citoyens, protestants de sectes diverses, sur les tribus noires de l'intérieur à moitié sauvages : le pays n'est pas même connu. - La capitale s'appelle Monrovia (5.000 h.), en l'honneur du président américain Monroe. Quant à la constitution, elle a été inspirée de celle des États-Unis : le Président est assisté d'un Sénat et d'une Chambre des représentants. Les blancs, exclus de toutes fonctions, ne peuvent acquérir le titre de citoyens.

Pour les deux tiers le commerce se fait par maisons allemandes; les exportations sont dirigées sur Hambourg et sur Liverpool.

III. Mise en valeur. - $1^{\circ}$ Agriculture. - Comme dans tous les pays neufs, à civilisation primitive, la cueillette des

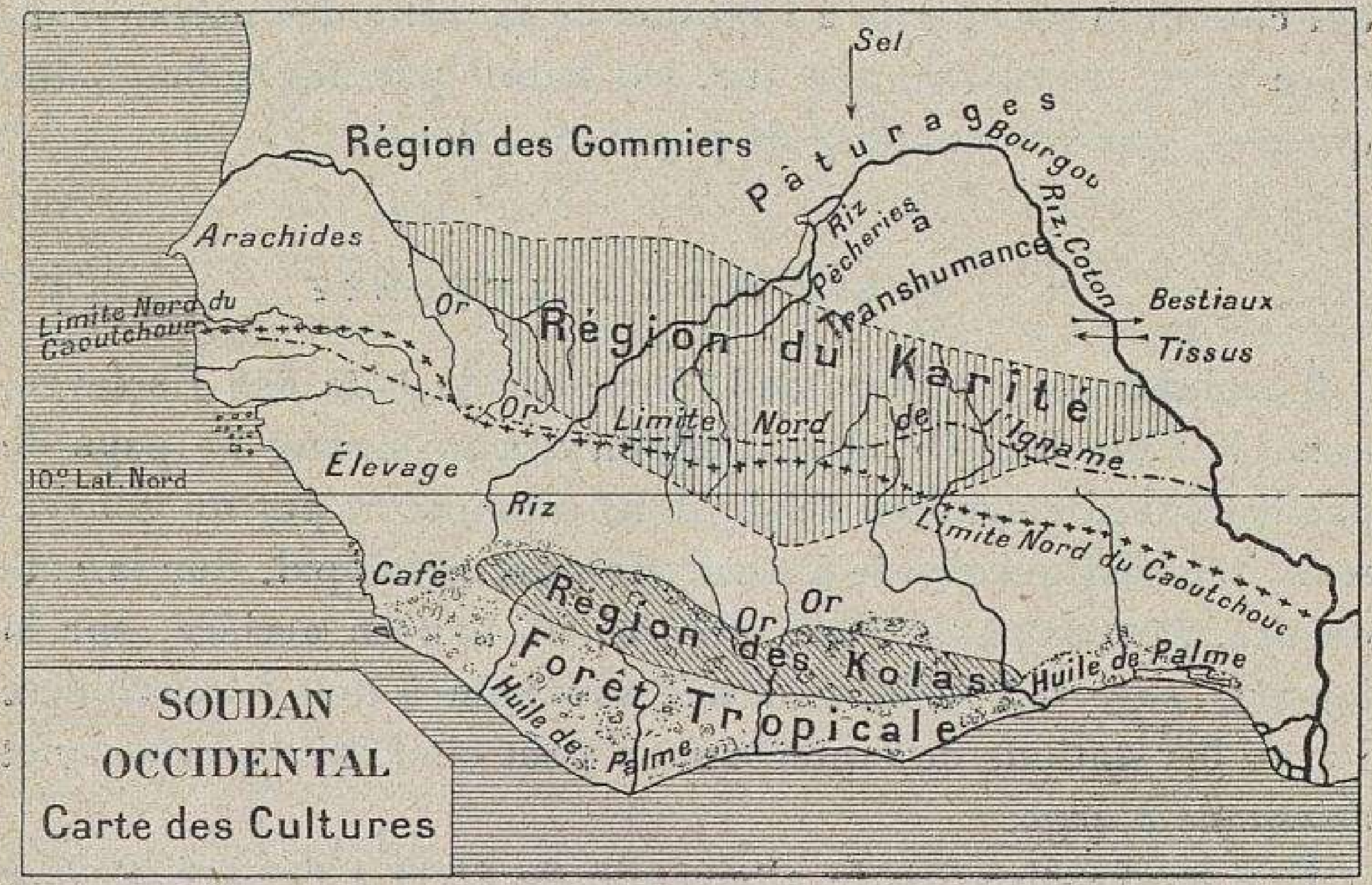

fruits que l'arbre produit de lui-même a précédé l'exploitation agricole, et celle-ci précède l'exploitation industrielle. Il sera nécessaire d'initier le Nègre aux méthodes européennes de culture; outre qu'il ne produit que pour sa consommation personnelle, des plus restreintes, il se contente de gratter le sol, de jeter la semence, de tasser la terre du pied et de récolter. 
c'est-à-dire qu'il pratique la « culture à la houe » et ignore l'usage de la charrue. Des tentatives de plantations semblent promettre des résultats, et toutes les colonies européennes possèdent leurs " jardins d'essai ».

La gomme (Kaarta), l'arachide (Cayor) sont produites par les régions à longue période sèche; elles fournissent à l'exportation un chiffre important. Bordeaux est le marché de la gomme, Marseille celui des arachides.

Le cotonnier, arbuste buissonneux qui réclame de la chaleur et de l'humidité, celle-ci sans excès, se cultive aux abords des villages; mais le coton n'est pas objet d'échange, et les Nègres se contentent de colporter les bandes tissées qu'il a servi à fabriquer. Il a semblé que le cotonnier pourrait, s'il devenait l'objet d'une culture rationnelle, donner un produit de meilleure qualité et alimenter un trafic d'exportation: dans les colonies francaises des essais sont actuellement tentés; s'ils réussissent, comme on est en droit de l'espérer, les filatures de France cesseraient d'être exclusivement tributaires de l'étranger et plus spécialement des ÉtatsUnis.

\section{De même on s'efforce} de développer les cultures

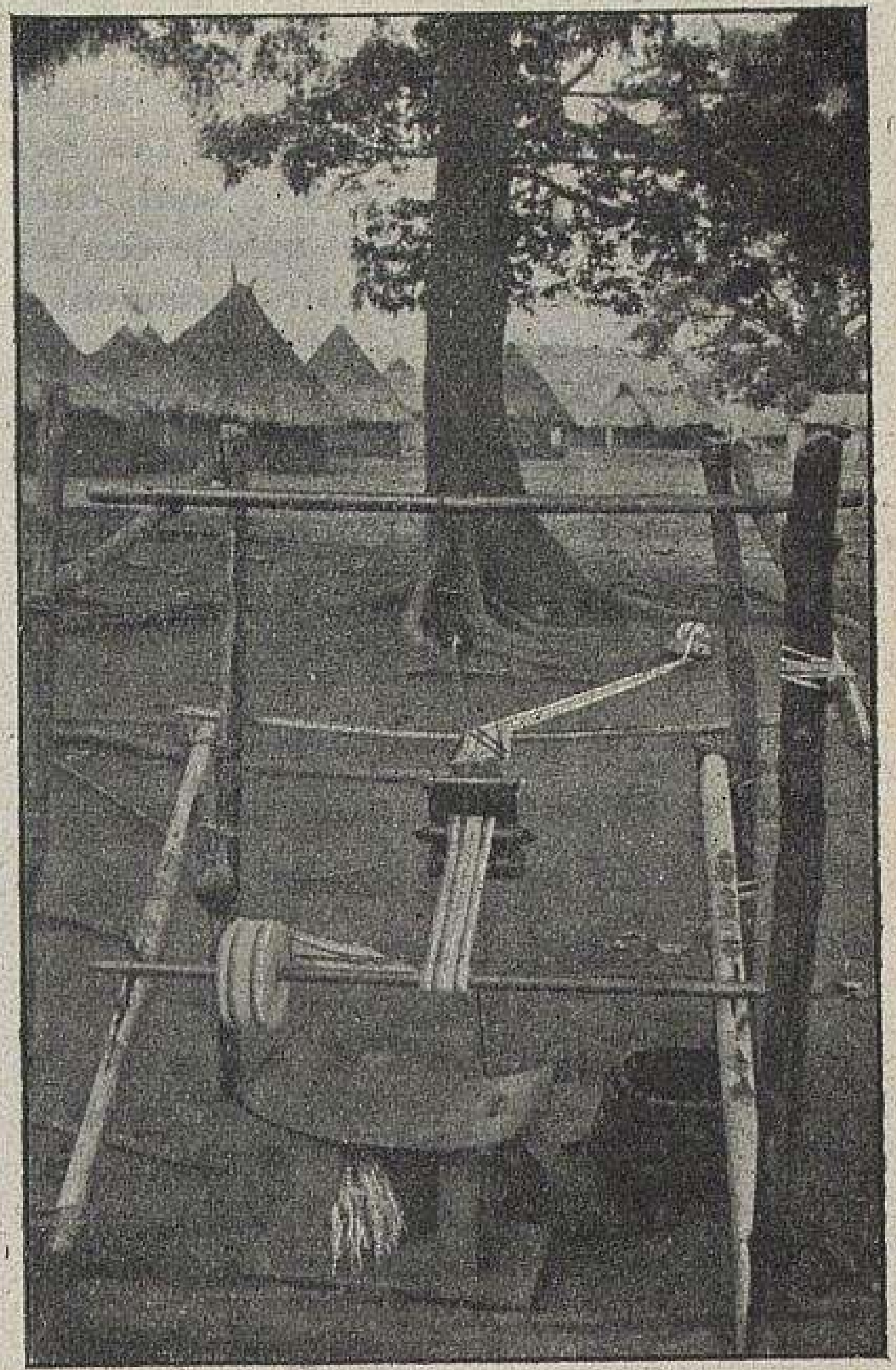

MÉTIER A TISSER AU SOUDAN.

(Photographie de la mission Binger, communiquée par l'Office colonial.)

Du fond vient la chaîne et l'étroite bande de coton, une fois tissée, s'enroule sur la gauche. Au premier plan, le siège de l'ouvrier. Au dernier, cases rondes coiffées de paillottes.

de l'indigo, du cacao, de la vanille, et le café de Libéria, très réputé, commence à se répandre dans nos colonies.

D'ordinaire fort négligents, les Nègres soignent de façon particulière les kolatiers, qui sont plantés aux alentours des villages dans une certaine zone (surtout entre $6^{\circ}$ et $7^{\circ} 30^{\prime}$ Lat. N.). C'est que la noix de kola est un précieux objet d'échange au Soudan, un objet aussi d'exportation européenne. Dans les 
contrées humides, le caoutchouc, l'huile et l'amande de palme sont de jour en jour plus demandés.

Le Kolatier, arbre au feuillage vert foncé, peut avoir plus de $15 \mathrm{~m}$. de haut et $2 \mathrm{~m}$. de circonférence. Le fruit est formé par des follicules charnus et allongés, groupés au nombre de quatre ou six, dont chacun renferme une dizaine de graines grosses comme des noix, de couleur rouge et blanche, simultanément sur le même arbre. - La noix de kola est regardée comme un aliment d'épargne remarquable et comme un stimulant des plus énergiques. Les nombreuses vertus qu'on lui prête, pour la plupart véritables, sont dues à la quantité considérable de caféine et de théobromine qu'elle contient. Mais elles les perd en perdant sa fraicheur; aussi les noirs prennent-ils les plus grands soins pour en éviter la dessiccation (A. BRESCHIN).

Une des grandes déceptions des Européens au Soudan est la privation du pain : mil, riz, maïs, manioc, igname, banane, tels sont, suivant les contrées, les aliments indigènes. Il faut faire venir les blés d'Europe; aussi ne se trouvent-ils que dans les ports ou à proximité des ports; ailleurs le pain est un objet de luxe. Il semble que certaines régions sont susceptibles de produire du bon froment, et déjà des moulins fonctionnent sur le Niger à Koulikoro.

Une plante spéciale à la région de Tombouctou, qui se développe dans les marais et les cours d'eau, et que les indigènes emploient à des usages multiples, le bourgou, contient dans ses chaumes et dans sa moelle beaucoup de sucre; les botanistes estiment qu'elle peut devenir, traitée suivant des méthodes industrielles, "la plante productrice du sucre de l'avenir ", au Soudan.

Plus d'une région se prête à l'élevage, en première ligne le Fouta-Djalon, et déjà les convois de bœufs sont acheminés sur la côte, à Konakry par exemple. Il sera facile d'améliorer les races.

Enfin l'exploitation des foréts fournit des bois de construction et d'ébénisterie.

En somme, la mise en valeur de ces territoires immenses est à la période des débuts et des tâtonnements. Longtemps le pays a été ravagé, dépeuplé par des conquérants barbares. Après bien des campagnes, la France lui a rendu une sécurité qu'il ne connaissait plus depuis des siècles.

$2^{\circ}$ Industrie. - Les rares industries européennes traitent les produits agricoles et commencent à extraire l'or. 
Les industries indigènes sont incapables de suffire aux besoins, pourtant restreints, des populations. Le Soudan a ses métiers à tisser (couvertures et pagnes à longues rayures), ses vanneries tressées, ses cuirs tannés, teints ou frappés. - Sur les plateaux ferrugineux du Fouta-Djalon les Nègres travaillent le métal; forgerons d'autant plus habiles que leur outillage est plus primitif, ils savent construire et manier de

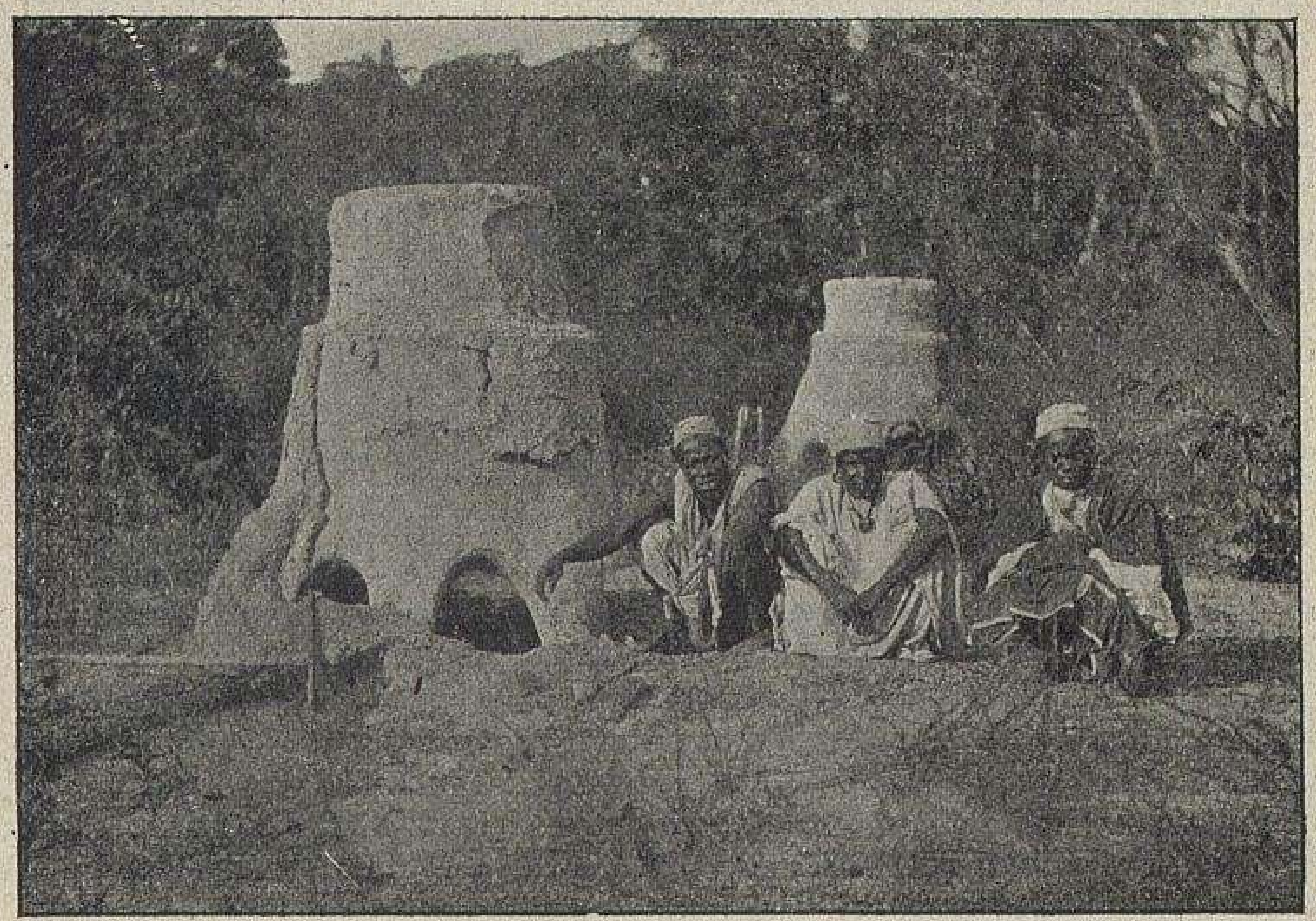

HAUTS FOURNEAUX ET FORGERONS DANS LA GUINEE FRANGAISE.

(Photographie communiquée par M. le Dr Maclaud.)

hauts fourneaux : c'est ainsi que le Dinguiray fabrique des pioches et des hoyaux, des armes (sabres, poignards, et même des fusils), des bijoux (bracelets de mains et de pieds, bagues, boucles d'oreilles).

De tout temps l'or en poudre a circulé de Tombouctou au Sénégal et à la côte de Guinée. Le paysan du Bambouk, des bords de la Falémé et de l'Ouassoulou, se fait mineur à ses heures perdues; il creuse un puits et lave la terre extraite par le procédé de la batée. Une faible partie de l'or ainsi recueilli est exportée brute, l'autre est travaillée sous forme de bijoux iradigènes. Récemment, dans la colonie anglaise de la Côte de 
l'Or, et sur les terres françaises de la Côte de l'Ivoire (Baoulé, Indénié), on a découvert des conglomérats aurifères, qui pourraient, selon les dires des prospecteurs, faire de ces contrées un nouveau Transvaal.

$3^{\circ}$ Commerce. - Les ports qui entretiennent des relations suivies avec l'Afrique occidentale sont : Marseille, qui reste malgré la concurrence le premier marché des huiles de palme; Bordeaux, surtout Liverpool et Anvers, marchés du caoutchouc; Liverpool encore, pour les acajous; Hambourg enfin lutte sans désavantage contre tous. - Les ressources exploitables de l'Afrique occidentale ne pourront se développer qu'à mesure que les voies de fer se substitueront aux moyens indigènes, lents et coûteux, aux caravanes de chameaux, de boufs à bosse, d'ânes et de porteurs nègres, à mesure que les sections navigables des fleuves seront améliorées ou pourvues de flottilles. Toutes les puissances rivalisent d'ardeur.

La France la première. Son objectif est la vallée du Niger, pompeusement appelé le Nil français. Le Sénégal est bien accessible en toute saison jusqu'à Podor, mais il ne l'est jusqu'à Kayes que lors des erues. Aussi le gouvernement général de l'Afrique occidentale vient-il d'élaborer un plan d'ensemble de voies ferrées qui constituera un jour un réseau bien homogène. Sur la ligne de Dakar, Rufisque et Saint-Louis $(260 \mathrm{~km}$.) qui a déjà complètement métamorphosé le Cayor, une GRANDE voIE GRNTrale s'embranchera vers l'Est : de Thiès elle traversera la région fertile et peuplée du Baol, s'infléchira au Sud-Est pour éviter le désert de Ferlo, et à tra. vers lo Bondo atteindra Kayes. - La ligne de Kayes à Koulikoro, avec embranchement sur Bamako, est achevée depuis 1904; or Koulikoro est la tête d'un bief navigable qui s'étend jusqu'aux rapides de Fafa et de Labezenga et depuis 1905 un service de bateaux à vapeur fonctionne jusqu'à Tombouctou, mise ainsi à 20 jours de Paris.

Sur ce tronc central viendront se souder les lignes entreprises dans chacune des colonies côtières : $1^{\circ} \mathrm{La}$ ligne de Guinée : elle part de Konakry, traverse le Fouta-Djalon et atteint depuis 1910 Kouroussa, sur le haut Niger ; là commence un bief navigable qui conduit à Bamako. $-2^{\circ} \mathrm{La}$ ligne de la Côte de l'Ivoire : elle part d'Abidjan pour desservir un jour le Baoulé, producteur d'or, et le pays de Kong, Les travaux entrepris à Petit Bassam, appelé maintenant Port Bouët, pour percer le cordon littoral et permettre aux navires d'accoster à Abidjan même, ont échoué ; Grand Bassam reste done le principal port. $-3^{\circ}$ La ligne du Dahomey : amorcée de Kotonou et de Ouida à Toffo, vers Abomé, elle est destinée à atteindre le Niger en amont des rapides de Boussa.

L'Angleterre a commencé une voie qui de Freetown pénétrera le FoutaDjalon : elle ne le franchirait que pour tomber en terre française; - une autre, dans la Gôte de l'Or, du port de Sekondi à Koumassi, à travers les contrées aurifères de Tarkona; - une troisième partie de Lagos atteint 
Djebba, sur le Niger; - enfin une quatrième est activement poussée de Baro, tête de la navigation permanente sur le Niger, à Bida, Zoungucrou, Saria et Kano.

L'Allemagne possède une ligne de Lomé à Palimé $(122 \mathrm{~km}$.$) , et une$ autre, de Lomé à Anecho (Petit Popo, $45 \mathrm{~km}$.).

Tous les travaux de ports, de navigation fluviale, de chemins de fer et d'assainissement, entrepris ou projetés par toutes les puissances, à commencer par la France, sont appelés à produire des résultats à la fois matériels et moraux. La « paix française » a ramené les populations au travail de la terre, à l'élevage, au commerce. Tout désigne la France pour un rôle prépondérant dans l'Afrique occidentale; et l'essor de notre vieille colonie du Sénégal, celui des colonies très jeunes (Guinée, Côte de l'Ivoire), l'œuvre enfin des Faidherbe, des Ballay, des Binger sont bien faits pour autoriser les espoirs les plus légitimes.

Nous n'avons pas un seul sanatorium en Afrique et le Soudan ne présente pas beaucoup de zones habitables. Mais les monts de Kong existent; les anciens atlas les dessinaient parallèlement à la côte de Guinée, puis les explorations accomplies depuis 1887 les ont fait biffer. Ils viennent d'être retrouvés : ce sont les hautes terrasses qui se déroulent sans inter. ruption depuis le Fouta-Djalon jusqu'à la Sassandra, au Nord-Ouest de la Gôte de l'Ivoire. Là est le sanatorium naturel de tout l'Ouest africain.

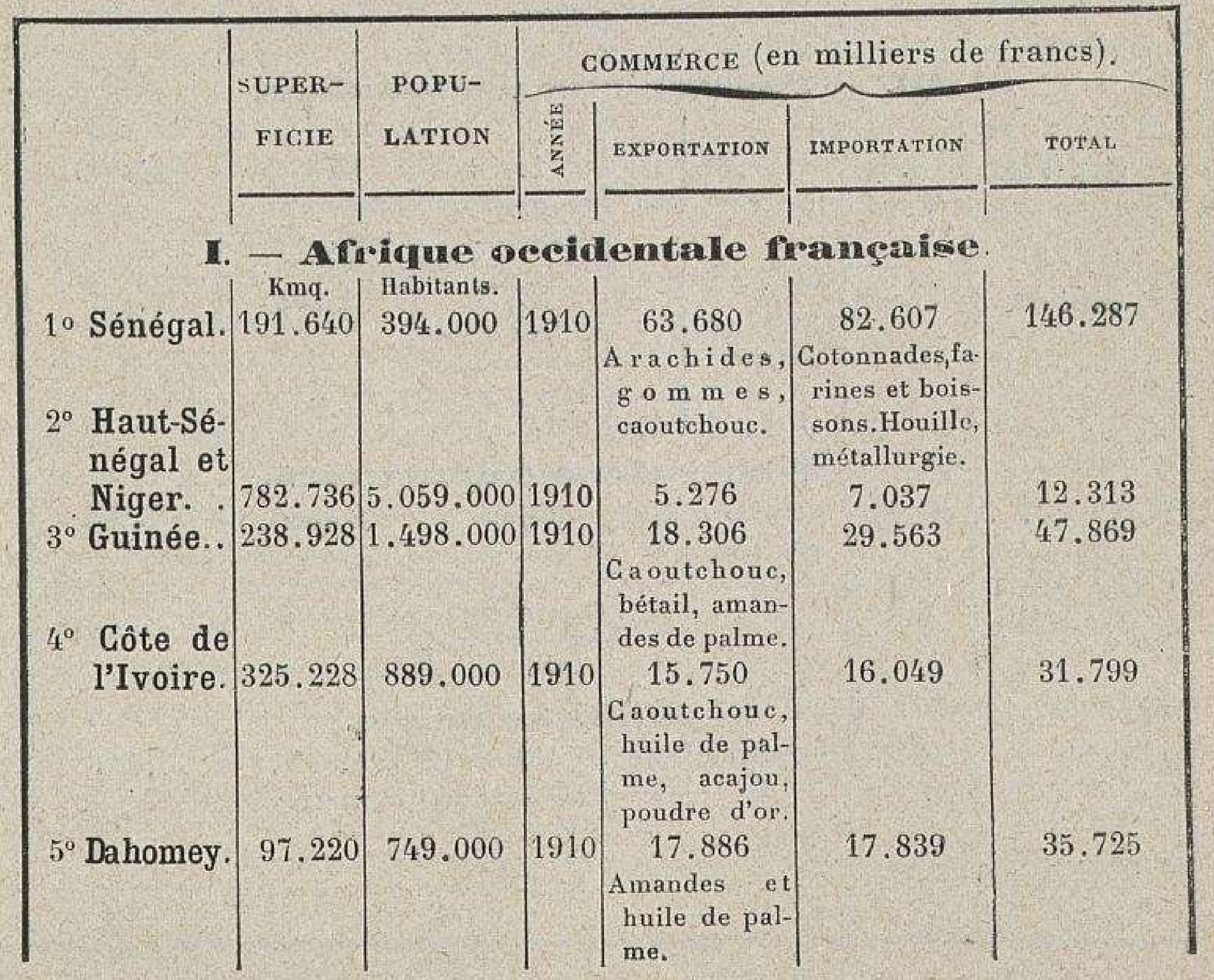




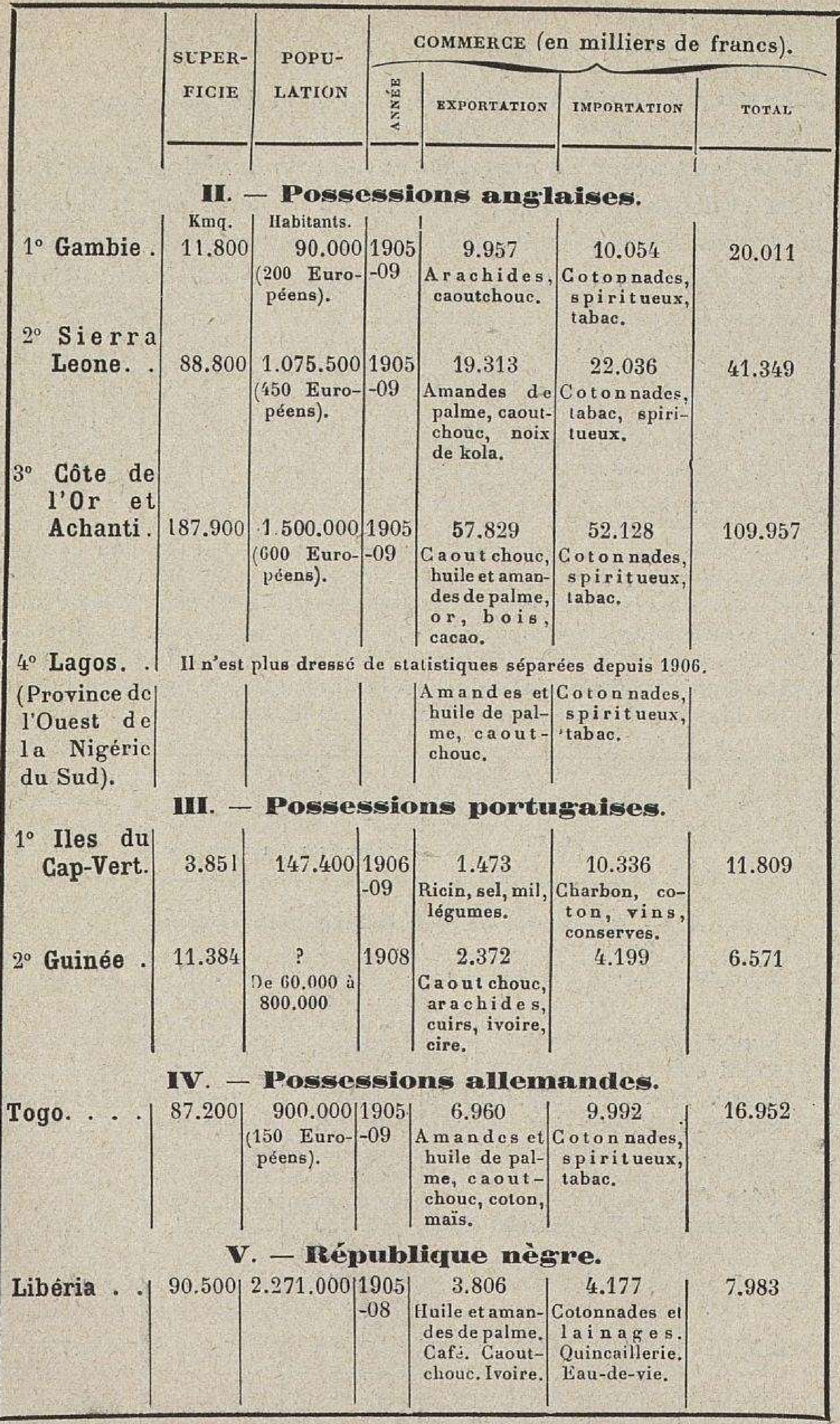




\title{
CHAPITRE X
}

\author{
SOUDAN CENTRAL
}

SOM MA IRE

Le Soudan central correspond au bassin du lac Tchad et du Chari; une partie des eaux s'écoule en outre par la Bénoué vers le Bas Niger.

I Relief. - Le lac Tchad occupe le fond d'un bassin déprimé, dont les bords se relèvent au Nord par les massifs volcaniques de l'Air (1.800 m.) et du Tibesti (2.600 m.), au Sud-Ouest par les massifs du Yacoba (2.100 m.) et de l'Adamaoua (3.000 m.) : la Bénoué a fait brèche entre ces derniers; - ils s'abaissent au contraire à l'Ouest et au Sud, où de larges seuils, à pente indécise, séparent la dépression du Tchad des bassins du Niger et du Congo. - Sur la mer, le Gameroun est un ancien volcan ( $4.075 \mathrm{~m}$.).

II. Climat. - $1^{\circ}$ Au Nord, sur les confins du Sahara, la région subdésertique, est sèche et sujette a des écarts sensibles de température.

2. Dans les plaines du Soudan proprement dit, les mois d'èté sont la saison des pluies tropicales, et nos mois de printemps la saison sèche.

$3^{\circ}$ Les régions élevées du Sud-Ouest reçoivent de fortes quantités d'eau : le Cameroun est après l'Inde la région du globe où les précipitations sont le plus abondantes.

$4^{\circ}$ Le littoral a une temperature constamment tiede et humide, fort malsaine.

III. Hydrographie. - $1^{\circ}$ Le Tchad est un lac désertique, qui se déplace suivant la direction du vent dominant, vers l'ouest; il est parsemé d'illes et sujet à des variations annuelles de niveau.

Il reçoit au Sud par plusieurs bouches le Ghari, fleuve permanent, fleuve de plaine. Lors des crues, le fleuve, son affluent le Logone et un affluent de la Bénoué unissent leurs eaur dans les marais de Toubouri.

2. La Bénoué $(1.400 \mathrm{~km}$.) fournit une voie navigable de pénétration jusqu'à Garoua.

$3^{\circ}$ Les fleuves côtiers, très puissants, sont coupés de rapides. 
IV. Côtes. - La baie de Gameroun se ereuse entre des promontoires volcaniques, dont les iles Fernando Po, San Thomé, etc., continuent l'alignement.

V-VI. La vie végétale et la vie animale sont les mêmes dans le Soudan central que dans le Soudan occidental; les conditions physiques sont en effet identiques.

VII. Vie humaine. - $1^{\circ}$ Dans les contrées subdésertiques du Nord vivent des nomades, pasteurs et guerriers, les Touareg, les Tibbou et des Arabes.

$2^{\circ}$ Au Soudan proprement dit, des peuples pasteurs, venus de l'Est, les Foulbé ou Peul, musulmans, ont asservi les Nègres, qui n'ont pu trouver un asile dans les montagnes, et créé de grands États. Partout circule un peuple de marchands, les Haoussa.

VIII. Gouvernement et villes. - $1^{\circ}$ Possessions françaises. Le territoire militaire de Zinder est rattachè au Gouvernement de l'Afrique occidentale. Du Congo relèvent le territoire du Tchad et l'Oubangui-Ghari, deux circonscriptions d'une même colonie.

$2^{\circ}$ Possessions anglaises. La Nigérie est divisée en Nigério du Sud (Lagos, Warri, Calabar) et Nigérie du Nord (Zounguerou) avec des villes populeuses en grand nombre (Sokoto, Kano, etc.).

$3^{\circ}$ Possessions allemandes. La colonie du Gamerouńn a pour centre administratif Bouéa et pour ville principale Douala.

$4^{\circ}$ Possessions portugaises : L'île du Prince, la perle des possessions coloniales des Portugais, et San Thomé.

$5^{\circ}$ Possessions espagnoles : Les iles Fernando Poet Annobon.

IX. Mise en valeur. - L'agriculture, l'industrie sont essentiellement indigènes.

Le commerce européen n'atteint encore que les régions littorales, productrices d'huile et d'amandes de palmes, de caoutchouc et, déjà, de cultures tropicales (café, cacao).

L'exploitation de l'intérieur est subordonnèe à l'établissement de voies commerciales, par eau et par chemins de fer; les débouchés par le golfe de Guinée remplaceront peu a peu l'ancienne voie des caravanes tripolitaines.

\section{DÉ VELOPPEMENT}

Le Soudan central correspond au bassin du lac Tchad et du Chari; une partie des eaux s'écoule en outre par la Bénoué vers le bas Niger.

Comme dans tout le Soudan, les granites et les gneiss forment le socle du continent, mais ils ont été décomposés par les agents atmosphériques en formations ferrugineuses, d'un brun rougeâtre, la latérite, que percent par endroits les roches cristallines, sous forme tantôt de massifs et tantôt de pics isolés. Au Sud du Tchad, jusque vers $10^{\circ}$ Lat., s'étalent d'immenses étendues d'argile, sans une pierre; les pluies tropicales s'y amassent et forment des marécages sans profondeur où pataugent les éléphants; on prend alors de simples marigots pour des rivières. A la saison suivante, tout se dessèche sous le soleil ardent, et le sol noir, fendillé, sans herbe, devient si dur qu'on ne peut l'entamer. 


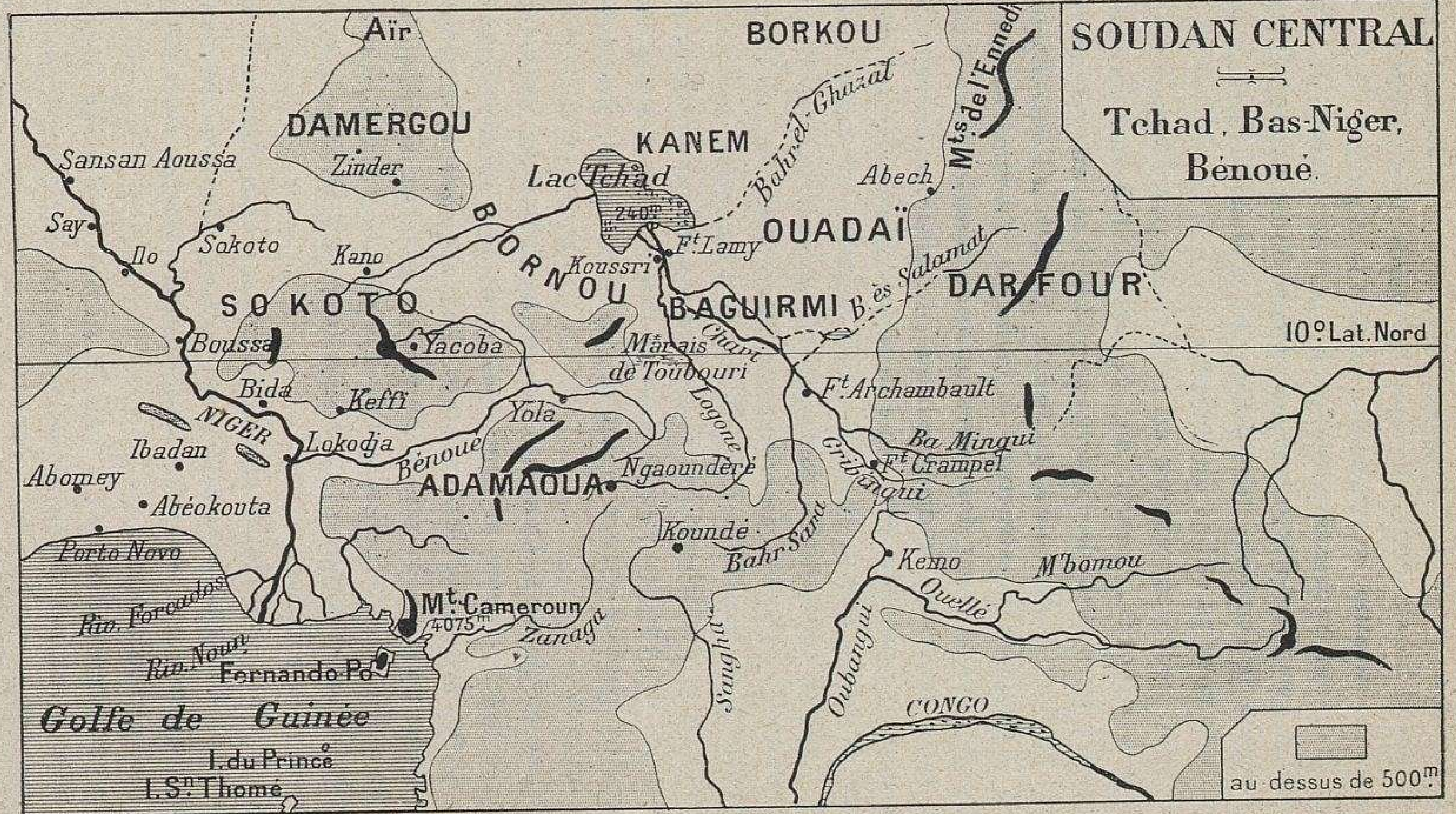


I. Relief- - Le lac Tchad occupe, sur le plateau, le fond d'un grand bassin déprimé, dont les bords très inégaux sont redressés, rabattus ou ébréchés, suivant la région.

$1^{0}$ Ils sont redressés au Nord, par le massif de l'Ä̈r $(1.800 \mathrm{~m}$.), au Nord-Est par celui du Tibesti (mont Tarso $2.600 \mathrm{~m}$.) qui rejoint le Darfour; tous deux sont d'anciens volcans, très loin de la mer, au milieu du désert.

Ils sont redressés encore au Sud-Ouest par d'autres soulèvements éruptifs, massif du Yacoba $(2.135 \mathrm{~m}$. au mont Saranda) et massif de l'Adamaoua ( $3.000 \mathrm{~m}$. au Ghendero), entre lesquels la Bénoué a fait brèche. Comme le Fouta-Djalon, dont il rappelle la structure et la forme, l'Adamaoua est un puissant condensateur des nuées qu'apportent les moussons et par suite un centre hydrographique de premier ordre. C'est une cime volcanique aussi que le mont Cameroun, qui de la plage littorale monte jusqu'à 4.075 mètres, et l'alignement des cratères se continue dans l'Océan même, par les îles de Fernando Po $(2.850 \mathrm{~m}$. au cratère de Sainte-Isabelle), du Prince (1.000 m.), de San Thomé $(2.140$ m.) et d'Annobon.

De l'Air et du Tibesti par le Borkou et le Bodelé, de l'Adamaoua et du Yacoba par le Bornou descendent des plateaux étagés où parfois encore pointent des pics isolés, des dykes volcaniques.

$2^{\circ}$ Les bords sont abaissés à l'Ouest et au Sud du lac Tchad. Vers le Niger s'ouvre un large seuil, sans la moindre ligne de faîte pour distinguer les versants. La pente est là tellement incertaine qu'après la saison pluvieuse les eaux se répandent sur un sol horizontal; elles inondent la plaine de Sokoto, tournée vers le Niger, et entourent de marais stagnants la ville de Kano, tournée vers le Tchad.

Même absence de relief entre l'Adamaoua et le Darfour : les bassins du Chari et celui du Congo sont séparés par une haute plaine, à pente peu sensible; dont l'altitude la plus forte est de 215 mètres seulement.

On comprend alors qu'à l'Ouest et au Sud du Soudan central, les mêmes nappes d'eau alimentent, lors de l'hivernage, des bassins différents. Là, dans ces régions indécises, c'est la hauteur des eaux, non la pente du sol, qui fait couler les rivières 
et corrige dans une certaine mesure l'insuffisance du modelé terrestre.

II. Climat. - Les conditions du climat sont les mêmes pour le Soudan central que pour le Soudan occidental. Les pluies tombent lorsque le soleil passe au zénith. Aux latitudes les plus basses, les passages du soleil sont assez écartés pour qu'il se produise deux saisons de pluies et deux saisons sèches, l'une étant plus longue que l'autre; mais plus on monte vers le tropique et plus les passages du soleil sont rapprochés, de sorte qu'il finit par ne plus y avoir dans l'année que deux saisons, une de sécheresse, très longue, et une de pluies.

$1^{\circ} \mathrm{Au}$ Nord, sur les confins du Sahara, est une région subdésertique : la sécheresse très forte amène des écarts de température sensibles. L'Aïr et le Tibesti doivent à leur élévation d'être encore arrosés par les pluies venues de l'Atlantique.

$2^{\circ}$ Dans les plaines du Soudan proprement dit, par exemple au Bornou, c'est pendant les quatre mois d'été, de juin à septembre, que s'abattent les pluies, par vents Sud-Ouest; alors la température oscille peu et se maintient à une moyenne de $23^{\circ}$. Cette période de l'année est fort malsaine pour les blancs. Très saine est au contraire la saison sèche (mars-juin), bien qu'elle soit intolérable; pendant le jour l'air est embrasé et le vent d'Est apporte d'impalpables poussières; même abrité, le thermomètre atteint $45^{\circ}$. - Entre les deux, d'octobre à mars s'établit une saison froide; les Nègres, fort sensibles aux abaissements de la température (ils grelottent au-dessous de $+25^{\circ}$ ) souffrent alors beaucoup : car le matin on note souvent $+5^{\circ}$ et même, dans le Baguirmi, on a constaté des froids de $3^{\circ}$ audessous du point de glace.

$3^{\circ}$ Les régions élevées, à proximité de l'océan Atlantique, reçoivent de fortes quantités de pluies. Sans doute l'année eśt toujours partagée en deux saisons; mais la saison sèche ne l'est que par comparaison, car il n'y a pas de mois sans pluies. Quant à la saison pluvieuse, elle est marquée par de vraies trombes et les orages sont si fréquents qu'on en compte 150 à 200 par an. L'Adamaoua est déjà très mouillé; le Camerourı l'est plus encore, et ce n'est que dans l'Inde, dans l'Assam, 
qu'on a relevé des chutes d'eau plus fortes. A Debundja la moyenne de 8 années accuse $10 \mathrm{~m} .45$.

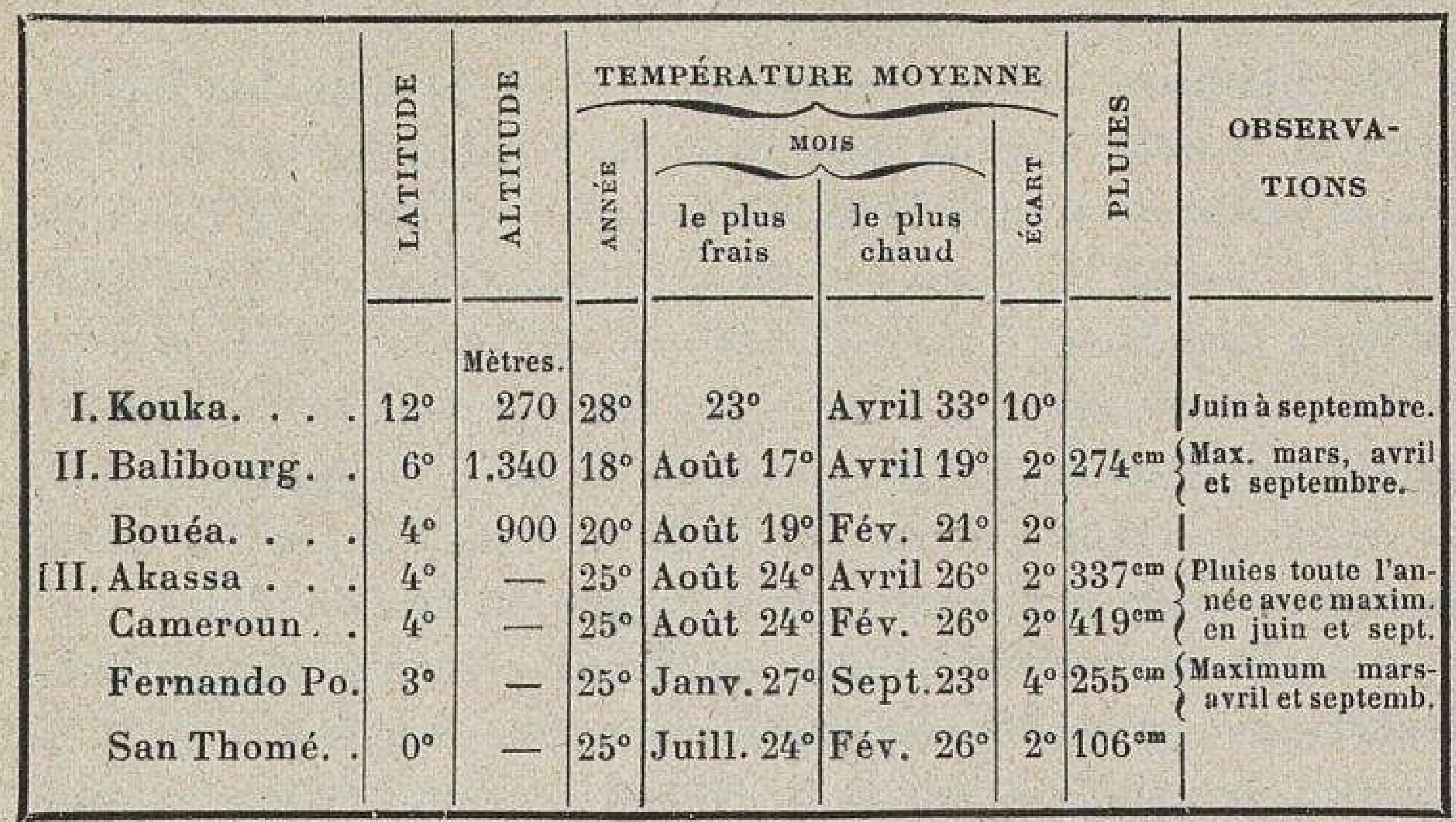

$4^{\circ}$ Enfin, les contrées basses du littoral sont soumises au climat équatorial; la température n'est pas excessive, mais elle est humide, égale et malsaine; les vents de Sud-Ouest prédominent.

III. Hydrographie. - Les eaux du Soudan central suivent deux directions : elles s'amassent dans la dépression du Tchad ou bien elles s'écoulent vers le Niger.

$1^{\circ}$ Bassin du Tchad. - Le lac Tchad (alt. $270 \mathrm{~m}$.) est une nappe immense, plus grande que la Belgique ou que notre Bretagne ( 30 à $40.000 \mathrm{kmq}$., longueur $300 \mathrm{~km}$., largeur $130 \mathrm{~km}$.). On ne peut le comparer ni à une mer intérieure : il ne rappelle en rien les grands lacs américains; ni à un marécage bourbeux : les gros vents d'Ouest peuvent brusquement y soulever des vagues redoutables. Il a tous les caractères des lacs désertiques.

On a cru longtemps avec Nachtigal que ses eaux se déplaçaient sui-, vant la direction de l'harmattan, de l'Est vers l'Ouest, où sont les plus grands fonds $(12 \mathrm{~m}$.). La vérité c'est qu'il s'assèche progressivement : l'abaissement du niveau est évalué à $0 \mathrm{~m}$. 15 par an. Une multitude d'îles le parsèment; réparties en deux groupes (archipel Kouri et archipel Boudouma), elles sont orientées Nord-Nord-Ouest, suivant la résultante des deux vents dominants Nord-Est et Ouest : les unes, toutes de sables, dépourvues de végétation, émergent à peine et servent de lits de repos aur caïmans; les autres, plus hautes, sont utilisées comme parcs 
naturels par les indigènes, qui y font paitre leurs bestiaux: d'autres enfin ont des dunes de 10 à $15 \mathrm{~m}$. et portent des villages, des champs cultivés, surtout des plantations de mil.

Le Tchad est situé à la limite du Sahara et du Soudan : les rives septentrionales sont désertiques, les rives méridionales

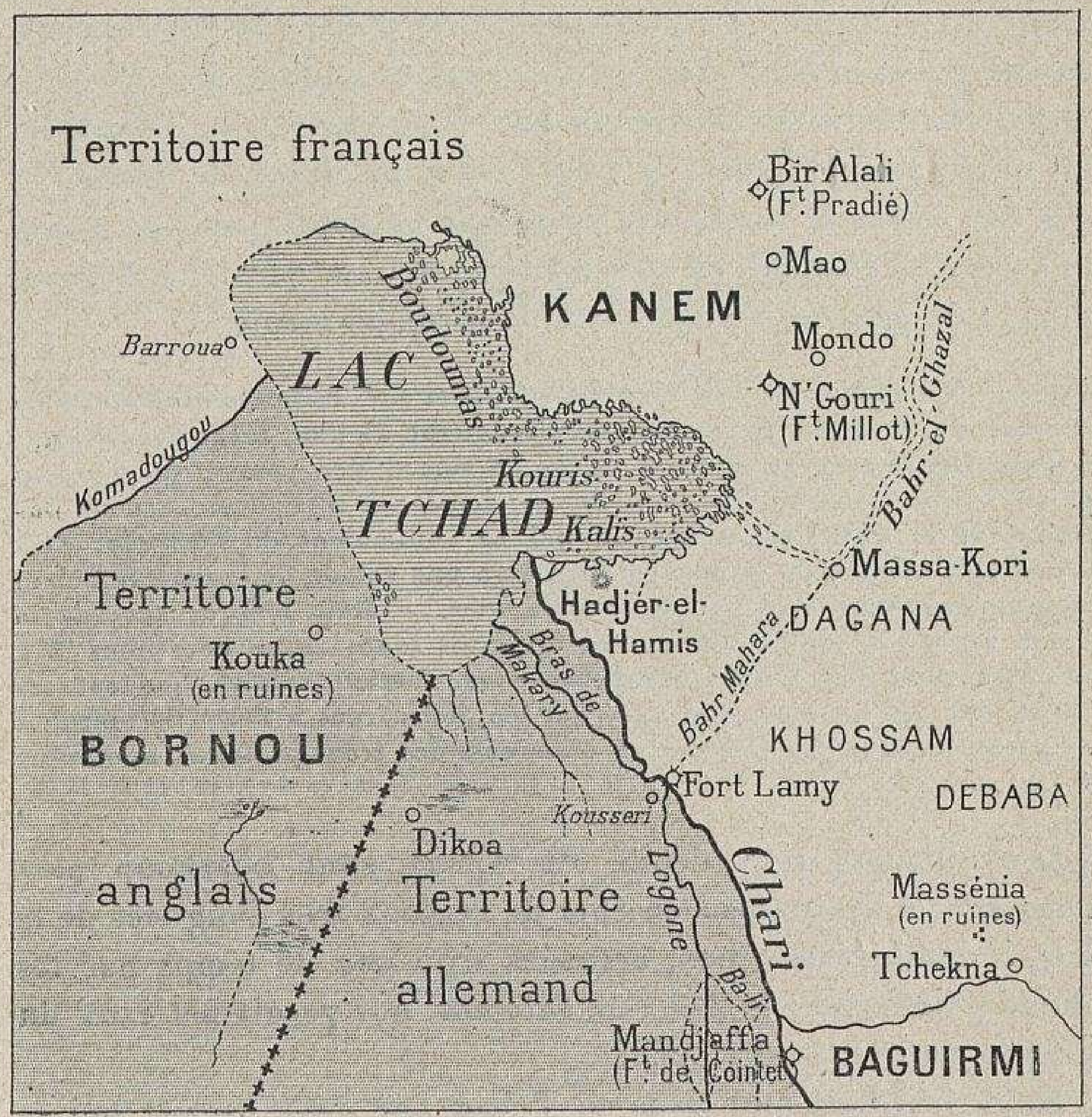

LAC TGHAD

d'après les travaux de la mission Destenave.

tropicales. Aussi les cours d'eau qui lui arrivent, sent-ils, suivant la latitude, temporaires ou permanents, et son niveau varie avec les saisons; il est en crue de juillet à fin octobre.

Temporaires les rivières du Bornou : le Yéou, appelé Komadougou dans son cours inférieur $(700 \mathrm{~km}$. env.), est assez profond lors des pluies, mais en saison sèche il ne présente qu'une. série de mares disjointes, de flaques sans écoulement. 
Temporaires aussi, celles de l'Ouadai. Le Bahr-el-Ghazal, ou fleuve des Gazelles, n'est pas un affluent, mais un effluent : le trop-plein des eaux du lac s'y écoule et fertilise son lit.

Permanent au contraire est, au Sud, le Ghari, fleuve magnifique, navigable sur tout son parcours en toute saison. Il est formé de la réunion de plusieurs cours d'eau : le Gribingui, le Ba-Mingui et le Bahr-Sara, tous venus de régions peu élevées, où les sources sont communes aux trois bassins du Tchad, du Nil et du Congo. Aussi le Chari est-il un fleuve de plaine, et lors des crues, la masse des eaux, que ne guide pas une pente suffisante, s'épanche en des marécages immenses. Le Logone, affluent de gauche, se comporte de la même manière.

Quand le Logone a recueilli les eaux tombées sur les pentes orientales de l'Adamaoua, il emplit le lac Toubouri (longueur $25 \mathrm{~km}$., largeur $1.500 \mathrm{~m}$.), et tous les fleuves se joignent après la saison des pluies, ne formant qu'une nappe immense sur laquelle on circule en pirogues. Ce n'est pas seulement le Chari et le Logone qui se confondent de la sorte; c'est encore le Logone et la Bénoué, si bien qu'à une saison de l'année le Tchad communique avec le Niger et avec la mer. - Mais lorsque succède la saison séche, la plaine découverte apparaît toute rayée de sillons (3 à $400 \mathrm{~m}$.), dont les fonds, craquelés sous l'action solaire, portent les empreintes des animaux sauvages qui les piétinèrent à l'état de marais : les pieds énormes des éléphants y ont creusé des trous profonds, nombreux et très serrés.

Les affluents rive droite du Chari sont beaucoup plus maigres; ils descendent en effet de régions très éloignées de la mer, à demi désertiques, arrosées trop peu de temps par les pluies océaniques; le Bahr-es-Salamat, qui reçoit les eaux du lac Iro, est le type des ouadi.

Enfin le Chari finit dans le Tchad par mille canaux qui se mêlent et s'enchevêtrent, par un delta large de 100 kilomètres, gigantesque coulée de fanges alluvionnaires et de boues pestilentielles.

$2^{\circ}$ Versant du Niger. - La Bénoue $(1.400 \mathrm{~km}$.) descend des pentes orientales de l'Adamaoua. A l'imitation de plus d'un fleuve africain, et du Niger tout le premier, elle commence par couler dans une direction opposée à la mer; comme le Logone, auquel l'unissent, lors des pluies, les marais de Toubouri, elle est d'abord orientée vers le Nord et le Nord-Nord-Est, comme si elle devait disparaitre dans le Tchad. Mais bientôt, elle se recourbe 
vers l'Ouest et fraie sa route à travers la montagne; de brèche en brèche, de cascade en cascade, elle adopte sa direction définitive et gagne le Sud-Ouest.

A Yola elle entre en plaine; la vallée seulement alors se dessine, encore étranglée de loin en loin par des ressauts montagneux; le lit se divise, enveloppe des îles et des archipels, et sur chaque bord arrivent des tributaires, qui entrent en crue à la même époque qu'elle et en font une grosse et large rivière. Après l'hivernage, la navigation la remonte jusqu'à Garoua, c'est-à-dire jusqu'à $1.300 \mathrm{~km}$.; il n'est pas au Soudan de voie fluviale de pénétration qui lui soit comparable. Alors les eaux couvrent les plaines riveraines, les indigènes se réfugient dans l'intérieur des terres sur les éminences qui portent leurs villages; ils en descendent après le retrait des eaux pour procéder sur le limon fécondant aux plantations du mäs et du mil. C'est à Lokodja que la Bénoué est absorbée par le Niger.

$3^{\circ}$ Fleuves côtiers. - Le versant Sud-Ouest de l'Adamaoua et le mont Cameroun écoulent leurs eaux directement à l'océan Atlantique, au fond du golfe de Guinée. Dans cette région, des plus arrosées du monde, les rivières sont puissantes, larges et profondes, mais comme elles descendent en cascades de hautes montagnes, leur valeur est par là bien diminuée : le Cross River finit, après une grande courbe, à Vieux Calabar; le Zanaga a ses dernières chutes à 50 kilomètres de la côte et son entrée est gềnée encore par une barre fort difficile.

IV. Côtes. - A l'Est de l'immense delta à seize bouches du Niger, la côte du Cameroun se hérisse de promontoires volcaniques et se creuse d'estuaires : la baie du Cameroun, dont le nom actuel dérivé du Portugais voudrait dire la baie des Crabes, est une magnifique position maritime. Mais le littoral est marécageux, insalubre, et déjà les Européens ont installé un sanatorium sur les hauteurs.

Les illes sont, nous l'avons vu, des pointements éruptifs audessus des eaux.

V. Vie végétale. - La végétation du Soudan central est identique à celle du Soudan occidental; de part et d'autre les conditions physiques, nature du sol, climat et relief, sont identiques. Au Nord, la région subdésertique est celle de Zinder et du Kanem. Puis vient la brousse, à grandes herbes, avec bouG. Lespagnol et M. Fallex. - - Afrique. 
quets d'arbres clairsemés. Les plateaux de S'aria et l'Adamaoua rappellent le Fouta-Djalon par leurs champs fertiles et leurs beaux pâturages. Enfin, en demi-cercle autour du golfe de Guinée, la forét tropicale a pour essence caractéristique le palmier à huile; le nom de " rivières d'huile " a même été donné aux rivières côtières que le palmier borde de forêts épaisses.

Le voisinage de la mer et l'altitude sont ici, comme partout, des facteurs importants. Les régions du haut Chari, moins abondamment et moins longtemps arrosées, appartiennent à la brousse soudanienne et pourtant elles sont à la même latitude que les rivières d'huile.

VI. Vie animale. - Pour les mêmes raisons, la vie animale du Soudan central reproduit celle du Soudan occidental.

Dans la région subdésertique de Zinder, les transports se font encore par chameaux, mais dans le Bornou, par boufs; l'on élève alors le cheval.

Les animaux sauvages (antilopes, gazelles, autruches, girafes, éléphants, hippopotames) ont le champ libre dans le Nord ou sur les rives du Tchad; ils deviennent moins nombreux vers le Sud, à mesure que la population est plus dense, et les espèces domestiques les remplacent.

VII. Vie humaine. - Les peuples noirs du Soudan central sont, comme ceux du Soudan occidental, extraordinairement métissés : le Soudan tout entier est naturellement ouvert aux migrations.

Dans la région subdésertique, les Touareg (Berbères), les Tibbou (Berbères mêlés de Nègres) et les Oulad Sliman (Arabes) ont tous ce trait commun d'être des peuples pasteurs, des nomades guerriers et pillards qui tiennent asservis les Nègres sédentaires et vivent en parasites à leurs dépens. Pour éviter leurs perpétuelles razzias, ceux-ci ont reflué vers le Sud et déserté le Kanem pour le Bornou; les îles du lac Tchad leur ont prêté un asile inviolable.

Au Sud du lac Tchad, d'autres conquérants ont passé, que nous avons déjà rencontrés dans le Soudan occidental : les Foulbé ou Peul. Venus par la route de l'Est, en pasteurs, ils 
fondèrent des États musulmans, à demi policés, toujours esclavagistes, États guerriers ayant leurs armées régulières de fantassins, leur cavalerie pourvue de casques et cuirassée de cottes de mailles. Moins nombreux que les vaincus, ils ont eu la force de se maintenir, parce que la religion de l'Islam leur donnait une cohésion qui fait défaut aux tribus nègres, paĩennes et fétichistes. Les Foulbé occupent en maîtres les villes, ils tiennent la plaine, ils parcourent les pâturages du plateau avec leurs troupeaux de boufs et de chevaux que gardent des esclaves. Mais dans les montagnes du Yacoba et de l'Adamaoua, les Nègres paiens ont trouvé un refuge : bloqués et comme assiégés par les Foulbé qui s'efforcent de les réduire, ils descendent souvent de leurs forteresses naturelles pour opérer des pillages fructueux. - Les Kanouri du Bornou, métissés de Nègres et de Berbères, sont des cultivateurs et des artisans habiles.

Au milieu des conquérants Foulbé, des Nègres indépendants et des Nègres soumis, circule tout un peuple de marchands, les Haoussa, de petite taille, très alertes, que leur vie aventureuse prédisposait à fournir des recrues braves et disciplinées aux armées coloniales des Européens. Leur domaine commercial n'est pas limité au Soudan central; il s'étend à l'Ouest dans ce que l'on est convenu d'appeler la boucle du Niger.

Vers le Sud enfin la forét fut toujours une barrière; les Foulbé s'y sont arrêtés, et les Nègres du bas Niger ont pu éviter le contact, sous son abri, des autres peuples.

VIII. Gouvernement et villes. - Les Européens ne se présentèrent que dans la dernière moitié du $\mathrm{xIx}^{\mathrm{e}}$ siècle. Sans se soucier de la géographie physique, sans tenir compte des divisions de races et de religions, Français, Anglais et Allemands se sont partagé le Soudan central par des conventions diplomatiques; ils procèdent aujourd'hui à l'occupation effective, ils préparent la mise en valeur écononique.

$1^{\circ}$ POSSESSIONS FRANGAISES

Pays de Zinder, Kanem, Ouadaï, Baguirmi, Chari : telle est la part que nous ont reconnue plusieurs conventions avec l/\$n-

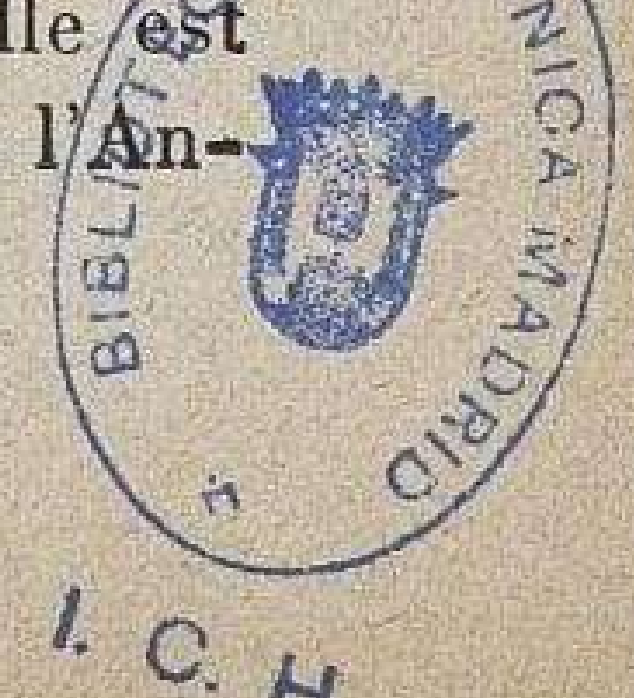


gleterre et avec l'Allemagne. Elle est grande, il est vrai, mais non pas, et de beaucoup, la meilleure; la jonction que le lac Tchad paraît établir sur la carte entre nos possessions méditerranéennes, soudaniennes et congolaises demeurera longtemps encore toute fictive. Zinder est le chef-lieu du territoire militaire du Niger et relève ainsi du gouvernement de l'Afrique occidentale. Le territoire militaire du Tchad et l'OubanguiChari sont deux circonscriptions d'une mème colonie (eheflieu Bangui) qui fait partie du Congo.

La convention franco-anglaise du 8 avril 1904 a sensiblement remanié la frontière établie par la convention du 14 juin $1898.1^{\circ}$ A l'Ouest les deux rives de la vallée du Dallol Maori nous sont reconnues ainsi que Birni N'Koni, un important noeud de routes. $2^{\circ}$ Au centre, notre cercle de Zinder recouvre les territoires méridionaux qui dépendaient jadis du sultanat et d'où il tire le meilleur de ses revenus. La ville est animée et riante; située sur la piste qui conduit de Sorbo-Aoussa sur le Niger à Barroua, sur le Tchad, elle est le chef-lieu d'une a marche n véritable entre le Sahara et le Soudan. $3^{\circ}$ A l'Est enfin la limite atteint par $13^{\circ} 28^{\prime}$ Lat. Nord le Komadougou, dont elle suit le thalweg jusqu'au lac. - De là sorte la route qui conduit du Niger au Tchad ne court plus sur des portions de désert, sans eaux ni vivres, et le pourtour du Sahara nous appartient en totalité.

Le Kanem subit de plus en plus notre influence; le Ouadaï entre chaque jour davantage dans notre sphère d'action : en 1909, nos troupes ont occupé la capitale Abéchr.

Le Baguirmi est en pleine transtormation; la capitale Massenya n'existe plus : elle a été remplacée par Tcheckna $(10.000$ h. $)$. Dans le Darel-Kouti, Ndélé est la capitale d'un sultan Senoussi, placé sous notre protectorat. Partout des centres nouveaux se créent et les indigènes délivrés des conquérants dévastateurs reviennent, sous l'abri de notre drapeau, à leurs occupations pacifiques, culture et élevage.

\section{$2^{\circ}$ POSSESSIONS ANGIAISES}

Les possessions anglaises du Soudan central forment les deux Nigérie.

La Nigérie du Sud comprend 3 provinces : le Lagos ou province occidentale (Lagos); le Nigen ou province centrale (Warri, Akassa, Forcados et Bénin); le Calabar ou province orientale (Galabar, Bonny, Degama et Brass).

La Nigérie du Nord (chef-lieu provisoire, Zounguerou) a englobé une série d'anciens États musulmans, divisés en 17 provinces; les plus peuplées sont celles de Kano, de Nassa- 
roua, des deux Bornou, occidental et oriental, et de Bassa. C'est une colonie d'avenir, à en juger par les ressources naturelles du pays et par le nombre des habitants.

Les villes reftètent l'image de la sociélé soudanienne, en ce sens qu'elles rassemblent les éléments divers dont elle est faite : Foulbé conquérants, Haoussa marchands, Nègres musulmans et Nègres païens, cultivateurs, artisans, esclaves. Fort nombreuses, elles sont actives, animées et toutes bâties d'après un type uniforme. Une enceinte épaisse, aux portes bardées

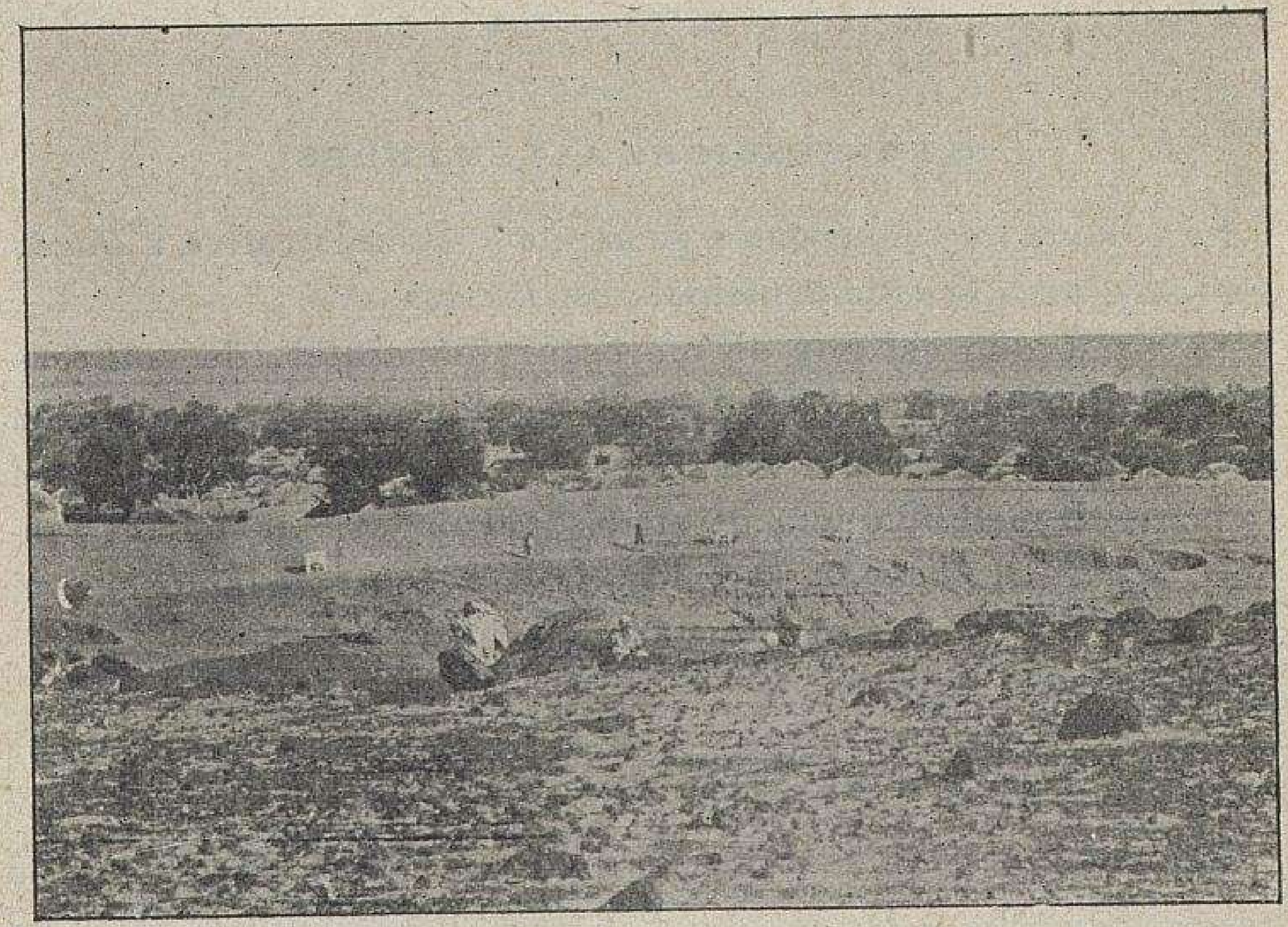

VOURNO, RESIDENGE DU SULTAN DE SOKOTO. TYPE DE VILLE AU SOUDAN CENTRAL.

Vue partielle.

(Photographie J. Thompson, communiquée par la Société de Géographie de Paris.)

de fer, se déroule, immensément longue, sur 20 et $30 \mathrm{~km}$. de tour. Mais à l'intérieur beaucoup d'espace reste vide; on peut y faire plasieurs kilomètres à travers des terrains vagues, des cultures, des jardins, des mares et des étangs, avant d'apercevoir aucune habitation. Perdues dans la verdure, celles-ci ont été bâties sans ordre le long d'avenues, larges et ombragées, poussière ou boue, suivant la saison. Les unes ont des toits plats à terrasses, et ce sont les plus importantes, le palais du roi, la demeure des ministres, à côté de la citadelle et des mosquées; les autres sont des cases rondes, huttes à toit conique, coiffées de chaumes, des "paillottes »: toutes d'ailleurs sont en pisé, gâchées avec une argile rouge ferrugineuse, et partout le sol apparait troué par les excavations, d'où la terre a été extraite. Ces deux modes de construction juxtaposés donnent à loutes ces cités une physionomie moitié arabe et moitié nègre. 
Sokoto, l'ancienne capitale, a été délaissée, à cause de son insalubrité, pour Vourno; Katsena; Kano, le plus grand et le plus célèbre marché du Soudan central; Saria, sur des plateaux fertiles à 600 mètres d'altitude; Bida, Keffi, Yacoba dans le Baoutchi, etc.

Kouka, à proximité du lac Tchad, a compté jusqu'à 200.000 habitants : elle est en ruines aujourd'hui; dans le Bas Bornou, Goudjba; enfin dans l'Adamaoua, Yola, etc.

\section{$3^{\circ}$ POSSESSIONS ALLEMANDES}

La colonie du Cameroun a sa capitale administrative à Bouéa (900 m.), mais la ville principale est Douala.

Le Cameroun est fait de morceaux disparates, de contrées sans lien les unes avec les autres : littoral, montagnes et plateaux de l'Adamaoua, terrasses du Bornou. L'occupation allemande se poursuit méthodiquement et des garnisons s'installent partout, à Bali, à Yaoundé, à Ngaoundéré, à Dikoa, à Kousseri, en face du poste français de Fort-Lamy.

\section{$4^{\circ}$ POSSESSIONS PORTUGAISES ET ESPAGNOLES}

Les quatre îles volcaniques du golle de Guinée sont partagées entre l'Espagne : Fernando Po et Annobon qui fut découverte le premier de l'an, d'où son nom de "bonne année " - et le Portugal : ile du Prince, qu'on peut bien appeler la perle de ses colonies; San Thomé, découverte le jour de la Saint-Thomas, (21 décembre 1470) et qui produit en abondance le cacas. Leur forte élévation lcur vaut un climat moins malsain qu'on ne supposerait; la végétation est riche, variée, et les cultures tropicales s'étagent au-dessus de la mer.

IX. Mise en valleur. - L'exploitation européenne est limitée aux régions côtières. Là, comme en Guinée, se récoltent l'huile et l'amande de palme, le caoutchouc, et les cultures tropicales, cacao, café, coton, etc., commencent à être essayées.

L'exploration, à plus forte raison l'occupation des régions de l'intérieur ne sont pas achevées; c'est assez dire qu'il n'est 
d'autre agriculture, d'autre industrie et d'autre commerce que ceux des indigènes. Encore est-il nécessaire de distinguer entre les régions voisines du lac Tchad (Bornou, Baguirmi et Chari) dévastées et dépeuplées par le conquérant barbare Rabah, et les États musulmans de demi-civilisation, entre Niger et Tchad.

Dans ces derniers, les cultures sont les mêmes qu'au Soudan occidental : plantes alimentaires (mil, maïs, riz, orge, un peu de froment, légumes, manioc et igname), plantes industrielles (coton, indigo), graines oléagineuses (sésame, arachide). L'élevage est très développé : chameau dans l'extrême Nord, brebis, chèvre, cheval, âne, surtout le gros bétail. Bref le Sokoto est pourvu de ressources agricoles incontestables.

De ressources industrielles également. Les noirs savent extraire l'huile d'arachide et de sésame, - laver, filer et tisser le coton ou la soie (Baoutchi), - fabriquer des bandes d'étoffes étroites, qu'ils teignent de couleurs variées, mais surtout en bleu mat, - tanner les peaux (boeufs, chèvres, moutons) et les maroquiner, ouvrer les cuirs, - fabriquer des poteries, des objets en métal (cuivre, argent, étain), de la quincaillerie et des verreries. Tous ces produits industriels des Etats musulmans sont fort estimés et très demandés; ils alimentent, avec l'ivoire, les plumes d'autruche et encore les esclaves, des transactions actives. A maintes reprises les explorateurs ont dépeint l'animation des pistes soudaniennes (Sokoto, Kano, etc.) où circulent et se croisent, véritables fourmilières en colonnes, les animaux porteurs et les marchands. Suivant une loi facile à comprendre, les échanges se font entre pays de climat et de productions différentes, c'est-à-dire du Nord au Sud; mais une voie commerciale est aussi orientée d'Ouest en Est, du Niger au lac Tchad et peut-être même par l'Ouadaï vers le Nil.

Ici se pose le même problème que dans le Soudan occidental, l'établissement par les Européens de moyens de transport rapides et économiques. Nous savons déjà que les-grandes caravanes tripolitaines déclinent de jour en jour et que de nouveaux débouchés s'ouvrent rers le Sud-Ouest. Impossible de se prononcer encore sur la valeur exacte de la Bénoué, comme voie fluviale de pénétration; en tout cas elle est presque exclusivement britannique. Pour atteindre le lac Tchad, la France est obligée à des circuits longs et dispendieux : ou bien en remontant le Niger, à condition de triompher des rapides, en terre anglaise jusqu'à Ilo, puis de là jusqu'à Sorbo-Aoussa, d’où une piste de caravanes en pays fertile mène vers Zinder, ou bien en remontant le Congo (chemin de fer belge et fleuve) et l'Oubangui, puis, après un portage, en descendant le Chari. On ne pourrait qu'atténuer, et non supprimer, ces inconvénients naturels : car ils résultent du tracé des frontières. Pourtant plusieurs projets ont été mis en avant : chemin de fer du Dahomey au Niger, en construction; chemin de fer courant sur le seuil de $150 \mathrm{~km}$. qui sépare les bassins du Congo et du Chari; chemin de fer transsaharien ou grand Central africain qui mettrait le Tchad à six ou sept jours de Paris.

Nos concurrents ont l'avantage de posséder des contrées riches et à proximité de la mer. Les Anglais ont achevé la voie ferrée de Lagos à 
Djebba sur le Niger; ils parlent de jeter un grand pont sur le fleuve pour que la locomotive atteigne Kano et Sokoto; nous avons dit déjà la ligne en construction de Baro à Kano. - Les Allemands ont leurs projets aussi au Cameroun.

Seul l'avenir précisera tous ces desseins, en révélant les ressources exactes du Soudan central et ses possibilités économiques.

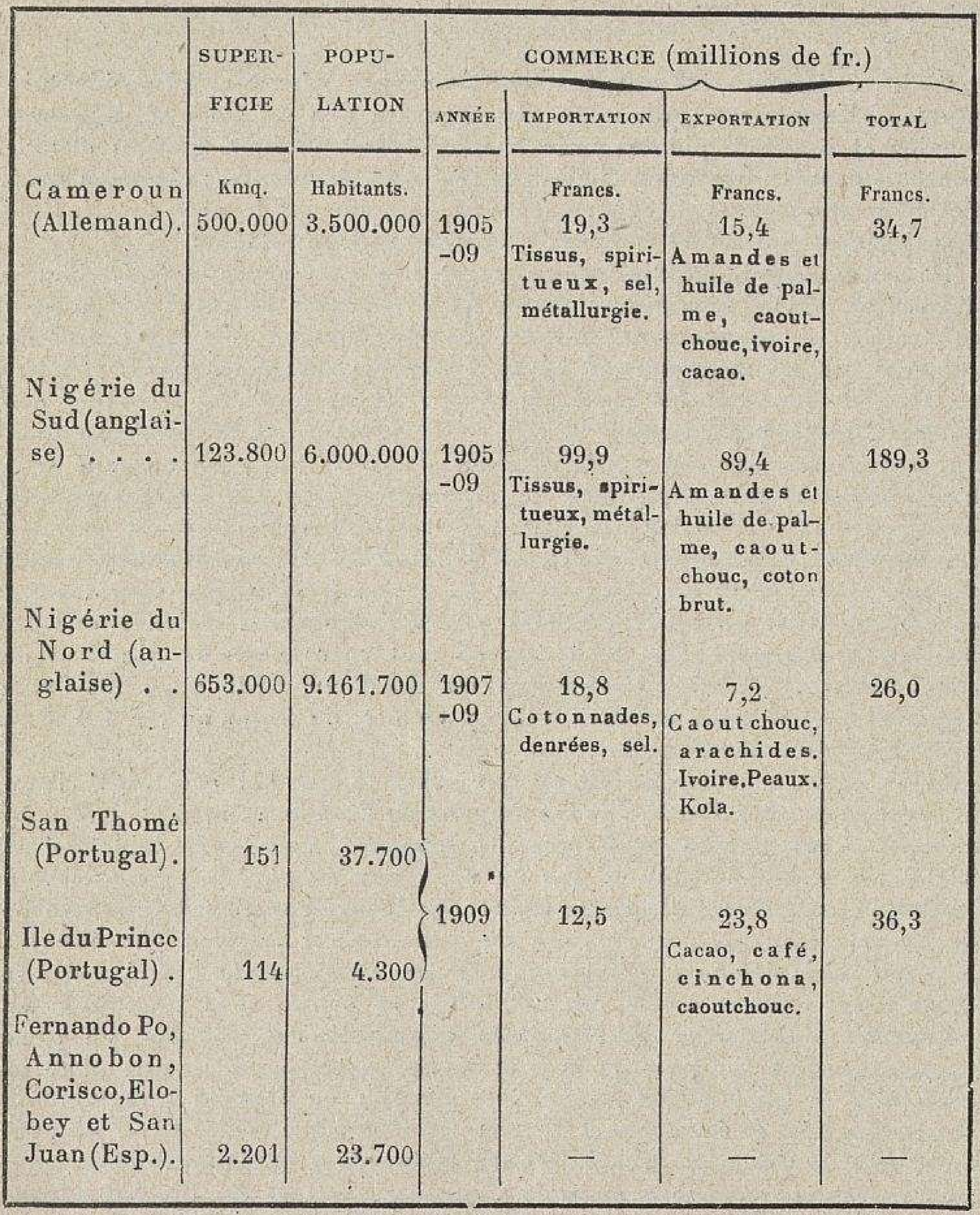




\section{CHAPITRE XI}

\section{BASSIN DU CONGO ET CONGO FRANÇAIS}

\section{SOMMAIRE}

1. Le bassin du Congo, coupé inégalement par l'équateur, n'est nulle part bordè de chaines de montagnes.

II. Superficie. - Environ 3 millions de $\mathrm{kmq}$.

III. Relief. - La région equatoriale du Congo est faite de terrasses superposées que les monts de Gristal à l'ouest et les monts Mitoumba au Sud-Est séparent en trois zones.

IV. Climat. - La tempèrature est uniformément chaude, sans être excessive. Ce sont les pluies qui distinguent les saisons, au moins à partir de $4^{\circ}$ Lat. $N$. ou $\mathbf{S}$.; car sous l'équateur l'année tout entière est pluvieuse.

y. Hydrographie. - $1^{\circ}$ Le Gongo, le second fleuve du monde par les dimensions du domaine et par le volume des eaux, décrit de ses sources à la mer la courbe caractéristique des rivières africaines, et, comme elles aussi, descend par des rapides les terrasses étagées de son bassin. Après les chutes de Stanley il est aussi large qu'un bras de mer, puis, quand il s'est épanoui, $1.450 \mathrm{~km}$. plus loin, dans le Stanley pool, il entaille les monts de Cristal et c'est du haut de 32 chutes qu'il se déverse dans l'océan Atlantique par un large estuaire.

Plusieurs des affluents qui l'ont rejoint sont aussi puissants que lui : l'Arouhouimi, l'Oubangui à droite, le Kassaï à gauche.

2. Parmi les fleuves côtiers, l'estuaire du Gabon et l'Ogooué qui finit en un delta vaseux, après avoir dégringolè par des rapides les gradins des plateaux.

VI. Côtes. - Au INord du cap Lopez, la côte est creusée de golfes profonds (rade de Libreville sur le Gabon); au Sud elle est basse et rectiligne.

VII. Vie végétale. - Elle est la même qu'au Soudan et comprend une région maritime, une savane ou une brousse, et la grande forêt qui remplit toute la cuvette du Congo moyen.

VIII. Vie animale. - Elle. varie d'une région à l'autre, de méme qu'au Soudan; l'espèce carastéristique est le singe. 
IX. Vie humaine. - Les populations du Congo, incultes, miséraibles et volontiers anthropophages, sont des Nègres, pour la plupart de race bantoue. Des nains ont trouvé, par places, asile dans la forêt.

X. Gouvernement et villes. - $1^{\circ} \mathrm{L}$ 'Etat indépendant du Gongo a été annexé à la Belgique (1908), après avoir été, depuis sa fondation (1885), la proprièté personnelle du roi des Belges, Léopold II; à Bruxelles est le gouvernement central, à Boma un gouverneur local.

Il n'existe pas de villes, mais seulement des stations : Matadi, port maritime; Léopoldville, port d'attache de la flottille fluviale; Nouvelle-Anvers; Stanleyville, etc.

$2^{\circ}$ L'A frique équatoriale française comprend 3 colonies : A) le Gabon, cap. Libreville; B) le Moyen Gongo, cap. Brazzaville; C) l'Oubangui-Chari-Tchad, cap. Bangui, divisé lui-même en deux circonscriptions, l'oubangui-Chari et le territoire militaire du Tchad.

$\mathbf{3}^{\circ}$ A l'Espagne appartient le Rio Mouni.

$4^{\circ}$ Au Portugal, Cabinda.

Xr. Misc en valeur. - Le Congo, français et belge, est un pays d'exploi. tation presque exclusivement agricole.

Les deux grandes richesses sont l'ivoire, de plus en plus rare, et le caoutchouc, de plus en plus abondant. Viennent ensuite les bois, les amandes et l'huile de palme. D'annèe en annèe se développent les plantations tropicales : cacao, café, vanille, tabac, ananas, etc.

Le Congo belge a eu pour commencer plus de vitalité que le Congo français. Un chemin de fer unit Matadi, sur la mer, à Lèopoldville, sur le fleuve; mais cette voie ferrée et celles que l'on projette ne seront jamais que les auxiliaires des voies fluviales : $18.000 \mathrm{~km}$. de rivières sont accessibles aux bateaux à vapeur.

\section{DÉVELOPPEMENT}

L'Afrique équatoriale comprend deux régions très distinctes : l'une, à l'Est, de hauts plateaux, volcaniques et lacustres, que nous étudierons ultérieurement; l'autre, au Centre et à l'Ouest, le bassin du Congo.

I. Limites du bassin du Congo. - Coupé inégalement par l'équateur, le bassin du Congo atteint $8^{\circ}$ Lat. N. et $13^{\circ}$ Lat. S. Nulle part ses bords ne sont faits d'une chaine de montagnes continue; ils se relèvent en plateaux qui font bourrelet à l'Est et à l'Ouest, et s'étalent en seuils très larges au Nord vers le Chari et le Nil, au Sud vers le Zambèze.

II. Superficie. - Environ 3 millions de kilomètres carrés.

III. Orogénie et relief. - Le bassin du Congo est un massif 
de terrains très anciens que l'érosion a émoussés et cumme rabotés. Toutes les fois que la roche primitive n'apparaît pas à la surface, e'est qu'elle a été recouverte d'un manteau de terres meubles, résultat de l'altération et de la désagrégation sur place, ou bien de sédiments

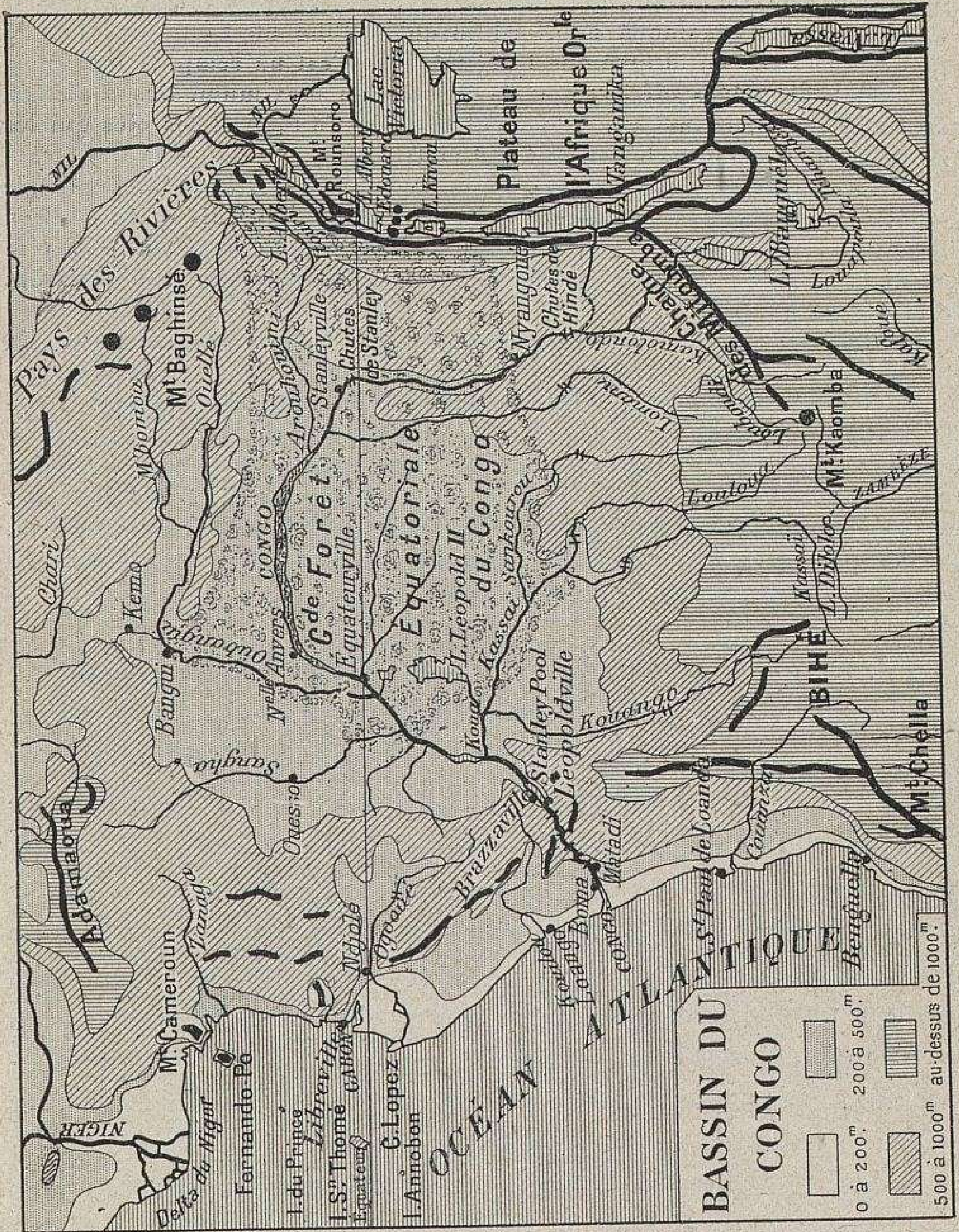

lacustres (grès et schistes argileux) déposés par les eaux qui ne trouvaient pas le chemin de la mer. A l'époque quaternaire, de grandes dislocations produisirent un affaissement des parties centrales et un redressement au contraire du pourtour.

De l'Atlantique aux grands lacs, la région équatoriale du 
Congo est faite de terrasses superposées. Deux soulèvements d'importance inégale la séparent en trois zones : les monts de Cristal et les monts Mitoumba

1. Parallèles à l'Atlantique, les monts de Cristal s'alignent depuis le Cameroun et l'Adamaoua au Nord jusqu'au Bihé au Sud, sans que la percée du Congo en interrompe la régularité; c'est un rempart de hautes collines échelonnées sur $550 \mathrm{~km}$. de largeur au maximum. Des plateaux, de 600 à $700 \mathrm{~m}$. en moyenne, forment la ligne de faîte et les pies qui les surmontent n'atteignent jamais 1.500 mètres.

$2^{\circ}$ Autrement puissante est la chaîne des monts Mitoumba. Depuis le mont Kaomba, sur les limites du Congo et du Zambèze, ils se dirigent en ligne droite au Nord-Est et bordent suceessivement $(2.000 \mathrm{~m}$.) la rive occidentale du lac Tanganyika, puis $(3.000 \mathrm{~m}$.) le lac Kivou, et s'affaissent au Nord du lac Albert.

Les trois zones ainsi formées sont : $1^{\circ}$ une zone inférieure : e'est la terrasse atlantique, d'étendue restreinte; $2^{\circ}$ une zone moyenne, centrale, entre les monts de Cristal et les monts Mitoumba: c'est la plus vaste ( 3 millions de $\mathrm{kmq}$.); elle se divise elle-même en plusieurs terrasses distinctes qui, à des àges géologiques très reculés, furent des bassins hydrographiques entièrement clos; $3^{\circ}$ une zone supérieure, faite également de plusieurs paliers dont le plus haut dépasse $1.500 \mathrm{~m}$. (terrasse du lac Kivou), et est dominé vers l'Est par des cimes très élevées, volcaniques ou non (le Rounsoro ou Rouvenzori, $5069 \mathrm{~m}$.).

IV. Climat. - La région du Congo, située sous l'équateur, jouit d'une chaleur uniforme. La température n'est pas excessive, mais elle varie peu; aussi est-elle pénible et débilitante pour les Européens. - Ge sont les pluies, et non la quantité de chaleur, qui distinguent les saisons : saison sèche et saison pluvieuse, lesquelles alternent suivant l'hémisphère, à partir du moins de $4^{\circ}$ Lat. N. ou S.; car sous l'équateur même, l'année tout entière est pluvieuse, c'est à peine si juin et juillet sont un peu moins mouillés que les autres mois. Les pluies tombent avec une extraordinaire intensité - mais elles durent peu accompagnées parfois de rafales de vent, de tornades, et presque toujours avec grand fracas d'éclairs et de tonnerre.

A égalité d'altitude, la température augmente $: 1^{\circ} \mathrm{du}$ Sud vers l'équateur; $2^{\circ}$ de la côte au milieu du continent. Et les pluies suivent la même loi. 


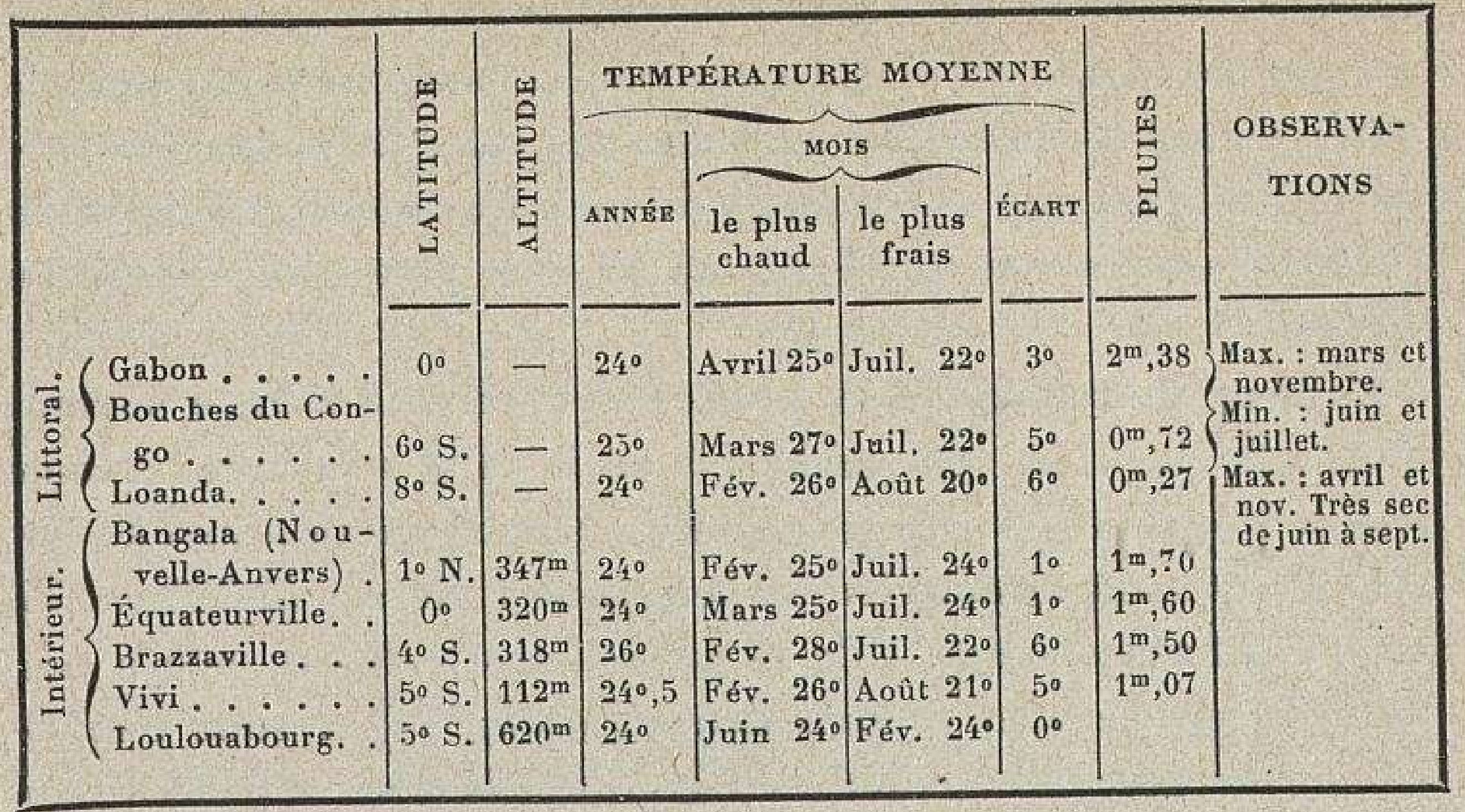

V. Hydrographie. $-1^{\circ}$ Le Congo est un fleuve géant, le second du monde par la dimension de son domaine et pour le volume des eaux (75 ou 80.000 mc. par seconde à l'embouchure). Son bassin est fait de terrasses superposées qui furent jadis des lacs immenses; ceux-ci se sont vidés les uns dans les autres et le dernier s'est vidé dans la mer. Sur chaque terrasse il est navigable, mais cesse de l'être d'une terrasse à l'autre; il bondit alors en cascades ou s'étrangle dans des gorges et ses affluents ont même allure. Son cours décrit des sources à la mer l'arc de cercle caractéristique des fleuves des plateaux africains.

Congo est une appellation européenne; sur son long parcours, le fleuve porte plusieurs noms indigènes. Où faut-il alors placer ses sources? Au Tchambézi, a-t-on dit pendant longtemps $(1.700 \mathrm{~m}$.). Non, répliquent les géographes mieux informés. Le Tchambézi-Louapoula n'est qu'un affluent : il draine péniblement le fond d'une des plus hautes terrasses, dont l'épuisement n'est pas encore achevé; partout le sol est une éponge; prisonnières, les eaux s'étalent en marécages bourbeux, couverts de papyrus géants (lac Bangouéolo) et surmontés de termitières; elles se rejoignent, s'épandent de nouveau dans le lac Moero et se rassemblent une dernière fois. Alors seulement, après un laborieux circuit depuis la source, elles trouvent une issue au Nord-Ouest, à travers la chaîne des monts Mitoumba, et, libres enfin, tombent victorieusement sur la 
terrasse inférieure (le Louapoula). C'est là en contre-bas, dans la zone moyenne, qu'il faut chercher la branche maîtresse, le fleuve en demi-cercle qui recueille les eaux de toutes les terrasses, et c'est sur les pentes du mont Kaomba, ou bien au Louboudi ou bien au Kouléchi, qu'on doit placer la source du Congo.

Torrent de montagne, le Louboudi devient à l'étage suivant rivière de lagunes; en même temps il perd son nom (Kamolondo). Nouvelles chutes (chutes Hinde) et nouvelle appellation : c'est maintenant le Loualaba « la grande rivière »'(1.200 m. de large aux basses eaux). Elle se dirige vers le Nord, peu à peu quitte la savane pour la forêt dense (Nyangoué) et sous l'équateur même descend un nouveau gradin : là sont les chutes de Stanley (Stanley-falls) et là commence le Congo des Européens. Désormais, sur un parcours de 1.450 kilomètres, aucune chute ne vient plus le rompre, avant les rapides des terrasses atlantiques.

A travers le fouillis inextricable de la grande forêt, c'est un fleuve immense, majestueux, calme, toujours égal; plus large qu'un bras de mer $(45 \mathrm{~km}$.), que le détroit de Gibraltar ou du Pas-de-Calais, il s'égare dans un "labyrinthe d'îles dont quinze ans de navigation n'ont pas encore démêlé les détours ” (Wauters).

En se recourbant vers le Sud, il double une seconde fois l'équateur, sort de la forêt, rentre dans la savane (à Loukolela), puis, rencontrant les gradins qui le séparent de la mer, rassemble ses eaux dans un lit unique et précipite son cours. Mais avant de forcer les passes, il s'épanouit dans une cuvette circulaire, le Stanley-pool ( $450 \mathrm{kmq}$., inférieure de $100 \mathrm{~km}$. au lac de Constance); c'est là que s'arrête la navigation. Quand il a ramassé toutes ses forces, par 32 chutes (chutes de Livingstone), il entaille les monts de Gristal, s'étrangle dans des gorges qui réduisent son lit parfois à 400 mètres de large, mais gagne en profondeur $(90 \mathrm{~m}$.) ce qu'il perd en surface, et à la vitesse vertigineuse de 13 mètres à la seconde, il bondit, gronde et tourbillonne. Par instants il se calme dans de grands bassins, des a chaudrons », il lèche des plages tranquilles, puis brusquement reprend son allure désordonnée (chutes de Yellala). L'estuaire 
enfin commence, vers Matadi, large au plus de 17 kilomètres. Son volume est tel qu'à une distance de 20 kilomètres les eaux de surface sont encore douces, que le fond sous-marin dessine une vallée, large de 500 mètres dont les berges sont des alluvions, et que la marée ne parvient pas à renverser son courant; enfin, saisi par les courants, par les vents du Sud, le Congo disparaît au Nord-Ouest dans l'Océan.

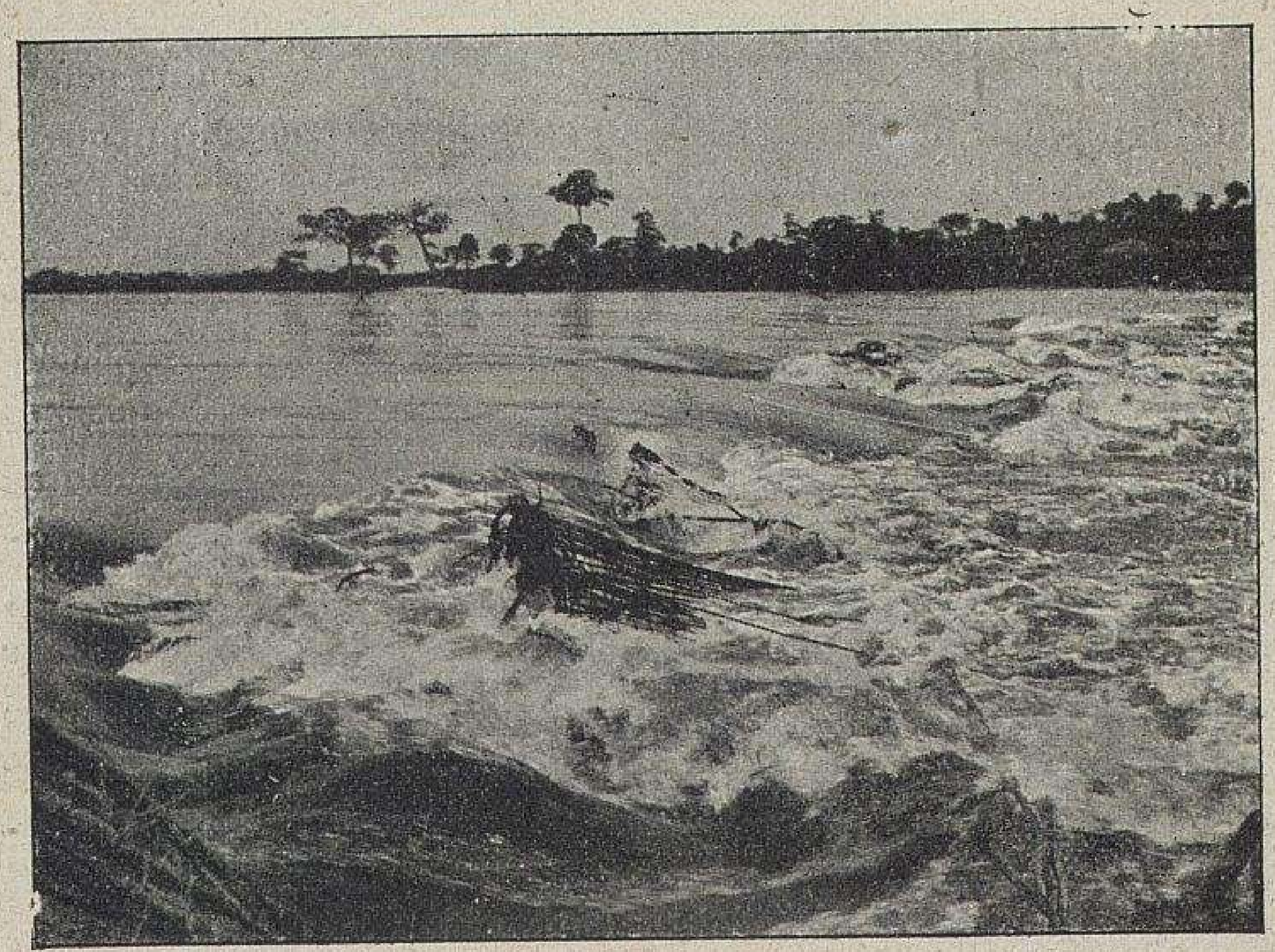

RAPIDES SUR L'ớbANGUi, AVEG NASSES ET ENGINS DE PÊGHE.

(Photographie communiquée par M. Binger.)

Les affluents, qui le rejoignent dans sa course sur les plateaux, sont aussi puissants que lui-même. A droite le Loukouga n'apporte que par intermittence l'excédent du lac Tanganyika. Mais à gauche le Lomami est alimenté par des pluies continues, et comme sa vallée est plate et qu'il s'ouvre toute l'année à la navigation, il conduit plus au Sud que le Congo lui-même. A droite l'Arouhouimi, le troisième affluent pour le volume, descend, coupé de rapides, la région du lac Albert. A droite encore, l'Oubangui se classe au second rang : par sa longueur $(2.270 \mathrm{~km}$.) il égale le Danube; c'est lui qui amène les eaux de la région septentrionale voisine et du Nil et du Chari. Dans 
une première partie, orienté d'Ouest en Est, il se forme de l'Ouellé et du M'bomou; puis quand il quitte le fond d'une ancienne terrasse lacustre, aux passes de Bangui ou de Zongo, il descend au Sud, tranquille et si large (2 à $3 \mathrm{~km}$.) qu'un jour par erreur un explorateur le remonta, croyant toujours naviguer sur le Congo. A droite encore, la Sangha descend de l'Adamaoua. Enfin parmi bien d'autres affluents, le Kassai apporte, rive gauche, la presque totalité des eaux méridionales; au point le plus bas de son bassin, sa nappe de 10 kilomètres de large reçoit d'immenses rivières, et le Sankourou qui ouvre une voie au cœur du continent, et le Couango, et encore un émissaire qui lui amène les eaux du lac Léopold $I I$, dernier témoin des grands lacs d'autrefois.

$2^{\circ}$ Fleuves côtiers. - Les fleuves côtiers sont coupés de rapides, navigables seulement par fragments, sur les biefs des plateaux ou dans la partie maritime. Le rio Campo limite au Sud le Cameroun allemand, le rio Mouni les possessions espagnoles; l'estuaire du Gabon reproduit les formes de la Gironde, à laquelle on le compare volontiers, mais il a plus de largeur et plus de profondeur aussi. LiOgooué, plus long que notre Loire, décrit la courbe classique de beaucoup de rivières africaines; né sur les plateaux au Nord-Ouest de Brazzaville, il est coupé de chutes jusqu'à $N^{\prime} d j o l e ́$, puis libre de tout obstacle il se répand, emplit des réservoirs latéraux et finit par un delta de sable et de hautes herbes qui enveloppe le cap Lopez. Le Kouilou, appelé Niari dans son cours supérieur, tantôt large et profond, tantôt coupé de cascades, a une longueur de 600 kilomètres, un peu moins que la Seine.

Tous ces cours d'eau sont au Nord de l'estuaire du Congo. Ceux du Sud, de plus en plus éloignés de l'équateur, prennent l'allure irrégulière des fleuves tropicaux : tel le Couanza.

IV. Côtes. - Le cap Lopez, la saillie la plus occidentale de l'Afrique du Sud, divise le littoral en deux sections assez différentes.

$1^{\circ} \mathrm{Au}$ Nord, la côte est élevée et attaquée par la mer, qui creuse des golfes profonds; l'estuaire du Gabon forme la belle rade de Libreville; les îlots du large sont des débris continentaux. 
$2^{\circ} \mathrm{Au}$ Sud la côte est basse, rectiligne; sur les plages de sables où se penchent les cocotiers, déferlent incessamment les lames à la crête blanche d'écume, tandis qu'en arrière les eaux saumâtres s'immobilisent dans des lagunes.

VII. Vie végétale. - De la côte vers l'intérieur, les régions végétales s'échelonnent aussi régulières qu'au Soudan. $1^{\circ}$ D'abord

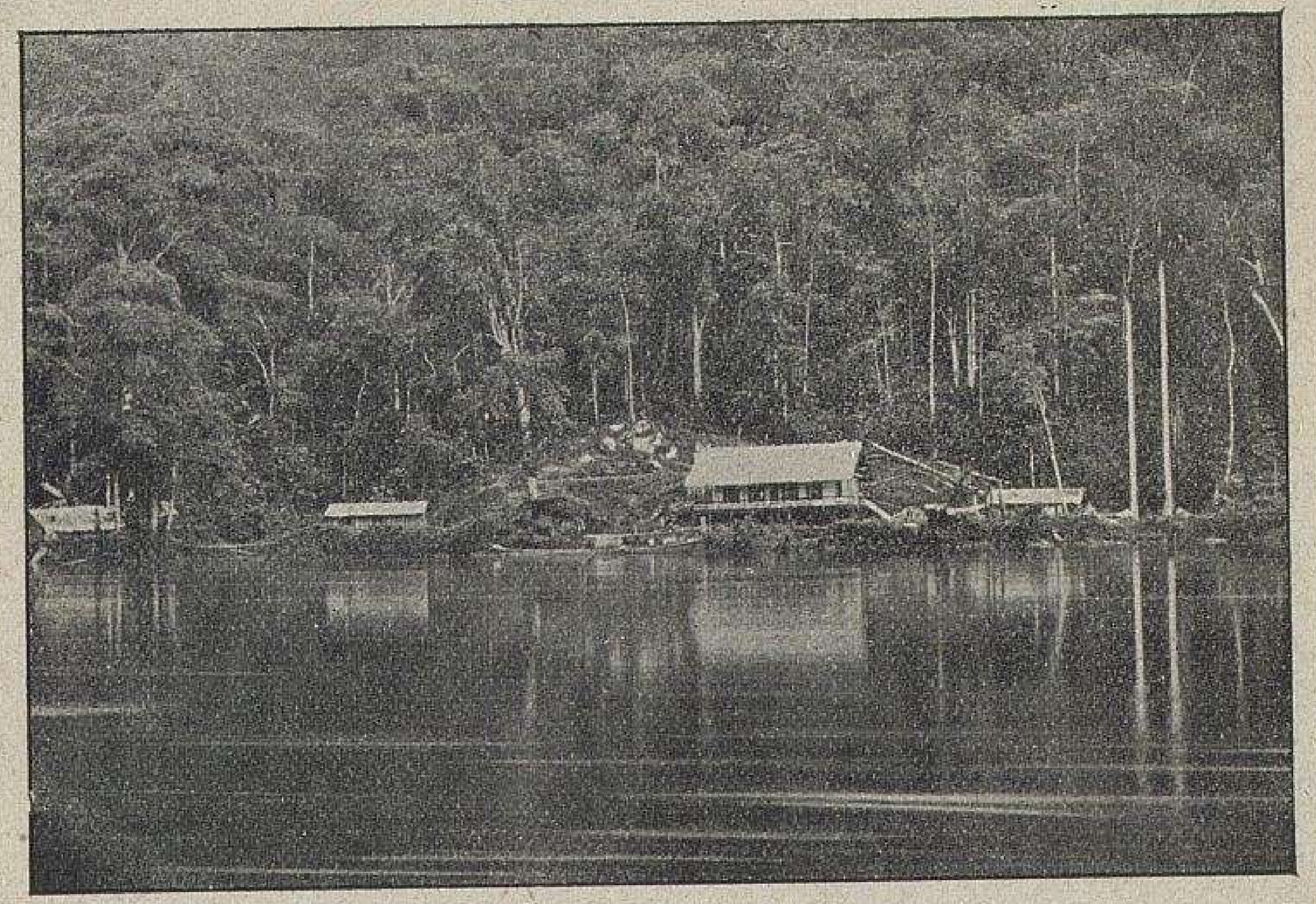

SUR L'OGOOUÉ : TALAGOUGA, PRES NDJOLE.

(Photographie Joaque, communiquée par la Société de Géographie de Paris.)

Type de végétation équatoriale. Pour construire les cabanes de la station, il a fallu déboiser et défricher la rive.

une région maritime, marécageuse, de palétuviers, de papyrus et de cocotiers. $2^{\circ}$ Puis la forêt, à plusieurs étages : palmiers à huile, fromagers ou arbres à coton, kolatiers, manguiers, lianes entrelacées, orchidées, plantes parasites. $3^{\circ}$ La savane aux grandes herbes, avec çà et là des arbustes aux cimes arrondies qui perdent leurs feuilles pendant la période sèche, la brousse que chaque année les indigènes débarrassent des insectes et des reptiles en y mettant le feu, tandis que le gibier effaré se rabat sur les chasseurs à l'affût.

C'est la brousse et la savane qui entourent le bassin du Congo, au Nord vers le Chari, à l'Est vers le Nil, au Sud vers G. Lespiagnol et M. Fallex. - Afrique. 
le Zambèze. Mais sous l'équateur, la cuvette qu'emplit le Congo moyen, est occupée par la grande forêt, déjà décrite.

Les cultures, perdues dans les clairières sommairement défrichées, sont les mêmes qu'au Soudan; dans les parties humides, le bananier, au large feuillage toujours vert, annonce la présence des cases indigènes.

VIII. Vie animale. - Les espèces animales varient d'une région à l'autre. Dans les hautes futaies les singes pullulent et parmi eux figurent les singes anthropomorphes, qui ressemblent à l'homme. Il en existe de toute taille depuis l'énorme gorille qui peut atteindre 2 mètres, depuis le chimpanzé qui ne dépasse pas $1 \mathrm{~m} .50$, jusqu'au singe pas plus gros que le poing; certaines variétés vivent par bandes tapageuses qui parfois s'abattent sur les plantations et les saccagent. Très peu d'animaux domestiques (chèvres, moutons; porcs et volailles); le chien ne sait que hurler : il n'aboie pas.

IX. Vie humaine. - Les populations du Congo sont des Nègres, pour la plupart de race bantou; les tribus naines ont trouvé un refuge, par places, dans la grande forêt. Divisés à l'infini, les Nègres ne connaissent d'autre groupement que le village et chaque village est indépendant. De quelques noms qu'ils s'appellent, nous avons déjà décrit leurs mœurs, au chapitre II.

L'Afrique centrale, jusqu'au dixième degré de latitude, au Nord et au Sud de l'équateur, est le foyer principal de l'Anthropophagie, et les langues nègres possèdent un terme spécial, nyama, pour désigner thomme comestible, Les Niam-Niam, les Mangbattou, les tribus de l'Oubangui et du Kassaï, les Bassango, les Manyema, etc., sont des cannibales qui achètent des esclaves ou capturent des hommes isolés pour les engraisser et les manger. C'est aux cris de "Viande! Viande! " que les Nègres poursuivaient les barques de Stanley, quand il exécuta la première descente du Congo. La superstition et surtout la nécessité expliquent ces coutumes atroces : la nourriture animale manque. Un des moyens de combattre l'anthropophagie serait done, semble-t-il, de tenter l'introduction du bétnil dans l'Afrique centrale.

X. Gouvernement et villes. - La Belgique et la France se partagent presque toute la région équatoriale du Congo. 
Le Congo français est la création de Savorgnan de Brazza, le Congo belge la création de l'explorateur Stanley et du roi Léopold 11 .

Nous verrons au chapitre suivant que la terrasse supérieure du Tchambézi-Bangouéolo est anglaise et que l'Ouest portugais atteint le cours supérieur du Kassaï.

$1^{\circ}$ Congo belge. - La colonie belge lu Congo a pour origine

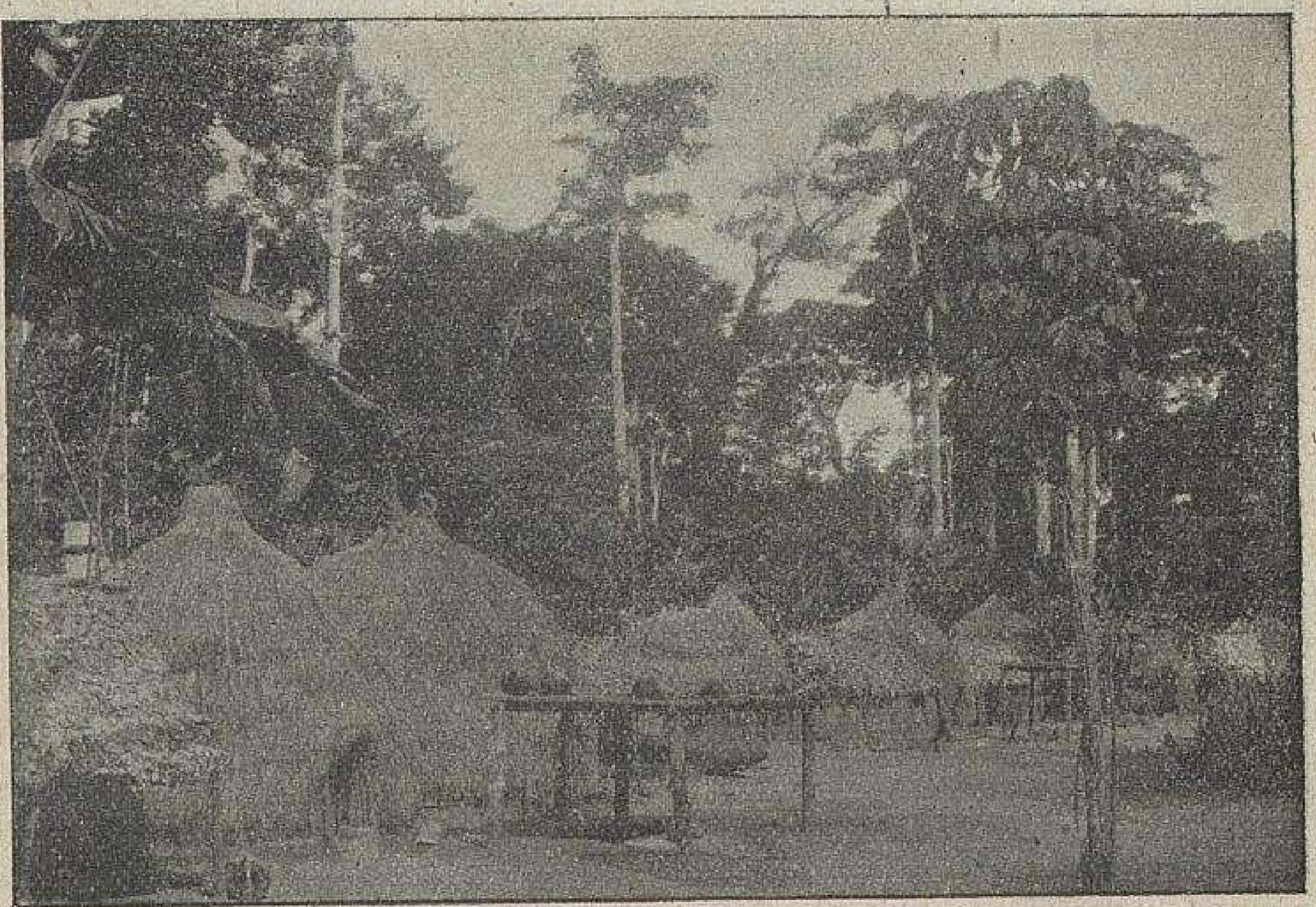

TYPE DE VILLAGE DANS XA FORÊT ÉQUATORIALE, AU CONGO BELGE. EVAMKOYO, VILIAGE DES BANZA, $3^{\circ}$ LAT. NORD.

(Photographie de M. Franz Thonner.)

Cases à toit d'herbes, hémisphériques. Devant, deux foyers, recouverts d'un dais sur lequel sont des marmites; à gauche, un mortier en bois à piler les grains de maïs, eté.

un État indépendant créé en 1885 par la Conférence de Berlin; propriété personnelle du roi des Belges, Léopold II, celui-ci a été repris par la Belgique en 1908 et doté d'une charte coloniale. Le gouvernement central est à Bruxelles; le gouvernement local provisoirement à Boma, sur l'estuaire.

Il n'existe pas de villes à proprement parler, mais seulement des stations, toujours à proximité des cours d'eau. Les maisons européennes (services administratifs, factoreries, missions), sous les grands arbres, au milieu des plantations, sont construites en briques rouges et protégées par un toit en saillie, 
comme une véranda. Sur l'estuaire du Congo, Boma, résidence du gouverneur, Banana et Matadi, ports maritimes animés. De Matadi part le chemin de fer qui contourne les chutes de Livingstone et aboutit à Léopoldville, port d'attache, sur le Stanley-pool, de la flotte fluviale. En amont, sur le fleuve, Equateurville, Bangala ou Nouvelle-Anvers, Stanleyville et Nyangoué. Le nombre de ces stations augmente avec les progrès de

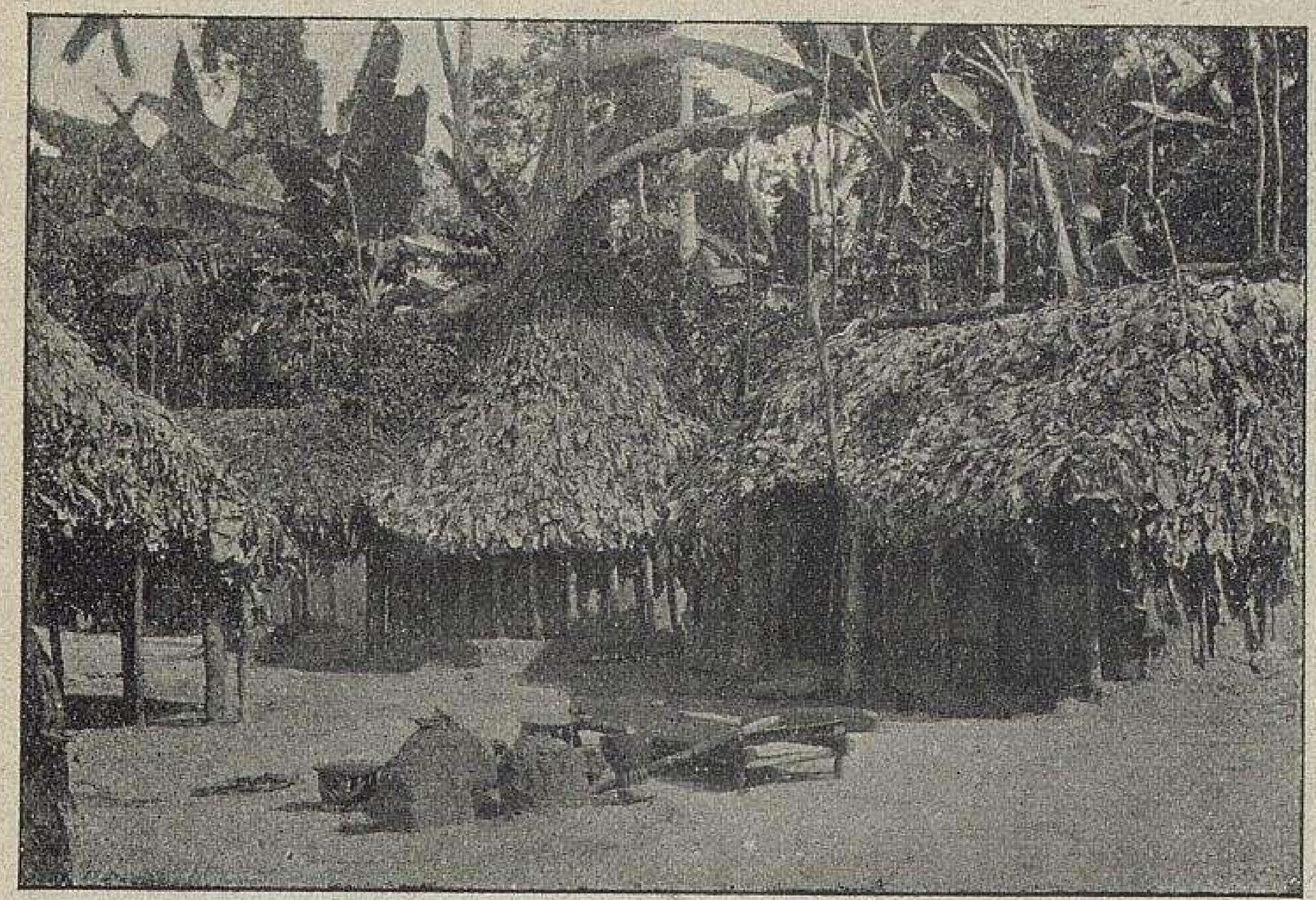

AUTRE TYPE DE VILLAGE DANS LA FORÊT EQUATORIALE, AU CONGO BELGE. BOGOLO, VILLAGE DES BANZA.

(Photographie de M. Franz Thonner.)

Les murs dec cases sont en écorce, et les toits coniques, ou en croupe à quatre pans, recouverts de feuillage. Au premier plan, deux pierres forment foyer; sur le foyer, une marmite; à côté, des tabourets en bois, un lit en nervures de feuilles de palmier avec appui-nuque en bois, un pilon à broyer le maïs, etc.

l'occupation; il en existe sur le Couango, sur le Kassaï et le Sankourou (Loulouabourg), sur le lac Léopold, et, au Nord, sur l'Oubangui, sur l'Ouellé, sur l'Arouhouimi. L'enclave de Lado, sur le Nil, a fait retour à l'Angleterre depuis la mort de Léopold II, conformément à la convention de 1906.

$2^{\circ}$ Afrique équatoriale française. - Elle comprend des territoires immenses, qui diffèrent par la nature du sol, le climat, les systèmes hydrographiques, les ressources, les moyens de communication et les régimes commerciaux. Le décret du 
15 février 1906 les a divisés en 4 circonscriptions formant 3 colonies. $1^{\circ}$ La colonie du Gabon, capitale Libreville, sur une rade vaste et bien abritée, au milieu d'une végétation exubérante. $-2^{\circ}$ La colonie du Moyen Congo, capitale Brazzaville, située sur un mamelon, rive droite du Stanley-pool, d'où l'on découvre un magnifique panorama. Sur la côte, le port de Loango est à proximité du Kouilou. - $3^{\circ}$ La colonie de l'Oubangui-Chari-Tchad, capitale Bangui, divisée en 2 circonscriptions, l'Oubangui-Ghari et le territoire militaire du Tchad.

Au moyen Congo réside un administrateur en chef qui a le titre de Gouverneur général depuis 1907; les autres colonies ont à leur tête un lieutenant gouverneur. Toutes jouissent de l'autonomie financière et administrative.

$3^{\circ}$ Le modeste territoire de Rio Mouni (14.500 kmq.) est précieux à l'Espagne, depuis la perte de Cuba et des Philippines, pour la production des denrées coloniales. En cas d'abandon, un droit de préemption a été réservé à la France.

$4^{\circ}$ Le petit territoire portugais de Cabinda ( $450 \mathrm{kmq}$.) enclavé entre le Congo français et le Congo belge, est-un district du gouvernement d'Angola; parmi leurs titres nombreux, les rois de Portugal portent depuis trois siècles celui de seigneurs de Cabinda.

XI. Mise en valeur. - Les régions équatoriales du Congo ne seront jamais que des colonies d'exploitation, nullement de peuplement. Et comme dans tous les pays neufs, l'exploitation est presque exclusivement agricole. De riches gisements miniers (cuivre, étain, zinc, fer et or) ont été reconnus dans le Katanga belge et dans le bassin français du Niari; mais l'exploitation commence à peine.

Les deux grandes richesses sont l'ipoire et le caoutchouc, si bien qu'on a défini le Congo " un cimetière d'ivoire et une mine de caoutchouc $»$.

Dans le monde entier la consommation annuelle de l'ivoire est de 700 tonnes : or l'Afrique à elle seule en produit 600. Le grand març̉é est Anvers; après lui, Londres et Liverpool. Mais le produit se fera de plus en plus rare : car les réserves enfouies par les indigènes s'épuisent et le nombre des éléphants décroît sensiblement, tant ils sont pourchassés. En 1909 , l'Afrique équatoriale française a exporté pour 2.960 .000 franes d'iroire; le Congo belge pour 6.583 .000 francs. Tout au contraire la pro- 
duction du caoutchouc suit une progression constante : Anvers, Hambourg, Liverpool et Bordeaux sont les principaux marchés de l'Europe. L'Afrique équatoriale française en a exporté pour 3.018 .000 franes en 1900 et pour 8.583.000 en 1909; le Congo belge pour 39.874.000 francs en 1900 et pour 42.569.500 franes en 1909.

Les produits végétaux, autres que le caoutchouc, n'entretiennent pas encore un trafic proportionné à leur abondance extraordinaire : les bois, les amandes et les huiles de palme sont les produits qui figurent au troisième et au quatrième rang, à l'exportation.

Les plantations de café, de cacao, de vanille, de tabac, d'ananas se développent d'année en année.

Les conditions physiques du Congo français et du Congo belge sont les mèmes, et pourtant jusqu'en 1898 , le peu de prospérité du Congo francais a contrasté avec l'essor rapide du Congo belge. Cet état de choses a commencé à se modifier depuis que le gouvernement français a octroyé de grandes concessions territoriales à des sociétés financières : celles-ci furent d'abord très éprouvées, mais elles triomphèrent de la erise des débuts et aujourd'hui elles réalisent de très beaux bénéfices. En 7 ans le commerce a triplé, la part de la France est devenue prépondérante et les étrangers qui réalisaient chez nous les profits les plus nets ont été évincés. Pour assurer à la colonie son plein développement économique, il importe d'abord de procurer aux Européens une sécurité complète, puis de créer un outillage qu'on n'a pas su prévoir, en aménageant notamment le réseau navigable, puis les routes et les chemins de fer qui font complètement défaut.

Le Congo belge est redevable de sa vitalité à l'initiative avisée et tenace du roi Léopold II. Celui-ci a triomphé des hésitations de son peuple, et suscité de grandes sociétés financières et commerciales, ne se laissant rebuter par rien, payant les déficits sur sa cassette particulière. C'est ainsi que l'État du Congo a su se donner le monopole des débouchés extérieurs : tandis que la France hésitait à construire une voie ferrée de Loango à Brazzaville par le Kouilou, plus résolus, les Belges se mettaient à l'œuvre et triomphaient de difficultés beaucoup plus grandes. Aujourd'hui un chemin de fer à voie étroite supplée le fleuve dans la portion de son cours que les rapides rendent inutilisable; de Matadi, sur la mer, il aboutit à Léopoldville, sur le Stanleypool $(400 \mathrm{~km}$.), et c'est la voie belge, dont les tarifs sont fort élevés, que la France est réduite à emprunter pour l'exploitation de ses concessions et le ravitaillement de ses postes (Congo et Oubangui). - Eneouragés par ce premier résultat, les Belges ont construit une ligne de Boma vers la province de Mayoumbé (60 km.) et zongent à établir autant de tronçons de voies ferrées qu'i] est nécessaire pour éviter les rapides des fleuves et réunir entre eux le. bieŕs navigables : $1^{\circ}$ ligne de $127 \mathrm{~km}$, inaugurée en 1906, de Stanleyville à Ponthierville, le long des chutes Stanley; le bief de StanleyvilleHinde $(442 \mathrm{~km}$.) a pu des lors être utilisé par la navigation à vapeur; $2^{\circ}$ ligne de $100 \mathrm{~km}$, en projet, de Kasongo à Kongola, le long des chutes 
de Hinde; $3^{\circ}$ ligne, concédée, de Stanleyville par la vallée de l'Arouhouimi à travers la forét équatoriale, jusqu'à la rive Nord-Ouest du lac Albert; $4^{\circ}$ ligne projetée enfin du Katanga vers le Tanganyika.

Dans l'A frique équatoriale française, deux tracés sont simultanément à l'étude, l'un au Nord de Libreville à Ouesso sur la Sangha, l'autre au Sud de Loango à Brazzaville.

Mais les routes ferrées ne seront jamais que les auxiliaires des routes fluviales : grâce au Congo et à la ramure de ses affluents, ces contrées disposent, d'après le calcul du géographe belge Wauters, de $18.000 \mathrm{~km}$. de rivières accessibles aux bateaux à vapeur, et les bras secondaires peuvent porter des pirogues, de telle sorte que " pas un seul endroit du bassin ne se trouve à plus de $160 \mathrm{~km}$. d'une escale quelconque abordable par eau " (Grenffell). A l'heure actuelle, par chemins de fer et par steámers on pénètre à 2.450 kilomètres.

Tous ces efforts ménagent à l'Europe du $\mathrm{xx}^{\mathrm{e}}$ siecle plus d'une surprise. Sans doute bien des atrocités ont été commises; mais il faut espérer que ce sont crises passagères de jeunesse et que les Européens iront toujours servir là-bas la eause de la civilisation. L'ouvre à réaliser est pratique autant qu'humanitaire; il s'agit de transformer les conditions matérielles et morales de l'Afrique centrale. Malgré quelques excès les Belges s en acquittent à leur honneur et leur splendide colonie leur attire déjà mainte jalousie. Quant à la France, si elle sait vouloir, elle trouvera là le complément de l'immense empire commercial dont l'a dotée en Afrique la vaillance de ses explorateur's et de ses officiers.

\begin{tabular}{|c|c|c|c|c|c|c|}
\hline & & & & $\mathrm{COM}$ & IMERCE & \\
\hline 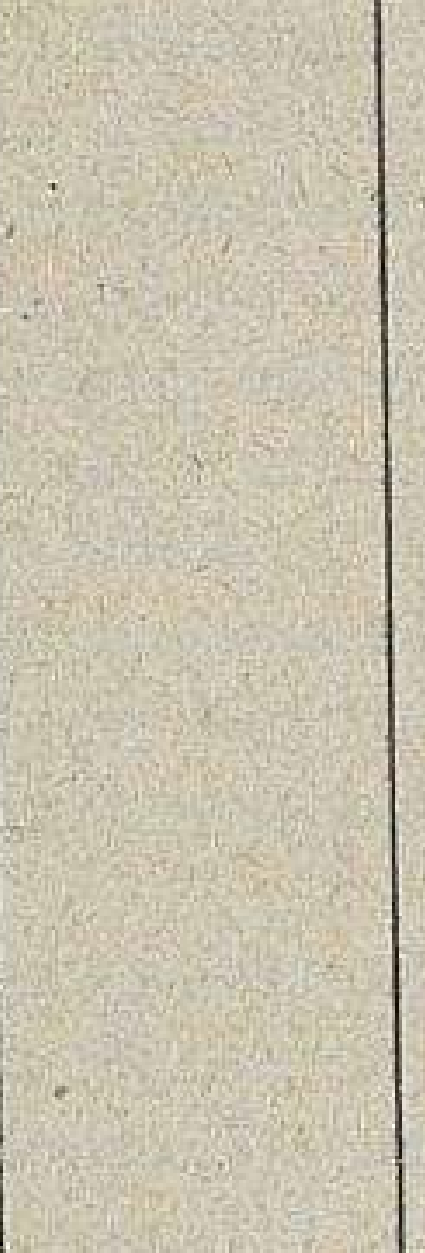 & $\begin{array}{c}\text { SUPER- } \\
\text { FICIE }\end{array}$ & $\begin{array}{l}\text { POPU- } \\
\text { LATION }\end{array}$ & , & 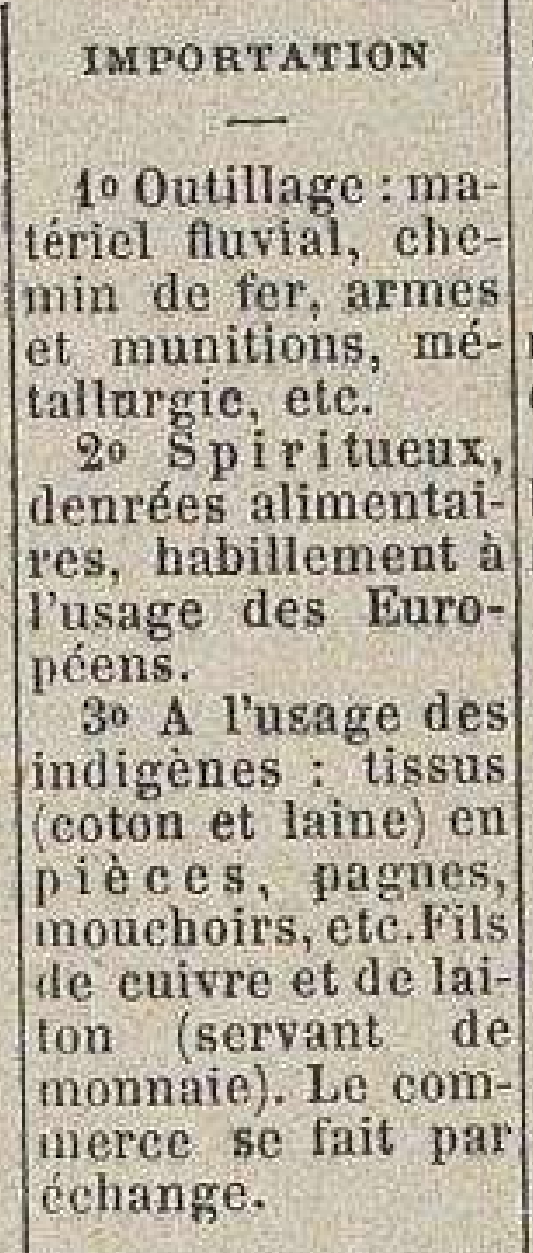 & $\begin{array}{c}\text { Exportation } \\
\text { - } \\
\text { Caoutchouc. } \\
\text { Ivoire. } \\
\text { Bois d'ébé- } \\
\text { nisterie et de } \\
\text { construction. } \\
\text { Amandes et } \\
\text { huile de pal- } \\
\text { mes; kola. } \\
\text { Café, cacao. }\end{array}$ & TOTAL \\
\hline $\left.\begin{array}{r}\text { I. - Con- } \\
\text { go belge. }\end{array}\right\}$ & $\begin{array}{c}\text { Kmq. } \\
2.450 .000 \\
(75 \text { fois la } \\
\text { Belgique; } \\
5 \text { fois la } \\
\text { France }) \text {. } \\
1.733 .888\end{array}$ & $\begin{array}{l}\text { Habitunts. } \\
14 \text { à } 30 \\
\text { millions } \\
\text { (Européens } \\
2.900) . \\
8 \text { millions }\end{array}$ & $\begin{array}{l}1900 \\
1909 \\
1900 \\
1910\end{array}$ & $\begin{array}{c}\text { Francs. } \\
24.724 .000 \\
22.127 .000 \\
10.554 .000 \\
13.190 .000\end{array}$ & \begin{tabular}{|c|} 
Franes. \\
\\
47.377 .000 \\
56.167 .000 \\
\\
7.443 .000 \\
24.631 .000
\end{tabular} & $\begin{array}{c}\text { Franes. } \\
72.101 .000 \\
78.294 .000 \\
\\
17.997 .700 \\
37.821 .000\end{array}$ \\
\hline
\end{tabular}




\title{
CHAPITRE XII
}

\section{AFRIQUE CENTRALE DU SUD. ZAMBÉZIE}

\author{
SOMMAIRE
}

1. Limites. - Au Sud du bassin du Congo, au Nord du tropique du Capricorne, l'Afrique centrale du Sud barre le continent d'un Océan à l'autre; elle correspond au bassin du Zambèze ou Zambézie.

II. Superficie. - Environ 3 millions et demi de $\mathrm{kmq}$.

III. Orogénie et relief. - Entre les plateaux qui s'étagent à l'Ouest au-dessus de l'océan Atlantique (Bihé), à l'Est au-dessus de l'océan Indien (monts Matoppo), le bassin du Zambèze est, comme celui du Congo, fait de terrasses superposèes, dont le centre est déprimé.

IV. Climat. - Situee dans l'hèmisphère Sud, à la même distance de l'équateur que le Soudan dans l'hèmisphère Nord, la Zambézie a comme lui un climat tropical, caractérisé par une saison sèche et une saison pluvieuse; mais l'èté austral correspond à notre hiver. - La côte de l'océan Atlantique est de plus en plus sèche et désertique vers le Sud; celle de l'océan Indien est chaude, humide et malsaine; sur les plateaux la température est inègale, mais salubre.

V. Hydrographie. - $1^{\circ}$ Les cours d'eau du versant Atlantique sont des torrents, coupés de rapides; leur régime temporaire s'accentue vers le Sud : Gouanza et Gounéné.

$2^{\circ}$ A l'océan Indien s'écoule le Zambèze : c'est le quatrième des fleuves africains par la longueur, par la superficie du domaine et par le volume. Alimenté par des " vallèes éponges ", il coule d'abord du Nord au Sud et tombe (chutes de Gonyé) sur une seconde terrasse: le relief est tellement informe que les eaux s'ètalent en marécages (Linyanti) ou bien qu'elles s'égarent au sud dans des lagunes et dans des bassins salés (ancien lac Ngami, bassin de Makarikari), sans pouvoir le rejoindre. Puis le Zambèze s'échappe vers l'Est par les chutes grandioses de Victoria $(140 \mathrm{~m}$. de haut sur $1.600 \mathrm{~m}$. de large), et se recourbe au Nord des monts Matoppo. Avant de commencer son delta marécageux, il reçoit le Chiré qui lui apporte les eaux du lac INyassa.

VI. Côtes. - $1^{\circ}$ Les côtes de l'océan Atlantique sont basses et mono- 


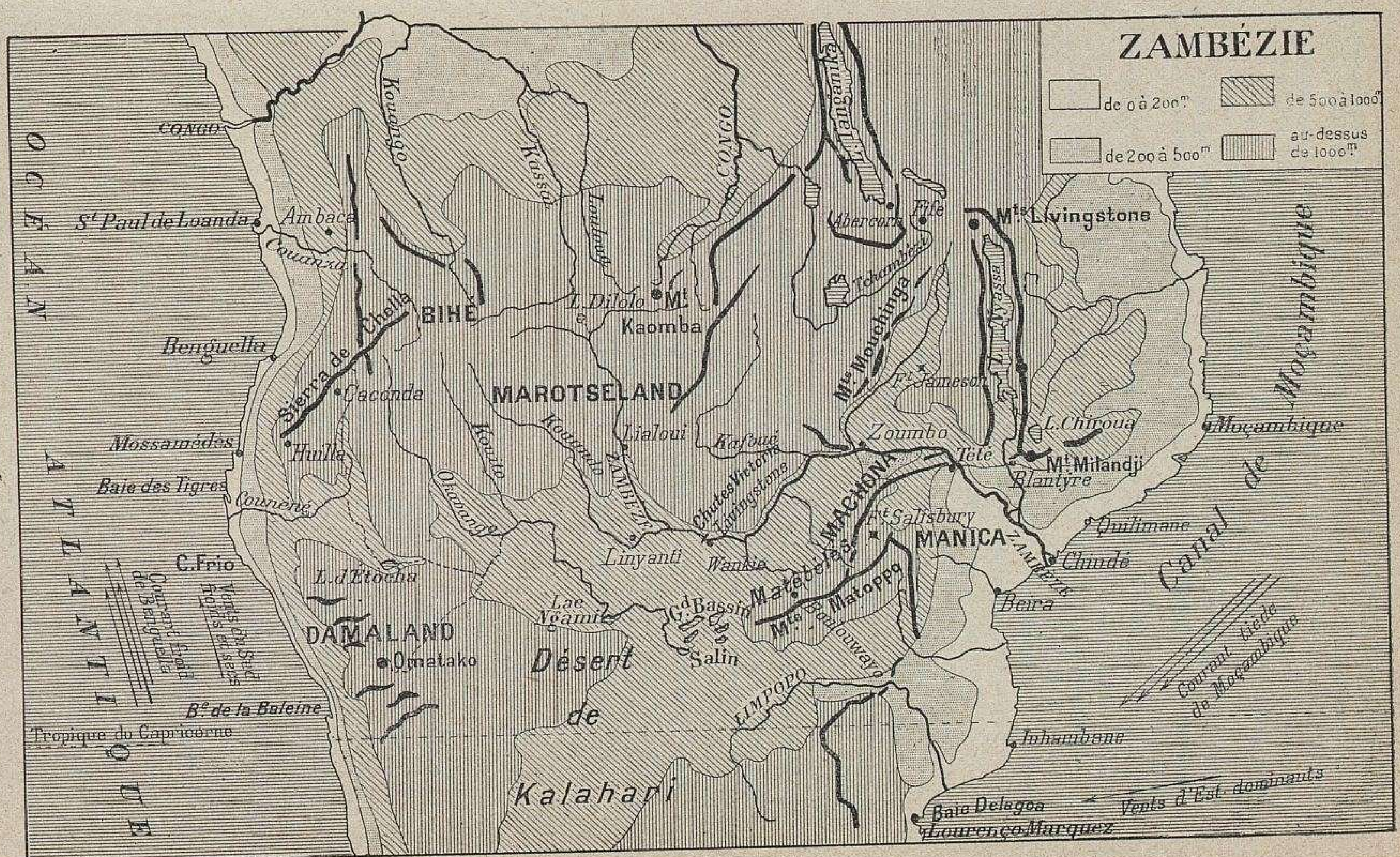


tones, de plus en plus froides (cap Frio) vers le Sud; pas de baies, sauf Port-Alexandre et la baie des Tigres, très poissonneuse.

$2^{\circ}$ Les côtes de l'océan Indien, sables ou vases, ne sont pas plus hospitalières. Au Sud du cap Corrientes ou des Courants s'ouvre la baie Delagoa avec le port de Lourenço Marquès.

VII. Vie végétale. - Les formations végétales sont au Nord celles de la savane, au Sud celles des steppes semi-désertiques. Les hauts plateaux de l'Ouest et de l'Est peuvent convenir aux cultures euro. péennes.

VIII. La vie animale est celle des savanes, celle des steppes. La piqûre de la mouche tsétsé est mortelle au bétail.

IX. Vie hamaine. - La Zambèzie est presque tout entière habitèe par des Nègres bantous.

X. Gouvermement et villes. - Le Portugal et l'Angleterre sont les deux puissances coloniales de l'Afrique centrale du Sud.

$1^{\circ}$ Les Portugais possèdent sur l'Atlantique, 1'Angola, cap. SaintPaul de Loanda, - et sur l'océan Indien, l'Etat de I'Afrique orientale, avec Moçambique, Chindé dans le delta du Zambèze et Lourenço Marquès, le port du Transvaal.

$2^{\circ}$ Les territoires britanniques constituent la Rhodésia (Rhodésia du Sud, cap. Salisbury, et Rhodésia du Nord, séparées par le Zambèse) et le Nyassaland, cap. Blantyre.

XI. Mise en valeur. - Il se peut que les hauts plateaux se prêtent aux cultures (tropicales et européennes) et à l'èlevage. Mais ce sont les métaux surtout qui attirent les Européens, l'or en première ligne, la houille, le cuivre, etc.

Le commerce suit une marche ascendante.

Les chemins de fer précèdent les voyageurs et les marchandises : la Rhodésia est déjả reliée au Cap, d'une part, et, de l'autre, au Congo belge; elle communique en outre avec Beira sur l'océan Indien.

\section{DÉ VELOPPEMENT}

I. Limites. - Située dans l'hémisphère austral, au Nord di tropique du Capricorne, l' “ Afrique centrale du Sud » barre le continent d'un Océan à l'autre; c'est une région naturelle immense, la Zambézie ou bassin du Zambèze. Mais les frontières politiques l'ont découpée suivant des tracés artificiels, vagues en plus d'un point et même provisoires.

II. Superficie. - Environ 3 millions et demi de kilomètres carrés.

III. Orogénie et relief. - Plus élevé que le bassin du Congo, le socle sur lequel pose la Zambézie est aussi ancien et tout entier de granite; le produit des roches désagrégées, les sables, les sédi- 
ments détritiques ne l'ont pas tellement recouvert que l' "ossature granitique ne perce éà et là sous la peau " (Livingstone). En maint endroit se rencontrent des quartz aurifères, de richesse plus ou moins grande.

Ici comme au Congo, le relief affecte la forme de terrasses superposées, déprimées dans leur milieu et qui se vident les unes dans les autres. Mais tandis que le Congo dessine son demi-cercle vers le Nord, pour atteindre finalement l'Atlantique, c'est vers le Sud que le Zambèze se recourbe, et c'est dans l'océan Indien qu'il se déverse : de la sorte, les deux bassins s'opposent symétriquement.

Deux soulèvements principaux, en bordure, l'un de l'océan Atlantique, l'autre de l'océan Indien, séparent la Zambézie en trois zones : deux sont extérieures et regardent vers les mers; la troisième, de beaucoup la plus étendue, occupe le centre.

$1^{\circ}$ Bord occidental. - Le plateau soulevé au-dessus de l'Atlantique continue les monts de Cristal, depuis le Bihé au Nord jusqu'aux monts Omatako au Sud. Une première terrasse surgit à 60 kilomètres de la côte en moyenne, deux autres lui succèdent, disposées en échelons, et montent au palier supérieur, d'une altitude de plus de 1.000 mètres; la hauteur va croissant vers le Sud. Un de ces gradins affecte l'allure d'une vraie montagne, la Serra de Chella, au-dessus des plateaux de Caconda, Huilla et Bihé.

Le Bihé est bien nommé " plateau des sources": il condense, au printemps, les pluies de l'Atlantique; en été, c'est-à-dire ici de décembre à mars, les pluies de l'océan Indien, et comme il est le point de rencontre de deux axes montagneux en forme de $T$ couché $(E)$, l'un parallèle et l'autre perpendiculaire à la côte, il envoie les eaux soit au Congo, soit au Zambèze, soit directement à l'Atlantique.

$2^{\circ}$ Bord oriental. - Du côté de l'océan Indien, les monts Matoppo $(1.700 \mathrm{~m}$.) sont le point de départ de hauteurs orientées au Nord-Est. Ils arrondissent leurs sommets granitiques en coupoles, en dômes, ou bien ils ont un aspect de ruines, tant ils sont déchiquetés; les filons de quartz qu'ils contiennent excitent les convoitises des chercheurs d'or. Comme le Bihé, ils constituent un centre important de dispersion : les plateaux ondulés et ridés des Matabélé et des Machona (de 1.600 à 1.000 m.) descendent au Nord-Ouest vers 
le Zambèze moyen; les plateaux du Manica à l'Est vers l'océan Indien; au Sud enfin les eaux rejoignent le Limpopo.

Par delà la percée du Zambèze, les plissements montagneux appartiennent déjà à une région de grande dislocation, celle de l'Afrique orientale, et de mêmeque nous avons vu au Congo les monts Mitoumba fermer de leurs escarpements le lac Tanganyika, ici les monts Milandji $(3.000$ m.) dominent les plateaux de Blantyre et le lac Chiroua. Quant au Nyassa, il occupe une partie effondrée et a des fonds de 800 mètres, avec des hauteurs qui atteignent plus de 1300 mètres à l'Est.

$3^{\circ}$ Centre. - Entre ce double bourrelet, le sol se relève au Sud vers le désert de Kalahari. Au Nord un seuil bombé (1.100 à $1.200 \mathrm{~m}$.) et sablonneux, une plaine découverte sépare les bassins du Congo et du Zambèze; sans qu'il y ait de chaîne de montagne à proprement parler, il existe cependant une “ dorsale " assez caractérisée pour que les rivières n'embrouillent pas leurs sources, comme on l'a cru pendant longtemps.

L'intérieur de la Zambézie se compose de plateaux superposés, anciens fonds de lacs aujourd'hui vidés ou en voie d'épuisement. Tantôt les eaux ont assez d'énergie pour descendre d'un gradin à l'autre et gagner la mer de chute en chute : tel le Zambèze. Tantôt, trop faibles, insuffisamment alimentées, elles séjournent et disparaissent dans des fonds salins, tel l'Okavango dans le Makarikari.

Livingstone comparait le grand plateau africain à un chapeau de feutre, déprimé au centre, bossué sur les bords : la comparaison est aussi juste qu'amusante.

IV. Climat. - La latitude de la Zambézie répète, au Sud de l'équateur, celle du Soudan au Nord : les conditions de climat sont donc identiques, mais l'ordre des saisons, sèche et pluvieuse, est renversé; ici les pluies tombent en déluges d'octobre en mars, coincidant toujours avec le passage du soleil $\mathrm{au}$ zénith, toujours plus tardives et de durée moins longue à mesure qu'on s'approche du tropique.

Ces conditions générales sont modifiées par l'orientation et l'altitude. $1^{\circ}$ La côte de l'océan Atlantique est comparable à la cote Pacifique 
de l'Amérique du Sud à même latitude. Sèche, d'une sécheresse de plus en plus forte, voire même désertique vers le Sud de la région qui nous occupe, mais très salubre, elle est refroidie par un courant marin (courant de Benguella); les vents Sud-Ouest qui prédominent sont des vents frais : ils s'échauffent au contact des terres, et n'apportent pas de pluies, seulement des brouillards (le cacimbo, de mai à septembre). Pour la latitude la température est basse.

La côte de l'océan Indien, au contraire, est très mouillée, chaude, même à une latitude méridionale, et fort malsaine. Elle est constamment battue par les vents d'Est, qui sont humides, et longée par un courant marin qui est tiède (courant de Moçambique).

$2^{\circ}$ Sur les plateaux élevés, les écarts de température s'accentuent; le climat est dur, mais sain, bon pour l'homme, sinon pour la plante. Caconda a des extrêmes absolus de $30^{\circ}$ et $9^{\circ}$, Salisbury de $33^{\circ}$ et de $1^{\circ}$.

$3^{\circ}$ Pour le centre de la Zambézie, on ne possède encore qu'un petit nombre d'observations; en général la sécheresse augmente - et avec elle les variations thermométriques - du Nord vers le Sud; dans le Nord il existe deux saisons pluvieuses, d'inégale durée, et deux saisons sèches.

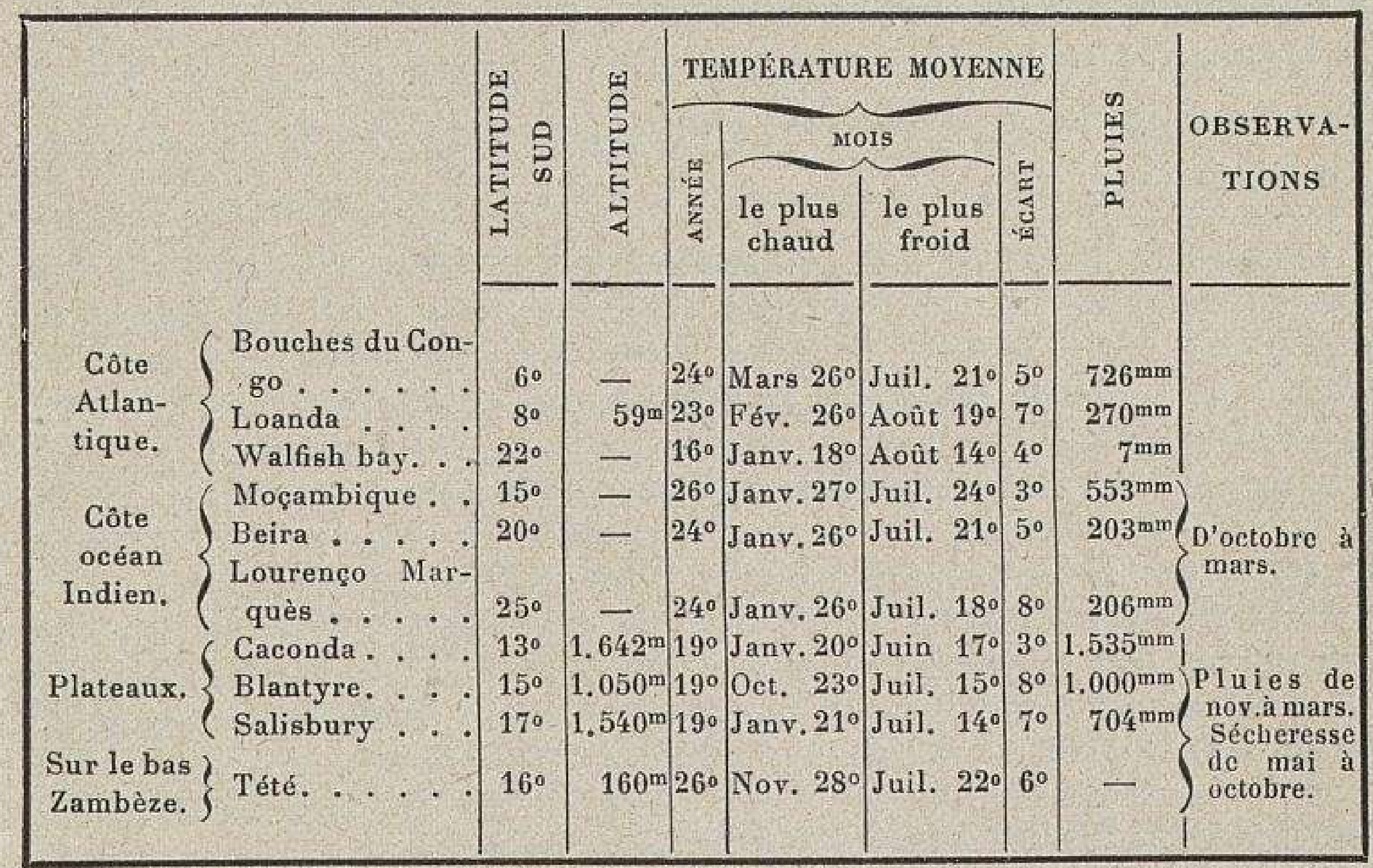

V. Hydrographie. $-1^{\circ}$ Versant atlantique. - Pour atteindre l'océan, les cours d'eau descendent par des rapides ou des cascades la triple série des gradins; ils ne peuvent servir à la navigation que sur les biefs de leur cours moyen et dans leur cours inférieur, ceux du Nord tout au moins. Car vers le Sud la sécheresse augmente et dure plus longtemps; il n'y a plus alors que des torrents temporaires.

Le Couanza $(900 \mathrm{~km}$.), le Counéné $(1.200 \mathrm{~km}$.), venus des 
mêmes plateaux (Bihé), dessinent en sens inverse deux courbes symétriques. Plus voisin de l'équateur, le Couanza a plus de vigueur et les affluents nombreux qui l'alimentent - encore mal connus - lui permettent de se frayer un chemin par des couloirs et par des cascades. Plus voisin du tropique, le Counéné appartient à la catégorie des cours d'eau que la saison sèche appauvrit et même tarit complètement; il offre une particularité curieuse : sa vallée moyenne est si plate que les pluies en font une nappe lacustre; faute de pente caractérisée, une partie des eaux s'épanche vers les lagunes salées d'Etocha, où elles s'évaporent; l'autre trouve le chemin de la mer, au moins pendant quatre ou cinq mois, de décembre à avril.

$2^{\circ}$ Océan Indien. A. Zambèze. - Le Zambèze est le quatrième des fleuves africains par la longueur, par l'étendue de son domaine et par son volume.

Gours supérieur. - A 1.525 mètres d'altitude, il est formé par le suintement de marais, inondant la base de hautes plaines sablonneuses.

Longtemps on a cru que ses sources étaient communes à celles des fleuves congolais; il n'en est rien, et la " dorsale " qui, les sépare est une plaine élevée que les indigènes utilisent comme route de commerce. Tandis qu'au Nord les ruisseaux filent elairs et rapides vers le Congo, les vallons zambéziens sont si peu inelinés qu'ils s'emplissent à la fois d'herbes et d'eau. Livingstone les a désignés d'un terme expressif « vallées éponges \%. L'eau qu'on dirait stagnante, tant elle est couleur de tourbe et recouverte d'une couche huileuse, filtre à travers les racines enchevêtrées comme à travers un tissu; c'est parmi ces prairies mouvantes, qui sous le pied s'ébranlent tout entières, que le Dilolo, étang bien fermé au Nord, épanche son trop-plein dans un affluent du Zambèze, sans qu'il y ait lit de rivière, ereux de vallée, thalweg en un mot. Ces amas lacustres s'expliquent aisément par la structure de la Zambézie : plateaux étagés, dont le centre déprimé fait cuvette.

Le fleuve est formé, son courant bien dessiné, quand il tombe (chutes de Gonyé) sur une seconde terrasse, dans un nouveau fond de marécages; là vient le rejoindre à droite, c'est-à-dire à l'Ouest, le Couando ou Linyanti. La plaine, inondée sur des espaces immenses, est terriblement fiévreuse; dans l'air dansent et tourbillonnent des myriades de moustiques, dans les marais se donnent rendez-vous les grands vols d'oiseaux, les hippopotames et les crocodiles. Quant aux hommes, ils sont rares; c'est sur pilotis qu'ils perchent leurs misérables cabanes. 
Sur ce sol nivelé, d'une horizontalité absolue, les rivières ne trouvent plus leur pente : ainsi le Kou-bango (ou Okavango) descendu des plateaux du Bihé, de même que le Counéné, envoie vers l'Est une branche qui, très vite, ne se distingue plus de la plaine et dont les eaux ne parviennent au Linyanti que durant deux mois. C'est par des nappes lacustres tout. à fait semblables que nous avons $v u$, au Soudan central, le Logone et le Chari communiquer entre eux, communiquer aussi avec la Bénoué. Peutêtre ce bras est-il l'ancien lit de l'Okavango, qui aurait été jadis tributaire du Zambèze, mais le dessin hydrographique est demeuré inachevé, informe. Celles des eaux qui continuent à descendre au Sud suivent un lit sinueux, vague, aux rives changeantes d'une saison à l'autre, tantôt larges, tantòt étroites; elles disparaissent complètement lors de la saison sèche. Le lac Ngami, qu'indiquaient encore des cartes récentes, n'existerait plus, et avec le lac toute vie a disparu de contrées vouées désormais a la stérilité : les végétaux ont dépéri, les animaux, l'homme ont fui. Au delà de ce qui fut le Ngami, le courant persiste après les pluies (Botletli ou Zouga), mais sans force, amorti encore par les roseaux; il finit par se perdre dans les lagunes du grand bassin salé, la " poêle à sel ", le Makarikari, "la plaine aux mille lacs".

Si le Zambèze ne s'égare pas dans les steppes désertiques, c'est qu'il se maintient à une latitude plus voisine de l'équateur et qu'il s'incline vers l'Est. Il a rongé le barrage qui l'emprisonnait dans les fonds lacustres, déchiré les roches basaltiques, et c'est par les chutes Victoria qu'il plonge sur une nouvelle terrasse.

Livingstone, le premier, les vit, en 1854 , les revit en 1860 et les baptisa du nom de la reine d'Angleterre : les indigènes les appellent la Fumée tonnante. Il n'est pas au monde de spectacle aussi grandiose, aussi terrifiant. A une distance qui varie de 10 à $30 \mathrm{~km}$. suivant l'orientation, on apercoit au ciel des colonnes de vapeur, qu'on prendrait pour la fumée des savanes incendiées. Large de $1.600 \mathrm{~m}$., le Zambèze tombe tout d'une nappe, avec un fracas de tonnerre, dans un énorme gouffre de $140 \mathrm{~m}$, le double du Niagara, puis, en bas, se rétrécit jusqu'à $75 \mathrm{~m}$. Et de la masse des eaux écumantes montent cinq colonnes de vapeurs, sur lesquelles le soleil du matin allume un triple arc-en-ciel. Pour compléter le décor, la poussière d'eau entretient dans les anfractuosités des roches une végétation épaisse : par une analogie un peu risquée, les explorateurs ont évoqué, devant ces " jardins suspendus " et inaccessibles, le souvenir d'une autre reine, Sémiramis.

Gours moyen. - Fréquemment obstrué de seuils rocheux et coupé de rapides, le Zambèze échappe à l'étreinte des plateaux entre Zoumbo et Tété, après les dernières gorges de Kebrabassa.

Des riviires lui arrivent à droile, en éventail, des monts Matoppo, bien pauvres à la saison sèche, mais grossies par les fortes pluies des tro- 
piques. A gauche, ce sont des cours d'eau incomplètement reconnus : le Kafoué, par exemple, traverse le fond d'un ancien lac, une plaine nue, tachetée de bosquets touffus, bosselée de termitières, que l'inondation annuelle transforme en îlots de refuge pour les rongeurs et les reptiles; plus loin le Loangoua draine les plateaux du Nyassaland.

Cours inférieur. - En aval de Tété, le Zambèze s'infléchit au Sud-Est. Limpide jusque-là, il se charge maintenant de boues et de débris, et quand il a dépassé les falaises rocheuses (200 m.) de Loupata, il s'étale sans contrainte sur plusieurs kilomètres, étire ses grandes coulées paresseuses entre des îles plates et dessine enfin la tête de son delta. Les bouches sont variables au point que les vases et les jungles ont obstrué celle de Quilimane; la navigation utilise depuis peu la passe de Chindé, une ville malsaine, qui pourtant se développe vite.

Le Chiré est l'émissaire du lac Nyassa, un lac d'effondrement (longueur $570 \mathrm{~km}$., largeur 50 à $100 \mathrm{~km}$.; superficie, $30.000 \mathrm{kmq}$., égale à la Belgique), de forme allongée, très profond, enserré dans de hautes montagnes. C'est une belle rivière; des hauts plateaux elle tombe par des chutes infranchissables (chutes Murchison) dans une région alluviale et pestilentielle où elle rejoint le Zambèze. Celles-ci sont tournées par un portage : en amont, en aval, les chaloupes à vapeur circulent, et le Chiré fournit ainsi une voie d'accès précieuse vers le Nyassa.

Comme voie navigable, le Zambèze ne peut se comparer au Congo. I1 n'a pas sa magnifique'ramure d'affluents; moins profond, moins large, gêné par des chutes plus nombreuses et plus rapprochées, il a en outre un caractère tropical accentué et ne soutient pas son débit comme le Congo, fleuve équatorial par excellence.

$2^{\circ}$ Océan Indien. B. Fleuves côtiers. - Au Nord du Zambèze, le Rovouma, que nous retrouverons dans un chapitre prochain, sert de limites entre les possessions allemandes et les possessions portugaises. Au Sud du Zambèze, le Poungoué, qui finit à Beira, a sa vallée remontée par une voie de fer. Le Sabi, né dans le Machonaland, est rivière tropicale, inconstante et pas navigable, large de 2 à 3 kilomètres aux crues, de 30 mètres aux sécheresses. Le Limpopo appartient déjà à l'Afrique australe. 
VI. Côtes. - $1^{\circ} 0$ céan Atlantique. - Basse et monotone, comme précédemment, lourde de formes, la côte devient du Nord au Sud de plus en plus désertique; les sables et les dunes remplacent peu à peu les alluvions à végétation dense, mais toujours la même barre déferle en avant de la plage, sur le premier palier immergé du grand plateau continental. Le cap Frio marque la seule saillie littorale; les meilleures baies s'abritent derrière les musoirs naturels que les courants marins et atmosphériques, venus du Sud, allongent au Nord-Ouest : le port Alexandre et la baie des Tigres, fort belle, si poissonneuse qu'on l'appelle encore Gross Fish bay, ne sont utilisés que par les pêcheurs. Sur des rades d'ancrage, Loanda, Saint-Philippe de Benguella et Mossamédès, que son climat salubre désigne comme résidence européenne.

$2^{\circ}$ Océan Indien. - Le littoral n'est pas beaucoup plus engageant. Au Sud de Moçambique et des îles Angoche, il est plat, d'une désespérante monotonie, et dessine de larges courbes concaves et convexes; le courant de Moçambique vient buter contre le cap Corrientes (ou des courants) et reflue partiellement vers le Nord. Par intervalle les dunes s'interrompent, mais c'est pour faire place aux vases fétides des rivières et à leurs deltas. Chindé a supplanté Quilimane, comme port du Zambèze et du Chiré. Sofala, qui eut un passé brillant, n'est plus qu'un village; l'activité s'est portée au Nord à Beira, d'où l'on accède aux plateaux intérieurs (Manica et Machonaland), et, plus au Sud encore, à Lourenço Marquès. Situé sur une grande baie, aux eaux profondes, tranquilles comme un lac, comme une lagune (en portugais « lagôa », d'où le nom de baie Delagoa), Lourenço Marquès est, en terre portugaise, le port du Transvaal britannique.

VII. Vie végétale. - On sait que la végétation se règle sur la quantité et sur la répartition annuelle des pluies. C'est pour cette raison que la Zambézie comprend au Nord une région de savanes, au Sud une région de steppes; la ligne idéale qui les partage est celle qui, sur la carte des pluies, sépare les précipitations inférieures et supérieures à $0 \mathrm{~m}$. 50; elle débute sur l'océan Atlantique vers Mossamédès et s'infléchit de plus

G. Lespagiol ex M. Fallex, - Afrique. 
en plus vers le Sud, sans jamais atteindre la côte de l'océan Indien, laquelle est humide et chaude. Savanes et steppes! nous les avons si souvent rencontrées qu'il est superflu de les décrire encore. - Mais l'altitude modifie les conditions du climat et par suite de la végétation; les plateaux de l'Angola, des Matabélé, etc, sont susceptibles de porter des cultures européennes à côté des cultures indigènes, arbres à fruits et céréales d'Europe à côté du manioc, du sorgho et des patates des Nègres; les gelées nocturnes sont à redouter autant que les sécheresses prolongées.

VIII. Vie animale. - Nous connaissons de même, sans qu'il soit nécessaire de recommencer l'énumération, les ani-

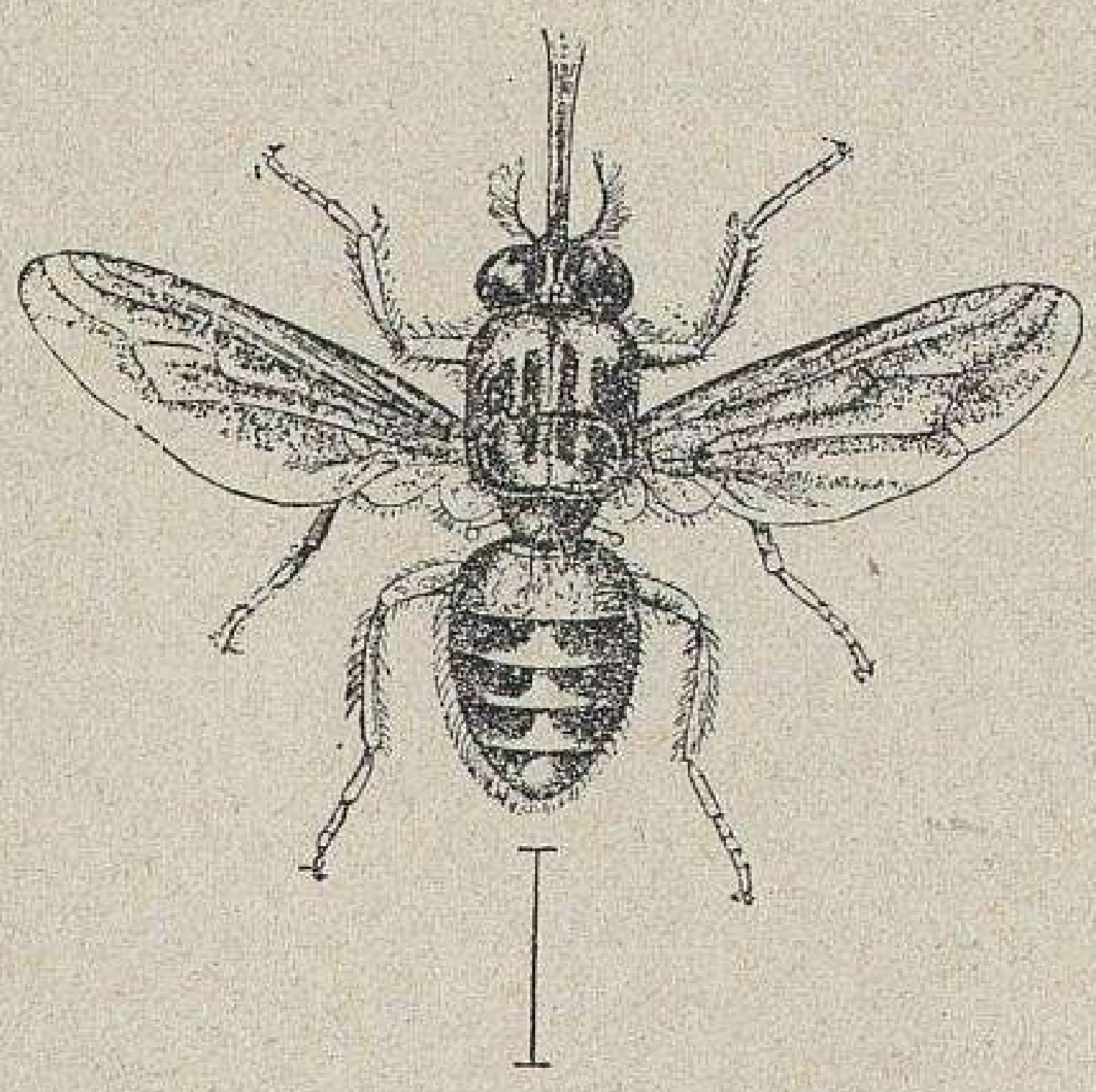

MOUChe TSÉtSÉ (Glossina morsitans) grossie trois fois. maux, herbivores et carnassiers, qui vivent sur les savanes et sur les steppes. Mais le jour n'est pas loin où l'Afrique centrale cessera d'être un paradis pour les chasseurs, un théâtre d'extraordinaires exploits pour les Nemrods d'Europe. Les espèces sauvages disparaissent avecles progrès du défrichement; elles céderont de plus en plus la place aux espèces domestiques, boufs, vaches, moutons. Actuellement le buffle abonde, mais il a, comme tout bétail d'ailleurs, un terrible ennemi, la mouche tsétsé, car il est sans défense contre sa piqûre mortelle. - Un dernier trait caractéristique : les côtes atlantiques sont aussi poissonneuses qu'à la hauteur du Sahara, mais les courants froids amènent des espèces nouvelles, les phoques à oreilles ou otaries, même la baleine. Sur les côtes de l'océan Indien on pêche la tortue et lea huîtres perlières. 
IX. Vie humaine. - La Zambézie presque tout entière est habitée par des Nègres bantous.

Ils sont sédentaires, et vivent, dans des proportions qui varient suivant les contrées, d'agriculture, d'élevage, de chasse et de pêche; les populations des rivières et des marais se servent de nasses et canalisent le poisson à l'aide de digues en roseaux. - Terrorisés jarlis par les traitants arabes, mais l'influence arabe recule, terrorisés encore par des potentats de couleur (les Matabélé, venus du Zoulouland et de la Cafrerie), les indigènes voient arriver aujourd'hui les Européens; parmi ceux-ci quelques-uns se font colons, le plus grand nombre parcourt le pays en quête de pépites, de filons d'or et de couches de houille. Et déjà les noirs, considérés comme des gêneurs, sont parqués dans des "réserves 》 suivant la méthode employée aussi bien dans l'Afrique australe que dans l'Amérique des États-Unis : un chef responsable " indouna " est mis à leur tête.

Vers l'Angola, les Pombeiros, métissés de Portugais brésiliens et de Nègres, se livrent au commerce; leurs caravanes de grands chariots, attelés de plusieurs paires de bœufs, relient les pays de l'intérieur aux comptoirs maritimes.

Des Boers ont immigré par familles jusqu'au Nord-Ouest du lac Ngami, en territoire tantôt portugais et tantôt allemand.

Vers le Sud-Ouest, sur les steppes désertiques, se rencontrent déjà, par groupes dispersés, des Hottentots et des Bochimans : nous les retrouverons au chapitre suivant.

Enfin, à la suite des Anglais, des Asiatiques ou Hindous pénétrent par l'Est dans l'intérieur du continent; leur main-d'œurre est fort appréciée, et cette immigration, qu'on n'aurait pu préroir, il y a quelques années, paraît appelée à progresser encore.

X. Gouvernement et villes. - Le Portugal et l'Angleterre sont les deux puissances européennes qui se partagent la presque totalité de l'Afrique centrale du Sud; l'Allemagne allonge une pointe au cœur de la Zambézie.

I. Possessions portugaises. - Coupées par l'Angleterre en deux tronçons, qui plus jamais ne pourront se rejoindre, les colonies portugaises comprennent : $1^{\circ}$ sur l'Atlantique, l'Angola; $2^{\circ}$ sur l'océan Indien, l'Afrique orientale portugaise.

$1^{\circ}$ L'Angola - du nom d'un ancien roi nègre - confine à l'État du Congo, à l'Afrique allemande du Sud-Ouest et dans l'arrière-pays à la Rhodésia britannique. De ce côté une sentence arbitrale du roi d'Italie (juin 1905) a fixé la frontière suivant des lignes artificielles. Le nouveau tracé remonte le cours du Kouando jusqu'au $22^{\circ}$ Long. Est Gr.; et se confond successivement avec le $22^{\circ}$ Long. Est Gr., le $13^{\circ}$ Lat. Sud et le $24^{\circ}$ Long. Est Gr. jusqu'à l'État indépendant. 
C'est sur la côte, et à l'entrée des plateaux, pour ménager les relations entre indigènes et Européens, que sont installés les villes ou les centres. Saint-Paul de Loanda, résidence du gouverneur général, est une ville ancienne dont la position sur la route des Indes par le cap de Bonne-Espérance fit la fortune; loin de décliner depuis l'ouverture du canal de Suez, elle s'est encore embellie et agrandie. Dans l'intérieur lui font vis-à-vis Ambaca, centre de colons (tabac et arachides), et Malangé où se forment les caravanes marchandes. - Benguella, ville gracieuse, bâtie en amphithéâtre sur la mer, est en relations avec les centres des plateaux, Belmonte et Caconda. - Enfin Mossamédès, la station littorale préférée des Européens, en raison de la salubrité, dessert Huilla, centre de colonisation boer, et Houmbé.

$2^{\circ} L^{\prime}$ " État de l'Afrique orientale », dont les frontières intérieures, des plus capricieuses, laissent à l'Angleterre presque tout le cours du Chiré, a une superficie d'environ 780.000 kilomètres carrés, et une population évaluée à 9 millions. Administrativement on $\mathrm{y}$ distingue :

A. - Le Moçambique au Nord. La ville de Moçambique $(5.500$ h.) occupe une position commerciale excellente : du haut de son îlot rocheux elle commande le détroit; c'est Vasco de Gama qui en prit possession au xvi ${ }^{\mathrm{e}}$ siècle et en fit une relâche fortifiée sur la route des Indes.

B. - La Zambézie au centre. Chindé $(1.300$ h.) est le port à la fois du Chiré (Nyassaland anglais) et du Zambèze; les chaloupes à vapeur remontent jusqu'aux postes de Tété et de Zoumbo. - Beira (3.400 h.) est le débouché de la Rhodésia. - Inhambane (pron. Gnambane) (3.300 h.), au fond d'une baie qu'abritent les cocotiers, était un centre de propagande musulmane : aussi a-t-elle sa mosquée à côté de ses églises.

G. - Lourenço Marquès (6.300 h.), du nom d'un ancien traitant, est sur une baie admirable que l'Angleterre a déjà convoitée, mais un arbitrage du maréchal de Mac-Mahon la déclara possession légitime des Portugais. C'est le port du Transvaal et notamment de Pretoria. La ville, fort jolie, est malsaine, malgré les travaux de drainage et les plantations d'eucalyptus.

Dans l'Afrique orientale comme dans l'Angola, le Portugal 
doit redouter les convoitises de ses puissants voisins, Allemagne et Angleterre.

II. Possessions anglaises. - C'est en venant du Sud, c'est-à-dire de la colonie du Cap, que les Anglais atteignirent le Zambèze, attirés par l'appât de l'or. En 1889 le Portugal fut brutalement sommé de reconnaître le protectorat de la Grande-Bretagne sur des territoires qu'il croyait sa propriété légitime; mais les exploits de ses explorateurs, les Serpa Pinto, Ivens et Capello, ne valaient pas une prise de possession effective. L'Angleterre mit fin ensuite aux États nègres qui s'étaient organisés dans le Matabéléland, et une compagnie à Charte se constitua sous la suzeraineté de la couronne.

Rhodésia, tel est le nom que l'on donne à la Zambézie britannique, de Cecil Rhodes, le financier et l'homme politique qui a le plus contribué à l'expansion anglaise depuis le Cap jusqu'aux grands lacs équatoriaux. Le Zambèze la sépare en deux : Rhodésia du Sud et Rhodésia du Nord.

$1^{\circ}$ La Rhodésia du Sud comprend elle-même deux provinces : le Matabéléland ou pays des Matabélé, capitale Boulawayo, et le Machonaland ou pays des Machona, capitale Salisbury (1.510 m.).

Boulawayo et Salisbury ne sont que des embryons de villes. Le long des rues, qu'on a tracées très larges, les habitations manquent encore; quelques-unes ont des toits de tuile rouge, mais les plus nombreuses sont des cabanes en tôle, des tentes, des huttes. Pourtant, déjà, les banques, les journaux, l'éclairage électrique, la gare, le champ de courses, etc. marquent ces cités futures d'une empreinte toute britannique.

Les autres centres de population ressemblent à des bourgs, à des villages : ainsi Gwelo et Wankie, dans un pays houiller; Victoria $(1.120 \mathrm{~m}$.), à proximité des ruines imposantes de Zimbabye, où l'on a cru retrouver l'Ophir de Salomon. Sont-ce les Phéniciens, sont-ce les Arabes qui ont élevé ces murailles aujourd'hui délabrées? On ne sait. Peut-être Zimbabye était-il une forteresse gardant des mines d'or que l'on aurait connues depuis une haute antiquité. Des ruines de mème nature ont été, d'ailleurs, découvertes dans les régions voisines, jusque dans le Kalahari.

$2^{\circ}$ La Rhodésia du Nord, plus jeune encore et naissant à peine, se décompose en deux portions :

Rhodésia du Nord-Est dont la capitale a été transférée à FortJameson, sur les plateaux au Sud du Tanganyika, avec les centres de Fife et Abercorn. Elle déborde sur les terrasses supérieures du bassin du Congo (lac Bangouéolo).

Rhodésia du Nord-Ouest ou Barotséland, avec 17 stations dont Kalomo et Livingstone, le chef-lieu, en aval des chutes Victoria. 
Lialoui, en amont, est la capitale d'un chef nègre placé sous le protectorat britannique.

Enfin le Nyassaland, désigné jusqu'en 1907 sous le nom de Bristish Central Africa, est un Protectorat britannique qui s'est substitué à une Compagnie particulière, souveraine. La capitale est Blantyre, sur les hauts plateaux du Chiré.

III. Possessions allemandes. - L'Afrique allemande du Sud-Ouest a accès sur le cours du Zambèze, au-dessus des chutes Victoria; elle possède une bande de terre, longue et étroite, dont la forme bizarre est familièrement comparée à un " bec de canard ».

XI. Mise en valeur. - Aussi bien dans les vieilles colonies portugaises, longtemps stagnantes, que dans les territoires britanniques, de date récente, la mise en valeur commence à peine. Les régions basses sont pestilentielles; aussi est-ce sur les hauts plateaux, d'un climat inégal, mais salubre et vivifiant, que se portent les efforts de la colonisation. A la cueillette du caoutchouc s'ajoutent de plus en plus les cultures des tropiques: café, tabac, arachides, canne à sucre. Il semble que la pomme de terre, les arbres à fruit, la vigne, sont susceptibles de s'acclimater en bien des régions. L'élevage est déjà pratiqué par les indigènes, lorsque la mouche tsétsé est absente; il peut donc être étendu et perfectionné. A Port-Alexandre, sur la baie des Tigres, la péche fournit des salaisons et des conserves.

L'inclustrie est à créer; mais la présence de l'or, de la houille, des métaux en général, la favorise. Déjà la Rhodésia du Sud possède des usines pour broyer et concasser les roches aurifères, et d'année en année la production de l'or progresse : 623.000 onces en 1909 (valeur 66 millions). - La houille, reconnue à Tuli, Gwelo, est d'une qualité supérieure à toutes les houilles de l'Afrique australe (153.000 t. en 1909).

Le commerce suit une marche ascendante, que la création des voies de transport ne peut qu'accélérer. Les indigènes ne connaissaient d'autre véhicule que la grande charrette traînée par des bœufs. Aujourd'hui des chaloupes à vapeur circulent sur le bas Zambèze, sur le Chiré, en aval et en amont des chutes, sur le Nyassa : mais c'est la voie de fer qui primera toutes les a atres. On peut dire que dans la Rhodésia la locomotive précède les voyageurs et les marchandises, c'est elle qui fait naître les villes. 
Les chemins de fer portugais de l'Angola conduisent ou conduiront de la côte sur les plateaux habitables, cultivables, vers les districts miniers : de Loanda à Lucalla (360 km.), puis en construction jusqu'à Malangé, et en projet jusqu'au Cassangé; - de Benguella à Catoumbella - de la baie de Lobito, au Nord de Benguella, vers Caconda $(1.500 \mathrm{~km}$.), ligne autorisée par la Chambre des députés; - de la baie des Tigres aux gisements de cuivre de Houmbé.

La Rhodésia du Sud est jointe au Cap par la ligne de Boulawayo et Salisbury; - de Boulawayo une voie franchit le Zambèze (Livingstone), atteint Kalomo depuis 1905 , la mine de Broken Hill depuis 1906 , et finalement se raccorde depuis 1910 au chemin de fer du Katanga, c'est-à-dire au Congo belge.

Enfin de la côte de l'océan Indien partent deux lignes : de Beira (Port.) à Salisbury; de Lourenço Marquès (Port.) à Pretoria, et une ligne est en construction, de Port Herald, sur le bas Chiré, à Blantyre et au Nyassa.

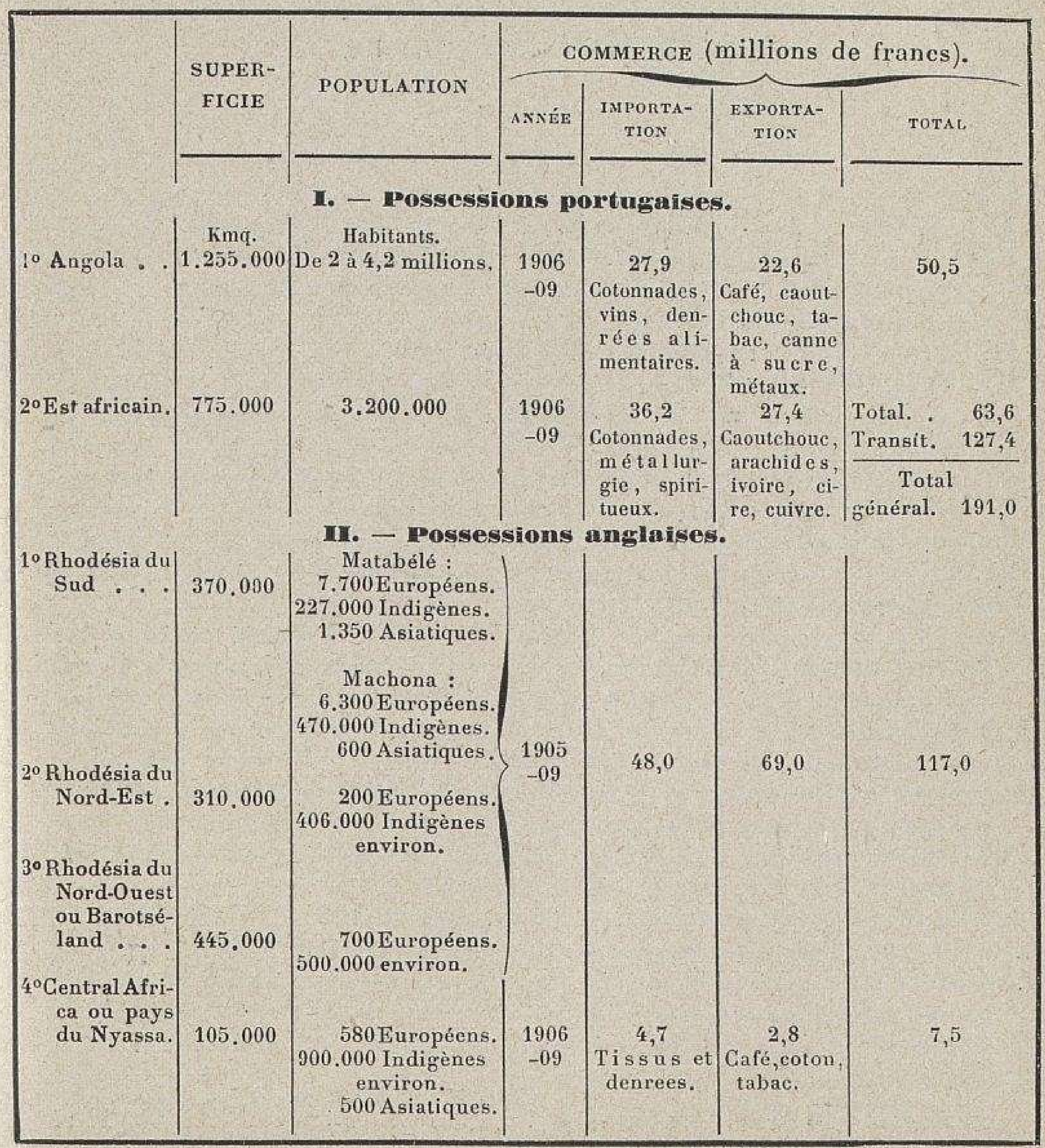




\title{
CHAPITRE XIII
}

\author{
AFRIQUE AUSTRALE
}

\section{SOM M A IRE}

I. Limites. - Traversèe dans sa partie Nord par le tropique du Capricorne, l'Afrique australe s'avance en forme de coin entre l'Atlantique et l'océan Indien qui s'unissent au cap des Aiguilles, en face des mers antarctiques.

11. Superficie. - Près de 3 millions de $\mathrm{kmq}$.

III. Orogénie et relief. - L'Afrique australe est un plateau, affa'zsé au centre, relevé sur les bords par des bourrelets montagneux : la montagne de la Table, près du Cap; le Drakensberg, le long de l'océan Indien, avec le mont aux Sources (3.355 m.). A l'intérienr, les Karrous sont des plateaux arides et secs; le veld est la stezpe nerbeuse du Transvaal et de l'Orange; le Kalahari est un désert.

IV. Climat. - L'èté austral correspond à notre hiver; il est la saison des pluies, sauf au Cap.

1. Le versant de l'océan Indien est chaud, mouillé et, dans §es parties basses, malsain; $2^{\circ}$ les plateaux intérieurs, soumis à ane sécheresse prolongée, sont d'un climat inégal, à variations brusques, mais salubre; $3^{\circ}$ la région atlantique, d'une sècheresse plus forte encore, toute dèsertique, a une température plus basse que ne le comporte la latitude; $4^{\circ}$ la région du Cap, tempérée-chaude, rappe'le les pays méditerranéens, mais avec de moindres chaleurs.

V. Hydrographie. - L'Afrique australe est pauvre en cours d'eau et ceux-ci ont un régime très irrégulier.

Le mont aux Sources est le centre principal de dispersion.

L'Orange (2.000 $\mathrm{km}$.) n'a pas un débit proportionnè à sa longueur; d'abord bien alimentè par les monts Drakensberg, il s'appauvrit sur les steppes, comme son affluent le Vaal, et saute les chutes de Georges IV pour expirer à travers les déserts dans l'océan Atlantique.

Les rivières de l'océan Indien, comme la Tugela, tombent de terrasses en terrasses jusqu'à la mer. Le Limpopo, né sur les plateaux 


\section{AFRIQUE AUSTRALE}

du Transvaal, finit après un long circuit dans une plaine marécageuse, très insalubre.

VI. Côtes. - Le littoral de l'Atlantique, d'abord sans eau douce et pauvre en abris (baie des Baleines et Angra Pequena) dessine au Sud la baie de la Table qui porte la ville du Cap et le cap de Bonne Espérance.

Le cap des Aiguilles est le point le plus méridional du continent.

Le littoral de l'océan Indien est rocheux et peu découpé jusqu'à

\section{AFRIQUE AUSTRALE}

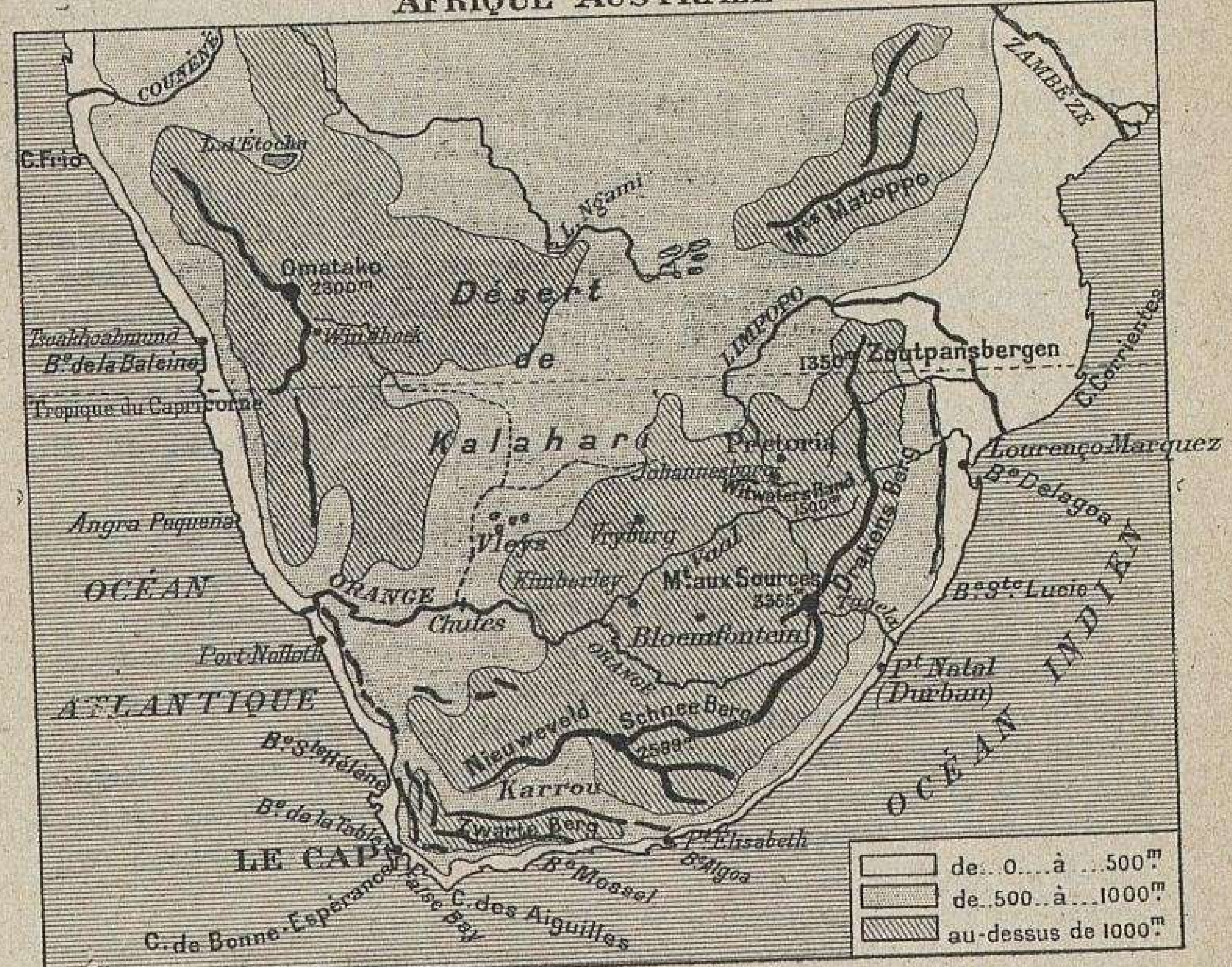

Port-Natal, puis bas et marecageux; Port-Elisabeth et Lourenço Marquès sont les deux ports les plus actifs.

Vill. Vie végétale. - $1^{\circ}$ L'Est, humide et tiède, convient aux espéces tropicales et aux forêts; $2^{\circ}$ les plateaux intérieurs sont des steppes herbeuses et des brousses à épines; $3^{\circ}$ la côte Ouest est aussi déshèritée que la côte du Sahara; 40 la région du Cap rappelle l'Algérie: arbres à feuilles toujours vertes, maquis, céréales, vigne et arbres fruitiers.

VIII. Vie animale. - Chassés de partout, les animaux sauvages peuplent le desert de Kalahari ; les espèces domestiques sont le bce ${ }^{\circ}$ a grandes cornes, le mouton et la chevre dite du Cap. Le cheval s'acclimate difficilement.

IX. Vie humaine. - Les peuples primitifs, Hottentots et Bochimans, mènent sur les steppes, où ils ont ètè refoulès, la vie misérable des nomades, pasteurs et chasseurs. 
Les nègres Bantous, parmi lesquels il faut distinguer les Cafres ou Zoulous, sont des peuples éleveurs de gros bètail.

Les premiers immigrants europeens furent des Hollandais ; de leur union avec des Français calvinistes est née une race de paysans robustes : les Boers.

Après un siècle d'exodes et de guerres, ils ont èté soumis par l'Angleterre.

X. Gouvernement et villes. - Sans le Sud-Ouest africain allemand, colonie immense, mais pauvre (capitale Windhouk), toute l'Afrique australe serait anglaise.

Les immenses possessions de la Grande-Bretagne comprennent : A. - L'Union Sud-Africaine, formée de 4 provinces : - $1^{\circ} \mathrm{La}$ province du Gap de Bonne-Espérance, cap. le Cap; ville principale, Port-Élisabeth. Kimberley est la cité du diamant. La baie des Baleines en dépend : c'est une enclave en terre allemande; $-2^{\circ}$ La province de Natal, avec le Zoulouland, cap. Pie termaritzbourg. Port-Natal ou Durban est plus populeux; - $3^{\circ}$ La province $d u$ Transvaal, cap. Pretoria. Grâce aux mines d'or, Johannesbourg, fondée en 1886, est la ville la plus populeuse de l'Union (158.000 h.); - 4. La province de l'État libre d'Orange, cap. Bloemfontein.

B. - Lé territoire du Basoutoland et le protectorat du Betchouanaland, à demi dèsertique.

G. - Les îles Ascension et Sainte-Hélène, deux stations de l'amirauté, qui servent de points de ravitaillement pour les flottes et de points d'atterrissement pour les câbles sous-marins.

XI. Mise en valeur. - Les plateaux se prêtent à la colonisation européenne, aux cultures (cèréales, vigne), à l'élevage surtout (moutons et chèvres du Cap, gros bètail, autruche).

Mais l'industrie des mines transforme toute l'Afrique australe : elle est le premier pays de la terre pour la production du diamant (Kimberley et Johannesbourg) et de l'or (Johannesbourg). On y exploite en outre la houille.

Presque tout le commerce se fait avec l'Angleterre et les colonies anglaises : les principaux objets d'exportation sont les diamants, l'or, les laines et les poils de chèvre, les plumes d'autruche, le cuivre, etc.

Les chemins de fer sont dejjà très développès : $1^{\circ}$ ligne du Cap à Kimberley, Mafeking et Salisbury dans la Rhodèsia; 2 ligne de Port-Elisabeth à Prétorir : avec embranchements sur Durban et sur Lourenço Marqués.

\section{DÉVELOP PEMEN T}

I. Limites. - L'Afrique australe s'avance, en forme de coin émoussé, entre l'Atlantique et l'océan Indien, qui choquent leurs flots au cap des Aiguilles; traversée au Nord par le tropique du Capricorne, elle atteint presque le $35^{\circ}$ Lat. S.

II. Superficie. - De 2 millions et demi à 3 millions de kilomètres cqrrés. 
III. Orogénie et relief. - Comme les régions précédemment étudiées, l'Afrique australe repose sur un soubassement de terrains très anciens; émergés dès l'époque primaire, ceux-ci n'ont plus été recouverts par les eaux marines et ils n'ont plus subi de plissement que sur la bordure orientale, par suite de l'effondrement qui détachait l'Afrique de Madagascar et de l'Inde. Au dessus des granites sont des grès, des quartzites, puis des conglomérats riches en or. - Lorsque le granite est à nu, le relief a des formes arrondies; sur le grès ce sont les formes tabulaires qui prédominent (montagne de la Table, près du Cap); enfin la décomposition des schistes, sur les terrains Jacustres des Karrous, donne un sol d'un brun rouge, une argile que la sécheresse stérilise. - Dans la langue géographique, veld désigne un champ, une plaine au relief adouci, ondulé; berg, des croupes escarpées.

La structure de l'Afrique australe est celle de l'Afrique en général : un plateau en forme d'auge ou de conque, affaissé dans son centre et relevé sur les bords par un bourrelet montagneux. C'est vers l'océan Indien que la bordure atteint la plus forte altitude (plus de $3.000 \mathrm{~m}$.), - nous venons d'en dire la raison; - vers l'Ouest, la pente s'incline doucement, pour former le bassin du fleuve Orange.

$1^{\circ}$ La bordure atlantique continue les plateaux de l'Angola, qui prolongeaient eux-mêmes ceux du Congo. Mais elle porte ici, dans le Damaland, de vraies montagnes (monts Omatako, $2.680 \mathrm{~m}$.) dont les pentes, en gradins vers la mer, s'allongent au contraire vers la dépression de l'intérieur. L'altitude faiblit dans le Namaland, pour se relever, après la percée du fleuve Orange, dans la colonie du Cap : le Winterhouk, " piton de l'hiver ", atteint 2.078 mètres; la montagne de la Table, composée surtout de grès $(1.082 \mathrm{~m}$.), a des parois verticales et une forme carrée.

$2^{\circ}$ Bordure méridionale. - Entre les deux océans, les plissements s'alignent en échelons parallèles et les plus méridionaux prennent la côte en écharpe : $1^{\circ}$ les Lange-bergen $(1.700 \mathrm{~m}$.); - $2^{\circ}$ les Groote Zwarte-bergen ou " grandes montagnes noires ", dont les derniers contreforts dessinent la baie d'Algoa; $-3^{\circ}$ le Nieuweveld Range et les Sneeuw-bergen $(2.592$ m.), ainsi nommées, parce que les neiges, sans être persistantes, les recouvrent chaque année de leur blanc manteau. D'une rangée à l'autre s'étale un plateau, un Karroo ou Karrou, terme hottentot qui signifie " aride » et « sec ». 
Les Karrous ont en effet l'aspect morne et silencieux des déserts; on n'y voit ni villes, ni villages, ni champs cultivés. Le sol, pierres et argile rouge, hérissé de cônes pointus, surmonté de tables rocheuses, ne porte autre chose que des broussailles, des buissons épineux, des bruyères rabougries, une herbe courte et dure qui pousse après les pluies avec une rapidité étonnante, mais se flétrit et sèche vite, ou encore des plantes charnues qui font provision d'eau pour résister aux longs mois de sécheresse : le tout très clairsemé. Dans ces solitudes, les stations du chemin de fer sont comme perdues; de loin en loin, un

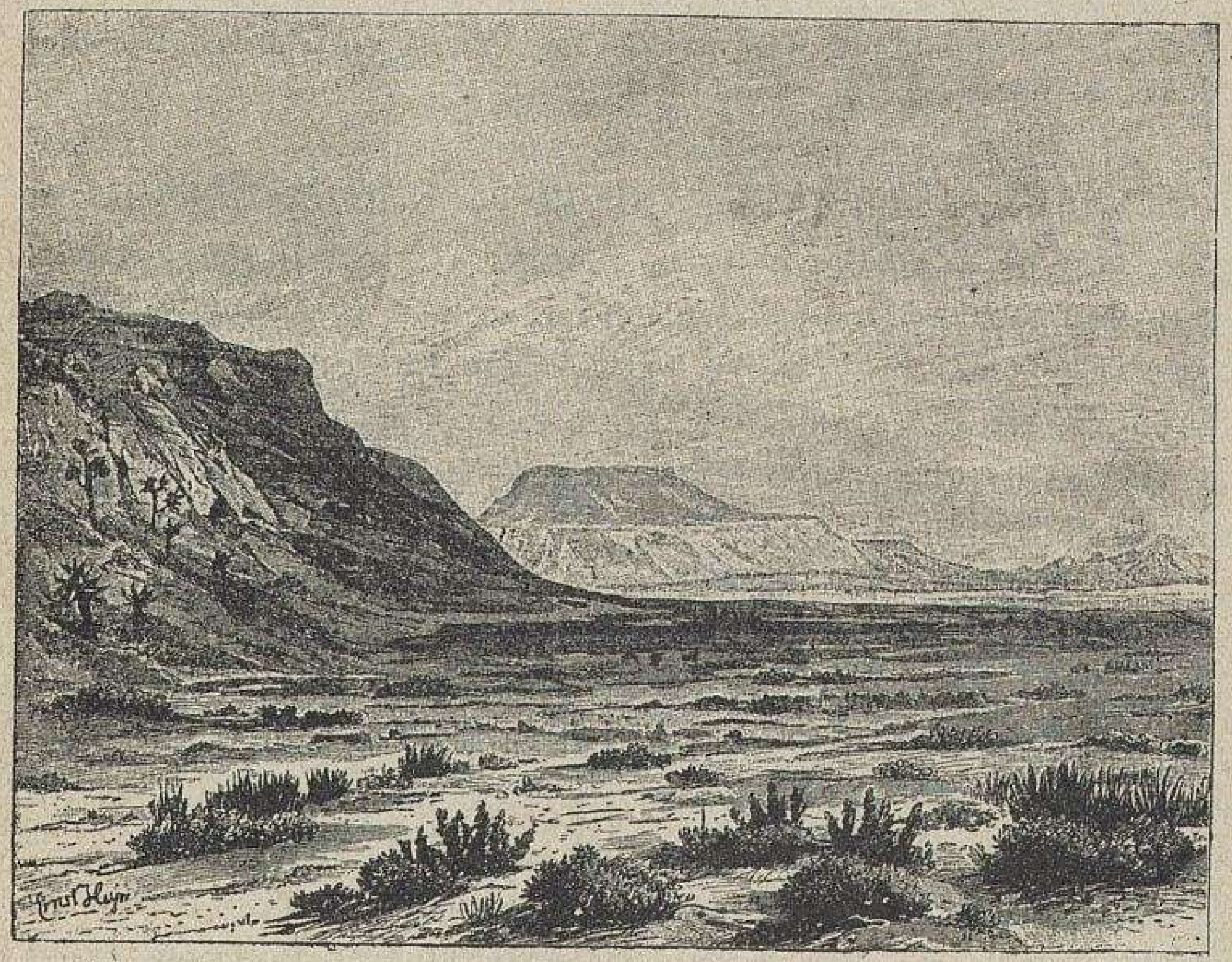

PLATEAU DU KARROU.

(D'après G. Fritsch.)

Végétation sami-désertique. Pas un être vivant. Montagnes aux formes tabulaires et géométriques.

troupeau de brebis et de chèvres, et près d'une source ou d'un puits artésien une ferme; le sol n'est infertile que parce que l'humidité fait défaut. L'air est sain, léger, vif et pur : c'est le ciel qui est beau, et la terre désolée.

$3^{\circ}$ Bordure orientale. - Les Sneeuw-bergen ou « montagnes neigeuses " sont un centre de bifurcation; tandis qu'une chaine reste fidèle à l'orientation de la rangée précédente, c'est-à-dire des Zwarte-bergen, et s'affaisse sur l'océan Indien, une autre 
se recourbe au Nord-Est, dans le sens du littoral : c'est la «montagne des Dragons » ou Drakensberg. Vue de la mer, elle se dresse comme une muraille dentelée, précédée de gradins que les gorges des torrents ont ravinés; mais des plateaux intérieurs, elle ne fait guère plus d'effet qu'une colline. Le mont aux Sources $(3.355 \mathrm{~m}$.) en est le point culminant; il dessine une

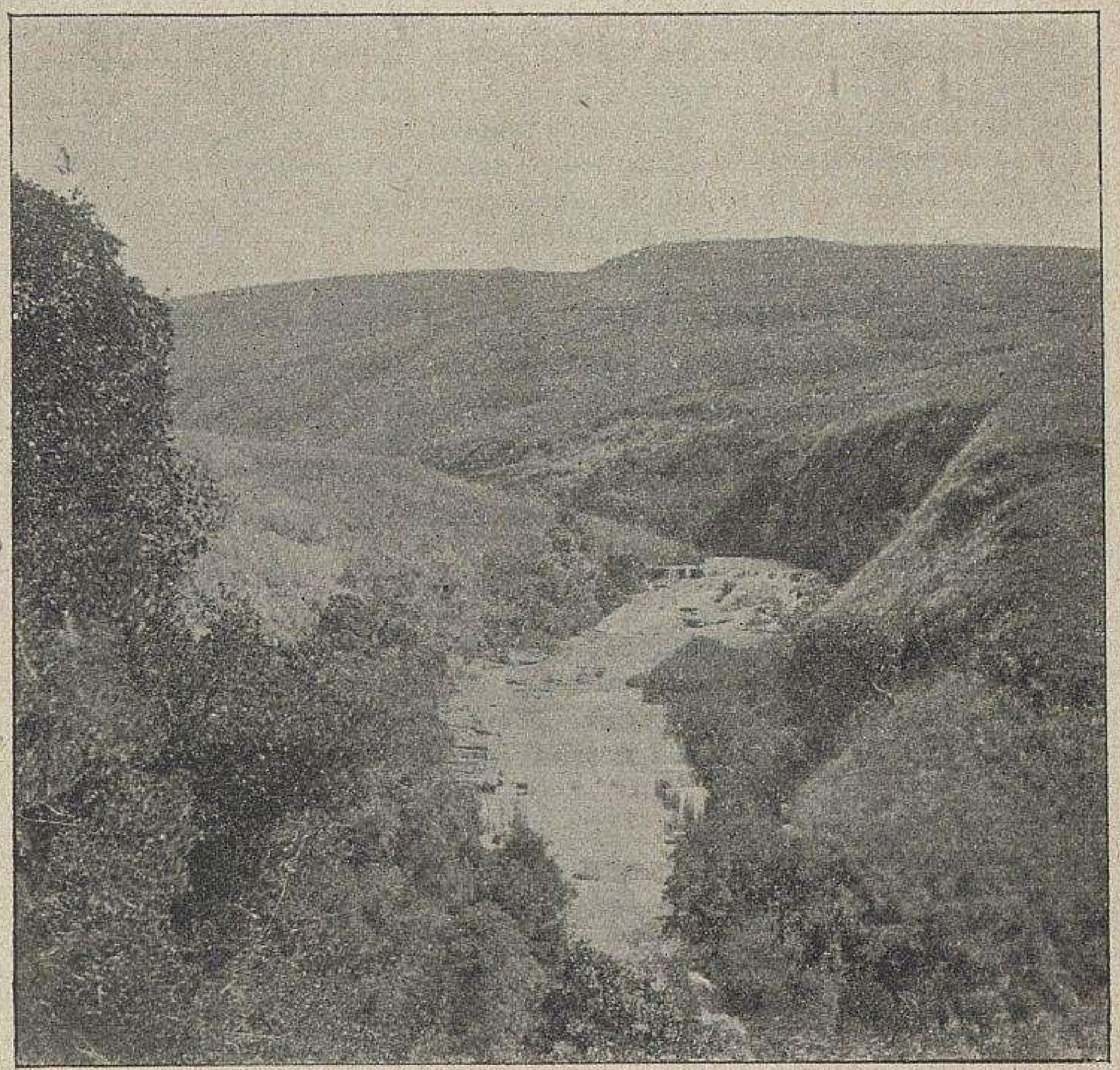

AU MATAL.

(Photographie Ferneyhough, communiquée par la Société de Géographie de Paris.)

Un torrent descend les marches d'un escalier naturel et tombe des hauts pâturages du Drakensberg dans la zone forestière.

rose des eaux. Peu à peu, vers le Nord, la bordure montagneuse s'écarte de la mer et l'altitude faiblit; elle se relève dans le Zoutpansbergen ou « monts des Salines » $(1.350 \mathrm{~m}$.), dont l'éperon contraint le Limpopo à se courber en demi-cercle.

4. Plateaux intérieurs. - Les plateaux, qui s'allongent 
à l'Ouest du Drakensberg, ont une altitude moyenne de 1.300 et 1.400 mètres; ils forment ce que les Hollandais de l'Orange et du Transvaal appellent le Veld.

Le Veld. - La campagne s'étend à perte de vue, sans arbres, hérissée de pointements granitiques (kopje), et, en dehors du lit encaissé de rivières inconstantes, les sources sont si rares que plus d'un nom de lieu se termine par le suffixe fontein, comme pour souligner l'importance exceptionnelle du point d'eau. Ce sont les richesses du sous-sol qui ont attiré l'étranger : au Sud de Johannesburg, la crête du Witwatersrand $(1.500 \mathrm{~m}$.), " la rangée de l'eau blanche », est riche en conglomérats aurifères. Quant au Boer, il quitte à la saison sèche le Hoogeveld, " haut pays ), et descend avec ses troupeaux sur le Boschveld ( 800 à $1.000 \mathrm{~m}$.), le " pays boisé ", où il trouve, avec une végétation de mimosées, un climat plus humide et moins excessif.

A l'Ouest du Limpopo supérieur, à l'Ouest du Vaal, les plateaux du Betchouanaland sont encore assez élevés $(1.000 \mathrm{~m}$.) pour que les pluies charriées de l'océan Indien entretiennent encore des pâturages, et pour que l'homme trouve des sources où grouper ses habitations. C'est sur eux que court la voie ferrée du Cap au Zambèze.

Mais à mesure qu'on s'enfonce davantage vers l'Ouest, le plateau s'affaisse et la sécheresse augmente. Les rivières tarissent complètement, des lacs sans profondeur (pan) évaporent leurs eaux saumâtres, et les pâturages de plus en plus maigres se réduisent à de simples terrains de parcours.

On donne à la région septentrionale le nom de désert de Kalahari.

G'est une plaine calcaire, sans eau, sans le moindre lit de rivière, tout unie ou ridée parfois de dunes sablonneuses; la végétation, pauvre, mais non absente, comprend des herbes dures, des broussailles et des épines; les Bochimans ou Bushmen (hommes de la brousse) y mènent la vie errante des peuples chasseurs, à la poursuite des girafes, des antilopes, etc. Le Kalahari rejoint au Nord les steppes de l'ancien lac Ngami, et se relève à l'Ouest vers les terrasses atlantiques. Peut-être fut-il un temps où le pays était moins sec, peut-être l'incendie des herbes, des forêts n'a-t-il pas peu contribué à diminuer la quantité des pluies et à augmenter la force de l'évaporation.

IV. Climat. - Nous distinguerons dans l'Afrique australe plusieurs régions climatériques. Mais il importe de se souvenir tout d'abord que le soleil atteint le tropique du Capricorne au 
mois de décembre et que l'été austral correspond à notre hiver.

$1^{\circ}$ Région orientale. - La chaîne du Drakensberg est pour les climats une frontière; sur elle, sur ses pentes orientales surtout, se condensent les nuées qu'apportent les alizés du Sud-Est: pluies, neiges, forêts concourent à en faire un grand réservoir d'eau, dont l'océan Indien est le pourvoyeur. - Le Natal fournit le type le plus parfaìt de cette région; bien que situé à $30^{\circ} \mathrm{Lat}$. S., il jouit d'une température semi-tropicale. On l'a souvent comparé au Mexique; comme lui, il possède : $1^{\circ}$ une zone maritime, " une terre chaude ", qui a du moins l'avantage d'être salubre; $2^{\circ}$ une “ terre tempérée »; $3^{\circ}$ enfin des terres relativement froides : ce sont les hautes terrasses.

$2^{\circ}$ Région des plateaux. - A l'Ouest du Drakensberg, les pluies diminuent, de l'Est à l'Ouest, en raison de l'éloignement de l'océan Indien, et du Nord au Sud, en raison de l'éloignement de l'équateur et du tropique, enfin elles diminuent encore avec l'altitude. Elles tombent toujours pendant l'été, mais fort irrégulièrement, par orages diluviens, souvent accompagnés de grêlons. La sécheresse provoque des écarts de $30^{\circ}$ en vingtquatre heures. Pour se préserver des brusques variations de l'atmosphère, l'habitant a, pour costume, adopté le Kaross, une peau de mouton, qu'il porte à son gré, toison en dedans, toison en dehors. Ce climat sec est vivifiant, très sain; la race indigène est forte et belle, forts et robustes également les Boers, qui sont des immigrants européens.

$3^{\circ}$ Région occidentale. - La région atlantique a été souvent comparée au Chili septentrional et central; c'est la même sécheresse désertique, le même courant marin froid, les mêmes vents Sud et Sud-Ouest peu humides (ceux Nord-Est, de mai à juillet, sont plus secs encore), enfin la même nébulosité. Mais dans aucun pays du globe, on ne trouve à cette latitude, qui est celle du tropique, ure température moyenne aussi basse, et la quantité de pluies tombée est la plus faible que l'on ait notée sur le bord de la mer : il ne pleut pas plus de cinq à six fois par an. Les plateaux intérieurs sont plus humides, sans l'être jamais beaucoup; mais avec l'altitude augmentent aussi les écarts de température.

$4^{\circ}$ Sud-Ouest. - La région du Sud-Ouest, celle du moins 
qui est voisine du littoral, car les Karrous sont des plateaux secs $(10 \mathrm{~cm}$. de pluies annuelles), tient le milieu entre la région désertique de l'Ouest et la région semi-tropicale de l'Est. La température est celle des contrées tempérées chaudes; moins élevée pourtant que dans les pays méditerranéens de même latitude; mais ici comme là, c'est l'hiver qui est pluvieux, et l'été sec, contrairement à ce qui a lieu dans le reste de l'Afrique australe. Grâce aux vents (Sud-Est de septembre à avril, Nord-Ouest en hiver), qui purifient l'atmosphère et tempèrent l'ardeur du soleil, le climat est beau, très salubre; rarerement le thermometre atteint en été $+33^{\circ}$ et rarement il descend en hiver au-dessous de $+8^{\circ}$.

\begin{tabular}{|c|c|c|c|c|c|c|c|c|c|}
\hline \multirow{3}{*}{ RÉGION } & \multirow{3}{*}{ LOGALITÉS } & \multirow{3}{*}{ 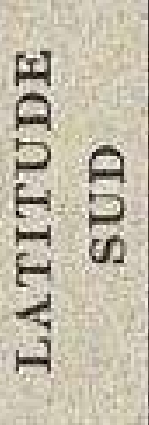 } & \multirow{3}{*}{$\begin{array}{l}0 \\
5 \\
5 \\
5 \\
\frac{5}{4}\end{array}$} & \multicolumn{4}{|c|}{ TEMPÉRATURE MOYENNE } & \multirow{3}{*}{$\frac{\substack{n \\
2}}{2}$} & \multirow{3}{*}{$\begin{array}{l}\text { OBSER- } \\
\text { VATIONS }\end{array}$} \\
\hline & & & & \multirow{2}{*}{$\frac{\stackrel{\omega}{\frac{\omega}{2}}}{2}$} & \multicolumn{2}{|c|}{ Mols } & \multirow{2}{*}{${ }_{\tilde{\pi}}^{5}$} & & \\
\hline & & & & & $\begin{array}{l}\text { le plus } \\
\text { froid }\end{array}$ & $\begin{array}{c}\text { le plus } \\
\text { chaud }\end{array}$ & & & \\
\hline Région & Durban .... & $29^{\circ}$ & $76^{\mathrm{m}}$ & $20^{\circ}$ & Juil. $17^{\circ}$ & Janv. $23^{\circ}$ & $6^{\circ}$ & & $\begin{array}{l}\text { Pluies } \\
\text { pendant }\end{array}$ \\
\hline (océan & burg.... & $29^{\circ}$ & $625^{\mathrm{m}}$ & $18^{\circ}$ & Juin $12^{\circ}$ & Janv. $22^{\circ} \mid$ & $10^{\circ}$ & $0^{m}, 740$ & $\begin{array}{l}\text { 1a saison } \\
\text { chaude : }\end{array}$ \\
\hline Indien). & Port-Elisabeth. & $33^{\circ}$ & $55^{\mathrm{m}}$ & $17^{\circ}$ & Juil. $14^{\circ}$ & Janv. 210 & 70 & $0^{\mathrm{m}}, 600$ & De nov, à \\
\hline Plateaux & Pretoria . : . & $25^{\circ}$ & $1.360^{\mathrm{m}}$ & $19^{\circ}$ & Juil. $15^{\circ}$ & Janv. 23० & $8^{\circ}$ & $\left.\mid 0^{\mathrm{m}}, 600\right)$ & 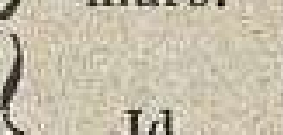 \\
\hline intérieurs. & $\begin{array}{l}\text { Bloemfontein, } \\
\text { Kimberley . }\end{array}$ & $28^{\circ}$ & $\begin{array}{l}1.370^{\mathrm{m}} \\
1.230^{\mathrm{m}}\end{array}$ & $\begin{array}{l}16^{\circ} \\
18^{\circ}, 6\end{array}$ & Juil. $12^{\circ}$ & Janv, 25 & $13^{\circ}$ & & 1d. \\
\hline $\begin{array}{c}\text { Région oc- } \\
\text { cidentale }\end{array}$ & Walfish bay & $22^{\circ}$ & - & $16^{\circ}$ & Juil. $14^{\circ}$ & Fév. $18^{\circ}$ & $4^{\circ}$ & $0^{m}, 007$ & Pluies \\
\hline ou atlanti- & Port-Nolloth & $29^{\circ}$ & & $14^{\circ}, 8$ & Juil. $11^{\circ}$ & Janv. 150 & $4^{0}$ & $\left.0^{\mathrm{m}}, 057\right\}$ & d'avril à \\
\hline que. & Windhouk. . & $22^{\circ}$ & $1.630^{\mathrm{m}}$ & $16^{\circ}$ & Juil. $8^{\circ}$ & Nov, $22^{\circ} \mid$ & $14^{\circ}$ & & \\
\hline Sud-Ouest. & Le Cap . & $33^{\circ}$ & $12^{\mathrm{m}}$ & $16^{\circ}$ & Juil. $12^{\circ}$ & $\mid$ Janv. $20^{\circ} \mid$ & $7^{\circ}$ & $0^{\mathrm{m}}, 630$ & $\left\{\begin{array}{c}\text { Pluies } \\
\text { d'hiver. }\end{array}\right.$ \\
\hline
\end{tabular}

V. Hydrographie. - L'Afrique australe est pauvre en cours d'eau et le régime des rivières est très irrégulier.

$1^{\circ}$ Versant atlantique. - Au Nord et au Sud du fleuve Orange, sur la côte et dans l'intérieur des terres, il n'existe pas de rivières permanentes.

L'Orange n'a pas un volume proportionné à sa longueur (2.000 km.), non plus qu'aux dimensions de son bassin (960.000 kmq.), lequel est sec pour une bonne moitié.

Les Hollandais l'appelaient de son nom indigène, Gariep, " grande 
eau ग. A la fin du $x{ }^{\prime} m^{\circ}$ siècle, les Anglais l'appelèrent Orange, en t'honneur de la dynastie régnante.

C'est du mont aux Sources qu'il descend et que descendent avec lui des rivières permanentes, telles que le Caledon. D'abord torrent de montagne, très encaissé, il arrive sur des plaines de plus en plus sèches. Le Vaal a déjà parcouru une distance plus longue, quand il le rejoint à droite; mais son

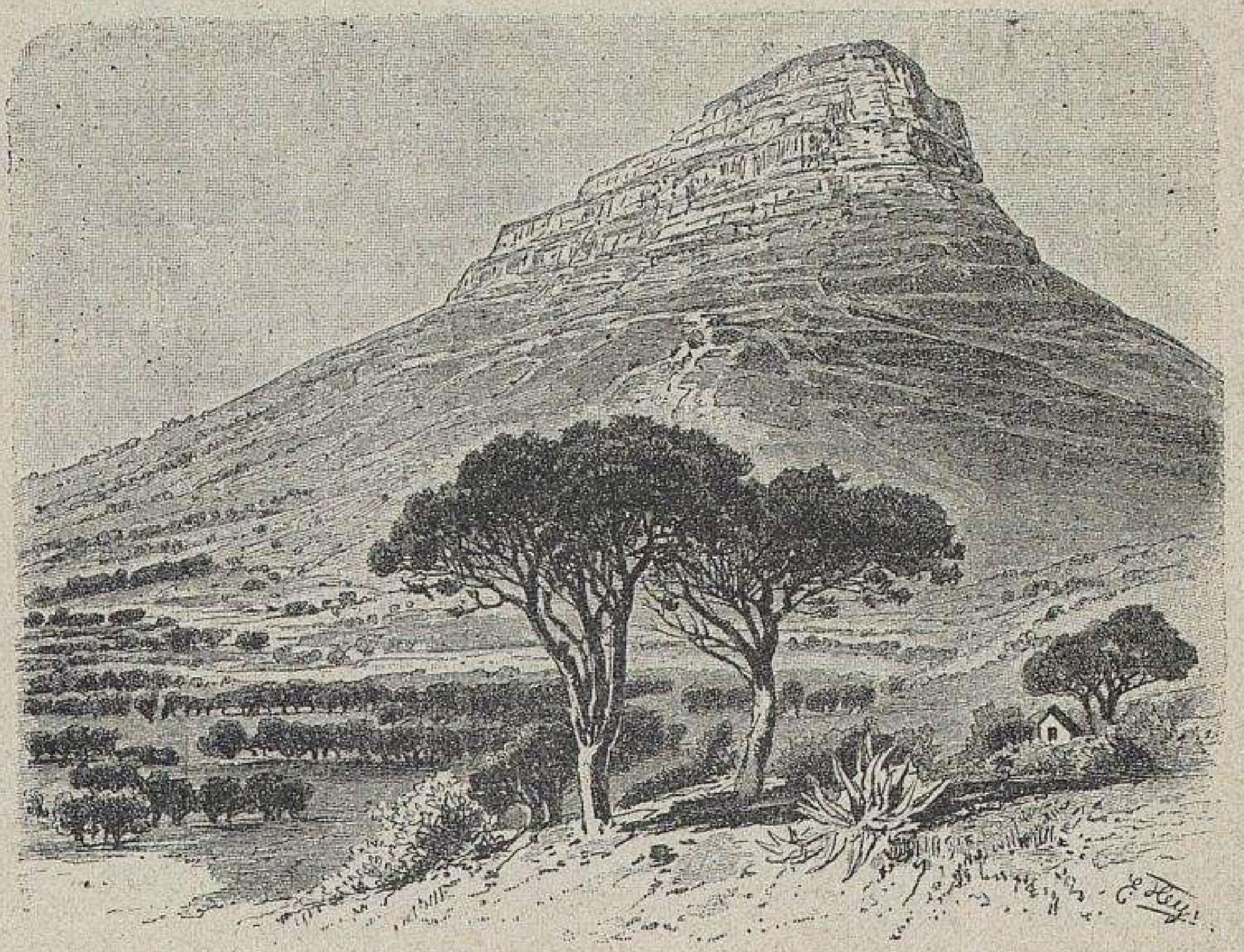

LA. TÊTE DU LION, PRES DE. LA VILLE DU CAP.

débit est moindre parce qu'il décrit un grand circuit à travers le Veld : c'est une rivière de steppes, abondante, mais sauvage, seulement après les pluies de l'été (de novembre à avril). Au delà, les cours d'eau n'ont plus même la force d'atteindre en toute saison le fleuve Orange : par exemple, le Molopo et son affluent le Nosob, au Nord; le Hartebeest au Sud. Les eaux, ne trouvant pas leur pente, s'amassent dans des mares sans fond, dans des cuvettes salines (vleis, pans) comparables aux sebakh du Sahara. Fort amaigri, l'Orange coule au travers des banes de sable pour arriver aux Cent chutes (Anghrabies ou chutes. de Georges IV); sur 25 kilomètres se succèdent les rapides, les

G. Ligpagnol et M. Fallex. - Afrique. 
écueils et les gouffres, les canaux, les bras vifs et les bras morts. - En aval commence la partie inférieure du cours; le fleuve devient sinueux à travers les montagnes qui lui barrent la route de l'Atlantique et toujours il s'appauvrit en avançant; lorsque ses rives ne sont pas escarpées, on peut le passer'à gué pendant presque toute l'année. En temps ordinaire, une barre gêne l'embouchure; puis, lors des crues, le courant devient si violent qu'on ne peut le remonter, de sorte que jamais l'Orange n'est accessible aux navires.

Plus au Sud, l'eau manque à l'Olifant's River, « rivière de l'Éléphant », d'un faible parcours (350 km.).

$2^{\circ}$ Versant de l'océan Indien. - Des pentes orientales du Drakensberg, les cours d'eau tombent de terrasses en terrasses et roulent au fond de cluses, aux parois verticales; aussi ne sont-elles jamais navigables, malgré leur débit, et toujours une barre ferme leur embouchure. Ce sont le Key, le $S^{t}$ John's river et la Tugela; rendue fameuse par les combats de 1899-1900 entre Boers et Anglais, celle-ci roule, dans son cours supérieur, au fond de cañons qui mesurent 2.000 pieds. - Au delà les montagnes s'écartent; les rivières finissent en terrain plat, elles s'égarent vers le Nord et meurent dans les lagunes. Le Komati finit dans la baie Delagoa. Le Limpopo, ou « rivière des Crocodiles », plus long (1.600 km.) qu'abondant, franchit à deux reprises le tropique. Né sur les plateaux de Pretoria, il descend par bonds, contourne l'éperon des Zoutpansbergen, reçoit à droite une longue rivière $(700 \mathrm{~km}$.) venue comme lui du Transvaal et qui porte un nom assez répandu dans l'Afrique australe, Olifant's river « rivière de l'Eléphant »; il se termine enfin dans des marécages malsains.

VI. Côtes. - $1^{\circ} 0$ cẻan Atlantique. - Au Sud du Counéné et des possessions portugaises, le littoral est toujours massif, peu hospitalier, et toujours le ressac déferle sur des plages de sable. En arrière s'allongent des dunes; plus hautes que celles de nos côtes landaises $(150 \mathrm{~m}$.), en certains points elles n'alignent pas moins de seize crêtes. Pas d'arbres, pas de sources : c'est le désert; force est de faire venir l'eau douce, par navires, du Cap ou bien de distiller l'eau de mer. - Du moins l'Océan est 
très peuplé : les poissons abondent, et le courant de Benguella, venu des mers antarctiques, apporte les phoques ou veaux marins et les baleines. Au large, pour compléter la ressemblance avec le littoral de l'Amérique du Sud, avec le Chili, quelques îlots habités par les " manchots " fournissent le guano, et c'est par vols compacts qu'en octobre et novembre, à l'époque des couvées, s'abattent les cormorans.

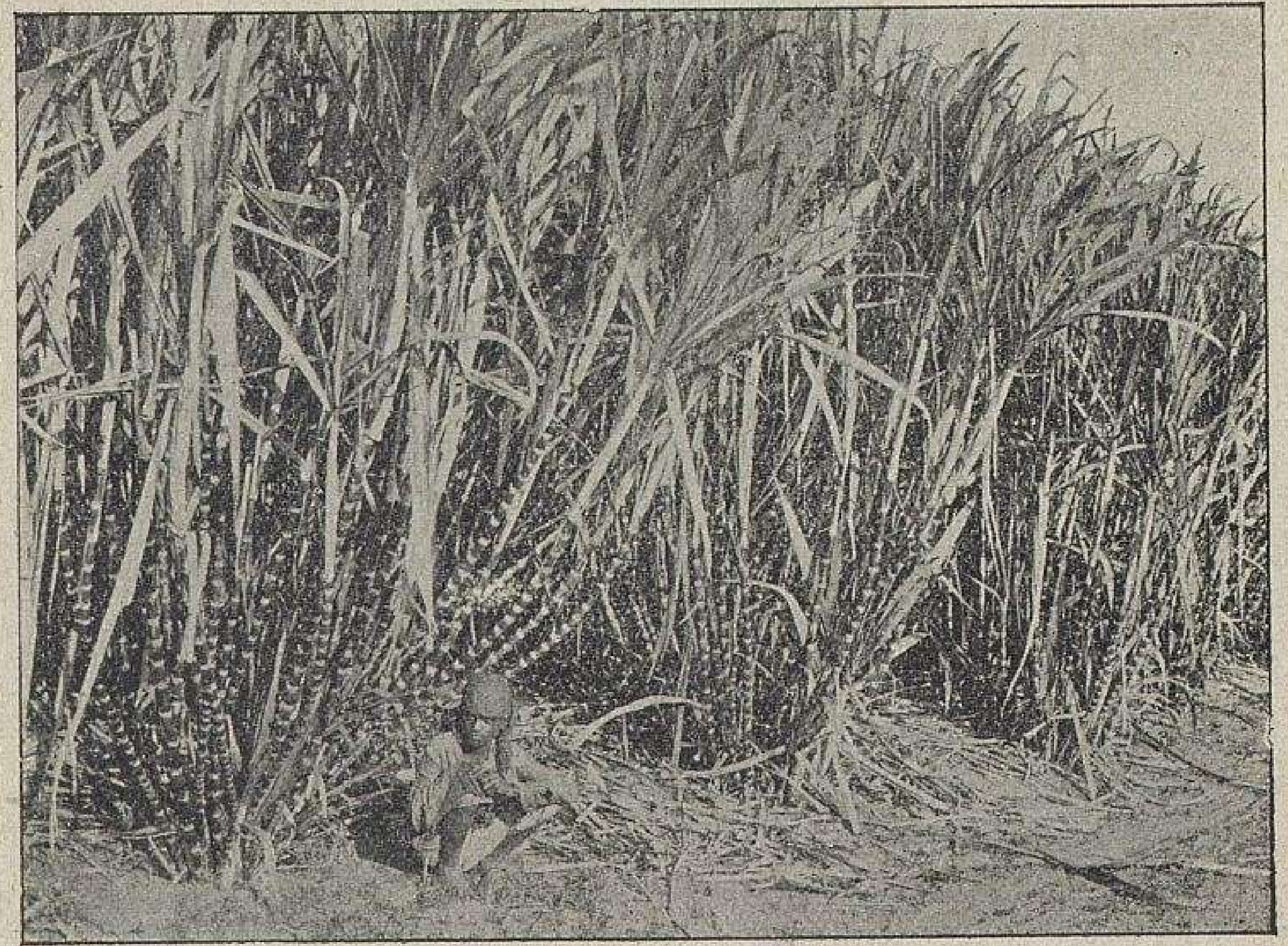

AU NATAL : CHAMP DE GANNE A SUCRE.

(Photographie Ferneyhough, communiquée par la Société de Géographie de Paris.)

Les deux seuls abris naturels sont Walfish bay ou « baie des Baleines 》, à l'Angleterre, et Angra Pequena, à l'Allemagne, vaste et profond, malgré son nom portugais, " petite baie". Au Sud du fleuve Orange, la côte, bien que de formes identiques, offre un plus grand nombre de saillies et de baies : baie Sainte-Hélène, baie de la-Table, avec la ville du Cap, False bay enfin, derrière le cap de Bonne-Espérance. Au cap des Aiguilles, les deux Océans se confondent; c'est la saillie la plus méridionale du continent.

$2^{\circ}$ Océan Indien. - Le rebord du grand plateau austral commence par se tenir à une faible distance de la mer; la côte 
alor's est rocheuse, mais peu découpée, les mouillages mauvais exposés aux vents et à la houle du large : derrière le cap Saint Blaise, Mossel bay; derrière le cap Recife, la baie Algoa avec Port-Élisabeth, la seconde ville de la colonie du Cap; East London, très dangereux, recherché, dit-on, par « les armateurs qui cherchent à perdre leurs navires, afin de toucher la prime d'assurance ». La baie de Port-Natal est plus sûre et vaste.

Au delà de la Tugela, les montagnes s'écartent, les plages étalent leurs sables, que les vents relèvent en dunes; en arrière, des lagunes, des étangs de forme allongée, et tout un enchevêtrement de marigots (baie de Sainte-Lucie). C'est ainsi que s'opère la jonction avec le littoral portugais précédemment décrit, avec la baie Delagoa et Lourenço Marquès.

VII. Vie végétale. - $1^{\circ}$ A l'Est, l'atmosphère tiède et humide convient aux espèces semi-tropicales. Mais des zones s'étagent suivant l'altitude : en bas, le cocotier, le bananier, la canne à sucre, l'indigo, le maïs et le riz, puis sur les coteaux, où les eaux peuvent s'écouler, l'arbre à thé; - à l'étage moyen, les céréales et les légumes de nos régions tempérées; - en haut enfin, sur les terres plus froides, des forêts vigoureuses et de beaux pâturages.

$2^{\circ}$ Sur les plateaux intérieurs, la végétation arborescente se confine le long des rivières et aux points d'eau; ailleurs ce ne sont que des tiges ligneuses, des euphorbes, des acacias, des mimosées, des épines : certaines espèces ont été qualifiées par les Hollandais d'un mot expressif “attends un peu » (wacht een beetje), parce qu'elles s'accrochent aux vêtements et les retiennent. - Le veld est donc le pays des steppes herbeuses et des pâturages : on y peut circuler plusieurs jours sans apercevoir un seul arbre. Au printemps, la campagne est belle, d'un vert émeraude; mais l'hiver, elle devient aussi jaune qu'un champ de grain mûr; puis, après les incendies, ce n'est plus qu'un tapis lugubre, charbon ou cendre. - Les cultures, localisées près des sources, sont celles que leur précocité met à l'abri de la sécheresse : le mais et le froment des Cafres, sorte d'orge commune. 
Le Kalahari, moins désertique que le Sahara, est le domaine de la brousse (le Bush des Anglais, le Bosjesveld des Hollandais). Des melons sauvages, aux bulbes succulents et aqueux, procurent à l'indigène et aux animaux un aliment providentiel.

$3^{\circ}$ A l'Ouest, le littoral est aussi déshérité que le rivage saharien. Une espèce caractéristique est un conifère désertique, le Welwitschia mirabilis. Les hauts plateaux atlantiques n'ont

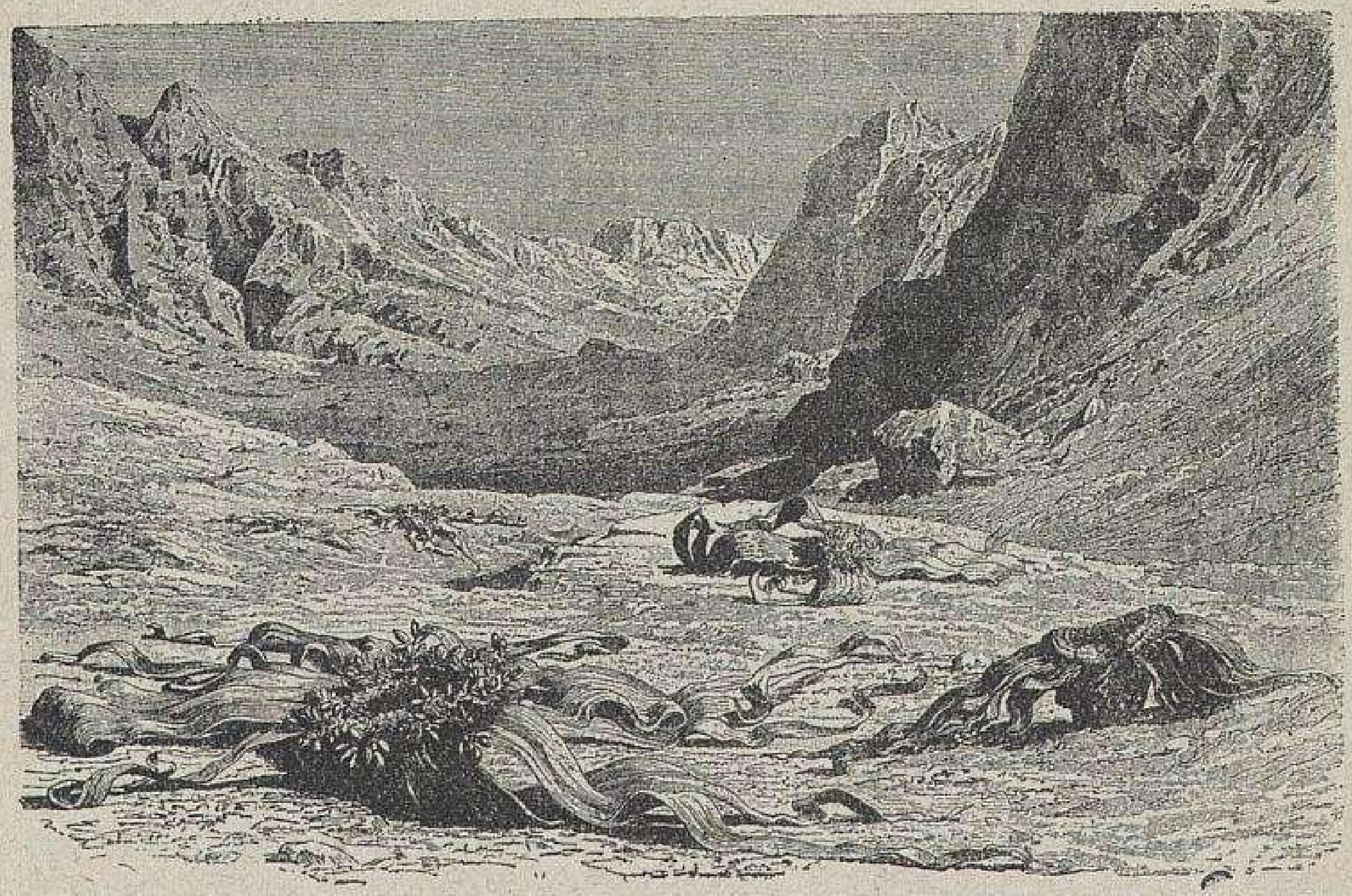

TYPE DE PAYSAGE DÉSERTIQUE, DANS LE SUD-OUEST AFRIGAIN ALLEMAND.

Le weltwitschia mirabilis est un conifère désertique, qu'on serait tenté d'abord de prendre pour un chou géant. Le tronc, épais, est enfoui dans les sables, et des feuilles coriacées, qui ne tombent jamais, s'étalent en rampant cur le sol à plus d'un mètre.

pas une végétation bien plantureuse (maquis, acacias épineux, et toute une végétation de plantes grasses, aloès, euphorbes, etc.). Certaines parties mieux exposées, plus mouillées, offrent des possibilités de vie pastorale et même de cultures; il s'y trouve de vrais arbres et des jardins.

4. Dans le Sud-0uest, contrée à pluies hiyernales, la végétation, si défectueux que soit le sol, est abondante et riche; grâce au soleil les plantes poussent d'elles-mêmes et ne réclament que peu de soin. Pas de forêts proprement dites, la sécheresse est trop prolongée, mais des maquis d'arbustes à feuilles toujours vertes, ainsi qu'en Algérie, de luxuriantes fou- 
gères, des bruyères, des plantes grasses (Euphorbes, Aloès...), des arbres au feuillage d'un vert sombre et bleuâtre, des plantes bulbeuses, etc. - Comme la température du Cap tient le milieu entre celle des régions tempérées et celle des régions tropicales, les céréales, les légumes, les fruits et la vigne d'Europe viennent aussi bien que les oranges, les citrons et les figues de Barbarie.

VIII. Vie animale. - Partout les animaux sauvages disparaissent et reculent devant les progrès de la civilisation. Les plus communs sont le léopard, la panthère et l'hyène. Mais l'éléphant qui, au xvir ${ }^{\mathrm{e}}$ siècle, à l'arrivée des Hollandais, abondait aux environs du Cap et qui a servi à dénommer plus d'une rivière, ne se rencontre plus que vers $20^{\circ}$ Lat., bien au Nord du tropique; de même, rhinocéros, hippopotames, crocodiles sont relégués aux embouchures de quelques rivières (Orange et lagunes de la côte orientale); le lion est rare; le buffle, le singe ont trouvé un refuge dans des réserves peu accessibles. Pour la même raison que les grands fauves, les troupeaux d'antilopes, de zèbres, la girafe, l'autruche sauvage ont émigré du Cap sur les Karrous, puis sur le Veld, finalement dans la brousse du Kalahari, qui demeure encore la terre promise des chasseurs. - Mais partout sont restés, véritable fléau, les serpents, quelques-uns comptent parmi les plus dangereux (serpent cracheur, scorpion, etc.), les termites et les rongeurs. La mouche tsétsé du moins ne monte pas sur les plateaux : la vallée moyenne du Limpopo est son domaine.

Les animaux domestiques prennent la place des animaux sauvages : le bouf aux cornes démesurément longues, le mouton et la chèvre dite du Cap; quant au cheval, il est d'importation européenne et s'acclimate difficilement. L'autruche a été domestiquée.

Rare dans les rivières, le poisson abonde en mer : thon, otarie, baleine, dans les eaux fraîches de l'Atlantique; huîtres, tortues et souvent requins, dans les eaux tièdes de l'océan Indien. On fait des pêches miraculeuses dans False bay.

IX. Vie humaine. - Les premiers habitants de l'Afrique 
Australe, les aborigènes, ont été les Hottentots-Bochimans; luur domaine s'étendait jadis jusqu'au Cap. Mais de l'Est et du Nord sont venus par terre les Bantous, qui les ont chassés devant eux. Puis du Sud, par mer, sont arrivés, à partir du $\mathrm{xvrr}^{\mathrm{e}}$ siècle, les immigrants Européens, qui, en s'avançant toujours plus loin, au cour du continent, les ont refoulés dans les steppes du centre et de l'Ouest, où ils sont condamnés à une existence misérable.

I. Les Hottentots-Bochimans forment deux groupes, ainsi que l'indique la juxtaposition des deux noms, mais deux groupes qui présentent de grandes analogies. Hottentot est un terme hollandais, synonyme de " borné, bête ": eux-mêmes s'appellent les Naman; Bochiman dérive d'un mot également hollandais, synonyme de " homme de la brousse »: eux-mêmes s'appellent les San.

Contraints de fuir vers l'Ouest, dans le sens de la plus grande sécheresse, les Hottentots vivent sur les steppes, en pasteurs nomades, et s'y construisent des kraal, faits de huttes hémisphériques, fort basses, auxquelles ils ne demandent qu'un abri momentané; dans un large espace, au milieu, on rassemble le troupeau la nuit.

Plus misérables encore, de petite taille, de teint jaune et la peau très ridée, les San, Bochimans ou Bushmen vivent sur des pays impropres aussi bien à l'élevage du bétail domestique qu'aux cultures : ce sont des chasseurs-nomades. Sans même se bâtir de huttes, ils s'abritent derrière des buissons épais, à grosses épines, ou bien dans des trous, à la manière des bêtes, vivant de fruits sauvages, de larves, d'oufs de fourmis, "le riz des Bochimans ", mais surtout donnant la chasse au gibier de la brousse (antilopes, girafes, autruches, etc.), armés de pierres aiguisées, d'arcs et de flèches empoisonnées. On comprend qu'une semblable existence ne comporte pas mème la plus simple des organisations sociales, celle de la famille; les individus errent isolés ou par petits groupes sans cohésion.

La langue des Hottentots-Bochimans est caractérisée par des sons particuliers, claquements ou clics, que les alphabets des missionnaires et les cartes traduisent au moyen de points d'exclamation, de croix et de barres.

II. Les Bantous de l'Afrique australe sont : à l'Est, les Cafres ou Zoulous, depuis le bassin de la Tugela jusqu'aux possessions portugaises; - au Centre, les Basouto, sur les plateaux d'oú descendent l'Orange et le Caledon; - les Betchouana, à l'Ouest du Vaal; - les Herero et les Ovampo dans l'Afrique allemande du Sud-Ouest, ete.

Seuls les Cafres-Zoulous ont gardé la pureté du type primitif, les Bantous de l'Ouest et du Centre s'étant plus ou moins mélangés aux Hottentots. La peau cuivrée plutot que noire, les eheveux laineux, la taille haute, ils forment une population vigoureuse, énergique, la plus intelligente de la race noire. C'est un peuple d'éleveurs, et le troupeau a déterminé la construction des huttes, disposées en enceinte circulaire formant le kraal, parc à bétail commun; il a même déterminé l'organisation sociale tout entière. Le bétail était l'enjeu de guerre. Aussi à la 
femme revenait le soin de cultiver le sol, à l'enfant celui de faire paître les grands boufs; l'homme était guerrier, et comme la famille n'eût.pas seule procuré la sécurité aux individus, les Cafres, soumis à une discipline rigide, se rangeaient sous des chefs héréditaires, véritables capitaines appelés Indounas. Ceux-ci furent des conquérants qui fondèrent des États militaires et jusque vers le Nyassa ils furent la terreur des peuples africains. Les Hollandais, plus tard les Anglais, rencontrèrent en eux des adversaires terribles, dont ils n'eurent pas raison du premier coup, et l'histoire a conservé le souvenir de sanglants désastres. Mais le temps est passé de ces sociétés guerrières, et la domination britannique parque les Cafres-Zoulous, race prolifique, dans des réserves, où ils ne connaissent plus maintenant d'autre occupation que l'élevage et la culture, sous la direction, mais aussi sous la responsabilité de leurs Indounas. Dans certaines régions, par exemple au Basoutoland, les mours se sont profondément modifiées sous l'action des missionnaires, au point que l'instruction reçue par les nègres et les négresses cafres peut soutenir la comparaison avec celle de nos écoliers d'Europe : ils obtiennent leur certificat d'études!

III. Boers (pron. Bours). - Ce fut la Compagnie hollandaise des Indes orientales qui fonda en 1652 , au pied du mont de la Table, lá ville du Cap, laquelle devait plus tard changer son nom de Kaapstadt pour celui de Gapetown. A partir de 1685 des émigrés français, calvinistes que la révocation de I'Édit de Nantes chassait du royaume, vinrent renforcer la colonie hollandaise; s'ils perdirent leur nationalité, si l'usage de leur langue fut interdit dès 1724 , si les mariages mixtes altérèrent le type primitif, du moins bien des noms sonnent encore français ou sont aisément reconnaissables sous la transformation qu'ils ont subie : Villiers, du Toit, Joubert, Botha, Crosnier devenu Cronje, etc.

Hollandais et Français engendrèrent là-bas un peuple nouveau, peuple de paysans et de fermiers : Boers ne veut pas dire autre chose. Race vigoureuse et robuste, taillée en colosse, portant la longue barbe en collier, trempée par la vie au grand air, par les luttes aussi bien contre les grands fauves que contre les guerriers cafres; excellents tireurs par suite et cavaliers infatigables; race réfléchie, flegmatique, éprise de liberté, profondément attachée à ses croyances, à toutes les vertus de la famille et très pure de moeurs. Leur vie fut celle des patriarches de l'Ancien Testament, la vie d'Abraham, d'Isaac et de Jacob, dont chaque jour l'ancêtre lit le récit devant la famille assemblée, dans un exemplaire du Livre sacré, très vieux et très usé : les Boers se disaient « le peuple élu de Dieu ", les noirs étant " les Chananéens ».

Gependant les Anglais fondaient en 1795 Port-Élisabeth sur la route des Indes; ils s'emparèrent du Cap et les traités de 1815 leur en reconnurent la possession. Mais telle était déjà l'antipathie des Boers pour l'Anglais, qu'ils refusèrent l'obéissance et qu'ils se mirent en quête d'une patrie nouvelle. 1836 est une date mémorable : elle inaugure une pérégrination de trois quarts de siècle, l'exode, en hollandais le trek.

Les Boers partirent, laissant là leurs terres et leurs fermes : sur le long chariot à quatre roues, sans ressorts, vrai wagon que piotège une toile tendue sur des arceaux de bois, ils chargèrent tout, femmes, enfants, meubles; à la chaîne de fer ils attelèrent les couples de boufs à grandes cornes; puis munis du long fouet en peau d'hippopotame, le fusil à la bretelle, sur la tête le large chapeau de feutre aux bords relevés, la pipe 
()

aux lèvres, en selle sur leurs petits chevaux, détraqués d'allure, mais adroits et vigoureux, ils s'ébranlèrent et disparurent. Ils allaient par les hauts plateaux stériles, par la brousse, par les sables, par les roches, et cette course errante les mena enfin, dans un pays enchanteur, sorte de Terre Promise : le Natal. Là ils fondèrent une ville qui des noms accolés de deux de leurs chefs, Pieter Rief et Gevrit Maritz s'appela Pietermaritzburg.

A peine avaient-ils triomphé des redoutables guerriers cafres, que les Anglais, toujours sur leurs pas, les atteignirent. Ils furent vaincus;

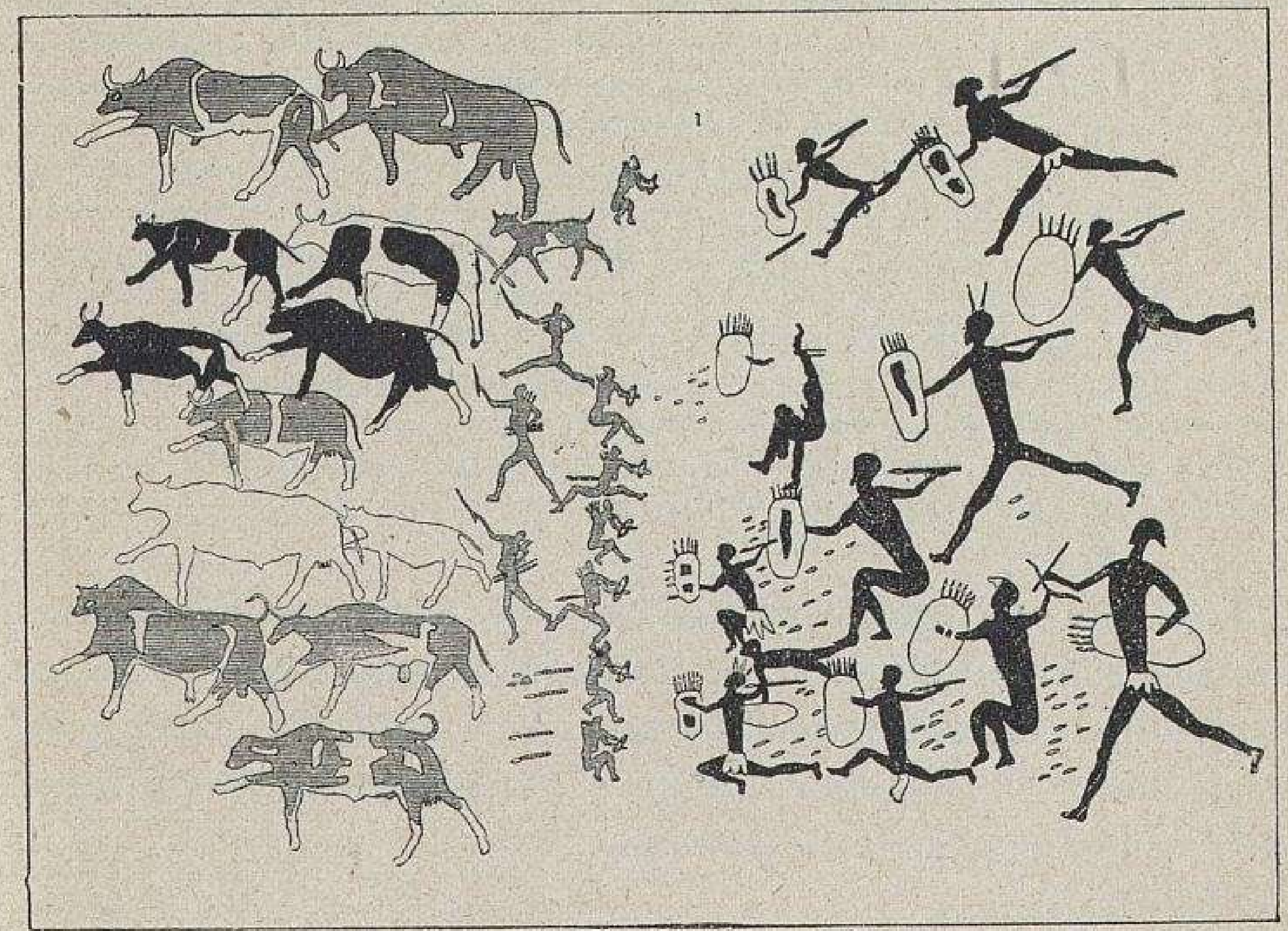

PEINTURE PRIMITIVE, SUR LES PAROIS D'UNE CAVERNE, PRĖS HERMON (COLONIE DU CAP).

La scène représente un rapt de bestiaux : elle peut donner une idée de l'importance du troupeau, en tant que centre et créateur de toute la vie sociale. - A droite les Cafres, grands, peints en noir, s'élancent à la poursuite des ravisseurs : ils s'abritent derrière des boucliers et brandissent leur sagaie. - Au centre, les Bochimans, tout petits, de couleur jaune, opposent aux assaillants une ligno de tirailleurs à genoux : ils sont armés de l'arc et du carquois. - Derrière eux, d'autres Bochimans, moins nombreux chassent à coups de trique le bétail volé qui détale, grands boufs à bosse ou jeunes veaux, do pelage varié.

tandis qu'une fraction demeurait au Natal, des bandes organisèrent un nouveau trek, et l'exode recommença. Les uns s'arrêtèrent sur les plateaux au Nord de l'Orange et construisirent leurs fermes, basses, au plancher de terre battue, près des ruisseaux, près des sources; les autres passèrent le Vaal : et ainsi naquirent deux Républiques. Mais toujours il fallait gagner le Nord et se dérober à la poursuite de l'Anglais qui ne perdait pas le contact. Tournés par l'Est et coupés de la mer, tournés par l'Ouest et coupés des établissements allemands, ils trouvèrent un jour la route barrée au Nord, vers le Matabéléland. Ils étaient cernés. La terre qu'ils 
occupaient en fermiers était riche en diamants et en or; e'en fut assez pour les perdre. Après bien des luttes et bien des vicissitudes, après une première annexion et un nouveau traité d'indépendance, la guerre suprême éclata. D'octobre 1899 à mai 1902, l'Europe impassible assista à cette lutte où l'on vit un petit peuple, un peuple de héros, lutter contre toutes les forces de l'empire britannique et lui infliger parfois des revers aussi désastreux que mortifiants. Le nombre eut raison du droit. - Le conflit avait mis aux prises « deux manières de vivre, deux états sociaux, deux civilisations : les Boers représentent une population patriarcale, pastorale, agricole, très conservatrice de ses traditions; les Anglais, l'élément caractéristique de la civilisation moderne, industrielle, commerçante, avec ses qualités et ses défauts, son activité fébrile et son esprit aventurier, son génie d'initiative et son manque de scrupule ».

L'Anglais en effet n'est pas un colon, un fermier, un rural : il est commerçant, industriel, mineur, banquier, d'un mot business man. Dans l'Afrique australe, les immigrants anglais sont une minorité, en face des Afrikander, c'est-à-dire des descendants des Boers, en face des noirs aussi qui par leur nombre ont su garder leur place dans une société policée. Il n'est pas facile d'établir des statistiques, et d'ailleurs elles varient suivant les tendances de ceux qui les font; on peut cependant évaluer le nombre des Anglais au dixième de la population totale et au tiers de la population de couleur blanche.

X. Gouvernement et villes. - L'Afrique australe serait anglaise sans exception si, en 1884, l'Allemagne n'avait planté son pavillon dans le Damaland et le Namaland; Bismarck préludait alors à la fondation d'un empire colonial germanique, par le Sud-Ouest africain allemand.

\section{AFRIQUE AUSTRALE ANGLAISE}

Les immenses possessions anglaises comprennent :

$1^{\circ} L^{\prime}$ Union Sud-Africaine qui groupe en un nouvel État la province du Cap de Bonne-Espérance, la province de Natal, la province du Transvaal et la province de l'État libre d'Orange; - $2^{\circ}$ la colonie du Basoutoland et le protectorat du Betchouanaland; - $3^{\circ}$ Ascension et Sainte-Hélène, qui sont deux stations de l'amirauté.

I. Union Sud-Africaine. - Elle a été inaugurée le 31 mai 1910. C'est un nouvel État, doté d'une Constitution, et groupant quatre colonies sous le nom de provinces.

Un gouverneur général nommé par le roi exerce le pouvoir exécutif avec l'aide d'un conseil exécutif, dont les membres sont choisis et convoqués par lui. - Le pouvoir législatif est exercé par un Parlement qui comprend un Sénat de 40 membres et une Assemblée de 121 membres. 
Pretoria est la capitale et le siège du gouvernement exécutif : Capetoswn, le siège de la législature.

Chaque province possède un administrateur, nommé par le Gouverneur général pour cinq ans, et un Conseil provincial, élu pour quatre ans; à chaque conseil est attac ¿é un comité exécutif de 4 membres.

Les Afrikanders et les Anglais ont les mèmes droits; le hollandais et l'anglais sont tous deux langues officielles. G'est aux dépens des noirs que les blanes se sont mis d'accord : exclus de la vie politique, les noirs sont si bien sacrifiés qu'ils constituent le gros problème de l'avenir.

Enfin les territoires de l'Afrique australe anglaise pourront èlre reçus dans l'Union et le Gouvernement des territoires indigènes pourra être transféré au gouvernement de l'Union.

\section{$1^{\circ}$ Province du Cap. -} Poste de relâche sur la route des Indes aux mains des Portugais, station de commerce aux mains des Hollandais, le Cap est devenu avec les Anglais le centre d'une grande

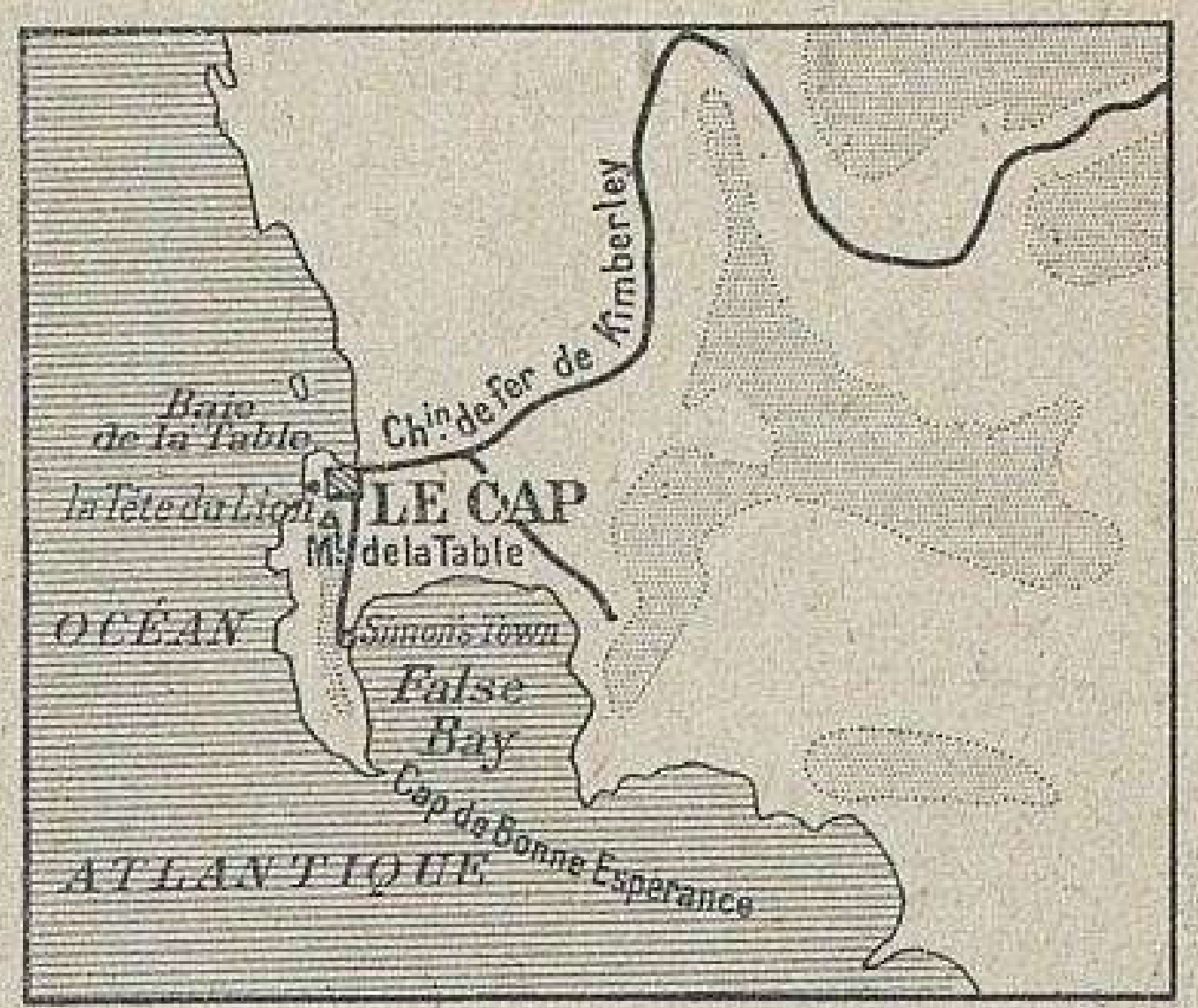
colonie de peuplement, dont les progrès, d'abord lents, se sont précipités lors de la découverte des diamants de Kimberley (1870) et de l'or au Transvaal (1886).

La capitale est Capetown ou le Cap (77.000 h.; avec la banlieue 83.700$)$; les villes principales, Port-Elisabeth (32.900 h.), Grahamstown (13.900 h.), East London (24.000 h.). Les autres localités ne méritent pas le nom de villes : ce sont de simples bourgades, ou bien des Kraal de Hottentots et de Cafres, ou encore des fermes isolées et des stations de missionnaires.

Du paquebot le panorama du Cap est merveilleux; la ville se blottit au fond de la baie de la Table, sous un ciel limpide, entre deux montagnes, le mont de la Table, carré, aplati et chauve, voilé souvent le matin de vapeurs blanches, et la Tète du Lion, à la végétation étrange, toute d'argent, trone, branches et feuilles en fer de iance (le Leucodendron argenteum). Mais la ville n'est pas belle : rues régulières, mal empierrées, boueuses ou poussiéreuses, maisons basses, à toits plats; seules font exception les vieilles demeures hollandaises précédéés de leur perron. C'est la population qui donne à la ville son pittoresque; elle est étrangement bigarrée : Hollandais au teint blond, Malais cuivrés, Cafres du plus beau noir, Hottentots à la peau jaune. Les Anglais ne se sentent pas ici chez eux; négociants et fonctionnaires habitent les villas de la banlieue. - De Capetown, la civilisation de l'Europe rayonne sur toute l'Afrique australe : là sont installés bibliothèque, musée, observatoire, 
jardin botanique où les arbres des tropiques poussent à côté des arbres de Seandinavie. - Le port est le premier de la province pour la valeur des marchandises : diamant et or. Et de là part la grande voie ferrée que l'ambition impérialiste des Anglais voit déjà dans son rêve achevée jusqu'au Caire. - L'Arsenal est derrière le cap de Bonne-Espérance, à Simon's Town. Port-Ëlisabeth, la ville anglaise par excellence, toujours prompte à manifester son loyalisme, possède un port plus animé que celui de Capetown, tête de plusieurs voies ferrées. Grahamstown est la capitale de l'Est, la résidence des autorilés administratives, judiciaires et religieuses. Il lui a fallu son port à elle, Port-Alfred. East London est le troisième port de la province.

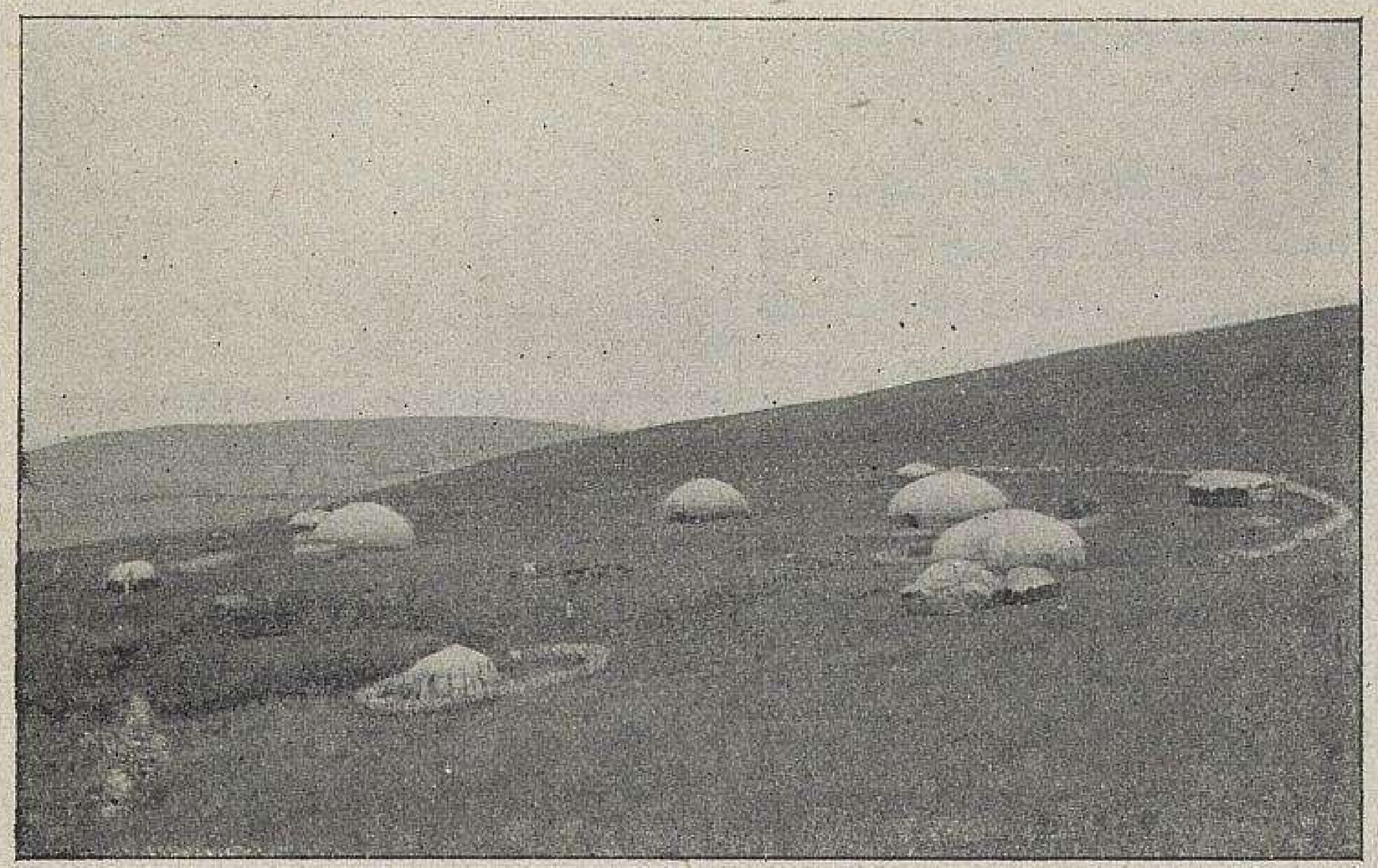

UN KRAAL AU PAYS DES CAFRES.

(Photographie Ferneyhough, communiquée par la Société de Géographie de Paris.) Les hultes sont groupées en cercle et protégées par une enceinte. Au centre le troupeau est parqué, à l'abri des surprises et des rapts.

De la province du Cap dépendent plusieurs territoires indigènes : $-1^{0}$ vers l'océan Indien, au Nord du Kei river, le Transkei, le Tembouland, le Pondoland et le Griqualand oriental : aucun ne contient à proprement parler de villes; $2^{\circ}$ au centre, le Griqualand occidental, que les treks hollandais avaient coupé du Griqualand oriental; le diamant a fait sa célébrité : c'est là qu'est Kimberley (34.300 h.), là encore Beaconsfield (10.500 h.); puis le Betchouanaland britannique, capitale Vribourg " ville libre », petite localité de fondation boer. Mafeking est une autre station de chemin de fer. Les cités nègres se déplacent suivant le caprice des chefs; $-3^{\circ}$ à 
l'Ouest, le petit Namalaind, chef-lieu Springbok, dans une contrée aride, mais riche en minerai de cuivre; Ookiep est le lieu d'extraction et Port Nolloth le port d'expédition; enfin Walfish Bay, une enclave de 1.114 kilomètres carrés dans le Sud-Ouest africain allemand; la diplomatie de l'Angleterre a su la sauver, ainsi que les îles à guano du voisinage, contre les ambitions de l'Allemagne; mais, malgré son port franc, la

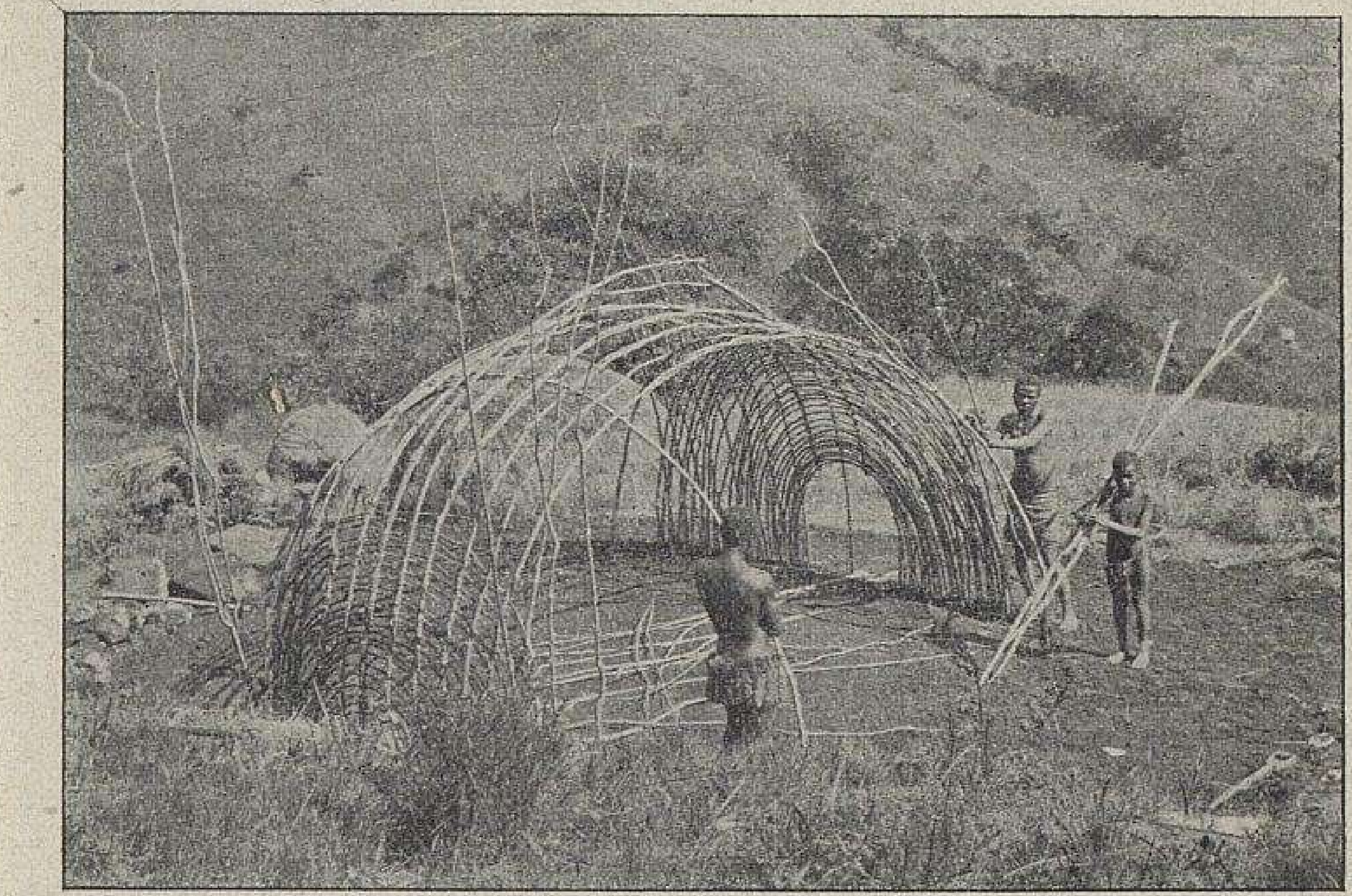

CONSTRUCTION D UNE HUTTE AU PAYS DES GAFRES.

(Photographie Ferneyhough, communiquée par la Société de Géographie de Paris).

La hutte est faite de branches flexibles et entrelacées, plantées en terre. L'architecte indigène a déjà ménagé dans la charpente la pcrte d'entrée.

localité ne semble pas appelée à un avenir brillant; la sécheresse est trop forte, l'eau douce fait totalement défaut. En 1904 on comptait 997 habitants, dont 144 Blancs.

$2^{\circ}$ La province de Natal, à laquelle a été incorporé le Zoulouland (1897), est grande comme onze ou douze départements français. Elle a pour ville principale Port-Natal (le nom fut donné à la baie par Vasco de Gama, parce qu'il y débarqua le jour de Noël 1497) ou Durban, en l'honneur d'un gouverneur du Cap (79.000 h.); ce sont en réalité deux villes eôte à côte, l'une de marins, débouché de la province d'Orange, et l'autre de 
bourgeois. Moins peuplée, Pietermaritzbourg (35.000 h.) a titre de eapitale; c'est une ville blanche en pays noir.

Dans le bassin de la Tugela, Ladysmith est célèbre par le siège qu'elle soutint contre les Boers; Nesveastle a des mines de houille. - Dans le Zoulouland la population blanche est en nombre insignifiant : des soldats occupent les fortins; des missionnaires, les temples et les écoles: Eshowe, oì réside le commissaire britannique, est un village.

3. La province du Transvaal est l'ancienne république boer. Les Boers, race de fermiers paysans, vivaient dispersés sur le Veld; leurs villes étaient seulement des marchés agricoles et des, centres religieux. C'est l'afflux des étrangers (Uitlanders) de toute nationalité, attirés par les mines d'or, qui donna naissance à Johannesbourg; avant la guerre de 1899, elle avait déjà plus d'habitants que le Cap. Mais. Pretoria, du nom du commandant boer Pretorius, était restée la capitale du Transvaal, et est depuis 1910 le siège du gouvernement exécutif de l'Union Sud-Africaine; elle n'a que 36.700 habitants, alors que Johannesbourg en compte 158.500.

Johannesbourg n'a été fondée qu'en 1886 après la découverte des mines d'òr. Elle a vite remplacé ses maisons de tôle galvanisée, que recouvraient, en guise d'ardoises, de vieilles boites à sardines, par des maisons de pierres et de brique-. Ville d'affaires, d'une activité fébrile, elle a eu un développement rapide et comptait, en 1904, 158.000 habitants. Les environs dénudés ont été retournés par les chercheurs d'or, et partout s'aperçoivent les tas de résidus de broyage, extraits du Witwatersrand. Au centre, la place du marché a gardé sa physionomie boer : elle est assez spacieuse pour contenir les grands attelages de boufs. Au-dessus des rues est suspendu tout un réseau de fils télégraphiques, téléphoniques, de trolleys électriques, etc.; partout de grands magasins, des clubs, des banques, des sociétés financières; une population très mêlée venue de tous les points du monde, population flottante et temporaire, s'y agite et cherche fortune.

Tout autre est l'aspect de Pretoria (36.700 h.); c'est un parc; les villas, les cottages sont disséminés de loin en loin, sur un espace immense, au milieu de magnifiques jardins. Mais voici que de nombreuses mines d'étain, de cuivre et de diamant ont été découvertes dans les environs.

$4^{\circ}$ La province de $1^{\prime}$ État libre d'Orange est la seconde des républiques boers annexées brutalement en 1902. La capitale Bloemfontein $(34.000$ h.) porte le nom du premier Boer, Bloem, qui s'installa près de la source avec sa famille et ses troupeaux: 
II. - Le Basoutoland, grand comme quatre départements français, est un territoire placé depuis 1884 . sous l'autorité directe de la couronne et administré par un Commissaire qui réside à Maserou, simple bourg de 1.300 habitants. C'est un pays d'agriculture et d'élevage. - Le Betchouanaland (551.670 kmq., environ 200.000 h.), tout à fait au Nord, a été organisé en protectorat (1885) sous la direction d'un Commissaire britannique; la contrée est immense, mais pauvre, habitée par des Nègres paisibles, dont les chefs paient tribut. Les centres de population se sont fixés à la base orientale du Kalahari, aux points d'eau, et c'est là que court la voie ferrée : Palapyé ou Palatchoué ou Palachwe (25.000 h.), Kanya, Molopololé, Mangwato ou Chochong. Kolobeng, station de mission fondée par Livingstone, autour de laquelle un village s'était formé, n'existe plus.

III. Ascension et Sainte-Hélène. - Ascension, île volcanique $\left(850 \mathrm{~m}\right.$.) par $8^{\circ}$ Lat. S., à 1.560 kilomètres de la côte de Guinée, est un hôpital où les soldats anglais viennent refaire leur santé éprouvée par le séjour sous les tropiques, une station récemment fortifiée pour la flotte, enfin un poste de câbles sous-marins. L'île mesure 90 kilomètres carrés et compte 400 habitants.

Sainte-Hélène, plus grande (121 kmq.), mais volcanique également, est d'une aridité effroyable; les chèvres ont fait disparaître les forêts. Le chef-lieu est Jamestown, sur la côte. A l'intérieur, la maisonnette de Longwood fut le lieu d'internement de Napoléon I ${ }^{\mathrm{er}}$, de 1815 à 1821. Sainte-Hélène a beaucoup perdu de son importance, depuis l'ouverture du canal de Suez et depuis la substitution de la marine à vapeur à la marine à voiles. On ne comptait plus en 1909 que 3.500 habitants, la garnison ayant été tout entière retirée. Le grand câble du Cap à Bathurst par Ascension y atterrit et l'amirauté y entretient un dépôt de charbon.

A l'Angleterre encore, un groupe d'îles à mi-chemin entre le Cap et l'Amérique du Sud, Tristan da Cunha. 


\section{II. - AFRIQUE ALLEMANDE DU SUD-OUEST}

Du Counéné jusqu'à l'Orange, l'Afrique allemande du SudOuest se développe sur 1.500 kilomètres de côtes et comprend le Damaland et le Namaland. Les frontières ne sont encore tracées que suivant des lignes géométriques et. s'avancent en pointe sur le Zambèze. Ces territoires immenses ( 830.000 kmq.), plus grands que l'Allemagne, sont pauvres, à population rare; les déserts et les steppes y dominent. Pas une seule grande ville ni un seul grand port. La colonisation, confiée à de grandes compagnies, est à l'état d'embryon. Le chef-lieu est dans l'intérieur $(1.660 \mathrm{~m}$. d'alt.) Windhoek « le coin du vent ». Sur la côte, Angra Pequena et Tsoakhoabmund (Swakopmund), où s'installe un port.

XI. Mise en valeur. Agriculture. - L'Afrique australe reproduit plus d'un trait du Magreb méditerranéen; elle se prête en général au peuplement de colons européens, à la vie agricole et pastorale. L'eau est rare, et c'est par une irrigation raisonnée des terres, barrages, réservoirs, adduction de sources, travaux hydrauliques de tout genre, que l'on doit combattre la sécheresse. Bien des terres ne sont stériles ou médiocrement fécondes que faute d'humidité; cela est vrai pour le Veld, pour le Sud-Ouest allemand, aussi bien que pour les Karrous.

On comprend que seules les pentes orientales du Drakensberg, bien arrosées, portent des forêts épaisses, qui pourraient fournir de beaux bois à l'exportation.

Les environs du Cap, l'Orange, le Transvaal, etc., produisent des céréales, mais les récoltes ne suffisent pas à la consommation; aussi importe-t-on, d'Australie surtout, des farines et des produits alimentaires. Ce n'est pas le froment que cultivent les Cafres du Natal et du Basoutoland, mais le sorgho et le mais.

Parmi les arbres fruitiers, la vigne mérite une mention spéciale : améliorée, sinon importée par les émigrés français, elle dınne au Cap des crus estimés (vins de Constance), mais elle n'est pas exempte de maladies, entre autres le phylloxera.

Le tabac vient sur les plateaux. Au Natal, l'arbre à thé et la 
canne à sucre rencontrent des conditions favorables, le premier sur les coteaux, la seconde sur les terres basses.

Élevage. - La nature impose à l'homme la vie pastorale. Toujours en raison de la sécheresse, l'élevage du mouton est très répandu; il fournit la viande de boucherie, une laine plus appréciée encore. On élève aussi la chèore d'Angora, à longs poils, mais dans des proportions moindres. Bien que les pares à autruche soient moins en faveur et que la trop grande production ait amené une dépréciation de la plume, c'est le Gap qui conserve toujours le monopole de ce commerce spécial. - Les bêtes à cornes trouvent les plus belles pâtures au Natal; ailleurs, sur les plateaux plus secs, le bétail se plie à une vie nomade et aux habitudes de transhumance. - Les chevaux sont relativement peu nombreux; ceux qui échappent à la maladie sont dits " salés «, et acquièrent une valeur exceptionnelle, non que la race soit belle; mais elle est bien en muscles, vigoureuse et robuste; on l'utilise pour la selle, rarement pour l'attelage. Que de fois lors de la récente guerre, les Anglais ont dû remonter leur cavalerie décimée par le climat!

Mines. - Ge sont les mines qui ont transformé la physionomie de l'Afrique australe; la découverte en est récente. L'or fut aperçu en 1864 par Karl Mauch, mais l'exploitation des filons ne commença qu'en 1884; le premier diamant fut trouvé en 1867 aux environs de Kimberley. Mineurs et prospecteurs accoururent de tous les points de la terre : ce fut le rush.

Le diamant est un carbone pur, que l'action chimique de la vapeur a cristallisé: on le trouve dans les anciens cratères, dans les cheminées volcaniques, dans la terre bleue. La production annuelle dépasse 100 millions de francs, et depuis l'origine il en a été extrait pour plus de 2 milliards. L'exploitation se fit d'abørd à ciel ouvert : le sol fut divisé en propriétés individuelles, claims de $100 \mathrm{mq}$. environ, que séparait un chemin étroit; à mesure qu'on creusait les claims, le chemin faisait muraille et la mine ressembla aux alvéoles d'un gâtean de miel; audessus étaient tendus les fils de fer, les courroies sans fin, et les baquets, les seaux passaient, chargés de terre diamantifère. Mais il arriva que les chemins-cloisons finirent par s'ébouler et par engloutir les travailleurs; on les abattit et la mine apparut alors comme une excavation énorme, raite de main d'homme, un trou de $150 \mathrm{~m}$. où la plus grande de nos eathédrales aurait disparu avec ses tours. Dans bien des endroits il fallut recourir à l'exploitation souterraine et creuser des galeries. - Aujourd'hui l'extraction est presque tout entière accaparée par la puissanie Compagnie de Beers. Les terres sont étalées sur les champs, séchées, pulvérisées,

G. Lespagnot et M. Fallex, - Afrique. 
puis on les lave à grande eau, on les porte à l'usine à vapeur, et le triage du diamant se fait en dernier lieu, à la main. Afin de prévenir les vols, on a imaginé un système de travail peu ordinaire; une fois son engagement signé avec la Compagnie, engagement de trois mois au moins, le mineur nègre ne sort plus du Compound: on appelle ainsi l'enceinte où il est séquestré. - Les centres diamantifëres autres que Kimberley sont Jaggersfontein, dans la province de l'Orange, la Mine Premier, près de Pretoria, au Transvaal, et, depuis 1908, la côte du Sud-Ouest africain allemand.

L'or se rencontre dans beaucoup d'endroits et nombrenx sont les gold fields inscrits sur les cartes. Mais c'est dans l'ancienne République Sudafricaine, au Transvaal - et cela causa sa perte - que les gisements sont le plus riches : le Witwatersrand, près de Johannesbourg, est le centre de l'extraction. Le précieux métal est engagé dans des conglomérats, que de puissantes usines à outillage perfectionné concassent et broient, au možen de gros pilons, dans des mortiers; puis des lavages chimiques dégagent l'or : les opérations sont nombreuses; on utilise le cyanure de potassium et l'eau de chlore. - Le Transvaal tient le premier rang parmi toutes les régions aurifères du globe. Après un arrêt passager, dủ à la guerre, la production reprend sa marche ascendante et l'année 1906 accuse le chiffre formidable de 620 millions de francs (4 milliards 612 millions de 1894 à juin 1907).

La présence de la houille, près des mines d'or, n'a pas peu contribué à faciliter l'exploitation de l'or et du diamant. Le cuivre abonde au Namaland (Ookiep et Windhouk).

Commerce. - Le Sud-Ouest africain allemand est entravé dans son développement commercial par une terrible insurreetion des Herrero. Le port de Swakopmund, relié déjà par voie ferrée à Windhouk, le principal centre agricole, et bientôt aù 'centre miner d'Otavi, exporte du' bétail et des produits animaux, des plumes d'autruche, du guano, des minerais et des diamants.

Les ressources fondamentales de l'A frique australe anglaise sont fournies par les mines : elle est un Eldorado qui extrait chaque année de son sol 225 millions de diamants et 700 millions d'or. Viennent ensuite, mais loin en arrière, les produits de l'agriculture et de l'élevağe : les laines, les poils de chèvre et les plumes d'autruche du Cap; quelques vins encore et des fruits du Cap; le thé et le sucre du Natal. Ce qui caractérise ces immenses possessions britanniques c'est leur impossibilité de se suffire à elles-mêmes; elles doivent tout faire venir du dehors, les denrées, le vêtement, les matériaux même de l'habi. tation, la quincaillerie, etc., et ainsi s'explique le chiffre énorme des importations.

Le principal foyer de consommation est le Transvaal, c'est-à- 


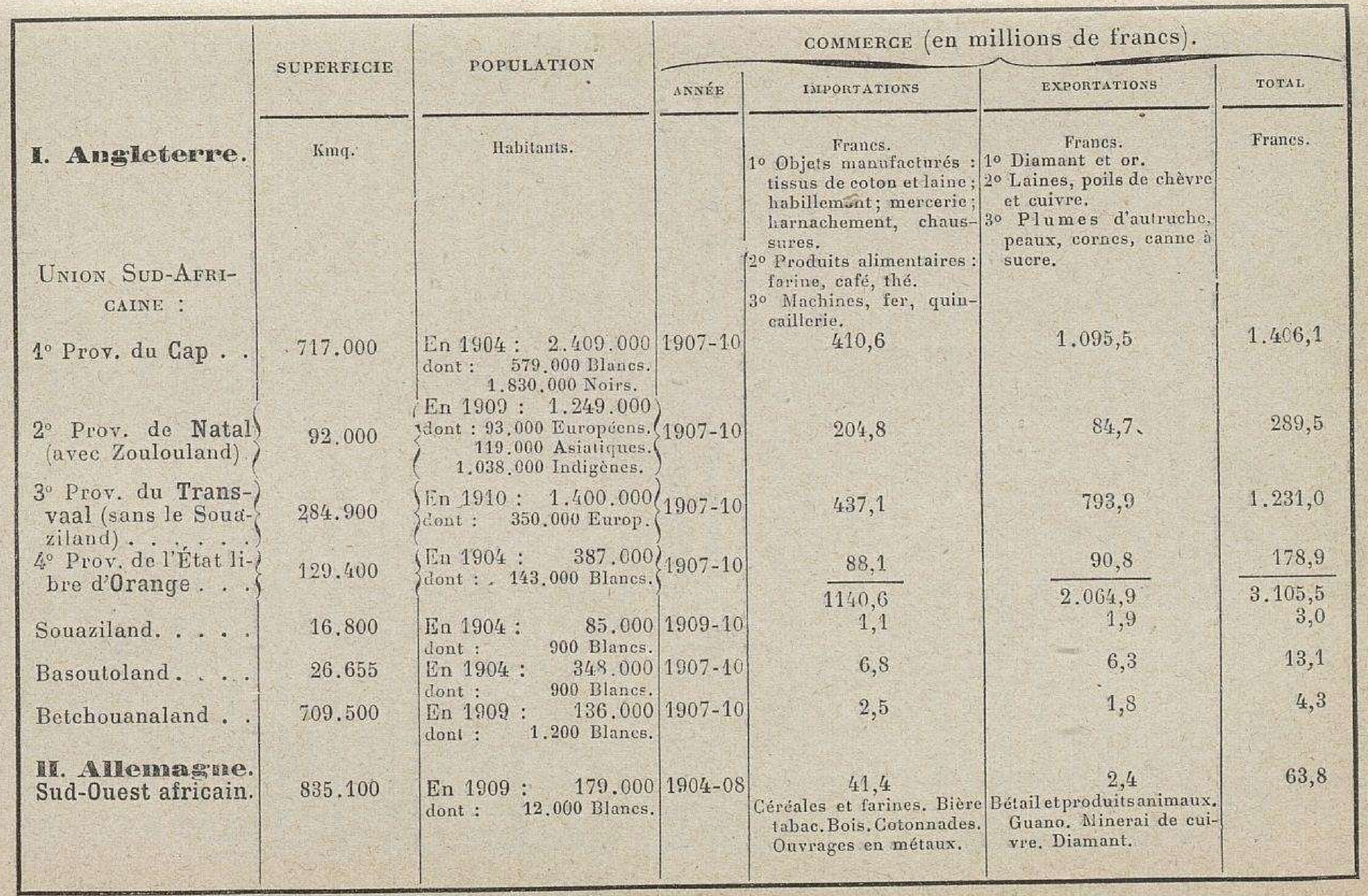


dire Pretoria, Johannesbourg et le Rand; là vit une étrange population, toute cosmopolite, Africanders, Anglais, Américains, Australiens, Italiens, Allemands, Juifs, Russes, Français, Hollandais, Suisses, Arméniens même et Syriens, qui tous travaillent avec énergie pour faire fortune et pour repartir, qui gagnent beaucoup, mais qui dépensent aussi beaucoup, par goût du confort et du luxe.

Le Cap, que l'ouverture du canal de Suez avait fait naturellement déserter, est devenu un des plus grands ports du monde; mais sa position excentrique lui fait perdre de jour en jour sa prééminence, au profit des ports qui s'échelonnent depuis PortÉlisabeth jusqu'à Lourenço Marquès, au profit surtout de Durban qui paraît être le port de l'avenir. Le commerce, très fort pour une population faible, se fait surtout avec l'Angleterre et avec les colonies anglaises.

Tous les ports sont le point de départ des lignes ferrées; car les rivières ne fournissent pas de voies de communication. Il n'existe de routes carrossables qu'au Cap et au Natal; ailleurs on utilise le lourd wagon boer, attelé de dix ou douze paires de boufs, moyen de transport primitif et fort lent.

Chemins de fer: Deux grandes lignes courent à peu près parallèlement du Sud au Nord. La première va du Cap, par Kimberley (1.040 km.), Mafeking (1.400 km.), Boulawayo et Salisbury, à Beira, au Portugal; c'est l'amorce du grand Transafricain que les Anglais rêvent de dérouler jus. qu'au Caire : de Boulawayo, la ligne traverse à l'Ouest les charbonnages de Wankie, atteint le Zambèze $(453 \mathrm{~km}$.), immédiatement au-dessous des chutes Victoria, et de là Kalomo, Broken Hill, d'où elle a été en 1910 prolongée jusqu'à la frontière du Congo belge : elle se raccorde avec le chemin de fer du Katanga, en attendant celui du Benguella. - La seconde part de Port-Élisabeth sur Bloemfontein, Johannesbourg et Pretoria; elle est rejointe par les embranchements de Port-Alfred, d'East London et de Durban; enfin de Pretoria elle descend à Lourenço Marquès, au Portugal. - Entre ces deux grandes artères, il n'y a encore que deux traits d'union, de De Aar à Naauw Poort et de Johannesbourg à Warrenton. - Afin de couvrir la distance entre Pretoria et Boulawayo. deux tronçons tendent l'un vers l'autre, celui de Pietersburg au Transvaal et celui de Gswanda, à $453 \mathrm{~km}$. de Boulawayo dans la Rhodesia du Sud. - Enfin une ligne locale unit les mines de Springbok et d'Ookicp à Port Nolloth sur l'océan Atlantique.

La création du nouvel État, l'Union Sud-Africaine, ouvre une ère neuvelle pour toute l'Afrique australe anglaise. 


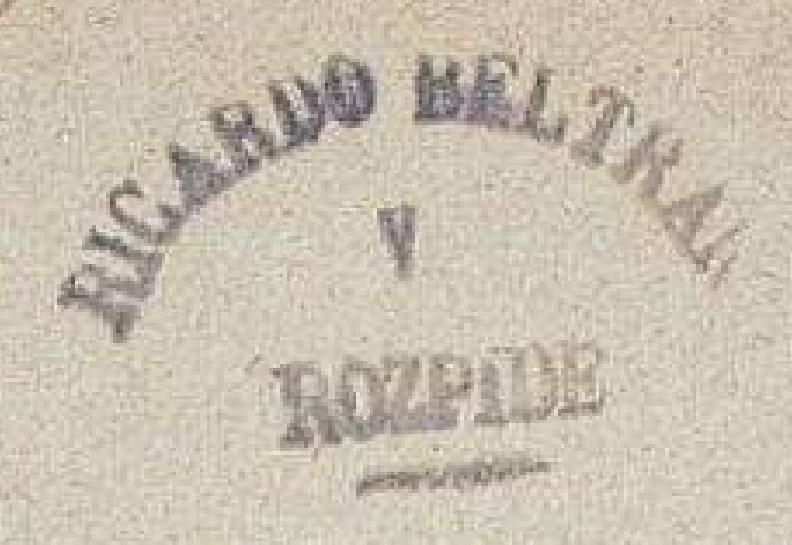

\title{
CHAPITRE XIV
}

\author{
AFRIQUE ORIENTALE OU PLATEAU \\ DES GRANDS LACS
}

Sis SOMMAIRE

I. Limites. - L'Afrique orientale s'ètend du lac Tanganyika à l'océan Indien. Au Nord elle bute contre l'Ethiopie, au Sud elle s'ouvre sur le Zambèze.

II. Superficie. - Environ 2 millions et demi de $\mathbf{k m q}$.

III. Orogénie et relief. - L'Afrique orientale est un haut plateau soulevé à une altitude moyenne de 1.200 metres et rompu du Sud au Nord par deux grandes fractures, volcaniques et lacustres.

Le socle primitif a èté redressé jusqu'à 5.069 mètres au mont Rouvenzori ou Rounsoro.

La cassure orientale n'est qu'un fragment de la vallée effondrèe qui se déroule sur une bande de plus de 5.000 kilomètres, du lac Nyassa à la mer Morte, par la mer Rouge. Sur ses bords se dressent des volcans récemment éteints: le Kilimandjaro, la plus haute cime de tout le continent (5.893 m.), le Kenia (5.200 m.).

La cassure occidentale est remplie par des lacs allongés, profonds, aux bords escarpés (le Tanganyika, l'Albert-Edouard etl'Albert); ou hérissée de volcans actifs, comme le Kirounga (4.000 m.).

IV. Climat. - L'Afrique orientale est située sous l'équateur; mais, en raison de sa forte altitude, elle ne présente pas partout les caractères du climat équatorial.

1. La règion littorale a une température humide, chaude, constante et malsaine. Nulle part sur le globe, le phénomène des moussous n'atteint la même intensité que sur l'océan Indien.

$2^{\circ}$ La région des plateaux entre les grands lacs et la côte a un climat plus sec, sujet par suite à des écarts plus sensibles, aussi capricieux que le relief.

$3^{\circ}$ La région voisine des lacs Albert et Victoria ménage la transition entre les hauts plateaux et le bassin équatorial du Congo.

V. Hydrographie. - La vie des fleuves est étroitement liée aux grands réservoirs lacustres; ils s'écoulent vers les trois mers. La fracture orientale aligne une série de bassins fermés. 
1. Le Nil, versant de la Méditerranee, a ux sources : à l'Est le lac Victoria, aussi grand que le bassin de la Seine; à l'ouest le lac Albert.

$2^{\circ}$ Le Congo, versant de l'Atlantique, recueille le lac Tanganyika.

$3^{\circ}$ A l'océan Indien appartiennent le lac $N y$ yssa et les bassins côtiers du Rovouma, du Roufidji.

4. La fracture orientale porte, parmi les lacs sans écoulement, le Rodolphe.

VI. Côtes. - Elles ne sont que le dernier palier des plateaux qui plongent sous la mer à de grandes profondeurs. Lourdement taillées, peu découpées et basses, elles sont vaseuses aux embouchures des rivières et garnies de paletuviers; ailleurs sablonneuses, avec bouquets de cocotiers, bordëes de lagunes et de franges de coraux.

Les iles Pemba, Zanzibar et Mafia sont le résultat d'un soulèvement.

Peu de bons ports; de simples mouillages.

VII. Vie végétale. - En raison de son relief et de son climat, l'Afrique orientale resume toutes les formes végétales du continent: forêt équatoriale, savane (parc et steppe), désert.

VIII. Vie animale. - Elle est de même le rendez-vous de presque toutes les espèces animales de l'Afrique : chacune y trouve le domaine qui convient à ses mours.

IX. Vie humaine. - Elle est enfin le carrefour où se sont heurtèes les principales races de l'Afrique.

Les non nègres sont les Hamites; venus du Nord-Est, ils sont pasteurs, chasseurs et pillards invétèrès.

Les Nègres sont les Bantous, venus du Sud, agriculteurs sédentaires, et les Nilotiques, venus du Nord-Ouest, agriculteurs et éleveurs.

Par mer arrivèrent les Arabes, portès par les moussons.

Au contact de ces influences diverses, des États s'étaient fondés. à demi civilisés, dans l'ouganda et à Zanzibar.

X. Gouvernement et villes. - L'Angleterre et l'Allemagne se sont partagé l'Afrique orientale en 1890.

I'Afrique orientale allemande, la plus grande des colonies de l'Allemagne, a son chef-lieu à Dar ès Salam.

L'Afrique orientale anglaise comprend: $1^{\circ}$ le suitanat protégé de Zanzibar ; capitale Zanzibar; $2^{\circ}$ le protectorat de l'Afrique orientale, chef-lieu IVairobi, ville principale $M o m b a z: 3^{\circ}$ le protectorat de l'ouganda, chef-lieu Entebbe, au Nord-Ouest du lac Victoria.

XI. Hise en valeur. - Il est impossible de se prononcer sur l'avenir de ces colonies naissantes.

L'Allemagne, qui a la moins bonne part, sutte difficilement contre la concurrence anglaise.

L'Angleterre s'est assurè un double avantage en se rendant maîtresse des sources du Nil, qui mettent l'Égypte à son entiere discrétion, et en faisant de l'Afrique orientale, qui est une dépendance économique de l'Inde, une terre britannique.

Les Hindous (Banians) fournissent la main-d'œuvre, font le commerce et la banque.

Un chemin de fer de plus de 900 kilomètres unit Mombaz á PortFlorence, sur le lac victoria. 


\section{AFRIQUE ORIENTALE \\ Platean des Grands Lacs. \\ Croquis physique}

Bande littorale de $0 \dot{a} 200 \mathrm{~m}$.

Plateaux au-dessus de $200 \mathrm{~m}$

- Chaînes de montagnes, hordures.

de plateaux, sommets.

« Régime du vent en janvier-février

„-.. Régime duvent en juillet-août

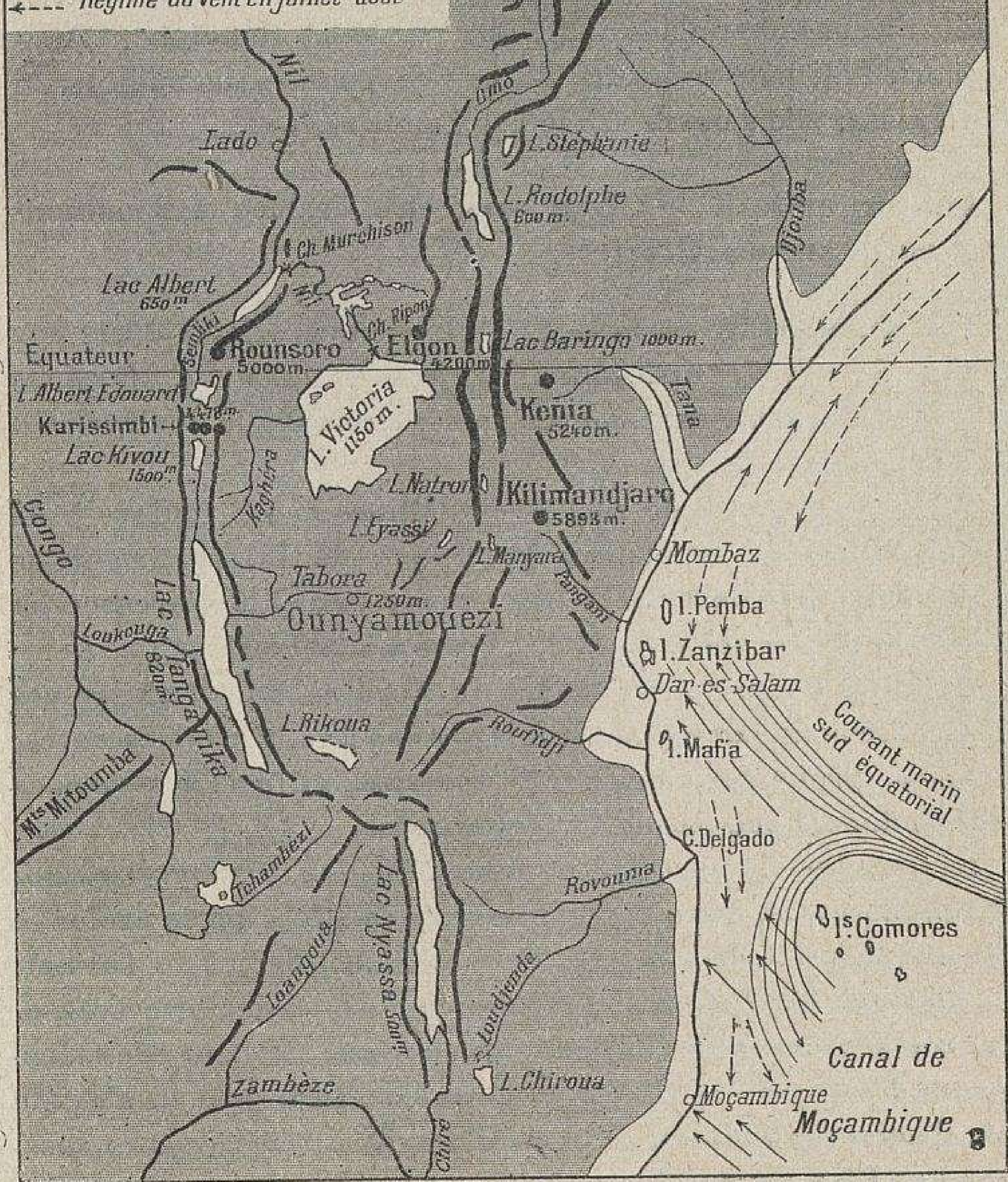


Zanzibar, port franc, est le grand marché de l'océan Indien.

Les paquebots européens le relient a Bombay, a Londres, a Ham. bourg et à Marseille.

\section{DÉVELOPPEMENT}

Comme le reste du continent, l'Afrique orientale est un plateau. Ses traits distinctifs sont le nombre, la forme et les dimensions de ses lacs, et aussi la hauteur géante de ses sommets.

I. Limites. - Les limites, très nettes à l'Est (océan Indien), et à l'Ouest (lacs Tanganyika, Kivou, Albert-Édouard et Albert), sont ailleurs indistinctes : au Nord, par le lac Rodolphe, l'Afrique orientale bute contre la falaise éthiopienne; au Sud, par le lac Nyassa, elle s'ouvre sur le bas Zambèze.

II. Superficie. - Elle peut être évaluée à 2 millions et demi de kilomètres carrés.

III. Orogénie et relief. - L'Afrique orientale est une région de grande dislocation, où le lent effort de pressions énormes a produit des mouvements corrélatifs de soulèvement et d'affaissement.

Le socle primitif, de roches cristallines, a été soulevé à de fortes altitudes : le plateau granitique de l'Ounyamouézi se maintient à plus de 1.200 mètres en moyenne et le Rouvenzori ou Rounsoro dresse ses masses de gneiss à 5.069 mètres.

En même temps se creusaient du Nord au Sud deux vallées d'effondrement, jalonnées à la fois par des lacs, véritables cuves, longues, profondes, aux bords escarpés, et par des volcans éteints depuis peu ou qui fument encore.

La première fracture (lacs Nyassa, Manyara, Natron, Baringo, Rodolphe) est un fragment du gigantesque sillon qui se prolonge sur environ 50 degrés (plus de $5.000 \mathrm{~km}$.) depuis le $15^{\circ} \mathrm{L}$ at. S. jusqu'au $35^{\circ}$ Lat. N., c'est-à-ảire jusqu'à la Syrie creuse, par la mer Morte et le Jourdain, la mer Rouge n'étant elle-même qu'une fosse remplie par les eaux de l'océan Indien. Il n'existe pas d'autre exemple sur le globe d'une fissure aussi nette, aussi longue. C'est ce fossé, un Graben pour les géographes allemands, qui forme ligne de partage des eaux. 
Sur le bord oriental, le Kilimandjaro, le plus célèbre des monts africains, dresse deux cratères majestueux : l'un, plus ancien et plus érodé, le Maouensi, atteint 5.152 mètres; l'autre le Kibo, plus jeune, intact, porte fièrement sa coupole de glace à 5.893 mètres. C'est le géant du continent. Le Dr Hans Meyer l'a le premier escaladé en 1889.

Plus au Nord, le Kenia $(5.200 \mathrm{~m}$.) ne fut gravi que dix ans

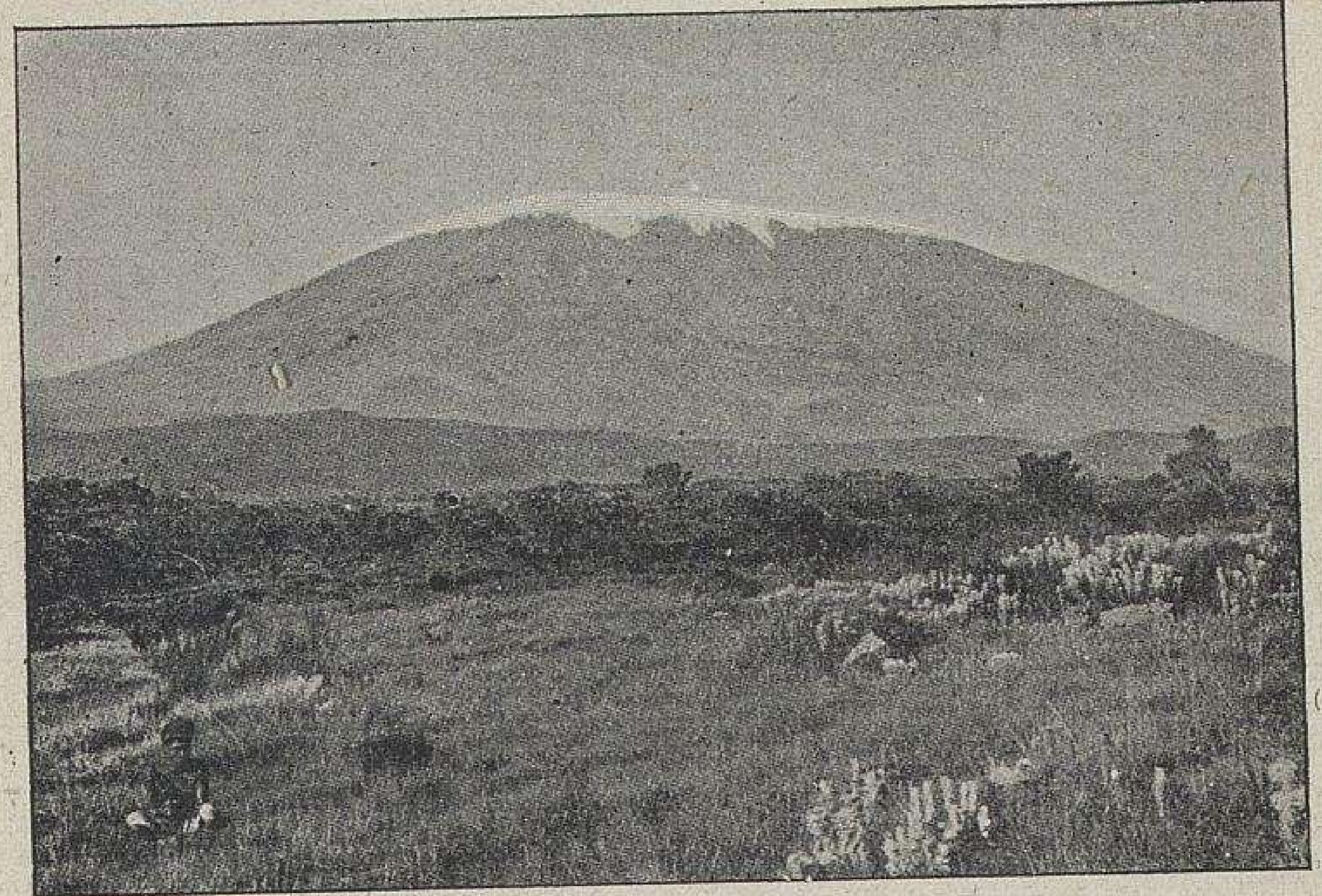

LE « KIBO », LA PLUS HAUTE DES DEUX CIMES DU ( KILIMANDJARO ) (5.893 m.)

(D'après Hans Meyer.)

Vue prise du Nord-Nord-Fst, par 2.500 mètres d'altitude, à la limite de la zone forestière et au commencement de la zone herbacée.

plus tard : il suspend à sa pyramide rocheuse une quinzaine de glaciers, et cela sous l'équateur même.

Du bord opposé, le cône du mont Elgon (4.000 à 4.600 m.) fait face au Kenia. Le panorama qui se déroule à sa base est peut-être le plus grandiose de toute l'Afrique, et aussi le plus heurté : au Sud et au Sud-Ouest la nappe bleue du lac Victoria, le Nil et un jardin de verdure, l'Ouganda; à l'Est et au Nord-Est, des régions désolées, effroyablement nues, un désert.

La seconde fracture est à l'Ouest : son double bourrelet enserre les lacs Tanganyika, Kivou, Albert-Édouard et Albert, 
et parmi tout un groupe de volcans, le Kirounga $(4.000 \mathrm{~m}$.) lance des panaches de fumée et de flammes. La vallée du Semliki, lequel écoule le lac Albert-Édouard dans le lac Albert, est une fosse caractéristique : une falaise de 1.200 mètres la domine à l'Ouest; à l'Est la marche du grand plateau monte à plus de 4.000 mètres et culmine à 5.069 mètres avec le Rounsoro ou Rouvenzori.

A ces fractures longitudinales, à ces lacs d'effondrement, à PROFIL SUIVANT L'ËQUATEUR

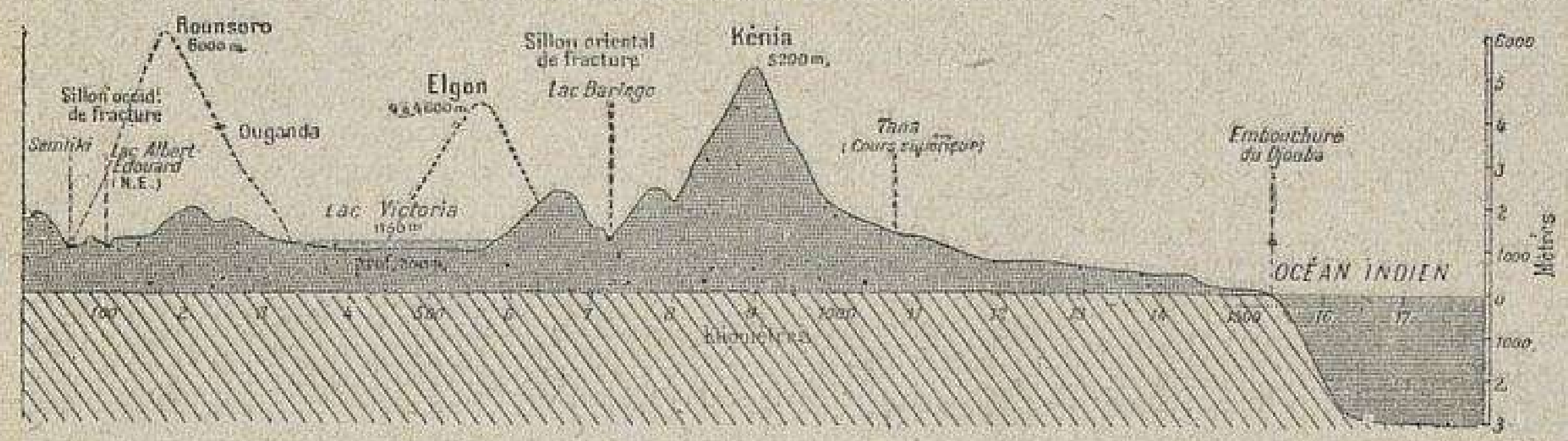

PROFIL SCHÉMATIQUE or PLATEAUX or L'AFRIQUE ORIENTALE

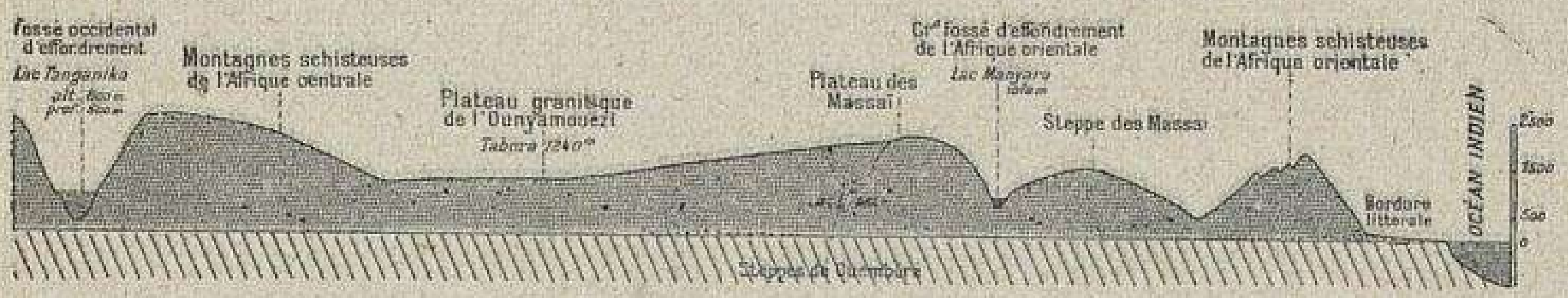

ces cồnes éruptifs, l'Afrique orientale doit l'originalité et la variété de son relief.

Un voyageur, parti de la côte dans la direction de l'Ouest, aurait à franchir successivement :

$1^{\circ}$ La plaine basse, malsaine, étroite, du littoral (terrains tertiaires et crétacés);

$2^{\circ}$ Les montagnes schisteuses de l'Afrique orientale, série de plateaux étagés, dont chaque bord donne, vu de l'Est, l'illusion d'une crête montagneuse;

$3^{\circ}$ La grande vallée d'affaissement : allongée entre des falaises verticales (hauteur relative, $200 \mathrm{~m}$.), criblée de lacs salés, boursouflée par les cratères ou bien encore toute nivelée et d'une absolue nudité;

$4^{\circ}$ Un plateau granitique, à perte de vue, l'Ounyamouézi, d'un relief indécis, uniforme, presque absolument plan et pauvre en eaux courantes (alt. moy., $1.200 \mathrm{~m}$.); sa masse rigide a résisté 
au plissement et n'a fléchi que dans sa partie médiane. Vers le Nord il s'affaisse sur une cavité immense qu'emplit le lac Victoria $(1.150 \mathrm{~m}$.) ;

$5^{\circ}$ Une nouvelle rangée de montagnes schisteuses. Au NordEst du lac Tanganyika, elle limite les bassins du Congo et du Nil, et sur une longueur ininterrompue de 50 kilomètres élève ses pics neigeux. Le Rouvenzori, de son vrai nom, le Rounsoro,

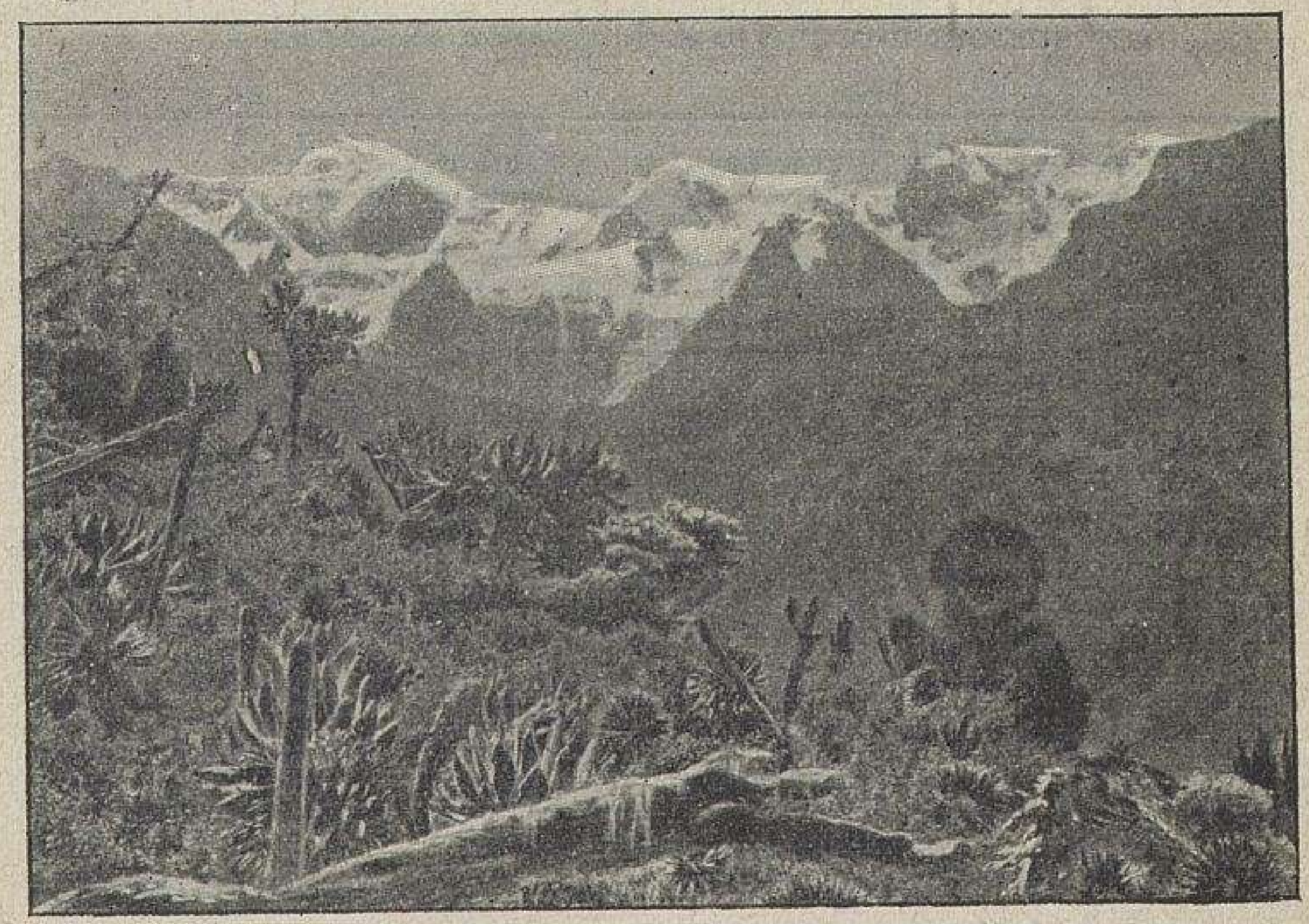

LE MONT ROUNSORO (env. 6.000 m.).

(D'après Stuhlmann.)

La vue est prise à une altitude d'environ 4.000 mètres, comme l'indique la végétation (Erica et séneģon arborescent).

n'est pas un volcan comme le crut Stanley: point de cratère, nulle trace de laves. Le duc des Abruzzes en a fait le premier l'ascension en 1906 et l'altitude de la plus haute cime a été fixée à 5.069 mètres (pic Marguerite);

$6^{\circ}$ La vallée occidentale d'effondrement. Au Nord du lac Kivou, les explorateurs n'ont pu retrouver le Mfoumbiro des cartes plus anciennes : ils lui ont substitué les monts Virounga avec le volcan de Kirounga;

$7^{\circ}$ Enfin la falaise occidentale de cette dernière fracture. Elle descend en terrasses sur le Congo. 
IV. Climat. - Le plateau des grands lacs est traversé par l'équateur, dans sa partie Nord. Mais le climat ne répond pas toujours à la latitude : l'altitude en est la cause ${ }^{1}$.

$1^{\circ}$ La région littorale est celle qui reproduit le mieux les traits du climat équatorial : encore est-elle soumise au régime des moussons.

La température n'est pas excessive, mais elle est constante, parce qu'elle est humide, et des plus malsaines. Il pleut tous les mois, mais surtout lorsque le soleil passe au zénith.

\begin{tabular}{|c|c|c|c|c|c|c|c|}
\hline \multirow{5}{*}{$\begin{array}{l}\text { Mombaz. . } \\
\text { Zanzibar. . }\end{array}$} & \multirow{3}{*}{$\begin{array}{l}\text { LAT. } \\
\text { SUD. }\end{array}$} & \multicolumn{4}{|c|}{ TEMPÉRATURE MOYENNE } & \multirow{3}{*}{ 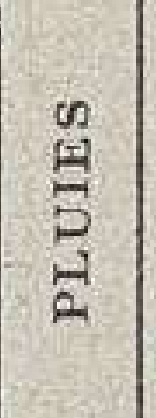 } & \multirow{3}{*}{ OBSERVATIONS } \\
\hline & & \multirow{2}{*}{$\begin{array}{c}0.0 \\
\text { हूँ } \\
\\
\end{array}$} & \multicolumn{2}{|c|}{ Mois } & \multirow[b]{2}{*}{ 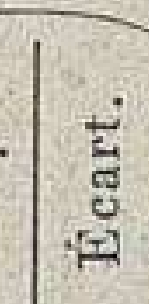 } & & \\
\hline & & & $\begin{array}{l}\text { le plus } \\
\text { chaud. }\end{array}$ & $\begin{array}{l}\text { le plus } \\
\text { frais. }\end{array}$ & & & \\
\hline & $4^{\circ}$ & $25^{\circ}$ & Mars $27^{\circ}$ & Juillet $24^{\circ}$ & $3^{\circ}$ & $\begin{array}{l}\mathrm{cm} . \\
121\end{array}$ & $\begin{array}{l}\text { 1. Saison des for- } \\
\text { tes pluies : mars- } \\
\text { mai. }\end{array}$ \\
\hline & $6^{\circ}$ & $26^{\circ}$ & Mars $27^{\circ}$ & Juillet $24^{\circ}$ & $3^{\circ}$ & 162 & $\begin{array}{l}\text {. Petite saison } \\
\text { pluvieuse : nov.- } \\
\text { déc. }\end{array}$ \\
\hline Lindi .... & $10^{\circ}$ & $25^{\circ}$ & Déc. $27^{\circ}$ & Août $23^{\circ}$ & $4^{\circ}$ & 83 & \\
\hline Moçambique. & $15^{\circ}$ & $26^{\circ}$ & Janv. $27^{\circ}$ & Juillet $24^{\circ}$ & $3^{\circ}$ & 53\{ & $\begin{array}{l}\text { Une seule saison } \\
\text { pluvieuse: janv.- } \\
\text { mars. }\end{array}$ \\
\hline
\end{tabular}

Le phénomène caractéristique de la région qui a pour centre Zanzibar est celui des moussons : il n'atteint nulle part une plus grande intensité que sur l'océan Indien. Nous le connaissons déjà : car nous l'avons rencontré dans l'Asie méridionale et nous avons alors trouvé son explication dans la différence de température entre les mers et les terres.

Pendant l'hiver boréal, la mousson d'Asie renforce les alizés de Nord-Est, qui franchissent alors l'équateur, mais en déviant à ce moment au Sud. De ce fait la région des calmes, qui normalement borde l'équateur, se trouve rejetée vers le $20^{\circ}$ Lat. S. La raison du phénomène n'est pas uniquement le déplacement du soleil, mais l'échauffement rapide des terres australes, même de celles qui sont au delà du tropique du Capricorne.

Pendant l'été boréal, les vents soufflent, au contraire, de

1. Se reporter à la carte des pluies du chapitre $\mathbf{x}$. 
AFRIQUE ORIENTALE OU PLATEAU DES GRANDS LACS 233 l'océan Indien vers la dépression saharienne. Au Nord de l'équateur ils sont emportés sur la droite, attirés par les fortes températures et par les faibles pressions des grands plateaux asiatiques.

Les vents périodiques des moussons ont été très justement appelés "vents de commerce ». Ils ont exercé une influence remarquable sur les relations entre l'Afrique orientale (Zanzi-

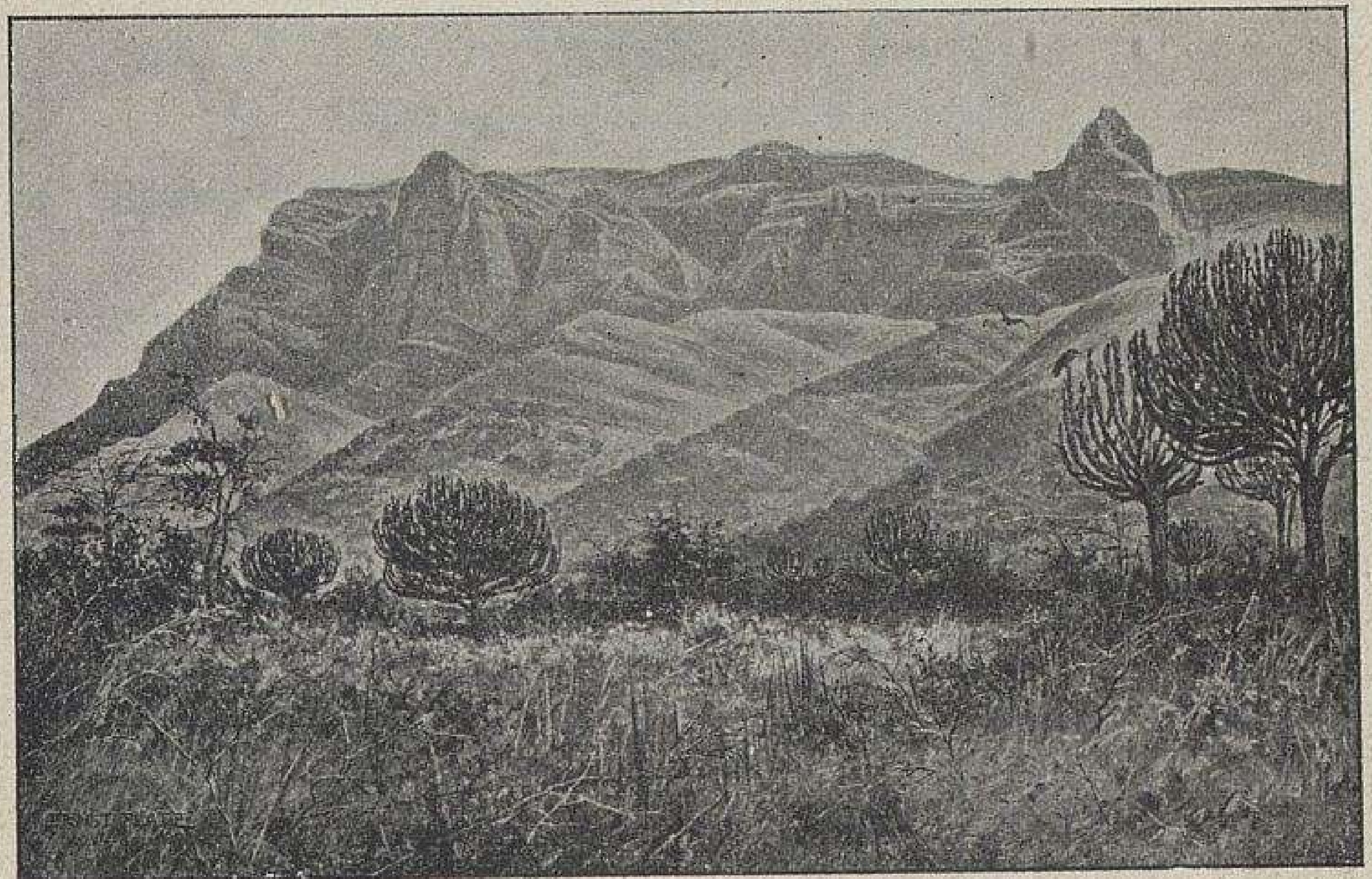

MONTAGNES SGHISTEUSES DE L'AFRIQUE ORIENTALE MONTS DE L'OUSAMBARA, PHÉS MAZINDÉ.

(D'après Hans Meyer.)

Le versant ici figuré est celui de l'Ouest: abrité des pluies qu'apporte l'océan Indien, il n'a qu'une végétation demi-désertique, d'euphorbes à candélabre.

bar), l'Arabie (Mascate) et l'Inde (Bombay) : avant l'invention de la vapeur, leur balancement réglait les longs voyages. Et dans l'intervalle des moussons, les vents variables favorisent la petite navigation de Zanzibar à la côte africaine : alors s'établit la " saison des deux voiles » suivant le terme pittoresque et très expressif des indigènes.

Grâce à ces conditions atmosphériques exceptionnelles, l'Afrique orientale possède des populations de marins, les seules, avec les piroguiers du cap des Palmes, que compte le continent.

$2^{\circ}$ La région des hautes terres, qui s'allonge obliquement 
entre les lacs Tanganyika et Victoria d'une part et le littoral de l'autre, n'est équatoriale que par sa situation et point par sa température.

En général le climat est plus sec que précédemment et sujet à des écarts plus sensibles. Le tableau suivant pourra suggérer des comparaisons intéressantes.

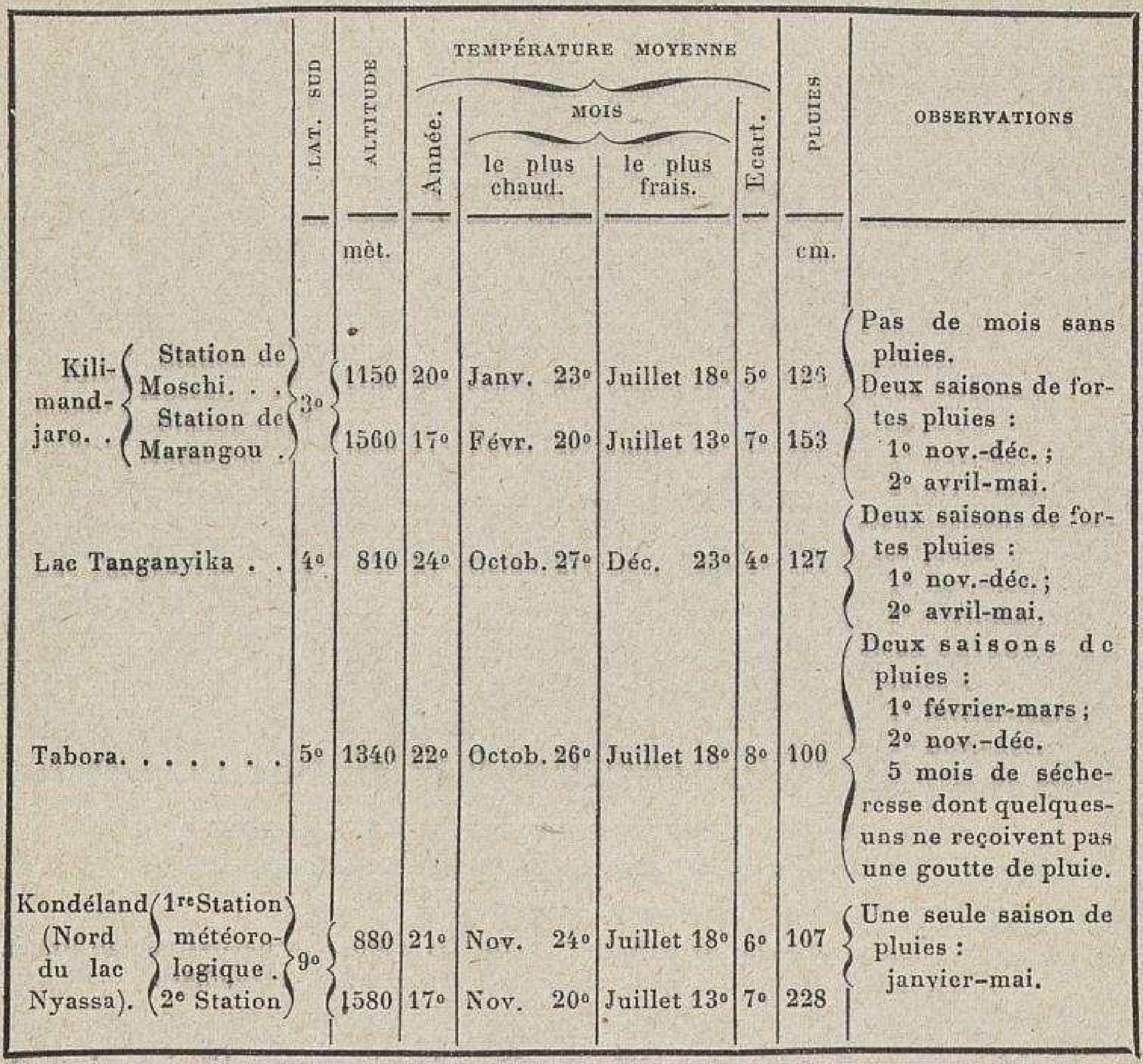

A de très faibles distances, on note des contrastes marqués, dus à des différences d'orientation et d'altitude sur les plateaux exposés à une sécheresse d'autant plus prolongée qu'ils sont plus loin de l'équateur : les collines forment des oasis permanentes de verdure; les sommets géants portent un manteau de neiges persistantes et des glaciers. Quant à la grande dépression, elle affecte l'allure des déserts : la pluie n'y tombe que pendant quatre mois, sans dépasser 30 et 40 centimètres, chiffre tout à fait insuffisant pour la végétation à cette latitude.

\section{$3^{\circ}$ Les contrẻes à l'Ouest du lac Victoria forment une troi-}


sième région climatérique : elles ménagent la transition entre les plateaux de l'Est qui n'ont d'équatorial que leur situation et le bassin du Congo, à l'Ouest, équatorial autant par sa situation que par son climat.

Sans doute l'Ouganda est un plateau élevé, où les extrêmes oscillent de $34^{\circ}$ à $8^{\circ}$ centigr. : mais il est sous l'équateur même, et le lac Victoria présente en outre une large surface à l'évaporation; aussi n'a-t-il pas de saison absolument sèche et l'amplitude moyenne est-elle insignifiante.

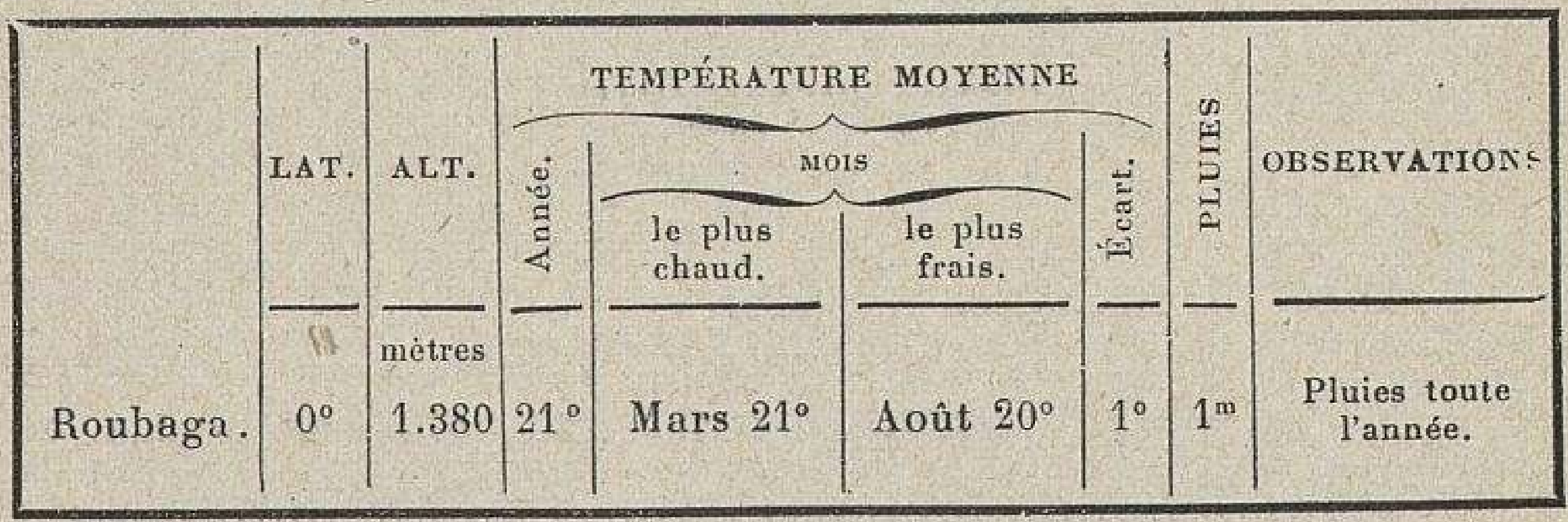

La vallée du Semliki, enfoncée entre de hautes montagnes, est toujours noyée dans des vapeurs moites : elle possède la température constante d'une serre chaude et humide.

On voit par tout ce qui précède que l'Afrique orientale présente toute la gamme des climats depuis lo climat équatorial jusqu'au climat polaire.

V. Hydrographie. - L'hydrographie résume celle du continent tout entier.

L'Afrique orientale a ses fleuves émissaires de lacs, ses fleuves à cascades, ses fleuves tropicaux, ses oueds désertiques, enfin ses bassins fermés; et les eaux courent aux trois mers africaines.

L'originalité des plateaux consiste dans le grand nombre, dans l'étendue immense des réservoirs lacustres : à eux est liée la vie des plus grands fleuves.

$1^{\circ}$ Versant méditerranéen : le Nil. - Il ne faut pas chercher ies sources du Nil ailleurs que dans les lacs : le lac Victoria forme la source orientale, le lac Albert la source occidentale.

A Speke revient l'honneur de la découverte (1858) : il donna 
au lac le nom de la reine d'Angleterre, qui, entre parenthèses, possède sur la surface du globe un nombre de lacs, de fleuves, d'îles, de chutes, de montagnes, de déserts, de comtés, de villes, etc., à remplir plusieurs pages d'un dictionnaire géographique.

Le lac Victoria, le plus grand de l'Afrique, est le second du globe, après le lac Supérieur (superficie de 80.000 kmq., égale au bassin de la Seine) : une "seconde mer », disent les Zanzibarites. Et c'est bien vrai : car il a ses golfes, ses promontnires hardis, ses archipels, ses ports, sa houle et même ses

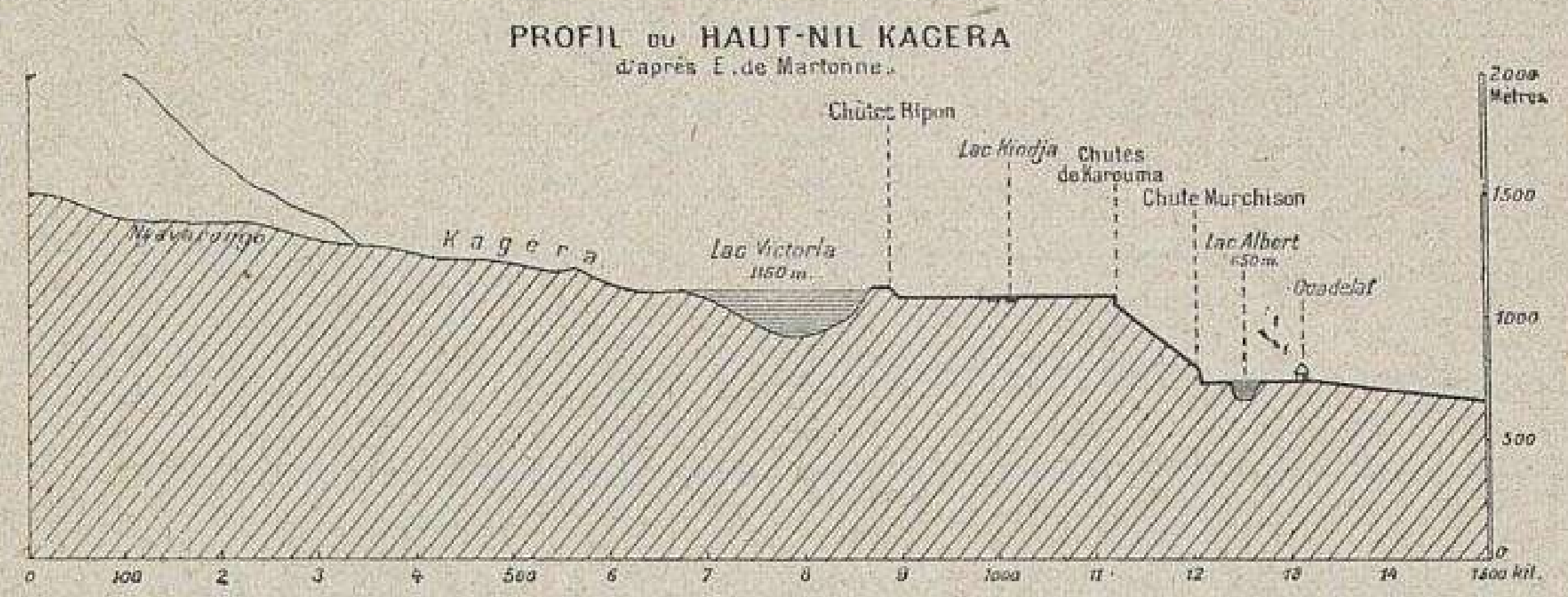

tempêtes (alt. $1.150 \mathrm{~m}$.; profondeur maxima $200 \mathrm{~m}$.). Comme nombre de lacs du plateau, il s'appauvrit progressivement et il est sujet à des variations annuelles périodiques. - Des rivières qui l'emplissent, la plus considérable est à l'Ouest, le Kaghéra, que l'on peut regarder comme la source la plus lointaine du Nil : d'abord torrent de montagne, puis rivière débordante en plaine, elle ne se prête pas à la navigation.

Le trop-plein des eaux n'a qu'une issue, au Nord : le Kivira, autrement dit le Nil. Large de 500 mètres, le fleuve prend tout de suite l'allure classique des cours d'eau africains : il plonge en cascade (chutes Ripon), puis s'épanche dans des marécages, dans des lacs (Ibrahim, Kiodja), à végétation si touffue qu'elle a écarté les explorateurs. C'est par des chapelets de lacs qu'arrivent aussi les eaux du mont Elgon. Après un crochet au Nord, brusquement le fleuve tourne à l'Ouest (Nil Somerset) et accélère sa vitesse : il bondit de gradin en gradin, il écume, il se précipite et tombe enfin d'une belle caseade de 35 mètres. Tranquille désormais il entre dans le lac Albert.

Ainsi nommé par Samuel Baker, en souvenir du prince 
consort, époux de la reine Victoria, le lac Albert, le plus bas de tous $(650 \mathrm{~m}$.$) , recueille encore au Sud le Semliki, rivière$ sinueuse et trouble qui étale ses vases sur la rive, et par le Semliki, les eaux de l'Albert-Edouard, lac de fracture également. Sur les escarpements qui les bordent, les cascades déroulent leurs rubans d'écume.

Lorsque le Nil enfin s'échappe des plateaux et prend sa course vers le Nord, il a puisé dans cet ensemble de grands réservoirs superposés l'énergie nécessaire pour couvrir la distance de

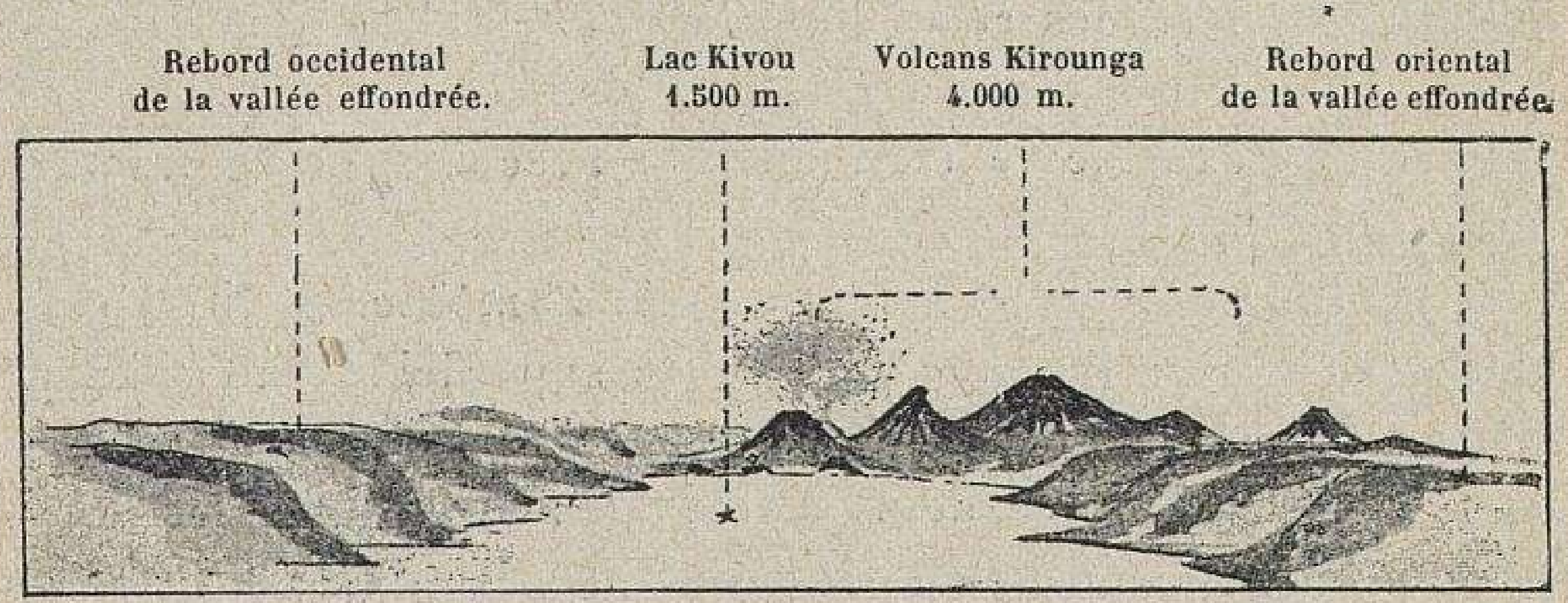

LAC KIVOU, TYPE DE LAG DE FRAGTURE

(d'après le Geographical Journal).

30 degrés de latitude qui le sépare encore de la Méditerranée : il durera en atpit des déserts.

$2^{\circ}$ Versant atlantique. - Le lac Kivou, le plus élevé de tous les lacs africains (env. $1.500 \mathrm{~m}$.), son émissaire le Roussizi, non encore reconnu, mais qui sans doute rachète, par nombre de cascades vigoureuses, sur un parcours de faible étendue, une différence de niveau de 700 mètres, et le Tanganyika $(820 \mathrm{~m}$.) s'alignent, comme les précédents, au fond de laı vallée affaissée de l'Ouest. Ils appartiennent donc bien aux plateaux de l'Afrique orientale : mais c'est au Congo que se déverse le trop-plein des eaux, par le moyen du Loukouga, perpendiculaire au grand axe du Tanganyika.

Celui-ci, long de 600 kilomètres, large au plus de 100 , avee des fonds de 600 mètres, est, par sa superficie (40.000 kmq.) supérieur d'un tiers à la Belgique et le second des lacs africains. Entre les montagnes hardies qui plongent sous ses eaux, il est secoué souvent par des tempêtes aussi brusques que terribles. Sa faune,

G. Lespignol et M. Fallex. - Afrique. 
des plus curieuses, rappelle celle des mers jurassiques, comme s'il s'était fermé pour toujours à ces âges géologiques lointains.

Le plus long tributaire vient de l'Est, le Malagarassi, rivière de steppes fort irrégulière, impropre à la navigation.

Au Sud-Est le lac Rikoua, reste d'une nappe jadis bien plus étendue, se serait déversé dans le Tanganyika, vers Karema. Il y a dix ans, il couvrait la plaine sableuse sur laquelle les pluies passagères n'étalent plus qu'une couche d'eau assez mince : les indigènes recueillent la croûte saline, que l'évaporation dépose sur ses rives changeantes.

Par lui s'effectue le trait d'union avec la grande fracture de l'Est.

$3^{\circ}$ Versant de l'océan Indien. - A. Zambèze. - Nous connaissons déjà le lac Nyassa : d'une superficie (30.000 kmq.) égale à la Belgique, il a comme tous ses congénères la forme d'une longue déchirure, des fonds de 800 mètres entre des escarpements de 500. L'écoulement des eaux est au Sud; le Chiré les entraîne vers le bas Zambèze.

B. Fleuves côtiers. - Tropicales au Sud, les rivières prennent au Nord le régime des cours d'eau des steppes désertiques. C'est la même proguression, mais en sens inverse, qui s'observe sur le versant atlantique depuis le golfe de Guinée jusqu'au Cap.

Le Rovouma sépare les possessions allemandes et portugaises. Dans un bassin supérieur à la moitié de la France (env. $334.000 \mathrm{kmq}$.) il décrit des méandres si capricieux, il est tellement embarrassé d'îles, de troncs d'arbres accumulés, de roches et finalement de bancs de sables, qu'il ne fournit pas la voie de pénétration souhaitée à l'intérieur du continent. Le Roufidji ne draine pas une surface sensiblement inférieure. Il devient en plaine accessible aux embarcations plates : mais alors ses crues obligent les indigènes à déserter leurs cabanes pour vivre sur des canots. Son delta fait face à l'île Mafia. Le Pangani dévale les pentes du Kilimandjaro, le Tana $(600 \mathrm{~km}$.) celles du Kenia. Ce dernier saute en cascades vertigineuses d'une hauteur de 4.000 mètres; les orages de la montagne, la fonte subite des neiges lui valent des crues très fortes. Le Djouba appartient à la région des Galla et 
des Somali : il limite les possessions anglaises et italiennes.

$4^{\circ}$ Bassins fermés. - Les cours d'eau du grand sillon oriental n'ont pas de communication avec les mers : ils ne sont pas permanents. Les lacs, lacs de cratère ou lacs de vallées qu'ont barrées les soulèvements volcaniques, sont salés et saumâtres. Le Manyara et le Natron ont dû ne former autrefois

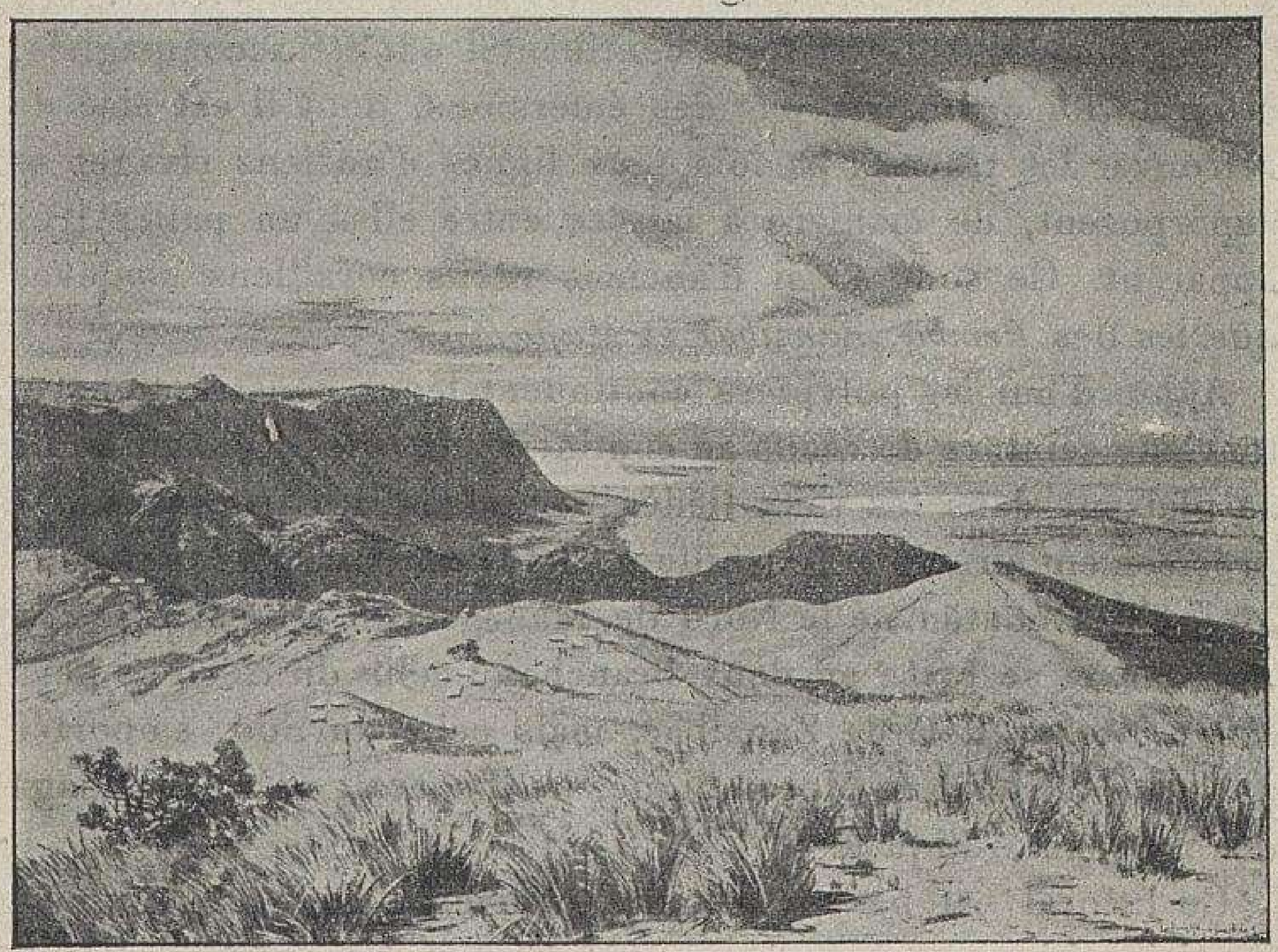

LA GRANDE VALLEEE D'AFFAISSEMENT

(d'après O. Baumann).

Au premier plan, touffes d'herbes; puis collines, cultivées et habitées. Au delà à gauche, la falaise du plateau (Irakou) laisse apercevoir le lac Manyara : à ses pieds une plaine, puis un second lac salé. A l'horizon, des masses volcaniques : le mont Mérou $(4.450 \mathrm{~m}$.) et le Kilimandjaro $(5.893 \mathrm{~m}$.$) , tout blanc de neige.$

qu'une seule nappe. Le lac Eyassi est au milieu de steppes, le Nä̈vacha au milieu de volcans. Le Baringo apparaît étrange, parmi tant de cratères. Le Rodolphe et le lac Stéphanie, auxquels la mission du comte Téléki a donné en 1888 les noms d'un archiduc et d'une archiduchesse d'Autriche, commencent la série qui borde la falaise éthiopienne.

VI. Côtes de l'océan Indien. - Le littoral de l'Afrique de l'Est n'est pas différent de tout le littoral africain : lour- 
dement taillé, sans échancrures profondes, il n'offre que des courbes de grand rayon, orientées comme les montagnes bordières. Les premiers gradins des plateaux ne laissent, de leur base à la frange de la mer, qu'une étroite bande littorale. Tout de suite, à une faible distance au large, la sonde descend à de grandes profondeurs et la ligne bathymétrique de 1.000 mètres moule très exactement les formes du rivage.

Ces affaissements du socle continental ont été accompagnés, selon la loi ordinaire, par des émersions, dont il est aisé de retrouver les traces : parfois deux lignes d'anciens rivages se superposent, de manière à laisser entre elles un palier très apparent. Ce sont aussi d’anciens récifs coralliens soulevés que les îles Pemba, Zanzibar et Mafia.

Aujourd'hui les polypiers continuent leurs constructions et font une ceinture de récifs au continent, aux îles. On sait qu'ils se plaisent dans les eaux tièdes et agitées des tropiques. Or précisément circule et tourbillonne ici le courant sud-équatorial: lorsqu'il a contourné le Nord de Madagascar, il heurte le cap Delgado et se brise en deux branches : celle du Nord se perd assez vite au delà de Zanzibar, mais celle du Sud, emportée à travers le canal de Moçambique, ne disparaît qu'au voisinage des mers antarctiques.

Ce littoral est bas en général, souvent bordé de lagunes. Sur les sables, aux blancheurs aveuglantes, les cocotiers hérissent les bouquets de leurs palmes; sur les vases, à l'arrivée des fleuves, les palétuviers mettent une végétation d'un vert foncé, très touffue, qui protège les rives.

On comprend que la navigation ne rencontre pas dans ces parages des conditions bien favorables. Il faut aux marins l'expérience des passes, et mieux encore, l'usage fréquent de la sonde. Les ports naturels se comptent; le plus souvent les navires mouillent au large et de leur bord à la plage vont et viennent les barques indigènes.

Zanzibar entretient depuis plusieurs siècles un commerce des plus étendus dans l'océan Indien.

Sur la terre ferme, Mombaz, Tanga, Bagamoyo, Dar és Salam, Lindi sont les points où les paquebots européens font le plus ordinairement relâche. 
AFRIQUE ORIENTALE OU PLATEAU DES GRANDS LACS 241

-VII. Vie végétale. - Toutes les formes de végétation, depuis la forêt dense jusqu'au désert, se rencontrent dans l'Afrique orientale. Par là se prolonge le Soudan qui dessine une sorte de circuit autour du bassin du Congo : mais au lieu de bandes parallèles, se suivant aussi régulières que les latitudes, la végétation traduit les caprices du relief et de l'humidité.

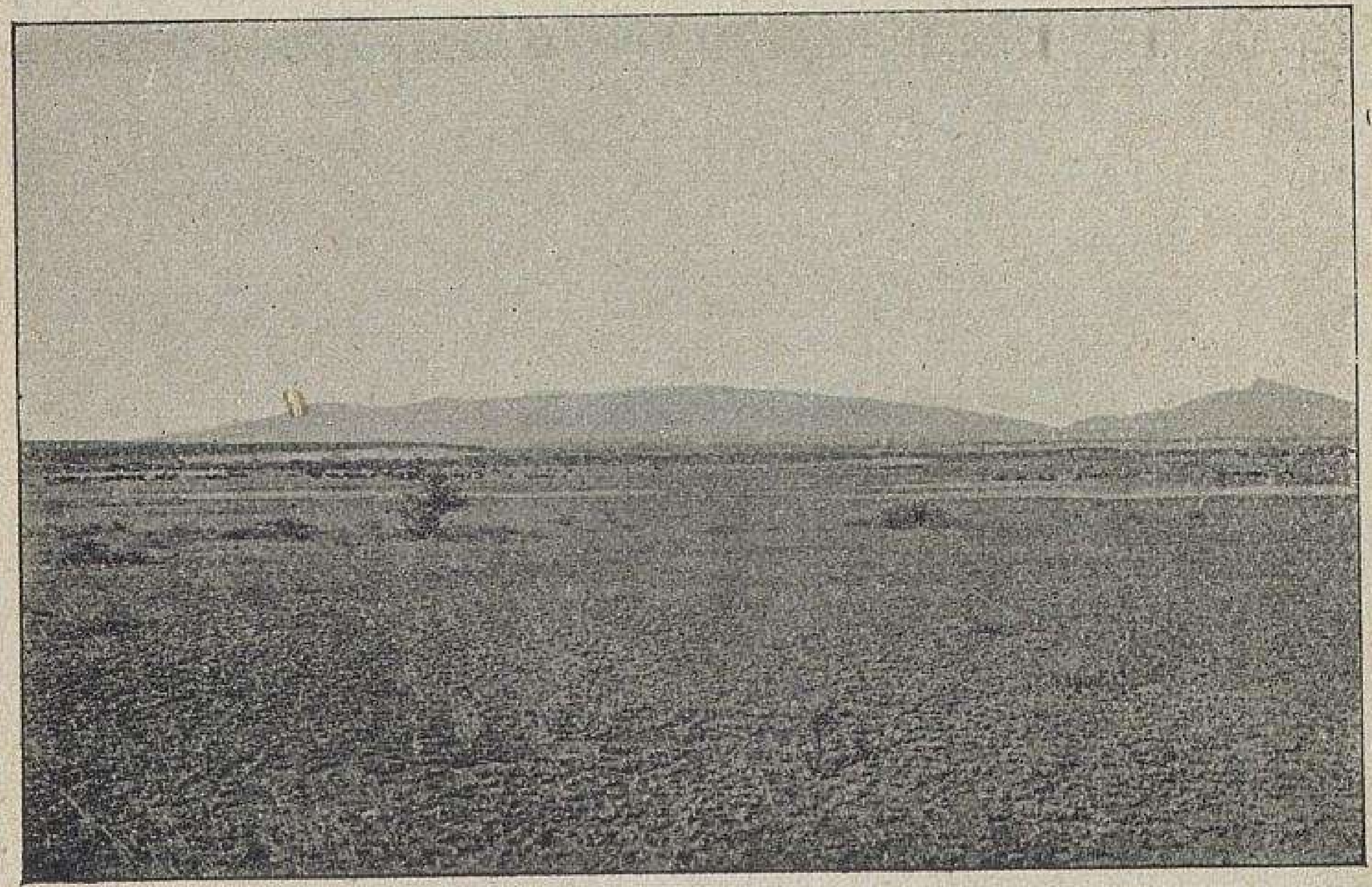

STEPPE DES MASSAï, ENTRE LE FLEUVE ROUVOU (PANGANI)

ET LES MONTS PARÉ

(d'après Hans Meyer).

Dans l'immensité de la plaine, l'alignement, à peine visible, de points noirs, à droite et à gauche, représente les troupeaux nomades des Massaï.

La forêt équatoriale, limite extrême de celle du Congo, couvre de sa végétation épaisse les chaudes vallées du Semliki et de l'Ounyoro: sur ces terres riches en humus, noyées d'averses abondantes et baignées de tièdes vapeurs, ni la plante herbacée ni l'arbre ne connaissent de repos.

A l'Ouest du lac Victoria, l'Ouganda (alt. moy: 1.000 m.) est une contrée privilégiée. Elle porte des plantes largement feuillues, le bananier surtout qui entoure les cases indigènes, des jardins (légumes), des céréales (maïs, dourah); dans les parties basses, marécageuses, aux eaux de rouille, l'excès d'humidité développe les longs roseaux de 3 mètres, le papyrus, 
l'ambatch qui plonge ses racines dans la vase pour épanouir ses fleurs à l'air, à une hauteur de 5 et 7 mètres.

Mais vers l'Est, la sécheresse augmente : alors prédomine la savane, à forme tantôt de parc et tantôt de steppe. Dans le parc, les clairières herbeuses, aux beaux pâturages, alternent avec les cultures, avec les bouquets d'arbres à feuilles caduques (sycomores, tamariniers, baobabs). Sur la steppe, les seules espèces arborescentes sont des broussailles épineuses et des plantes grasses (acacia parasol, cactus, surtout l'euphorbe à

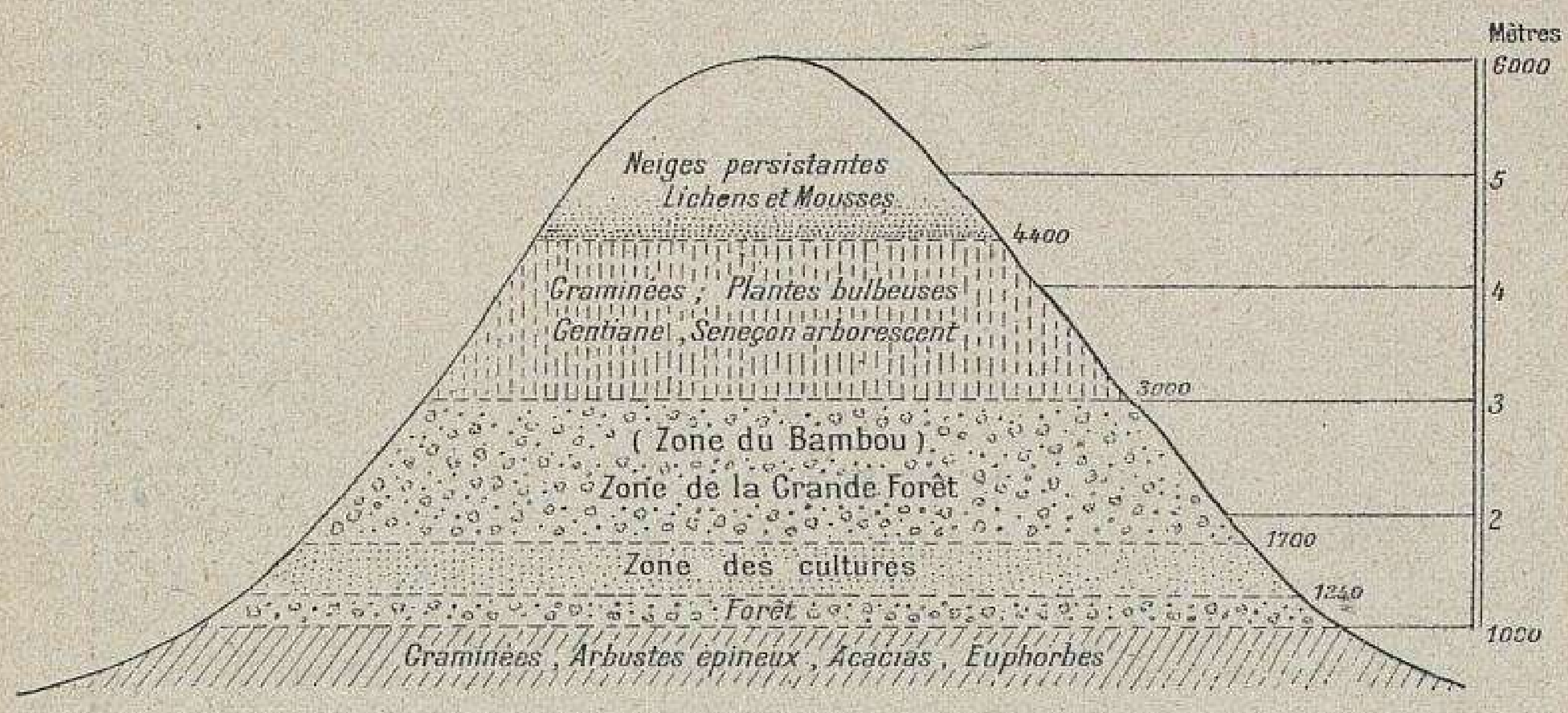

ZONES EN TERRASSES DES FORMES VÉGÉTALES sur le KILIMA NDJARO.

candélabre); le sol, ailleurs encore, ne nourrit plus qu'une herbe dure, fortement imprégnée de sel, que les pluies font instantanément verdir, et que la sécheresse de nouveau étiole et brûle : telles les steppes du Ouembéré et des Massaï.

L'Ounyamouézi tient le milieu entre la savane et la steppe; le sol, d'argile rougeâtre, se prête à la culture des céréales indigènes. La grande dépression a la nudité d'un désert, mais d'un désert étrange, avec ses alignements de cônes volcaniques, ses tufs et ses scories. Enfin la forét forme galerie dans les fonds humides, le long des cours d'eau; elle recouvre les sommets dont l'altitude n'est pas excessive; elle entoure d'une ceinture les cimes géantes.

Bref, partout le seul aspect des formes végétales suffit à révéler ies conditions générales du climat, avant toute observation météorologique. 
AFRIQUE ORIENTALE OU PLATEAU DES GRANDS LACS 243

VIII. Vie animale. - L'Afrique orientale, on le devinerait par tout ce qui précède, est le rendez-vous de toutes ou presque toutes les espèces animales du continent. Le chameau excepté, chacune y trouve l'aire qui convient à son genre de vie.

Dans les fleuves, dans les roselières des marais circulent les crocodiles et se vautrent les hippopotames. Dans la grande

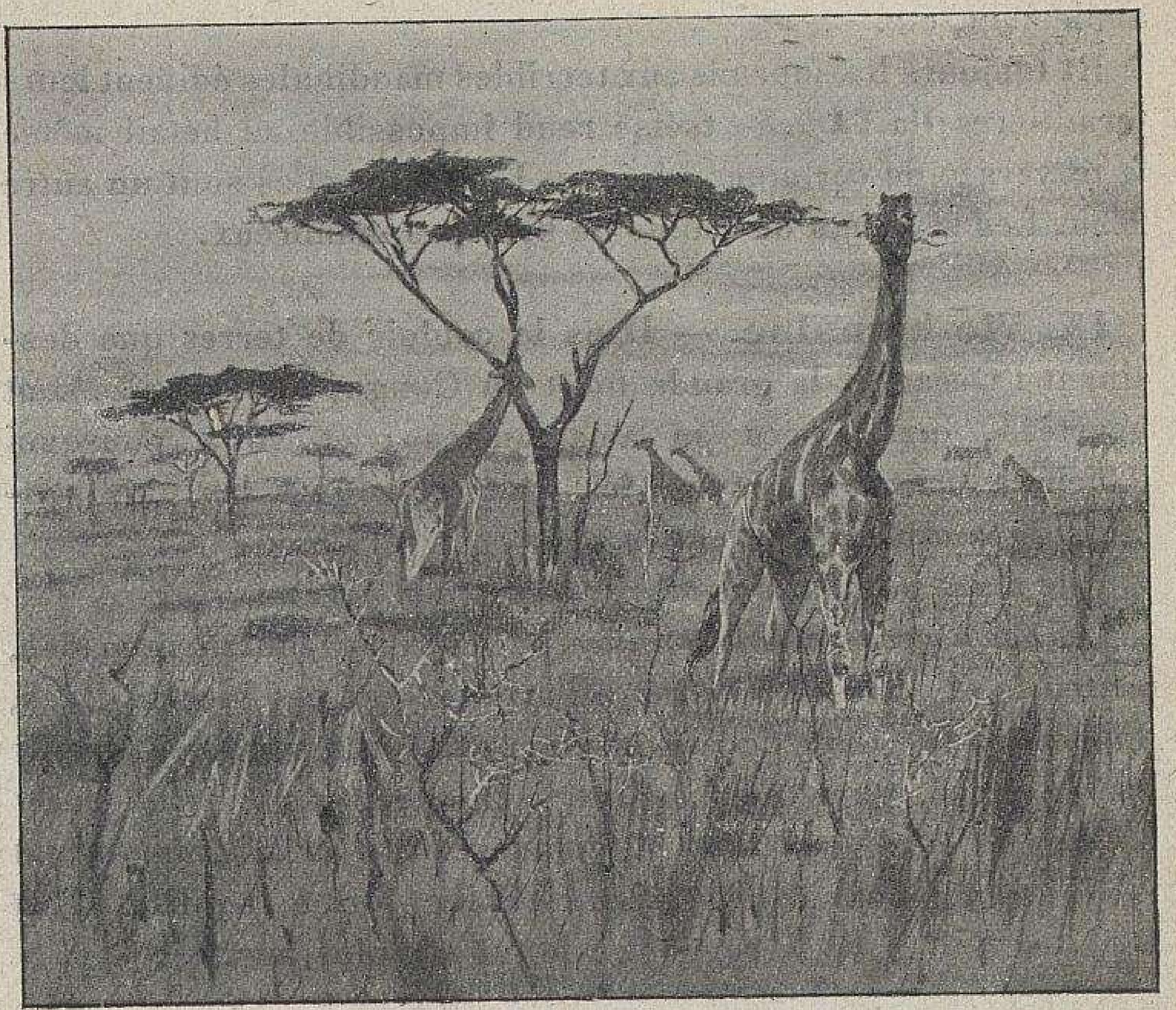

TXPE DE SAVANE-STEPPE, AVEG ACACIAS PARASOLS

(d'après Stuhlmann).

forêt manquent l'air et l'espace : aussi point de grands animaux. C'est dans les branches que se réfugient le monde multicolore des oiseaux et toute la famille gambadante et grimpeuse des singes.

Sur les savanes, les grands mammifères : en premier lieu les herbivores : l'éléphant; déjà au second siècle de notre ère, l'ivoire arrivait de la région des grands lacs, et depuis, la destruction des éléphants, qui vivaient par troupeaux innombrables, n'a pas cessé; aussi l'espèce se fait-elle de plus en plus rare, 
jusqu'à ce qu'elle disparaisse; - le rhinocéros; le sanglier; les animaux coureurs : antilopes très variées, troupeaux de gazelles, de girafes, de zèbres, de buffles, autruches, etc. Le bouf domestique (zébu) porte une large bosse entre les deux épaules. Mais la steppe giboyeuse attire les carnassiers : le lion d'abord, le léopard dans le Sud, partout l'hyène au rauque aboiement, etc.

Et toujours les fourmis aux terribles mandibules édifient leurs termitières; la mouche tsétsé rend impossible au bétail même la traversée de certaines régions. Les sauterelles sont un autre fléau. Les serpents du moins ne sont pas nombreux.

IX. Vie humaine. - Dans le couloir de terres que dessinent l'Océan et la grande forêt du Congo, les races se sont heurtées, juxtaposées ou amalgamées : et voilà pourquoi l'Afrique orientale résume les traits ethniques les plus saillants du continent tout entier.

Elle a ses populations nègres et ses non nègres.

Les non nègres sont les Hamites, parents des Sémites : nomades, pasteurs et chasseurs, donc pillards et bandits incorrigibles, ils mènent le genre de vie qui donne la force nerveuse, éveille les énergies, physiques ou intellectuelles, qui fait les races hardies et entreprenantes. De couleur café au lait, ils portent des cheveux ondulés; le nez est bien formé, aquilin. C'est chez les Galla que se rencontre le type le plus pur.

Les nègres sont les Bantous et les Nilotiques.

Peuples d'agriculteurs, l'es Bantous ont l'indolence des sédentaires : au physique, des traits mous, le nez sans os, les cheveux laineux. Les Nilotiques, agriculteurs et éleveurs tout ensemble, ont plus de fierté, plus d'initiative que les Bantous, mais moins que les Galla : de corps svelte, la jambe maigre, comme les échassiers, ils sont venus à travers les marais.

Le mode de culture imposé par les conditions de climat et de sol différencie les mœurș: où pousse le bananier, le nègre n'a d'autre peine que d'arracher les feuilles mortes et de cueillir les fruits. L'humidité est-elle moindre, il sème et récolte les céréales (dourah), non pas les céréales d'Europe, et non pas davantage suivant nos procédés : point d'animaux domestiques 
pour tirer la charrue; on herse le sol, on le gratte avec un instrument à main, un hoyau primitif et la bêche. La hutte, plus solidement bâtie, se complète alors d'un grenier; ce grenier est une hutte plus petite de forme conique ou bien une sorte de panier fuselé, coiffé de chaume, que l'on perche sur un pieu vertical. Des postes de refuge, des observatoires sont installés sur pilotis et dans les arbres, pour constituer des miradors. Habitation,

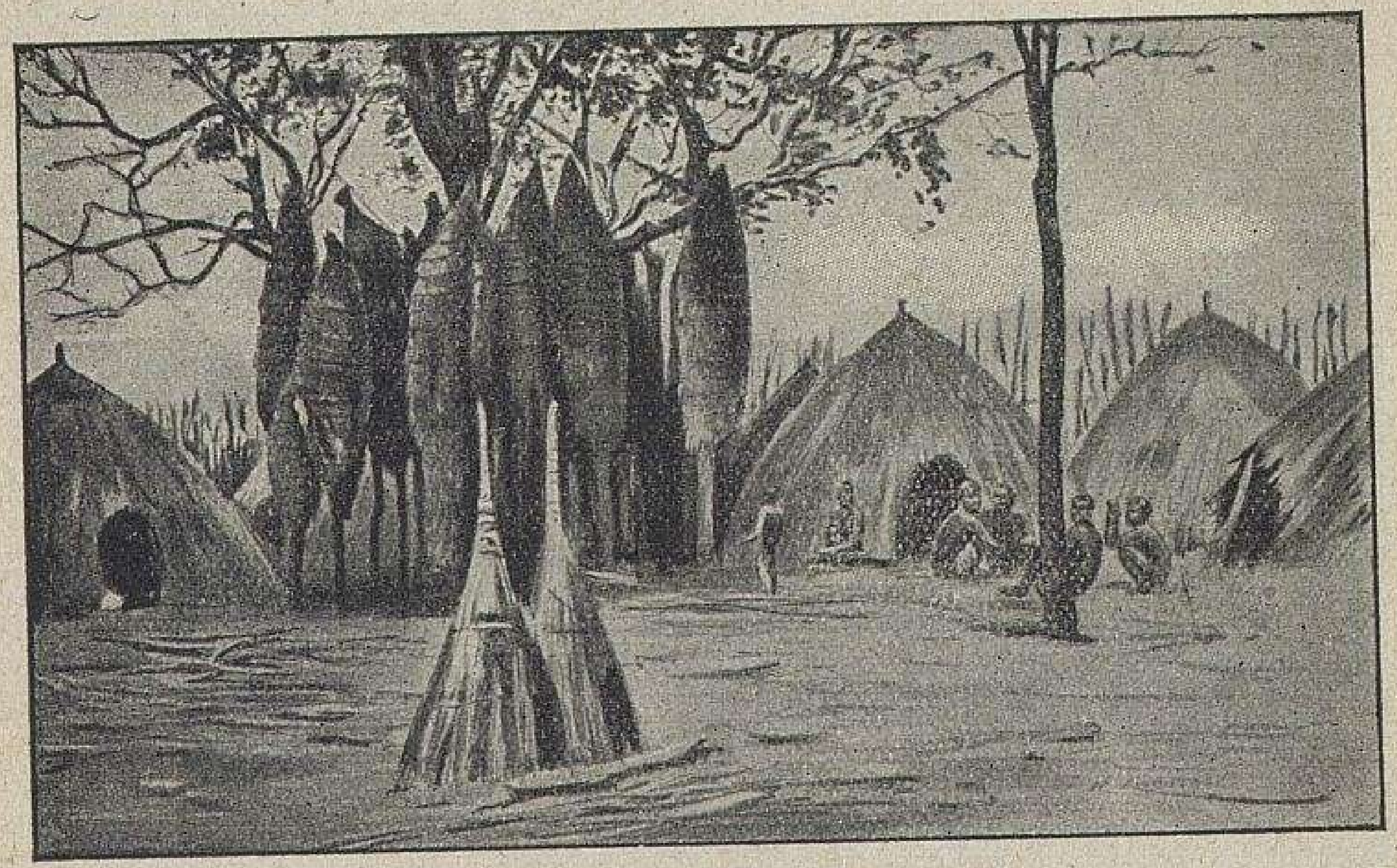

TYPE D'HABITATION DANS UNE CONTREE SEGHE

(OUSINDJA, S.-S.-O. DU LAC VICTORIA)

(d'après Stuhlmann).

Dans une enceinte palissadée, sans le moindre bananier, sont réunies les huttes d'habitation; au premier plan, cabanes plus petites, abritant les fétiches; au milieu, les fuseaux en paille, fichés sur un pieu, sont les réserves de grains, les " greniers ".

mobilier, vêtements et armes sont empruntés aux produits végétaux.

Les Hamites arrivèrent par le Nord-Est, des plateaux Galla, - il n'y aurait pas plus de cent ans - s'insinuant entre les Bantous, qui venus du Sud avaient atteint les rives occidentales du lac Victoria, et les Nilotiques qui le long du Nil remontèrent jusque sur les rives orientales. La rencontre a produit des mélanges de sang et de civilisation. Les Massaĩ sont des Nilotiques, chez qui l'élément hamite l'emporte, peuple de fiers guerriers, à la taille haute, bien disciplinés, divisés en clans, en tribus, vivant en nonades sur la steppe, effroi des agri- 
culteurs sédentaires qu'ils méprisent et qu'ils pillent. Fortement métissés aussi de Hamites sont les Bantous de l'Ouganda, de l'Ounyoro, du Karagoué, du Rouanda: ils y ont gagné en vigueur : là des chefs à l'instinct dominateur ont fondé des États. Ils avaient ou ont encore leur cour, tout un personnel de nobles vassaux pour gouverner les provinces, leur armée de fantassins et leur flotte de grands canots de guerre.

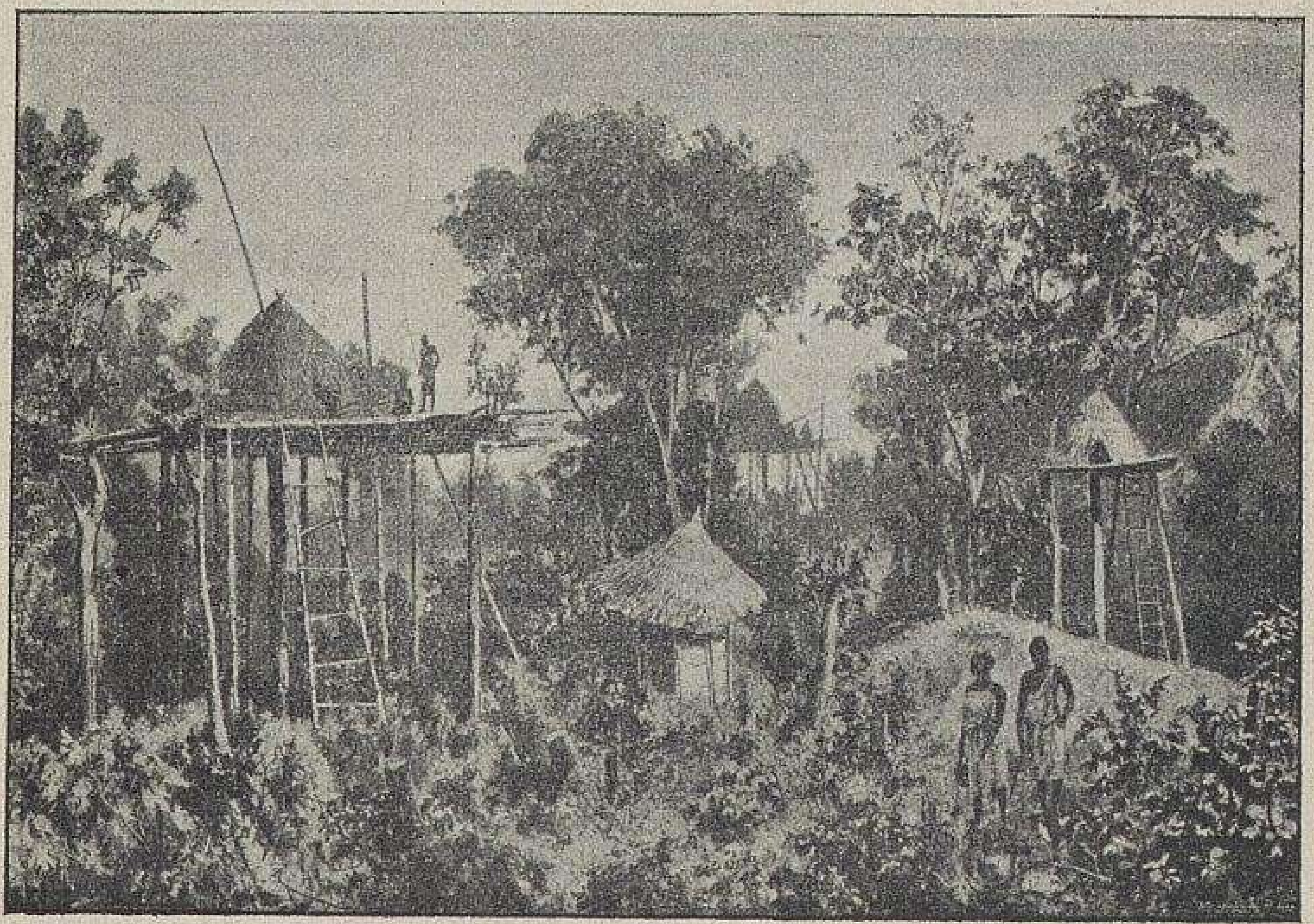

AUTRE TYPE D'HABITATION : HUTTES SUR PILOTIS, MIRADORS, DANS LA RÉGION DU MALAGARAZI

(d'après 0 . Baumann).

Mais l'Afrique orientale a subi d'autres influences erscore; des peuples sont venus par mer, portés par les moussons : les Arabes. Le mélange de ces Sémites avec les nègres Bantous a engendré un peuple nouveau : "les gens de la côte », en arabe Souaheli (de Sahel), en nègre les Oua-Mrima. D'un teint brun clair, plus ou moins jaune, Arabes de costume et de religion, ils se sont faits les courtiers du commerce, commerce de l'ivoire, commerce surtout de chair humaine : ils étaient les pourvoyeurs de l'horrible traite. Leur langue, le Ki-Souahéli, mi-arabe, mibantoue, compte parmi les plus importantes du globe, langue littéraire, langue sacrée, langue commerciale surtout : elle se 

parle à Zanzibar aussi bien que sur les lacs, aussi bien qu'à Bombay, Aden et Mascate. Forts de la supériorité de leur demicivilisation, les Arabes s'imposèrent en maîtres et fondèrent un grand empire, le sultanat de Zanzibar, de forme musulmane et despotique.

A la longue, les grands États des conquérants Hamites et Sémites, subirent la contagion amollissante des races vaincues. C'est alors que les Européens se présentèrent, en explorateurs d'abord, puis en missionnaires, enfin en propriétaires. Les plus fiers de ces peuples guerriers ne pouvaient avoir l'avantage final contre les mitrailleuses Maxim, ni contre les balles des fusils Mauser.

X. Gouvernement et villes. - L'Angleterre et l'Allemagne se sont adjugé la plus grande partie de l'Afrique orientale, en vertu d'une convention signée en 1890. La France a fait abandon de ses droits, dont les copartageants n'avaient pas tenu compte, moyennant la reconnaissance de Madagascar.

$1^{\circ}$ Afrique orientale allemande ${ }^{1}$. - C'est la plus grande des colonies de l'Allemagne. En façade sur l'océan Indien depuis Oumba jusqu'au cap Delgado, elle ne possède pourtant qu'une seule des trois îles : c'est Mafia; à l'intérieur, elle couvre les plateaux jusqu'aux lacs Victoria, Tanganyika et Nyassa et confine ainsi à l'Afrique orientale anglaise, à l'État indépendant du Congo, à la Rhodésia et au protectorat britannique de l'Afrique centrale, enfin à l'Afrique orientale des Portugais. C'est un pays de protectorat : à sa tête est un gouverneur, que nomme l'empereur.

La prise de possession est encore trop récente pour qu'il $\mathrm{s}^{\prime} \mathrm{y}$ rencontre autre chose que de rares établissements européens

1.

\begin{tabular}{|c|c|c|c|}
\hline \multirow[b]{2}{*}{ SUPERFICIB } & \multicolumn{3}{|c|}{ population (1910) } \\
\hline & Indigènes. & $\begin{array}{l}\text { Asiatiques. } \\
\text { (Arabes et Hin- } \\
\text { dous). }\end{array}$ & Européens. \\
\hline $\begin{array}{c}950.000 \mathrm{kmq} \text {. } \\
\text { (Allemagne, } 540.596 \text { ) }\end{array}$ & $6.750 .000 \mathrm{env}$. & 15.000 & 3.750 \\
\hline
\end{tabular}


au milieu des cases indigènes; peu de villes à proprement parler.

Dar ès Salam (24.000 h.), sur la côte, est le chef-lieu administratif et compte environ deux cents maisons bâties en pierre. Son importance croît au détriment de Bagamoyo (5.000 h.) dont le port, est moins sûr, et qui pourtant sert de point de départ aux caravanes des lacs Victoria et Tanganyika.

Tabora, sur l'Ounyamouézi, fut, comme Mpouapoua, une étape commerciale importante au temps de la traite : dans le groupe de villages à enceintes palissadées, quelques maisons plus riches sont habitées par les marchands arabes et par les missionnaires qui ont construit chapelles et écoles (37.000 h.).

Kaouélé (Oudjidji), sur le Tanganyika, était un grand marché indigène : denrées agricoles, bestiaux, ivoire et poisson. Une partie de la population se compose de bateliers qui vivent de la pêche. C'est près de là que Stanley retrouva en 1871 Livingstone.

Sur la côte encore, Pangani; Tanga choisi comme base de pénétration vers l'Ousambara et le lac Victoria (Mouanza); plus bas les deux Kiloa et Lindi, qui s'efforcent de drainer la région septentrionale du Nyassa, le Kondeland (Langenburg) sur lequel on fonde de grandes espérances.

$2^{\circ}$ Afrique orientale anglaise ${ }^{1}$. - Elle touche au Sud à l'Afrique allemande, à l'Ouest à l'État indépendant du Congo, à l'Est au protectorat italien de la côte des Somali, au Nord à l'Éthiopie : la frontière anglo-éthiopienne a été réglée par la convention du 6. décembre 1907; enfin elle s'ouvre par la vallée du Nil sur le Soudan anglo-égyptien.

L'administration de ces immenses territoires est encore confuse et n'a rien de définitif. On distingue trois protectorats. 1.

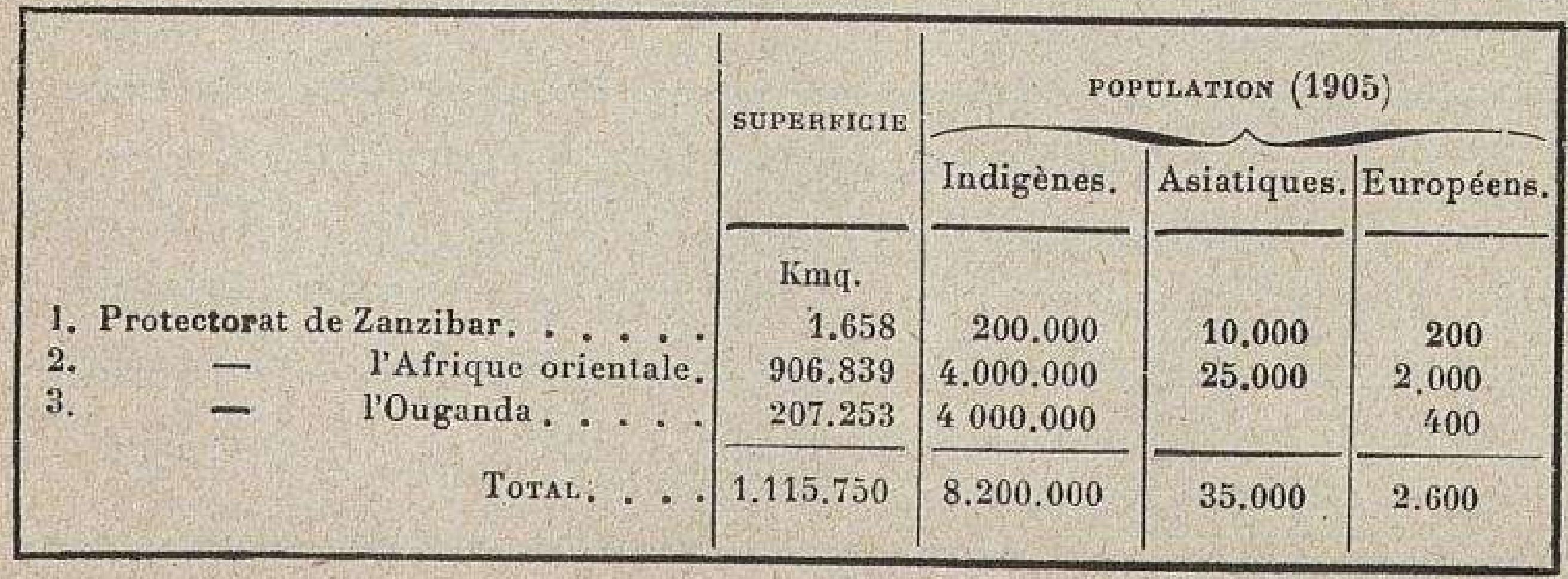


A. Protectorat de Zanzibar. - Dépouillé de ses territoires continentaux, réduit aux deux îles Pemba et Zanzibar, le sultan, depuis qu'il est protégé par la Grande-Bretagne, est un personnage purement décoratif.

Zanzibar (50.000 à 60.000 h.), la capitale, présente de la mer un aspect séduisant : ses maisons blanches, les vieux forts, les grosses tours disparaissent dans la “ corbeille de verdure » des cocotiers, des manguiers, des orangers, des citronniers, etc. Mais en dehors de quelques maisons arabes, de la mosquée, du palais et de l'hôpital français, tout n'est que fouillis de rues tortueuses et malpropres, entassement de cases misérables. Un monde extrêmement mélangé s'y agite : Souahéli, Comoriens, Hindous, Arabes, Persans; on compte les Européens. Déclaré port franc, Zanzibar demeure le grand centre commercial de toute l'Afrique de l'Est.

B. Protectorat de l'Afrique Orientale. - Placé sous le contrôle immédiat du Foreign Office, il a son chef-lieu à Nairobi, dans l'intérieur; mais Mombaz (27.000 h.) est la plus grande ville; trop malsaine pour se développer, elle n'est que la gare de départ vers les plateaux plus salubres de l'intérieur : les Européens sautent du bateau dans le wagon.

Lamou est également desservi par les grandes lignes de paquebots.

C. Protectorat de l'Ouganda. - Les Anglais ont récemment transféré le chef-lieu administratif de Mengo, la capitale du souverain indigène, à Entebbe, sur la rive même du Victoria.

Port-Florence, au Nord-Est du lac, est le terminus provisoire du chemin de fer de Mombaz, dit de l'Ouganda.

XI. Mise en valeur. - Il n'est pas possible de se prononcer encore sur la valeur économique de l'Afrique orientale.

1. L'Allemagne n'a pas, tant s'en faut, la meilleure part. La proportion des bons terrains ne serait que d'un cinquième, autrement dit très faible. La côte chaude et humide convient aux récoltes et aux cultures tropicales; les steppes herbeuses des plateaux, à l'élevage. L'attention des Allemands se porte de préférence vers les contrées situées au Sud-Ouest du lac Victoria (Karagoué, Rouanda), de population relativement dense, et sur- 
tout sur le Kondeland, au Nord du Nyassa, qui, par son altitude, la variété du relief, par le climat, la fertilité de ses terres volcaniques, se prêterait à toutes sortes d'entreprises agricoles, et même à l'industrie; car on y a trouvé la houille.

Si médiocres qu'aient été jusqu'ici les résultats, si écrasante que soit la concurrence anglaise, l'Allemagne ne désespère pas; elle s'acharne, et la discipline de tout son personnel, administrateurs, commerçants et financiers, finira peut-être par triompher à la longue. Afin de remplacer les caravanes de porteurs, un chemin de fer a été ébauché de Tanga à Korogoué qui pourrait devenir un centre important; dans le projet primitif cette ligne, dite de l'Ousambara, devait aboutir au lac Victoria : mais l'Angleterre a l'avance. D'autres tracés sont à l'étude : contre l'opposition de coloniaux allemands des plus compétents, le gouvernement impérial vient de reprendre pour son compte le projet, abandonné une première fois, d'une voie ferrée qui de Dar ès Salam joindrait Tabora, pour rayonner au Nord sur le Victoria, à l'Ouest sur le Tanganyika, vers lequel se hâtent les chemins de fer congolais, au Sud enfin vers la Rhodésia. Une autre ligne est préconisée de Lindi au Kondeland.

Dans l'Afrique allemande, comme dans les territoires britanniques, le commerce est aux mains des Hindous (Banians) et des Arabes. Les lignes de paquebots sont les mêmes de part et d'autres, ligne allemande (Hambourg), anglaise (Londres et Bombay) et française (Marseille).

$2^{\circ}$ L'Angleterre, avant même toute exploitation, s'est assuré des résultats de premier ordre.

Du haut des plateaux de l'Ouganda, du haut de la région des sources, l'Angleterre commande toute la vallée du Nil; elle tient l'Égypte à son entière discrétion; à tout jamais elle a écarté la menace redoutable d'une attaque à revers. - Elle aborde en outre sur le front Sud les plateaux d'Éthiopie qu'elle cerne à l'Ouest, par le Soudan : d'un mouvement habile elle enveloppe les réservoirs du second Nil, du Nil bleu; elle s'assure une position d'attente, une position offensive, pour le jour qu'elle escompte peut-être, qu'elle prévoit du moins et qu'elle prépare, où s'ouvrira la question éthiopienne. - Enfin l'Afrique orientale a de tout temps été une dépendance économique de l'Inde : 
comme l'Inde, la voilà terre britannique, et la vieille colonie se fait la tutrice de la colonie naissante. L'Inde y trouve un exutoire pour ses populations compactes et résout ainsi du premier coup la question qui se pose, très aiguë, dans les autres colonies d'Afrique, en fournissant une main-d'œuvre inépuisable. Parmi les Hindous, terrassiers, agriculteurs, se recrutent encore les commerçants et les banquiers des villes maritimes, et c'est par roupies que comptent les statistiques anglaises de Zanzibar. Il est vrai que l'Inde importe et que la Grande-Bretagne exporte. Mais de la sorte, Zanzibar, le grand marché de l'océan Indien, est deux fois anglais.

Nos voisins ont donc le droit de compter sur l'avenir - le présent n'est pas brillant encore -; déjà les coloniaux d'outreManche voient dans leurs rêves impérialistes une nouvelle Angleterre sur les bords du lac Victoria.

Afin d'atteindre les pays les plus riches et les plus populeux, un chemin de fer de 930 kilomètres a été construit en cinq ans (1896-1901) de Mombaz à Port-Florence : et pourtant l'œuvre présentait des difficultés énormes, climat terriblement malsain dans la zone littorale, crêtes abruptes dressées jusqu'à 2.500 mètres dans l'intérieur, etc. Le tempérament tenace des Anglais, leurs capitaux, les réserves de terrassiers hindous, dont les équipes toujours décimées se renouvelaient toujours, ont triomphé de tous les obstacles.

Ambitieuse, l'Angleterre veut plus encore : elle conçoit un projet nouveau : celui d'unir le lac Victoria à Khartoum et par conséquent au Caire. La vallée du Nil ne fournit pas le tracé voulu : c'est ailleurs qu'on posera les rails. Parmi les clauses du traité signé en octobre 1902 avec le négus Ménélik, il en est une qui concède à la Grande-Bretagne le droit d'établir un chemin de fer en territoire éthiopien. Le jour où il sera achevé, qui peut-être n'est pas loin, la grande ligne impériale du Cap au Caire comptera un long ruban de plus.

Conclusion. - L'avenir se chargera de révéler si l'Allemagne et l'Angleterre ont fait un placement fructueux sur l'Afrique orientale; mais peut-être donnera-t-il raison aux optimistes. Que ne,peuvent en effet, même dans des contrées peu favorisées en apparence, et la paix substituée au brigandage, 
au despotisme, aux razzias d'esclaves, et une judicieuse exploitation des ressources locales, et l'initiative hardie des capitaux, que ne peut en un mot la civilisation moderne, importée, même avec une brutalité cynique, comme elle le fut ici, chez des peuples barbares ou à demi barbares?

Commerce (en millions de francs).

\begin{tabular}{|c|c|c|c|c|}
\hline & ANNÉES & $\begin{array}{l}\text { EXPontation } \\
\text { - } \\
\text { Ivoire. } \\
\text { Noix et aman- } \\
\text { des de coco, } \\
\text { caoutchouc, ca- } \\
\text { fé, céréales. } \\
\text { Bétail, peaux, } \\
\text { cornes. } \\
\text { Bois de char- } \\
\text { pente. }\end{array}$ & $\begin{array}{l}\text { IMDontation } \\
\text { Cotonnades et } \\
\text { tissus. } \\
\text { Produits ali- } \\
\text { mentaires, riz, } \\
\text { grains, épices, } \\
\text { spiritueux. } \\
\text { Quincallerie, } \\
\text { verroterie. }\end{array}$ & TOTA. \\
\hline & & FR. & F R, & FR. \\
\hline $\begin{array}{l}\text { Afrique orientale allemande. } \\
\text { Afrique anglaise: }\end{array}$ & $1904-08$ & 12.6 & 26.1 & 88.7 \\
\hline 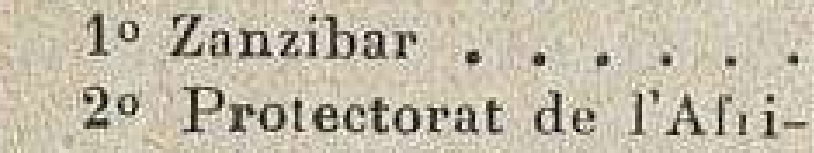 & $1,907-10$ & 25.4 & 25.7 & 51.1 \\
\hline que crientale .... & $1907-10$ & 12.6 & 19.7 & $3^{*} \cdot 3$ \\
\hline $3^{\circ}$ Ougania. . . . . . & $1907-10$ & 3.7 & 9.2 & 12.9 \\
\hline
\end{tabular}




\title{
CHAPITRE XV
}

\author{
ÉTHIOPIE. - SOMALIE. - ERYTHREE
}

\section{S OM M A IRE}

I. Limites. - Le pays des Somali dessine la "Corne orientale " de l'Afrique entre le golfe d'Aden et l'océan Indien; l'Ethiopie ou Abyssinie confine à l'Afrique orientale anglaise, au Soudan angloègyptien et à l'Érythrèe, c'est-à-dire aux possessions italiennes de la mer Rouge.

II. Supcrficic. - Environ $1.120 .000 \mathrm{kmq}$.

11I. Orogénie et relief. - La contrée appartient à la grande région de dislocation de l'Afrique orientale : au centre un sillon de fracture, volcanique et lacustre, s'évase vers la mer Rouge et le golfe d'Aden; sa falaise orientale est le rebord du plateau des Somali, incliné au Sud-Est; sa falaise occidentale le rebord du plateau éthiopien, incliné au Nord-Ouest, vrai chaos de monts volcaniques (1e Ras Dachan, $4.620 \mathrm{~m}$.).

1V. Climat. - 1. La côte de la mer Rouge et du golfe d'Aden est un des points les plus chauds du globe : chaleur sèche et continue.

$2^{\circ}$ Les plateaux Somali ont une temperature plus inégale : les pluies tropicales tombent pendant l'èté, apportées par les vents de l'océan Indien.

$3^{\circ}$ L'Éthiopie présente trois zones de climat, en rapport avec l'altitude : la ( kolla " est chaude, humide et malsaine; la " voina déga ") a la température moyenne de Naples; la " déga " est la zone alpine. Les pluies et les neiges tombent de mars à septembre.

V. Hydrographie. - $1^{\circ}$ Le versant de la mer Rouge et du golfe d'Aden ne présente que des vallées sèches et courtes; la plus longue est celle de l'Aouache.

$2^{\circ}$ A locéan Indien arrive le Djouba

$3^{\circ}$ La grande vallèe d'effondrement contient plusieurs bassins fermes, entre autres celui du lac Rodolphe alimentè par l'omo.

4. Vers le Nil blanc s'ecoulent le Sobat, puis des rivières aux crues périodiques dont le limon rouge ira plus bas féconder l'Égypte : le Nil bleu ou Abbaï, qui traverse le lac Tana et l'Atbara, grossi du Takkazè.

G. Lespagiol et M. Fallex, - Afrique. 
VI. Côtes. - Le cap Guardafui détermine deux sections littorales : l'une sur la mer Rouge, le detroit de Bab-el-Mandeb et le golfe d'Aden, de tout point semblable à la côte d'Arabie, déserte et torride, sans autre découpure que la baie de Tadjoura avec le port de Djibouti; l'autre sur l'océan Indien, d'abord rocheuse et tout aussi aride, puis plus verte au Sud et garnie d'un plus grand nombre de ports indigènes.

VIII. Vie végétale. - $1^{\circ}$ Le littoral a la végétation des déserts.

$2^{\circ}$ Le versant de l'océan Indien présente à l'ouest des montagnes feuillues et des vallèes fertiles que cultivent les Galla, à l'Est des steppes et des brousses que parcourent les Somali.

3. L'Éthiopie se distribue suivant trois zones : les "kolla ", à végétation tropicale exubérante ; les " voina dèga ", qui conviennent á la vigne, aux céréales, au caféier et aux prairies; enfln les "dèga ", avec des pâturages alpestres.

VIII. Vie animale. - Dans la forêt chaude et épaisse vivent les animaux arboricoles et quelques grands mammifères.

Sur la brousse les carnassiers poursuivent les animaux coureurs

Parmi les espèces domestiques, on retrouve chez les Somali le chameau, et partout on élève le cheval, le bceuf à bosse, la chèvre
et le mouton.

1X. Vie humaine. - Les peuples sont de race hamitique.

Les Galla, de l'Éthiopie méridionale, sont des agriculteurs et des èleveurs.

Les Somali sont des nomades pasteurs, ainsi que les Danakil.

Les Abyssins ont sur tous la superiorité dune civilisation plus avancée ; cultivateurs et éleveurs, ils sont chrétiens monophysites. X. Gonvernement et villes. - 1. L'Éthiopie est une monarchie absolue, de forme féodale, gouvernèe par un négous (capitale, Addis Ababa) et divisée en provinces. Les garnisons abyssines occupent les pays Galla et notamment la ville de Harar.

2. Les possessions italiennes forment l'Érythrée, sur la mer Rouge (Massaoua et Asmara) et la côte Sud des Somali sur l'océan Indien.

$3^{\circ}$ La côte française des Somali a pour capitale Djibouti (10.000 h.), importante escale pour nos lignes maritimes et débouché
du Choa.

$4^{\circ}$ La côte britannique des Somali a pour chef-lieu Berbera et pour centre commercial Zeila.

$5^{\circ}$ La presqu'ile des Somali est encore indèpendante.

XI. Mise en valeur. - L'Éthiopie est un pays d'agriculture et d'élevage. Lindustrie suffit á peine aux premiers besoins. Les richesses minières abondent, mais ne sont pas exploitées.

L'Italie aborde l'Éthiopie par le Nord, la France par le Sud-Est (chemin de fer de Djibouti), les Anglais par la vallée du Nil.

Quant au pays des Somali, il n'a qu'une valeur économique très
ince. 


\section{DÉVELOPPEMENT}

I. Limites. - Le Pays des Somali dessine la « Corne orientale » de l'Afrique entre le golfe d'Aden et l'océan Indien. L'Éthiopie ou Abyssinie s'élève au-dessus du pays des Galla, du Soudan anglo-égyptien et de l'Érythrée. Érythrée est le nom, renouvelé des anciens, qui désigne les possessions italiennes de la mer Roug'e.

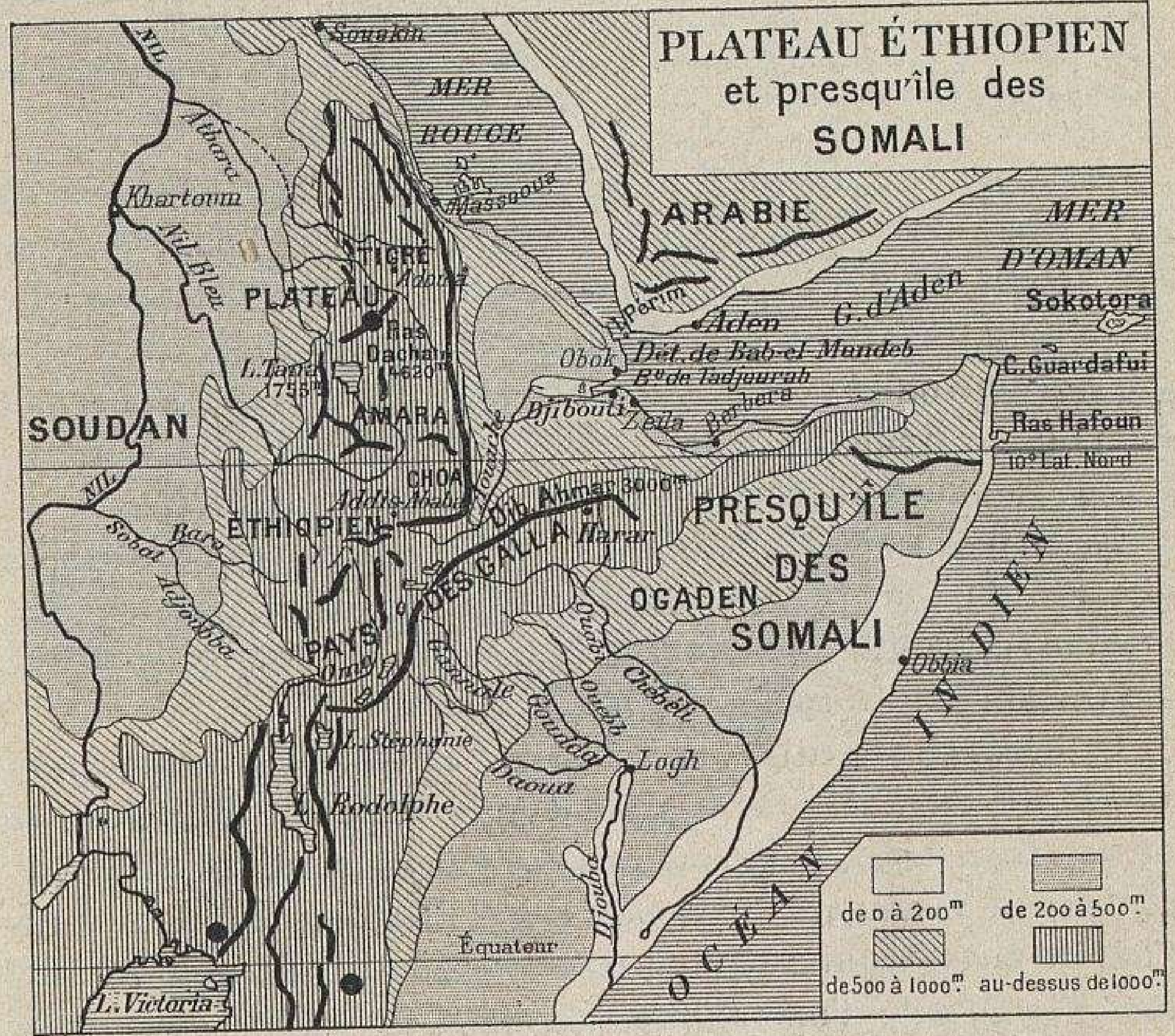

11. Superficie. - On peut l'évaluer à un million et demi ¿e kilomètres carrés, environ trois fois la France.

III. Orogénie et relief. - Éthiopie, Somalie, Érythrée appartiennent à la grande région de dislncation de l'Afrique orientale et du Sud-Ouest de l'Asie, et la vallée de fracture qui soupe l'Éthiopie de la Somalie est un tronçon de la longue ligne d'affaissement du Nyassa à la Syrie creuse. Ici, comme partout 
ailleurs, le fond du fossé est occupé par des lacs (lac Rodolphe) et toute la contrée a été bouleversée par les phénomènes éruptifs à un point qu'on ne saurait imaginer : partout des cônes volcaniques, des cratères éteints, des coulées de lave et des sources thermales.

Les explorations sont encore trop récentes et trop incomplètes pour qu'on sache les formes et les dimensions exaetes de ces lacs; on n'est pas encore fixé sur les noms de beaucoup d'entre eux. Le niveau des eaux semble varier avec la quantité de pluies tombée dans l'année; il en est même qu'une sécheresse exceptionnelle aurait fait disparaître complètement : le lac Stéphanie, par exemple, n'a plus été révélé aux derniers explorateurs que par des eoquillages et des squelettes de poissons. Ce fait, parmi d'autres, donnerait lieu de croire qu'on se trouve en prósence non pas de lacs de cratère, mais de lacs de barrage volcanique.

Les bords du sillon effondré s'écartent au Nord, le long de la mer Rouge et le long du golfe d'Aden. La rivière de l'Aouache qui écoule les eaux éthiopiennes en marque le fond, mais elle s'épuise à travers les déserts et finit dans une dépression sans pouvoir atteindre la mer. Non loin et à 20 kilomètres seulement du golfe de Tadjoura, le lac Assal s'enfonce à 174 mètres, témoignant ainsi des dislocations qui ont bouleversé la surface.

Les falaises montagneuses du grand sillon de fracture sont les rebords de plateaux symétriques : plateau des Somali, incliné au Sud-Est, vers l'océan Indien, plateau éthiopien incliné à l'Ouest et au Nord-Ouest, vers le Nil.

La bordure orientale, en s'écartant au Nord-Est vers le pays de Harar, serre de près le golfe d'Aden et plonge sous les flots au cap Guardafui, pour émerger une fois encore à l'île Socotora. En Arabie les monts du Yémen et de l'Hadramaout sont tranchés de même manière et ont même âge, même origine. Le plateau des Somali, d'une altitude moyenne de 1.400 mètres, a eu ses calcaires jurassiques soulevés d'une seule masse: mais toujours les roches volcaniques apparaissent, sous forme de blocs noirâtres, de pitons isolés, de massifs et même de montagnes véritables $(2.078 \mathrm{~m}$.) qui dessinent le réseau hydrographique. La partie centrale ou Ogaden est une steppe de 8 à 900 mètres, à peine ondulée, avec de grands espaces pierreux.

Plus hardie, s'il est possible, la bordure occidentaie de la grande vallée d'affaissement s'élève d'un seul jet au-dessus de 
l'Aouache et porte le plateau Éthiopien. Les roches volcaniçues (basaltes, trachytes, etc.) font un chaos prodigieux de montagnes, dont la Suisse ne saurait pas même donner une idée; mais les Alpes sont plus grandioses : car ici le socle est trop élevé. Les sommets ont facilement 3 et 4.000 mètres d'altitude sarıs garder jänais de neiges persistantes, et dans le haut pays du Simen, le

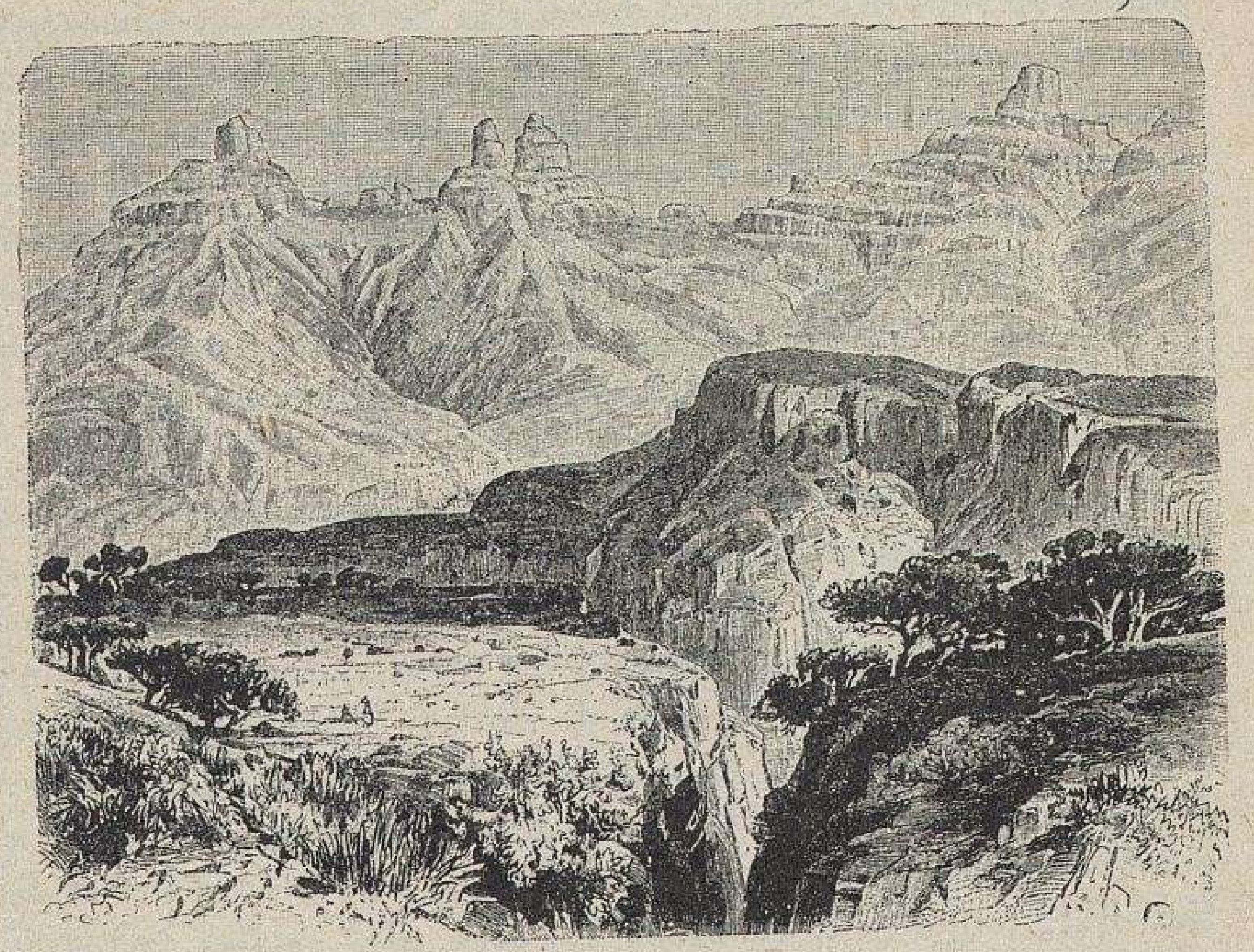

PAYSAGE DES HAUTS PLATEAUX EN ÉTHIOPIE, DANS LE SIMEN.

(D'après Rohlfs.)

Phénomènes d'érosion : cañons, tables et amba.

Ras Dachan atteint presque le chiffre du mont Blanc $(4.620 \mathrm{~m}$.). Compact à l'origine, le bloc éruptif a ẻté découpé, tailladé en terrasses par une érosion d'une extraordinaire puissance; les rivières s'engouffrent au fond de cañons, quolla, de 1.500 à 2.000 mètres de profondeur, et toute la région est débitée en compartiments, en tables, en districts naturellement autonomes. C'est l'érosion encore qui a formé les $a m b a$, pyramides isolées, verticales, tantôt de grès rouge et tantôt de basalte.

IV. Climat. - Situées entre l'équateur et le tropique du Cancer, les régions qui nous occupent ont dans leur ensemble 
un climat tropical et les pluies coïncident avec le passage du soleil au zénith. Mais l'altitude et l'orientation troublent sensiblement ces conditions normales.

$1^{\circ}$ La côte de la mer Rouge et du golfe d'Aden est un des points les plus chauds du globe : la température s'élève jusqu'à $46^{\circ}$ et ne descend pas au-dessous de $18^{\circ}$; les nuits ellesmêmes ne sont pas fraîches. Le climat de Massaoua est extrêmement pénible. La réverbération sur les sables et sur les roches éblouit; tout miroite et brûle. Mais ces fortes chaleurs sont sèches, d'une sécheresse toute désertique $(25 \mathrm{~cm}$. de pluie par an), et très saines. Normalement les pluies devraient tomber en été, mais elles sont alors arrêtées par l'écran des hautes montagnes de l'arrière-pays; et ce sont les vents Nord et NordEst qui apportent pendant l'hiver des ondées, rares, très espacées, mais d'une extrême violence.

$2^{\circ}$ Pour le plateau des Somali, on ne possède encore que des données imparfaites, trop peu nombreuses et de trop courte durée. En général, en raison du relief, les chaleurs sont moins fortes, les nuits plus fraîches et les précipitations plus abondantes. On évalue la moyenne de l'hiver à $24^{\circ}$, celle de l'été à $30^{\circ}$, les maxima à $32^{\circ}$ et plus, les minima à $8^{\circ}$. Les pluies, provoquées par le passage du soleil, tombent de mars à octobre et mieux encore d'avril à juillet, par vents d'Est et de Sud-Est, toujours à de longs espaces, par rafales fortes et courtes.

$3^{\circ}$ L'Éthiopie présente de violents contrastes, et les indigènes sont les premiers à discerner trois zones de climat, qui déterminent elles-mêmes trois étages de végétation :

A. La Kolla ou Quolla (jusqu'à 1.700 mètres) a un climat tropical et malsain; pendant l'été la chaleur est étouffante $\left(40^{\circ}\right)$, pendant l'hiver elle descend rarement au-dessous de $22^{\circ}$.

B. La Voïna déga (de $1.700 \mathrm{~m}$. ̀̀ $2.300 \mathrm{~m}$.) a un climat subtropical et salubre, rarement plus de $27^{\circ}$ et rarement moins de $14^{\circ}$. C'est la température moyenne de Naples. Aussi est-ce sur cette zone que se sont fixées les agglomérations urbaines.

C. Enfin la Déga (de $2.300 \mathrm{~m}$. à $4.620 \mathrm{~m}$, , point culminant) est la zone alpine; la moyenne oscille de $7^{\circ}$ à $17^{\circ}$. Lors de la saison d'hiver, une couche de glace recouvre les nappes d'eau et la 
neige tombe sur les montagnes jusqu'à 3.500 mètres, sans toutefois persister; la latitude ne le permet pas.

D'une façon générale, les précipitations, pluies ou neiges, 0 : lieu en été. Les régions septentrionales ne connaissent qu'une saison pluvieuse, d'arril en septembre, avec maximum en juillet et en août; les régions méridionales, une petite saison pluvieuse (février-mars).et une plus grande (juillet à septembre). Le grand pourvoyeur est toujours l'océan Indien. C'est par torrents diluviens, par bourrasques, avec coups de foudre, que les pluies se précipitent; la terre, toute desséchée, réduite en poussière ou durcie comme de la brique, commence par absorber l'eau sans rien restituer; puis c'est de partout un ruisselleme- intense, les rivières s'emplissent et roulent de puissantes masses d'eau; la montagne se désagrège et les torrents en charrient les débris.

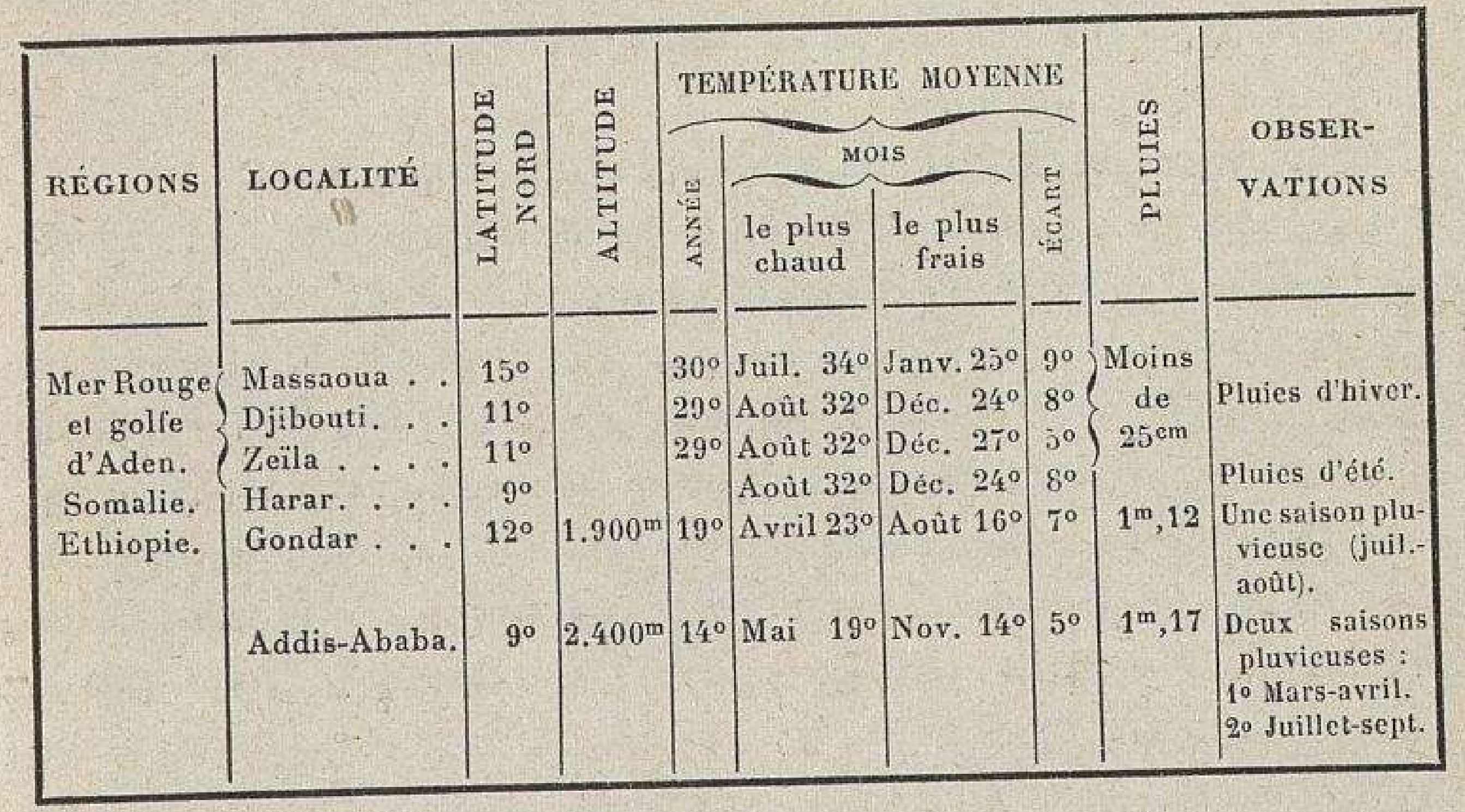

V. Hydrographie. - Les eaux suivent quatre directions principales.

$1^{\circ}$ Le versant de la mer Rouge et du golfe d'Aden ne présente que des oueds dont les vallées sont aussi sèches que courtes. Seul l'Aouache a d'abord des eaux vives, parce qu'il égoutte les hauts plateaux de l'Éthiopie méridionale, mais elles s'évaporent vite dans la fournaise du désert; et seule sa vallée est longue, parce qu'elle emprunte le fond du grand sillon volcanique; elle fournit une voie de pénétration précieuse.

$2^{\circ}$ Le versant de l'océan Indien a de l'ampleur, mais on le connaît mal encore. L'Ouabi Chebeli ou "fleuve des léopard p) et le Djouba (1.200 km. env.), appelé d'abord Gannalé Gquádda. s'alimentent à de fortes altitudes $(3.000$ et $3.500 \mathrm{~m}$.) et stor les s'alimentent à de fortes altitudes $(3.000$ et $3.500 \mathrm{~m}$.) et sor
plateaux suffisamment arrosés des Galla Aroussi. Ma 
mesure qu'ils descendent, ils atteignent la région des steppes semi-désertiques; leur débit se soutient de moins en moins; les affluents se font plus rares et plus irréguliers. L'Ouabi Chebeli n'a pas l'énergie de forcer la barrière des dunes littorales : il se perd dans des lagunes. Le Djouba, dont le bassin plus méridional est aussi plus ramilié, apporte encore assez d'eau à l'Océan, pour qu'on ait pu le remonter malgré sa barre jusqu'à 300 kilomètres de la mer.

$3^{\circ}$ Les lacs, qui se succèdent au fond de la grande vallée d'affaissement, sont des bassins fermés. Le plus grand de tous, le Rodolphe, reçoit l'Omo, qui lui arrive de plus de 2.000 mètres de hauteur, à travers les pays Galla, par une vallée en couloir profonde et tortueuse.

$4^{\circ}$ Le versant du Nil est de tous le plus important.

Le Sobat descend de l'Éthiopie méridionale, fertile et relativement froide, vers les contrées chaudes, marécageuses et malsaines du Soudan. Les deux cours d'eau principaux qui le forment sont au Nord le Baro, au Sud l'Adjouba; dès qu'ils sortent de la montagne, ils disparaissent dans les roseaux des marécages, inondent périodiquement la plaine sur de grandes étendues et forcent les indigènes à construire leurs hultes sur des monticules artificiels. Le Baro semble pouvoir porter des chaloupes à vapeur pendant huit mois et permet de s'avancer à moins de 50 kilomètres de la falaise des Galla du Bouré; la mission Marchand l'a remonté (1S98-99) dans sa retraite de Fachoda sur Djibouti, et peut-être est-il appelé à fournir un débouché commercial vers le Nil de Khartoum.

Les autres rivières descendent des hauts plateaux de l'Éthiopie proprement dite; toutes sont des torrents de régime très inégal, coupés par tant de ressauts qu'elles ne peuvent servir à la nạvigation, et leurs vallées encaissées, chaudes et humides, sont si malsaines que pas une ville ne s'y est installée. Mais leurs crues exercent une influence périodique sur le régime du Nil et c'est leur limon' rouge qui plus bas s'en va féconder l'Égypte.

Le Nil bleu, appelé au Soudan Bahr el Azrek et en Éthiopie Abbaï, est alimenté par un lac si beau qu'il a enthousiasmé tous les voyageurs qui l'ont aperçu. Situé à 1.750 mètres d'altitude, 
cinq fois et demi grand comme le lac de Genève (3.000 kmq.), profond d'une centaine de mètres, le lac Tana est dominé par des roches éruptives dont les promontoires fendent ses eaux pures, et parsemé d'îles volcaniques tantôt nues, tantôt couvertes d'une riche végétation; c'est dans l'une d'entre elles, l'île Sainte ou le mont de Marie (Debra Mariam) que se trouve,

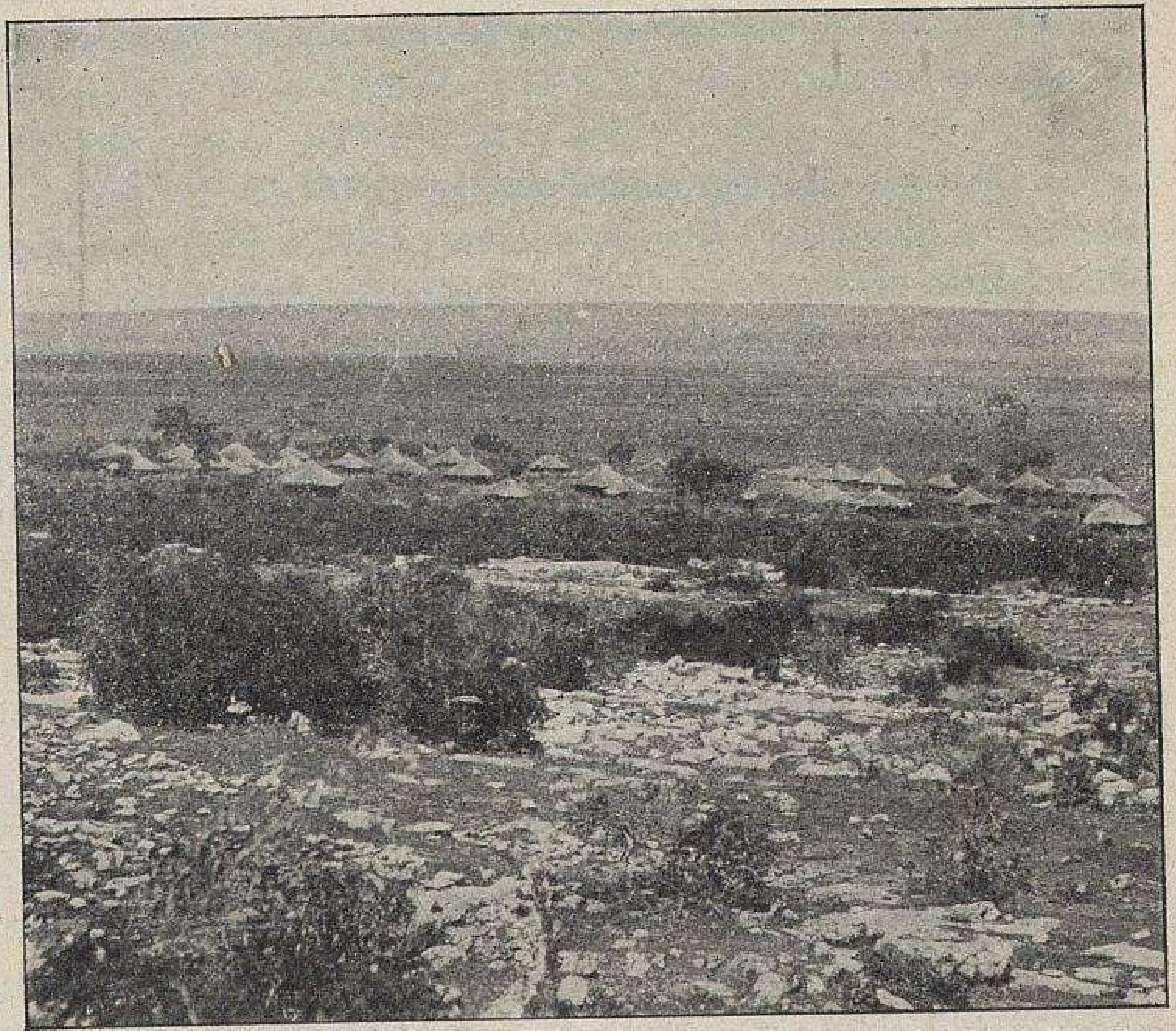

VILLAGE GALLA : PLAINE DE BOUBASSA, AU SUD DE HARAR.

(Photographie Bidault de Glatıgné, communiquée par la Société de Géographie de Paris.)

auprès d'un sanctuaire vénéré, la résidence de l' " Abouna » ou métropolitain d'Abyssinie. Dans les eaux abondent les poissons, sur les rives les oiseaux aquatiques, pélicans, ibis, hérons, canards, etc.; beaucoup d'hippopotames, mais pas un seul crocodile. L'Abbaĩ qui entre dans le lac au Sud-Ouest en ressort purifié au Sud; il décrit un vaste circuit autour des monts du Godjam, tombe de chute en chute, resserré entre des parois basaltiques, reçoit de gros affluents venus du Choa, comme la Didessa, et entre en plaine un peu avant Famaka. 
L'Atbara, né dans la région de Gondar, n'a qu'une très faible partie de son cours en Éthiopie et c'est dans le Soudan angloégyptien que lui arrive une rivière beaucoup plus forte que luimême, le Sćtic ou Takkazé (800 km.). Les gorges encaissées, au fond desquelles coule ce dernier, coupent le Gondar et le Simen, à l'Ouest, du Tigré, au Nord-Est. Le Mareb serait un autre affluent de l'Atbara, s'il ne s'infiltrait dans les sables soudaniens et s'il n'était de plus détourné par les travaux d'irrigation des indigènes.

VI. Côtes. - Le cap Guardafui, "cap des Aromates " chez les anciens, dresse ses falaises calcinées (275 m.) au-devant de l'île anglaise de Socotora et détermine deux sections littorales.

$1^{\circ}$ Depuis l'Érythrée italienne jusqu'au cap Guardafui, la côte de la mer Rouge, du détroit de Bab-el-Mandeb et du golfe d'Aden a été tranchée par les effondrements qui ont séparé l'Arabie de l'Afrique. Elle est d'une monotonie désolante. Au large, des récifs de coraux (Massaoua) et des îlots volcaniques; sur le rivage, des dunes de sable aride qui tremblent sous les chaudes vibrations de l'air, des plaines embrasées d'où surgissent des buttes noirâtres, de la même manière que l'îlot de Périm émerge des flots; en arrière encore, des falaises nues, que viennent par endroits déchirer des ravins caillouteux, des ouadi. Pas de découpures profondes, rien que des mouillages, fort nombreux, mais médiocres. Seule la baie de Tadjoura s'enfonce en angle dans la grande dépression volcanique que dominent de part et d'autre les rebords des plateaux de l'Éthiopie et de la Somalie. Massaoua à l'Italie, Djibouti à la France, Zeïla et Berbera à l'Angleterre, voilà les seuls points que touchent les paquebots européens, mais de nombreux bateaux arabes font le cabotage.

$2^{\circ} \mathrm{Du}$ cap Guardafui à l'embouchure du Djouba, sur l'océan Indien, les marins arabes, les seuls à fréquenter ces parages, distinguent la "côte rocheuse » au Nord; mêmes plages torrides et mêmes falaises noirâtres que précédemment; le ras Hafoun est la saillie extrême du continent vers l'Est - et la " côte des ports» au Sud, de plus en plus verte à mesure que s'accentuc l'influence des pluies saisonnières. Ce sont les mous- 
sons qui favorisent l'aller et le retour des “ boutres 》 arabes : ceux-ci apportent aux Somali de l'intérieur les produits que le climat leur refuse ou que leur paresse ne se résigne pas à demander à la terre. L'Italie avait un moment fondé de grands espoirs sur Opia où réside un Sultan.

VII. Vie végétale. - 10 Désertique, le littoral n'a qu'une végétation misérable d'arbustes épineux. Sur la côte de l'océan Indien, le palmier dattier pọsse à l'état sauvage; les Somali ne savent pas le féconder, ni le faire fructifier.

$2^{\circ}$ Sur le versant de l'océan Indien, les hautes montagnes et les vallées arrosées qui sont à leur pied retiennent les agriculteurs Galla; leur végétation feuillue, leur fertilité contrastent avec les plateaux moins élevés, avec les steppes semi-désertiques que parcourent les Somali. Là les sécheresses prolongées ne comportent plus que des arbres clairsemés et des brousses épineuses, des herbes dures qui se hâtent de fleurir et de fructifier après les pluies de l'été, des mimosées en forme de parasols invariablement penchés dans tous les sens, des euphorbes à candélabre, enfin les gommiers qui sécrètent l'encens et la myrrhe.

$3^{\circ}$ En Éthiopie nous savons déjà que les formes végétales se distribuent sur trois zones comme le climat : en bas, les kolla ont une végétation splendide qu'active une atmosphère étouffante et humide : lianes, bambous, palmiers, baobabs et tamariniers... Là se cultivent le maïs, le sorgho et les plantes tropicales, comme le cotonnier; - à l'étage moyen, les voïna déga, moins exubérantes, doivent leur nom à la vigne, qui fut prospère avant les ravages de l'oïdium; c'est la zone des céréales, des légumes, surtout du caféier et des prairies; - enfin, tout en haut, les déga n'ont plus qu'une végétation chétive; la gelée sévit, les bois ont disparu et les plateaux portent des pâturages alpestres.

VIII. Vie animale. - Par ce qui précède il est facile de deviner comment les espèces animales se répartissent.

Dans la forêt épaisse et chaude, rien que des animaux arboricoles, des singes, des oiseaux, et tout le monde des insectes; 
le crocodile sur les rivières, l'hippopotame, le rhinocéros, le sanglier, le buffle, sur les terres noyées, enfin l'éléphant.

Sur la brousse, lions, panthères, léopards et chacals donnent la chasse aux gazelles, aux antilopes, aux ânes sauvages, à l'autruche et toujours les fourmis élèvent leurs termitières. Le chameau, que nous n'avons plus rencontré depuis le Sahara, fait ici sa réapparition; on l'élève même comme viande de bou-

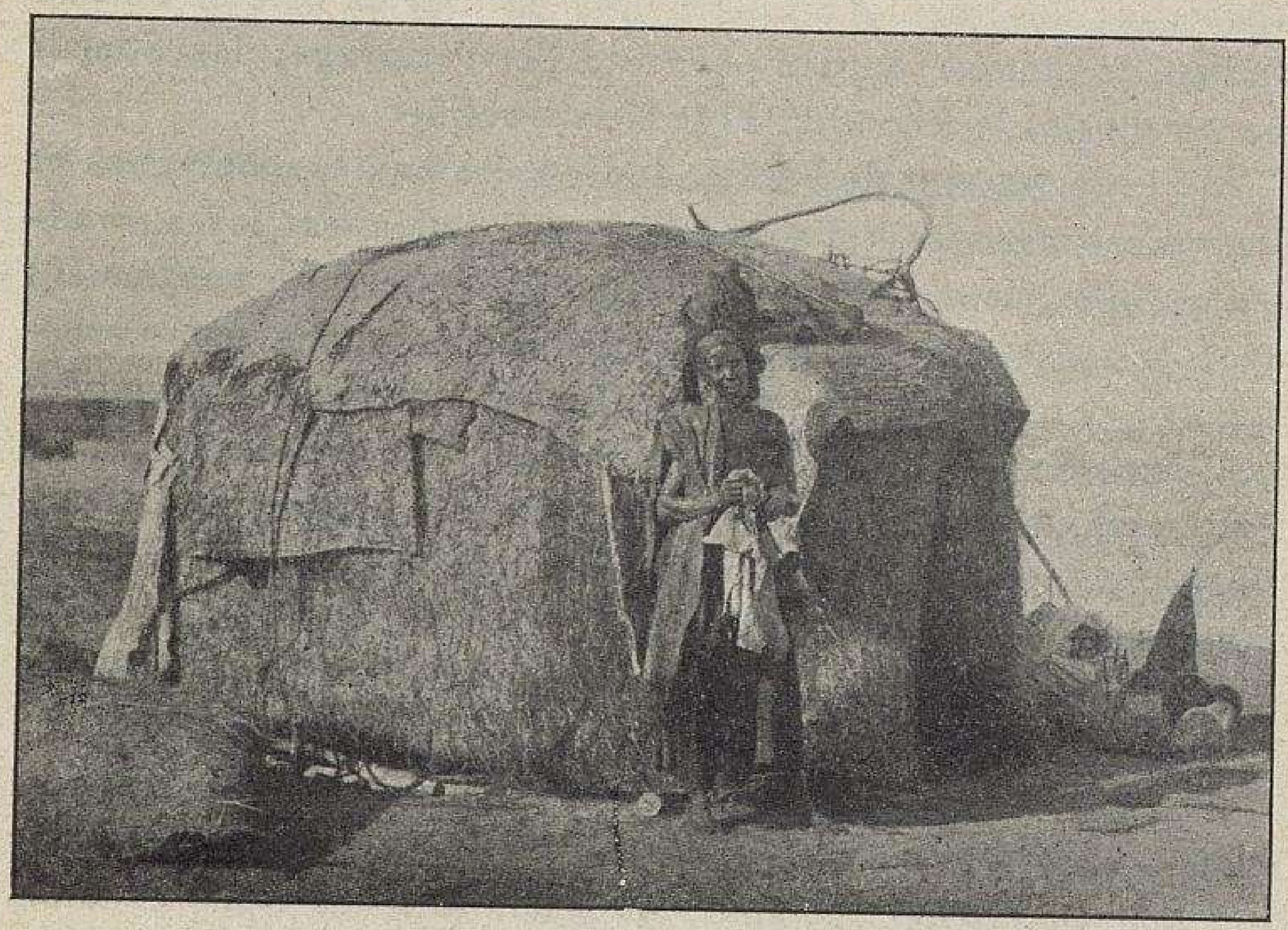

GOURGUI OU CAMPEMENT SOMALI.

Vue extérieure.

(Photographie G. Revoil, communiquée par la Socićté de Géograplice de Paris.)

La hutte en forme de ruche ronde est construite au moyen de cerceaux disposés en roùte et soutenus par une flèche centralc. Cette carcasse est recouverte de peaux de houfs ou de chameaux, de nattes en paille ou en écorce. - La vieille femme du premier plan assouplit, en la frollant, une peuu de mouton, qui confectionnera un vêtement.

(D’après G. Revoil.)

cherie. Les autres animaux domestiques sont le bœuf à bosse, les chèvres, les moutons et le cheval des Somali, dont les qualités rappellent celles du cheval arabe. En Abyssinie les abeilles donnent un miel fort estimé.

Dans les eaux tièdes de l'océan Indien, on pêche le requin, dont les ailerons sont destinés aux Chinois, très friands de ce régal, le corail et les huîtres perlières. 
IX. Vie humaine. - Les peuples des contrées qui nous occupent appartiennent à la race hamitique. Leurs cheveux frisés tiennent le milieu entre les cheveux bouclés des Arabes et les cheveux crépus des Nègres; la peau est foncée, d'un brun

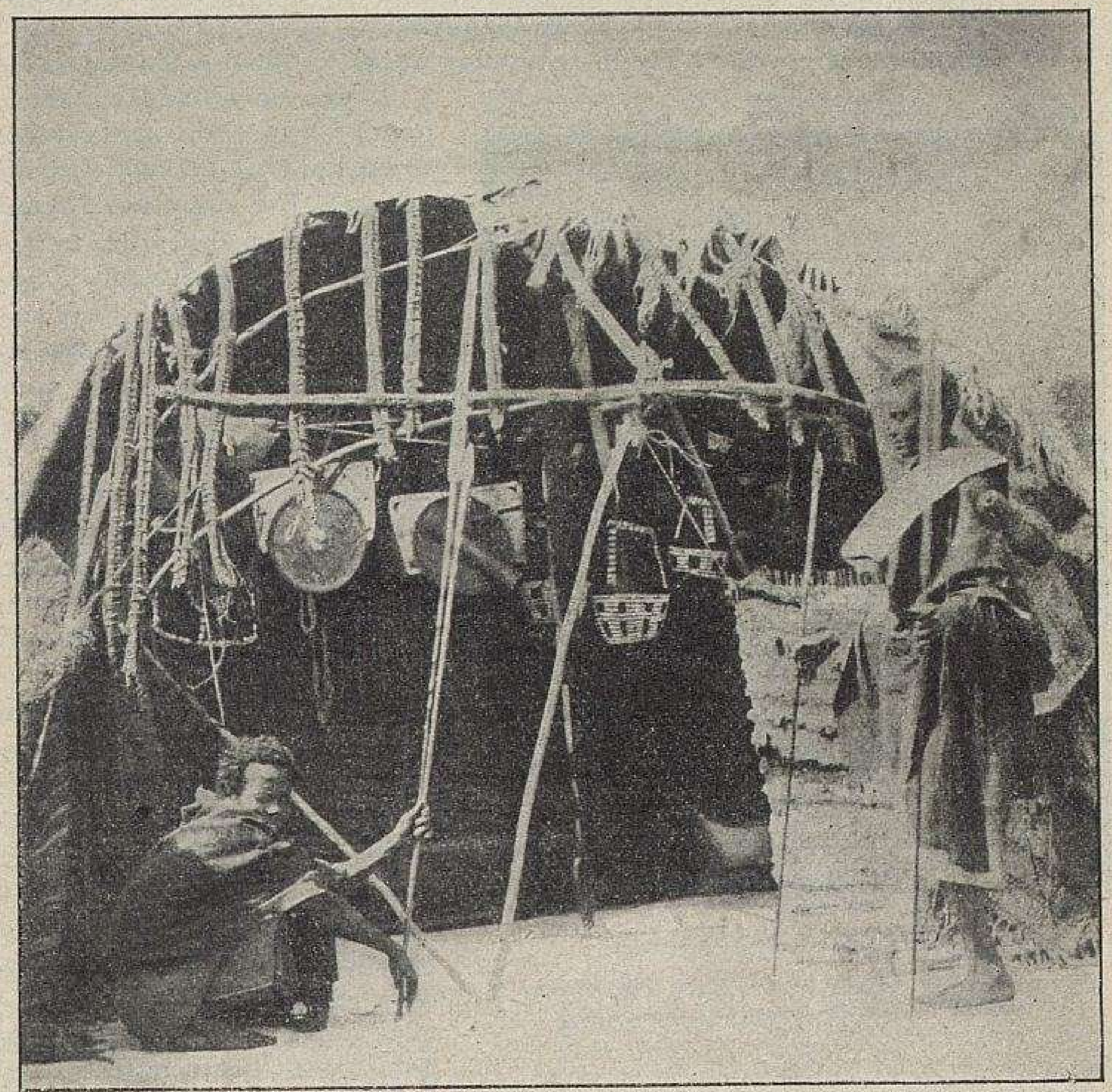

GOURGUI OU CAMPEMENT SOMALI.

Vue intérieure.

(Photographie G. Revoil, communiquée par la Société de Géographie de Paris.)

A ux cerceaux et aux supports sont accrochés les armes, les calebasses pour le lait, les sacs pour le linge, etc., composant l'ensemble des ustensiles employés dans la vie quotidienne par les Somali. (D'après G. Revoil.)

rougeâtre, les épaules larges, la taille maigre et élancée, le nez fin et proéminent. Assez pure chez les Galla, la race a été plus ou moins mélangée de sang arabe chez les Somali, les Danakil et les Abyssins.

Les Galla occupent les plateaux de l'Éthiopie méridionale jusque vers le 
$4^{\circ}$ Lat. Excellents cavalicrs, à l'allure martiale, très belliqueux, ils ont soutenu de longues luttes contre les Abyssins et ont fini par être vaincus, après avoir touché au succès. Pour armes, ils ont le sabre, la lance et le bouclier; pour vètement, une pièce d'étoffe, en coton, dans laquelle ils se drapent; pour habitations, des huttes rondes, à toit conique, construites avec des matières végétales. La fertilité des terres qu'ils occupent en a fait des peuples agriculteurs et éleveurs, de civilisation plus avancée que les Somali et les Danakil. Ils sont musulmans.

Les Somali se dispersent sur les plateaux de la "Corne orientale »; ils

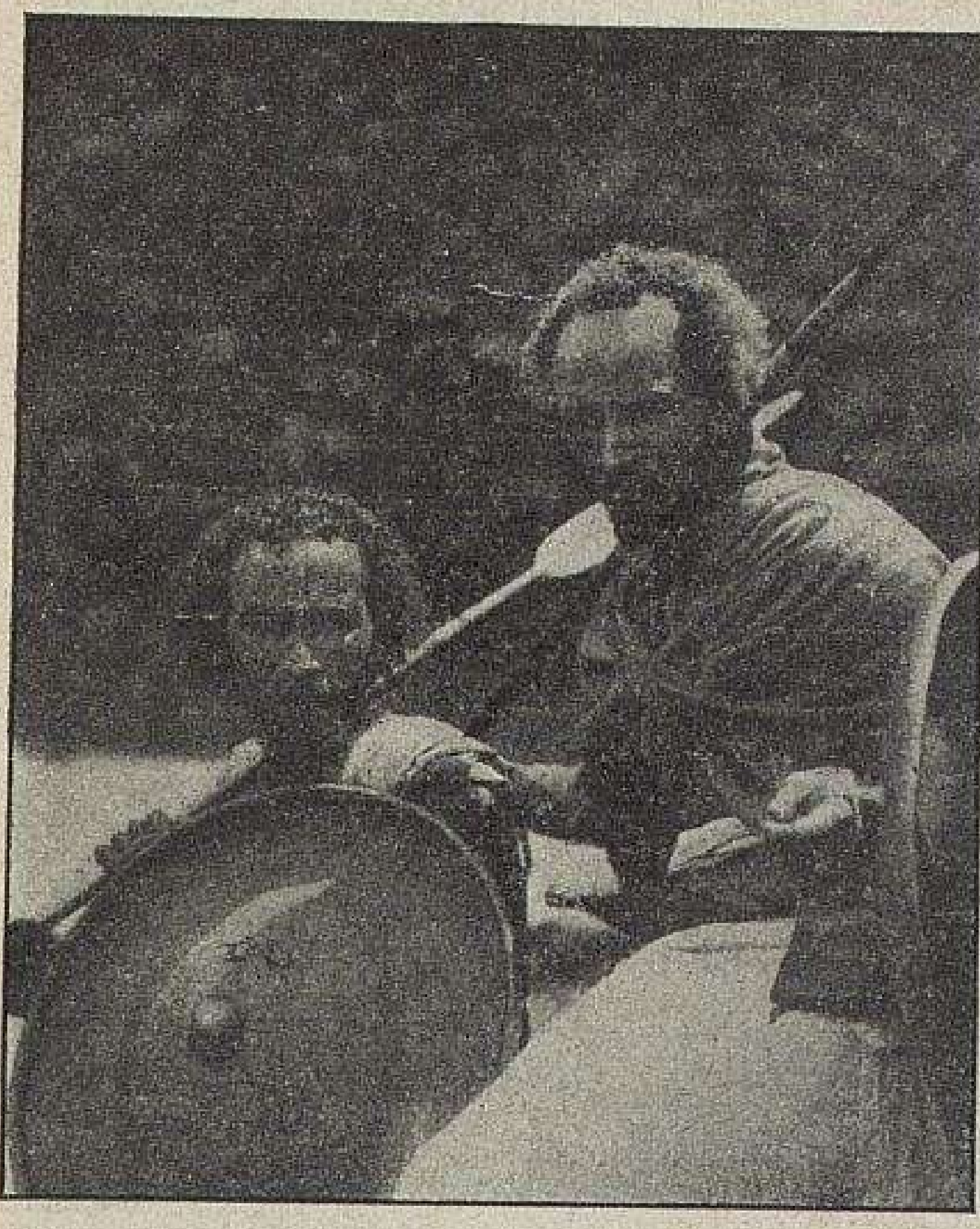

TYPES DE DANAKIL.

(Photographie Bidault de Glatigné, communiquée par la Société de Géographie de Paris.) y vivent en nomades, dédaigneux du travail de la terre et en général de tout travail manuel. Des nomades ils ont la maigreur physique, la sobriété et l'endurance, les mours guerrières, l'organisation par tribu; ils aiment l'espace et l'air libre, toujours prêts à razzier les sédentaires, à voler le bétail, à détrousser les caravanes. Et c'est le troupeau qui fait toute leur richesse (chameaux, gros bétail, chèvres, moutons, chevaux et ânes), c'est lui qui règle leur vie, des plus simples, et les oblige à se mettre en quête de pâturages toujours nouveaux; le règne animal leur fournit entore vètements, nourriture, mobilier, armes et matériaux pour leurs habitations. L'lslam les a pénétrés; mais ils sont peu religieux, nullement fanatiques et beaucoup sont restés fétichistes. Sur la côte, au contact d'autres races, ils se font marins, pêcheurs et marchands; tous les voyageurs, qui les voient à notre escale de Djibouti, ont été frappés de la longueur de leurs bras, qui, maigres, noirs et hâlés, sortent d'étoffes blanches et flottantes.

Les Danakil ou Afar habitent les déserts compris entre les plateaux éthiopiens et la côte, depuis Massaoua jusqu'à Djibouti. Nomades, ils mènent une vie errante, plus misérables que les Somali, dont les pâturages sont meilleurs. De même famille que ceux-ci, ils les rappellent à beaucoup d'égards, mais jls sont plus maigres, plus secs et de visage plus ridé.

Le terme d'Abyssins, que l'on emploie pour désigner d'ordinaire les habitants de l'Éthiopie, n'a qu'un sens politique, tout comme en Europe la qualification d'Autrichien. Il dérive d'un mot arabe, injurieux et offensant, synonyme de "ramassis". Les Abyssins ont sur tous leurs voisins, même sur les Galla, une supériorité de culture incontestable; ils la Ǵjivent en partie au pays qui les porte : la forteresse naturelle que forment 
les hauteurs nırcelées des plateaux a éearté les envanisseurs ou bien les a retenus, en favorisant leur assimilation. Au Nord et au Sud se sont fait sentir des influences sémitiques; une colonie juive habite la région du lac Tana et la tradition fait descendre la dynastie actuelle d'un fils de Salomon et de la reine de Saba. En outre, le contact avec les marchands d'Alexandrie, avec les Grees de Byzance, plus tard avec les Arabes, explique le métissage de la race et l'étut avancé de la civilisation.

Au physique le type est fort mélangé, mais les traits ont de la noblesse; la peau a toutes les nuanees, depuis le noir frane jusqu'an bronze. Le costume national se compose d'une grande toile de coton - le tobé - qui fait robe, toge, si l'on veut, et dans laquelle l'individu se drape, non sans dignité. Les maisons sont des ehaumières à pans de bois, ou bien à murs d'argile, avec des toits de chaume coniques. Culture, élevage, telles sont les occupations des Abyssins.

Convertis a christianisme à l'époque de Constantin ( $11^{e}$ siècle), ils acceptèrent sous Justinien la doctrine qu'ils professent encore : ils sont monophysites (e'est-à-dire qu'ils ne reconnaissent en Jésus-Ghrist qu'one nature, la nature humaine) de rite copte et ont pour la Vierge une vénération spéciale. Leur église, nominalement rattachée au patriarche d'Alexandrie, est en réalité indépendante. La

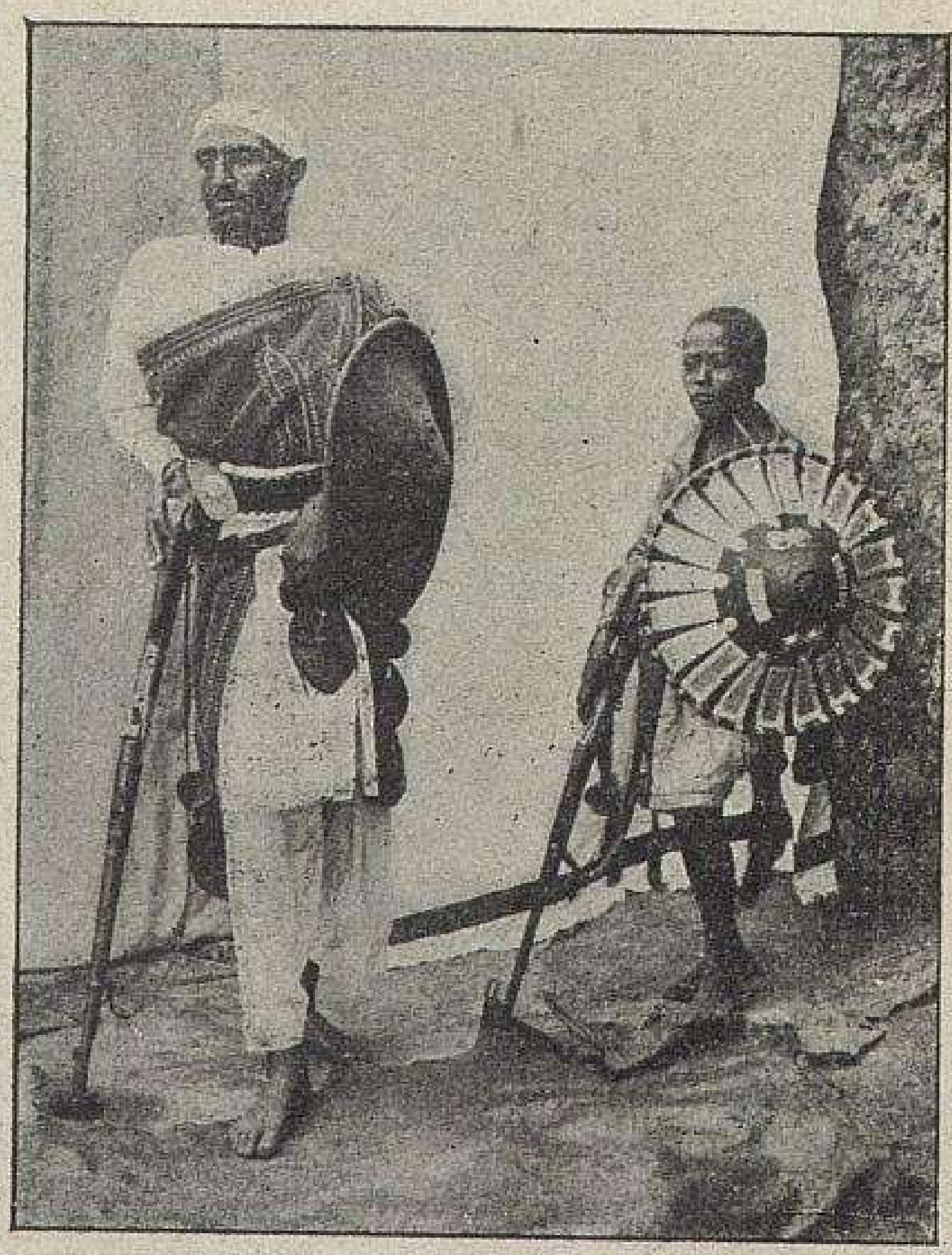

GUERRIEI ABYSSIN ET PAGE.

(Photographie Bidault de Glatigné, communiquée par la Société de Géographie de Paris.) vie monastique, l'art religieux s'inspirent des traditions byzantines, et les affinités qui les rapprochent des Russes, en matière de croyance, sont habilement exploitées par ceux-ci dans un intérêt politique.

\section{Gouvernement et villes. - $1^{\circ}$ Éthiopie. - Les} frontières de l'Éthiopie ont été fixées tout récemment par une série de conventions : en 1902, avec les Italiens, au Nord, du côté de l'Érythrée, et à l'Ouest, vers le Soudan anglo-égyptien; en 1907, au Sud, avec les Anglais, du côté de l'Afrique orientale anglaise; en 1908 enfin, avec les Italiens encore, au Sud-Est, vers la Somalie.

Les calculs les plus récents évaluent sa superficie à 
1.120.000 kilomètres carrés et sa population à environ 8 millions d'habitants.

L'Éthiopie est une monarchie absolue, gouvernée par un souverain chrétien, de rite copte : le " négous " ou roi des rois. Le négous actuel, Ménélik, a réalisé l'unité politique que visèrent ses prédécesseurs; le Tigré, l’Amhara, le Godjam, le

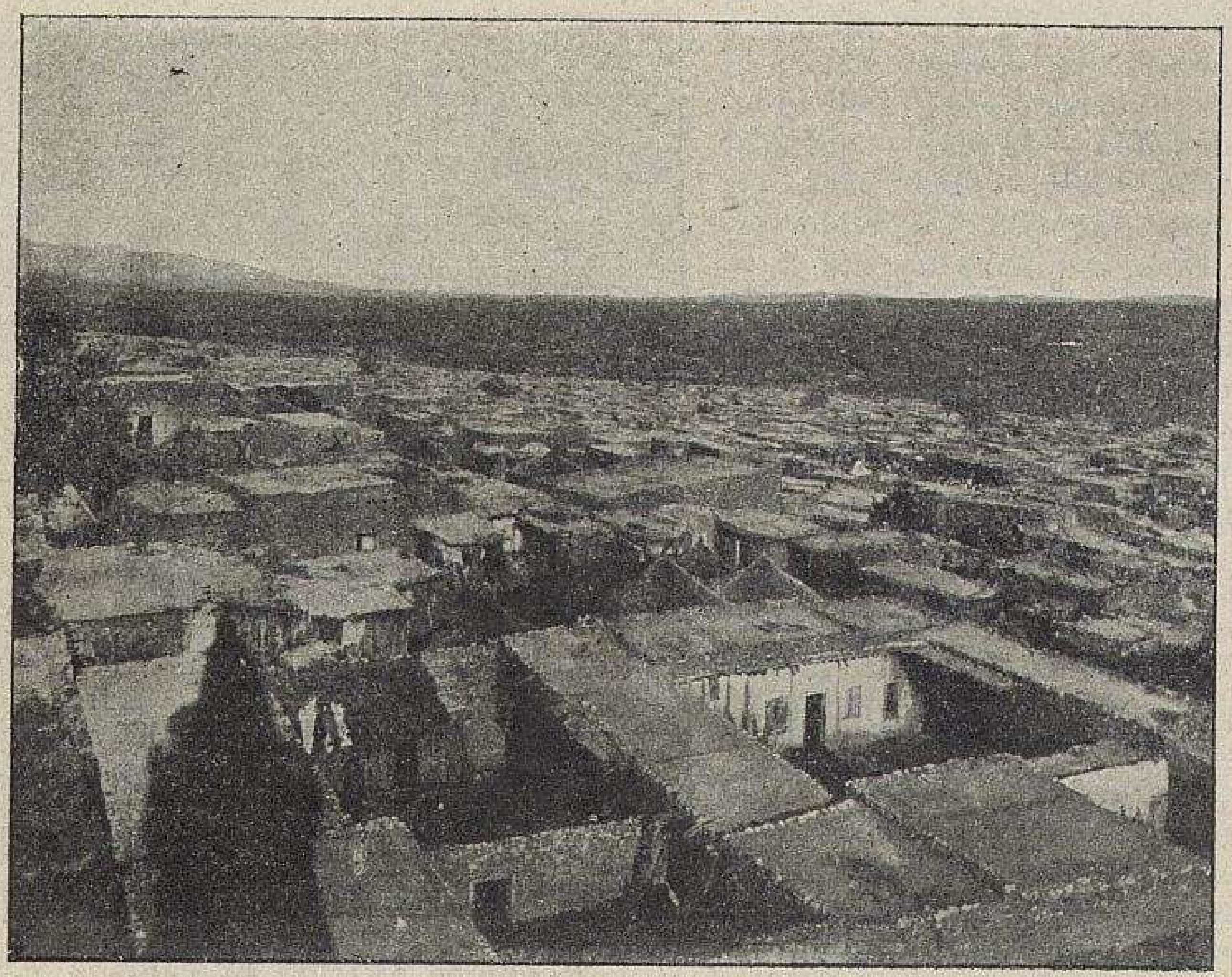

HARAR : CÖTE SUD-EST.

(Photographie Bidault de Glatigné, communiquée par la Société de Géographie de Paris.) La vue, prise de haut, laisse apercevoir les cours intérieures des maisons à toits plats.

Choa furent autrefois des États particuliers dont le morcellement physique du sol favorisait l'autonomie; ce sont aujourd'hui des provinces que gouvernent des vassaux appelés raz. Les dedjaz (ducs), propriétaires de fiefs immenses, rappellent nos barons du Moyen âge, et l'Éthiopie tout entière forme une féodalité militaire, qui peut réunir 200.000 combattants.

Les capitales, comme d'ailleurs les divisions administratives, changent fréquemment suivant le caprice des souverains et des feudataires. Actuellement c'est à $A d d$ dis $A b a b a(30.000$ h.), que réside le négous; autour du đ guébi „ (enceinte) impérial, 
s'étale une ville de paillottes, un campement, le " Katama ». Rien donc qui ressemble à une ville européenne. Tout à la ronde, le pays a été déboisé et le négous s'est construit, à quelques heures au Nord-Ouest, un palais, en pierre cette fois, Addis Alem (Addis = nouveau). - Addis Ababa est bâti sur un

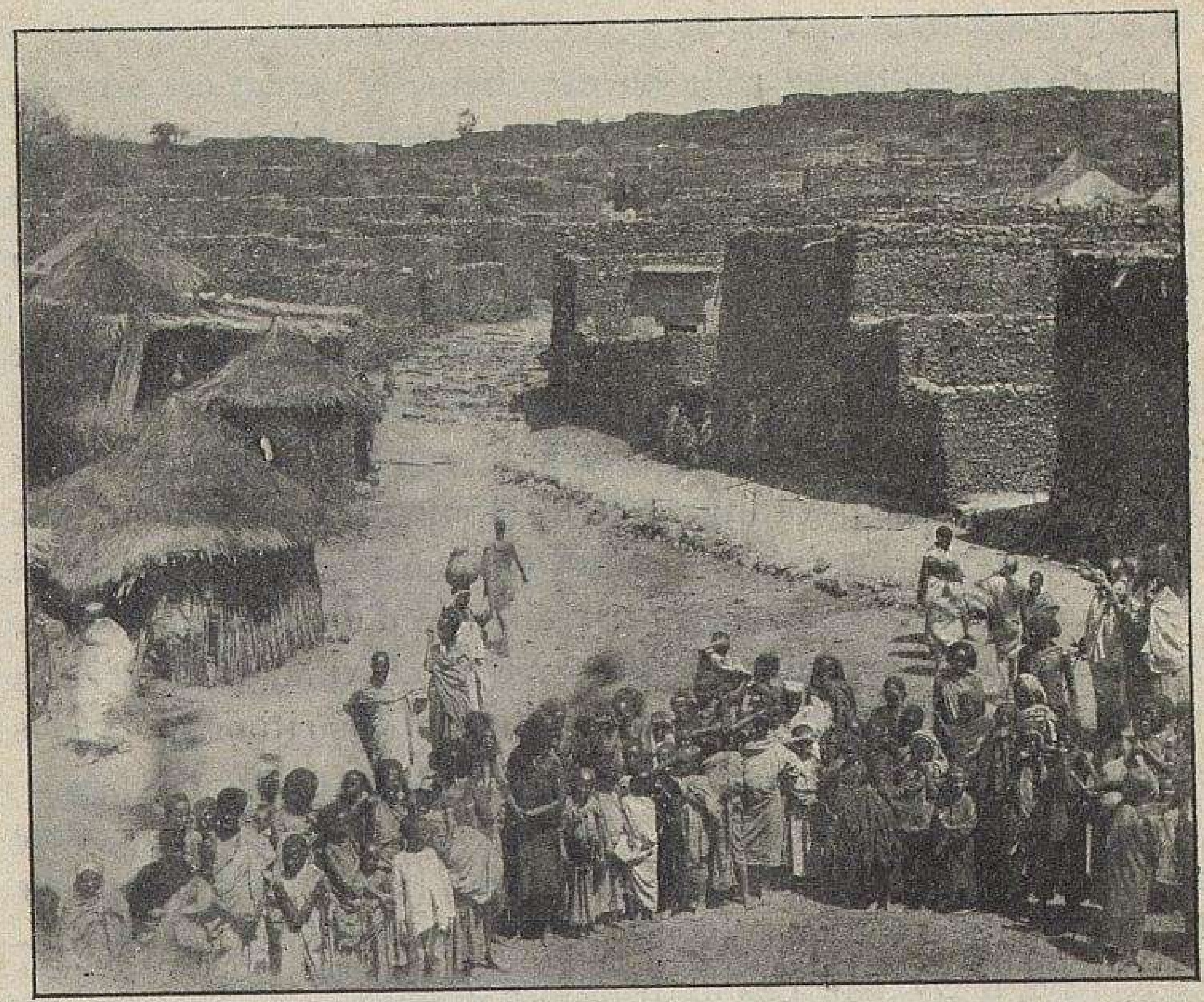

HARAR： UNE RUE.

(Photograplie Bidanlt de Glatigné, communiquée par la Société de Geographie de Paris.) Maisons en terre et paillottes. La foule fait cercle devant l'appareil du photographe, aveuglée par le soleil.

plateau : aucune agglomération en effet ne se fixe sur les cours d'eau. Ankober (2.000 h.) fut autrefois la capitale du Choa. Gondar ( 5.000 h.) est le centre de l'Amhara, Adoua (3.000 h.) celui du Tigré. Axoum ( 5.000 h.) est une vieille métropole en ruines. Quant, aux pays galla, ils ont été rattachés par la conquête et sont occupés par des garnisons abyssines : au Sud le Kaffa, au Sud-Est le Harar, avec la ville du même nom, fort populeuse $(35.000 \mathrm{~h}$.$) , en relations naturelles avec notre colonie$ de Djibouti.
G. Lespagiol et M. Fallex, - Afrique. 
$2^{\circ}$ Les possessions italiennes forment deux groupes : l'Érythrée sur la mer Rouge et la Gôte Sud des Somali sur l'océan Indien ou Benadir.

L'Érythrée, administrée par un gouverneur civil que nomme le roi d'Italie, se compose de trois régions distinctes : l'une maritime, l'autre éthiopienne, c'est la plus favorisée, et la troisième soudanienne. Massaoua $(1.200$ h.) occupe un îlot madréporique qu'une digue relie au continent; le climat est torride, l'eau douce fait défaut. Sur la côte encore, Assab, Zoulla. Le siège des principales administrations a été installé sur les plateaux intérieurs dont la température est moins intolérable, à Asmara. - Keren est le centre des Bogo.

La Côte italienne des Somali, dépendance administrative de l'Érythrée, forme une bande de 180 kilomètres de profondeur le long de l'océan Indien depuis le cap Guardafui jusqu'au Djouba. C'est un pays ingrat et les Italiens se sont heurtés à l'hostilité farouche des indigènes, chaque fois qu'ils ont tenté de pénétrer à l'intérieur. Opia, résidence d'un sultan protégé, est un lieu de campement plus encore qu'un village. Magdichou forme un autre centre de ravitaillement maritime pour les nomades des plateaux.

$3^{\circ}$ Possessions françaises. - Le protectorat de la " Côte française des Somali » est délimité sur la mer, à l'Ouest par l'Érythrée, à l'Est par les possessions anglaises; dans l'arrière-pays il n'existe pas de frontière arrêtée.

La capitale, Djibouti, de fondation récente (1888), compte déjà 10.000 habitants dont 1.500 Européens; elle se développe comme par enchantement. Elle a sur Aden l'avantage d'avoir de l'eau douce, des jardins potagers et des bestiaux. C'est à la fois un dépôt de charbon, un port de ravitaillement pour nos lignes maritimes (Marseille et le Havre) des Indes et de l'ExtrêmeOrient, de l'Afrique orientale, de Madagascar et de l'Australie, un point d'atterrissement pour le câble sous-marin de Périm, enfin le débouché du Choa et la gare de départ d'un chemin de fer (en 1909, 223 navires entrés, de 445.300 tx.). Son marché très animé réunit un monde bruyant.

Les autres localités sont Tadjoura, sur la baie du même nom, et Obock, aujourd'hui dépossédé de son rang de chef-lieu. 
$4^{\circ}$ Possessions anglaises. - Le protectorat de la Gôte britannique des Somali est une colonie de la Couronne. Le gouverneur réside à Berbera (30.000 h.), la ville la plus considérable, quoique Zeïla ait un commerce plus actif. Seul le littoral est effectivement occupé.

$5^{\circ}$ Pays indépendant. - L'intérieur de la presqu'île des Somali, préservé autant par le climat et par la nature du sol que par l'énergie guerrière des habitants, est encore sans maître. Comme ville, on ne connaît que Bardera, sur le Djouba, et l'on croit qu'en dehors d'elle il n'y a que des villages. Cernés de tous côtés, par l'Éthiopie, par l'Angleterre et par l'Italie, les Somali sont condamnés à perdre fatalement leur indépendance; mais ils la défendent avec énergie.

X. Mise en valeur. - En prenant position sur le littoral, les Italiens, les Anglais et les Français visaient l'exploitation des riches contrées de l'Éthiopie. Comme tous les pays de demi-civilisation, celle-ci est essentiellement un pays d'agriculture et d'élevage. L'industrie est limitée aux premiers besoins de la vie; or la vie est fort simple. Le sol contient des richesses minérales, l'or entre autres, abondantes, mais non encore reconnues.

Une ligne imaginaire tracée à la latitude d'Addis Ababa couperail 1'Éthiopie en deux parties dont les ressources économiques sont assei différentes.

Au Nord, l'homme a fui l'almosphère chaude et humide des kolla, at, tant que la froidure des déga, pour s'installer sur les voïna déga. Cø plateaux d'altitude moyenne sont tristes; ils s'étendent à perte de vue; car les forêts ont été coupées pour les constructions, pour le chauffage et jamais on ne reboise. Les habitants sont de petits propriétaires fonciers, dont les huttes rondes, à toit pointu, s'aperçoivent à de grandes distances; tout à l'entour, les champs, d'une culture facile, produisent abondamment les céréales (blé et orge) et les légumes (lentilles et fèves), tandis que les vallées chaudes, d'en bas, sont réservées au caféier et an cotonnier; l'indigène y descend pour visiter et surveiller ses plantations. Les plateaux fournissent en outre des pâturages étendus, excellents, où s'élèvent les boufs, les moutons et les chevaux. Comme il n'existe pas de routes, que les transports sont des plus difficiles dans une région découpée en tranches par une érosion intense, les seuls produits qui s'exportent sont ceux de l'élevage : les troupeaux, amenés sur les marchés, s'échangent contre des objets manufacturés (étoffes de laine, tissus de coton et de soie, chapeaux, chaussures, quincaillerie, armes et munitions). Ces contrées septentrionales sont donc susceptibles de devenir, pour les industries euro. 
péennes, un pays de consommation et de fournir une clientèle qui partage nos besoins.

Tout autre, bien plus riche, plus variée est l'Éthiopie méridionale ou pays des Galla. Là, sous un climat parfait (température de $10^{\circ}$ à $25^{\circ}$ ),

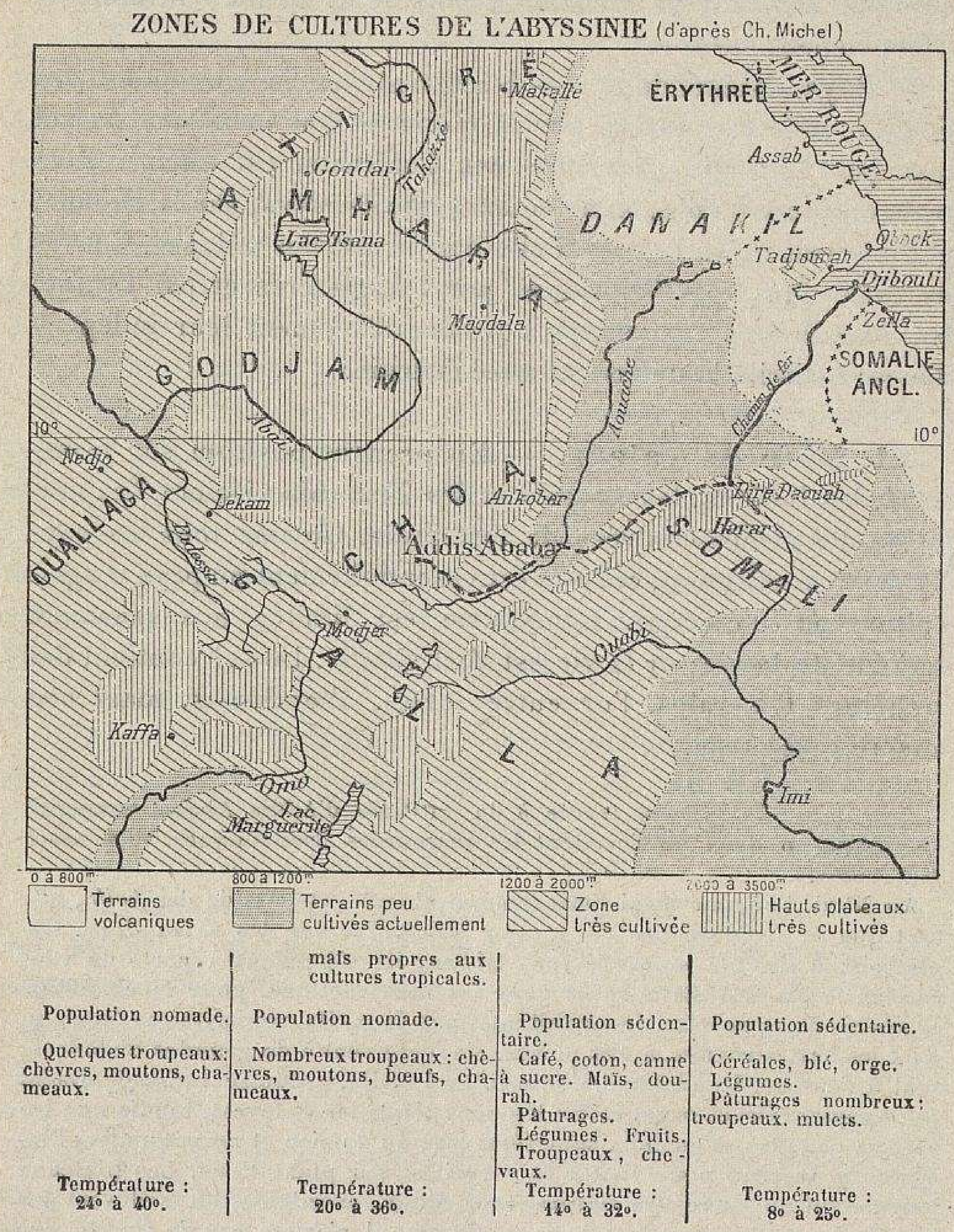

grâce à des pluies abondantes et régulières, le sol donne de lui-même jusqu'à deux récoltes par an. Dans les fonds, le cotonnier; à mi-cóte, les céréales (maïs, sorgho, orge, blé), les légumes (lentilles, fèves, pois, pommes de terre, ehoux géants de plus d'un mètre), et encore le tabac, le gingembre. La région mérite bien le nom de "terre promise " que lui 
donne l'explorateur Gh. Michel, à qui nous empruntons ces détails; il y vérifia l'exactitude des paroles de son guide indigène: “Dans l'Ilou Bahor et le Caffa, tu ne pourras pas couper un bâton qui ne soit du caféier; tu verras des ruches d'abeilles à tous les arbres et tu ne pourras jeter une pierre sans qu'elle tombe dans un champ. "Il ne vit en effet que des caféiers dans les vallées de la Gabba, du Godjeb et du Baro, pendant des kilomètres, 80, 100 et 200; une infime partie est récoltée, le reste tombe et pourrit sur place. - Les Galla, réduits à la condition de serfs, ne possèdent pas le sol; la terre est la propriété du négous, il en laisse la jouissance à ses grands feudataires abyssins, mais il peut en faire don à qui il lui plait. Toutes ces conditions réunies, physiques, sociales et politiques, permettent aux Européens l'espoir d'importantes concessions et de plantations fructueuses.

Offre de bestiaux et demande de produits manufacturés au Nord, possibilités de grandes exploitations agricoles au Sud, voilà certes, sans parlex des richesses minières, de quoi exciter les convoitises européennes.

Voies de pénétration. - L'Éthiopie est abordable de trois cótés.

Au Nord, les Italiens, établis sur l'îlot torride de Massaoua, ont d'abord jeté un chemin dêfer de $27 \mathrm{~km}$. jusqu'à Saati, par-dessus l'horrible plaine volcanique; ils l'ont ensuite prolongé jusqu'à Asmara, d'où ils visent l'intérieur de l'Ethiopie. Par là en effet ils pourront drainer les contrées septentrionales.

Les deux autres voies s'ouvrent au Sud, l'une française au Sud-Est et l'autre anglaise au Sud-Ouest. Jusqu'ici nous avons l'avance : de Djibouti une voie ferrée a été construite jusqu'à Addis Harar (308 km.), puis jusqu'à Diré Daouah, "véritable pont lancé sur le désert ". Addis Harar est relié à Harar par une route carrossable. Le point terminus que vise ce chemin de fer est Addis Ababa, par la vallée de l'Aouache.

Quant aux Anglais, deux routes s'offrent à leur activité tenace : le SobatBaro, le Bahr-el-Azrek - Abbaï, et des actes récents révèlent clairement leurs intentions. Par le traité d'Addis Ababa (1902) l'Angleterre a obtenu sur le Baro l'enclave de Itang (400 ha.), pour l'installation d'établissements commerciaux et maritimes, et encore la faculté de construire une voie ferrée en terre éthiopienne, d'où la possibilité d'unir Khartoum et par conséquent le Gaire à l'Ouganda. Ce n'est pas tout encore : maîtresse des sources du Nil blane, l'Angleterre prend soin d'écarter en outre ses concurrents du $\mathrm{Nil} \mathrm{bleu,} \mathrm{et} \mathrm{le} \mathrm{négous} \mathrm{s'interdit} \mathrm{de} \mathrm{construire} \mathrm{des} \mathrm{ouvrages}$ sur le lac Tana, sur l'Abbaï et sur le Sobat, sauf après entente commune. De la sorte la fertilité de l'Égypte est à la diserétion entière de la Grande-Bretagne.

- On voit quel champ d'activité féconde et variée l'Éthiopie fournit à l'Europe. Les conditions ne sont pas semblables au pays des Somali. De l'intérieur arrivent à la còte le bétail, et, portés par le bétail, les produits obtenus par cueillette (gomme, encens, myrrhe); de la côte vers l'intérieur montent les denrées alimentaires (riz et dattes), les tissus (cotonnades), le fer pour les armes, le tabac et la verroterie. Ces échanges d'une société pastorale ne sauraient de longtemps alimenter un mouvement commercial, même de second ordre. 
AFRIQUE. CHAPITRE XV

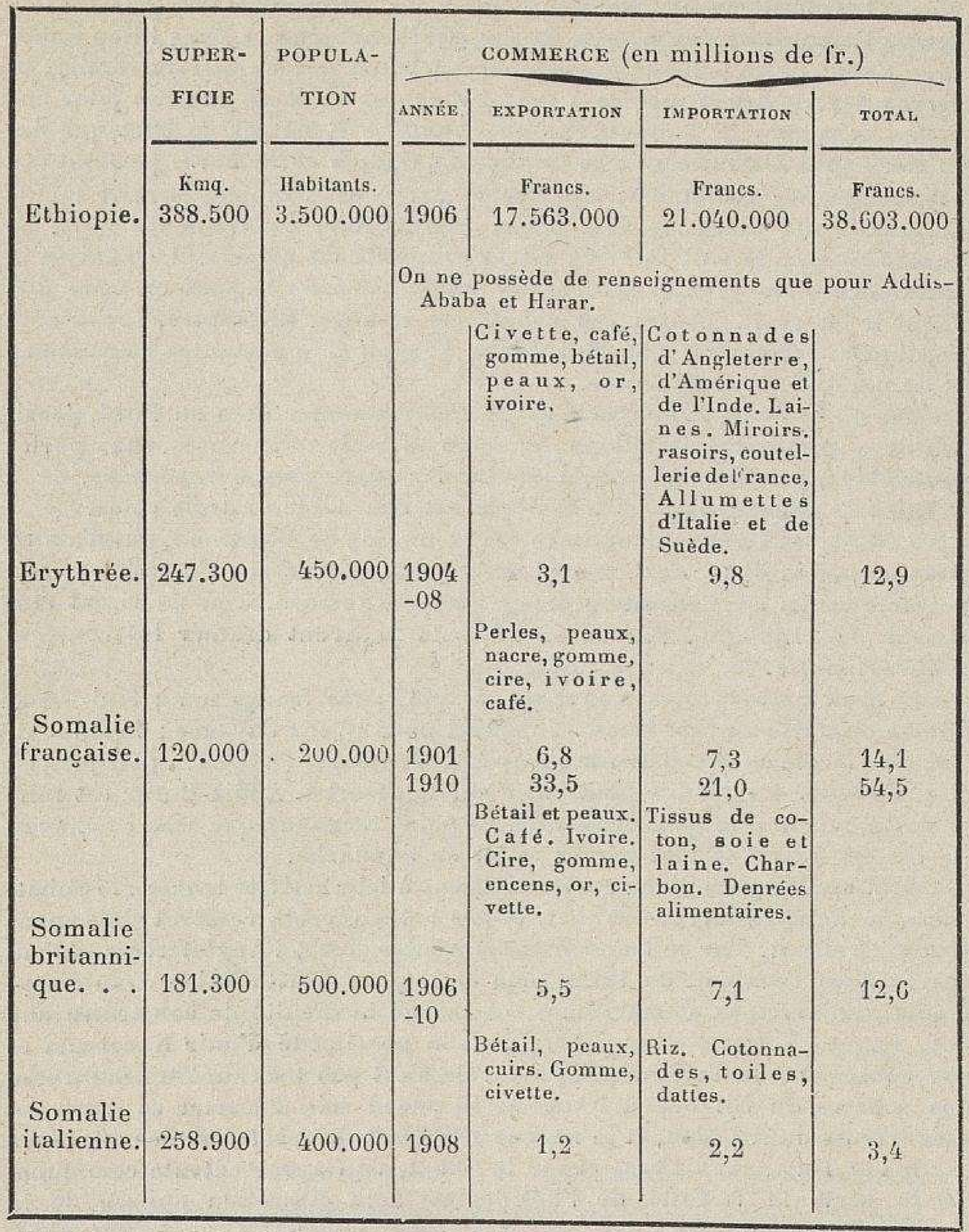




\title{
CHAPITRE XVI
}

\author{
SOUDAN ANGLO-EGYPTIEN
}

\section{SOMMAIRE}

1. Simites. - Le Soudan anglo-ègyptien se compose du Soudan oriental et de la Nubie.

II. Superficie. - Environ 2 millions et demi de $\mathrm{kmq}$.

III. IRelief. - Le Soudan oriental dessine une grande cuvette circulaire entre le massif éthiopien, le plateau des grands lacs, la ligne de partage des eaux, fort vague, entre Congo-Chari et Nil, les monts du Darfour et du Kordofan.

Les plateaux gréseux de Nubie sont coupés par la sinueuse vallée du Nil.

1V. Climat. - Du Sud au Nord se succède une sèrie de régions climatériques : $1^{\circ}$ Les contrées méridionales, de climat subéquatorial, ont une température toujours égale, jamais excessive.

$2^{\circ}$ Les contrées du centre, de climat tropical, ont une saison sèche, de huit et neuf mois, très saine, et une saison de pluies, peu salubre.

$3^{\circ}$ Les contrées du Nord, sont de climat désertique.

V. Hydrographie. - Le Nil draine tout le Soudan oriental et traverse la Nubie.

1. Dans le fond de la cuvette du Soudan, le Nil et son affluent, le Bahr el Ghazal, sont fleuves de marais, aux eaux verdâtres, embarrassées par les roseaux et les grandes herbes. Au delá, le massif èthiopien lui envoie le Sobat, puis le $N$ il bleu, qui roule lors des crues des eaux limoneuses et rouges.

$2^{\circ}$ En Nubie, le Nil est fleuve de desert, sans aucun affluent; il dessine une boucle en forme d's et descend six cataractes ou rapides de Khartoum à Assouan.

VI. Côtes. - Les côtes de la mer Rouge, torrides, rocheuses et sans découpures, possèdent un bon port, Port-Soudan, qui a remplace Souakin.

VIII. Vie végétale. - Du Sud au Nord se sucèdent le parc, la savane, la steppe et le désert.

VIII. La vie animale s'harmonise avec la vie vègètale et avec le climat.

IX. Vic lnumaine. - La population, très clairsemèe, comprend : 
$1^{\circ}$ des Nères: les Niam-Niam, chasseurs et anthropophages; les Vieux-Nilotiques, agriculteurs, èleveurs et forgerons; les Nè-Nilotiques, pasteurs, guerriers et pêcheurs.

$2^{\circ}$ des peuples mètissés d'Arabes, de Berbères et de Hamites, tous nomades du désert.

$3^{\circ}$ enfin les Barabra ou Nubiens, cultivateurs de la vallèe du Nil. X. Giouvernement et villes. - Le Soudan anglo-ègyptien est, comme son nom l'indique, sous le protectorat, de l'Angleterre et de l'Égypte : mais l'Angleterre y est prépondérante " par droit de conquête 1$)$.

La capitale est Khartoum, au confluent des deux Nils : son port est Souakin, sur la mer Rouge, doublèe maintenant de Port-Soudan.

XI. Wise en valenr. - Le Soudan anglo-égyptien, pays immense, à population très clairsemée, n'offre pas de grandes ressources naturelles.

Les Anglais s'efforcent de résoudre le problème des communications, en améliorant la voie fluviale du Nii et en projetant des lignes de chemin de fer; ils espèrent faire de Port-Soudan le grand port. d'entrèe et de sortie.

Mais il faudra de longues annèes pour réparer les ruines causées par les insurrections et les guerres.

\section{DÉVELOPPEMENT}

I. Limites. - Soudan anglo-égyptien est une dénomination administrative sous laquelle ont été réunies deux régions naturelles distinctes : le Soudan oriental et la Nubie.

Le Soudan oriental constitue le bassin du Nil moyen. Il dessine une grande cuvette circulaire entre la mer Rouge, l'Érythrée et l'Éthiopie à l'Est, le plateau des Grands lacs et l'Afrique orientale anglaise au Sud, les bassins du Congo et du Chari au Sud-Ouest et à l'Ouest, les monts du Darfour et le plateau de Kordofan au Nord.

La Nubie, en dehors de la ligne de verdure que dessine la vallée étroite et sinueuse du Nil depuis Berber, porte de sortie du Soudan, jusqu'à Assouan, porte d'entrée de l'Égypte, ne comprend que des steppes et des déserts, aussi bien à l'Est jusqu'à la mer Rouge qu'à l'Ouest où les horizons de sable sans fin de la Libye prolongent le Sahara.

II. Superficie. - On peut l'évaluer à 2 millions et demi de kilomètres carrés.

III. Orogénie et relief. - La nature des roches et les formes du relief sont les mêmes ici que dans le reste du Soudan. Sur une base de 
granite et de gneiss posent des plateaux de grès et des terrasses ferrugineuses, à latérite, que découpent le Nil et ses affluents ou qu'ils recouvrent de leurs alluvions; en maint endroit pointent des roches éruptives.

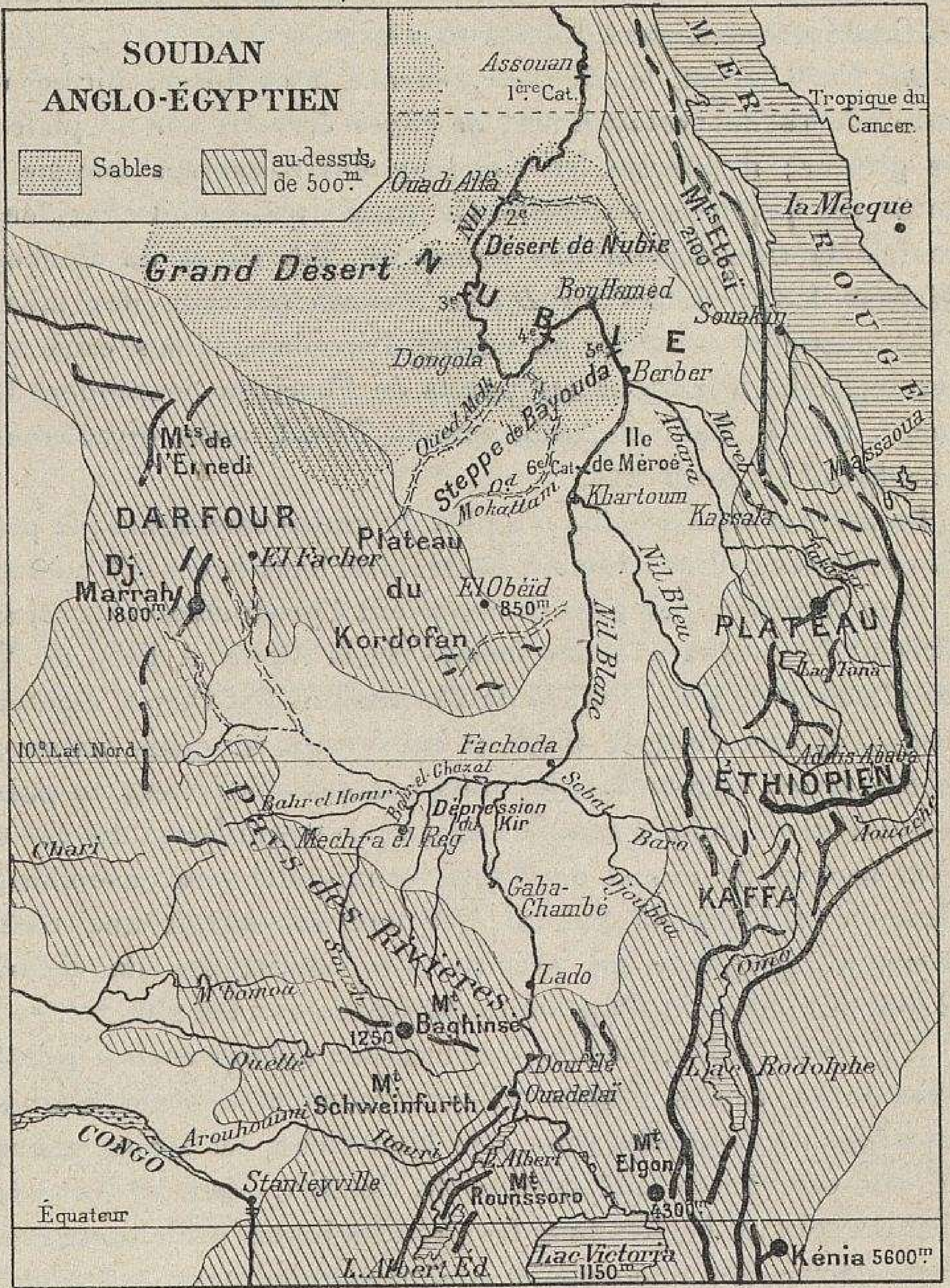

1.a falaise $(1.500 \mathrm{~m}$.) qui porte le plateau éthiopien, et les montagnes volcaniques $(2.500$ et $3.000 \mathrm{~m}$.) qui ferment le bassin du Rodolphe, dominent les plaines alluvionnaires du Nil à l'Est et au Sud-Est.

Par contre, il n'existe pas de ligne de faîte caractérisée au 
Sud-Ouest; aucune crête continue ne sépare le Nil du Congo ou le Nil du Chari. Cà et là des croupes granitiques, comme le Baghlinsé $(1.250 \mathrm{~m}$.), surmontent des plateaux ferrugineux, dont l'altitude s'abaisse de 1.200 à 700 mètres.

Au Nord-Ouest, le Darfour, encore à explorer, forme un chaos de roches volcaniques, de cônes éruptifs sur un plateau de granite; il domine les étendues environnantes comme le ferait une forteresse naturelle. Ce massif, qu'on doit considérer comme la terminaison des monts du Tibesti et du Borkou, dépasse 1.800 mètres au Djebel Marrah (altitude des monts d'Auvergne) et constitue un centre d'écoulement des eaux fort remarquable. Vers tous les points de l'horizon descendent les ouadi, vers le Bahr el Arab, vers le Tchad, enfin directement vers le Nil au Nord-Est.

Le plateau du Kordofan n'a plus de vraies montagnes; la plus élevée de ses collines domine $E l$ Obeïd du haut de ses 800 mètres.

Vers Khartoum les grès commencent à prédominer; ils caractérisent la structure et les formes de la Nubie. A l'Est du Nil les plateaux de grès, coupés de dépressions Est-Ouest, montent jusqu'à la mer Rouge, affectant les formes les plus diverses, tables, tours, pyramides; les plus friables s'émiettent au point d'être à demi enfouis sous les sables, de sorte que l'Atmour c'est le nom du désert de Nubie - rappelle tout ensemble la Hamada et l'Erg du Sahara. Par endroits surgit une roche ancienne, porphyre ou granite. Les montagnes du littoral $(2.000 \mathrm{~m}$.) plongent d'une chute brusque sous les eaux.

A l'Ouest du Nil, mêmes grès friables, mêmes roches primitives dures et nues, mêmes vallées étroites et mêmes solitudes. La steppe de Bayouda, sans être bien riche, est moins pauvre en eau, car elle est aux confins du Soudan. Mais au Nor'd les chaînes sont ensevelies sous les grandes dunes sablonneuses; à perte de vue, pas une oasis et pas un seul habitant.

Entre ces mornes solitudes, le Nil occupe une vallée étroite et sinueuse et franchit par six cataractes les roches primitives qui barrent son lit.

IV. Climat. - Situé entre l'équateur et le tropique du Cancer, le Soudan anglo-égyptien présente du Sud au Nord 
une série de climats gradués, climat subéquatorial, climat tropical et climat désertique.

$1^{\circ}$ Climat subéquatorial. - C'est la région qui s'ètend du plateau des Grands lacs jusqu'à une ligne imaginaire tracée au Sud du Bahr el Homr, du Bahr el Ghazal, du Nil et du Sobat inférieur. La température, toujours égale, mais point excessive, ne s'abaisse pas au-dessous de $16^{\circ}$ et encore pendant quelques heures seulement. L'éloignement du soleil, tantôt à un tropique et tantôt à l'autre, détermine deux saisons sèches, l'une de quatre mois (novembre à février) et l'autre de deux mois (juin-juillet).

\begin{tabular}{|c|c|c|c|c|c|c|c|c|}
\hline \multirow[b]{3}{*}{ Lado. } & \multirow{3}{*}{$\frac{{ }^{2}}{5}$} & \multirow{3}{*}{ 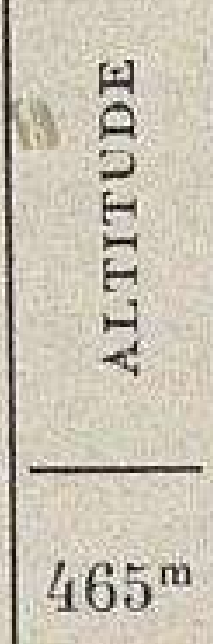 } & \multicolumn{4}{|c|}{ TEMPÉRATURE MOYENNE } & \multirow{2}{*}{ 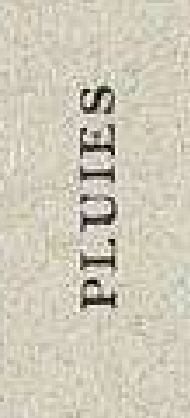 } & \multirow{2}{*}{$\begin{array}{l}\text { OBSER- } \\
\text { VATIONS }\end{array}$} \\
\hline & & & ANNĹE & $\begin{array}{l}\text { le plus } \\
\text { chaud }\end{array}$ & $\begin{array}{c}\text { le plus } \\
\text { frais }\end{array}$ & ÉCART & & \\
\hline & & & $27^{\circ}$ & $\operatorname{Vars} 30^{\circ}$ & Aoùt $25^{\circ}$ & $5^{\circ}$ & $95^{\mathrm{cm}}$ & (Arril et octobre). \\
\hline
\end{tabular}

$2^{\circ}$ Climat tropical. - Plus au Nord, c'est-i-dire au Darfour, au Kordofan, à Khartoum, dans le Dar Sennar, les passages du soleil au zénith se rapprochent; aussi n'y a-t-il plus que deux saisons par an, l'une de pluies, assez courte, l'autre de sécheresse, longue de huit et même de neuf mois. - C'est l'été (Karif) qui est l'époque pluvieuse ; progressivement les averses, les fortes ondées s'établissent du Sud au Nord (avril, puis mai) précédées de tourbillons de sable,

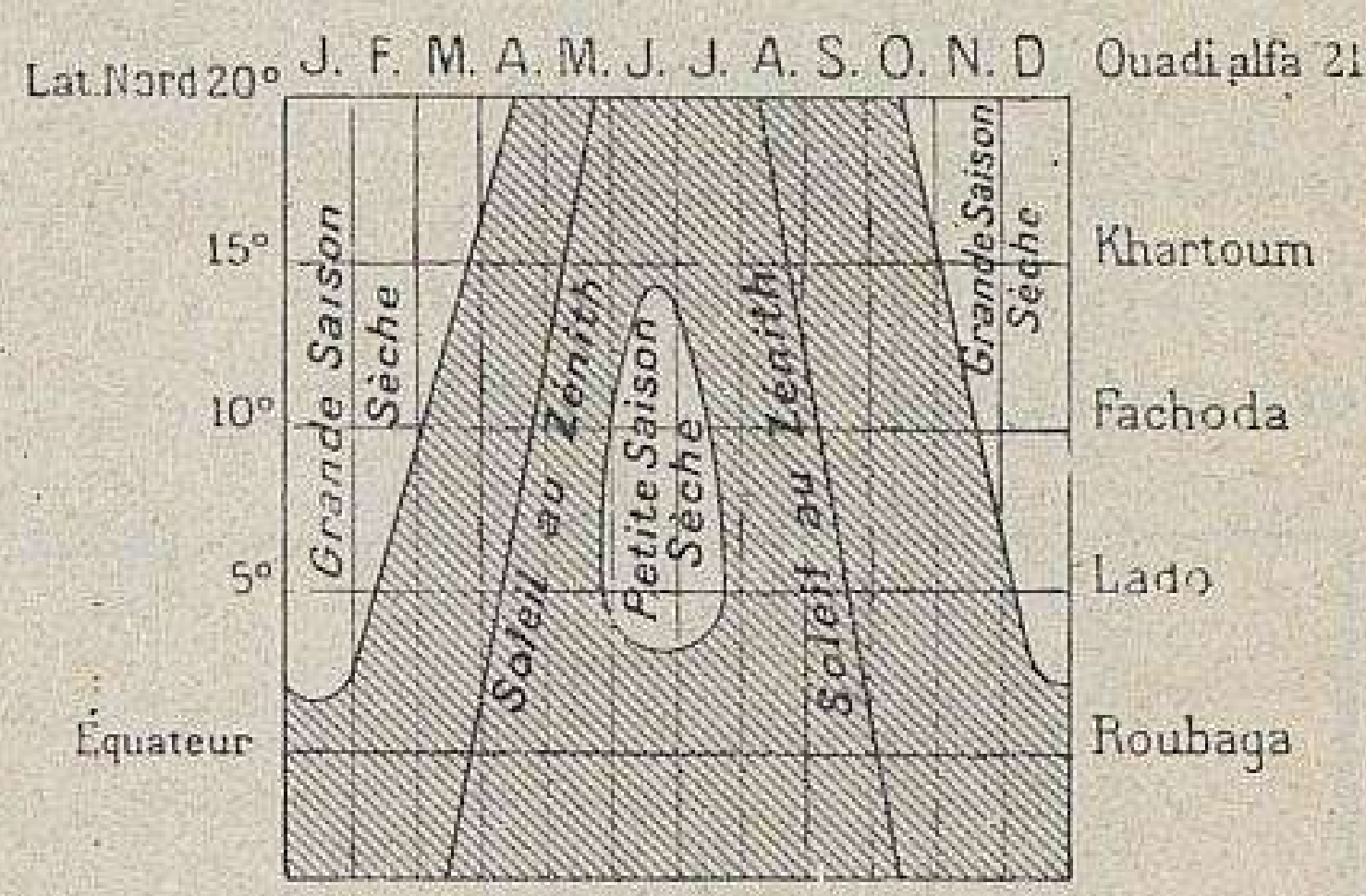

REPRÉSENTATION DES PLUIES.

(D'après $E$, de Martonne.) suivies de miasmes fiévreux, plus abondantes sur les parties élevées, qui sont toujours plus froides. La dépression du Kir, c'est-à-dire les marécages du Nil et du Bahr el Ghazal, fournissent une aire d'évaporation très étendue. Quant au Darfour il est encore touché par les pluies venues de l'océan 
Atlantique. - L'hiver est sec et très sain; les eaux tarissent, tout le pays est brûlé : les vents soufflent du Nord (El Sef) et ont pour résultat des écarts sensibles entre le jour et la nuit.

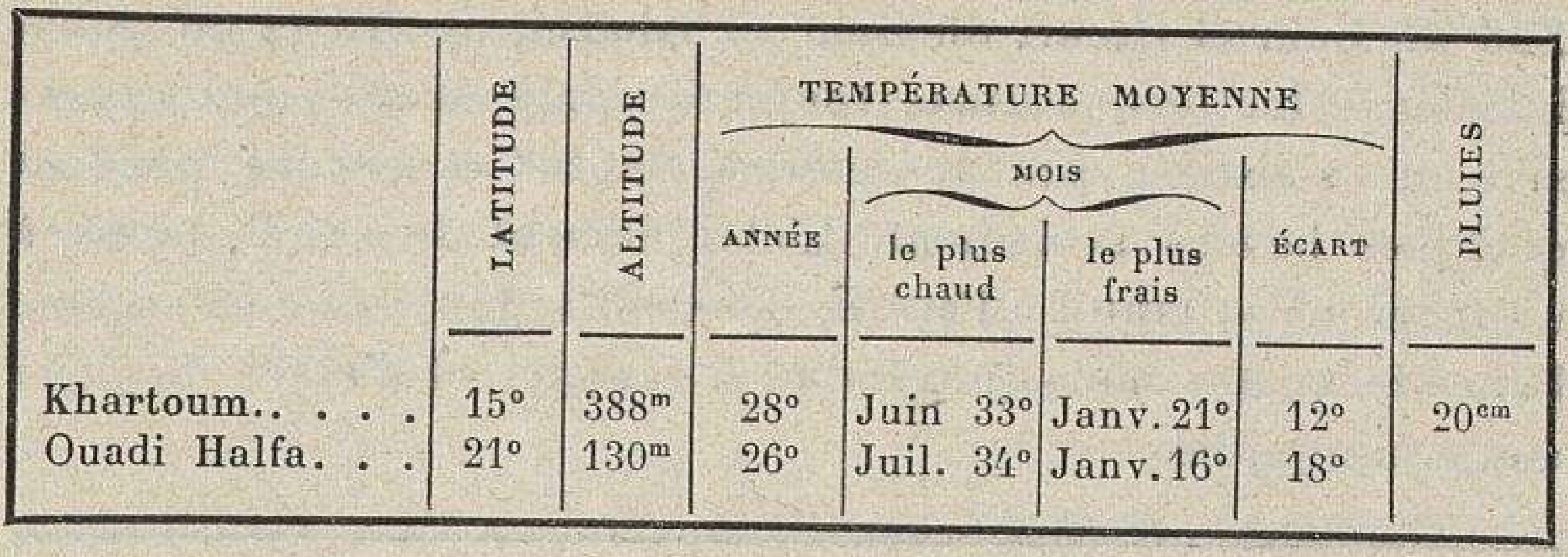

On a remarqué qu'au Nord de Berber, les toits en pente étaient remplacés par des toits plats, ce qui est l'indice d'un climat sans pluie. Plus on s'approche du tropique, et moins le soleil a le temps d'appeler les vents du Sud; la sécheresse du vent du Nord, du R'amsin, alors prédominant, élève pendant le jour le thermomètre à $47^{\circ}$ et l'abaisse avant le lever du soleil à $5^{\circ}$.

$3^{\circ}$ En dehors de la vallée du Nil, c'est le désert; le vent du Nord y règne en maître. Sur les sables et les roches de l'Atmour, les cadavres des chameaux, qui jalonnent les pistes de caravanes, se dessèchent sans entrer en pourriture. A la même latitude que Khartoum, Kassala, pour lequel on possède des observations météorologiques, a un climat franchement désertique et, sur la mer Rouge, Souakin est aussi torride que Massaoua.

\begin{tabular}{|c|c|c|c|c|c|c|c|c|}
\hline & 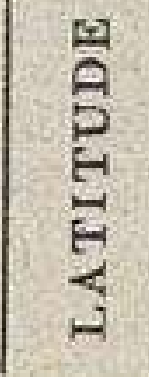 & 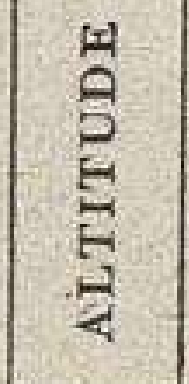 & 舀 & $\begin{array}{l}\text { MAXIMUM } \\
\text { ABSOLU }\end{array}$ & $\begin{array}{l}\text { MINIMUM } \\
\text { ABSOLU }\end{array}$ & $\begin{array}{l}\text { ÉCART } \\
\text { ABSOLU }\end{array}$ & $\frac{\infty}{5}$ & $\begin{array}{c}\text { OBSERVA- } \\
\text { TIONS }\end{array}$ \\
\hline Kassala. & $15^{\circ}$ & $515^{\mathrm{m}}$ & $29^{\circ}$ & $\begin{array}{c}50^{\circ} \\
\text { Mai-Juin. }\end{array}$ & $\begin{array}{c}13^{\circ} \\
\text { Janv.-Fév. }\end{array}$ & $37^{\circ}$ & {$[\mathrm{cm}$} & $\begin{array}{c}5 \mathrm{j} \text {. de pluie } \\
\text { par an. }\end{array}$ \\
\hline
\end{tabular}

V. Hydrographie. - Le Nil draine à lui seul tout le Soudan oriental. Arrivé à Berber, en Nubie, il commence à présenter ce spectacle unique sur la terre, d'un fleuve qui, sur 
un parcours de 2.700 kilomètres, ne reçoit pas un seul affluent ni à droite ni à gauche.

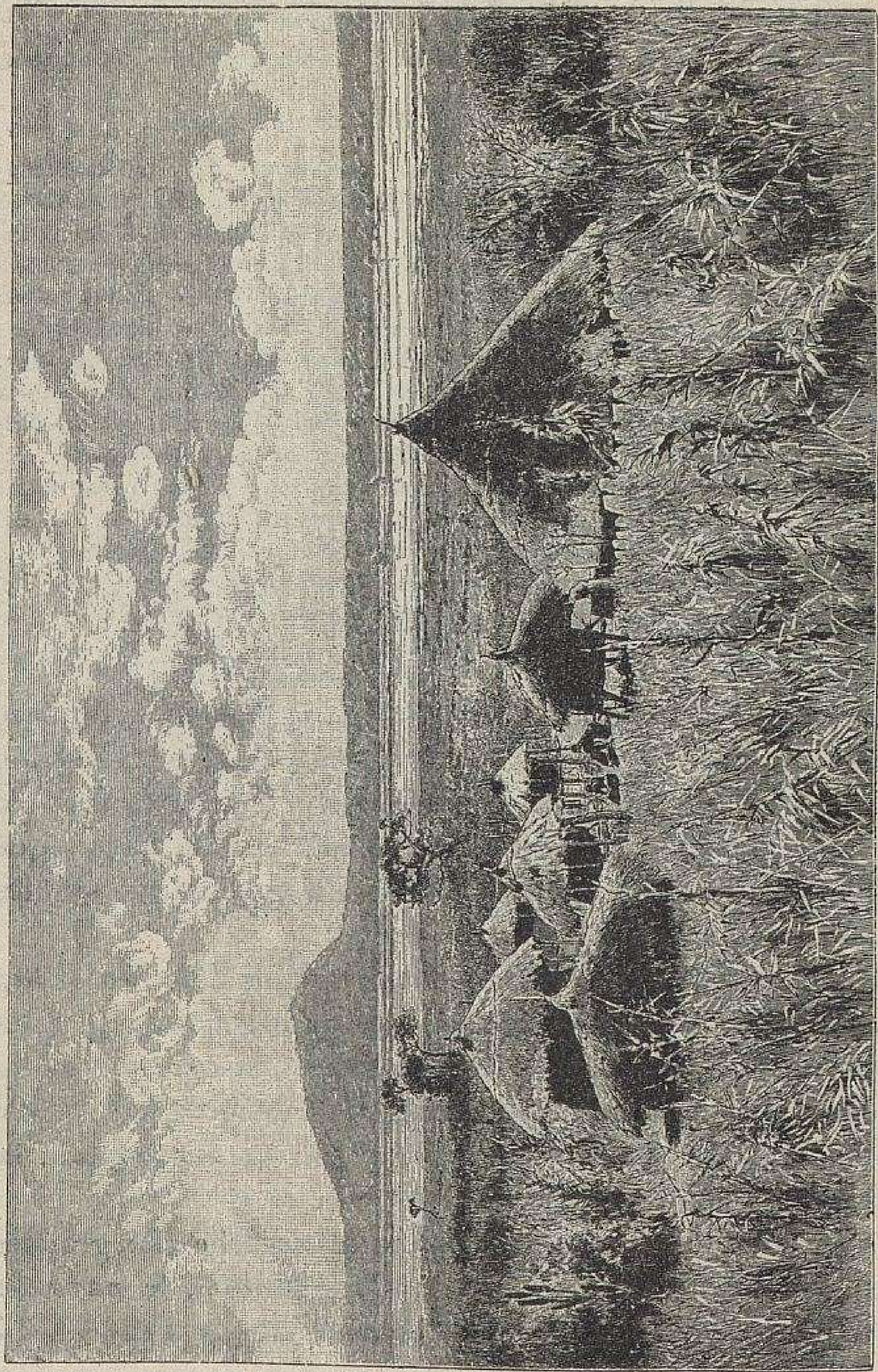

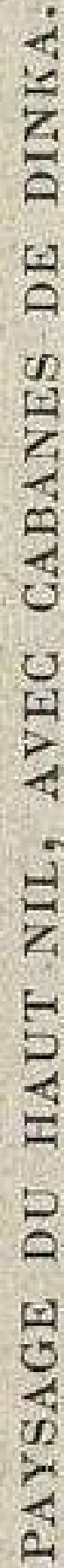

$1^{\circ}$ Nil soudanien. - A sa sortic du lac Albert, le Nil blanc (Bahr el Djebel), large de 1.500 mètres, descend une pente encore forte (rapides de Doufilé). Mais à Lado il atteint la plaine 
du Soudan, et à Gaba Chambé l'inclinaison devient nulle. Alors il erre au hasard entre des rives basses et peu solides; une crue de un mètre inonde d'immenses espaces; les marais latéraux, les bras se multiplient, et le chenal est réduit à presque rien par le double mur d'une végétation serrée, grands roseaux, papyrus, oum souf et ambatch.

Les crues, les tornades d'avril, les vents dominants de Sud-Est détachent des berges des îlots d'herbes ( 80 à $100 \mathrm{~m}$. de diamètre) qui d'abord flottent à la dérive, puis s'entassent dans les coudes, dans l'étroitesse des chenaux, se compriment et s'agglutinent si bien que les grands animaux peuvent y marcher sans enfoncer. Le fleuve alors est tout entier bouché par des barrages temporaires d'herbes flottantes, en arrière desquels le plan d'eau s'élève et qui rendent impossible toute navigation. C'est le Sedd. Dix-huit siècles avant Samuel Baker, le sedd arrêta les deux centurions que Néron avait envoyés à la recherche des sources du Nil. Pour s'ouvrir un passage, il faut désagréger ces masses compactes, en travaillant dans l'eau à coups de pelles et de pioches, ou bien les crocher avec le grappin des chaloupes à vapeur; à mesure qu'une section est découpée, on l'envoie dans le courant et l'on s'attaque à la suivante.

C'est un barrage d'herbes qui a formé le Bahr el Saraf ou "fleuve des Girafes ), puissant ou insignifiant selon que le sedd y refoule ou non les eaux du Nil.

Au centre de cette grande dépression, appelée Kir, se place le lac No: le Bahr el Ghazal y arrive, sans qu'il soit possible de discerner le confluent. Bahr el Ghazal, c'est en français la " rivière des Gazelles » : chaque fois que la végétation aquatique laisse une éclaircie, on aperçoit ces gracieux animaux sur les plaines basses, hérissées de termitières.

Simple chenal de drainage pour marais depuis Mechra el Reg jusqu'au lac No, le Bahr el Ghazal n'est point alimenté par les contrées du Nord (Darfour) ni par celles de l'Ouest (Dar Fertit): là les cours d'eau ont un régime irrégulier, désertique; et c'est ainsi que le Bahr el Arab, dont le bassin est fort étendu, se vide, lui et ses affluents, à la saison sèche.

Mais au Sud le réseau hydrographique est riche : six grandes rivières ont mérité au pays tout entier son nom, le pays des Rivières (sup. env. $350.000 \mathrm{kmq}$, les $2 / 3$ de la France). Le Soueh, la plus importante $(700 \mathrm{~km}$.), appelée encore " rivière des Diours ", d'une peuplade riveraine, descend du mont Baghinsé et recueille les eaux du seuil commun au Nil et au Congo. 
Toutes, les plus grandes comme les moindres, ont même caractère : $1^{\circ}$ lc cours supérieur, torrentueux entre des berges à pic, entaille profondément les terrasses du plateau ferrugineux, les savanes et le pare; $2^{\circ}$ le cours moyen est une vallée d'inondation avec champ d'herbes; $3^{\circ}$ enfin dans le cours inférieur, les berges disparaissent totalement, et, à l'inverse de ce qui se produit d'ordinaire, la largeur du chenal diminue à mesure que le fleuve avance, réduite, par les roseaux, à 40 , à 30 , à 10 , à $2 \mathrm{~m}$. et même à 0 . La rivière, qui coule à peine, s'épanche dans un marais sans profondeur. - Drues et serrées, les herbes font l'office à la fois de filtres,

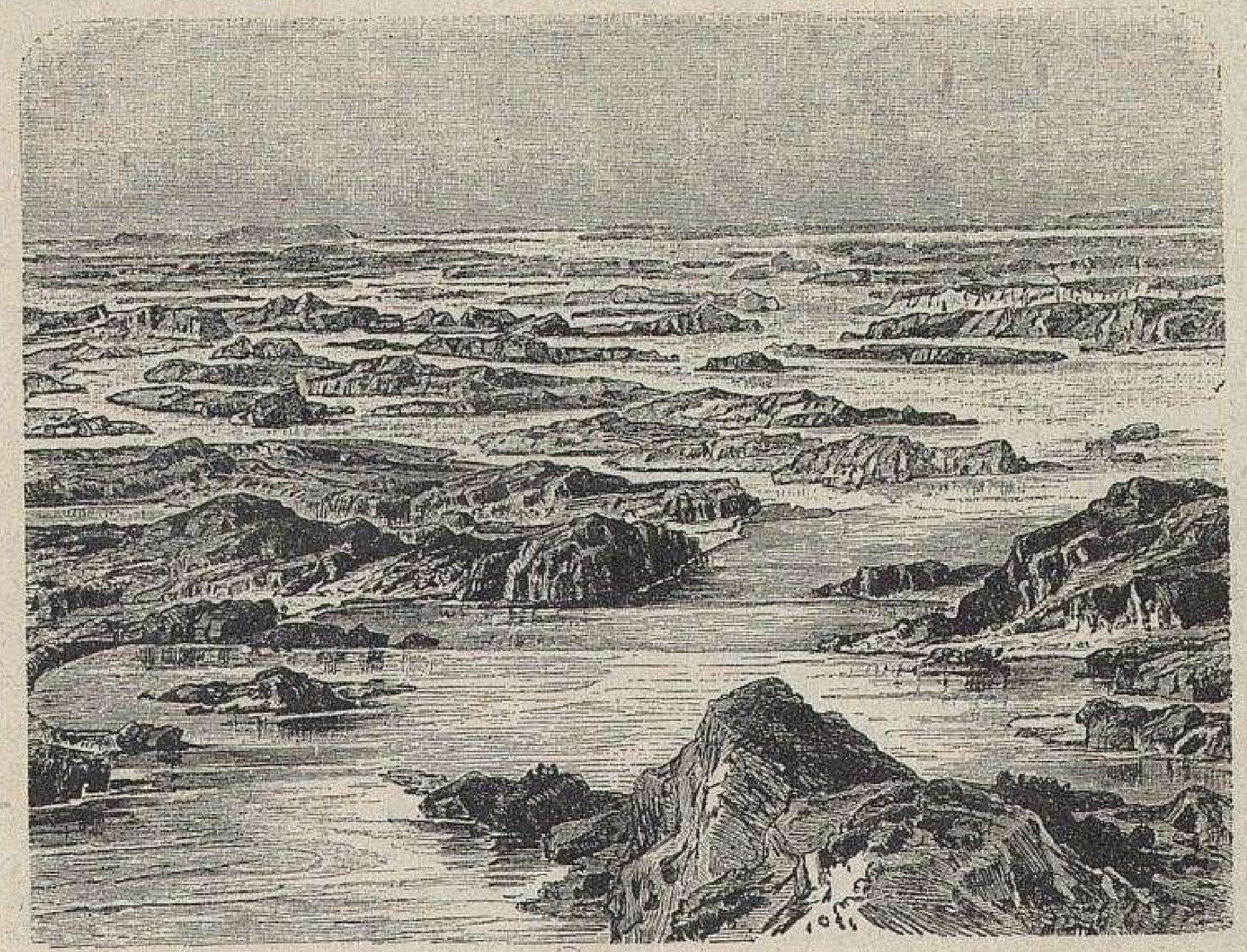

LA PREMIÉRE CATARAGTE DU NIL, AU-DESSUS D'ASSOUAN.

d'où les eaux terreuses ressortent claires, et de barrages qui régularisent les crues et maintiennent le plan d'eau en aval. Par suite le Nil a un courant permanent, en toute saison, et ses crues sont lentes, mais elles sont considérables; elles s'annoncent en avril et atteignent leur maximum en septembre, montant de $370 \mathrm{mc}$. à $4.350 \mathrm{mc}$. à la seconde; les eaux vertes, toutes chargées de matières organiques, inondent le pays à plusieurs kilomètres de distance.

Après le Bahr el Ghazal, le Nil ne voit plus venir à gauche que des vallées sèches et sableuses, des ouadi. Mais à l'Est le massif éthiopien constitue, nous le savons déjà, un puissant réservoir; il envoie le Sobat, le Bahr el Azrek ou Nil bleu et l'Atbara, dont les crues, de juillet à septembre, roulent des eaux limoneuses et rouges. 
Nous pouvons comprendre maintenant le role respectif des deux Nil : “ G'est le Nil blane qui maintient le Nil jusqu'à la mer; mais c'est le Nil bleu qui cause l'inondation nourricière. Sans le premier fleuve, il n'y aurait pas d'Égypte; sans le second, l'Égypte n'aurait pas sa merveilleuse fécondité. »)

$2^{\circ}$ Nil nubien. - A Berber, le Nil sort du Soudan et entre en Nubie, c'est-à-dire dans le désert. A droite, à gauche, rien que des ouadi, vallées où l'on ne rencontre l'eau qu'en creusant le sol : l'oued Mokattam découpe à travers les steppes de Bayouda une route naturelle, qui évite le détour du Nil, de Khartoum à Amboukol; l'oued Melek conduit de Dongola au Darfour, le long du Djebel Ain; l'oued Galgabba enfin, par le désert de Nubie, vers la mer Rouge.

C'est dans l'étroite vallée du Nil que la population se concentre et que s'allonge une étroite lisière de cultures. Le fleuve ne s'étale plus et ne court plus en ligne presque droite comme en amont; il dessine une boucle en forme d'S, et s'encombre de roches grises, noirâtres, très déchiquetées; par six cataractes il rachète la différence de niveau de Khartoum à Assouan; on les compte en remontant le fleuve.

C'est une erreur de croire que les cataractes sont des cascades; ce sont des rapides dont les plus longs, quatrième cataracte, ont $60 \mathrm{~km}$. Le courant se divise, se précipite et découpe les bancs de roches en îlots innombrables. Bien qu'elles puissent être franchies par de petites embareations, elles n'en sont pas moins un obstacle sérieux pour la navigation, qui ne dispose que de biefs superposés. La "grande cataracte » est la seconde, en amont de Ouadi Halfa $(15 \mathrm{~km}$.); elle marqua longtemps la limite Sud de la domination égyptienne, la limite de la civilisation méditerranéenne et de la barbarie africaine.

VI. Côtes. - Les côtes de la mer Rouge ont ici les mêmes caractères que dans l'Érythrée italienne, les mêmes aussi qu'en face, dans l'Arabie; elles forment une étroit palier entre les plateaux intérieurs et la mer. Pas de grosses presqu'îles, mais des promontoires rocheux appelés, d'un terme générique, ras; en mer des rochers font saillie, parfois très nombreux. Enfin dans ces eaux chaudes les polypiers travaillent activement à de belles constructions de coraux. Le meilleur port de toute la mer Rouge est ici : Port-Soudan, un peu au Nord de Souakin.

VII. Vie végétale. - Partout la chaleur est suffisante 


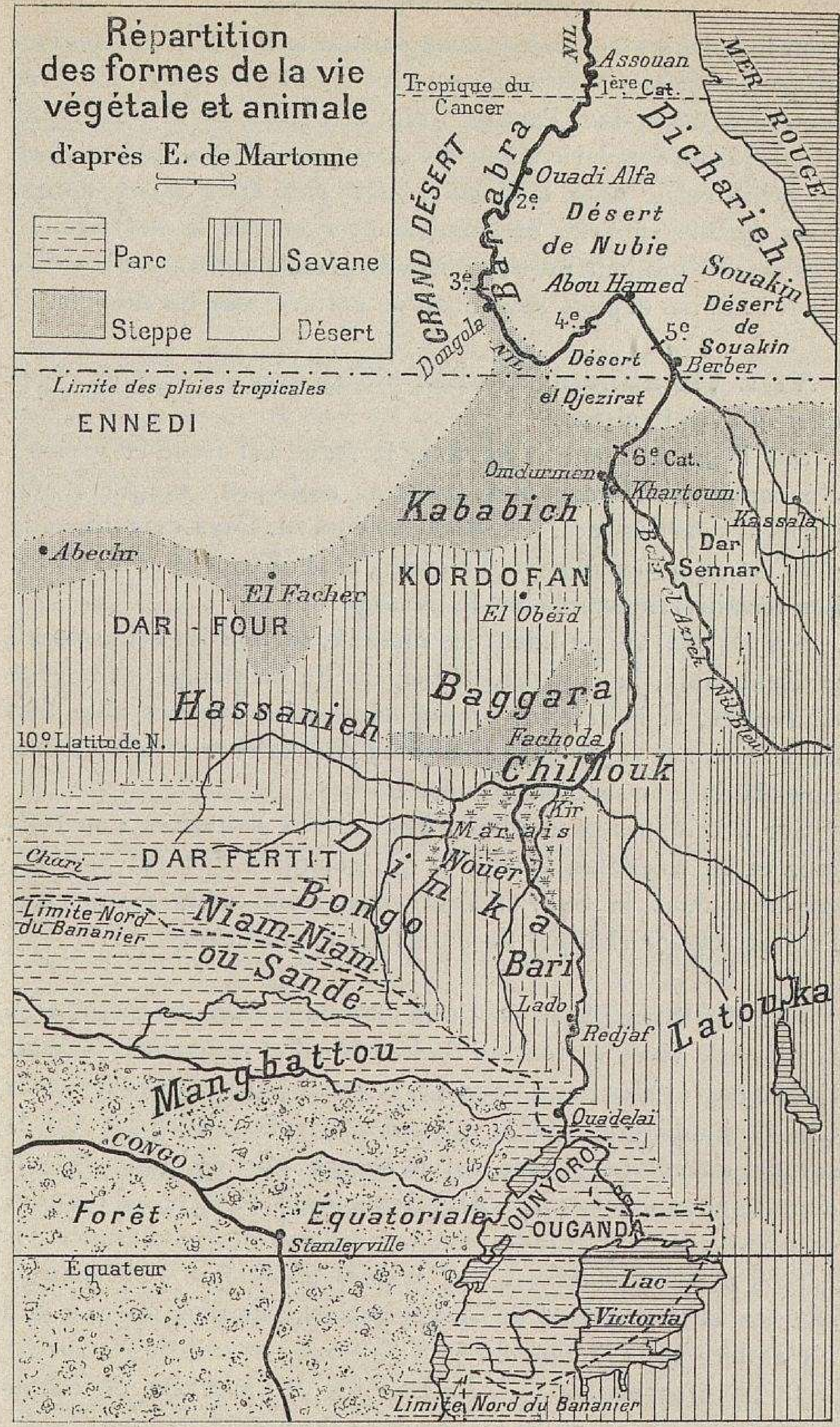

G. Lespagnol et M. Fallex. - Afrique. 
pour les plantes tropicales; mais suivant la loi naturelle, les formations végétales s'harmonisent avec la quantité des pluies, avec leur répartition dans l'année. Point de place pour la forêt équatoriale; la forêt galerie même est une exception. Du Sud au Nord se succèdent le parc, la savane, les steppes et le désert, dont il nous semble superflu de recommencer encore la description. Les marais ont leur flore spéciale de grands roseaux et la vallée du Nil nubien déploie son ruban de cultures sur les déserts.

VIII. Vie animale. - Elle diffère avec les régions végétales et avec le climat.

Sur le parc et sur la savane, la faune est riche et variée : éléphants, girafes, buffles, zèbres, antilopes, sangliers, et, parmi les carnassiers, le lion et le léopard. Pays de culture, le parc est en outre un pays d'élevage, bêtes à cornes et moutons. Les termitières complètent le paysage.

Sur les marais pullulent les oiseaux, surtout les échassiers : pélicans, ibis, la cigogne, messagère du printemps, et la grue couronnée, si belle. Les hippopotames, les caïmans abondent dans les cours supérieurs et moyens des rivières et se font plus rares là où poussent les grandes herbes.

Sur les steppes se montrent des espèces nouvelles : au Darfour et au Kordofan le cheval qui remplace le bœuf porteur, employé dans le Sud, et l'autruche. Enfin nous savons que l'animal caractéristique du désert est le chameau.

IX. Vie humaine. - Le nombre des êtres humains, leur manière de vivre varient du Sud au Nord et reflètent les conditions géographiques du pays. C'est sur le parc et dans les oasis que la population est le plus dense; elle s'éclaircit sur la savane, davantage encore sur la steppe; elle est nulle dans la dépression du Kir, nulle dans les grands déserts sablonneux de Libye : la trop grande abondance d'eau et l'exubérance des herbes marécageuses ont les mêmes effets que l'absence de sources et la pauvreté de la végétation; pas plus ici que là il n'y a place pour l'homme.

$1^{\circ}$ Peuples nègres. - Au Sud les Niam-Niam ou Sandé appartiennent encore au monde de la forêt. 
On ne sait pas exactement leur origine, mais c'est une race de conquérants, venue du bassin du Congo et qui s'est répandue dans le haut pays des Rivières. De taille médiocre, plus nerveux et plus clairs de teint que le Nègre, d'esprit plus vif aussi, ils ont la passion de la chass'e et leur amour de la viande est poussé jusqu'à l'anthropophagie. Pour se préserver de l'humidité à la saison pluvieuse, ils bâtissent leurs cabanes de roseaux sur pilotis.

\section{Parmi les Nilotiques, on distingue les Vieux-Nilotiques et} les Néo-Nilotiques.

Les Vieux-Nilotiques sont à la longue devenus des populations d'agriculteurs paisibles, d'éleveurs sédentaires, engourdis et sans initiative. On range parmi eux les Bari, qui sont de vrais fermiers, les Dinka et les Bongo. Le minerai de fer abonde sur les terrasses à latérite et a provoqué un genre d'occupation ailleurs inconnu : les Bongo ont la réputation de forgerons habiles. Ils réduisent le minerai dans de hauts fourneaux d'argile, chauffés au charbon de bois, puis avec des outils très primitifs, un soufflet, une grasse pierre pour enclume, une masse de fer allongée en guise de marteau, un morceau de bois vert fendu comme pince, ils fabriquent artistement des fers de lance, des fers de bêche, très recherchés comme monnaie courante, et encore des bracelets, des anneaux, etc.

Les Néo-Nilotiques, Nouer et Chillouk, restés pasteurs, guerriers et pêcheurs, sont la terreur des Vieux-Nilotiques devenus pour eux des ,étrangers. Très dispersées, leur's bandes se sont avancées dans le Sud jusque sur les plateaux des Grands lacs. De haute taille, le corps grêle, long et svelte, ils occupent parmi les hommes, dit Schweinfurth, la même place que les flamants parmi les oiseaux : comme eux ils habitent les plaines marécageuses, comme eux ils savent se tenir immobiles sur une. jambe, l'autre appuyée au-dessus du genou, prêts à harponner le poisson qui passe à portée; secs et décharnés, ils enjambent les grands roseaux, et la ressemblance avec les échassier's est complétée encore par une tête petile, déprimée, emmanchée sur un long col. Entièrement nus, ils se couvrent de cendres pour se garantir des piqûres de moustiques. Ceux de l'extrême Sud vivent dans un pays meilleur, où l'on ne connaît ni les longues sécheresses, ni la famine; aussi sont-ils plus robustes et mieux proportionnés.

$2^{\circ}$ Arabes, Berbères et Hamites. - A mesure qu'on s'approche des steppes et des déserts du Nord, on entre dans un monde nouveau : les Nègres y sont mélangés d'Arabes, de Berbères, de Hamites, et l'Islam succède au fétichisme.

L'élément arabo-berbère prédomine chez les Baggara, qui, au Sud du Kordofan, sont des Nilotiques arabisés, éleveurs de chameaux et de chevaux, conducteurs de caravanes, et chez les Kababich, àu Nord du Kordofan. Les Foriens ou Nègres du Darfour ont été asservis de même au $\mathrm{xrx}^{\ominus}$ siècle par les Arabes et les Berbères; là a été fondé un sultanat, à forme orientale, musulmane et despotique, et les expéditions allaient loin au Sud s'approvisionner d'esclaves. 
Entre le Nil et la mer Rouge, chez les Bicharieh ou Bedja, ou encore sur les steppes de Bayouda chez les Hassanieh, prédomine au contraire l'élément hamitique.

De quelque nom qu'ils s'appellent, ces habitants du désert mènent le même genre de vie, celui qu'impose une nature implacable, despotique, et tous d'ailleurs se disent Arabes, parlent arabe. Groupés par familles et par tribus, sous la direction de chefs, ils ne connaissent que la propriété collective, et vivent en nomades, sous la tente de cuir, à la recherche des pâturages. Les troupeaux (chameaux, bœufs à grandes cornes, moutons, brebis, chèvres et ânes) sont toute leur fortune. Ils se nourrissent de viande et boivent du lait. Leur maigreur nerveuse, leurs traits flétris avant l'âge expriment éloquemment leur vie de misère, les souffrances de la faim et de la soif, les fatigues dues au climat, au "r'amsin ", à la réverbération des sables, etc. Race famélique, les nomades sont de terribles brigands, qui tiennent asservis et pillent périodiquement les agriculteurs sédentaires.

$3^{\circ}$ Enfin dans la vallée du Nil, entre la première et la quatrième cataracte, vivent les Barabra, appelés quelquefois Nubiens; métissés de Hamites, d'Arabes et de fellahs égyptiens, ils ménagent la transition avec le monde méditerranéen.

Le teint est bien encore d'un noir franc, mais la chevelure n'est pas crépue, les lèvres ne sont ni grosses ni bouffies. La ligne droite et ferme du nez, la largeur du front, le peu de saillie des pommettes constituent autant de ressemblances avec le type européen. - Cantonnés dans les îles et sur les rives du Nil, ils habitent des maisons en terre séchée, eultivent les - céréales (doukn et dourrah), arrosent leurs champs à l'aide du chadouf égyptien, élèvent des chevaux - la race de Dongola est fameuse - et par un labeur incessant luttent contre la sécheresse et contre l'envahissement du désert. - Vigoureux et de belle prestance, c'est eux que les traitants de Khartoum recrutaient pour exécuter leurs razzias d'esclaves et d'ivoire, sur le haut Nil et dans le pays des Rivières. Cette ressource aujourd'hui leur manque, et comme la partie cultivable entre le fleuve bienfaisant et les steppes arides est de trop peu d'étendue ( 7 à $15 \mathrm{~km}$. de largeur) pour suffire à leur nourriture, ils émigrent et se louent pour divers métiers dans les villes de la'Basse Egypte.

X. Gouvernement et villes. - Conquis par l'Égypte à partir de 1821, depuis Assouan jusqu'au lac Albert, au Darfour et à l'Éthiopie, le Soudan oriental fut perdu par elle de 1881 à 1898. Un " derviche ", e'est-à-dire un religieux mendiant, Mohammed Ahmed, se dit envoyé de Dieu (Mahdi) et profita du mécontentement provoqué par l'administration oppressive des Égyptiens pour eréer un empire immense. Quand il eut pris Khartoum en 1885, malgré l'héroïque résistance de Gordon, il fonda Omdourman, à quelque distance sur la rive gauche du Nil; car il ne voulait pas d'une capitale souillée par le séjour des Infidèles. Pendant treize ans, sous lui et sous son successeur, sous le "Gouvernement des derviches "), le Soudan fut complètement fermé à l'Europe, et ce furent treize ans de barbarie, de guerres, de fanatisme, de brigandage, de mi- 
sère et de famine. Enfin trois campagnes méthodiques rendirent les troupes anglo-égyptiennes du Sirdar Kitchener maîtresses d'Omdourman (1898); le mausolée du Mahdi fut détruit à coups de boulets et ses restes jetés au Nil : son empire n'existait plus.

La convention anglo-égyptienne de janvier 1899 a placé le Soudan oriental, " par droit de conquête », sous le protectorat

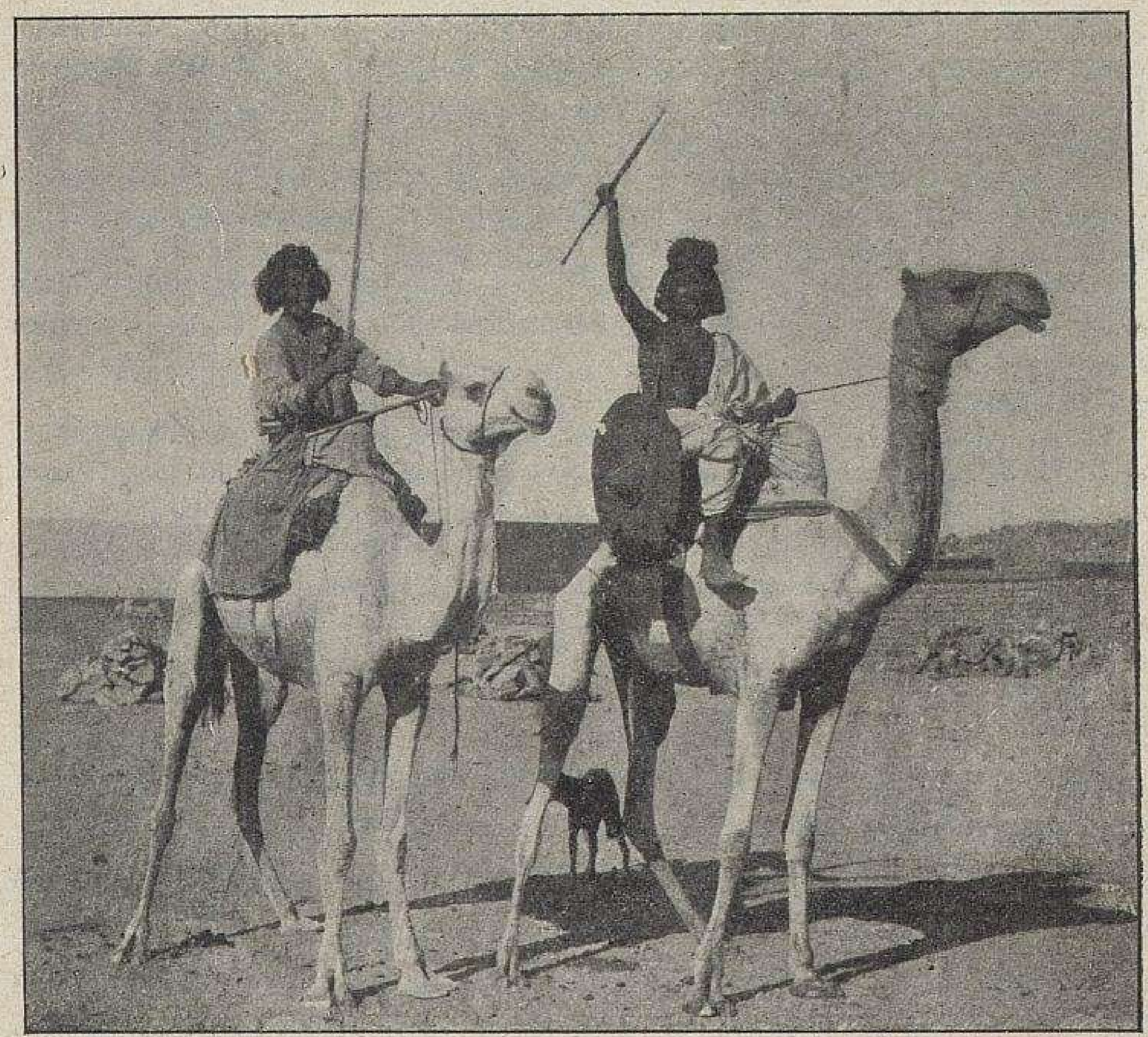

TYPES DE NOMADES BICHARIEH.

(Photographie Zangaki frères, communiquée par la Société de Géographie de Paris.)

de la Grande-Bretagne et de l'Égypte; tous les territoires au Sud de $22^{\circ}$ Lat. sont administrés par un officier qui a le titre de Gouverneur général et qui est nommé par le Khédive avec la sanction de l'Angleterre.

De la sorte le Soudan a été détaché de l'Égypte, et comme l'acte de 1899 ne fait aucune mention de la suzeraineté du Sultan de Constantinople sur les possessions soudaniennes du Khédive, en fait c'est l'Angleterre qui a établi son protectoral sur toute la vallée du Nil, et le Soudan oriental 
est moins une dépendance de l'Égypte qu'un gouvernement, une possession britannique.

Au temps où les derviches triomphaient, la Grande-Bretagne avait accepté le concours de l'Italie du côté de la mer Rouge, le concours de l'État belge du côté de Lado; mais quand elle eut réoccupé Khartoum, elle trouva le pavillon francais planté à Fachoda : la ligne qu'elle prétendait tracer de l'Ouganda à l'Égypte était à demi coupée. Au prix de difficultés inouïes, la mission Marchand, partie du Congo, avait pris à revers les derviches et poussé des reconnaissances au-devant d'une autre mission qui devait venir par l'Est, de l'Éthiopie; moins heureuse, celle-ci n'arriva pas. Pour des raisons que nous n'avons pas à dire ici, notre pavillon fut amené (novembre 1898) et Fachoda évacué. Le traité qui suivit (11 mars 1899) consacra la prise de possession du Soudan par la GrandeBretagne; la frontière était fixée à la ligne de partage des eaux Nil-Congo jusqu'à $11^{\circ}$ Lat. Nord, et de ce point jusqu'au $15^{\circ}$ elle séparait en principe le Ouadaï de ce qui était avant 1882 la province égyptienne du Darfour.

Depuis, les Anglais ont procédé à l'occupation du Bahr el Ghazal. Mais alors ils rencontrèrent les Belges; suivant la convention de mai 1906 , ils sont rentrés en possession, à la mort de Léopold II, du territoire de Ladu qu'ils lui avaient cédé à bail en 1894 .

La frontière a de même été fixée à l'Est : les Italiens ont évacué Kassala, un instant occupé par eux; en vertu du traité de mai 1902 avec l'Abyssinie, le Soudan anglo-ėgyptien s'avance jusqu'au pied de la falaise éthiopienne, il en suit les contours depuis le Sétit jusqu'au Baro, puis descend jusqu'au Sobat pour remonter par la rivière Akabo ou Adjoubba jusqu'à $6^{\circ}$ Lat. S., point de rencontre avee la limite que, d'accord avec I'Italie toute seule, la Grande-Bretagne a marquée à ses territoires de l'Afrique orientale.

Le Soudan anglo-égyptien couvre une superficie de 2 millions et demi de kilomètres; sa population est évaluée à 3.500 .000 habitants; administrativement il est divisé en provinces et en districts.

La capitale est Khartoum $(21.000$ h.); fondée en 1821 sous Méhémet Ali, au confluent des deux Nil, dans une situation stratégique incomparable qui lui permet d'étendre son action au Sud sur la haute vallée du fleuve, à l'Est sur le Sennar, à l'Ouest sur le Kordofan et le Darfour, elle compta au temps de sa prospérité plus de 60.000 habitants et par elle s'établissait le contact entre l'Europe et la barbarie africaine. Détruite en 1885, elle s'est relevée de ses ruines depuis 1898. Omdourman (42.000 h.),' l'ancienne capitale des derviches, est toute délabrée et fort malpropre; les Anglais n'y conservent qu'un marché pour les nomades. En face, une nouvelle ville se développe rapidement, Halfaya. - Entre l'Égypte et Khartoum s'échelonnent, dans la vallée, Ouadi Hal/a, Dongola vers lequel conver- 
gent les caravanes du Darfour, du Kordofan et de Khartoum; Berber enfin, rive droite, sur la courbe orieritale du Nil entre la cinquième et la sixième cataracte, point de départ de la route vers Souakin.

Souakin est, sur la mer Rouge, une place forte, le poiıt d'arrivée des caravanes, le port des pèlerins, le point d'atterrissement des câbles sous-marins, la clef en un mot du Soudan. Mais le havre ayant été jugé insuffisant, un nouveau port, dont le mouillage est excellent, se construit à $50 \mathrm{~km}$. plus au Nord, afin de répondre aux besoins nouveaux du commerce; on l'a baptisé d'un nom significatif, Port-Soudan; les Anglais se proposent d'en faire une ville maritime de premier ordre.

Au Kordofan, El Obeïd est un marché nègre assez fréquenté.

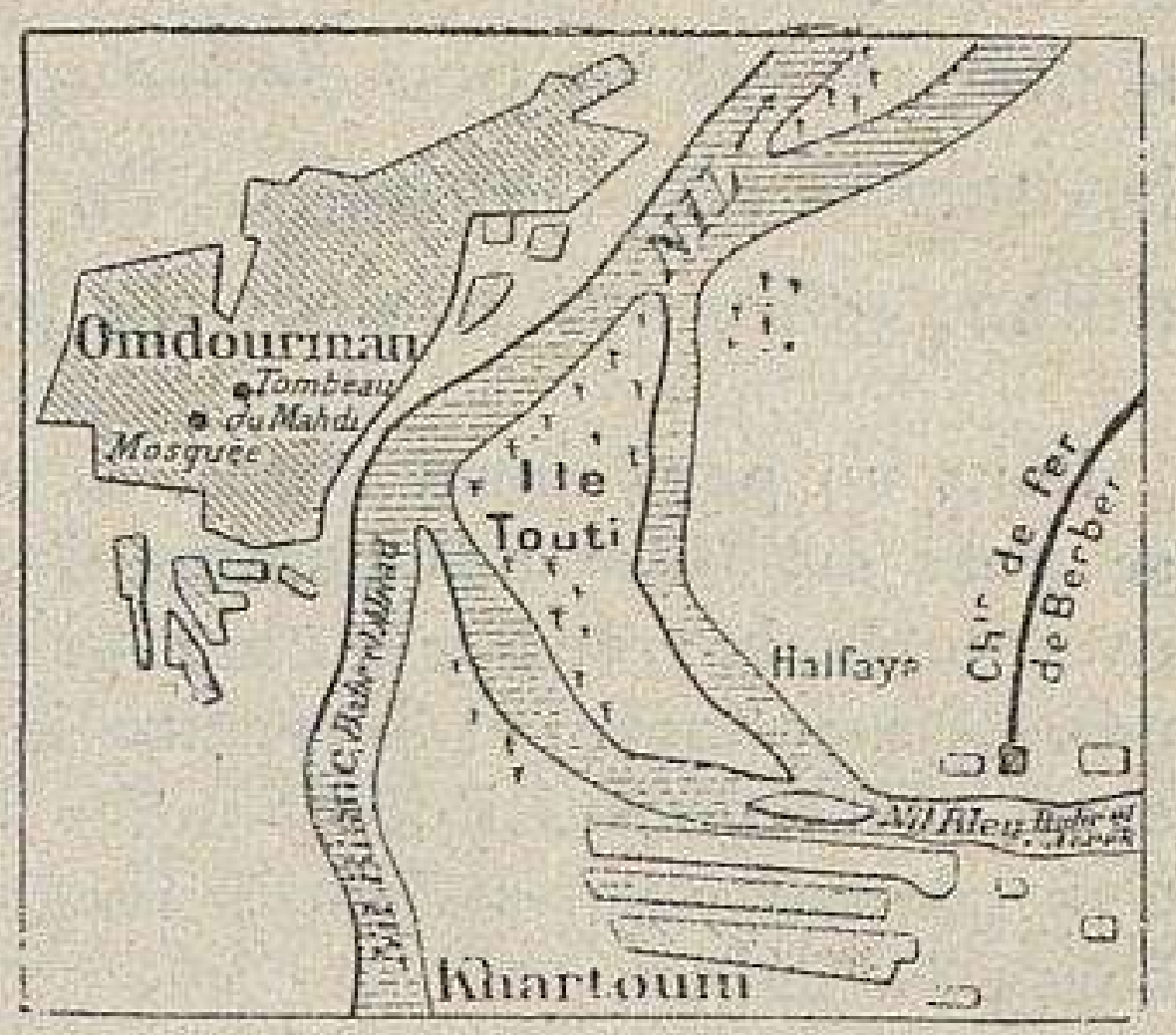
La mosquée, centre de ralliement, élève son minaret au-dessus des habitations en terre battue, couvertes de toits en paille ou en briques séchées.

Vers l'Éthiopie, Kassala, toute en gâchis de paille et de boue, est des plus malpropres : les immondices remplissent les rues et les transforment en égout. Mais Kassala préserve Khartoum d'une attaque orientale, surveille l'Abyssinie et garde la route de Souakin. - Oued Medineh, sur le Nil bleu, remplace l'ancienne capitale Sennar, qui n'est plus qu'un amas de décombres.

Quant au Darfour, c'est un sultanat indigène, dans la sphère britannique. El Facher, " la résidence » du souverain, appelé encore Tendelti $(720 \mathrm{~m}$.), comprend un groupe de huttes en terre argileuse avec toits coniques de roseaux; la verdure de la vallée contraste avec l'aridité des pays environnants qui n'ont pas un arbre. - Le centre marchand est Kobé; chaque maison a son enceinte palissadée et, de plus, un espace en friche l'isole des habitations voisines.

Les territoires du Haut Nil et du pays des Rivières ne comptent pas de villes à proprement parler; toutes les localités que l'histoire des découvertes et des guerres a fait inscrire sur 
les cartes ne sont que des huttes indigènes, entourées de palissade (Zériba) : tel Fachoda, appelé aujourd'hui Kodok. Quant a Gondokoro, célèbre dans l'histoire des explorations, longtemps station de missionnaires, il est abandonné.

XI. Mise en valeur. - Puiné par l'insurrection mahdiste, démoralisé de longue date par l'esclavage et par une série de mauvais gouvernements, le Soudan anglo-égyptien n'offre pas de grandes ressources, et la population, très clairsemée, n'est un peu dense que dans l'étroite vallée du Nil, sur les terres alluvionnaires du Dar Sennar, au Darfour et au Kordofan, enfin sur le parc du pays des Rivières.

Dans un pays aussi vaste, aussi peu peuplé, la première question qui se pose est celle des communications. La voie du Nil blanc, coupée de cataractes, barrée par les herbes du sedd, ne vaudra rien tant qu'elle n'aura pas été améliorée; et le serait-elle qu'une autre difficulté sera à résoudre : avec quel combustible chauffer les chaloupes à vapeur? De charbon on n'en connait pas, et depuis longtemps le bois ne se trouve plus sur les bords du fleuve.

Aux caravanes, qui autrefois apportaient de Kobé, de El Obeïd, du DarSennar et de Kassala à Khartoum, à Berber et à Dongola les plumes d'autruche, les gommes, le henné, l'encens, le musc, l'or, les esclaves (la traite a été interdite par la convention anglo-égyptienne de 1898) et même l'ivoire, les Anglais s'efforcent de substituer d'autres voies plus rapides et moins coûteuses. Aujourd'hui un chemin de fer unit Khartoum à Ouadi Hulfa par Berber; aux deux extrémités il faut procéder à des transbordements qui majorent les prix. Aussi les Anglais ont-ils construit une voie ferrée du confluent de l'Atbara et du Nil sur Port-Soudan; c'est vers Port-Soudan qu'ils voudraient dériver tout le commerce de l'Afrique centrale; ils comptent en faire une cité maritime de premier ordre et détourner vers lui une bonne partie des marchandises qui jadis gagnaient Alexandrie par la vallée du Nil. - Il ne faut point en outre oublier ni les efforts actifs et méthodiques de la Grande-Bretagne pour faire de l'Ethiopie une dépendance économique du Soudan anglo-égyptien, ni le projet de chemin de fer de l'Ouganda par Itang à Khartoum, ni encore une clause du traité franco-anglais de 1899 qui étend au Soudan français et au Bahr el Ghazal la réciprocité commerciale : cette clause, l'Angleterre entend l'utiliser pour faire du Soudan anglo-égyptien un centre de distribution des marchandises dans nos possessions, qui, moins favorisées, sont loin de toute base d'opérations.

En évinçant tous ses concurrents du haut Nil et du Nil moyen, la Grande-Bretagne a atteint de grands résultats; sans se laisser arrêter par aucun scrupule, même par des questions de droit international européen, elle pense s'ètre réservé les avantages exclusifs de l'exploitation économique; elle a foi dans le succès, fallùt-il beaucoup de temps et une longue patienre; et elle agit en conséquence. 


\title{
CHAPITRE XVI!
}

\author{
EGYPTE
}

(i)

\author{
SOMMAIRE
}

I. Limites. - L'Égypte est limitèe par le Soudan anglo-égyptien, le désert de Libye, la Mèditerranèe et la mer Rouge.

II. Superficic. - Sur les $640.000 \mathrm{kmq}$. qu'elle couvre, $33.200 \mathrm{seu}$ lement sont habités.

111. Orogénie et relief. - L'ètroite vallèe du INil s'ètale au Nord pour former le Delta; de chaque côté s'étendent des plateaux désertiques, désert de Libye à l'ouest, désert Arabique à l'Est. L'isthme de Suez (160 km.) est bas et alluvionnaire.

10. Climat. - L'Égypte fait partie de la région désertique de l'Ancien continent : de là un climat sec, excessif, un ciel presque toujours serein, sans pluies. Les vents " étésiens" souffient du Nord pendant l'èté, le "R'amsin " du Sud-Ouest pendant l'hiver.

V. Hydrographie. - Sans le Nil l'Égypte serait un désert. De sa crue annuelle dépend toute la vie de la vallee : elle a lieu de juin a septembre. Le delta commence au Nord du Caire; ses deux bouches principales sont à l'Ouest celle de Rosette, à l'Est celle de Damiette.

VI. Vie végétale. - C'est le Nil qui règle les formes végétales de l'Égypte. En dehors de la vallée il n'y a que des déserts, et seul celui de Libye possède des oasis. Les limons de la vallee conviennent aux plantes qui réclament le travail de l'homme, beaucoup plus qu'aux arbres; c'est le palmier qui donne au paysage des bords du Nil sa physionomie propre.

VII. Vie animale. - L'Égypte réunit les espèces animales des regions sèches et chaudes, et celles des régions chaudes et marécageuses. La plupart des animaux domestiques sont, comme les plantes, d'importation ètrangère.

VIII. Vie humaine. - Plus de 11 millions d'habitants peuplent l’Égypte : 334 habitants par kmq. sur les terres cultivables.

Le fond de la population comprend des paysans, les Fellahs, et des bourgeois, les Goptes. Les Turcs sont les conquérants; les Euro- 
péens appartiennent à des nationalitès diverses. Les Bédouins sont les nomades du désert.

IX. Gouvernement et villes. - L'Égypte forme une province autonome de l'Empire turc, gouvernèe par un Khèdive, mais, en réalité, par l'Angleterre.

Dans la Basse Égypte, le Gaire (654.000 h.), la plus grande ville de toute l'Afrique; Alexandrie, le principal port ègyptien.-Dans la Haute Égypte, Asiout, Assouan et Medinet el Fayoum. - Sur la Méditerranée, Port-Saïd à l'entrée du canal de Suez. - Parmi les oasis de Libye, Siouah, célèbre dans l'antiquité par le temple de Jupiter Ammon.

X. Hise en valenr. - Terre d'alluvions, l'Égypte est un pays d'agriculture, où tout dèpend de l'irrigation; aux cèréales et aux légumes, qu'elle produit depuis la plus haute antiquite, elle joint aujourd'hui les cultures tropicales, coton, riz et canne à sucre.

Ce sont les produits agricoles que traite l'industrie et que le commerce exporte.

L'ouverture du canal de Suez (1869), œuvre gigantesque due à un Français, Ferdinand de Lesseps, a detournè vers l'Égypte une partie appréciable du commerce du monde, en abrégeant les distances entre l'Europe et l'Extrême-Orient.

\section{DÉ VEL OPPEMENT}

I. Limites. - L'Égypte est limitée au Sud par la première cataracte du Nil et le Soudan anglo-égyptien, à l'Ouest par les

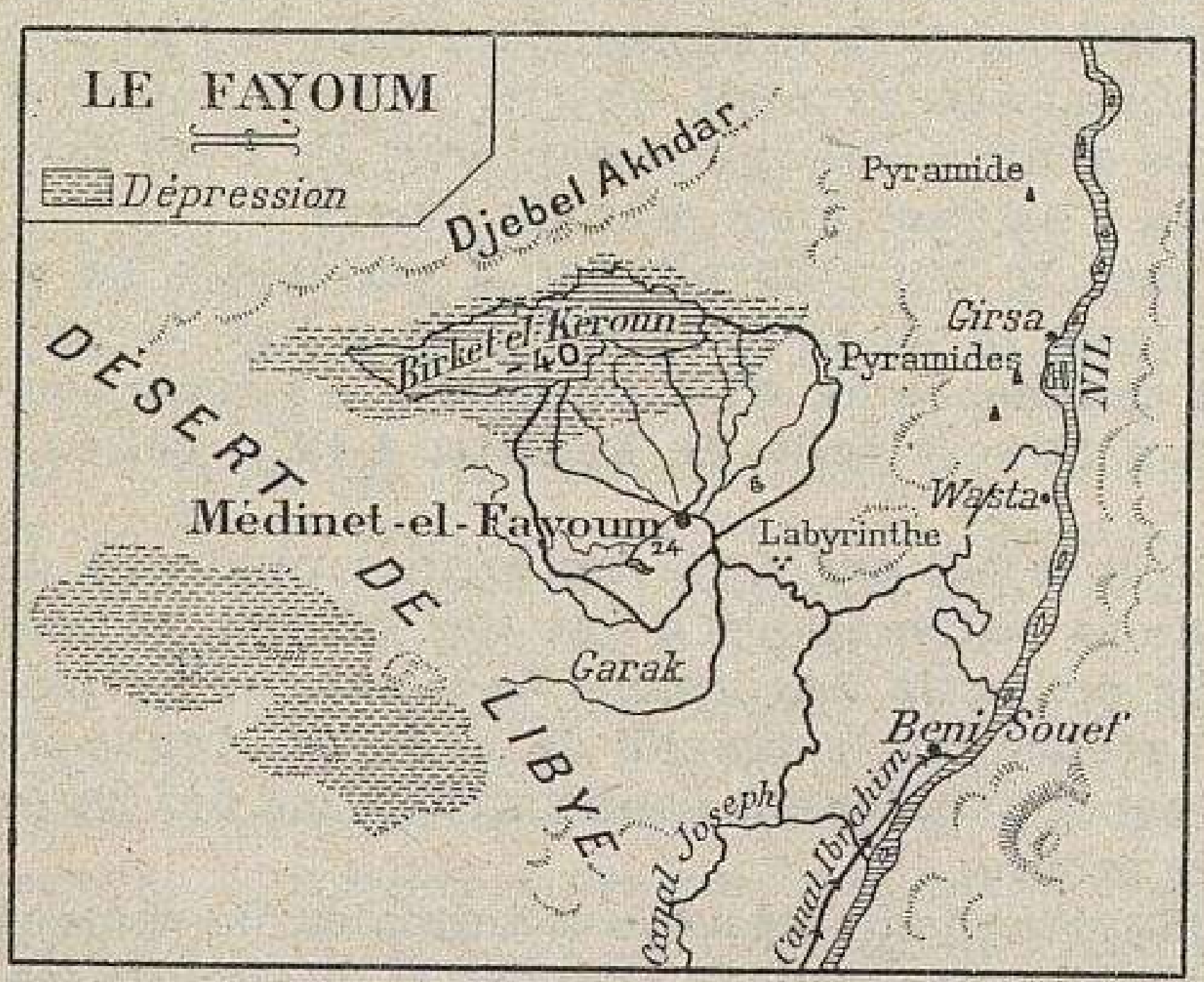
déserts de Libye, au Nord par la Méditerranée, à l'Est par la mer Rouge. $\mathrm{Au}$ delà de l'isthme de Suez, le territoire d'El Arich et la presqu'ille $d u$ Sinaï sont compris dans ses frontières politiques.

\section{Superficie.}

- L'Égypte couvre 640.000 kilomètres carrés, mais 33.200 seulement sont habités; c'est à peu près l'étendue de six de nos départements.

III. Orogénie et relief. - Le Nil coule d'abord sur les 
grès de Nubie, que barrent des roches de granite, des porphyres et des syénites, du nom même de la ville de Syène. C'est là que les anciens Égyptiens taillaient sur place leurs grands monolithes. - Il coule ensuite, à partir d'Esneh, entre des falaises calcaires : de là furent extraites les pierres des Pyramides, de là s'extraient aujourd'hui celles qui servent à construire les grands barrages d'irrigalion. - Ses apports ont comblé un ancien golfe marin : les dépôts argileux, épais de 30 mètres environ, et le limon fertile qui les recouvre s'étalent au Nord du Caire pour former le Delta.

De chaque côté de l'étroite vallée s'étendent des plateaux désertiques : désert de Libye à l'Ouest, désert Arabique à l'Est.

Le désert de Libye forme une immense table calcaire, sur laquelle les vents, par un effort séculaire, ont amoncelé les grains de quartz provenant de la désagrégation du grès nubien qui s'étend largement au Sud. A perte de vue s'étend un océan de sables; les dunes, longues de plusieurs kilomètres, montent jusqu'à $100 \mathrm{~m}$. de haut. Parallèlement au Nil, le plateau est déchiré par une vallée où des sources abondantes alignent les oasis de Khargeh, Dakhel, Farafrah et Baharieh. La température souveı élevée des eaux semble témoigner de dislocations terrestres, et l'hypothèse trouve sa, confirmation dans la présence d'effondrements, comparables i la vallée du Jourdain ou bien aux chotts tunisiens du Sud : le Fayoum, qu'une crête étroite sépare du Nil, descend (lac Birket el Keroun) à $40 \mathrm{~m}$. au-dessours du niveau de la Méditerranée, l'oasis de Siouah à - $75 \mathrm{~m}$.

Bien différent est le désert Arabique. D'Ouest en Est se succèdent trois natures de roches (calcaires, grès et roches cristallines) et trois formes de relief (vallée, plateau et montagne). Les montagnes bordent la mer Rouge sur $2.500 \mathrm{~km}$, avec des sommets de plus de $2.200 \mathrm{~m}$, , et tombent sur elle en pente roide, tranchées pour ainsi dire par l'affaissement de la fosse marine. Surmonté de pics isolés, de blocs pyramidaux, en granite rouge, et de dykes volcaniques, le plateau est entaillé par des vallées sèches, à pente plus longue vers le Nil; l'érosion des granites noirs, moins durs, les a emplies de sables; elles ouvrent des voies naturelles de communication entre la vallée du fleuve et la mer Rouge (Suez et Kosseïr.) Tout le pays, pierreux et brûlé, est d'une nudité sauvage. Aucune oasis. Rien qu'une végétation misérable d'arbustes épineux. De rares sources ou des eiternes naturelles. C'est dans le désert Arabique que se retirèrent les premiers ermites et la Thébaïde est le berceau du monachisme. C'est de là aussi que furent extraits par les Égyptiens, plus tard par les Romains, les granites et les porphyres, destinés par les uns aux sarcophages et aux statues, par les autres aux temples des villes méditerranéennes. Grenats, émeraudes, toutes sortes de cristaux précieux s'y rencontrent encore.

L'isthme de Suez (160 km.) est constitué par une bande étroite et basse d'alluvions; c'est la preuve que les deux mers 
communiquaient jadis l'une avec l'autre : alluvions récentes du Nil, intercalées entre les dépôts, récents aussi, de la Méditerranée au Nord et de la mer Rouge au Sud. Le point culminant ne s'élève pas à plus de 16 mètres.

IV. Climat. - Située au Nord du tropique du Cancer, entre $24^{\circ}$ et $31^{\circ}$ Lat. N., l'Egypte fait partie de la grande région désertique de l'Ancien continent.

$1^{0}$ C'est le désert qui règle le climat de la vallée du Nil. Sécheresse et absence de phénomènes électriques, tels sont les traits dominants. Les pluies ne tombent qu'à de rares intervalles, par fortes ondées, et ne fournissent au total qu'une couche très mince. G'est la sérénité du ciel qui, depuis cinq mille ans, conserve intacts les monuments de l'ancienne Égypte. Mais aussi les écarts de température sont fort sensibles : le thermomètre oscille au Caire de $43^{\circ}$ à $2^{\circ}$, extrêmes moyens; de $37^{\circ}$ à $7^{\circ}$ seulement à Alexandrie, en raison de l'influence de la mer.

Le régime des vents n'est plus ici celui du Sahara et de la Tripolitaine. En été, ils soufflent Nord et Nord-Nord-Ouest et rendent un peu plus supportables les chaleurs du Caire; les Grecs les appelaient étésiens, c'est-à-dire annuels. En automne, ils s'établissent du Sud, prennent plus de force en décembre et janvier, et empêchent la température de descendre trop vite; ils sont toujours pénibles, mais aucun ne l'est autant que le R'amsin: chaud, sec, énervant, il charrie du Sud-Ouest d'impalpables poussières et provoque une suffocation douloureuse.

$2^{\circ}$ L'amplitude s'exagère encore dans les déserts. Rohlfs a constaté en Libye des chaleurs de $50^{\circ}$ pendant l'été, et des froids nocturnes de $-5^{\circ}$ en février. En 1886, dans le désert Arabique, le thermomètre ne s'abaissa pas au-dessous de $45^{\circ}$ pendant dix jours et se maintint souvent, même la nuit, à $47^{\circ} \mathrm{et}$ $48^{\circ}$ : les animaux mouraient; les cadavres de chameaux qui jalonnent les pistes de caravanes se dessèchent sans pourrir et se conservent comme du parchemin. Nlais, au même endroit, il neigeait en janvier et l'on se serait cru dans les Alpes.

3o Enfin nous savons déjà que la mer Rouge est un des endroits les plus torrides du globe. 


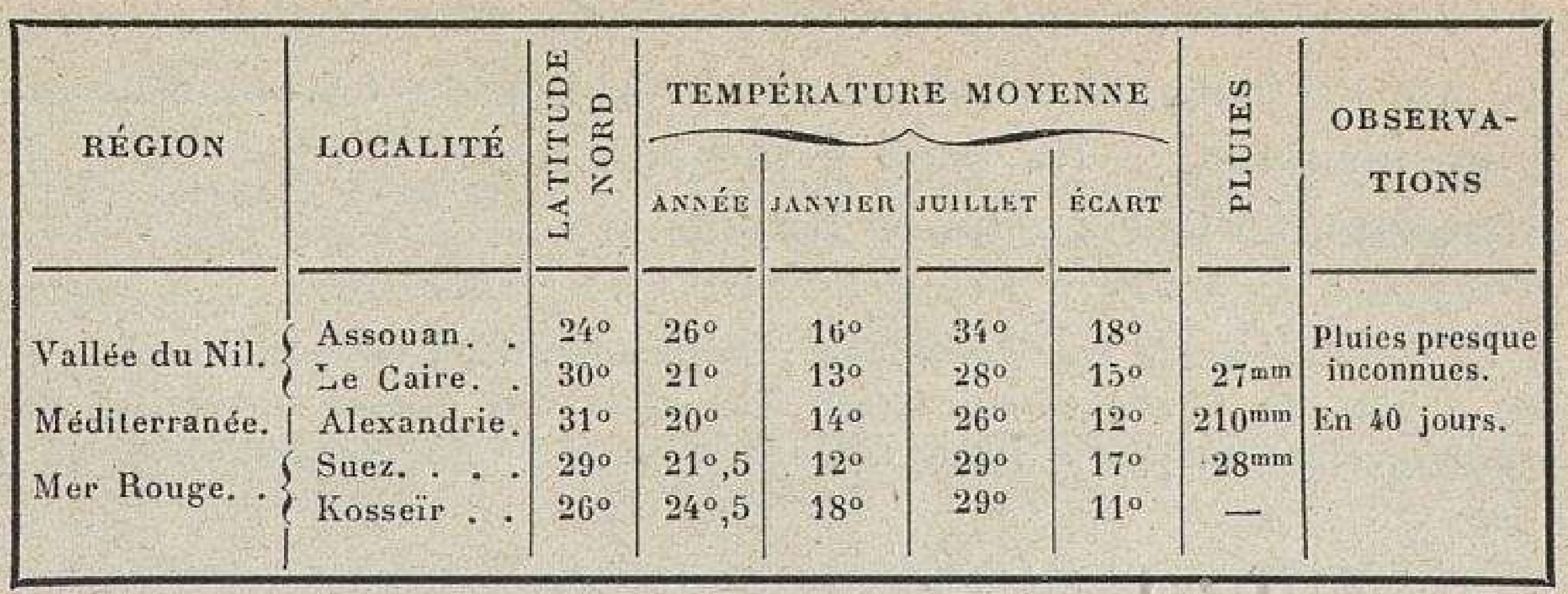

V. Hydrographie. - C'est le Nil qui a fait l'Égypte; les Anciens répétaient avec Hérodote : " l'Égypte est un présent du fleuve ", et ce bienfait continue à se renouveler chaque année.

Du Sud au Nord, d'Assouan à la mer, le Nil mesure à vol d'oiseau $800 \mathrm{~km}$., et $1.200 \mathrm{~km}$. avec les sinuosités. Sa largeur varie avec les saisons, de $450 \mathrm{~m}$. à $2.000 \mathrm{~m}$. dans la Haute et Moyenne Égypte, de $200 \mathrm{~m}$. à $900 \mathrm{~m}$. dans le delta. La vallée s'amplifie de $8 \mathrm{~km}$. à 20 , puis à 50 , en même temps que la pente s'atténue : d'Assouan au Caire $90 \mathrm{~m}$., soit $11 \mathrm{~cm}$. par kilomètre, et en aval $4 \mathrm{~cm}$.

Le Nil met un long ruban de verdure entre les falaises fauves et brûlées, qui l'accompagnent sur chaque rive, mais de plus près à droite qu'à gauche. "La végétation et les cultures vont exactement aussi loin que l'eau... et la ligne de démarcation entre la zone verte et le désert est une ligne aussi nette et, pour ainsi dire, aussi brutale que l'est sur une carte une division administrative, une frontière d'état ou de province " (J. Brunhes). Sur sa gauche principalement, il alimente des dérivations entretenues de mains d'homme : le Bahr Sohagiyeh (prise d'eau de Sohâg), appelé plus loin Bahr Yousef ou canal Joseph, conduit les eaux dans le bassin à étages, dans la dépression du Fayoum.

Déjà dans l'antiquité, le Fayoum servait de régulateur, et le lac Mcris y excitait l'admiration curieuse d'Hérodote. "Les eaux du lac, dit-il, ne sont pas le produit naturel du sol qui dans cette contrée est particulièrement sec. Elles viennent du Nil par un canal et s'écoulent six mois du Nil dans le lac et pendant six autres mois du lac dans le Nil." Llles changeaient et changent encore le désert en un jardin tout rempli de vignes, de roses et d'oliviers; là se voient encore les constructions enchevêtrées du Labyrinthe, les ruines d'Arsinoé ou Grocodilopolis. 
C'est à 23 kilomètres au Nord du Cairc que commence la pointe du Delta; le fleuve se ramifie et déploie l'éventail de ses bras nombreux : les deux principaux sont, à l'Est celui de Damiette, à l'Ouest celui de Rosette.

Le front du delta mesure $600 \mathrm{~km}$. Sa formation est des plus normales : les dépôts du fleure élevaient sur ses rives des digues naturelles qui s'allongeaient toujours; l'intervalle de l'une à l'autre se comblait peu à

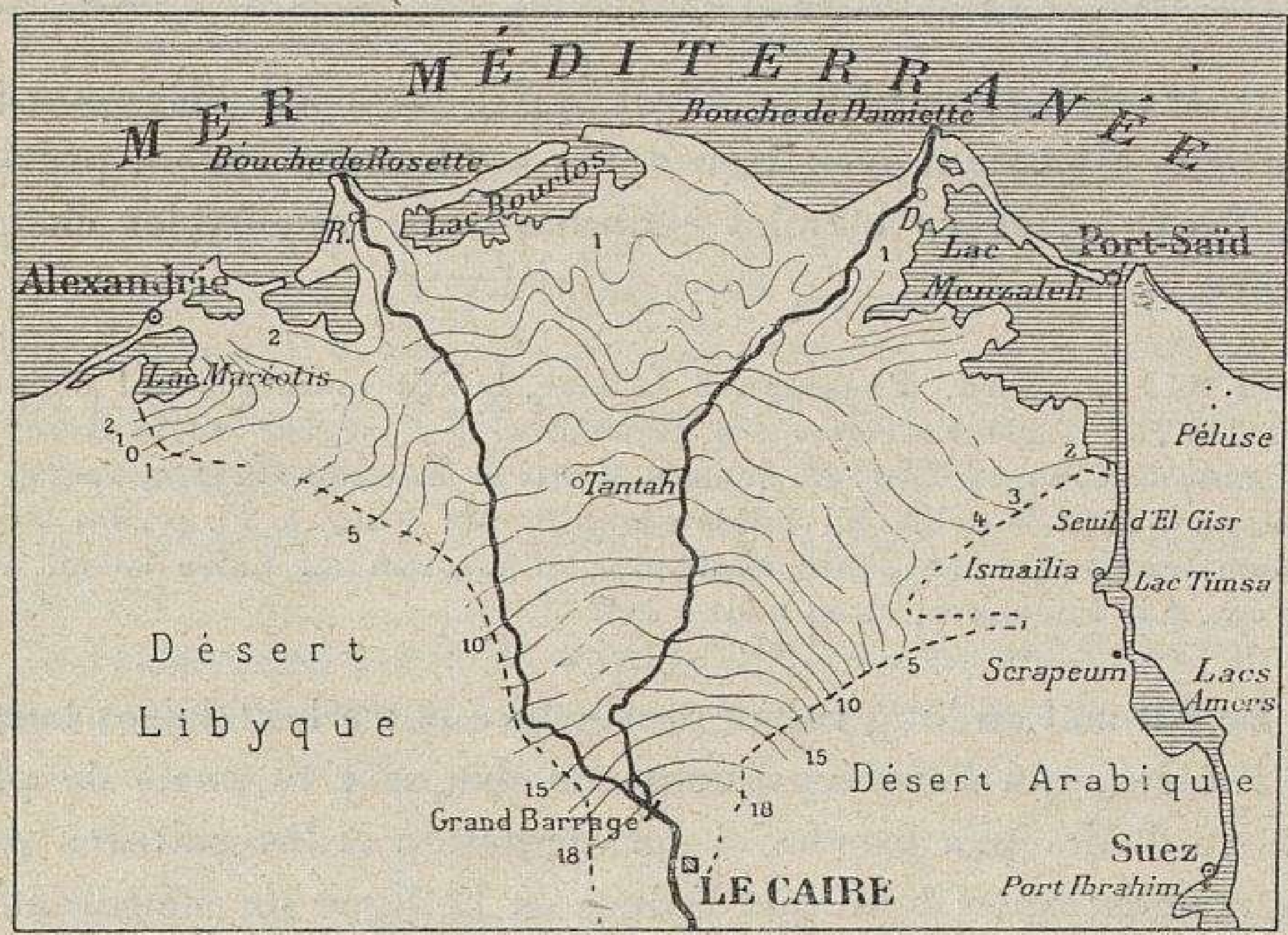

DELTA DU NIL avec courbes hypsométriques dapres Willcocks

\section{ET CANAL. DE SUEZ}

peu et le cône de déjection allait s'étalant, s'aplatissant sous les eaux de la mer. Là les vagues séparèrent les sables et les limons et façonnèrent des flèches sablonneuses qui se courbaient en ares de cercle d'une bouche à l'autre. Les parties que le fleuve n'a pas comblées forment des lagunes : a I'Ouest le lac Maréotis, à l'Est le lac Menzaleh. Aussi loin qu'il nous est possible de remonter dans l'histoire, les rivages ne se sont pas plus modifiés que les bouches du fleuve : les uns et les autres demeurent tels qu'il y a trois mille ans.

L'Égypte n'a pas de pluies, mais elle a le Nil. Sans lui, elle se changerait en un désert, semblable aux déserts qui l'étreignent. Toute la vie, celle des plantes, des animaux et des hommes, est entretenue par le fleuve : ce sont ses crues qui fécondent la vallée. Sans doute elles ne sont pas égales d'une 
année à l'autre, mais elles se produisent avec la régularité des saisons.

On s'imagine d'ordinaire que le fleuve déborde au-dessus de ses rives; s'il en était ainsi, ses inondations ne causeraient que des ruines. Il monte, et ses eaux refluent, soit dans des canaux, qui tous, du plus grand au plus petit, répandent au loin la fertilité, soit dans des bassins de

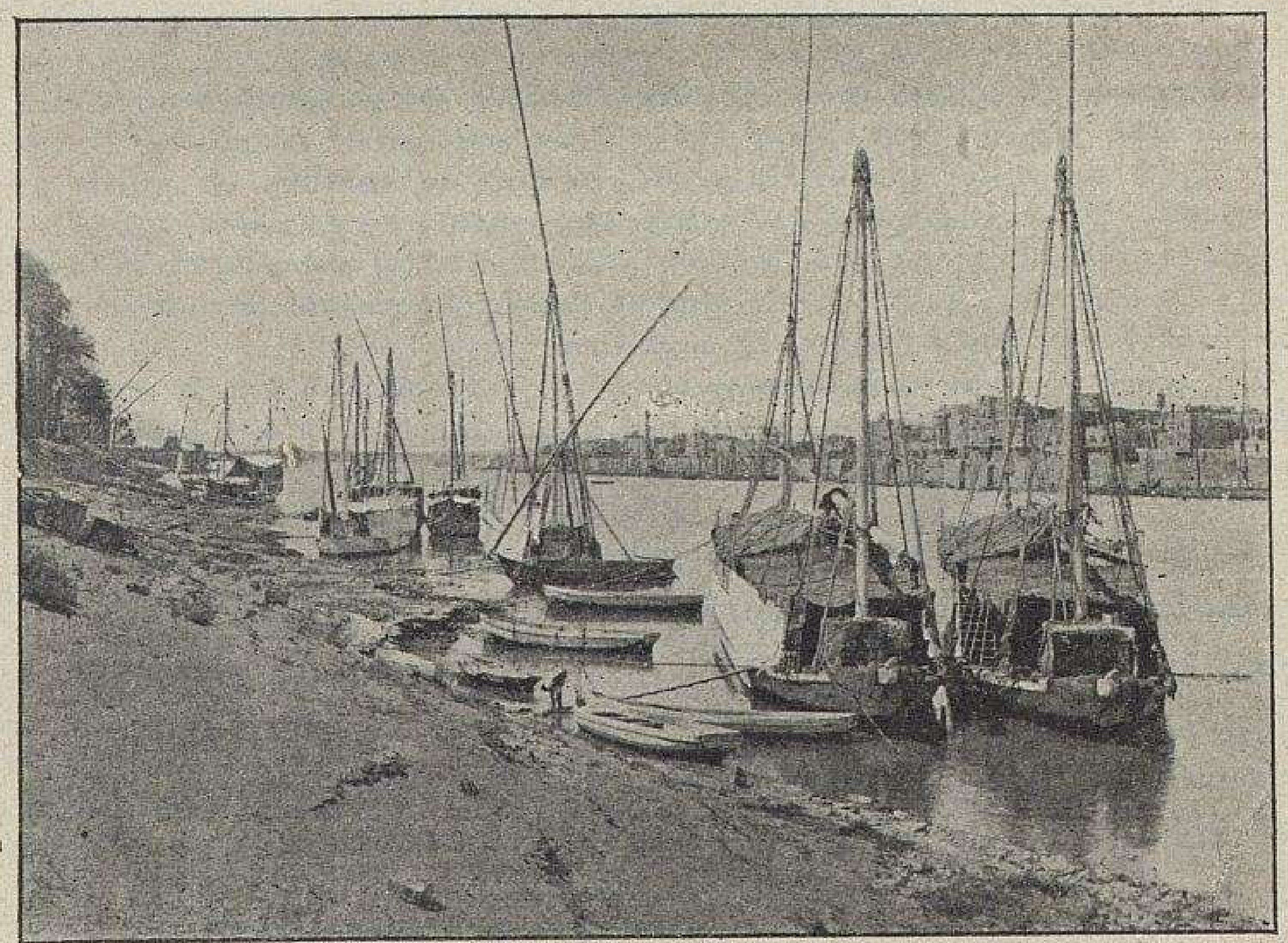

LE NIL A BOULAQ AVEC BARQUES OU DAHABIEH.

(Photographie Zangaki, communiquée par la Société de Géographie de Paris.)

réception, qui se videront ensuite, pour recevoir les semences sur leurs boues fécondes.

Le phénomène présente une telle régularité qu'il détermine en Égypte trois saisons agricoles : $1^{\circ}$ la crue s'annonce en juin, s'accentue en juillet et atteint son maximum en septembre : c'est l'automne; $2^{\circ}$ après des oscillations les eaux baissent d'octobre à janvier : e'est l'hiver; $3^{\circ}$ de février à mars, elles sont à leur niveau le plus bas : c'est l'été.

Le 20 juin est, depuis un temps immémorial, jour de fête, fète du nokta ou de la goutte. C'est qu'à cette date la crue, impatiemment espérée, s'annonce par un changement dans la couleur des eaux : de bleu clair, elles deviennent verdâtres, gluantes comme les matières végétales quielles apportent des marais équatoriaux : c'est le Nil rert. Mais le flot se fait de plus en plus tumultueux et se charge d'un limon rougeâtre, celui que les torrents arrachent aux terres volcaniques de l'Éthiopie : c'est alors le Nil rouge.

Des observatoires sont installés, l'un à Assouan, un autre en amont du Caire dans l'île de Rodah, un troisième à la fointe du delta. Les progrès 
de la crue se mesurent sur les colonnes graduées des nilomètres et, trois fois par jour, des crieurs publies proclament dans les rues du Gaire le niveau du fleuve.

Cependant le fellah, le paysan, a les yeux fixés sur le Nil; il l'observe avec anxiété, prêt à ouvrir les canaux. La crue paraît-elle normale, il est dans la joie; parait-elle insuffisante, ou bien ne se soutient-elle pas, le voilà au désespoir; menace-t-elle au contraire de monter trop haut, ce sont de vives alarmes; car elle risque de rompre les digues, et alor's que de désastres! Les récoltes ruinées, les bestiaux emportés, la famine, la peste enfin! Tout ce qu'il y a d'hommes valides monte la garde en permanence, et si une levée de terre menace de se rompre ou d'étre submergée, vite des centaines, des milliers parfois de fellahs se précipitent; à coups de pioche, à grand renfort de couffins en guise de brouettes, ils la consolident ou l'exhaussent; trones de palmiers, branches d'arbres, roseaux même, lout est bon. En arrière, les femmes, les enfants ont pris l'alerte et se hâtent de gagner le large, poussant devant eux les bestiaux, emportant le misérable mobilier.

Les crues qui sont bienfaisantes atteignent de $7 \mathrm{~m} .50$ à $8 \mathrm{~m} .10$ au nilomètre d'Assouan; au-dessous, elles sont trop faibles, et ce sera la famine; ar-dessus, elles sont trop fortes, et c'est le désastre.

Cette régularité de régime, pour un fleuve qui traverse une contrée sans pluie, étonnait les anciens; ils ne comprenaient pas, car ils ne connaissaient pas de fleuves tropicaux. Les grands lacs (Victoria, Albert, etc.), les marais sont d'immenses réservoirs; ils s'emplissent avec les grosses pluies qu'amène le passage du soleil au zénith. De Khartoum à Assouan, la pente faiblit, mais alors les cataractes maintiennent le plan d'eau. Lacs et cataractes se complètent : sans eux le Nil ne serait tantôt qu'un torrent fougueux et dévastateur, et tantôt qu'une rivière paresseuse, inutile, entre des rives de sable; grâce à eux le Nil est le fleuve béni. Les anciens Égyptiens en avaient fait un Dieu, le Dieu Hapi, et c'est avec enthousiasme que de très vieux cantiques entonnent sa louange et chantent ses bienfaits. "Salut, ô Nil, toi qui viens en paix pour donner la vie à l'Égypte! Dieu caché, irrigateur des vergers qu'a créés le soleil! créateur du blé! producteur de l'orge! S'il décroît, les hommes dépérissent; se lève-t-il, la terre est remplie d'allégresse. Il fait toutes les bonnes choses; il prodigue l'abondance de tous les biens!»

VI. Vie végétale. - C'est le Nil qui détermine les formes végétales de l'Egypte. Les plantes aquatiques ont disparu, par exemple le lotus, qui joua un rôle prépondérant dans la religion 
des anciens Égyptiens, et le papyrus, devenu sans utilité depuis l'invention du papier. Les limons de la vallée conviennent aux plantes herbacées, beaucoup plus qu'aux arbres; aucune de ces plantes ne pousse spontanément, toutes réclament le travail de l'homme. Aussi la plupart sont-elles d'importation étrangère, et à tout prendre la végétation est assez uniforme.

Parmi les plantes, que l'homme sème et cultive, figurent principalement les céréales (blé, orge, dourah, maïs, riz), les légumineuses (fèves et haricots), les plantes potagères (l'oignon dont la réputation est très ancienne, la tomate, les cucurbitacées), les plantes textiles (chanvre, lin, coton) et la canne à sucre. Parmi les plantes d'agrément, la rose, dont on distille l'essenee, est beaucoup moins cultivée depuis que les produits européens font concurrence à la parfumerie indigène. Quant à la culture du tabac, elle a été interdite par le gouvernement et les droits d'entrée sur les tabacs sont un des revenus les plus clairs du fisc.

L'arbre, si rare en Égypte, ne forme que des bouquets clairsemés : jamais de forêts ni de bois, comme dans nos contrées. Il en est un qui donne à la vallée sa physionomie propre, e'est le palmier, palmier dattier qu'il faut le plus souvent féconder artificiellement, et dans la Haute Égypte palmier doum dont le trone se divise en deux grosses branches. Il fournit les bois de charpente; avec ses feuilles on fait des paniers et des couffins, avec les fibres des cordes; les dattes se mangent sur. place et ne s'exportent pas. Ce sont ensuite plusieurs variétés d'acacias, acacia lebbak surtout, au tronc très gros, aux branches garnies de feuillage presque toute l'année : il est l'arbre des jardins publics des villes. Le sycomore était employé au temps des Pharaons pour la fabrication des cercueils, parce que son bois est dur et incorruptible; aujourd'hui comme autrefois, il donne un feuillage épais. Citons encore le peuplier, le mûrier, le tamarix, et, dans le Fayoum, l'olivier. - Les arbres fruitiers ne sont pas aussi aboridants qu'on pourrait le croire; ce n'est guère que dans les grandes villes ou dans leurs environs, et dans les oasis libyques que se rencontrent l'abricotier, le prunier, le poirier, le figuier, le cactus, le grenadier, l'oranger, le citronnier et la vigne, les essences en un mot des pays méditerranéens.

En dehors de la vallée du Nil, il n'y a que des déserts, et, seul, celui de Libye possède quelques oasis.

VII. Vie animale. - L'Égypte réunit les espèces animales des régions chaudes et sèches, et celles des régions chaudes et marécageuses.

Certaines ont disparu (le lion, l'éléphant, l'hippopotamej un disparaissent : le crocodile, animal sacré dans l'ancienne Égypte, ne se rencontre plus que sur le cours supérieur du Nil. Les carnassiers qui restent sont l'hyène et le chacal, le loup et le renard; ce sont encore les serpents, et l'on sait le rôle de l'urceus ou cobra, pris comme symbole

G. Legpagnol ex M. Fallex. - Afrique. 
aux temps pharaoniques - puis les morustiques et les mouches, un véritable fléau; l'indigène se résigne à les porter collées sur la bouche et sur les yeux. - Les oiseaux de marais, les échassiers, sont les familiers du fellah qui les respecte (héron, grue, flamant rose, ibis, pélican); ils pataugent de compagnie dans les boues. La caille est un oiseau de passage; elle arrive d'Europe en septembre et repart en avril avec sa couvée; c'est au filet qu'on la chasse, et si le gouvernement ne la protège pas, elle finira par être totalement détruite.

Comme la plupart des plantes, les animaux domestiques sont d'importation, sauf peut-être le bouf. On n'emploie pas le cheval aux cultures; l'äne a des formes belles et vigoureuses, au point que l'âne d'Europe ne lui est point comparable; on connaît du reste les âniers du Caire. Le chameau ne fut pas connu des Égyptiens des premières dynasties. Le buffle, introduit par les conquérants arabes, est un animal à demi amphibie, restant vautré des heures entières dans le Nil. Le chien pullule, et, comme dans toutes les rues des villes de l'Orient, il erre sans maître, jusqu'au jour où la police, par mesure sanitaire coṇtre la rage, ramasse les chiens errants, et en fait un massacre. Quant au chat, tout lui demeure permis : dans l'ancienne Égypte il était sacré, sa tête symbolisait la déesse Sekhet et son meurtrier était lynché par les foules; aujourd'hui il a libre accès dans les mosquées d'Allah et s'y sent le maître.

Rappelons pour mémoire qu'en dehors de la vallée du Nil, les troupeaux sont la principale richesse des nomades (chameaux, chèvres, moutons, cheval, etc.) et que l'antilope, la gazelle sont le gibier des contrées sèches.

VIII. Vie humaine. - Plus de 11.190 .000 habitants sc pressent sur les terres cultivables (33.200 kmq.); la densitẻ atteint le chiffre très élevé de 334 habitants au kilomètre carré.

On peut bien, sans exagération, dire qu'en Égypte l'homme est une création du fleuve; le Nil l'a modelé à son image, l'a étroitement lié à son limon; en lui imposant une forme de vie, il a fixé le type de la race. Par un phénomène peut-être unique, le paysan égyptien est resté à travers les siècles immuablement le même, et sa force de résistance est telle qu'il a fini par absorber et par s'assimiler les peuples conquérants. L'examen des momies, l'étude des peintures et des statues de l'ancienne Égypte établissent, à n'en pas douter, ce caractère de stabilité. Il y a cinquante ans, Mariette exhumait la statue d'un intendant de la $V^{\bullet}$ dynastie; elle datait de quarante siècles. Or les paysans qui travaillaient aux fouilles reconnurent en elle, trait pour trait, le chef du village et tous de s'écrier : "Cheik el beled ). Depuis, le nom est resté à la statue.

Le fond de la population appartient à la race hamitique, laquelle serait venue de l'Asie antérieure et de l'Arabie; elle comprend les Fellahs et les Coptes. 
Le Fellah habite la campagne, et son nom même signifie laboureur, paysan. Robuste, de haute taille, les articulations fortes, comme il convient à un peuple marcheur, les cheveux noirs et ondulés, l'ceil fendu en amande, le front bas, le crâne dur et épais, il est, au moral, timide, craintif et docile, comme le sont les races agricoles, et comme elles, il a toujours été exploité. Tout le long de l'année, il mène une vie de travail et de misère; il laboure avec une charrue de mème type que celle des anciens Égyptiens; il sème, herse, récolte, mais surtout il arrose avec le

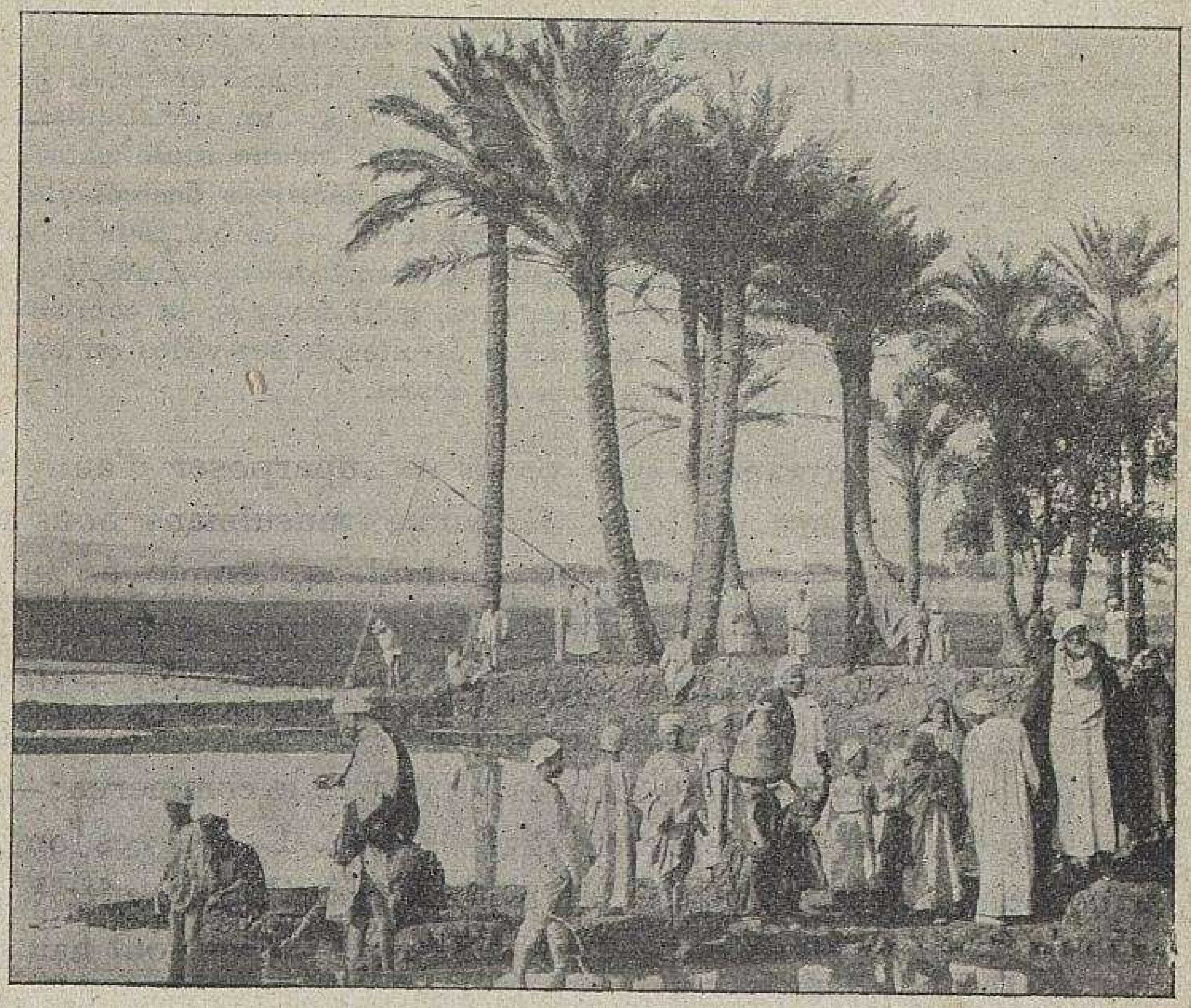

AU BORD DU NIL.

(Photographie Zangahi freres, communiquée par la Sociéte de Géographie de Paris.)

On aperçait, au second plan, le chadouf : sur un montant de bois est fixée une longue perche horizontale, alourdie à son extrémité la plus courte et la plus forte par un contrepoids, et retenue à l'autre bout par une corde où pend le récipient. L'homme tire sur la corde, emplit le récipient qui remonte automatiquement par un mouvement de bascule et le déverse dans la rigole d'arrosage. Ce procédé n'est pas plus particulier à l'Égypte que la nataleh (Voir page 309).

seau à puiser et toujours il barbote dans un limon puant et fécond; le rythme du Nil a rythmé sa vie. Quand il a vaqué tout le jour aux travaux des champs, courbé, hâve sous le grand soleil, il regagne la levée de terre qui le ramène au village, avec ses ânes et ses buffles. Sa pauvre eabane, faite en boue du Nil, quatre murs recouverts de paille, n'est qu'un gîte de nuit; pour tout mobilier, des nattes et quelques ustensiles grossiers. Sobre, il se nourrit d'un pain de farine de dourah s'il habite la haute Égypte, ou de maïs s'il habite le delta, et encore de fèves, d'oignons, de 
concombres, tout comme autrefois. Nul pittoresque dans son vêtement : une chemise bleu indigo, à large échancrure pour passer la tête, une culotte de coton large, courte et à coulisse, un ample manteau brun en poil de chèvres, pieds nus le plus souvent, ou des babouches.

Le Copte habite la ville : c'est un bourgeois. Des anciens Égyptiens, dont il descend en droite ligne, il a conservé le nom, déformé par les Arabes. Il exerce des métiers délicats (orfèvre, tailleur, brodeur en or, ébéniste) ou bien il tient la profession de secrétaire, de comptable pour le compte des particuliers ou de l'État; aussi est-il de teint plus clair que le fellah et d'articulations plus fines. C'est la religion qui a sauvé en lui la pureté originelle du type. Le fellah s'est arabisé, il parle arabe, il est musulman; le Copte au contraire est chrétien, mais d'un christianisme à forme spéciale : il ne reconnaît en Jésus-Ghrist qu'une seule nature, d'où le nom de la secte, monophysite. Rebelle aux décisions des conciles, il a gardé depuis le $v^{0}$ siècle la doctrine d'Eutychès, et ce fut pour lui la cause d'humiliations et de perséeutions; il eut le sort des opprimés. G'est par haine de Byzance et de ses persécuteurs, qu'il favorisa la conquête musulmane, qu'il s'enferma dans les ruelles étroites de ses villes ou bien dans des monastères fortifiés aux confins du désert.

Sur ce fond permanent sont venus se superposer d'autres peuples : des Barabra, émigrés de Nubie, musulmans bons à tous les métiers; - des Nègres soudaniens, employés aux services les plus vils; - des Turcs : c'est le peuple conquérant, peuple de fonctionnaires, par suite, ou de marchands; - des Levantins de Syrie, des Arméniens, des Juifs, nombreux dans les cités, où leur entente des affaires leur livre le commerce; enfin des Européens de nationalité diverse. Les Grees ont, comme leurs ancêtres, le don du négoce, grand ou petit; les Italiens s'occupent à de menus métiers; les Français sont hauts fonctionnaires, architectes et ingénieurs; les Anglais, venus les derniers, accaparent de plus en plus toutes les administrations.

Dans les déserts circulent les Bédouins, d'un mot arabe, qui veut dire nomades, et parmi eux les Bicharieh.

L'indépendance de leur vie en a fait un peuple fier, de mâle allure, dont l'énergie contraste avec l'humilité du fellah et du copte; entre les uns et les autres existe le même contraste qu'entre le désert et la vallée du Nil. Comme la nature se charge d'éliminer les enfants chétifs, le type du Bédouin est beau : la peau foncée, les cheveux magnifiques portés longs ou bien en tresses, ils ont les membres fins et grêles, le cou mince, semblables à la gazelle et au chameau dont ils partagent le genre de vie, et toujours la figure se creuse de rides précoces. Musulmans, mais peu attachés au dogme, de langue arabe, et se disant Arabes, ils vivent par familles et par tribus et campent sous la tente, sans cesse à la recherche de pâturages nouveaux. 


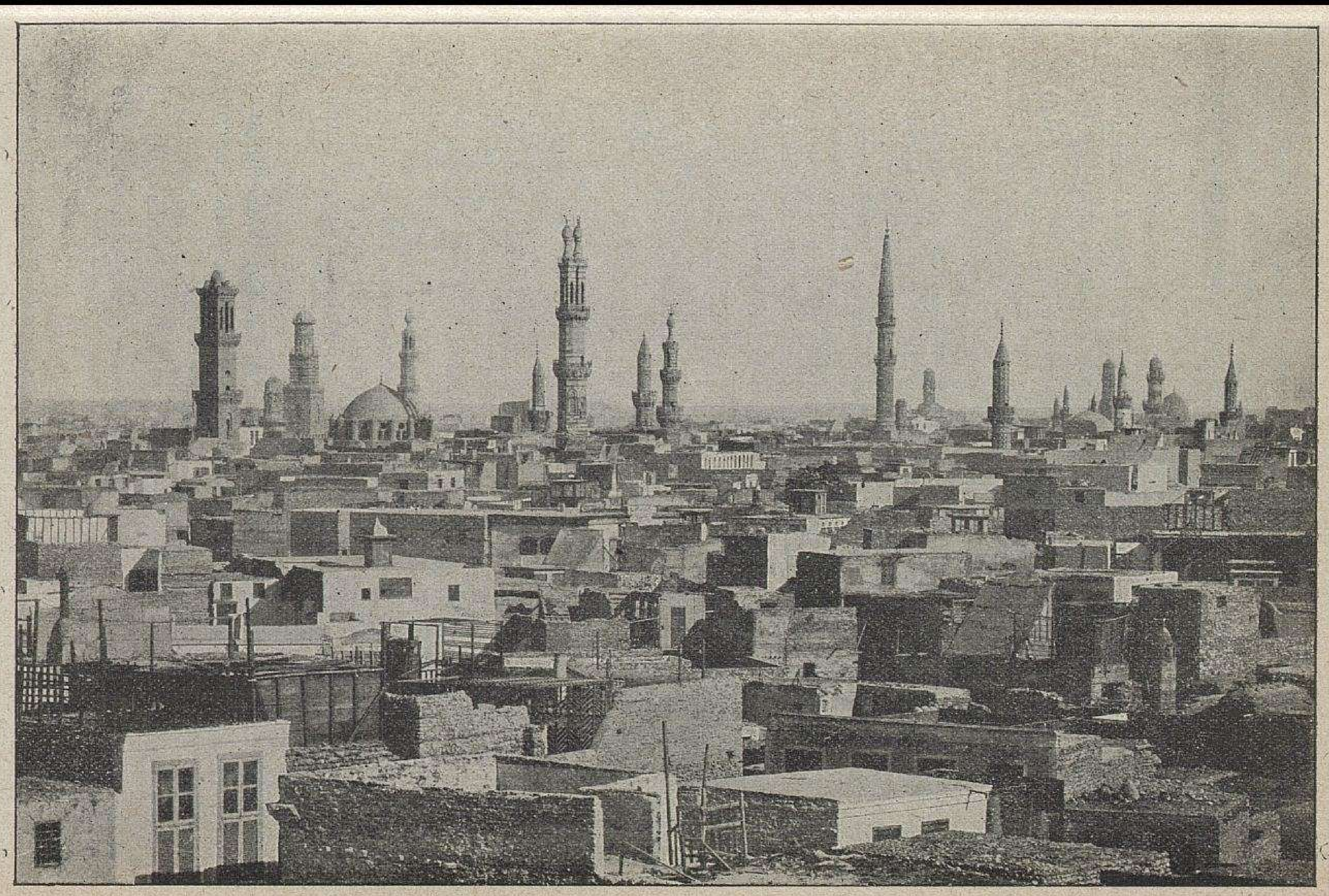

LE CAIRE.

(Photographie Zangali frères, eommuniquée par la Societe de Géographie de Paris.)

Au-dessus des maisozs à terrasses, les coupoles et les minarets des mosquées sont les merveilles d'une architecture ingénieuse et variée. 
Quant aux peuples des oasis du désert Libyque, ils sont, comme toujours, sédentaires, de race fort mêlée et de constitution moins saine : l'humidité des canaux d'arrosage engendre en effet les fièvres.

\section{Gouvernement et villes. - L'Égypte forme une} province autonome de l'Empire turc; les rapports de vassal à suzerain ont été réglés par des traités et des firmans en 1840 et 1841.

La dynastie régnante est celle de Méhémet Ali; le chef s'appelle Khédive et a titre d'Altesse. Le gouvernement est héréditaire, mais il se transmet, suivant la loi musulmane, au plus âgé des proches parents. Dans les grandes villes, des gouverneurs; dans les provinces, des moudirs. Le pouvoir absolu du Khédive est limité vis-à-vis des étrangers par les Capitulations, e'est-à-dire par des traités que la Porte a consentis aux puissances chrétiennes. Le Khédive a de plus aliéné une bonne part de son pouvoir judiciaire par la création de tribunaux mixtes et il a admis un contrôle sur ses finances par une institution internationale, la Caisse de la dette.

En Égypte, terre française à bien des égards, l'Angleterre s'est créé une situation exceptionnelle. En 1875 sur le refus de notre gouvernement, elle acheta les actions du canal de Suez que le Khédive cherchait à négocier et eut ainsi qualité pour organiser avec la France un contrôle financier à deux, le Condominium. Survint l'insurrection d'Arabi pacha en 1881 : la France commit la faute, impossible à réparer aujourd'hui, de ne pas s'associer à l'Angleterre pour rétablir l'ordre. Seule l'Angleterre se chargea de ce soin. Puis elle abolit le Condominium et graduellement s'annexa l'Égypte, absorbant son gouvernement. Elle tient l'armée, la police, l'administration sanitaire, les finances, les douanes, les travaux publics, l'instruction publique, et elle a réoccupé le Soudan égyptien. Les idées, les móurs, la langue anglaises remplacent de plus en plus celles de la France. - Le Khédive a un pouvoir apparent, l'Angleterre le pouvoir réel. Par la convention d'avril 1904, la France a reconnu cet état de choses en faisant abandon de certains droits financiers, fort gênants pour le service de la Dette. Mais la souveraineté ottomane et les institutions internationales subsistent intégralement.

Un bien petit nombre de villes modernes occupent l'emplacement des villes d'autrefois. Alexandrie est la seule; encore date-t-elle de l'hellénisme, et non des Pharaons.

$1^{\circ}$ Basse Égypte. - Le Caire (654.000 h.) est la plus grande et la plus belle ville non seulement de l'Égypte, mais de l'Afrique entière.

Fondée par les conquérants arabes, d'où son nom "la Victorieuse ", elle s'adosse aux pentes du Djebel Mokattam $(200 \mathrm{~m}$.) et atteint la rive 
droite du Nil. A côté de ses ruelles, de ses impasses étroites et tortueuses, tour à tour poussière ou boue, à còté de ses " bazars \#, c'est-àdire des rues occupées par un même corps de métier, à côté de ses

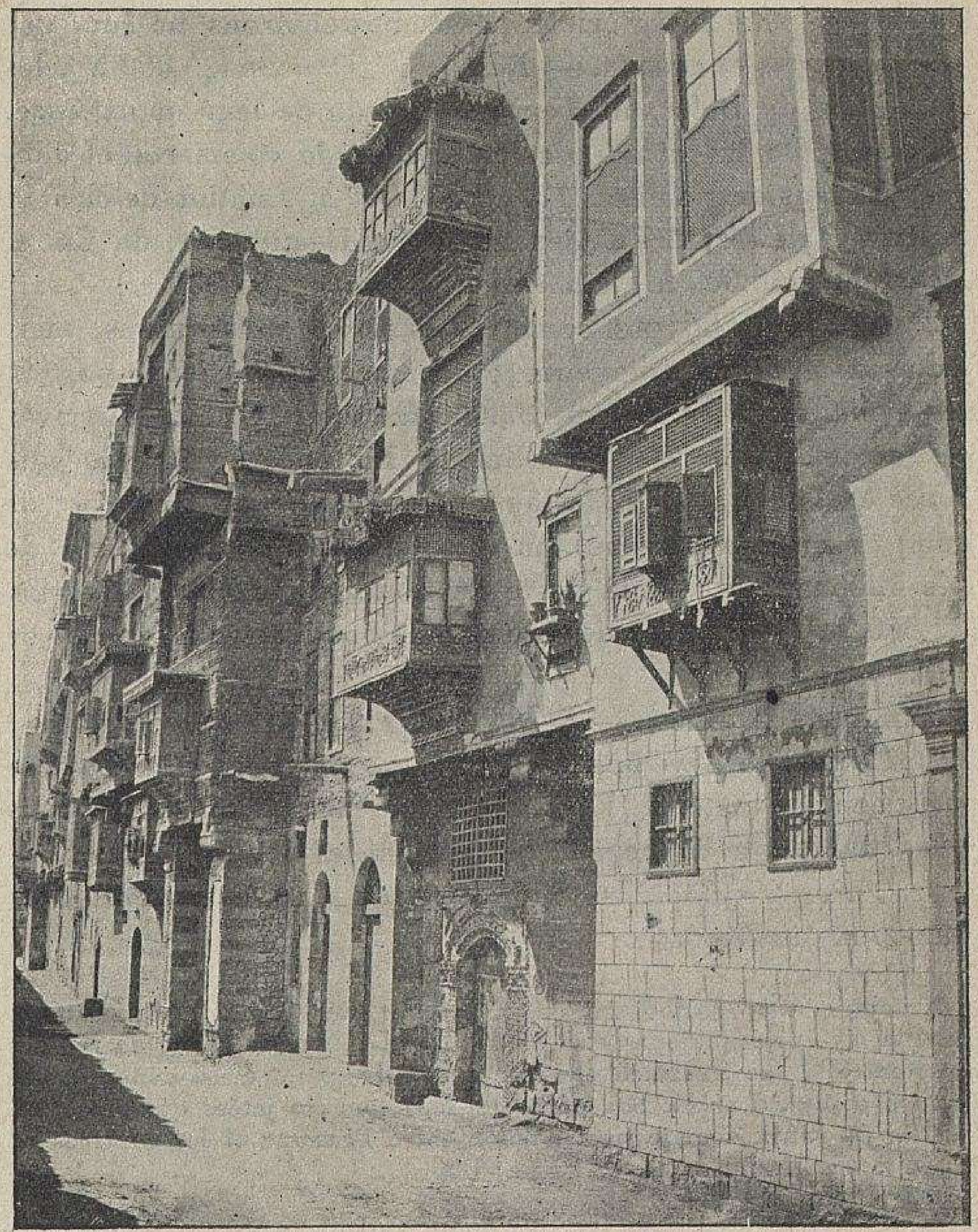

LE GAIRE : RUE DE LA MOSQUEE DE TOULOUN.

(Photographie Zangahi frères, communiquée par la Socièté de Géographie de Paris.,

Maisons peintes avec moucharabieh ou balcons fermés.

maisons peintes, à « moucharabieh », elle montre des quartiers européens, des voies régulières, spacieuses et de grands édifices publies. G'est un foyer de culture arabe et un centre d'études pour les antiquités égyptiennes. 
Alexandrie (332.000 h.), la seconde ville et le premier port, est au point de contact de trois continents. Reconstruite sur les ruines du bombardement de 1882, elle n'a rien d'oriental, et rien ne rappelle son glorieux passé. Ses environs ne sont que sables, marais et canaux. - Rosette et Damiette (29.000 h.), les deux ports du Delta, ont beaucoup perdu de leur importance. Dans le delta lui-même, plusieurs villes de commerce et d'industrie, sans originalité : Tantah $(54.000$ h.), station de chemin de fer à égale distance d'Alexandrie, de Damiette et du Caire, Mansourah (40.000 h.), Damanhour, Zagazig (35.000 h.).

$2^{\circ}$ La Haute Égypte compte des villes nombreuses, mais toutes d'importance moyenne ou médiocre; plusieurs portent des noms célèbres. Asiout (39.000 h.) était le point d'arrivée des caravanes du Darfour. Sur le Nil encore, Girgeh, puis Keneh et Esneh, au Nord et au Sud de l'ancienne Thèbes et de Louqsor. Assouan (Syène), au voisinage de l'île de Philæ et de lîle Eléphantine, est la porte du Soudan. Medinet el Fayoum ( 37.000 h.), au milieu de jardins, de bouquets d'arbres et de riches cultures.

$3^{\circ}$ Isthme de Suez. - Suez $(17.000$ h.), sur la mer Pouge, n'a pas pris le développement que semblait lui promettre le percement de l'isthme. En revanche le canal a fait naître trois villes, d'importance inégale, qui portent les noms de trois Khédives : Port-Ibrahim, au Sud, Ismaïlia au centre, Port-Saïd (49.000 h.) au Nord.

De toutes c'est Port-Saïd qui a pris le plus grand essor; sans le canal il n'y aurait toujours à sa place qu'une langue de sable, au ras des flots, entre le lac Menzaleh et la Méditerranée, point d'eau douce et pas l'ombre d'un seul arbre. Son port, ses deux longues jetées qui protègent l'entrée du canal, sont le trait d'union entre l'Europe et les contrées de l'Orient.

Kosseï, sur la mer Rouge, au débouché de la route de Keneh, est insignifiant.

$4^{\circ}$ Les 0 asis sont à moitié enfouies sous les sables du désert de Libye: Khargeh, Dakhel, Farafral et Baharieh. - Siouah au-dessous du niveau de la Méditerranée, secoué par les tremblements de terre, possède des sources thermales et du soufre; son temple de Jupiter Ammon a été débité par les indi- 
gènes, comme une carrière à ciel ouvert, et bien peu de personnes songent que le nom de sel ammoniac a là son origine. Enfin Faredgha (Djaraboub) fut longtemps la résidence du chef des Senoussi.

\section{Mise en valeur.}

- Terre d'alluvions, l'Egypte est un pays d'agriculture; sa mise en valeur dépend tout entière de l'irrigation.

Quand les premières sociétés humaines prirent possession de la vallée, le problème qui se posa fut de régler l'inondation du Nil, lequel, abandonné à lui-même, était plus nuisible qu'utile. Le procédé employé pour les cultures fut celui de la submersion : des digues parallèles et perpendiculaires au fleuve retinrent et dirigèrent à volonté les eaux dans des bassins superposés; on jetait ensuite la semence sur les terres détrempées. En même temps se

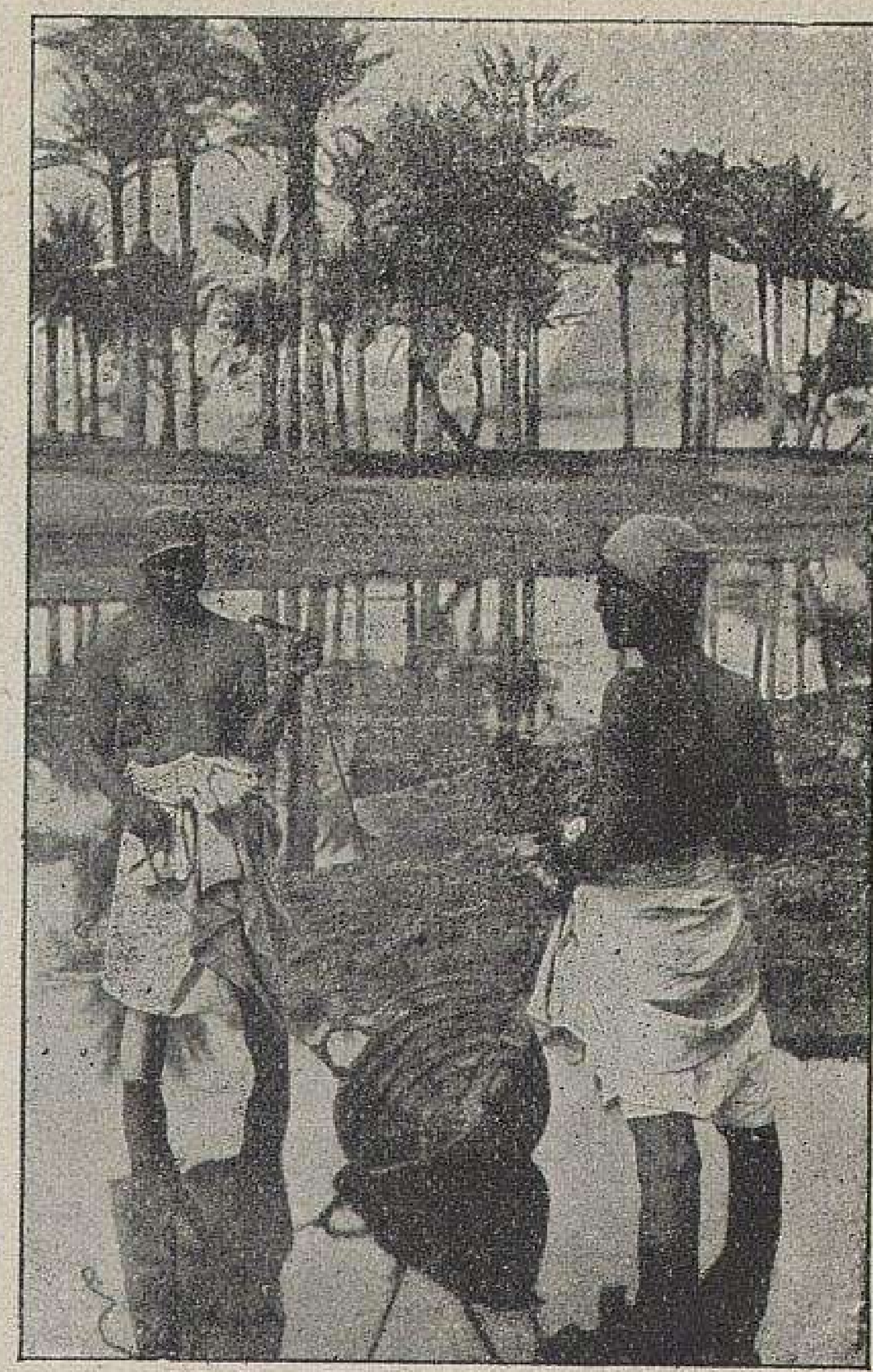

MODE PRIMTTIF D ARROSAGE SUR LES BORDS DU NIL.

(Photographie Zangaki frères,

communiquée par la Société de Géographie de Paris.)

La nataleh ou couffe d'osier est munie de deux cordelettes : deux hommes, placés vis-à-vis, lui impriment en cadence un double mouvement pour l'omplir et la déverser. Ce moyen primitif, qui donne un mince résultat pour un grand effort, n'est pas particulier à l'Égypte : par exemple les Annamites le pratiquent dans les rizières du Tonkin.

dessinait un réseau compliqué de canaux et de rigoles d'arrosage, que l'on emplit au moyen de systèmes de plus en plus perfectionnés : la nataleh ou couffe d'osier, le chadouf à bascule, la saquieh ou roue à pots, enfin, à partir du $\mathrm{xIx}^{\mathrm{e}}$ siècle, les moulins élévatoires à vent ou à vapeur.

C'est grâce à ses travaux hydrauliques que, dans l'antiquité, 
l’Égypte fut la terre par excellence des céréales et des légumes; on l'appelait communément un grenier.

A l'irrigation temporaire les ingénieurs modernes substituent l'irrigation continue, et celle-ci est en train de modifier les conditions agricoles de la vallée. Car elle permet des cultures

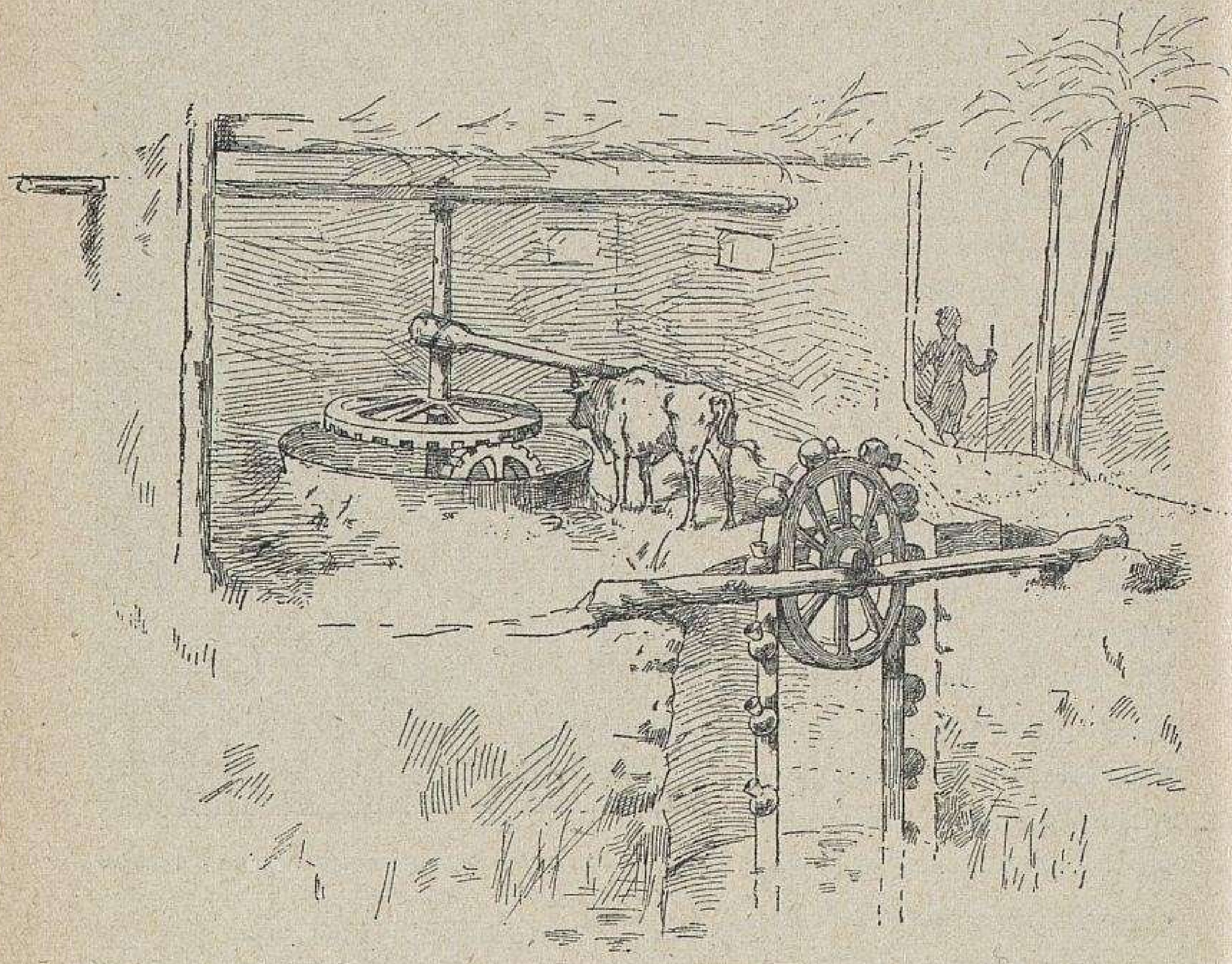

AUTRE MODE D ARROSAGE.

Dessin extrait de A. Chélu, le Nil, le Soudan et l'Égypte (Ghaix et Garnier frères).

LA SAQUIEH OU ROUE HYDRAULIQUE A POTS.

Un bouf, attelé à un manège, met en mouvement un arbre vertical et une roue motrice; celle-ci s'engrène à une seconde roue verticale, d'où la force est transmise à une troisième, garnie d'un chapelet de pots de terre, qui s'emplissent au bas de la course et se vident au sommet.

nouvelles, celles des plantes tropicales, coton, riz et canne à sucre. Ce furent des Français, qui, au temps de Méhémet Ali, inaugurèrent le système des barrages en travers du fleuve; de la sorte, le niveau des hautes eaux est maintenu, la durée de l'irrigation s'allonge et la superficie arrosée s'étend. Mais il était réservé à l'Angleterre, que notre abstention en 1881 laissa 
maîtresse de la place, de continuer et de mener à bout l'œuvre commencée par nous : le barrage de la pointe du Delta, entrepris en 18ł3, a été terminé en 1890; depuis 1902, le barrage d'Asiout refoule les eaux dans le canal Ibrahimieh de façon à féconder le Fayoum; enfin le barrage d'Assouan, insubmersible et mobile, a été construit de 1899 à 1903 : on l'exhausse encore actuellement.

Par contre-coup la culture du blé décline dans de fortes proportions, et contre ce réel danger le gouvernement est obligé de prendre des mesures rigoureuses ${ }^{1}$.

Naturellement, ce sont les produits agricoles que traite surtout l'industrie européenne : sucreries et raffineries, minoteries, tanneries et mégisseries, coton.

Quant à l'industrie indigène, elle occupe beaucoup de petits métiers : la confection des meubles arabes et la fabrication d'antiquités égyptiennes viennent au premier rang. Les poteries de Keneh et d'Asiout conservent leur réputation.

Ce sont encore les produits agricoles qui alimentent le commerce d'exportation. Alexandrie, au con-

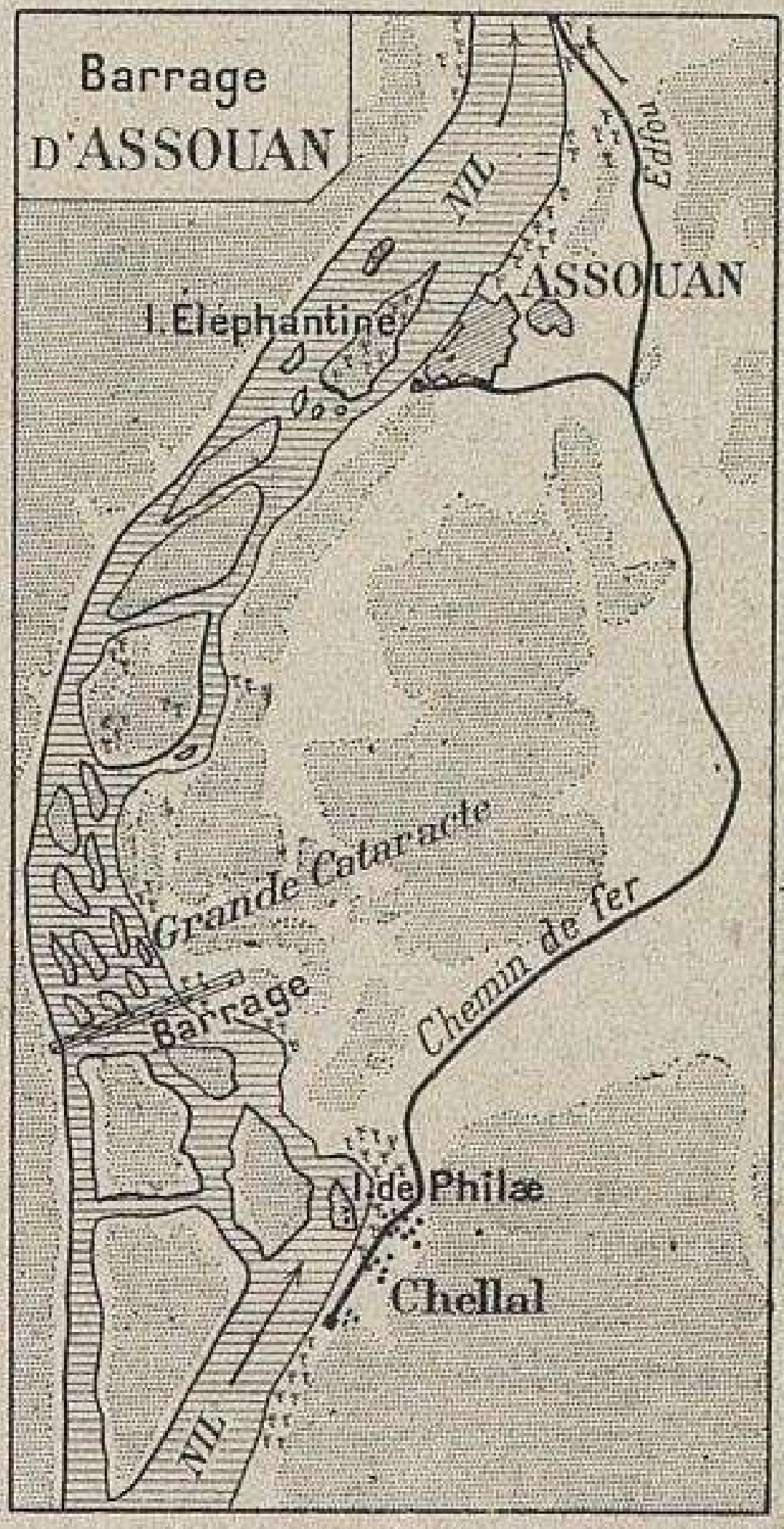
tact de trois continents, est restée ce qu'elle fut dès sa fondation, le centre des échanges internationaux. Le port comnunique par voie ferrée avec le Caire, d'où les lignes rayonnent sur Suez et sur Assouan, et la vallée du Nil ouvre une voie précieuse de pénétration à l'intérieur de l'Afrique.

1. Superficie cultivée en 1902 :

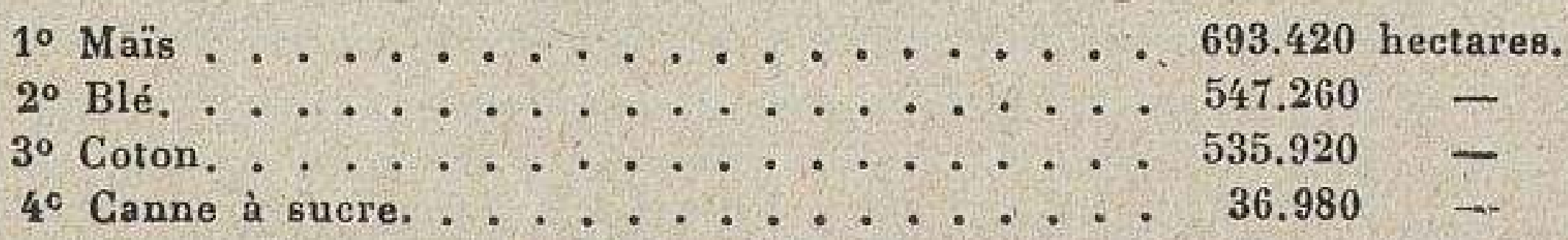


Commerce extérieur de l’Égypte (1905-09).

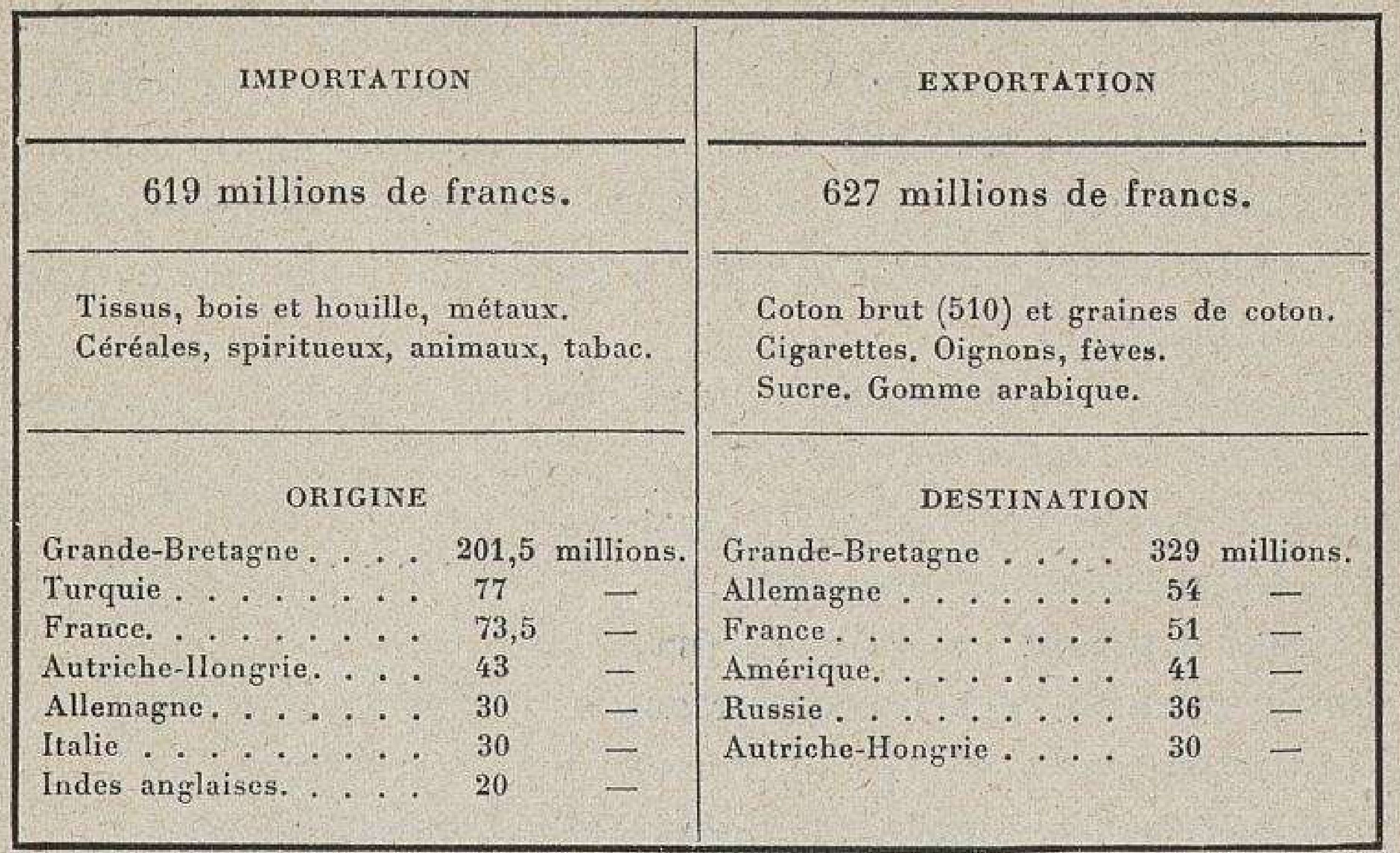

Depuis le percement de l'isthme de Suez, la situation commerciale de l'Égypte est sans égale. C'est vers elle que s'est détournée une partie appréciable du commerce du monde; car les distances entre l'Europe, l'Inde, l'Extrême-Orient et l'Australie ont été sensiblement réduites; par exemple la route de Marseille à Bombay s'est trouvée abrégée de 3.200 kilomètres.

Le canal de Suez est une ouvre gigantesque, dont rien n'approchera, tant que l'isthme de Panama ne sera pas ouvert. L'idée d'unir la Méditerranée à la mer Rouge est des plus anciennes; mais ce fut un Français qui la réalisa, FERDinand DE LESSEPS : il triompha de tout, des difficultés matérielles aussi bien que de l'hostilité jalouse de l'Angleterre. La construction a demandé dix ans et coûté plus de 200 millions; l'ouverture solennelle du canal a eu lieu le 17 novembre 1869.

$$
\begin{aligned}
& \text { Longueur du canal.. . . . . . . . } 160 \mathrm{~km} \text {. } \\
& \text { Largeur au niveau de l'eau ..........66 } 60 \text { à } 100 \mathrm{~m} \text {. } \\
& \text { - au plafond............. } 22 \mathrm{~m} \text {. } \\
& \text { Profondeur. ............ } 8 \mathrm{~m} \text {. . } \\
& \text { Durée de la traversée. . . . . . . . . } 15 \text { à } 24 \text { heures. }
\end{aligned}
$$

Pour ne pas faire écrouler les berges de sable, les navires ralentissent la vitesse, et, malgré cette précaution, des dragues puissantes ont à entretenir constamment le chenal. - Les frais de passage ont beau être élevés, il n'y a plus guère que les grands voiliers, chargés de matières lourdes, qui doublent le cap de Bonne-Espérance; les vapeurs trouvent un avantage appréciable de temps et d'argent à emprunter la voie du canal et il s'en présente une moyenne de dix par jour ou par vingt-quatre heures. La traversée peut en effet se faire de nuit; chaque navire doit alors s'éclairer de projecteurs électriques. 


\begin{tabular}{|c|c|c|c|c|}
\hline ANNÉE & PAVILLON & $\begin{array}{c}\text { NOMBRE } \\
\text { DE } \\
\text { NAVIRES }\end{array}$ & $\begin{array}{c}\text { TONNAGE } \\
\text { NET }\end{array}$ & $\begin{array}{c}\text { NOMBRE } \\
\text { DE } \\
\text { PASSAGERS }\end{array}$ \\
\hline 1909 & $\begin{array}{l}\text { Grande-Bretagne. } \\
\text { Allemagne... } \\
\text { France. . . } \\
\text { Hollande. } \\
\text { Autriche-Ilongrie. } \\
\text { Japon . . . } \\
\text { Russic. . . . } \\
\text { Italie..... } \\
\text { Total. . }\end{array}$ & $\begin{array}{r}2.561 \\
600 \\
231 \\
251 \\
148 \\
76 \\
74 \\
90 \\
\ldots . \\
4.239 \\
\end{array}$ & $\begin{array}{r}9.592 .000 \\
2.382 .000 \\
802.000 \\
801.000 \\
520.000 \\
358.000 \\
222.000 \\
208000 \\
. \ldots \ldots . \\
15.407 .000 \\
\end{array}$ & 213.100 \\
\hline
\end{tabular}

La Convention de Gonstantinople a neutralisé le Canal en 1888, e'est-adire qu'elle l'a placé à l'abri des actes de guerre; mais le passage des troupes y est libre, à condition que celles-ci s'abstiennent d'actes d'hostilité. En réalité, comme l'Égypte est accaparée par l'Angleterre, c'est l'Angleterre qui est maittresse de la sécurité du Canal : or il est le point stratégique par excellence de l'empire des mers.

Conclusion. - « L'Égypte, disait Renan, a une place exceptionnelle dans l'histoire du monde \%. Cette place, elle la doit au Nil.

Dans aucune autre contrée, l'influence exercée par la nature sur les progrès de l'humanité et sur la marche de la civilisation ne s'est manifestée de façon aussi éclatante. Le Nil a stimulé toutes les énergies créatrices de l'homme. Il lui a enseigné à construire des digues, à drainer l'inondation, à creuser des canaux, à élever les eaux, à prévoir l'époque de la crue : ainsi est née la science hydraulique. Mais le fleuve submergeait chaque année les bornes des champs, dans les bassins de réception : arpenteur et géomètre, l'homme apprit à dresser le cadastre. L'intérêt commun exigeait la soumission à des règlements : une législation se forma, la vie politique s'organisa et l'État fut constitué.

Mieux armé, grâce aux progrès de la science, l'homme aujourd'hui s'attaque à des problèmes plus ardus, et qui sait si le système de l'irrigation continue ne trouvera pas son application dans des contrées analogues, et si les conditions économiques, les formes mêmes de la vie n'y seront pas un jour transformées, comme elles l'ont été en Égypte?

Si l'on se souvient en outre qu'à l'isthme de Suez l'homme a discipliné la nature, que l'ouverture du canal a marqué dans les relations commerciales une révolution qui de l'ensemble des grands États de l'Europe s'est répercutée sur une notable partie du globe, n'est-on pas en droit de corclure avec Renan : "L'Égypte n'est pas une nation : une terre qui importe à ce point au reste du monde ne saurait s'appartenir à elle-mème ». Elle est internationale, elle appartient à l'humanité. 


\title{
CHAPITRE XVIII
}

\section{MADAGASCAR ET ARCHIPELS DE L'OCÉAN INDIEN}

\author{
SOMMAIRE \\ 1. - MADAGASCAR
}

1. Limites et superficie. - L'ile de Madagascar, plus grande que la France, est un petit continent distinct de l'Afrique (592.000 kmq.) II. Orogénie et relief. - Débris d'un ancien continent disloqué, Madagascar forme un grand plateau central, terminé à l'Est et à l'Ouest par des falaises à pic et surmontè de roches volcaniques : le Tsiafa-Javona atteint $2.650 \mathrm{~m}$. dans le massif de l'Ankaratra. Les parties les plus hautes ont de grandes cuvettes alluvionnaires et marécageuses,

III. Climat. - Située dans l'hémisphère austral et traversèe par le tropique du Capricorne, l'île appartient à la région des alizès, sauf le Nord, touché par les moussons. L'Est est chaud, très humide et malsain, d'une température toujours égale. L'Ouest connait une saison pluvieuse et une saison sèche. Le Sud-Ouest est soumis a un climat subdésertique. Enfin les hauts plateaux du centre forment une enclave tempérée au milieu des régions tropicales.

IV. Hydrographie. - Les torrents du versant oriental n'ont pas en général de place pour se dèvelopper; ils sont coupès par des chutes: Mananjary et Mangoro.

Beaucoup plus longs sont les fleuves de l'Ouest: le Betsiboka et l'Ikopa, qui fertilise la plaine de Tananarive, finissent ensemble dans la rade de Majunga.

V. Les cótes sont peu découpées dans leur ensemble. Celles de l'Est, rectilignes, basses, accompagnèes de lagunes, ne possèdent que des rades ouvertes : Fort-Dauphin et Tamatave; - celles du Nord dessinent, entre autres, la baie magnifique de Diego-Suarez; celles du Nord-Ouest sont rongèes par la mer et rompues par l'arrivée des fleuves : ainsi la baie de Majunga; - celles de l'Ouest n'ont que des plages de sables et de vases; - enfin celles du Sud se relèvent et sont précédées de coraux : Tuléar est là le meilleur port.

VI. La vie végétale diffère avec le climat. La région littorale de l'Est a une végétation très feuillue et des cultures tropicales; - l'Ouest, 
où la savane l'emporte sur la forêt, produit abondamment le raphia; - les plateaux du centre, faits d'une argile rouge et stérile appelée latérite, n'ont qu'une vègétation d'herbes; les rizièes occupent les fonds des vallees; - enfin le Sud-Ouest porte les arbustes grêles et épineux des terres subdésertiques.

VII. Vie animale. - Madagascar a une faune spéciale : c'est la terre des lémuriens, lesquels sont des quadrumanes, en même temps que des pachydermes grimpeurs.

VIII. Vie humaine. - La population dépasse a peine trois millions d'habitants. Les Hovas sont des conquérants; venus sans doute de l'Asie, ils se sont établis sur les plateaux, s'imposant aux Betsiléo et aux Betsimisaraka.

Les Sakalava, au Nord-Ouest et á l'Oüest, ont subi l'influence arabe et musulmane.

Les régions du Sud sont habitees par des peuples guerriers, comme les Antandroy.

IX. Gouvernement et villes. - Nadagascar est une colonie françise, administrée par un Gouverneur général qui réside à Tananarive (60.000 h.). Fianarantsoa est le centre du Betsiléo. Sur la cóte orientale Tamatave, le premier port de l'île, occupe une position centrale entre Fort-Dauphin, un des plus anciens comptoirs et Diégo-Suarez belle position militaire. Majunga est le port du Nord-Ouest, Tuléar celui du Sud-Ouest.

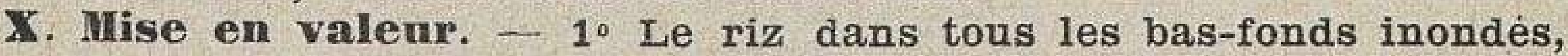
les cultures tropicales sur la côte de l'Est, les forêts et l'élevage fournissent les principales ressources agricoles.

$2^{\circ}$ L'industrie nait seulement : parmi les richesses minières, qui paraissent abondantes, la production de l'or augmente rapidement.

$3^{\circ}$ De grands travaux sont entrepris pour doter l'île de voies de communication (routes, canaux et chemins de fer) et pour ameliorer les ports. Les exportations consistent en or, caoutchouc, raphia et bètail, les importations en tissus, spiritueux et outillage mécanique. Les trois quarts du commerce se font sous pavillon français.

Madagascar est colonie à la fois de peuplement, d'exploitation et de commerce.

\section{1. - MASCAREIGNES}

L'archipel des Mascareignes forme trois iles volcaniques : la Réunion, colonie française; Maurice et Rodriguez, a l'Angleterre.

De climat chaud et humide, d'une végettation par suite fort riche, elles produisent la canne à sucre, le café et la vanille.

Saint-Denis est la capitale de la Réunion et la pointe des Galets le principal port. L'île Maurice a son centre administratif à PortLouis.

\section{III. - COMORES}

L'archipeı volcanique des Comores, chaud, très humide et d'une végétation exubérante, produit la canne á sucre et la vanille. Il forme une dépendance administrative de Madagascar. Mayotte est la plus ancienne colonie française du groupe. 
IV. - AMIRANTES ET SECHELLES

Possession anglaise, les Amirantes et les Sèchelles présentent les mêmes conditions économiques que les archipels précédents. Mahé est une position stratégique de premier ordre et un port fréquenté.

\section{V. - NOUVELLE-AMSTERDAM, SAINT - PAUL ET KERGUELEN}

La France a pris possession, dans l'océan Indien, des iles Nouvelle-Amsterdam, Saint-Paul et Kerguelen. Situèes sur la route du Cap á l'Australie, perdues dans les brumes et sans autre végétation que des mousses, elles sont habitées par les oiseaux de mer et la mer abonde en poissons.

\section{DÉVELOPPEMENT}

\section{I. - MADAGASGAR 1}

I. Limites et superficie. - On appelle volontiers Madagascar la grande ile africaine. Grande, elle l'est en effet, puisqu'elle n'est surpassée que par la Nouvelle-Guinée et par Bornéo : sa supérficie $(592.000 \mathrm{kmq}$.) l'égale à la France, à la Belgique et à la Hollande réunies; - a fricaine, elle l'est bien par sa situation : 300 kilomètres seulement séparent Moçambique et le cap Saini-André.

En réalité, Madagascar est un petit continent à part, distinct du grand depuis une époque géologique très ancienne, séparé de lui par de grandes profondeurs (2 et $3.000 \mathrm{~m}$.) et par des courants violents. Malgré la distance $(4.000 \mathrm{~km}$.) il existe une plus grande analogie avec l'Inde. Les Amirantes, les Séchelles et les Mascareignes, qu'on range parmi les archipels africains, les Maldives et les Laquedives qu'on joint à l'Asie, avec, dans l'intervalle, les îles Tchagos qu'on ne sait auquel des deux continents attribuer, reposent sur des socles sous-marins qui tendent les uns vers les autres et que les cartes bathymétriques des atlas scolaires laissent nettement apercevoir.

II. Orogénic et relief. - Peut-être Madagascar, une fois détachée de l'Afrique (époque du trias), a-t-elle fait partie d'un grand continent qui se serait étendu jusqu'à l'Inde et dont les archipels voìsins subsistent comme des témoins, d'un continent peuplé de lémuriens (pachydermes grimpeurs): d'où le nom de Lemuria que lui donnent les géolo-

1. Pour la rédaction de ce chapitre, nous devons beaucoup à l'étude de E.-F. Gautier : Madagascar. Essai de géographie physique (A. Challamel), 1902. 


\section{MADAGASCAR}

d'après E.F. Gautier

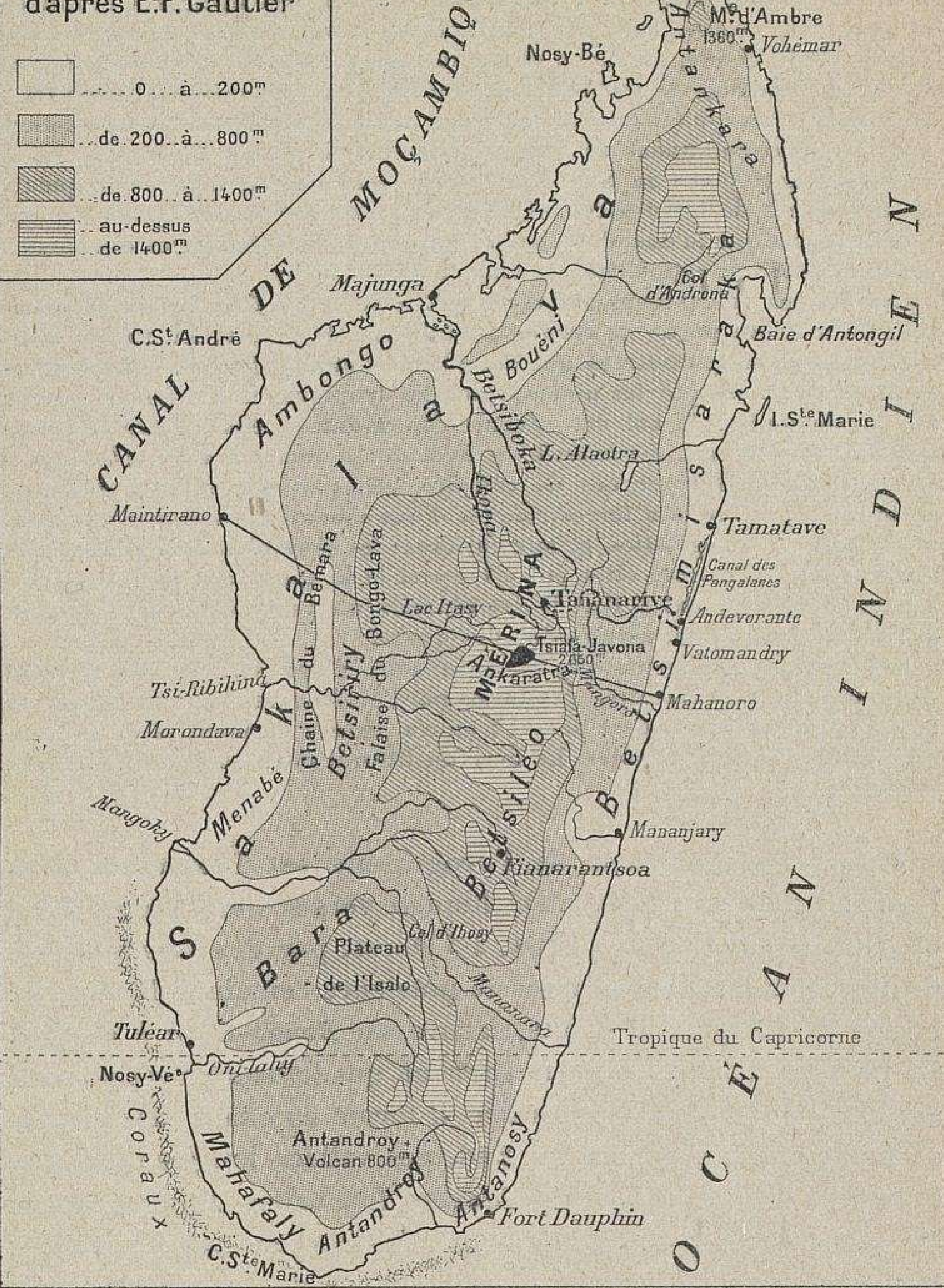

Profil de Maintirano (Cóte Ouest) à Mahanoro (Côte Est)

Échelle des hauteurs zoforsplus grande

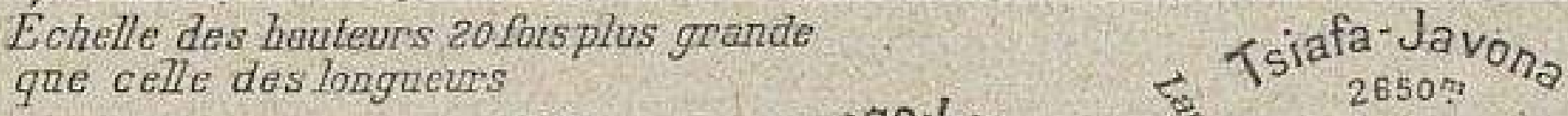

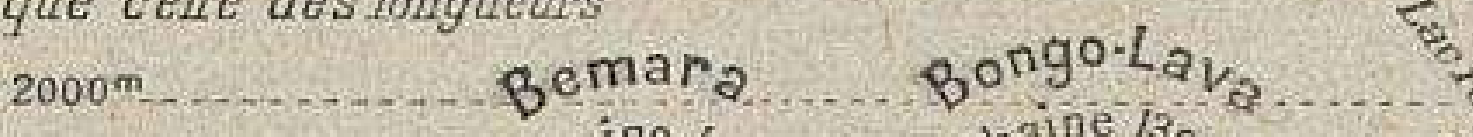

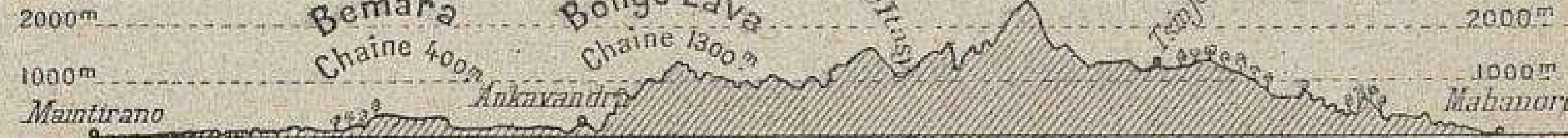

G. Lespagnol ex M. Faliex - Afrique. 
gues. En arrière de la côte orientale de l'île s'aligne un front de hauteurs de $1.500 \mathrm{~m}$.; en avant la sonde descend à des abîmes de 4 et $5.000 \mathrm{~m}$. : il y aurait donc eu effondrement, et l'effondrement a été accompagné d'éruptions volcaniques, comme cela est constant, et manifeste par exemple dans les îles de la Sonde, au Japon et sur la côte occidentale d'Amérique. Les laves, les basaltes se trouvent en profusion sur un même alignement : montagne d'Ambre $(1.360$ m.) au Nord, massif de l'Ankaratra au centre avec le point culminant de toute l'ile le Tsiafa-javona $(2.650 \mathrm{~m}$.), mont d'Antandroy $(800 \mathrm{~m}$.) au Sud. Les volcans sont éteints, mais de fréquents tremblements de terre secouent l'île, au point que les indigènes croient qu'elle repose sur le dos d'une baleine, et les sources thermales abondent: celles d'Antsirabé rappellent certaines eaux de Vichy.

Ces masses volcaniques ont recouvert le socle de l'ille, lequel est composé en majeure partie de roches cristallines, de gneiss; les roches sédimentaires ne se rencontrent que dans l'Ouest et dans le Sud. - La décomposition du gneiss par les pluies tièdes des tropiques donne à Madagascar sa physionomie : le sol est revêtu d'un manteau épais d'argile rouge (souvent 50 à $80 \mathrm{~m}$.), de latérite : “ c'est de la roche à différents degrés de pourriture ». Dépourvues de calcaire, très pauvres en phosphore, en azote et en potasse, ces terres rouges, d'une monotonie désespérante, sont réfractaires à la végétation et aux cultures; les eaux pluviales glissent sur elles sans les pénétrer; elles ont “ l'aspect et la compacité de la brique " Le fer abonde; quant à l'or, il est répandu un peu partout à la surface et l'on vient de le découvrir dans des quartz.

Les terrains sédimentaires, presque tous d'âge secondaire, forment d'immenses tables calcaires, produites par l'érosion; les terrains primaires font presque complètement défaut : on n'a trouvé de houilles qu'en tranches minces et insignifiantes. Le long du littoral enfin sont des lambeaux tertiaires.

“ Le trait dominant de l'orographie est l'existence d'un immense plateau central ». Déchiqueté vers ses extrémités Nord et Sud, il est limité, à l'Est, à l'Ouest, par des lignes toutes droites, par des falaises à pic de plusieurs centaines de mètres : falaise de l'Angavo à droite, falaise du Bongo-Lava à gauche. Ce plateau qui dessine de la sorte un quadrilatère n'est pas une surface plane; bien au contraire, il forme un chaos inextricable de montagnes. Du Nord au Sud, des vallées longitudinales se creusent, comme celles du Mangoro (ou vallée d'Ankay) et du lac Alaotra; le plateau est coupé d'Ouest en Est de vallées transversales qui ont joué dans l'histoire des peuples un rôle prépondérant. Sur les parties les plus hautes de ce plateau central se dessinent de grandes cuvettes alluvionnaires, qui jadis furent des lacs e : sont aujourd'hui des plaines marécageuses : par exemple l'ímérina, où circule, paresseuse, dans un lacis de canaux et de r zières, la rivière de l'Ikopa, et plus au 
Sud le Betsiléo « chapelet de cirques et de hautes vallées très closes ».

III. Climat. - Située dans l'hémisphère austral entre $11^{\circ} 57^{\prime}$ et $25^{\circ} 39^{\prime}$ Lat. S., Madagascar est coupée par le tropique du Capricorne à la hauteur de la baie de Saint-Augustin. Seule donc l'extrémité Sud est en dehors de la région intertropicale, ce que les indigènes ont bien remarqué, en s'étonnant qu' « à Fort-Dauphin le soleil restât toujours dans le Nord ».

L'île appartient tout entière à la région des alizés, mais les moussons se font sentir dans la partie Nord. En outre, elle se comporte comme un quatrième petit continent austral, comme l'Amérique du Sud, l'Australie et l'Afrique : le climat diffère moins du Nord §u Sud que de l'Est à l'Ouest, moins dans le sens des latitudes que dans le sens des méridiens. Dans l'Est, l'alizé est vent ascendant de la côte au plateau intérieur, il se refroidit et les pluies se déversent; puis à mesure qu'il chemine vers l'Ouest, il redescend, s'éloigne du point de saturation et se réchauffe, et alors c'est la sécheresse. La distribution des pluies est donc fort inégale et la température varie avec les cotes d'altitude.

$1^{0}$ Climat de l'Est. - Le climat de la côte orientale est maritime, à faible amplitude, très fatigant et très malsain. La vapeur d'eau, la température de serre chaude conviennent à la végétation, mais point à l'homme. Les pluies diminuent en avril et mai, en octobre et novembre, mais pendant huit mois de l'année il pleut quinze jours sur trente. Les ouragans et les cyclones sont fréquents et redoutés.

Dans le Nord de l'ile, Diégo-Suarez et Nosy-bé ont un climat complexe qui ménage la transition entre l'Est et l'Ouest.

$2^{\circ}$ Le climat de l'Ouest fait antithèse avec celui de l'Est; les saisons sont très tranchées, l'une humide, l'autre sèche. De là, et une température moyenne annuelle plus forte, et aussi un écart plus sensible. Pendant la moitié de l'année, le pays souffre de la sécheresse : plantes, animaux, vie humaine, tout s'en ressent. - Les moussons alternent avec les alizés; mais du moins l'épaisseur de l'île met la côte du canal de Moçambique à l'abri des cyclones.

$3^{\circ}$ Glimat de la Gôte Sud-Ouest. - Située au delà du tropique, la côte Sud-Ouest constitue une nouvelle région climatérique, et comme un monde à part dans l'ille Malgache. La température ne diffère pas sensiblement de celle de Majunga, mais pendant sept mois la sécheresse est grande et le ciel implacablement pur. Si les contrées de l'Est rappellent les forêts du Natal, celles-ci (pays des Antandroy et des Mahafaly) ont des analogies frappantes avec le Namaland; la différence est que Mada- 
gascar ne dépasse pas $25^{\circ}$ Lat. S, et ce climat subdésertique est limité au littoral; car dans l'intérieur l'élévation provoque les pluies.

$4^{\circ}$ Climat $d u$ centre. - Les hauts plateaux sont comme une enclave de la zone tempérée au milieu des tropiques. Les pluies tombent dans la saison ehaude, comme sur la côte Ouest, à Majunga. "Lorsque le grand drapeau claquant au sommet de l'ancien palais de la Reine, actuellement Ecole Le Myre de Vilers, après être resté des mois obstinément tendu vers le lac Itasy (vers l'Ouest, par alizés d'Est) se retourne vers AnkeraMadinika (Est), la saison des pluies commence \#. Pluies d'orages, avec coups de foudre, qui ruissellent sur le sol sans le pénétrer. La neige est absolument inçonnue; quant à la glace, c'est une rareté. En somme, le climat convient à l'Européen; il est salubre, il est doux, ce qui ne veut pas dire qu'il ne semble pas rigoureux aux indigènes, drapés de cotonnades. Cette rigueur même a fixé l'habitant au sol, l'a astreint à mieux construire sa maison, à savoir tisser les étoffes : Hovas et Betsiléo sont intellectuellement et moralement supérieurs aux autres races de l'île. Le sol, le climat n'ont pas peu contribué à marquer cette différence.

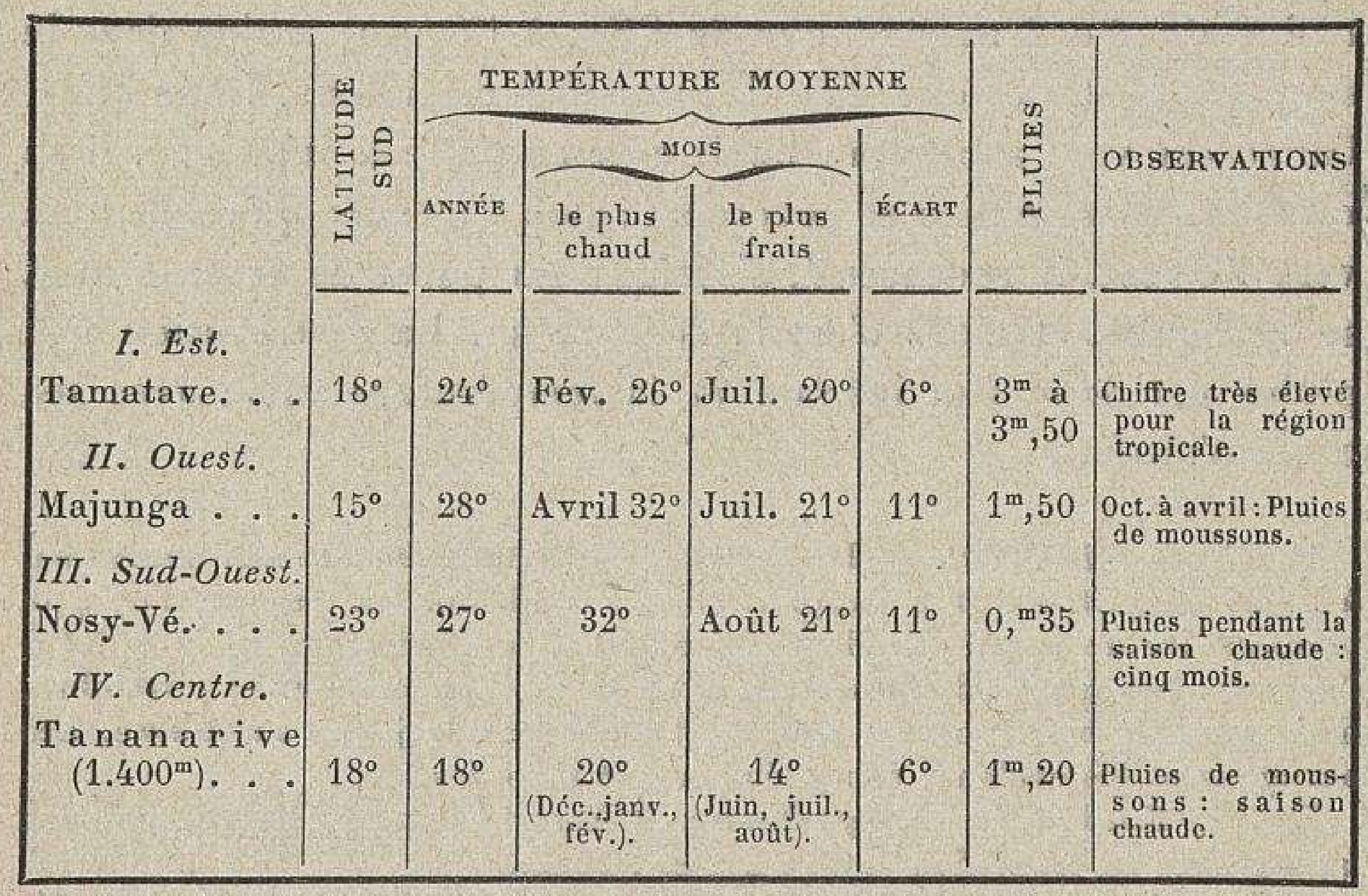

IV. Hydrographie. - $1^{\circ}$ Versant oriental. - La falaise orientale du plateau fait ligne de partage des eaux. Comme elle suit de très près la côte, et cela sans discontinuité, les cours d'eau de l'Est n'ont de longueur que s'ils empruntent les vallées longitudinales avant de trouver leur issue vers la mer, ou s'ils utilisent les vallées transversales. Coupés de chutes, ils se ralentissent seulement dans la zone littorale, mais alors la navigation est gênée par la barre mobile de leur embouchure Le Mananjary est connu par les comptoirs européens ins 
tallés à son embouchure. Plus étendus sont le Mangoro, qui, pendant une centaine de kilomètres, coule du Nord au Sud, dans la longue et étroite vallée d'Ankay, parallèlement à la côte, et le Mananara, qui rassemble trois grandes rivières du plateau.

$2^{\circ}$ Versant occidental. - Les fleuves de l'Ouest, beaucoup plus longs, traversent les vallées perpendiculairement, sans les

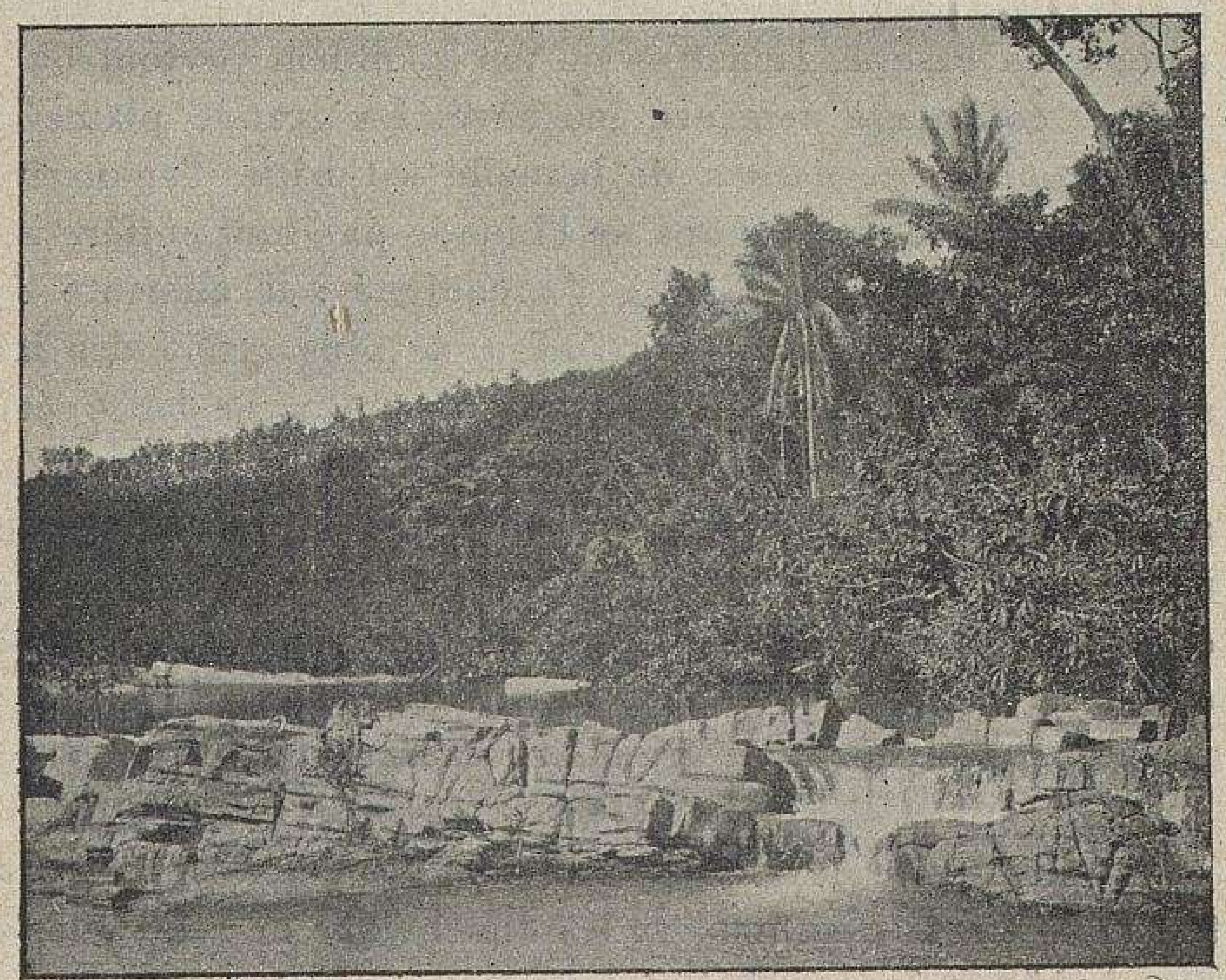

TYPE DE RIVIËRE AVEG GHUTES A MADAGASGAR.

TORRENT PRÉS D'AMBODIMADIRO.

(Photographie communiquée par M. Dybowsli.)

emprunter; aussi, des plateaux à la mer, ils franchissent une série d'obstacles, creusent des couloirs et des cañons, ou s'étalent dans des fonds lacustres et marécageux. Enfin le régime de leur cours inférieur est très inégal, parce que la saison sèche, fort prolongée dans cette partie de l'île, ne maintient pas les eaux à un niveau suffisamment élevé; alors des banes de sable gênent la navigation et servent de lit de repos aux crocodiles. Après les pluies, le courant devient si fort que les chaloupes à vapeur n'en triomphent pas.

Le Betsiboka et l'Ikopa qui fertilise la plaine de Tananarive 
finissent dans la rade de Majunga; la navigation les remonte jusqu'à Marovoay seulement ou bien jusqu'à Maevatanana (240 km.) suivant la saison. Le Tsi-ribilitina, descendu également du massif de l'Ankaratra, est remonté de même par les barques arabes, jusqu'aux premières chutes (env. $140 \mathrm{~km}$.). Le Mangoka n'est pas moins long, mais il n'est navigable qu'à son embouchure. L'Oni-lahy finit dans la baie de Saint-Augustin.

En général, tous ces fleuves travailleurs ont comblé de leurs alluvions les bassins lacustres ou les comblent partout où le travail de colmatage demeure inachevé. La grande plaine de Be-tsi-milatatra, au-dessus de laquelle est bâtie Tananarive, est un ancien lac, et si l'lkopa ne l'inonde pas tout entière à la saison des pluies, c'est qu'on l'a endigué : il alimente des rizières à perte de vue. - L'Alaotra, le plus grand des lacs encore existants $(55 \mathrm{~km}$. de long sur 5 à $6 \mathrm{~km}$. de large) était plus étendu, avant que les eaux aient fait brèche à travers les montagnes de l'Est; il n'est qu'un marais sans profondeur, aux rives incertaines, envahi par la végétation. - Le lac Itasy occupe le fond d'une vallée barrée par les laves volcaniques; profond de 5 à 6 mètres dans une partie, il est déjà comblé dans une autre et porte de grands roseaux vert sombre.

V. Côtes. - Le développement total des côtes est d'environ 5.000 kilomètres; c'est peu, vu les dimensions de l'île; elles ne sont pas découpées en général.

$1^{0}$ La côte Est est rectiligne, comme la falaise du plateau central, et basse. L'alizé, le grand courant équatorial empêchent les sables de se déposer au large et les alignent en cordons littoraux, derrière lesquels s'égrènent des chapelets de lagunes; les seuils de portage (pangalana), qui séparent les lagunes, sont très courts : percés déjà en partie, ils ont donné leur nom au canal des pangalanes, qui forme une voie de navigation continue, parallèle à la mer.

Point de bons ports : au Sud, Fort-Dauphin possède la rade la plus accessible et la plus sûre. Au Nord, la baie d'Antongil s'encombre de coraux. L'íle Sainte-Marie fournit un abri tout à fait insuffisant. Tamatave est une rade ouverte. Andevorante est gênée par une barre mauvaise. 
Ces inconvénients sont aggravés par la fréquence des cyclones et par l'absence de voies fluviales de pénétration.

$2^{\circ}$ Pointe Nord. - Le dessin des côtes Nord, fort original, s'explique par des soulèvements récents; entre les presqu'îles montagneuses et les îlots volcaniques s'ouvrent des ports bien clos, profonds et vastes. Tels le port Radama; la baie de

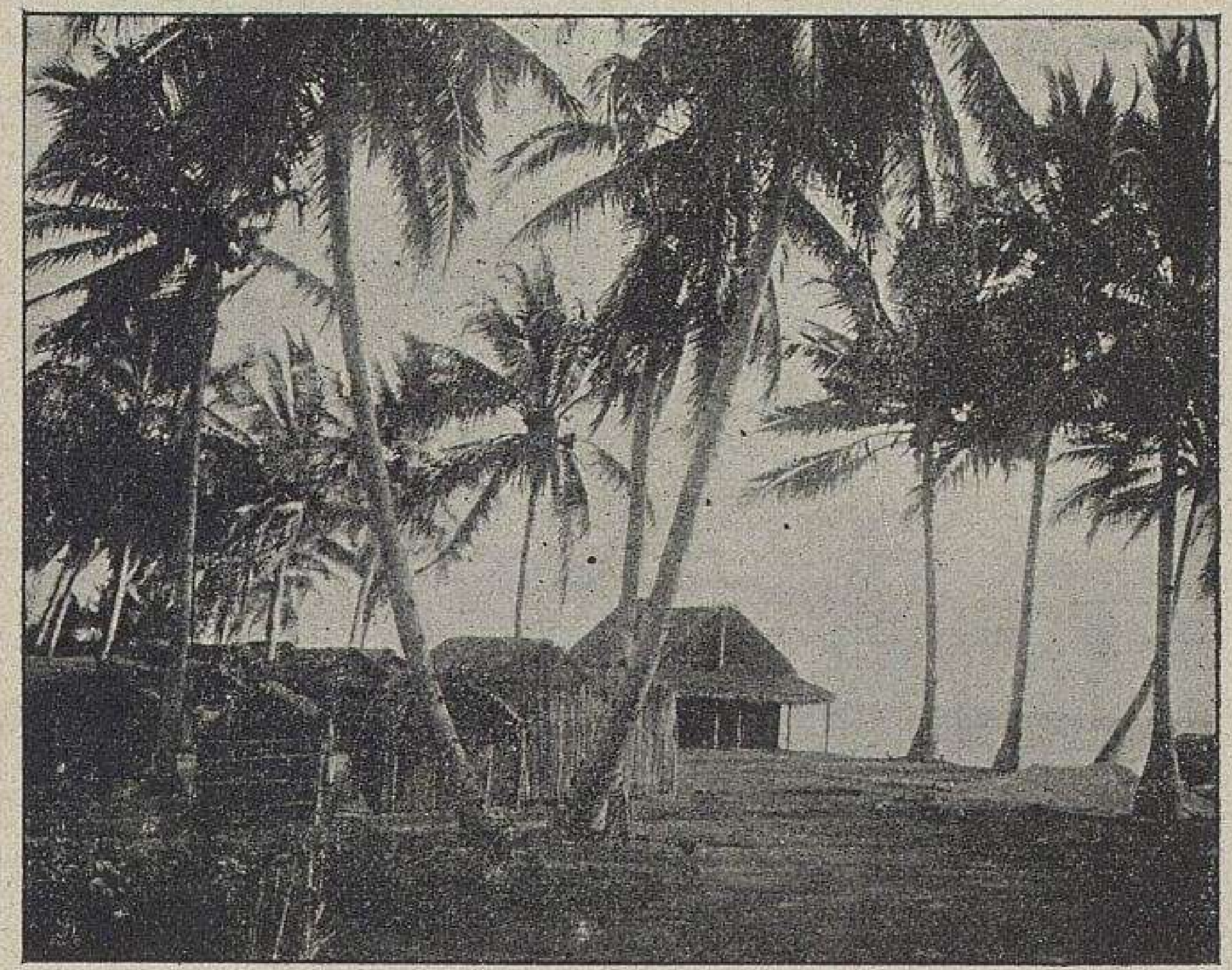

COCOTIERS ET GASES INDIGENES A AMBATO.

(Photographie communiquée par M. Dybowski.)

Le Cocotier est un beau palmier, renflé à la base, dont les feuilles s'élèvent jusqu'à $25 \mathrm{~m}$. dans les airs. Il se plaît sur les grèves sablonneuses de la mer : car le sel lui est indispensable. - Les feuilles s'utilisent pour les toitures des cases et servent à confectionner des articles de vannerie. Les fruits sont groupés en régimes d'une dizaine de noix chacun : fraìches, celles-ci contiennent une amande crémeuse, entourée du lait de coco, liquide incolore, légèrement acidulé, assez froid pour glácer une boisson; sèches, elles sont capitonnées à l'extérieur d'une bourre brune, de fibres très résistantes qui servent d'étoupe aux marins et avec lesquelles on fabrique des tapis, des brosses et des cordes. L'amande, en séchant, est devenue le coprah, dont on fait du savon, de l'huile d'éclairage, des graisses pour essieux, des pommades, etc. (D'après A. Breschin).

Pasindava, fermée par Nosy-bé; enfin Diégo-Suarez, une rade superbe et très ramifiée : malheureusement, les courants violents, qui battent le cap d'Ambre, en rendent l'accès difficile aux petits vapeurs; et puis, l'arrière-pays n'est pas assez étendu pour donner naissance à un port de commerce; c'est, en revanche, une station de guerre de premier ordre. 
$3^{\circ}$ Côte Nord-Ouest, depuis la baie Narinda jusqu'au cap Saint-André. L'aspect change : des falaises calcaires, rongées par la mer, rompues par l'arrivée des fleuves, forment de véritables mers intérieures, communiquant par un goulet avec le large : baie Narinda, baie de Mahajamba, baie Bombetola, sur laquelle s'est établi Majunga, baie Bali, toutes également bonnes, en dépit des vases et des sables. Beaucoup plus hospitalière que la côte orientale, la côte Nord-Ouest semble appelée au plus grand avenir commercial; elle a en outre l'avantage d'être reliée à l'Afrique par l'archipel des Comores, et les moussons y ont de tout temps favorisé la navigation.

$4^{\circ}$ Côte de l'Ouest central. - Les falaises ont disparu : vents, courants et marées accumulent les vases et les sables sur les plages. Les pirogues à balancier des indigènes ont bien pu trouver la des conditions favorables, la moindre crique est pour elles un abri, mais non pas la navigation européenne. Maintirano, Morondava n'offrent que des rades médiocres et pourtant ne sont pas sans animation. L'embouchure de la Tsi-ribihina peut paraître indiquée pour un port futur.

$5^{\circ}$ Côte Sud. - Au Sud du Mangolky jusqu'à Fort-Dauphin les falaises réapparaissent, peu élevées, calcaires, précédées de récifs de coraux : “ à travers l'eau très claire, on voit passer sous la quille, comme à portée de la main, une merveilleuse prairie de coraux multicolores, verts, rouges et bleus ». A l'arrivée de l'Oni-lahy, qui, chose rare, finit non par un delta, mais par un estuaire, Tuléar est le meilleur port : il a en outre l'avantage de regarder l'Afrique australe, déjà européanisée.

VI. Vie végétale. - $1^{\circ}$ Est. - Au-dessus de la zone littorale à végétation feuillue et à cultures tropicales. (tanguin, lequel fournit un poison célèbre, et pandanus) s'élève la région des collines (50 à $800 \mathrm{~m}$.), caractérisée par l'arbre du voyageur ou ravenale qui déploie le large éventail de ses feuilles et renferme une eau fraîche, bonne à boire; puis la région des montagnes avec les forêts, d'essences variées, mais difficilement exploitables, faute de routes.

$2^{\circ}$ Ouest. - Comme le climat est sec pendant une partie de l'année, un tiers environ de l'Ouest est désolé, le reste se par- 
tage entre la forêt et la savane, mais la savane l'emporte de

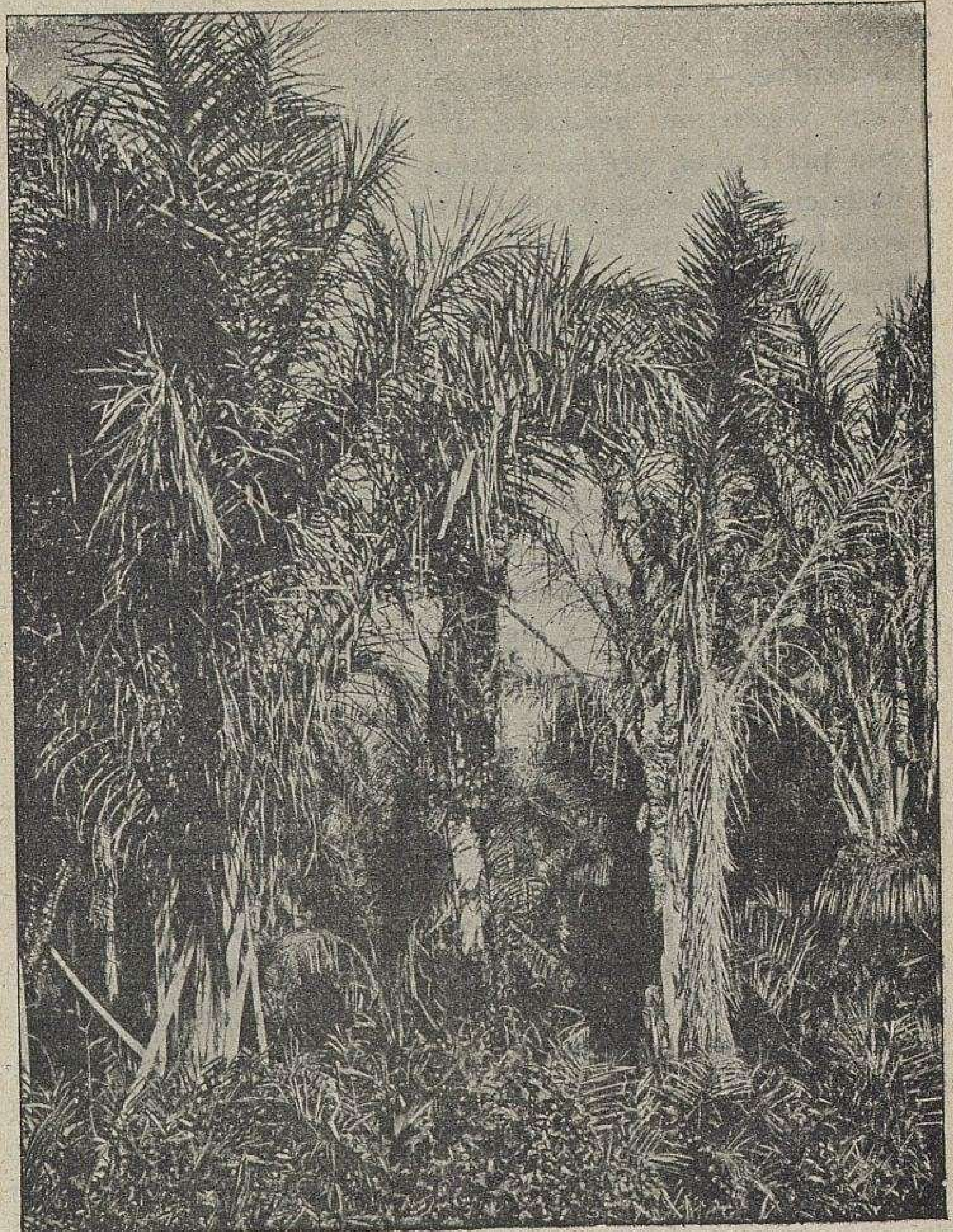

RAPHIA.

(Photographie communiquée par M. Dybowskt.)

Le Raphia est un palmier au trone peu élevé, mais dont les branches atteignent 6 à 7 mètres de longueur. Avec l'écorce on fait des nattes et des liens, avec les fibres des tissus et la nervure est utilisée comme charpente. La sève constitue un vin fort prisé des indigènes. (D'après A. Breschin.)

beaucoup, avec ses touffes herbacées et ses bouquets d'arbres clairsemés (latanier, tamarinier, baobab). Le raphia, plus abon- 
dant ici qu'à l'Est, est un palmier dont les fibres fournissent un ohjet d'exportation et la sève une boisson aigrelette, appréciée des Sakalava.

$3^{\circ}$ Centre. - L'argile rouge ou latérite est stérile et ne porte qu'une végétation herbacée. La nudité des hauts plateaux a valu aux Hovas, qui les habitent, le nom de "ceux qui vivent sous le ciel », par opposition aux peuplades qui ailleurs vivent " sous les bambous " et sous les arbres. A perte de vue, on n'aperçoit que des solitudes désolées. Les fonds des vallées, où se sont accumulées les alluvions et les terres volcaniques, sont, au contraire, fort riches, et le travail de l'homme fait rendre beaucoup aux steppes de l'Imérina et du Betsiléo.

$4^{\circ}$ Sud-Ouest. - La végétation du Sud-Ouest, subdésertique comme le climat, grêle, souffreteuse, se défend contre la sécheresse par une écorce dure, des épines ou bien par des racines bulbeuses et des branches succulentes. Cactus, baobabs, euphorbiacées, caoutchouc sans feuilles, constituent, avec une série d'arbres étranges, les espèces les plus ordinaires.

VII. Vie animale. - La faune de Madagascar, tout à fait originale, embarrasse les savants qui ne peuvent la faire entrer dans les classifications en usage. Les lémuriens ou maques, très nombreux, de toute couleur et de toute taille, sont des quadrumanes, en même temps que des pachydermes grimpeurs; le sanglier a une physionomie spéciale; un insectivore (tendrec) rappelle notre hérisson avec ses piquants; un rat a les pieds palmés; la moitié des oiseaux appartient à des genres particuliers.

Par contre, on ne trouve à Madagascar aucun des grands mammifères de l'Afrique, ni lions, ni tigres, ni panthères, ni girafes, ni antilopes, ni éléphants, ni singes. Le seul animal à redouter est le crocodile; car c'est là un des traits particuliers de la faune malgache d'être inoffensive; les serpents, très nombreux, n'ont pas le moindre venin.

Et ce ne sont pas les espèces actuelles qui seules sont à ce point remarquables: les fossiles ne le sont pas moins. A Madagascar vivait un oiseau colossal, l'épiornis : parent des easoars, il avait $3 \mathrm{~m}$. de haut, ses pattes étaient aussi massives que celles de l'éléphant; son œuf, d'une capacité de huit litres, correspondait par son volume à 148 de nos oeufs de 
poule. Lorsque la faune malgache n'est pas originale, c'est avec celle de I'Inde qu'elle présente le plus d'affinités.

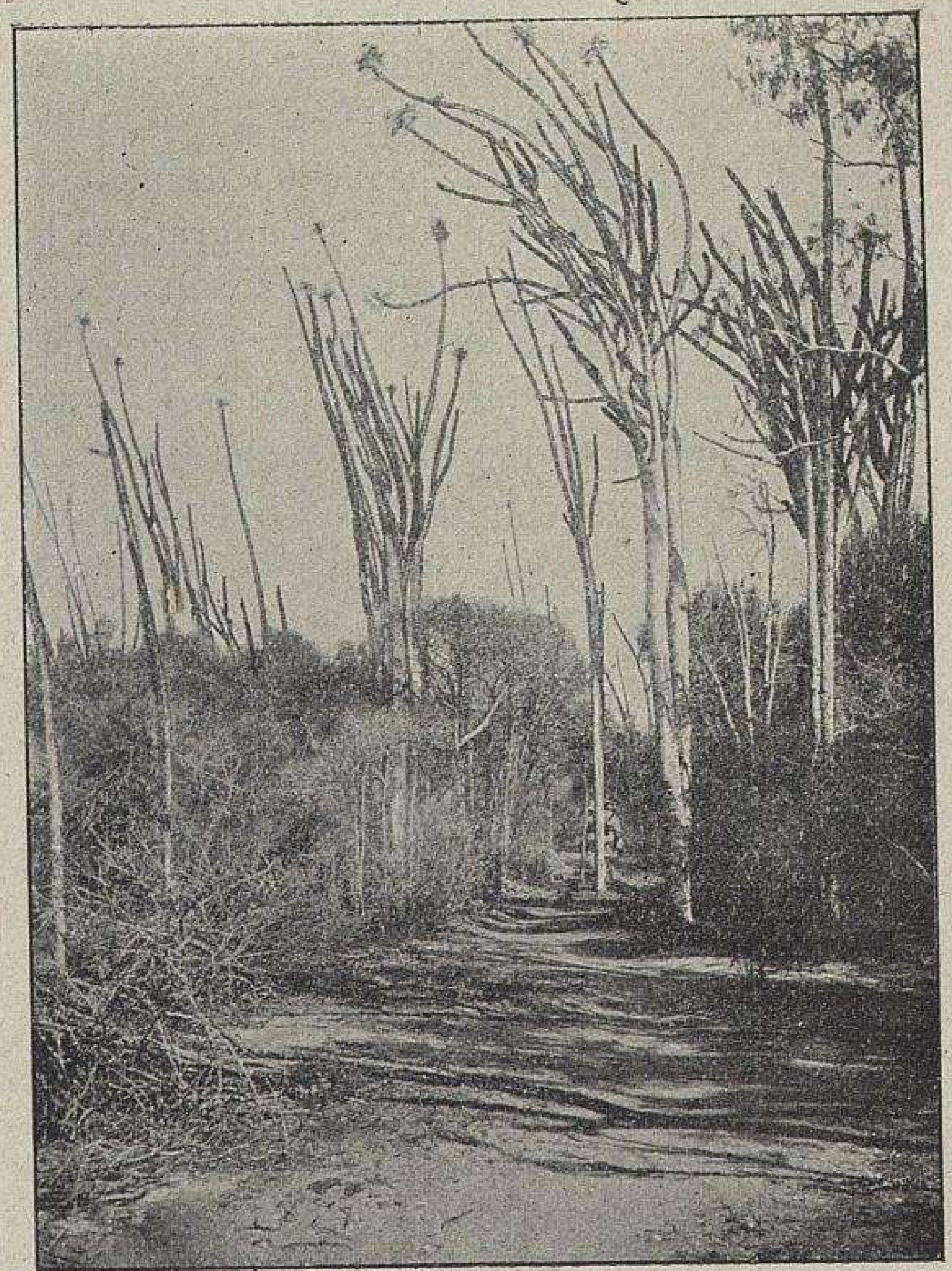

VÉGÉTATION SUBDÉSERTIQUE DU SUD DE MADAGASCAR.

(Photographie communiquée par M. Dybowski.)

10 Euphorbiacée à caoutchouc (euphorbia intisy). L'arbuste atteint au maximum de 6 á 7 mètres; il n'a pas de feuille; le lait se recueille par incision sur le tronc et s'exporte par Tulléar et par Fort-Dauphin.

20 La plante arborescente qui émerge au-dessus de la brousse est à écorce épineuse (fantsi-holitse). Les branches, au lieu de diverger, prolongent le tronc en brins de balais; chacune se termine à son extrémité par ce qui doit être une fleur. Lemaire les compare à un faisceau de trompes d'éléphants. (E.-F. Gautier.)

VIII. Vie humaine. - La population de Madagascar dépasse à peine 3.054 .000 habitants. Très peuplées sont les deux provinces centrales, Imérina et Betsiléo, qui à elles seules possè dent plus du tiers du chiffre total, et aussi la côte Sud-Est. Partout ailleurs, les habitants sont très clairsemés, et l'on 
rencontre d'immenses étendues totalement vides dans la moitié occidentale de l'intérieur.

Tous les peuples n'auraient pas même origine. Le fond malgache, de couleur noire, les cheveux crépus, non laineux, les joues glabres, serait apparenté aux Indonésiens, ainsi que le prouvent beaucoup de coutumes, beaucoup de mots de la langue. Les tempêtes ont bien pu porter les migrations humaines à Madagascar, de la même manière que les vents $\mathrm{y}$ ont poussé des pierres ponces, lors de l'éruption du Krakataou en 1883.

Ceux des peuples de l'île que nous appelons Hovas (pron. Houves), par l'extension d'un nom de caste à toute la tribu, ont le teint clair, les cheveux lisses et roides; ils sont des conquérants, venus seulement au $\mathrm{xvin}^{\mathrm{e}}$ siècle, on ne sait d'où, mais viaisemblablement de l'Asie, sans qu'il soit permis de déterminer le point précis.

Établis sur les hauts plateaux, où ils trouvèrent un elimat salubre, exempt de la malaria, ils ont essayé d'étendre leur domination à l'île entière. De toutes les races, e'est la mieux douée, pour le travail de la terre comme pour le commerce et pour l'industrie; le sentiment qu'ils ont de l'autorité, leur respect de la discipline leur donnent des aptitudes spéciales aux fonctions administratives. Le costume se compose d'un chapeau de paille de riz et d'un lamba, grande pièce d'étoffe dans laquelle ils se drapent comme dans une toge; la base de leur alimentation est le riz, et c'est d'argile séehée qu'ils construisent leurs maisons.

Ils s'imposent plus ou moins aux autres populations de l'île : aux Betsiléo, qui eux aussi habitent les vallées closes des hauts plateaux; et aux Betsimisaraka, de la côte orientale, indolents, paresseux, réfractaires au progrès, vivant des fruits que porte la terre humide et naturellement engraissée, sans qu'il soit besoin de la cultiver.

Les Sakalava, sur la côte Nord-Ouest et Ouest, ont subi l'influence arabe et ont été rattachés par les moussons au monde musulman de l'Arabie et de l'Inde, dont ils portent par exemple, sur la côte, la grande chemise blanche, le caftan et le fez, dont ils parlent la langue commerciale, le Souahéli. Ceux de l'intérieur, retenus aux villages et aux rizières, lors des pluies, se répandent en pillards sur les pays voisins, à la saison sèche.

Au Sud, enfin, les régions subdésertiques sont habitées par des races guerrières, les Antandroy et les Mahafaly. 
Ils mènent une vie misérable, habitent des huttes sous lesquelles ils entrent en rampant, se nourrissent des baies du cactus et de feuilles pilées pour en extraire et en boire les réserves d'eau. Comme le sol et le climat interdisent les cultures, ils vivent très dispersés, par petits groupes, en pasteurs, rebelles à toute discipline, à tout travail. Chaque soir ils parquent leurs immenses troupeaux de boeufs pour les mettre à l'abri des coups de main : car le pillage, le vol des bestiaux sont chez eux une habitude, et leur société revêt une forme anarchique.

\section{Gouvernement et villes. - Déclarée Golonie fran-} caise par la loi du 6 août 1896, Madagascar est administrée par un Gouverneur général, assisté d'un conseil d'administration purement consultatif. L'île est divisée en « circonscriptions territoriales, répondant autant que possible à des groupements ethniques distincts : elles portent le nom de provinces ou de cercles, suivant qu'elles sont placées sous le régime de l'administration civile ou sous celui de l'autorité militaire. Il est fait appel au concours des chefs indigènes, dans la mesure où leur autorité ne constitue pas un péril ». Les principales villes ont été érigées en communes, avec un maire.

Le gouverneur général réside à Tananarive, sur les hauts plateaux de l'Imérina.

Au pied de sa montagne de granite (env. $1.500 \mathrm{~m}$.), sous un ciel clair, se déroule un immense panorama : la plaine où l'Ikopa décrit ses méandres et multiplie les canaux n'est qu'une immense rizière d'un seul tenant (plaine de Be-tsi-mitatatra, que les Hovas appellent familièrement le ventre de l'Imérina) et ainsi s'explique que dans un pays privé de routes et de moyens de transport, dans un pays où les plus fortes agglomérations urbaines comptent seulement quelques centaines d'habitants, une ville de 60.000 ámes ait pu naître : elle avait à portée de la main sa subsistance, et du haut des plateaux elle put exercer sa puissance dominatrice sur les contrées voisines. A côté des paillottes indigènes et des maisons de bois s'élevaient les palais, les temples, une cathédrale, un observatoire; l'administration française a rectifié l'alignement des rues, créé des écoles (écoles primaires, école de médecine, école professionnelle, école normale Le Myre de Vilers), une bibliothèque, un jardin d'essai, un théâtre, un vélodrome... et tracé des routes à tous les points cardinaux.

Fianarantsoa $(1.300 \mathrm{~m}$.) commande le Betsiléo, dont il reste le gros centre $(6.000 \mathrm{~h}$.$) ; l'ouverture de voies commerciales vers$ l'Est ne pourra qu'accroître le mouvement des échanges. Sur la côte orientale, Andevorante, Vatomandry, et surtout Tamatave (11.000 h.).Fort-Dauphin (2.000 h.) et Diégo-Suarez (5.000 h.) occupent les deux points extrêmes au Sud et au Nord. 
Le premier port de l'île, en relations avec l'île de la Réunion, avec l'Europe, en relations avec l'intérieur par un réseau naissant de routes, de canaux et de chemins de fer, Tamatave offre des avantages tels qu'il fut question d'y transférer la capitale. C'est moins une ville qu'une plage de sable immense, sur laquelle on a tracé des rues parallèles, ombragées par l'épaisse végétation des tropiques.

Fort-Dauphin fut un des premiers comptoirs fondé aux siècles précédents par les Européens; il possède un bon mouillage; l'arrière-pays, de population dense, produit abondamment le caoutchouc. Diégo-Suarez ou Antsirane, sur une rade magnifique, encadrée de hautes montagnes, que l'on compare volontiers à Rio de Janeiro et à Sydney, est une position militaire de premier ordre, à la fois un centre de refuge et de ravitaillement. De grands travaux s'exécitent pour la construction de bassins de radoub, de cales de carénage, etc.; un sanatorium existe à $900 \mathrm{~m}$. sur les pentes de la montagne d'Ambre, enfin des routes s'ouvrent sur des régions fertiles, riches en bétail et populeuses.

Vohémar $(6.000$ h.) est en décadence. Sur le canal de Moçambique, l'île de Nosy-bé, trait d'union entre Madagascar et les Comores, possède une rade superbe, celle de Hellville (2.000 h.). Majunga $(3.000$ h.) est heureusement située : sa position à l'arrivée de la Betsiboka et de l'Ikopa la désigne pour être le débouché occidental de Tananarive, le lien avec l'Afrique occidentale et l'Europe; son commerce, en progrès, ne peut que grandir encore; un câble sous-marin la joint à Moçambique.

Si Maintirano et Morondava sont des centres anciens, Tuléar, avec sa baie spacieuse, semble appelée à devenir le grand marché du Sud-Ouest; elle étend de plus en plus ses relations avec les colonies portugaises et anglaises du continent.

X. Mise en valeur. - L'exploitation économique de Madagascar n'est pas encore sortie des tâtonnements et des tentatives.

$1^{\circ}$ Agriculture. - Les hauts plateaux du centre, à argile rougeâtre, paraissent condamnés à une stérilité irrémédiable. Dans l'Imérina et dans le Betsiléo, où le riz est la grande production et fait la base de l'alimentation indigène, on s'applique à perfectionner le système des digues et de l'irrigation et à régénérer les cultures.

C'est sur la côte orientale que l'on essaie les grandes planta. tions : entre Tamatave et Mananjary, aussi bien qu'à Vohémar et à Fort-Dauphin, on s'efforce d'acclimater les arbres à caoutchouc, les cacaoyers, les caféiers, les girofliers; les résul- 
tats les plus prompts, les meilleurs, ont été fournis par le vanillier. La canne à sucre viendrait bien, mais il serait nécessaire de perfectionner en même temps l'outillage des sucreries.

La zone intermédiaire est par excellence celle de l'élevage.

Enfin, sur les monts exposés aux pluies de l'Est, les foréts

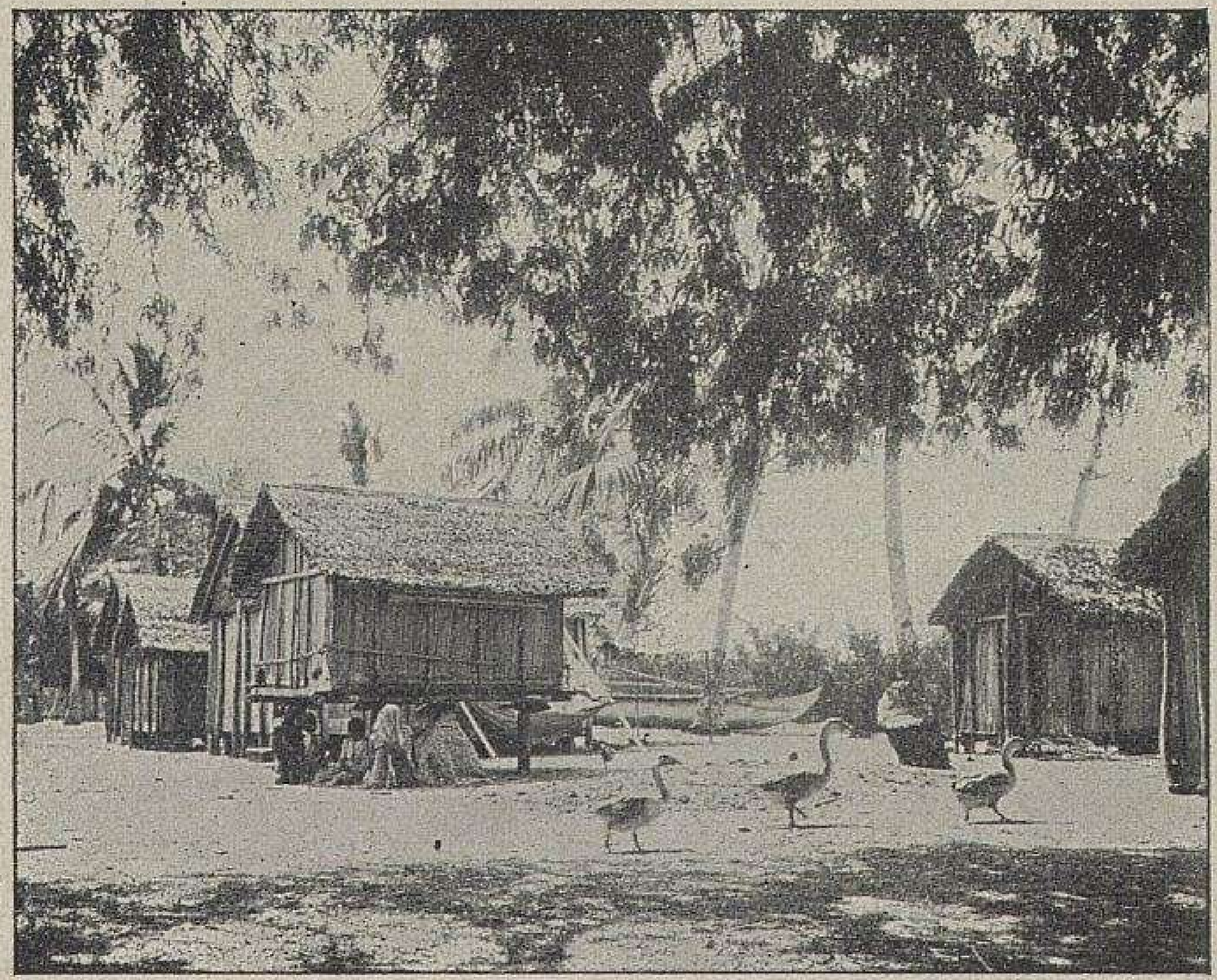

GRENIER A RIZ A NOSY-BË.

(Photographie communiquée par M. Dybowski.)

s'exploitent à mesure que se développent les routes : ébène, acajou et raphia, principalement.

Ces efforts méthodiques ont amené la création d'une chambre d'agriculture à Tamatave, de comices et de missions agricoles.

$2^{\circ}$ L'industrie est encore dans l'enfance. Avec les terres argileuses elle fabrique des briques et des tuiles; elle conserve la viande des bestiaux, elle recueille le sel des salines (DiégoSuarez). Le fer s'exploite partout, mais l'absence d'autre combustible que le bois rend impossible l'exploitation en grand. L'extraction de l'or marque un progrès rapide; on le rencontre surtout dans les alluvions, en bordure des hauts plateaux ${ }^{1}$.

1. Exportation de l'or : $1909 \ldots \ldots 10.937 .000 \mathrm{fr}$. 
Partout des prospecteurs sont à la recherche des richesses du sous-sol, pierres précieuses, graphite, cristal de roche, fer, quartz, cuivre, platine, etc. Des concessions de sources minérales ont été accordées, dont les propriétés rappellent tantôt la Grande-Grille de Vichy, tantôt Contrexéville et Saint-

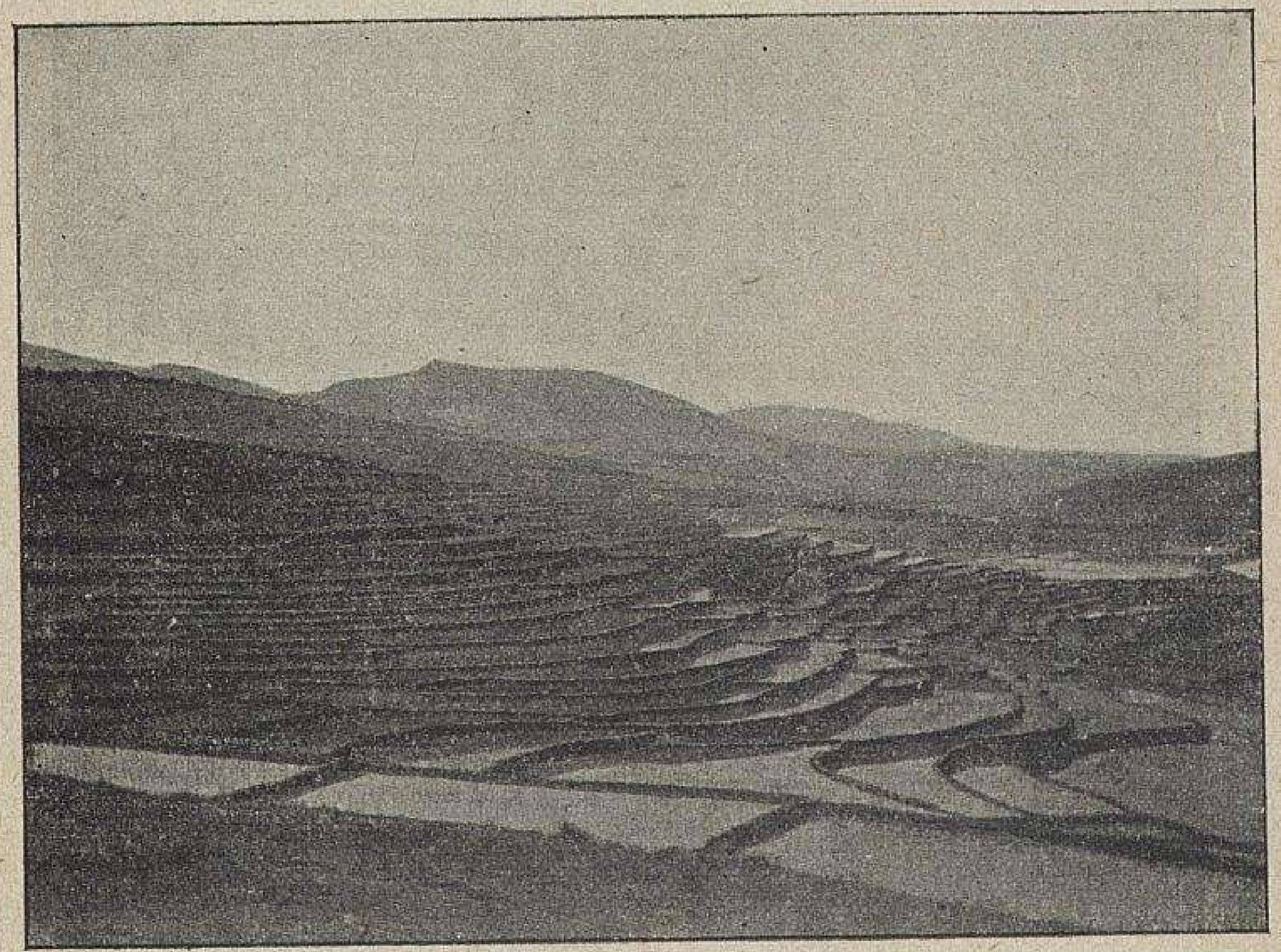

RIZIÈRES EN GRADINS DU BETSILEO.

(Photographie communiquée par M. Dybonsli.)

On remarquera, en même temps que l’ingénieuse disposition des cultures sur les pentes de la montagne, l'absence absolue d'arbres.

Galmier. Des encouragements sont donnés à la sériciculture; de nombreuses écoles distribuent l'enseignement professionnel et l'industrie des chapeaux de paille est prospère, malgré la concurrence des panamas (export. en $1909,23.500 \mathrm{~kg}$., valant 922.000 fr.).

$3^{\circ}$ Commerce. - Comme dans tout pays neuf, le problème dont la solution est la plus urgente est celui des moyens de transport. Aujourd'hui deux routes partent de Tananarive, l'une vers l'Est (Mahatsara), l'autre vers l'Ouest (Mævatanana et Majunga); une route joint Fianarantsoa à Mananjary. Au portage à dos d'homme on substitue les charrettes à bras ou à mulets, et même la traction mécanique. Les routes sont com- 
plétées par des canaux : le canal des Pangalanes (100 km.), qui porte de gros remorqueurs, aboutit au Nord à 20 kilomètres de Tamatave, et sera continué jusqu'à Mananjary, au fur el à mesure des besoins et de la prospérité. - Un chemin de fer a été achevé en 1909 de Tananarive à Brickaville; là les marchandises prennent le canal des Pangalanes, puis l'Ivondro, d'où un petit railway conduit à Tamatave. De grands travaux d'art sont prévus et, la main-d'œuvre indigène faisant défaut, l'on a dû introduire des travailleurs hindous et chinois.

Dans les ports on établit des appontements, des phares, des balisages; partout on amène les eaux douces, on écoule les eaux stagnantes; on assainit, on dessèche le sol et la preuve du développement de Madagascar est fournie par le chiffre des exportations, maintenant supérieures aux importations. Des tarifs protecteurs assurent l'avantage aux produits manufacturés de France, et c'est sous pavillon français que se font les trois quarts du commerce de l'île. Les premiers résultats sont de bon augure pour l'avenir; par la diversité de son relief et de son climat, Madagascar présente le triple avantage, rarement réuni, d'être à la fois colonie de peuplement, colonie d'exploitation et colonie de commerce.

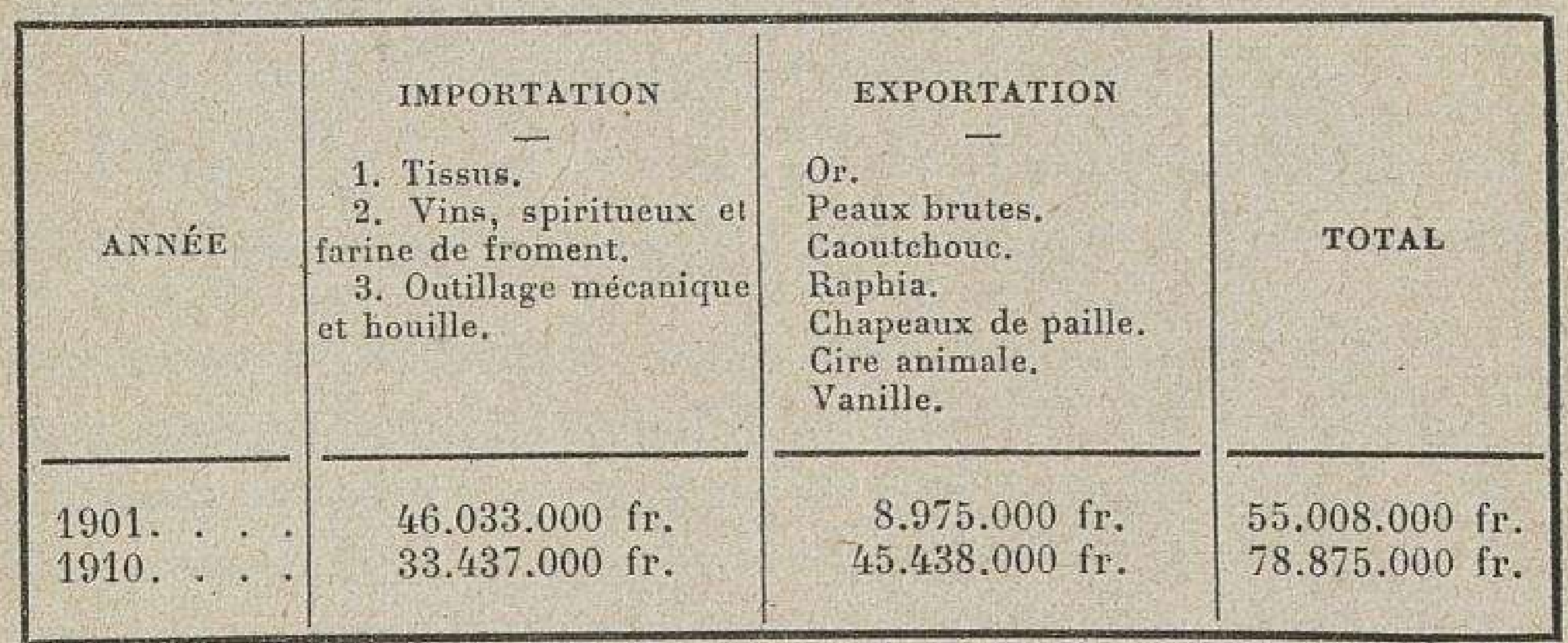

II. - MASGAREIGNES

Ainsi nommées du Portugais Pedro de Mascarenhas, qui les visita en 1545 , les Mascareignes sont au nombre de trois îles : La Réunion, Maurice et Rodriguez.

La Réunion, appelée Bourbon jusqu'en 1790, est la plus grande des trois (env. $2.600 \mathrm{kmq}$.). C'est une île volcanique :

G. Lespagnol et M. Fallex, - Afrique, 
au centre le piton des Neiges $(3.069 \mathrm{~m}$.) dépasse en altitude le plus haut sommet de Madagascar et domine des cirques qui sont des cratères effondrés (cirque de Salazie).

Volcanique comme la Réunion, Maurice (anc. île de France) est un peu plus petite (1.900 kmq.) et moins haute $(826 \mathrm{~m}$.).

Rodriguez (111 kmq. seulement), granitique et volcanique, n'atteint pas 400 mètres.

Situées dans l'hémisphère austral, entre l'équateur et le tropique du Capricorne, les Mascareignes ont un climat chaud et très humide. En général, on distingue une saison pluvieuse (novembre-avril) et une saison sèche (mai-octobre), mais il ne se passe pas de mois sans pluie. Les ouragans sévissent plus particulièrement sur Maurice. L'archipel ne mérite plus son ancienne réputation de paradis; à Maurice les fièvres sont particulièrement dangereuses.

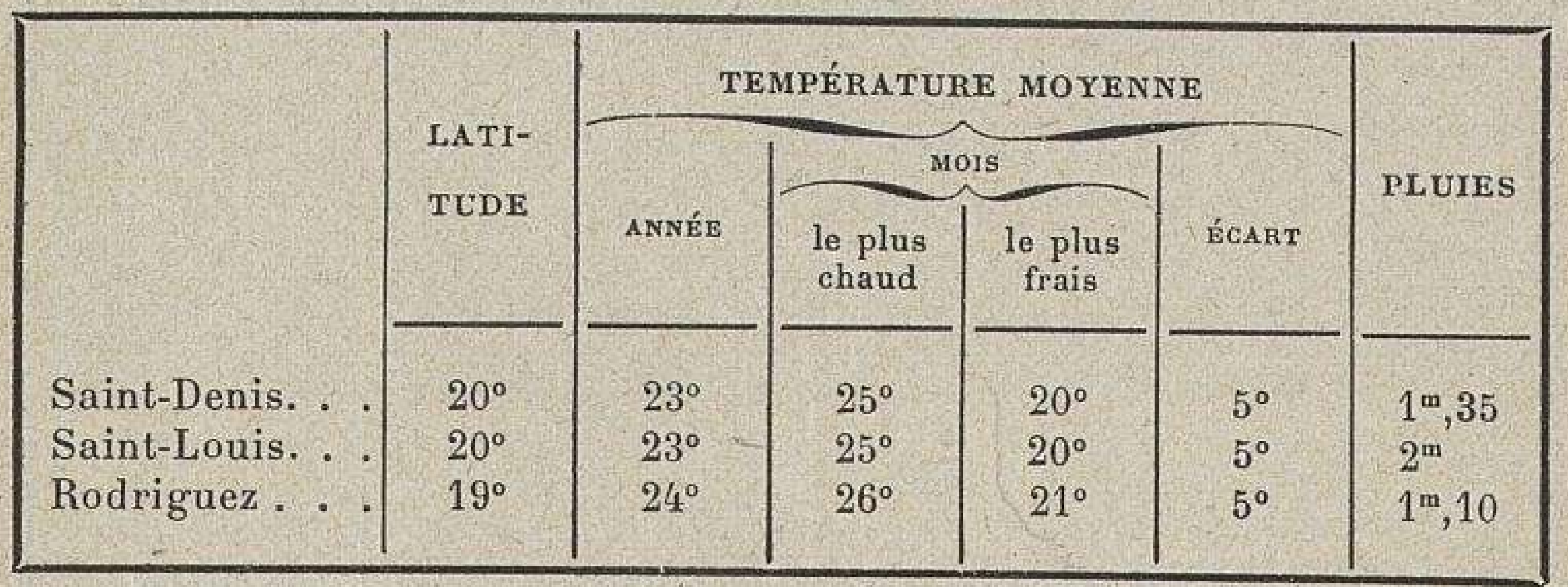

Les rivières sont des torrents au débit très inégal; elles ruissellent sur des roches imperméables, le long de pentes très raides, et accumulent à leur embouchure une quantité considérable de galets et d'alluvions. - Les côtes de l'île Maurice sont plus découpées que celles de la Réunion; rocheuses en général, mal articulées, elles n'offrent pas d'abri naturel, seulement des mouillages. La mer est sauvage et les raz de marée fréquents. Entretenue par une abondante humidité, la végétation est fort riche, bien que la vieille flore des îles ait disparu. En bas, sur le littoral et dans les plaines, les cultures tropicales et les arbres fruitiers; au-dessus, des forêts exubérantes, à bois d'ébénisterie et de construction; à 1.800 mètres la flore devient celle 
des régions tempérées; les sommets enfin ne portent plus que des arbustes rabougris et des broussailles. - L'ancienne faune, des plus remarquables, a disparu : les tortues géantes, qui se comptaient au xvIr siècle par bandes serrées de 2 à 3.000 individus, ont été totalement détruites; de même un pigeon géant (le dronte), qui ne pouvait ni voler ni courir, a été tué à coups de bâton: iln'en reste plus d'échantillon que dans les Muséums.

La Réunion, la plus voisine de Madagascar, est comme nos Antilles une vieille colonie française; Maurice et Rodriguez sont anglaises depuis 1815 .

$1^{0}$ Saint-Denis, capitale de la Réunion $(27.400$ h.), sur la côte Nord, cache ses villas sous une abondante verdure. Comme la rade n'est pas bonne, un port a été récemment creusé dans les terres, la pointe des Galets; un chemin de fer y conduit par un des plus longs tunnels du monde $(10 \mathrm{~km} .1 / 2)$.

La Réunion cultive la canne à sucre, le café et la vanille. Pour les travaux agricoles, il est fait appel aux Hindous, aux Cafres et aux Chinois.

Les habitants (178.000) sont les descendants des colons français qui occupèrent l'île, alors déserte, il y a trois cents ans; leur développement est un exemple de la vitalité de la race française sous le ciel tropical, à rapprocher de celui que fournissent les Canadiens dans une région tempérée froide.

$2^{\circ}$ L'île Maurice a pour capitale Port-Louis (52.000 h.), mal bâtie sur la côte Nord-Ouest et si malsaine que la population habite les hauteurs et ne descend à la ville que pour ses affaires. Le jardin botanique de Pamplemousse, l'observatoire, sont des institutions scientifiques célèbres.

Le fond primitif de la population est français de langue et de mours. Aux Nègres d'Afrique se sont ajoutés, depuis la suppression de l'esclavage, des Hindous, des Chinois et des Arabes.

$3^{\circ}$ Rodriguez, dépendance de l'île Maurice, a une population mêlée qui jouit d'un fort mauvais renom.

\section{III. - GOMORES}

L'archipel volcanique des Gomores barre l'entrée du canal de Moçambique; il compte quatre îles principales, entourées de 
coraux, Mayotte, Anjouan, Mohéli et Grande Comore. Celle-ci renferme le plus haut cratère $(2.650 \mathrm{~m}$.).

Toujours humides, les Comores reçoivent les fortes pluies des moussons, de février à mars : c'est la saison de l'hivernage, marquée par de grandes chaleurs, des abats d'eau torrentiels et des orages journaliers. Juillet et août sont les mois les plus frais et les plus secs. - Jamais la roche n'est à nu, tant la végétation est exubérante. Mais les animaux sont peu variés et peu nombreux; ce sont des lémuriens, comme à Madagascar. D'une superficie totale de 1.972 kilomètres carrés, l'archipel possède une population très mêlée, de 85.000 habitants : Arabes et Hindous, amenés par les moussons, Cafres et Malgaches. Tous parlent le Kisouahéli.

Mayotte est une colonie française depuis 1843; les Comores, protégées depuis 1886, le sont devenues en avril 1908 et le groupe tout entier a été rattaché au gouvernement général de Madagascar, mais en conservant un administrateur spécial.

L'archipel, d'une valeur coloniale réelle, produit la canne à sucre (sucreries et distilleries de rhum) et la vanille; le café, lo thé, le cocotier et le caoutchouc ont été très éprouvés. En 1910 l'exportation de Mayotte et des Comores dépassait 2.444.000 et l'importation 1.158 .000 francs. Enfin la Grande Comore possède un important dépôt de charbon.

L'archipel des Glorieuses, composé de trois ilots, entre les Comores et le Nord de Madagascar, est également français.

\section{IV. - SËGHELIES}

Les Amirantes (83 kmq.) et les Séchelles (264 kmq.) - du nom du Français Moreau de Séchelles - reposent, par $5^{\circ}$ Lat. S. environ, sur le même plateau sous-marin que les Mascareignes et Madagascar et sont, comme elles, les restes d'un effondrement. Leur point culminant atteint 988 mètres.

Le climat est très chaud et constant. Mahé ( $4^{\circ}$ Lat. S.) a une moyenne annuelle de $27^{\circ}$, et seulement un écart de $2^{\circ}$ entre avril, le mois le plus chaud $\left(27^{\circ}\right)$, et juillet, le mois le plus frais $\left(25^{\circ}\right)$. Les pluies $(2 \mathrm{~m} .45)$ tombent surtout de novembre à avril.

Les cultures sont les mêmes que dans les îles précédentes, et la population, très mêlée $(20.000$ h.), comprend des créoles 
français des Mascareignes, des Nègres, des Hindous, des Chinois, etc.

La principale île, Mahé, est une position stratégique de premier ordre, entre Aden et Maurice d'une part, Zanzibar et l'Inde de l'autre, un dépôt de charbon, le port où convergent les lignes de navigation anglaises, allemandes et françaises, enfin le point d'atterrissement du câble de Maurice à Zanzibar et à la mer Rouge. Le centre administratif s'appelle indifféremment Mahé - parce que la découverte est due à l'initiative de Mahé de la Bourdonnais - ou Port Victoria.

\section{V. - NOUVELLE-AMSTERDAM, SAINT-PAUI i. ET KERGUELEN}

Perdus dans l'océan indien par $38^{\circ}$ Lat. S., la Nouvelle. Amsterdam et Saint-Paul sont des îlots volcaniques sur la route du Cap à l'Australie. Enveloppés de brumes, battus par les grands frais d'Ouest, ils sont inhabités, couverts de mousses et de lichens, à peu près stériles; les oiseaux de mer (albatros, pétrels, manchots) y pullulent et la pêche est si fructueuse (morues, otaries, phoques, baleines et langoustes) que la Nouvelle-Amsterdam, tout au moins, attire pendant l'été les pêcheurs de la Réunion.

L'archipel des îles Kerguelen ( $48^{\circ}$ Lat. S.) est sur les limites de l'océan Indien et des mers antarctiques; également voleanique, avec des montagnes de 2.000 mètres environ, il ne connaît d'autre saison qu'un perpétuel automne - étés peu chauds par vents du Sud, hivers peu froids grâce à l'influence océanique - et ne porte d'autre végétation que des herbes, des mousses et des lichens. Les îles Kerguelen font l'objet d'une tentative intéressante de colonisation (pêche de la baleine et du homard, chasse au phoque, élevage du mouton).

La France a pris effectivement possession de la NouvelleAmsterdam, de Saint-Paul et des Kerguelen. 


\section{INDEX DES NOMS GÉOGRAPHIQUES}

Sont exclus de l'index les sommaires, les cartes, les illustrations et les tableaux statistiques du commerce.

\begin{tabular}{|c|c|c|c|}
\hline $\begin{array}{l}160 . \\
\text { outa } 140 . \\
\text { orn } 193 . \\
138,146 . \\
\text { y } 139 . \\
\text { nie } 255 . \\
\text { ns } 266 . \\
\text { ti } 134,140 . \\
141 . \\
\text { oua } 152,153, \\
\text { baba } 259,268, \\
\text { Alem } 269 . \\
\text { Harar } 273 . \\
\text { a } 260,290 . \\
269 . \\
\text { lo9. } \\
\text { i6. }\end{array}$ & $\begin{array}{l}\text { Akassa } 154,160 . \\
\text { Akkas } 29 . \\
\text { Akkra } 140 . \\
\text { Alaotra } 318,322 . \\
\text { Albert } 6,229,235, \\
\quad 236,237 . \\
\text { Albert-Edouard } 6, \\
\quad 229,237 . \\
\text { Alexandrie } 8,13,296, \\
\quad 297,308 . \\
\text { Alger } 8,14,65,68, \\
\quad 73,77 . \\
\text { Algérie } 62-78 . \\
\text { Algoa } 208 . \\
\text { Alhucemas } 54 . \\
\text { Ambaca } 192 . \\
\text { Amboukol } 284 . \\
\text { Ambre } 318,323 . \\
\text { Amhara } 268 . \\
\text { Amirantes } 316,336 . \\
\text { Amour } 64 . \\
\text { Amsterdam } 337 . \\
\text { Anacho } 147 . \\
\text { Andevorante } 322,329 . \\
\text { Angavo } 318 . \\
\text { Anghrabies } 205 . \\
\text { Angoche } 189 . \\
\text { Angola } 191 . \\
\text { Angra Pequena } 207, \\
220 . \\
\text { Anjouan } 336 . \\
\text { Ankaratra } 318 . \\
\text { Ankay } 318 . \\
\text { Ankober } 269 . \\
\text { Annobon } 152,162 . \\
\end{array}$ & $\begin{array}{l}\text { Arguin } 104,126 . \\
\text { Arich (el) } 294 . \\
\text { Arméniens } 304 . \\
\text { Arouhouimi } 171,17 \\
\text { Arzeu } 68,77 . \\
\text { Ascension } 219 . \\
\text { Asiout } 308,311 \text {. } \\
\text { Asmara } 270,273 \text {. } \\
\text { Assab } 270 . \\
\text { Assal } 256 . \\
\text { Assinie } 127 . \\
\text { Assouan } 276, \\
\text { 299, } 308,311 . \\
\text { Atbara } 262,283 . \\
\text { Atlas } 50-51,63-64,8 \\
\text { Atmour } 278 . \\
\text { Aurès } 64,70 . \\
\text { Axoum } 269 . \\
\text { Azdjer } 97 .\end{array}$ & $\begin{array}{l}\text { Bahr Sara } 156 . \\
\text { Bahr Sohagieyeh } 29 \\
\text { Bahr Yousef } 297 . \\
\text { Bakel } 136 . \\
\text { Bakhoy } 123 . \\
\text { Baleines (baie des)1 } \\
\text { Bali 162, 324. } \\
\text { Balibourg } 154 . \\
\text { Bamako } 120, \\
\quad 136 . \\
\text { Bambara } 133 . \\
\text { Bambouk } 143 . \\
\text { Ba-Mingui } 156 . \\
\text { Banana } 176 . \\
\text { Bandama } 125 . \\
\text { Bangala } 169,176 . \\
\text { Bangouéolo } 169 . \\
\text { Bangui } 160,172,17 \\
\text { Bani } 120 . \\
\text { Bantous } 29,191,21 \\
\quad 244 . \\
\text { Baol } 146 . \\
\text { Baoulé } 123,125,14 \\
\text { Baoutchi } 163 . \\
\text { Barabra } 288,304 . \\
\text { Bardera } 271 .\end{array}$ \\
\hline
\end{tabular}


Bari 287.

Baringo 228, 239.

Barka 104.

Baro 260.

Barotsé 193.

Barroua 160.

Basouto 211, 216.

Basoutoland 219.

Bassa 161.

Bassam 125, 127, 138 146.

Bassango 174.

Bathurst 119.

Batna 65, 75 .

Bayouda 278, 284.

Beaconsfield 216.

Bedja 288.

Bédouins 304 .

Beira $185,189,192$ $195,224$.

Béja 90.

Belmonte 192 .

Bénadir 270 .

Benghazi 104,108, 112

Benguella (courant) $14,185$.

- (ville) 192, 195.

Beni-Abbès 109.

Bénin 160 .

Beni-Ounif 109 .

Bénoué 123, 152, 156 , 163.

Berber 276, 280, 284, 291, 292.

Berbera 262, 271.

Berbères 28, 34, 55, $70,87,106,158,287$.

Berbérie 49 .

Berguent 109.

Berrouaghia 112 ,

Betchouana 211.

Betchouanaland 202, 219.

Betsiboka 321.

Betsiléo 319,327 , 328,330 .

Be-tsi-mitatra 322 329.

Betsimisaraka 328 .

Biban 64 .

Bicharieh 288, 304.

Bida 162.

Bihé 183.

Bilma 137.

Bingerville 138.

Birket-el-Keroun 295

Birni N Koni 160 .

Biskra $65,76,77$, 109, 112.

Bismarckbourg 141. Canaries (îles), 104. Dakhla 85.

Bissao 141.

Bizerte $13,77,85,89$, $92,93$.

Blanc (cap) 4, 104 .

Blantyre $184, \quad 185$, $194,195$.

Blida 69,74 .

Bloemfontein 204 , 218, 224.

Bobo-Dioulaso 137.

Bochimans 30,32 , 191, 202, 211.

Bodelé 152.

Boers 191, 212.

Boghar 66 .

Boma $175,176,178$.

Bombetoka 324 .

Bon (cap) 86.

Bôre 64, 68, 75, 77 .

Bongo 287.

Bongo Lava 318.

Bonne-Espérance (cap) $15,207$.

Bonny 160 .

Borkou 152.

Bornou 152, 153, 158, 160.

Boschveld 202.

Botletli 187.

Bou Denib 109.

Boudouma 154.

Bouéa 154, 162.

Bougie $66,68,74,77$.

Boulam 141.

Boulawayo 193, 195 , 224.

Boussa 122.

Brakna 136.

Brass 160

Brazzaville 169 .

Brickaville 333.

British Central A frica 194.

Broken Hill 195, 224.

Bushmen 202.

Gabinda 177.

Caconda $183, \quad 185$, 192,195 .

Cafrerie 216.

Cafres 30, 211.

Caire (le) 296, 207, 306.

Calabar 160 .

Galedon 205.

Galle (la) 65 .

Cameroun 152,153 , ameroun 152, 153
Cap (le) ville 8, 204, $214,215,224$.

- (col.) 214.

Cape Coast Castle 140.

Carbon 68 .

Carnotville 139.

Carthage 89.

Casablanca 54, 58 .

Casamance 124.

Catoumbella 195.

Cavally 125.

Cayor 143,146 ,

Ceuta 51, 54, 57.

Chabet-el-Akra, 66.

Chaouia 70 ,

Chari 11, 152, 156, 159.

Chelia 64 .

Chélif 64,66 .

Chemtou 92.

Chergui 68.

Chillouk 287.

Chindé 188, 189, 192.

Chiré 188, 238.

Chiroua 184.

Choa 268.

Chochong 219.

Colomb Béchar 7 , 109, 112.

Comoé 125.

Comores 324, 335-336

Congo (fl.). 11, 14, 42 , $152,169-172$.

Congo belge 175.

- français 176 .

Constance 220.

Constantine 64, 67, 74,77 .

Copte 304 .

Corrientes 189.

Côte de l'Ivoire 138.

Côte de 1'Or 127, 140.

Couando 186

Couango 172.

Couanza 172, 185, 186.

Counéné 185, 186.

Cristal 168, 170.

Grosś River 157.

Cyrénaïque 104.

Dahomey 138.

Dahoméens 134.

Dahra 64.

Dakar 3, 14, 126, 136, 146.

Dakhel 295, 308.
Dallol Maori 160.

Damaland 199,220 . Damanhour 308.

Damiette 298, 308.

Danakil 266.

Dar el Kouta 160.

Dar es Salam 240, $248,250$.

Darfour 278, 279, 286 287, 291.

Daro 117.

De Aar 224.

Débo 120.

Debun dja 154

Degama 160.

Delagoa $15,189,208$.

Delgado 240.

Didessa 261.

Diego Suarez 15, 319, $323,329,330,331$.

Dikoa 162.

Dilolo 186.

Dinguiray 120,138 , 145.

Dinka 287.

Dioula 134 .

Djanet 109 .

Djaraboub 108, 309.

Djebel Oust 92.

Djelfa 110.

Djenné 137 .

Djerba $86,90,92$.

Djerid $83,85,80$.

Djibouti 15, 259, 262, $270,273$.

Djouba 238, 259.

Djurdjura 64 .

Dongola 284, 290, 292.

Douala 162.

Doufilé 281.

Draa 5́.

Drakensberg 201.

Drouplé 117.

Durban 204, 217, 224.

East iondon 208, 215, 216,224 .

Ebrié 125, 127.

Edough 64 .

Egypte 294-313.

Elgon 229.

Elmina 140.

Entebbe 249.

Equateurville $\quad 169$ 176.

Erg 99.

Erythrée 255, 270.

Eshowe 218. 
Esneh 308.

Ethirpie 6, 255, 267.

Ethiopiens 28.

Etocha 186.

Eyassi 239.

Facher (el) 291.

Fachoda 290, 292.

Fafa 146.

Faguibine 120.

Falémé 145.

False Bay 207, 210.

Famaka 261.

Famovana 333.

Farafrah 295, 308.

Faredgha 108, 308.

Fayoum 295, 297,311.

Fellah 303.

Felou 123.

Ferlo 124, 128, 146.

Fernando Po 152, $154,162$.

Ferryville 89.

Fez 56,57 .

Fezzan 108.

Fianarantsoa 329 , 332.

Fife 193.

Figuig 50, 107.

Forcados 123, 139, 160.

Foriens 287.

Fort Dauphin, 322, $329,330$.

Fort Flatters 109.

Forthassa 109.

Fort Jameson 193.

Fort Lallemand 109 .

Fort Lamy 162.

Fort Mac-Mahon 109.

Fort Miribel 109.

Fort National 74.

Foulbé voir Peul.

Fouta Djalon 116 , $128,144,145,146$.

Freetown 139, 146.

Frio 189.

Gaba Chambé 282.

Gabès $4,84,86,90$, 104.

Gabon $8,14,169,172$, 177.

Gafsa $84,90,91,92$. Galgabba 284.

Galla 28, 265.

Gambie 12', 139.

Gannalé Goudda 259. Gao 137
Gariep 204.

Garoua 157.

Géryville 65, 109.

Georges IV 205.

Gharbi 68 .

Ghardaïa 110.

Ghardimaou 92.

Gharsa 8́. .

Ghendero 152.

Gibraltar 2.

Girgeh 308.

Glorieuses 336 .

Godjam 268.

Goléa (el) 109.

Gondar 259, 269.

Gondokoro 292.

Gonyé 186.

Gorée 119, 126.

Gondjba 162.

Goulette (la) 89 .

Gourara 109.

Grahamstown 216.

Gribingui 156.

Griqualand 216.

Groote Zwarte Bergen 199.

Gross Fish Bay 189.

Guardafui 4, 15, 256, 262.

Guelma $64,67,75$.

Guinée (col.) 138.

- (golfe) 4, 14.

- (port) 141.

Guir 54, 10 .

Gwanda 224;

Gwelo $193,194$.

Hafoun 263.

Halfaya 290.

Hamada 98.

Hamites $28,34,244$, 287.

Hammamet 92 .

Hammam Lif 92 .

Hammam Meskoutine 76 .

Haoussa 159.

Harar 256, 259, 269.

Hartebeest 205.

Hassanieh 288.

Hassi Inifel 109 .

Hellville 330.

Henchir Souatir 92.

Herero 211.

Hinde $170,178$.

Hodna 68 .

Hoogeveld, 202.
Hottentots 30,191 , 211.

Houmbé 192, 195.

Hovas 328.

Huilla $183,192$.

Ibadan 140 .

Ibrahim 236 .

Idjil 138.

Igharghar 104.

Iguidi 100 .

Ikopa 321.

Ilo 163 .

Ilorin $140,147$.

Imérina $318,327,330$.

Indénié 146.

Inhambané 192.

Iro 156.

Ismailia 308.

Isser 66 .

Itang $273,292$.

Itasy 322.

Jaggersfontein 222 . Jamestown 219.

Johannesboung 218 , 224:

Juifs $32,55,72,87$, 304.

Kaarta $124,128,137$, 143.

Kababich 287.

Kabyles 28.

Kabylie $64,69,70$.

Kaffa 269.

Kafir 30.

Kafoué 188.

Kaghéra 236.

Kairouane $85,89,91$, 92.

Kalaat ed Djerda 92.

Kalaat-ès-Senam 83, 92.

Kalahari 184, 202, $209,210$.

Kalomo 193, 195.

Kamolondo 170.

Kanem 157, 158, 159, 160.

Kankan 120.

Kano $152,160,162$, $163,164$.

Kanouri 159.

Kanya 219.

Kaomba 168.

Kaouar 137.

Kaouélé 248.

Karagoué 246.
Karrou 199, 200, 210.

Kasongo 178.

Kassaï $172,174$.

Kassala $280, \quad 290$, $291,292$.

Katsena 162.

Katanga 178.

Kayes $119,123,136$, $137,146$.

Kebabo 108.

Kébir (el) 67.

Kebrabassa 187.

Kef $84,90,92$.

Keffi 162.

Kef sidi Amar 64 .

Kenadsa 112.

Keneh 308.

Kenia 6, 229.

Keren $270,273$.

Kerguelen 337 .

Kerkenah 90.

Key 206.

Khargeh 295, 308.

Khartoum 278,279 , $280,288,290,292$.

Khroumirie 82,8 ', 85 , 86,90 .

Kibo 229.

Kilimandjaro 6,229 , 234.

Kiloa 248.

Kimberley 204, 216, 221,224 .

Kiodja 236.

Kir 279, 282, 286.

Kirounga 230, 231.

Kita 119, 137.

Kivou 229, 237.

Kobé 291, 292.

Kolobeng 219.

Komadougou 155 , 160.

Komati 206.

Konakry $138,146$.

Kondéland 234, 248, 250.

Kong $125,138,146$.

Kongola 178.

Konian 117.

Kordofan 278, 279, $286,291$.

Korogoué 250.

Kosseir 297, 308.

Kotonou 127, 139 , 146.

Koubango 187.

Koufra 108, 112.

Kouilou 172.

Kouka 154,162 . 
Kouléchi 170.

Koulikoro 146.

Koumassi 140 ,

Koumi 146.

Kouranko 117.

Kouri 154 .

Kouroussa 138, 146.

Kousseri 162.

Krou 16, 134.

Ksour 64.

Labezenga 146.

Lado $176,279,281$, 290.

Iadysmith 218.

Laghouat $8,110,112$.

Lagos $127,140,146$, 160,164 .

Lahou 125, 127.

Lamou 249.

Lange-bergen 199.

Langenburg 248.

Lacquedives 316 .

Lella Khedidja 64 .

Lemuria 316.

Léopold II 172.

Léopoldville 176,178 .

Levantins 304.

Lialoui 194.

Libéria 141.

Libreville $172,177$.

Libye $96,97,100$, $104,295,296$.

Limpopo 188, 201, 206.

Lindi $232,240,248$, 250.

Lfnyanti 186.

Livingstone 170,193 , 195.

Loanda $169,185,189$, 195.

Loango 177.

Loangoua 188.

Lobito 195.

Lokodja 122, 157.

Lomami 171.

Lomé 141,147 ,

Longwood 219.

Lopez 172.

Loualaba 170.

Louapoula 170.

Louboudi 170.

Loukolela 170.

Loukouga 171.

Loulouabourg 176.

Loupata 188.

Lourenço Marquès Massenya 160.

Macina 121.

Macta 66. $27,316-333$.

Madère 141.

Mafia 238, 240.

Mafou 124.

Magdiohou 270.

Maghreb 49.

Mahdia 92 .

Mahé $336,337$. $330,332$.

Malangé 192.

Maldives 316 .

Mananara 321.

Mandé 132.

Mangoki 322.

Manica 184.

Mansourah 308.

Manyema 174.

Maouensi 229.

Mareb 262.

Marie 261.

Maroc 50-59.

Marovoay 322.

Marrah 278.

Mascareignes 333-335̃.

Maserou 219.
15, 185, 189, 192, | Matabélé 183, 191, Narinda 324.

$195,208,224 . \quad 193 . \quad$ Nassaroua 160.

Matadi 171, 176, 178. Natal 217, 220.

Matoppo 183. Natron 228, 239.

Mateur 92.

Maures $55,72,131$. N'djolé 172

Machona 183, 193.

Madagascar $3,7,15$,

Maevatanana 332.

Mafeking 216, 224.

Mahafaly $319,328$.

Mahajamba 324.

Mahutsara 332.

Maintirano $324,330$.

Majunga 320,324 ,

Makarikari 184, 187.

Malagarassi 238.

Mananjary $320,332$.

Mangbattou 174.

Mangoro $318,321$.

Mangwato 219.

Manyara 228, 239.

Marabouti 108.

Maréotis 298.

Marguerite (pic) 231.

- (ville) 52,57 .

Marsa (la) 89.

Mascara 64, 74 .

Maurice $334,335$.

Mauritanie 136.

Mayel Balevel 120.

Mayotte 336.

Mecheria 109.

Mechra el Reg 282.

Médéa 65,74 .

Médine 124, 131.

Medinet el Fayoum 308.

Medjerda 67, 85 .

Melek 284.

Melghir 104.

Melilla 54 .

Mellègue 85 .

Menzaleh 298.

Messaoura 54.

Metlaoui 91, 92.

IM'bomou 172.

Mia 104.

Milandji 184.

Miliana 74 .

Miliane 85 .

Mitidja 64 .

Mitoumba 168.

Moçambique 185 , $189,192,232$.

Mœris 297.

Moero 169.

Mogador 52, 54, 58, 112.

Mohéli 336.

Mokattam 284, 306.

Moknine 92.

Molopo 205.

Molopolé 219.

Mombaz 232, 240, $249,251$.

Monrovia 142.

Morondava $324,330$.

Mossamédès 189, 192 .

Mossel Bay 208.

Mossi 125, 137.

Mostaganem 74, 77 .

Mouanza 248.

Moulonia 50, 53 .

Mpouapoua 248.

Murchison 188.

Mzab 110.

Naauw Port 224.

Namaland 199, 217, 220. $195,228,238$.
Nebeur 91.

Nefza 91, 92.

Nègres $32,56,72$, $131-134,158,174$, $191,244,286,304$.

Négrilles 29.

Neiges (Piton des) 334.

Newcastle 218.

Ngami 6, 187.

Ngaoundéré 162 .

Niamey 137.

Niam-Niam 174,286 287.

Niari 172.

Nieuweveld Range 199.

Niger $10,12.39,117$, 120-123.

- (territ.) 137.

Nigérie $140,160$.

Nigritie 29.

Nil $11,12,40,235$ $237,280-284,297$ 300.

Nil bleu 12, 260.

Nilotiques 244, 245 , 287.

Nimba 117.

Niero 137.

No 282.

Nosy-bé $8,319,323$.

Nosy-vé 320.

Nouer 287.

Noun 54, 123.

Nouvelle-Anvers 169 , 176.

Nubie 276, 278, 295.

Nubiens 28, 288.

Ǹyangoué $170,176$.

Nyassa $6,184,188$,

0asis (territ.) 109.

Obéid (el) 278, 291, 292.

Obock 270.

Ogaden 256 .

Ogooué 14, 172.

Okavango 184, 187.

Olifant's River 206.

Omatako 183, 199.

Omdourman 288, 290.

Omo 260. 
Oni-lahy 322,324 .

0okiep 217, 222, 22' . Opia 263, 270.

Oran $65,68,69,74$, 77,112 .

Orange(fl) $12,204-206$. - (col.) 218.

Orléansville $i 4$.

Ouabi Chebeli 259.

Ouadaï $112,159,160$.

Ouadi Halfa 280,284 , $290,292$.

Ouaghadougou 137.

Ouardine 92.

Ouargla 109, 112.

Ouarsenis 64 .

Ouassoulou 145.

Oubangui $171,174$.

Oubangui-Chari 160 , 177.

Oudjidji 248.

Oued (el) 109.

Oued Medinet 291.

Ouellé 172.

Ouembéré 242.

Ouémé 125.

Ouesso 178.

Ouezzan 57.

Ouganda 235, 241, $246,249,273$.

Ouida 139, 146.

Oulad Naill 64, 110.

Oulad Sliman 158.

Oum er Rbia 53.

Ounioro 241, 246.

Ounyamouézi 228 , $230,242$.

Otavi 222.

Ovampo 221.

Palapyé 219.

Palimé 147.

Palmés (cap des) 14, 126.

Pamplemousse 335 .

Pangalanes 333.

Pangani 238, 248.

Pasindava 323.

Pemba 240.

Périm $15,262$.

Peul 29, 134, 158.

Philippeville 68,74 , $77,112$.

Pietermarit z burg $204,213,218$.

Pietersburg 224.

Podor 118, 119, 136.

P o in te-des-Galets 335.
Pombeiros 191.

Pondoland 216.

Ponthierville 178.

Popo $139,141,147$.

Port Alexandre 189, 194.

Port Alfred 216,224.

Port Bouët 146.

Port Elisabeth 204 $208,212,216,224$. Portes de Fer 64.

Port Florence 249, 251.

Port Herald 195.

Port Ibrahim 308.

Port Louis 335 .

Port Natal 203, 208, 217.

Port Nolloth 20' 217, 224.

Porto Novo 119,129 , 138.

Porto Seguro 141.

Port Saïd 13, 308.

Port Soudan 15, 284, 291, 292.

Port Victoria 337.

Poungoué 188.

Premier (Mine) 222.

Pretoria 195, 204, 218,224 .

Prince(îledu)152,162,

Quilimane $188,189$.

Rabat 58.

Radama 323.

R'adamès $108,109$.

Ras Dachan 257.

R'at 108.

Recife 208.

Réunion (la) 333-335.

Rhodésia 193.

Rif 51.

Rikoua 238.

Rio Campo 172.

- de Oro 107.

- Grande 124.

- Mouni 172, 177.

- Nunez 126.

Ripon 236.

R'ir (cap.) 51, 54 . (oued) 110.

Rivières (pays des) $282,291$.

Rodah 299.

Rodolphe $6,228,239$, $256,260$.

Rodriguez 334,335 .
Rosette 298, 308.

Rouanda 246.

Roubaga 235.

Roufidji 238.

Rouge (mer) 6.

Roummel 66 .

Rounsoro 6, 168, $228,230,231$.

Roussizi 237.

Rouvenzori

Rounsoro.

Rovouma 188, 238.

Rufisque 136, 146.

Saati 273

Sabi 188.

Sahara 62, 96-112.

Sahel (Bougie) 64, 66.

- (Tunisie) 87, 90.

Saint-André 324 .

- Blaise 208.

- Denis 334, 335.

- John's River 206.

- Louis 119,124 , $136,146,334$.

- Paul 337.

- Paulde Loanda192

- Philippe 189:

- Vincent 140.

Sainte (ile) 261.

- Hélène (baie, 207.

- - (ile) 219.

- Isabelle 152.

- Lucie 208.

- Marie (île) 322.

- Marie de Bathurst 139.

Sakalava 328 ,

Salaga 119.

Salazie 334.

Salisbury 185,193 , 19 วั, 224.

San 32, 211.

Sandé 286.

Sangha 172.

Sankourou 172.

Sansanné Mango 141.

San Thomé 152, 154, 162.

Saoura 50, 104, 152 .

Saria 158, 162.

Sassandra 125.

Sbeitla 92.

Sebou 53.

Séchelles 316, 336 .

Sedhiou 136.

Ségou $120,137$.

Sekondi 146 .
Semliki 230, 235̃, 237, 241.

Sénégal (fl.) 117,123 $124,146$.

Sénégal (col.) 136. - (Haut)etNiger136.

Sennar 279, 291.

Serra de Chella 183. Sétif $64,56,74$.

Sétit 262.

Seybouse 67 .

Sfax $90,92,93$.

Sherbro 126.

Sidi bel Abbès 64,66 , 74.

Sierra Leone 119,139 .

Siguiri 120.

Simen 257.

Simon'stown 216.

Sinaï 294.

Síouah 108, 295, 308. Sneeuw-bergen 199. Sobat 260, 273, 282.

Socotora 256, 262.

Sofala 189.

Sokoto $147,152,162$, 163,16 '

Somali 266.

Somalie 255 .

Somerset 236 .

Sonhraï 132.

Sorbo-Aoussa 160 , 163.

Sotouba 120.

Souaheli $16,30,246$.

Souakin 15, 284, 291.

Soudan 114-164, 276292.

Soueh 282.

Sources (mt aux) 261. Sous 51,53 .

Sousse $89,90,92,93$.

Springbo kf ontein $217,22^{\prime} t$.

Stanley falls 170 .

- pool 11, 170.

Stanleyville 176, 178 .

Stèphanie 239, 256.

Stora 68 .

Suez 3, 15, 295, 297, 308,312 .

Swakopmund 220 , 222.

Syrte $4,13,104$.

Tabarka 85.

Table 15, 199, 207.

Tabora 234, 248, 250.

Tadjoura 262, 270. 
Tafilelt 54, 58, 107. Tafna 66 .

Tagant 136.

Talkkazé 262.

Talzaza 109.

Tamatave 320,322 , $329,330$.

Tamentit 109.

Tamjoutt 51 .

Tana 238, 261, 273.

Tananarive 320,328 , 332.

Tanga $240,248,250$.

Tanganyika 6,229 , $234,237$.

Tanger 52, 54, 57, 77 .

Tantah 308.

Taodeni 108, 138.

Tar'it 109.

Tarkona 147.

Tarso 152.

Tassili 97.

Taza 51, 57.

Tchad 6, 97, 152, $154,158,160$.

Tchagos 316 .

Tchambẻzi 169.

Tcheckna 160.

Tébessa 64, 65 .

Telemsi 108.

Tell $63,65,82,90$.

Temassinine 109.

Tembike 117.

T. anbouland 216.

Tendelti 291.

Tensift 53 .

Tété $185,187,192$.
Tetouan 54, 57.

Thiès 146 .

Tibbou $106,158$.

Tibesti 97, 152, 153 .

Tidikelt 109.

Tidjikdja 136.

Tigres (baie des) 189 , 195.

Tigré 268 .

Timbo 119, 138, 146 .

Timmimoun 109.

Tinkisso 120.

Tizi-Ouzou 74 .

Tlemcen $64,65,66$, $74,77$.

Toffo 146 .

Togo 141.

Togoland 141.

Tombouctou 118,119 , 131, 137.

Toúareg $28,106,131$, 158.

Touat $97,110,112$.

Toubouri 156.

Touggourt 109, 110.

Tozeur 90.

Transsaharien 112.

Transkei 216.

Transvaal 218.

Trarza 136.

Tripoli 104, 108, 112.

Tripolitaine 96, 108.

TristandaGunha219.

Trois fourches (cap des) 51 .

Trois pointes (cap des) 54, 127.
Tsiafa-javona 318. | Yacoba 152, 162. Tsi-ribihina 322,324. Yaoundé 162.

Tsoakhoabmund 220 Yarboutenda 136.

Tugela 206.

Tuléar 324, 330.

Tuli 194.

Tunis $13,84,85,88$, $92,93$.

Tunisie 80-93.

Tures, 304 .

Vaal 205.

Vatomandry 329.

Veld 202, 210.

Vert (cap) 4, 14, 126 .

- (ìles du cap) 3,140 .

Victoria (chutes) 11 , 187.

-(lac) $12,231,235,236$

- (ville) 193.

Virounga 231.

Vivi 169 .

Vohémar 330.

Volta 125.

Vourno 162.

Vribourg 216.

Waffish Bay 185,20 ', $207,217$.

Wankie $193,194,224$.

Warrenton 224.

Warri 160.

Windhouk $8,204,220$, 222.

Winterhouk 199.

Witwatersrand 202, Zoutpansbergen201. 


\section{TABLE DES MATIÉRES}

\section{AFRIQUE}

I. - Etude générale :

$1^{\circ}$ Géographie physique.

II. $-2^{\circ}$ Vie végétale. Vie animale. Vie humaine. .

III. - Explorations et partage politique. . .

IV. - Région de l'Atlas : $1^{\circ}$ Maroc ...... 47

v. $-2^{\circ}$ Algérie ...... 60

VI. $-3^{\circ}$ Tunisie. . . . . 79

VII. - Sahara. Tripolitaine . 94

VIII. - Soudan occidental . Sénégal. Guinée :

$1^{\circ}$ Géographie physique. ....... 113

IX. $-2^{\circ}$ Géographie humaine. 129

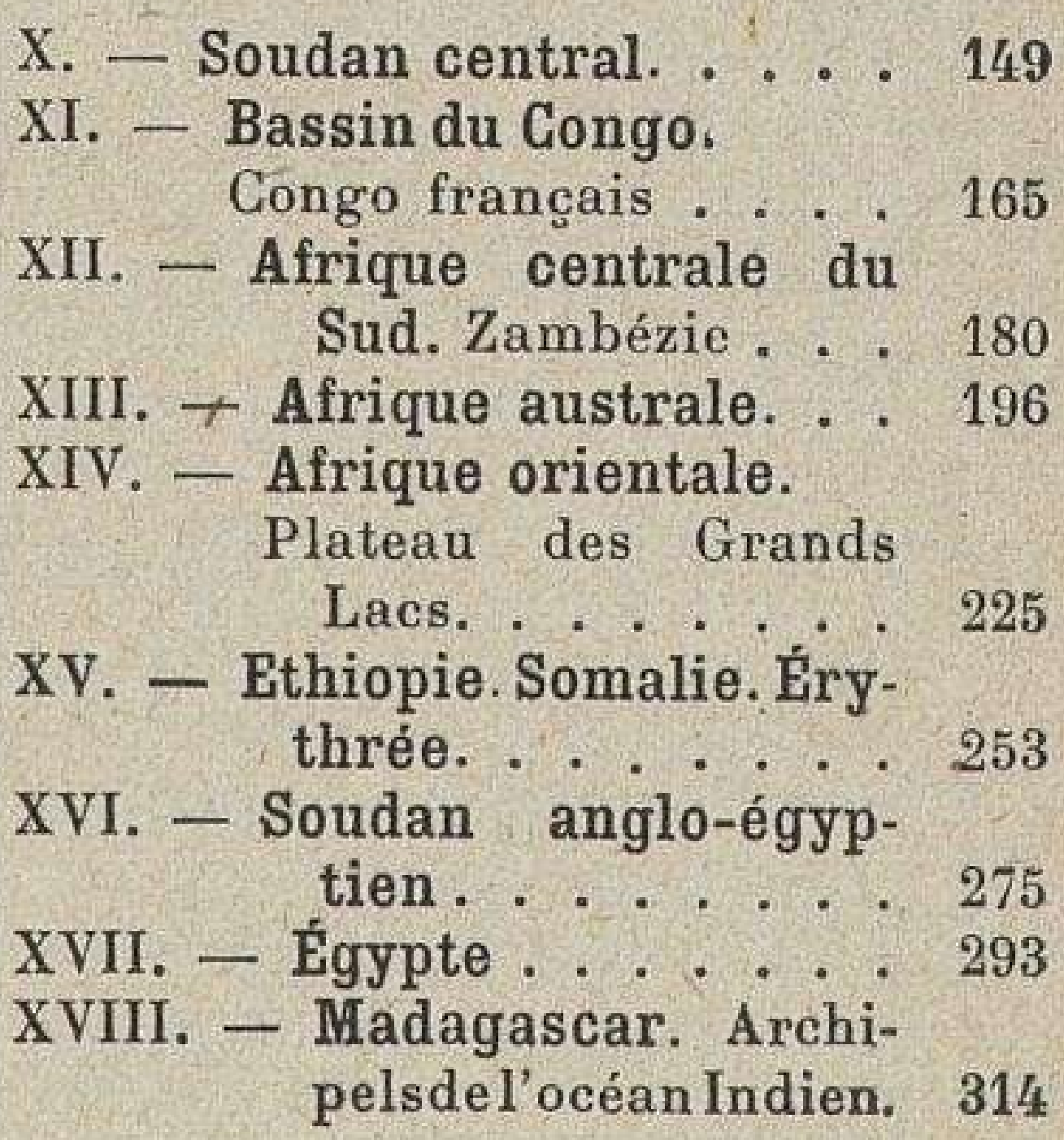

\section{TABLE DES GARTES ET GRAVURES}

\section{AFRIQUE}

Hauteurs comparées des plus hauts sommets. . . . . . . . 5

Hauteur moyenne de la pluie. . . . . . . . . . . . . 10

Grands fleuves de l'Afrique, longueur et bassins. . . . . . . . . 11

Tronc d'un fromager à Konakry. . . . . . . . . . . . . 19

Palmiers à huile. . . . . . . . . . . . . . . . . . 20

Forêt-galerie et baobabs.................. 21

Savane de l'Afrique équatoriale. . . . . . . . . . . . . 22

Type de forêt dans les pays de elimat sec. Somalie. . . . . . . . 23

Au Sahara, une oasis. . . . . . . . . . . . . . . 24

Répartition des espèces animales. . . . . . . . . . . 25

Au Sahara, une caravane en marche. . . . . . . . . . 27

Races et civilisations de l'Afrique. . . . . . . . . . . . 29

Commerce intérieur : moyens de transport. . . . . . . . . 31

Au Sahara, Kattara ou puits d'irrigation. . . . . . . . . 33 
Portrait de Barth. . . . . . . . . . . . . . . 39

Portrait de Stanley. . . . . . . . . . . . . . . 41

Portrait de Livingstone.................... 42

Portrait de Savorgnan de Brazza. .............. 43

Carte du Maroc. ..................... 48

Gorges du Chabet-el-Akra. ................ 63

Gorges du Roummel. .................. 67

Carte de l'Algérie. . . . . . . . . . . . . 68, 69

Type de côte algérienne, Oran. .............. 69

Type de village dans la grande Kabylie. . . . . . . . . . 71

Campement de nomades sahariens. . . . . . . . . . . 73

Vue d'Alger. .................. 75

Carte de la Tunisie. .................. 81

La Kalaat-ès-Senam. . . . . . . . . . . . . 83

Un gourbi tunisien. ................. 87

Vue générale de Tunis. . . . . . . . . . . . . . 89

La rue Saussier à Kairouan. . . . . . . . . . . . . . . 91

Carte du Sahara. ................ 95

Falaise et Gour du désert libyque ............. 98, 99

La Hamada noire du Tademaït. . . . . . . . . . . . 100

Dunes de l'Erg. . . . . . . . . . . . . . . 101

Un gassi de l'Erg. .................... 102

Le chott Melrhir. .................. 103

Types Touareg. . . . . . . . . . ....... 107

Laghouat . . . . . . . . . . . . . . . 109

Un Ksar, el Goléa. ................... 110

Carte du Soudan occidental et de la Guinée. . . . . . . . 115

Chute du Tinkisso, dans le Fouta-Djalon. . . . . . . . . 117

Lac Débo et environs de Tombouctou. . . . . . . . . . . 121

Vue du Niger, en aval des rapides de Boussa........... . 122

Chutes du Felou, sur le Sénégal . . . . . . . . . . . 123

Type de rivière à la Côte de l'Ivoire. . . . . . . . . . 125

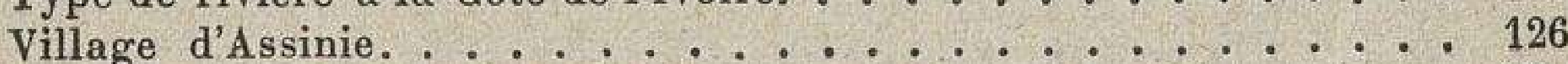

La barre sur la Gôte de Guinée. . . . . . . . . . . . . 127

Village de Say, sur le Niger. . . . . . . . . . . . 131

Une rue de Bondoukou. .................. 132

Village de la brousse, Gôte de l'Ivoire. . . . . . . . . 133

Mosquée de Dinguira. ................... 134

Dakar. . . . . . . . . . . . . . . . 136

Lagune de Grand Bassam. .. . . . . . . . . . . . 138

Soudan occidental. Carte des cultures. . . . . . . . . . . 142

Métier à tisser au Soudan. . . . . . . . . . . . . . . 143

Hauts fourneaux et forgerons dans la Guinée française. . . . . . 145

Soudan central, Bas Niger et Bénoué. . . . . . . . . 151

Lac Tchad. . . . . . . . . . . . . . . . . 155

Vourno, type de ville au Soudan central. . . . . . . . . . 161

Bassin du Gongo. . . . . . . . . . . . . . . 167

Rapides de l'Oubangui. ................. 171

Sur l'Ogooué, Talagouga. ................. 173

Types de villages dans la forêt équatoriale ....... . 175, 176

Zambézie. .................... 181

Mouche tsétsé. ..................... 190 
Afrique australe. . . . . . . . . . . . . . 197

Plateau du Karrou. . . . . . . . . . . . . . . . . . 200

$\mathrm{Au}$ Natal, paysage. . . . . . . . . . . . . 201

La Tète du Lion, près du Cap ... . . . . . . . . . 205

Au Natal, champ de canne à sucre. . . . . . . . . . . . 207

Paysage désertique, dans le Sud-Ouest africain allemand. . . . 209

Peinture primitive, sur les parois d'une caverne, près Hermon. . . 213

Le Cap. . . . . . . . . . . . . . . 215

Un Kraal et construction d'une hutte au pays des Cafres . . 216, 217

Afrique orientale. Plateau des Grands Lacs. . . . . . . . . . 227

Le Kilimandjaro. . . . . . . . . . . . . . . . 229

Profils de l'Afrique orientale............. 230

Le mont Rounsoro................. 231

Montagnes schisteuses de l'Afrique orientale. .........2233

Profil du Haut Nil-Kagera. . . . . . . . . . . . . . . 236

Type de lac de fracture, le Kivou. . . . . . . . . . . . . 237

La grande vallée d'affaissement. . . . . . . . . . . . . 239

Steppe des Massaï. . . . . . . . . . . . . . . 241

Zones des formes végétales sur le Kilimandjaro. . . . . . . . 242

Savane-steppe avec acacias parasols. . . . . . . . . . . 243

Type d'habitation dans une contrée sèche. .......... 245

Huttes sur pilotis et miradors. . . . . . . . . . . . . . 246

Plateau éthiopien et presqu'île des Somali. . . . . . . . . 255

Paysage des hauts plateaux en Éthiopie. . . . . . . . . . . 257

Village galla.................... . . 261

Gourgui ou campement somali. .......... 264, 265

Types de Danakil. . . . . . . . . . . . . . . 266

Guerrier abyssin et page. . . . . . . . . . . . 267

Harar, vue générale et rue. . . . . . . . . 268, 269

Zones de cultures de l'Abyssinie. . . . . . . . . 272

Soudan anglo-égyptien. .............. ${ }^{2} 77$

Représentation des pluies. . . . . . . . . . 279

Paysage du Haut Nil et cabanes de Dinka. . . . . . . . . . . . 281

La première eataracte du Nil. . . . . . . . . . . . . . . 283

Répartition des formes de la vie végétale et animale. . . . . . 285

Nomades Bicharieh. . . . . . . . . . . . . . . 289

Khartoum. . . . . . . . . . . . . . . 291

Le Fayoum. . . . . . . . . . . . . . . . . . . 294

Delta du Nil et canal de Suez. . . . . . . . . . . . . . 298

Le Nil à Boulaq. . . . . . . . . . . . . . . . . . . 299

Au bord du Nil. .................. . 303

Le Caire, vue générale et rue de la mosquée de Touloun . . . 305, 307

Mode d'arrosage, nataleh et saquieh. . . . . . . . . 309, 310

Barrage d'Assouan. . . . . . . . . . . . . 311

Madagascar. ................. 317

Rivière avec chutes à Madagascar. . . . . . . . . . . . . . 321

Cocotiers et cases indigènes. . . . . . . . . . . . . . . . 323

Raphia. .................. . . . 325

Végétation subdésertique du sud de Madagascar. . . . . . . 327

Grenier à riz, Nosy-bé. . . . . . . . . . . . . . . 331

Rizières en gradins du Betsiléo. . . . . . . . . . . 332 
Vi 


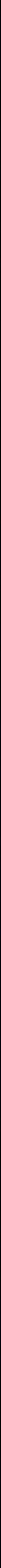




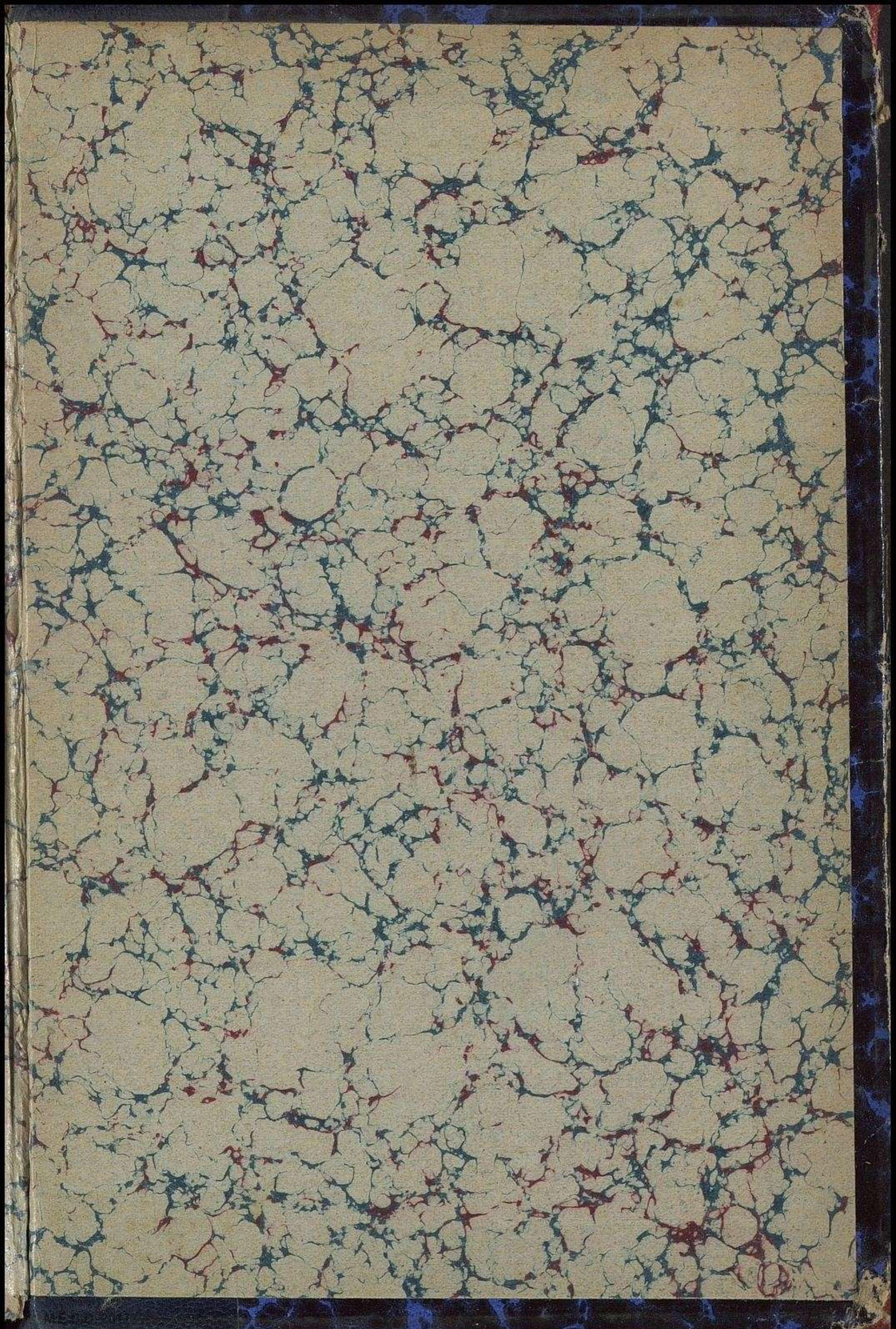

